\title{
AUF DEM WEG ZUR LANDESUNIVERSITÄT
}

\author{
Studien zur Herkunft \\ spätmittelalterlicher Studenten \\ am Beispiel Greifswald
}

(1456-1524) 
von

Achim Link

Göttingen 1998

Inhaltsverzeichnis 
Abstract

Vorwort

Widmung

1. Einleitung

1.1. Zielsetzung der Arbeit und Forschungsstand

1.2. Zur Geschichte der Universität Greifswald

2. Die Greifswalder Inskriptionen 1456-1524

2.1. Zur Frequenz der Greifswalder Universität

2.2. Räumliche Herkunftsangaben in der Greifswalder Matrikel

2.2.1. Zur Quellenlage

2.2.2. Zur Unterscheidung einzelner Betrachtungsgebiete

2.2.3. Zur Verteilung der Studenten auf einzelne Gebiete

2.3. Angaben zur sozialen Herkunft der Studenten

3. Die soziale Herkunft der Greifswalder Studenten

3.1. Der Adel

3.2. Die geistlichen Würdenträger

3.2.1. Die hohe Geistlichkeit

3.2.2. Der weltliche Niederklerus

3.2.3. "domini"

3.2.4. "presbyter" und "clericus"

3.2.5. Der Ordensklerus

3.3. Sonstige Angaben

3.3.1. "pauperes" 
3.3.2. Berufe

3.4. Akademische Grade

3.5. Resümee: soziale Differenz in Greifswald

4. Die Sozialstruktur im Spiegel der Gebührenzahlung

4.1. Zusammenhänge von räumlicher und sozialer Herkunft

4.2. Die Angaben zur Gebührenzahlung

4.3. Studenten mit voller Inskriptionsgebühr

4.4. Studenten mit Teilgebühren

4.5. Studenten ohne Inskriptionsgebühr

4.6. Resümee: Sozialstrukturen im Wandel

5. Einzugsbereiche und Wirkungsgrade Greifswalds 1456-1524

5.1. Zur "regionalen Existenz" der Universität Greifswald

5.2. Die Orte mit den höchsten Studentenzahlen

5.3. Die Ausstrahlung Greifswalds auf die umliegende Region

5.3.1. Die Herkunftsorte der pommerschen Studenten

5.3.2. Die Nachbarländer

5.3.2.1. Die Herkunftsorte der mecklenburgischen Studenten

5.3.2.2. Die Herkunftsorte der brandenburgischen Studenten

5.3.3. Resümee: Die regionale Basis in Greifswald 1456-1524>

5.4. Die Ausstrahlung Greifswalds auf überregionale Gebiete

5.4.1. Die Verteilung der Studenten auf entfernte Reichsgebiete

5.4.1.1. Die Herkunftsorte im niedersächsischen Kreis 
5.4.1.2. Die Herkunftsorte in den rheinischen Kreisen

5.4.1.3. Die Herkunftsorte im burgundischen Kreis

5.4.1.4. Die Herkunftsorte in den übrigen Reichsgebieten <

5.4.2. Die Verteilung der Studenten auf ausländische Gebiete

5.4.2.1. Die Herkunftsorte in Dänemark

5.4.2.2. Die Herkunftsorte in Schweden, Norwegen und Finnland

5.4.2.3. Die Herkunftsorte der Gebiete des Deutschen Ordens

5.4.2.4. Die Herkunftsorte in den übrigen ausländischen Gebieten

5.4.3. Resümee: Die "Universität für den Norden Europas"

5.5. Veränderungen des Einzugsbereichs von 1456 bis 1524

5.5.1. regionale Existenzsicherung und Ostseeuniversität

5.5.1.1. Die ungewöhnliche Eröffnungsphase von 1456 bis 1462

5.5.1.2. Die Etablierung der Ostseeuniversität von 1463 bis $1469>$

5.5.1.3. Die Konzentration auf Dänemark von 1470 bis 1476

5.5.1.4. Die erste regionale Ausdehnung von 1477 bis 1483

5.5.2. Die Hochphase in Greifswald

5.5.2.1. Die Krise in Rostock - Überregionalisierung von 1484 bis 1490

5.5.2.2. Die Normalisierungsphase von 1491 bis 1497

5.5.2.3. Die Humanisten - eine letzte Hochphase von 1498 bis 1504

5.5.3. Auf dem Weg zur Landesuniversität

5.5.3.1. Die Konkurrenz von Frankfurt und Wittenberg von 1505 bis 1511

5.5.3.2. Die fortschreitende Regionalisierung von 1512 bis 1518

5.5.3.3. Greifswald während der Reformation 1519 bis 1524 
5.6. Resümee: "Ostseeuniversität", "hansische Universität" und "Landesuniversität" 6. Konkurrenz und Migration zwischen den Universitäten

6.1. Zielsetzung und Methode

6.2. Pommersche Studenten auf anderen Universitäten

6.2.1. Die Orte der direkten Umgebung

6.2.1.1. Greifswalder auf anderen Universitäten

6.2.1.2. Stralsund: Konkurrenz zwischen Rostock und Greifswald

6.2.1.3. Demmin: starke Bindung zur Landesuniversität >

6.2.1.4. Anklam: Konzentration auf die Ostseeuniversitäten

6.2.1.5. Barth: Grenzlage und Konkurrenz

6.2.1.6. Grimmen: stärkere Beteiligung seit 1456

6.2.1.7. Wolgast: Dominanz der Landesuniversität

6.2.2. Zentralpommersche Orte

6.2.2.1. Stettin: mitteldeutsche Universitäten treten hervor

6.2.2.2. Stargard: eine kleine Mehrheit an der Landesuniversität

6.2.2.3. Pasewalk: von Leipzig nach Greifswald

6.2.2.4. Pyritz: höhere Beteiligung am Leipziger Studium

6.2.3. Orte in Hinterpommern

6.2.3.1. Kolberg: Küstenorte und Ostseeuniversitäten

6.2.3.2. Stolp: Distanz führt zu größerer Vielfalt

6.2.3.3. Treptow an der Rega: Zuwachs an den Ostseeuniversitäten

6.2.3.4. Belgard: geringe Frequenz und dominierende Stellung Greifswalds 
6.2.3.5. Kammin: Frequenzsteigerung und Bedeutungsgewinn Rostocks

6.2.3.6. Köslin: Rückgang der Bedeutung Greifswalds

6.2.3.7. Rügenwalde: Rostocker Dominanz

6.2.4. Resümee: zur dominierenden Stellung Greifswalds in Pommern

6.3. Herkunftsorte der Nachbarn

6.3.1. Neubrandenburg: Landeszugehörigkeit und Universitätsauswahl

6.3.2. Friedland: geographische Nähe führt zur Greifswalder Dominanz

6.3.3. Prenzlau: von Leipzig über Greifswald nach Frankfurt

6.3.4. Malchin: Studentenzuwachs aufgrund der Rostocker Krise

6.3.5. Resümee: "Nähe" als Kriterium der Universitätsauswahl

6.4. Überregionale Herkunftsorte

6.4.1. Danzig: von Leipzig nach Krakau und Frankfurt

6.4.2. Lübeck: im regionalen Einzugsbereich Rostocks

6.4.3. Groningen: im Einzugsbereich von Köln und Löwen

6.4.4. Hamburg: von Rostocker Dominanz zu größerer Vielfalt

6.4.5. Resümee: zur Relativierung der überregionalen Bedeutung Greifswalds

6.5. Resümee: Greifswald und die "Konkurrenz"

7. Zusammenfassung: Greifswald auf dem Weg zur Landesuniversität

Anmerkungsapparat

Abbildungsverzeichnis

Tabellenverzeichnis

Abkürzungsverzeichnis

Quellenverzeichnis 
Ungedruckte Quellen

Gedruckte Quellen

Literaturverzeichnis

Kartenteil

Herkunftskarte der Greifswalder Studenten 1456-1524

Teilausschnitt 1

Teilausschnitt 2

Teilausschnitt 3

Teilausschnitt 4

Teilausschnitt 5

Die Reichskreise

Universitätsgründungen in Nord- und Mitteleuropa im Spätmittelalter 1400-1524 


\section{AUF DEM WEG ZUR LANDESUNIVERSITÄT:}

Studien zur Herkunft spätmittelalterlicher Studenten am Beispiel Greifswald 1456-1524

von Achim Link

\section{Abstract}

Gegenstand der Arbeit sind Studenten und Universitäten im späten Mittelalter, wobei die 1456 gegründete Ostseeuniversität Greifswald den Ausgangspunkt der Studien bildet. Anhand einer systematischen Auswertung der Greifswalder Matrikel werden die geographischen und sozialen Herkunftsstrukturen der Studenten analysiert, die sich bis 1524 dort inskribierten. Damit folgt die Arbeit einer sozialgeschichtlichen Perpektive der Universitätshistoriographie.

Das zentrale Ergebnis liegt in dem Nachweis, daß bereits im Jahrzehnt um 1500 die Universität Greifswald sich zur Landesuniversität entwickelt hat. Damit ist für eine Universität die Grundsatzfrage gelöst, die insgesamt für die europäische Universitätsgeschichte noch ihrer Klärung harrt: Wann und durch welche Umstände ist die im Prinzip universal gedachte Universität zu jener Hochschule des Landes geworden, als die sie seit dem ausgehenden 17. und im 18. Jahrhundert entgegentritt.

Die Arbeit untersucht in einem ersten Kapitel die Frequenz der Universität Greifswald zwischen 1456 und 1524 sowie die Aussagequalität der Matrikel. In einem weiteren Kapitel werden die sozialen Herkunftsstrukturen der Studenten beleuchtet, die den sozialgeschichtlichen Hintergrund eines mittelalterlichen Universitätsstudiums belegen. Die Angaben zur Gebührenzahlung der Studenten machen deutlich, daß sich auch innerhalb der Universität eine starke soziale Differenzierung vollzog. Dabei gab es einzelne Phasen, in denen der Prozentsatz zahlungskräftiger Studenten besonders niedrig war, doch zählten Greifswalder Studenten gegenüber anderen Universitäten zu den zahlungskräftigsten Universitätsbesuchern, wofür man die wohlhabende Oberschicht wendischer Hansestädte als Ursache anführen kann.

Im Hauptteil der Arbeit werden die Herkunftsorte und -regionen der Studenten erfaßt, die von über 90 Prozent der etwa 3000 Studenten angegeben wurden. Der sich wandelnde Einzugsbereich der Greifswalder Studenten wird außerdem durch Karten und Grafiken veranschaulicht. Gegen Ende des Betrachtungszeitraums zeigt sich, wie aus der "Universität für den Norden Europas" eine reine Landesuniversität Pommerns geworden ist.

In einer Art Gegenprobe werden in einem weiteren Arbeitsschritt die Matrikel anderer Universitäten auf Studenten aus Pommern und Nachbarländern hin untersucht, um so das zentrale Ergebnis vom Wandel der Greifswalder Universität zu einer reinen Landesuniversität zu überprüfen bzw. zu stützen. Dabei wird deutlich, wie sich das dichter werdende Universitätsnetz in den Immatrikulationszahlen der einzelnen Universitäten widerspiegelt: Vor allem die Universitätsgründungen in Wittenberg (1502) und Frankfurt/Oder (1505) sind für den Rückgang überregionaler Studenten in Greifswald zu Beginn des 16. Jahrhunderts verantwortlich. 
Außerdem wird der in den Sozialstrukturen der Greifswalder Studenten sichtbar gewordene prozentuale Rückgang wohlhabender Studenten durch die gestiegene Gesamtfrequenz aus Pommern und die dadurch verbreiterte soziale Herkunftsbasis erklärbar. 


\section{Vorwort}

Bei der vorliegenden Arbeit handelt es sich um die überarbeitete Fassung meiner Dissertation, die ich im Sommersemester 1998 an der philosophischen Fakultät der Georg-August-Universität Göttingen eingereicht habe. An dieser Stelle möchte ich mich bei allen Personen und Einrichtungen bedanken, die am Zustandekommen der Arbeit beteiligt waren.

Mein erster Dank gilt meinem akademischen Mentor Professor Dr. Hartmut Boockmann, der die Arbeit nicht nur angeregt, sondern in der längsten Zeit ihrer Entstehung begleitet und vorbildlich betreut hat. Viel zu früh und unerwartet starb er kurz vor Abschluß meiner Studien. Seine fachliche Kompetenz und seine stets hilfsbereite und menschliche Persönlichkeit haben bei mir einen nachhaltigen Eindruck hinterlassen, so daß ich die Arbeit seinem Angedenken widmen möchte.

Daß mein Promotionsverfahren noch 1998 abgeschlossen werden konnte, verdanke ich den Professoren Dr. Ernst Schubert und Dr. Rudolf Vierhaus, die sich nach dem Tode meines Doktorvaters bereit erklärten, die Gutachten zu übernehmen.

Für die Beschaffung und Bereitstellung der Quellen und der Literatur sei an dieser Stelle den Mitarbeitern in allen benutzten Bibliotheken und Archiven gedankt.

Ein letzter Dank gilt meinen Eltern, Verwandten und Freunden, die mir während des Studiums eine wichtige persönliche Stütze waren, ohne die ich diese Arbeit nicht hätte schreiben können.

Göttingen, im August 1999

Achim Link

[Widmung] 
Professor Dr. Hartmut Boockmann

(1934-1998) 


\section{Einleitung}

\subsection{Zielsetzung der Arbeit und Forschungsstand}

Die vorliegende Untersuchung soll Studien zur Herkunft spätmittelalterlicher Studenten bieten, wobei die Ostseeuniversität Greifswald im Mittelpunkt des Interesses steht. Ihre Studenten von 1456 bis 1524 stellen die Ausgangsbasis der Arbeit dar, die als Beitrag zur Universitätsgeschichte des späten Mittelalters gedacht ist. Während die traditionelle Geschichtsschreibung zur Universität ihr Interesse weitgehend auf institutions- und verfassungsgeschichtliche Fragen gerichtet hat, liegt die Zielsetzung bei dieser Arbeit grundsätzlich anders. Sie begreift Universitätsgeschichte als Teil der Sozial- und Gesellschaftsgeschichte, indem sie ihr Interesse auf den Personenkreis richtet, der eine Universität in einer bestimmten Zeit frequentierte. Die Forschung der letzten Jahrzehnte hat sich intensiv um die sozialgeschichtlichen Aspekte der Universität bemüht. Nicht zuletzt durch Peter Classen wurde sie dazu angeregt, der 1966 eine "Sozialgeschichte der akademisch Gebildeten als notwendiges Korrelat" zur Geschichte der Universitäten gefordert hatte. ${ }^{1}$

Um einen möglichst repräsentativen Eindruck dieser Personengruppe zu erhalten, reicht es aber nicht aus, nur deren Spitze zu beleuchten, nämlich solche Universitätsabsolventen, die später als Universitätslehrer oder gelehrte Praktiker Bedeutung gewannen. Dies waren häufig genug Personen, die schon ihrer Herkunft wegen bessere Chancen hatten. Eine "Sozialgeschichte der akademisch Gebildeten" muß von den Matrikeln selbst ausgehen.2 In den Matrikelbüchern der Universitäten finden sich die Namen von tausenden Studenten verzeichnet, die in ihrer Gesamtheit eine Personengruppe darstellen, deren geschichtliche Bedeutung kaum zu überschätzen ist. Obwohl die Matrikelbücher fast aller Universitäten des Reiches bereits seit dem letzten Jahrhundert ediert vorliegen, sind sie immer noch nicht sämtlich ausgewertet worden. ${ }^{3}$ Die Forschung hat sie bisher vornehmlich dazu genutzt, Namen von Studenten einzelner Orte und Regionen zu erfassen, um so ein Bild über eine örtliche Bildungssituation zu erlangen. ${ }^{4}$ Andererseits hat man sie genutzt, um den Lebensweg verschiedener Personengruppen nachzuvollziehen. ${ }^{5}$ In einer großangelegten Studie über die Universitätsbesucher im 14. und 15. Jahrhundert hat Rainer Christoph Schwinges gezeigt, wie vielfältig die Möglichkeiten für weitere Auswertungen sind. ${ }^{6}$ So können die verschiedenen Angaben über die Studenten auch weitreichende Erkenntnisse über einzelne Universitäten liefern. Anhand der geographischen Herkunftsangaben läßt sich der Einzugsbereich einer Universität bestimmen. Außerdem können Veränderungen bei der Universitätsauswahl ganzer Regionen festgestellt werden. Aus den Angaben über die soziale Herkunft des Studenten lassen sich Erkenntnisse über soziale Voraussetzungen für ein mittelalterliches Universitätsstudium ableiten. Ganze Bevölkerungsgruppen können so in ihrer Vorliebe für einzelne Institutionen erfaßt werden. Auch über die Struktur und Beschaffenheit verschiedener Herkunftsregionen und -orte geben die Matrikel Auskunft.

Im Hauptteil der folgenden Untersuchung soll deshalb anhand der von Ernst Friedländer 1893 edierten Greifswalder Matrikel eine systematische Untersuchung der Studentenschaft für die Universität Greifswald von ihrer Gründung 1456 bis zum Jahre 1524 versucht werden. ${ }^{7}$ Zum 500jährigen Jubiläum der Universität hatte Roderich Schmidt einen Beitrag über ihre Anfänge 
geschrieben, und dort die ersten 553 Studenten auf ihre Herkunft hin untersucht. 8

Während sich seine Arbeit allerdings auf die Analyse der räumlichen Herkunft beschränkte, soll die vorliegende Untersuchung weiter greifen. In ihr sollen neben den räumlichen, auch die sozialen Angaben über die Studenten verwertet werden. Außerdem sollen durch Ausweitung des zeitlichen Radius Veränderungen und Verschiebungen des Einzugsbereichs dargestellt und dann in Beziehung zu historischen Ereignissen gesetzt werden. Ein weiterer Schwerpunkt liegt im Vergleich der Ergebnisse mit anderen Universitäten. So wird es in einer weiteren Untersuchung darum gehen, die Greifswalder Ergebnisse im Rahmen der gesamten damaligen Universitätslandschaft zu untersuchen. Dazu werden wichtige Herkunftsorte Greifswalder Studenten dahingehend untersucht, wie oft sie in anderen Universitäten als Herkunftsort genannt wurden, um so eine objektive Einschätzung der Bedeutung Greifswalds für diese Orte zu erlangen. 9

Es sind bereits einige Arbeiten von unterschiedlicher Qualität entstanden, die sich Universitätsmatrikel zur Quellengrundlage einer Auswertung nahmen, um auf diese Weise den sozialen und geographischen Einzugsbereich einer Universität zu ermitteln. ${ }^{10}$ Wenn man von einer älteren Arbeit über Königsberg absieht, das erst in nachreformatorischer Zeit gegründet wurde, hat es bisher keine Untersuchung zu einer Universität der nördlichen deutschen Landesteile gegeben. Man hat den Universitäten Rostock und Greifswald häufig eine Sonderstellung innerhalb der spätmittelalterlichen Universitätslandschaft eingeräumt. ${ }^{11}$ Man verwies darauf, daß sie aufgrund ihrer Lage am Meer eine wesentlich größere Ausstrahlungskraft auf ausländische Gebiete vorzuweisen hatten. ${ }^{12}$ Außerdem brachte man das Argument vor, daß sich die Wirtschafts- und Handelsverbindungen durch die Zugehörigkeit der Universitätsstädte zum Hansebund auch auf den Universitätsbesuch ausgewirkt hätten. 13 "Ostsee- und Hanseuniversität" fungierte nicht nur als "terminus technicus", sondern stand für eine programmatische Aussage über die Wirksamkeit Rostocks und Greifswalds innerhalb des europäischen Universitätssystems. ${ }^{14}$ Ziel der Untersuchung soll nicht zuletzt die Überprüfung solcher pauschalen Urteile sein, insbesondere wenn diese im Widerspruch mit anderen universitätsgeschichtlichen Erkenntnissen stehen. ${ }^{15}$ Wie schon aus dem Titel hervorgeht, wird als übergreifende Themenstellung die Frage der Herausbildung der "Landesuniversität" im späten Mittelalter genommen. Das 15. Jahrhundert gilt in der Forschung als Übergangsphase, in der sich dieser Prozeß vollzog. ${ }^{16}$ Während die ersten Universitäten des Reichsgebietes noch eher einem "universalen" Modell zuzuordnen sind, beginnt sich ab der zweiten Hälfte des 15. Jahrhunderts der neue Typ durchzusetzen. Die Untersuchung der Herkunft der Greifswalder Studenten soll helfen, den Herausbildungsprozeß einer "Landesuniversität" am Beispiel Greifswalds zu beleuchten und die Ergebnisse im Rahmen der Gesamtentwicklung im Reich zu bewerten. Dabei soll die Arbeit einerseits versuchen, Gründe und Ursachen zu erforschen, andererseits soll sie zeigen, wie und wann dieser Prozeß im einzelnen verlief sowie nachweisbaren Konsequenzen und Folgen nachgehen. Die Forschung hat im 15. Jahrhundert geradezu eine zweite Gründungswelle konstatiert, die mit der Greifswalder Gründung 1456 einsetzte und das regional begrenzte Modell im Reich etablierte. ${ }^{17}$ Die Bedeutung eines Vergleichs Greifswalds mit dem älteren Rostock liegt daher auf der Hand und soll in dieser Frage zu mehr Klarheit führen. Außerdem soll geklärt werden, ob die struktur- und entwicklungsgeschichtlichen Unterschiede zwischen nord- 
östlichen und süd-westlichen Reichsteilen, die offensichtlich am Ausgang des Mittelalters noch vorhanden waren, auch für den Universitätsbesuch im nördlichen Pommern von Bedeutung waren.18 Worin unterschied sich die Schicht der akademisch Gebildeten in den verschiedenen Reichsregionen? Gab es eine besondere Sozialstruktur bei Studenten aus Pommern? Im Hauptteil der Arbeit soll eine ausführliche Auswertung des Quellenmaterials erfolgen. Methodisch wurde dabei die bereits 1935 erschienene Dissertation von Wolfgang Keck zur Herkunft der Leipziger Studenten von 1409 bis 1430 als Anregung und Vorbild herangezogen, während die übergreifenden Aussagen in der Arbeit von Schwinges zum Teil als wichtige inhaltliche Orientierungshilfe genutzt werden konnten. Außerdem boten die verschiedenen älteren Arbeiten die Möglichkeit des quantitativen und qualitativen Vergleichs mit anderen Universitäten.

Zur besseren Überschaubarkeit galt es, Tabellen und Grafiken in die Arbeit einzufügen, die Text und Zahlen begleiten. Dafür war eine computergestützte Aufbereitung der Daten in den Matrikeln hilfreich, die für diesen Zweck in eine Datenbank übertragen wurden. Sie ermöglichte einen flexiblen Zugriff, so daß auch komplexere Fragen, die einen höheren Rechenaufwand erforderten, zügig beantwortet werden konnten. Während verschiedene neuere Forschungen eine Art Stichprobenverfahren gewählt haben, bei dem nur einzelne Jahrgänge in gewissen Zeitabständen betrachtet werden ${ }^{19}$, soll die vorliegende Untersuchung alle Studenten des gewählten Zeitraums umfassen. Da Greifswald zu den kleineren Universitäten des Reiches gehörte, hätte ein anderes Verfahren leicht zu entstellenden Ergebnissen geführt. Außerdem soll ein zentrales Anliegen der Arbeit sein, als Informationsquelle für andere Forschungen zu dienen, was nur durch eine vollständige Auswertung des Materials zu erreichen ist. Die zeitliche Begrenzung wurde auf das Jahr 1524 gesetzt, und war dadurch gegeben, daß mit diesem Jahr eine Matrikellücke bis zum Jahr 1539 einsetzt. Obwohl die Reformation bei fast allen Universitäten im Reich einen starken Rückgang der Studentenzahlen auslöste, bewirkte sie doch nur in Greifswald das völlige Ausbleiben der Studenten. ${ }^{20}$ Ab etwa 1526 bis zur Eröffnung der protestantischen Universität im Jahre 1539 durch Herzog Philipp I. mußte sie ihren Unterricht einstellen, so daß diese natürliche Zäsur den Zeitraum von 1456 bis 1524 als erste oder mittelalterliche Phase der Universität erscheinen läßt. ${ }^{21}$

Nach einer kurzen Einführung über die Umstände der Greifswalder Gründung und ihrer Eröffnung 1456 sowie Einzelheiten und Besonderheiten zur Inskriptionsweise in der Greifswalder Matrikel beginnt die Arbeit mit einer Analyse der Gesamtfrequenz der Greifswalder Studenten zwischen 1456 und 1524. Darin sollen die Wachstums- und Abstiegsphasen des Greifswalder Universitätsbesuchs erfaßt und in Beziehung zu besonderen historischen Konstellationen und Ereignissen gesetzt werden. Im Anschluß daran werden die Angaben zur sozialen Herkunft der Greifswalder Studenten analysiert, um auf diese Weise einen Eindruck vom sozialgeschichtlichen Hintergrund eines spätmittelalterlichen Universitätsstudiums zu erlangen. Im Vergleich mit neuesten Erkenntnissen über andere Universitäten des Reiches sollen einerseits regionale Unterschiede innerhalb des Reiches hinterfragt werden, andererseits sollen die Besonderheiten der pommerschen Universität gegenüber anderen Universitäten herausgearbeitet werden. Im eigentlichen Hauptteil werden die geographischen Herkunftsangaben analysiert. Die Analyse erfolgt sowohl vertikal, indem nach einzelnen Gebieten und aus ihnen stammenden Studenten gefragt wird, als auch horizontal, bei der die Veränderungen und Verschiebungen der Gesamtbesucherschaft innerhalb des Zeitraums systematisch erfaßt werden. Auch hier sollen wichtige Herkunftsgebiete und -orte der Studenten hinsichtlich besonderer struktureller Voraussetzungen für ein Universitätsstudium analysiert werden. Anhand 
prosopographischer Literatur sollen außerdem weitere Erkenntnisse über den sozialen Hintergrund der Studenten einzelner Städte gewonnen werden. Die Gegenprobe, in der 26 meistbeteiligte Orte einzeln dahingehend untersucht werden, wie oft sie in anderen Universitätsmatrikeln als Herkunftsort genannt werden, bildet das Abschlußkapitel, und soll, ausgehend von der einleitenden Fragestellung nach der Herausbildung der "Landesuniversität", die vorher für Greifswald erzielten Ergebnisse überprüfen bzw. stützen.

Abschließend sei hier noch über die Form der Verweisung anzumerken, daß eine solche selbstverständlich nicht für jeden einzelnen Studenten mit entsprechender Seite in der jeweiligen Matrikel erfolgen kann. Bei über 10.000 bearbeiteten Matrikeleinträgen hätte dies den Rahmen der Arbeit gesprengt. Daher werden die Angaben nur unter Nennung der jeweiligen Herkunftsmatrikel zusammengefaßt.

\subsection{Zur Geschichte der Universität Greifswald}

Obwohl man die Greifswalder Gründung von 1456 allgemein als Beginn einer zweiten Gründungswelle bezeichnet, hängt ihre Entstehung eng mit den Anfängen der Universität Rostock zusammen, deren kurzzeitige Auslagerung nach Greifswald 1437 bis etwa 1439/40 erst dazu beitrug, den Gedanken an die Gründung einer Greifswalder Hohen Schule zu wecken. ${ }^{22}$

1431/32 hatte König Sigismund die Reichs- und Oberacht über die Stadt Rostock verhängt, nachdem die Hansestädte 1427 im Krieg gegen König Erich dem Pommer unterlegen waren und daraufhin Rostocks Ratsherrschaft durch die aufgebrachte Bürgerschaft gestürzt worden war. ${ }^{23} 1434$ kam es dann auch noch zur Belegung der Stadt mit Bann und Interdikt durch das Baseler Konzil und Papst Eugen IV. Die Universität wurde aufgefordert, jeden Kontakt mit dem exkommunizierten neuen Rat und den übrigen Einwohnern abzubrechen, woraufhin sie sich gezwungen sah, am 13. März 1437 Rostock zu verlassen. Anfang April befand sie sich bereits in der pommerschen Hansestadt Greifswald und übte ihre Tätigkeit dort über fünf Semester ordnungsgemäß aus. ${ }^{24}$ Als im Januar 1440 der Kirchenbann und 1442 die Reichsacht über Rostock wieder aufgehoben wurde, fanden bald Verhandlungen zwischen Rat und Universität statt, die zur Rückkehr der Universität am 7. Mai 1443 führten. ${ }^{25}$

Während es wohl zu weit geht, die Universität Greifswald als Tochtergründung Rostocks zu bezeichnen, ${ }^{26}$ lassen sich doch enge Zusammenhänge sowohl in personeller und verfassungsgeschichtlicher Hinsicht feststellen. ${ }^{27}$ Diese Zusammenhänge treten allerdings zurück gegenüber der bedeutenden Stiftergestalt Heinrich Rubenows, dem die Bedeutung als Gründer und Initiator der Universität zuteil wird. ${ }^{28}$ Zwar lag die Universitätsgründung auch im Interesse von Landesfürstentum, Kirche und Stadt, deren Repräsentanten hatten aber lediglich mitwirkende Bedeutung an der Gründung. ${ }^{29}$

Rubenow stammt aus einer alteingesessenen Handelsherrenfamilie, die in Greifswald und Stralsund im Rat saß. Seit 1436 studierte er an der Universität Rostock und folgte der Universität bei deren Exodus nach Greifswald. ${ }^{30} 1447$ wird er als baccalaureus legum in Leipzig immatrikuliert, wo er bereits im gleichen Jahr zum Lizentiaten des römischen und Bakkalaureus des kanonischen Rechts 
promoviert wird, und sich bald danach als legum doctor bezeichnet. ${ }^{31} 1447$ übernimmt er das Amt des Syndicus der Stadt Greifswald, 1449 wird er Bürgermeister und gibt zwei Jahre später der Stadt eine neue Verfassung, die bis 1651 in Kraft bleiben sollte. Als Gesandter Greifswalds sammelte er diplomatische Erfahrungen auf den Tagfahrten der Hansestädte und knüpfte weitreichende Beziehungen. Ferner soll er auch als Kanzler Herzog Wartislaws IX. und des Unionskönigs Erich von Pommern tätig gewesen sein. Er erscheint in den Quellen als die bemerkenswerte Gestalt eines spätmittelalterlichen gelehrten und zugleich handelnden Bürgers, der, erprobt in den Geschäften der Welt und im Umgang mit mächtigen Personen aus Staat und Kirche, selbst ein Mächtiger und ein Weltmann war. ${ }^{32}$

Bis zu seiner Ermordung in der Sylvesternacht des Jahres 1462 hat Rubenow faktisch die Geschicke der Universität geleitet. Daß die Universität gedeihen konnte, lag nicht zuletzt an den zahlreichen finanziellen Zuwendungen, die er der jungen Gründung zukommen ließ. Insgesamt beliefen sich Rubenows Aufwendungen, die er in einer Urkunde von 1456 zusammenstellte, auf viele tausend Mark; dazu kamen juristische Bücher im Werte von mehr als tausend Gulden.33

Im Stiftungprivileg für die Universität Greifswald, das auf den 29. Mai 1456 datiert wurde, erlaubte Papst Calixtus III. die Errichtung eines studium generale in Greifswald. Zuvor hatte Herzog Wartislaw IX. von Pommern sich mit der Bitte an den Papst gewandt, dem zu errichtenden Generalstudium ein solches Privileg zu gewähren. Am 31. Juli 1455 ist dann in Rom die Entscheidung gefallen, ein Verfahren über das Begehren des Pommernherzogs zu eröffnen. Dafür mußte geprüft werden, ob die Angaben des Herzogs der Wahrheit entsprachen und die "Doktoren und Magister bei diesem Studium in genügender Zahl angemessen unterhalten werden können."34 Bischof Stephan Bodeker von Brandenburg wurde schriftlich von der Kurie beauftragt, zu überprüfen, ob die finanziellen Voraussetzungen dafür vorhanden seien.

Rubenow hatte nicht nur eigene Mittel für sein Ziel eingesetzt, sondern er wußte auch die Stadt Greifswald, den Herzog, die Äbte der Klöster Eldena, Neuenkamp und Pudagla und manche andere zu wirksamer Mithilfe zu gewinnen. So erreichte er, daß die vom Papst für den Unterhalt der Professoren geforderten tausend Gulden jährlich gesichert waren, und daß ein Kollegiatstift an St. Nicolai errichtet wurde, dessen 28 Pfründen den Lehrern der Universität vorbehalten werden sollten. ${ }^{35}$ Außerdem wurden drei Pfarrpfründen außerhalb der Stadt zur Finanzierung der Theologieprofessuren reserviert. Das Patronat über die drei städtischen Pfarrkirchen wurde der Universität vom Kloster Eldena übertragen, während der Greifswalder Rat neben einem medizinischen Lehrstuhl zusammen mit dem Herzog drei Kollegien für die Juristen und die Artisten stiftete. 36

Nach Befragung mehrerer glaubwürdiger Zeugen bestätigte der Brandenburger Bischof die Wahrhaftigkeit der Aussagen und schickte alle Unterlagen an die Kurie, die ein weiteres Mal durch den in Rom befindlichen Bischof Johannes von Pavia überprüft wurden. Erst jetzt konnte das Privileg für die Universität Greifswald erteilt werden. Am 15. Dezember 1455 erließ Wartislaw IX. eine Bekanntmachung, daß er mit Zustimmung seiner Räte, des Bischofs von Kammin, der Äbte der pommerschen Klöster, der Stadtgemeinden und der Vasallen ein Generalstudium in Greifswald zu errichten beabsichtige. Am gleichen Tag verkündeten Bürgermeister und Ratsherren der Stadt Greifswald, die nötige Fürsorge für Unterbringung und Unterhalt desselben zu tragen. ${ }^{37}$ 
Die Ausstellung der Papstbulle wurde noch einmal gefährdet, nachdem die Universität Rostock Abgesandte nach Rom geschickt hatte, um die Greifswalder Angelegenheit zu hintertreiben. Diese Aussagen sind in zwei Briefen überliefert, die der Greifswalder Beauftragte an der Kurie, Nicolaus Bruckmann, an Rubenow schickte. ${ }^{38}$ Am 16. Juni 1456 bittet Bruckmann in einem Schreiben, daß Rubenow für die Einlösung der auf den 29. Mai 1456 datierten Stiftungsbulle den erforderlichen Betrag von 75 Gulden übersenden solle. ${ }^{39}$ Nach Einlösung des Stiftungsbriefs und Überbringung an den Kamminer Bischof, verordnete dieser am 21. September 1456, ein consilium universitatis zu bilden, einen Rektor zu wählen und Statuten zu erlassen. Am 28. September erließ der Herzog einen landesherrlichen Stiftungsbrief, so daß am 17. Oktober die Universität Greifswald eröffnet werden konnte, indem das Privileg in feierlicher Prozession auf den Hauptaltar durch den Kamminer Bischof Henning Iwen niedergelegt wurde. ${ }^{40}$ 


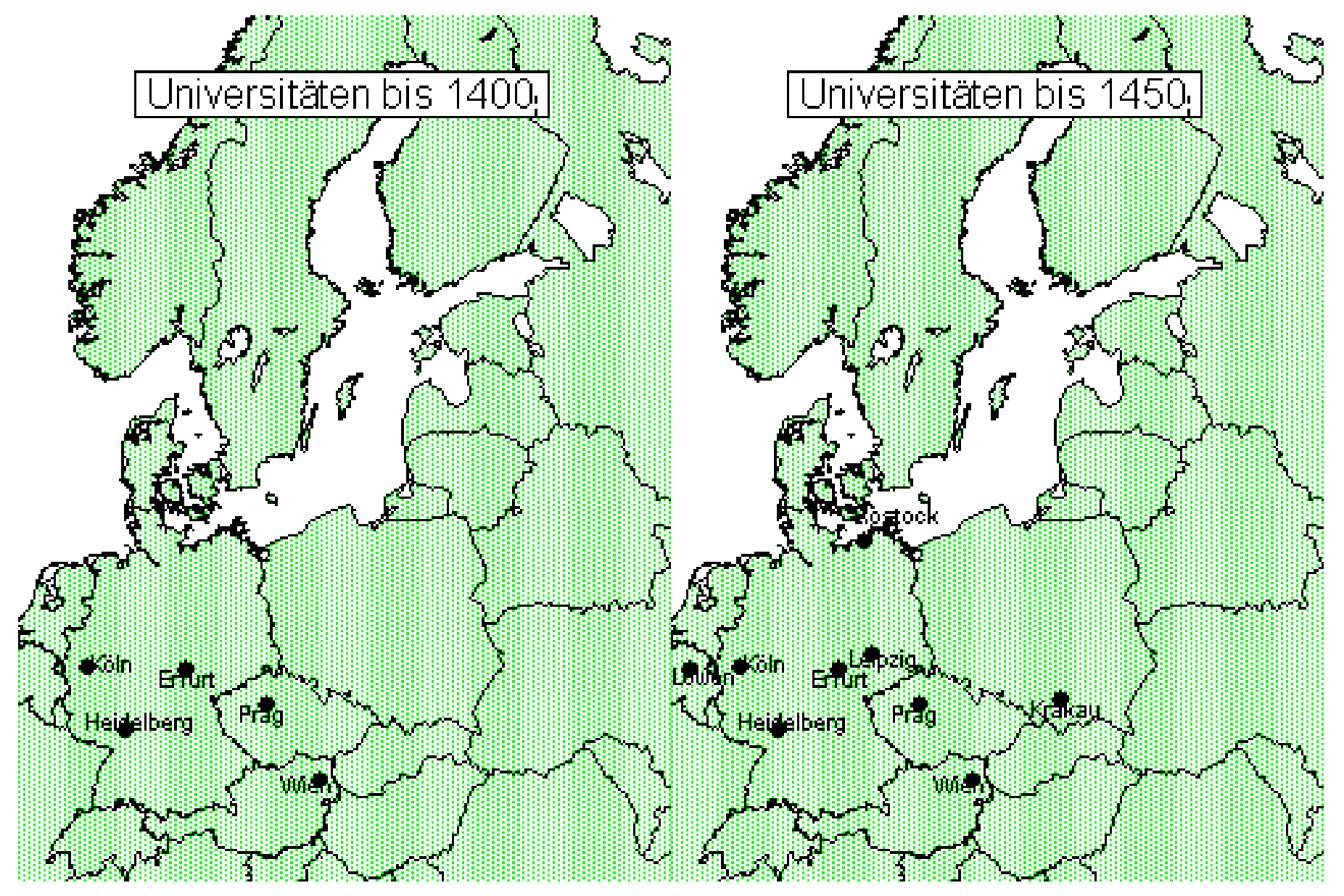




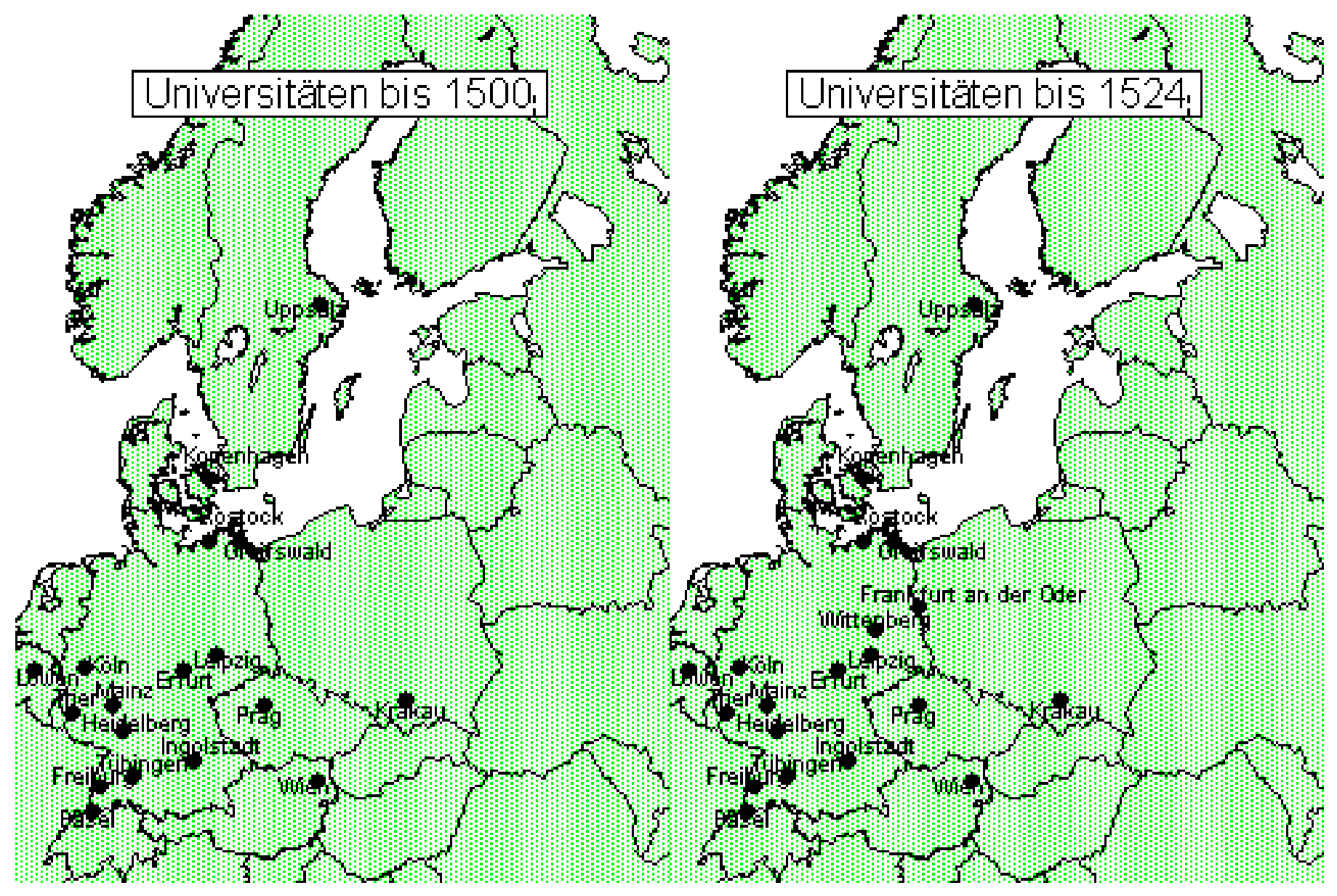




\section{Die Greifswalder Inskriptionen 1456-1524}

\subsection{Zur Frequenz der Greifswalder Universität}

Am 19. Oktober begann die Immatrikulation mit zuerst 61 Ehrenpersonen, die umsonst eingetragen wurden, da sie sich zum Teil um die Errichtung des Studiums verdient gemacht hatten sowie acht Beamten des Bischofs auf dessen Bitte. Während des ersten Rektorats Rubenows wurden außerdem noch 173 reguläre Studenten eingeschrieben. ${ }^{41}$

Diese Zahlen sollten im behandelten Zeitraum nie wieder erreicht werden und sind als Ausnahmeerscheinung im Zusammenhang mit der Universitätsgründung zu werten. Bis zum Jahre 1524 wurden insgesamt 3317 Studenten immatrikuliert. ${ }^{42}$

Die durchschnittlichen Inskriptionszahlen belaufen sich in der Zeit zwischen Gründung und Reformation auf jährlich etwa 50 Studenten. Dabei kommt es zu erheblichen Schwankungen in den einzelnen Jahren. Wenn man vom Gründungsjahr absieht, wird der höchste Wert im Jahre 1487 mit einer Zahl von 100 Immatrikulationen erreicht, während im Jahr 1463 nicht ein einziger Student eingeschrieben werden konnte. Die Schwankungen der Frequenz werden in der folgenden Grafik sichtbar. Man erkennt dort, daß die Studentenzahlen nach der Universitätsgründung bis 1463 einen starken Abstieg erlebten. Dieses Phänomen findet sich in allen mittelalterlichen Universitäten, freilich nicht in solch ausgeprägter Form wie in Greifswald, wo im achten Jahre nach der Gründung kein einziger neuer Student immatrikuliert wird. Von 1464 bis etwa 1487 kommt es zu einer Konsolidierungsphase, in der das Niveau leicht ansteigt. Wenn man die drei Studenten des Jahres 1485 zu den 67 des Jahres 1486 zählt, dann sieht man, daß diese Phase des Anstiegs 1487 ihren Höhepunkt erreicht, und dann ein wellenartiger Abstieg der Immatrikulationen erfolgt, unterbrochen von den kurzen Hochphasen 1499 und 1514. 


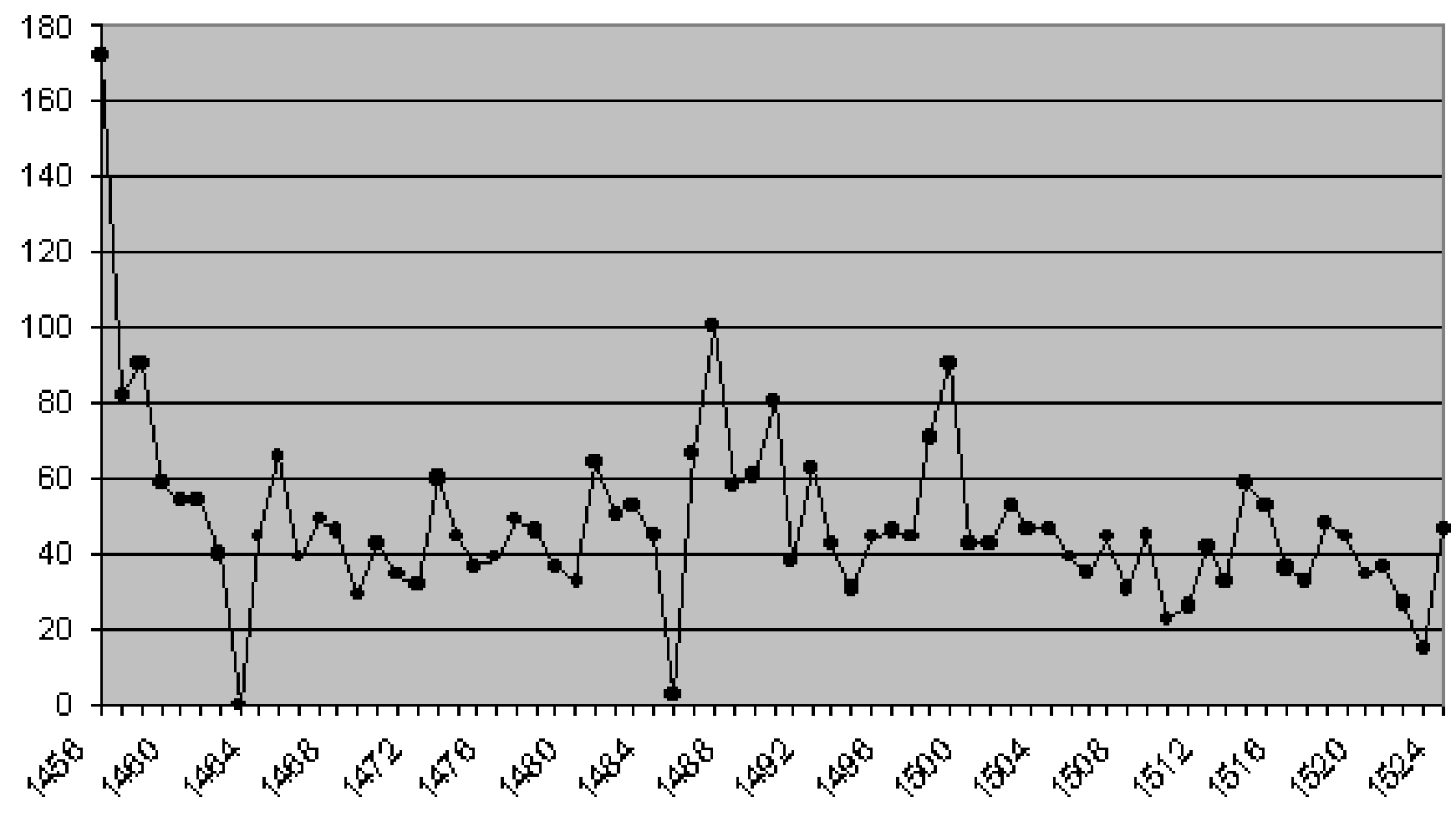

Abbildung 1: Frequenzkurve 1456-1524

Diese Wachstums- und Abstiegsphasen hingen mit inneren und äußeren Umständen der Greifswalder Universität zusammen, die im folgenden erläutert werden sollen. Zuerst zu den Jahren niedriger Frequenz: in der Sylvesternacht 1462 wurde der Universitätsgründer Heinrich Rubenow ermordet. Die darauf folgenden Wirren sind als Grund für das Ausbleiben der Immatrikulationen im Jahr 1463 zu werten. ${ }^{43} 1485$ berichtet die Matrikel von einer Pest in Greifswald. Sie führte zur geringen Frequenz in diesem Jahr. 44

Die höheren Inskriptionszahlen in den achtziger Jahren des 15. Jahrhunderts hingen mit einem äußeren Ereignis zusammen. In diese Zeit fällt eine schwere Krise an der Rostocker Universität, die zum Abzug vieler Studenten nach Greifswald führte. 1484 bis 1487 war Rostock gebannt durch den Erzbischof von Bremen, 1487 bis 1491 durch den Ratzeburger Bischof. 1487 bis 1488 mußte die Universität nach Lübeck auswandern, doch konnten die Differenzen mit der Stadt erst 1491 vollständig beigelegt werden. Die Krise wird allgemein als "Rostocker Domfehde" bezeichnet, da es um die Einrichtung eines Domstifts an der Rostocker St. Jakobi-Kirche zur Unterhaltung der Universitätsprofessoren ging. Ein solches Domstift hätte den Einfluß des Landesherrn in Rostock verstärkt, was bei einem großen Teil der Rostocker Bürger auf erheblichen Widerstand stieß. ${ }^{45}$

Die starke Frequenz um 1500 ist mit der Anwesenheit zweier berühmter italienischer Humanisten, Petrus und seines Sohnes Vincentius aus Ravenna, zu begründen, die Herzog Bogislaw X. auf einer Pilgerfahrt als Lehrer für die Greifswalder Universität gewinnen konnte. Ihre Anwesenheit ist für die Jahre 1498 bis 1503 belegt. Während Ulrich Huttens Anwesenheit 1509 keine Wirkung auf die Frequenzkurve hatte, ist ein weiterer jedoch geringer Ausschlag 1514 zu vermerken. In diesem Jahr konnte der Herzog mit Johannes Hadus für kurze Zeit einen weiteren berühmten Gelehrten für die 
pommersche Universität gewinnen. Von nun an bis zum Ende des Betrachtungszeitraums 1524 war die Zahl der Inskriptionen recht gleichbleibend. Einzelheiten über die genannten Ereignissen und weitere geschichtliche Hintergründe während des Zeitraums erfolgen später in den jeweiligen Kapiteln, so daß dieser Überblick hier genügen soll.

Die Greifswalder Universität bietet eine günstige Ausgangslage für eine Analyse der Studentenschaft, da sich das Matrikelbuch durch seine Ausführlichkeit auszeichnet. Neben den Namen und Herkunftsorten finden sich häufig Angaben über Herkunftsdiözesen, Herkunftsländer oder -regionen, über geleistete Gebührenzahlungen, wobei vereinzelt sogar auf die besondere finanzielle Situation des Studierenden eingegangen wird. Ferner sind Angaben über Berufe, den sozialen Status, über Ämter und Würden, akademische Vorbildung sowie über Graduierungen an anderen Universitäten zu finden. Ein allgemeines Problem bei der Verwertbarkeit aller mittelalterlichen Matrikelbücher besteht darin, daß solche Angaben nicht regelmäßig vorhanden sind. Die Rektoren unterschieden sich in Zuverlässigkeit und Genauigkeit der Inskription. Da in manchen Semestern nur vereinzelte Herkunftsangaben zu finden sind, können allgemeine Aussagen nur mit Einschränkungen vorgenommen werden. Im Vergleich zu anderen Universitätsmatrikeln dieser Zeit sind die Angaben für Greifswald zwar verhältnismäßig günstig, allerdings darf man nicht übersehen, daß die Frequentierung der Greifswalder Hohen Schule nur sehr gering war. Bei Betrachtung der Studentenzahlen der anderen deutschen Universitäten dieser Zeit liegt Greifswald mit seiner Frequenz weit hinten. ${ }^{46}$ Neben strukturgeschichtlichen Besonderheiten Pommerns, auf die später noch eingegangen werden soll, ist der geringe Zulauf vor allem auf die Konkurrenz zur Nachbaruniversität Rostock zurückzuführen. ${ }^{47}$ Lückenhafte Herkunftsangaben können sich aufgrund der geringen Datenmenge entstellend auf ein Ergebnis auswirken, so daß man solche Zahlen nur als Annäherungswerte verstehen darf.

Ein weiteres Problem besteht in der Tatsache, daß ein beträchtlicher Teil der Immatrikulierten nachweislich nicht studiert hat. Die Privilegien, die eine Universität im Mittelalter zu vergeben hatte und in deren Genuß jedes Mitglied kam, bildeten für viele einen großen Anreiz. So ist es zu erklären, daß sich fast jeder, der in eine nähere Beziehung zur Universität trat, in die Matrikel einschreiben ließ, um damit Mitglied zu werden. Dazu zählten neben den Dienern der wohlhabenden Studenten auch Buchdrucker, Buchbinder oder Verleger, die nur von Berufs wegen mit der Universität verkehrten. ${ }^{48}$ Bei einem weiteren Teil der Immatrikulierten handelt es sich um Ehrenpersonen, die sich, entweder zur Ehre der Universität oder zu ihrer eigenen, inskribieren ließen. ${ }^{49}$ Da die Studienordnung keine scharfe Trennung zwischen Lehrenden und Studierenden zuließ und ein Magister der Artistenfakultät sein Studium an einer der höheren Fakultäten zumeist fortsetzte, umfaßten die Matrikel außerdem auch immer die Professorenschaft. Aus all dem ergibt sich, daß die Zahl der wirklichen Studenten nicht genau ermittelt werden kann, zumal nicht alle von ihnen überhaupt in der Matrikel verzeichnet sind. Man kann bei allen mittelalterlichen Universitäten von einer hohen Dunkelziffer von Studierenden ausgehen, die Vorlesungen hörten, ohne eingeschrieben zu sein. Bei einer Bewertung der folgenden Ergebnisse muß dies berücksichtigt werden. Endgültige Zahlen zum Universitätsbesuch kann man aufgrund der Quellenlage nicht erreichen. 
Zuerst sollen nun die verschiedenen Angaben über die Studenten auf ihre Repräsentativität und Qualität hin überprüft werden. Dabei lohnt es sich mit den geographischen Herkunftsangaben zu beginnen, da sie in allen mittelalterlichen Matrikeln zu den häufigsten Daten gehören. Um die räumliche Herkunft der Studenten überhaupt ermitteln zu können, muß man in der Lage sein, die Herkunftsorte der Studenten exakt zu bestimmen. Leider weisen die Matrikel immer wieder Mängel auf, die eine solche genaue Zuordnung verwehren. An der Zahl fehlender Herkunftsangaben in der Greifswalder Matrikel kann man bereits die Unregelmäßigkeit konstatieren. Von den 3317 Studenten, die in dem Zeitraum zwischen 1456 und 1524 immatrikuliert wurden, ist für 183 überhaupt keine Herkunftsangabe gemacht worden, was einem Prozentsatz von etwa 5,5 entspricht. Aus der folgenden Tabelle geht hervor, daß vor allem in der Anfangszeit solche Lücken zu verzeichnen sind, während sie in den folgenden Jahren unbedeutender werden. Der Überschaubarkeit halber war es sinnvoll, verschiedene Betrachtungszeiträume festzulegen, die eine Tendenz oder Entwicklung sowohl tabellarisch als auch grafisch veranschaulichen können. Der Betrachtungszeitraum von 69 Jahren wurde dafür in neun Siebenjahresabstände (1456-1518=63 Jahre) und einen Sechsjahresabstand (1519-1524=6 Jahre) unterteilt. ${ }^{50}$

Tabelle 1: Fehlende Herkunftsangaben

\begin{tabular}{|l|l|l|l|l|l|l|l|l||l|r||}
\hline I & II & III & IV & V & VI & VII & VIII & IX & X & Gesamt \\
\hline \hline 85 & 26 & 32 & 8 & 0 & 4 & 9 & 9 & 7 & 3 & 183 \\
\hline $15,37 \%$ & $9,52 \%$ & $11,07 \%$ & $2,40 \%$ & $0,00 \%$ & $1,30 \%$ & $2,28 \%$ & $3,70 \%$ & $2,30 \%$ & $1,47 \%$ & $5,52 \%$ \\
\hline
\end{tabular}

Mit 5,5 Prozent fällt der Anteil fehlender Angaben für Greifswald erheblich niedriger aus als für Leipzig, wo er zwischen 1409 und 1430 bei 21,6 Prozent ${ }^{51}$ lag, während Köln mit seinen 1,6 Prozent $^{52}$ als musterhaft zu bewerten ist. Zwar bewegt sich die Zahl fehlender Herkunftsangaben in Greifswald noch in einer annehmbaren Größenordnung, doch muß man die gemachten Herkunftsangaben in Qualität und Ausführlichkeit unterscheiden. 781 der Studenten gaben nur ein Land oder eine Diözese als Herkunftsbezeichnung an, was einem Anteil von 23,6 Prozent entspricht. Diese Zahl liegt weit über denen anderer Universitäten (Leipzig: 1,5\%, Köln: 6,2\%). Studenten mit solchen Herkunftsbezeichnungen können nur für eine grobe Richtungsuntersuchung in Betracht kommen, während sie bei einer Analyse der örtlichen Beschaffenheit natürlich wegfallen müssen. ${ }^{53}$ Vor allem in den besucherreichen Jahrgängen 1484 bis 1490 und 1498 bis 1504 sind viele solcher Angaben zu verzeichnen, während sie ab 1512 stark zurückgehen (siehe folgende Tabelle).

Tabelle 2: Land- und Diözeseangaben

\begin{tabular}{|l|l|l|l|l|l|l|l|l||l|r||}
\hline I & II & III & IV & V & VI & VII & VIII & IX & X & Gesamt \\
\hline \hline 90 & 55 & 84 & 72 & 150 & 79 & 127 & 82 & 24 & 18 & 781 \\
\hline
\end{tabular}




\begin{tabular}{|l|l|l|l|l|l|l|l|l|l|l|}
\hline $16,27 \%$ & $20,15 \%$ & $29,07 \%$ & $21,62 \%$ & $36,14 \%$ & $25,65 \%$ & $32,15 \%$ & $33,74 \%$ & $7,89 \%$ & $8,82 \%$ & $23,55 \%$ \\
\hline
\end{tabular}

Für weitere 34 Studenten sind die Herkunftsangaben mängelhaft, so daß auch sie sich nicht genau bestimmen ließen. Mit einem Anteil von weniger als einem Prozent fallen sie freilich nicht ins Gewicht, doch sollen die Faktoren hier aufgezeigt werden, die eine örtliche Zuordnung verhindern konnten. Da es keine einheitliche Rechtschreibung gab, wurden die Ortsnamen durch den Rektor nach Gehör aufgeschrieben und häufig ins Lateinische übersetzt. Dies führte zu Verballhornungen, die eine Identifizierung dieser Orte erschwerten. ${ }^{54}$ Außerdem wurden Orte verzeichnet, deren Namen entweder überhaupt nicht bekannt sind, oder mehrere Möglichkeiten der Zuordnung zuließen. ${ }^{55}$

Mehrfache Zuordnungsmöglichkeiten bedurften zur näheren Bestimmung einer weiteren Eingrenzung z.B. durch Angabe der Diözese oder des Landes. Im Allgemeinen konnte das Orts- und Personenverzeichnis der Matrikeledition als Grundlage für die Herkunftszuordnungen genommen werden, und nur in seltenen Fällen mußte davon abgewichen werden. ${ }^{56}$ Bei Auswertung aller Daten konnte folgendes Ergebnis erzielt werden: ausführliche Angaben, bei denen Ort und Land oder Diözese verzeichnet waren, wurden von 1266 der Studenten gemacht, was einem Anteil von mehr als 37 Prozent entspricht. Von den auswertbaren Ortsangaben ohne weiterer Eingrenzung konnten 1053 (=32\%) eindeutig identifiziert werden, so daß man zusammen etwa 70 Prozent auswertbare Daten für eine genaue örtliche Untersuchung, und 93 Prozent für eine grobe Richtungsuntersuchung erhält (siehe folgende Grafik). Insgesamt wurden 397 unterschiedliche Orte und 75 unterschiedliche Länder, Landschaften und Diözesen genannt.

Wichtig für die Frage nach der räumlichen Herkunft ist schließlich, welcher Ort überhaupt eingetragen wurde, der Geburtsort, der nahegelegene größere Ort oder etwa der Ort des letzten Aufenthalts. Für andere Universitäten konnte in einzelnen Fällen bewiesen werden, daß es sich um den Geburtsort handelte, da man das weitere Schicksal des Studenten kannte. Solche Stichproben lassen vermuten, daß dies auch für die Greifswalder Inskriptionenen gilt und man in der Regel von zuverlässigen Angaben ausgehen kann, dennoch bleiben in dieser Hinsicht Unsicherheiten. ${ }^{57}$ 


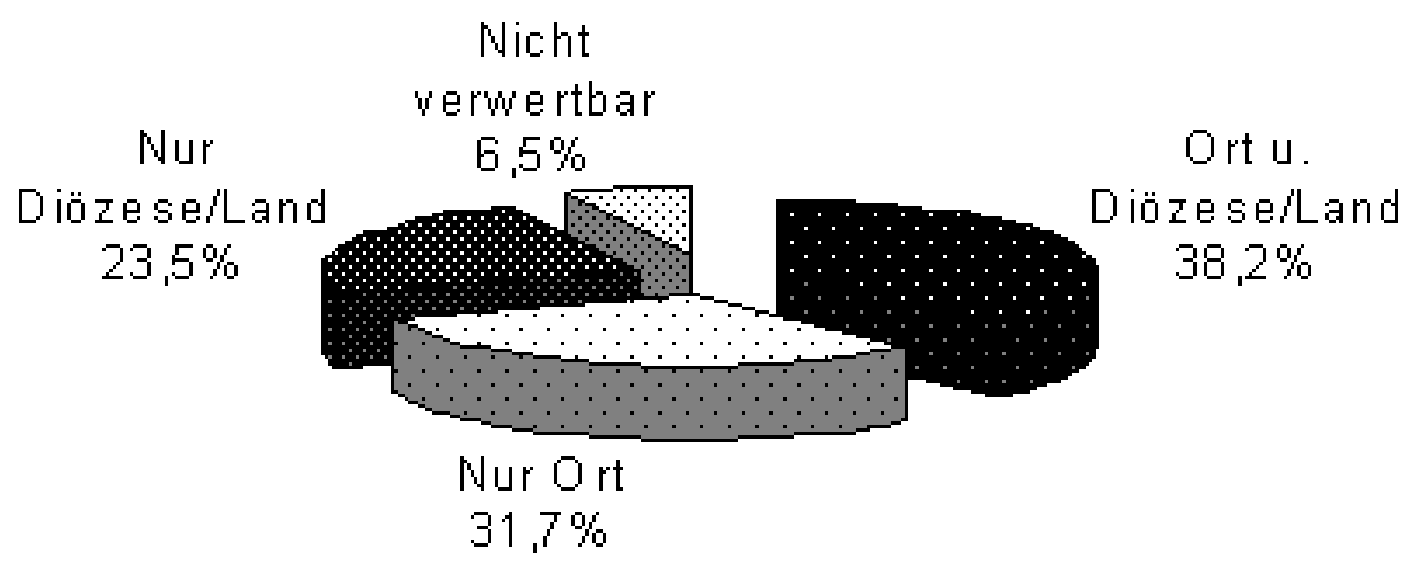

Abbildung 2: Herkunftsangaben

\subsubsection{Zur Unterscheidung einzelner Betrachtungsgebiete}

Um die Herkunft der Greifswalder Studenten darzustellen, müssen zuerst einzelne Gebiete unterschieden werden. Da die Greifswalder Universität keine Nationeneinteilung hatte, die ein günstiger Ausgangspunkt für eine Betrachtung ist ${ }^{58}$, müssen hier recht willkürliche Grenzen gezogen werden. Pommern erstreckt sich über die heutigen Grenzen der BRD hinaus, so daß eine Unterscheidung zwischen ausländischen und deutschen Gebieten in den Grenzverläufen des ausgehenden 20. Jahrhunderts nicht ratsam erscheint. Daher wurde zwar auch die heutige Lage der Orte bestimmt, doch sollten die Grenzen im 15. Jahrhundert den Ausgangspunkt bilden. Das gesamte Territorium Pommerns 59 wurde als zusammenhängendes Betrachtungsgebiet aufgefaßt.

Die Hansestadt Greifswald liegt im westlichen Teil Pommerns. Ihre Entfernung von Orten in Mecklenburg und Brandenburg ist zum Teil geringer als von Orten innerhalb Pommerns. Eine unterschiedliche Qualifizierung der drei Territorien ist daher nicht sinnvoll. Das zweite Betrachtungsgebiet umfaßt deshalb all jene Studenten, deren Herkunftsort in diesen beiden Nachbarländern liegt, die damit ebenfalls von regionaler Herkunft sind. Für das dritte Gebiet wird der Betrachtungsradius ausgeweitet. Sämtliche Reichsgebiete werden ihm zugeordnet, während das vierte Gebiet alle übrigen Länder und Landschaften Europas umfaßt. Durch die Überschneidungen und Verschachtelungen der einzelnen Territorien sollen einige Entscheidungen über die Zuordnung zu einem Land im Vorfeld geklärt werden.

Das gesamte Deutschordensgebiet (preußische und livländische Territorien) wurde aufgrund seiner Sonderstellung dem Ausland zugezählt. Im Reich selber wurden die Kreiseinteilungen, obwohl erst gegen Ende des Betrachtungszeitraums (1500/1512) eingeführt, der Überschaubarkeit halber als 
grobe Orientierung genommen. ${ }^{60}$ Zum obersächsischen Kreis zählten die wettinischen und thüringischen Gebiete, zum niedersächsischen Kreis gehörte das Herzogtum Braunschweig, Holstein, Hamburg und Bremen, während Schleswig bereits als Teil Dänemarks behandelt wurde. Schlesien und Böhmen waren nicht eingekreist, so daß sie einzeln zu behandeln sind. Im westlichen Reichsteil wurde der niederrheinisch-westfälische und kurrheinische Kreis im Zusammenhang betrachtet, während der burgundische Kreis, der etwa den heutigen Beneluxstaaten entspricht, den Greifswalder Einzugsbereich im Westen abschloß. Die südlichen Territorien des Reiches sind durch den oberrheinischen, fränkischen, schwäbischen, bayrischen und österreichischen Kreis vertreten.

\subsubsection{Zur Verteilung der Studenten auf einzelne Gebiete}

Die folgende Grafik stellt die Verteilung der Studenten auf die vier grob eingeteilten Gebiete Pommern, Nachbarn (Mecklenburg und Brandenburg), übriges Reich und Ausland dar. Das Ergebnis zeigt zunächst das Bild einer regional organisierten Studentenschaft mit dem hohen Anteil von fast 49 Prozent Studenten aus Pommern. Nimmt man die Nachbarländer Mecklenburg und Brandenburg hinzu, so kamen im behandelten Zeitraum fast zwei von drei Studenten aus dem Kerngebiet des Greifswalder Einzugsbereichs. Gegenüber den anderen Universitäten der zweiten Gründungswelle ist der Anteil jedoch als recht niedrig anzusehen. Vergleichszahlen sind schwierig zu ermitteln, da man Größe und Bevölkerungsdichte des jeweiligen Territoriums mitberücksichtigen muß. Pommern, Mecklenburg und Brandenburg stellten zwar ein großes Gesamtgebiet dar, doch wäre die gleiche Fläche im Süden des Reiches wesentlich dichter besiedelt gewesen. Dies ist zu berücksichtigen, wenn man die Angaben für Tübingen (etwa 50\% aus dem kleinen Territorium Württemberg) ${ }^{61}$ und Ingolstadt (etwa 70\% Bayern) ${ }^{62}$ betrachtet. Man kann jedoch erkennen, daß die Greifswalder Ergebnisse für Pommern darunter liegen. Nur die Universitäten der ersten Gründungswelle konnten im 15. und beginnenden 16. Jahrhundert eine größere Zahl auswärtiger Studenten anziehen. Die Konfessionalisierung führte später auch dort zu einer Verkleinerung der Einzugbereiche. ${ }^{63}$ Andererseits liegt der Ausländeranteil in Greifswald mit 20 Prozent erheblich höher als in anderen Universitäten des Reiches, wo ausländische Studenten gegenüber anderen Reichsangehörigen prozentual überhaupt keine Rolle gespielt haben. ${ }^{64}$ Dies ist zum einen mit der Randlage im Reich, zum anderen mit der Ostseelage Greifswalds zu begründen. Die übrigen Reichsterritorien gehören ebenfalls zur Kategorie der überregionalen Gebiete, so daß man auf knapp 35 Prozent Studenten überregionaler Herkunft kommt. Damit ist das Greifswalder Ergebnis vergleichbar mit Köln, wo die Werte im gesamten 15. Jahrhundert bei etwa 38 Prozent lagen, und dies, obwohl Köln noch der ersten Gründungswelle angehörte. 65

Doch ist auch hier vor allem der unterschiedliche Anteil an ausländischen Studenten zu bemerken: Nur etwa 5,5 Prozent der Kölner Studenten kam aus Gebieten, die nicht dem Reich angehörten. ${ }^{66}$ Anhand der Karten, die der vorliegenden Untersuchung beigefügt sind, kann man eine Vorstellung von der räumlichen Ausprägung des Greifswalder Einzugsbereichs gewinnen. ${ }^{67}$ Sie verdeutlichen, daß fast der gesamte Norden Europas als Herkunftsgebiet Greifswalder Studenten angesehen werden 
muß.

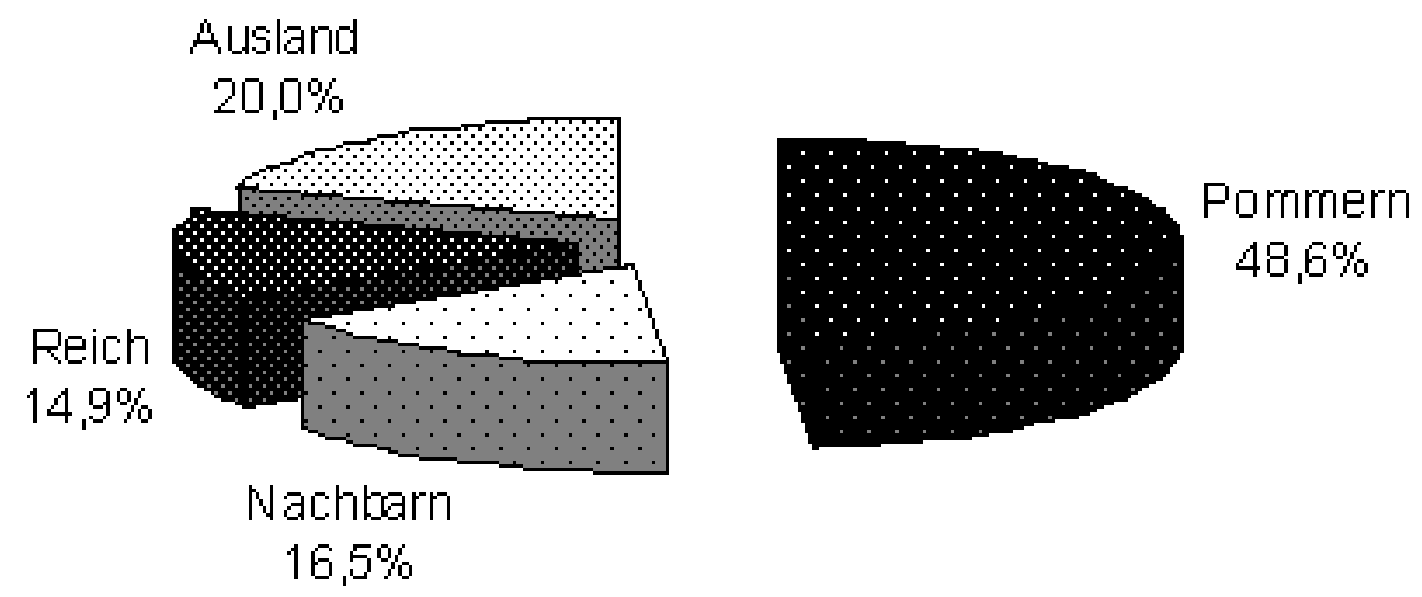

Abbildung 3: Grobe Verteilung auf Gebiete 1456-1524

\subsection{Angaben zur sozialen Herkunft der Studenten}

Wie eingangs erwähnt wurden in die Matrikeln nicht nur räumliche Herkunftsbezeichnungen eingetragen, sondern es wurden auch Angaben über die soziale Herkunft eines Studenten gemacht, die den sozialgeschichtlichen Hintergrund eines Universitätsstudiums im späten Mittelalter belegen können. Im Gegensatz zu den räumlichen Herkunftsangaben lassen solche Personenangaben allerdings nur begrenzte Aussagen zu. Sie sind für eine repräsentative Auswertung zu ungleichmäßig vorhanden, wie schon bei früheren Untersuchungen anderer Universitäten gezeigt werden konnte. ${ }^{68}$ Nur von etwa 1000 Studenten (30\%) waren weitergehende Informationen zu finden, deren Ausführlichkeit sich außerdem noch deutlich unterschied. Immerhin sind von etwa 90 Personen weitergehende Angaben vorhanden, bei denen vorher keine räumliche Herkunftsangabe gemacht worden ist. Ausführliche Informationen findet man vor allem über einflußreiche Persönlichkeiten und Würdenträger, während man vom "Normalstudenten", um den es in dieser Untersuchung in erster Linie geht, zumeist nur den Herkunftsort erfährt. Einzig die Gebührenzahlung kann in dieser Hinsicht weiterhelfen, denn solche Angaben finden sich von über 3000 Studenten (90\%). Der Quellenwert dieser Kategorie ist eigentlich erst in jüngster Zeit erkannt worden. ${ }^{69}$ Die spätmittelalterlichen Universitäten unterschieden sich nicht nur in ihrer Gebührenordnung: auch innerhalb der Studentenschaft gab es deutliche Unterschiede in der Zahlungsfähigkeit trotz festgelegter Summe bei den verschiedenen Hochschulen. Damit lassen sich grobe Aussagen über die soziale Zusammensetzung der Studentenschaft machen, die nicht nur Hinweise auf äußere Zustände und Konjunkturen geben, sondern auch unterschiedliche Entwicklungen bei den Universitäten aufzeigen können. Hinsichtlich der Herausbildung der Landesuniversität können sie die sozialgeschichtlichen 
Zusammenhänge und Hintergründe beleuchten helfen.

Im folgenden Abschnitt sollen die verschiedenen Personenangaben zur sozialen Herkunft der Studenten zusammengefaßt werden, um einen Eindruck vom sozialen Hintergrund der Greifswalder Gründung zu erlangen. Da nur hohe Ämter und Würden regelmäßig verzeichnet wurden, und die Angaben immer unregelmäßiger werden, je niedriger der Rang des Einzelnen war, können die Ergebnisse nur unter besonderem Vorbehalt verwertet werden. Sie sollen am Beispiel Greifswalds einen allgemeinen Überblick vermitteln. Im Anschluß daran werden die Angaben zur Gebührenzahlung systematisch ausgewertet, die vom größten Teil der Studenten vorhanden sind. Sie erlauben Aussagen über besondere Kennzeichen und Entwicklungen bei der sozialen Herkunftsstruktur der Greifswalder Studenten. 


\section{Die soziale Herkunft der Greifswalder Studenten}

\subsection{Der Adel}

Im allgemeinen verzeichnete die Matrikel einen Zusatz hinter dem Namen eines Studenten, wenn dieser dem adeligen Stand angehörte. Die Bezeichnungen variierten zwischen "nobilis", "illustris" oder auch "militaris". Für Greifswald konnten Adelsbezeichnungen bei 37 Personen gefunden werden, was einem Anteil von nur 1,1 Prozent der gesamten Studentenschaft entspricht. Unter diesen Adeligen befindet sich ein Hochadeliger, nämlich Herzog Swantobor, zwei Grafen, Ludwig von Sankt Bonifaz aus Verona und Wolfgang von Eberstein aus Naugard sowie einen adeligen Kanoniker des Roeskilder Domkapitels, und zwar Christoph Nicolai aus Dänemark.

Wenn man die Zahlen mit anderen Universitäten vergleicht, so fällt auf, daß der Greifswalder Anteil sehr niedrig ist, geringer noch als der Anteil Kölns, der zwischen 1405 und 1505 bei etwa 2,3 Prozent $\operatorname{lag}^{70}$, während Heidelberg als "Adelsuniversität" ${ }^{71}$ mit 5,5 Prozent an der Spitze steht. ${ }^{72}$ Leipzig verzeichnete 3,2 Prozent Adelige. ${ }^{73}$

Die Ergebnisse machen deutlich, daß im 15. Jahrhundert ein Universitätsstudium für den Adel keineswegs selbstverständlich war. Die politischen und militärischen Funktionen dominierten gegenüber dem Bedürfnis nach universitärer Bildung. Erst ab der zweiten Hälfte des Jahrhunderts ist ein leichter Anstieg zu verzeichnen, der allerdings parallel zur allgemeinen Frequenzgeschichte verlief. ${ }^{74}$ Von den Universitäten der zweiten Gründungswelle kann man die süddeutschen Universitäten Ingolstadt, Freiburg und Tübingen zum Vergleich heranziehen. Ingolstadt verzeichnete zwischen 1470 und 1520 5,6 Prozent adelige Studenten, Freiburg 2,3 Prozent, Tübingen 4,3 Prozent, wobei innerhalb der Zeitspanne vor allem Ingolstadt einen Anstieg zu verzeichnen hatte, wie der folgenden Tabelle zu entnehmen ist. ${ }^{75}$

Tabelle 3: Adel an süddeutschen Universitäten 1470-1520

\begin{tabular}{|l|l|l|l||}
\hline Zeitspanne & Ingolstadt & Freiburg & Tübingen \\
\hline \hline $1470-80$ & $2,58 \%$ & $1,72 \%$ & $4,52 \%$ \\
\hline \hline $1481-90$ & $3,97 \%$ & $2,74 \%$ & $5,48 \%$ \\
\hline \hline $1491-00$ & $6,85 \%$ & $2,66 \%$ & $3,64 \%$ \\
\hline \hline $1501-10$ & $7,21 \%$ & $1,55 \%$ & $3,90 \%$ \\
\hline \hline $1511-20$ & $8,88 \%$ & $2,91 \%$ & $3,95 \%$ \\
\hline $1470-1520$ & $5,6 \%$ & $2,3 \%$ & $4,3 \%$ \\
\hline
\end{tabular}


Auch in Greifswald findet ein leichter Anstieg statt, denn 26 der 37 Adeligen (über zwei Drittel!) kamen erst ab 1490, also in der zweiten Hälfte des Zeitraums. Die hohe Beteiligung des Adels an den süddeutschen Universitäten spiegelt eine strukturgeschichtliche Gegebenheit des alten Reiches wider, da die Adelsdichte in den südlichen Reichsteilen wesentlich höher war als etwa in Pommern oder anderen norddeutschen Gebieten, die durch eine eher bürgerliche Bevölkerungsstruktur gekennzeichnet waren. ${ }^{76}$ Insgesamt wird der Anteil des Adels an der Gesamtbevölkerung des Reiches auf 1,5 bis 2 Prozent geschätzt ${ }^{77}$, so daß der Anteil am allgemeinen Universitätsbesuch mit diesen Werten in etwa korrelierte.

Interessant am Zuzug des Adels nach Greifswald ist die territoriale Verteilung der Studenten. Die Hälfte der Adeligen (18) stammt aus Pommern, was fast genau dem Verhältnis PommernNichtpommern an der Gesamtbesucherschaft entspricht. Von sechs Personen sind keine oder unzulängliche Herkunftsangaben vorhanden, doch die übrigen 12 Adeligen kommen, bis auf einen Brandenburger, aus dem Ausland. 10 aus Dänemark, einer aus dem Ordensland, einer aus Italien. Nicht ein einziger Adeliger kommt demnach aus dem übrigen Reichsgebiet und selbst die Nachbarn sind unterrepräsentiert. Eine Bewertung solcher Zahlen ist angesichts der Größenordnung problematisch. Wenn man jedoch Wechselwirkungen zwischen dem Prestige einer Universität und dem Besuch durch privilegierte Kreise konstatiert, dann scheint dieses geringe Adelsinteresse zu belegen, daß die Greifswalder Universität in erster Linie als Domäne des Bürgertums und der Kaufleute zu verstehen ist: diese prägten maßgeblich ihr Erscheinungbild im 15. Jahrhundert, während es sonst nur vereinzelt Adelige aus Pommern an die eigene Landesuniversität zog. Der Reichsadel orientierte sich eindeutig nach Süden, wobei die italienischen Universitäten sicherlich noch beliebter waren als die deutschen. ${ }^{78}$ Die folgende Grafik stellt die Frequenz des pommerschen Adels gegenüber der Gesamt-Adelsfrequenz dar. Man sieht, daß der Zuwachs in der zweiten Hälfte des Zeitraums vor allem dem pommerschen Adel zu verdanken ist, während die ausländischen Adeligen in dieser Zeit kaum noch vertreten sind. Die steigende Tendenz verdeutlicht, daß auch für den heimischen Adel die Gründung einer Landesuniversität in Pommern längerfristig studienfördernd wirkte. Daß auch die Adelsfrequenz mit dem Auftauchen der Humanisten aus Italien "kurz und strohfeuerartig" in Greifswald angestiegen wäre, wie Schwinges behauptet ${ }^{79}$, kann ich aus der Matrikel nicht ersehen, die im besagten Zeitraum (1497-1503) nur drei Adelige verzeichnete. In der gleichen Zeitspanne vor und nach ihrem Wirken werden höhere Werte erreicht, und zwar sechs von 1490 bis 1496, und vier von 1504 bis 1510. 


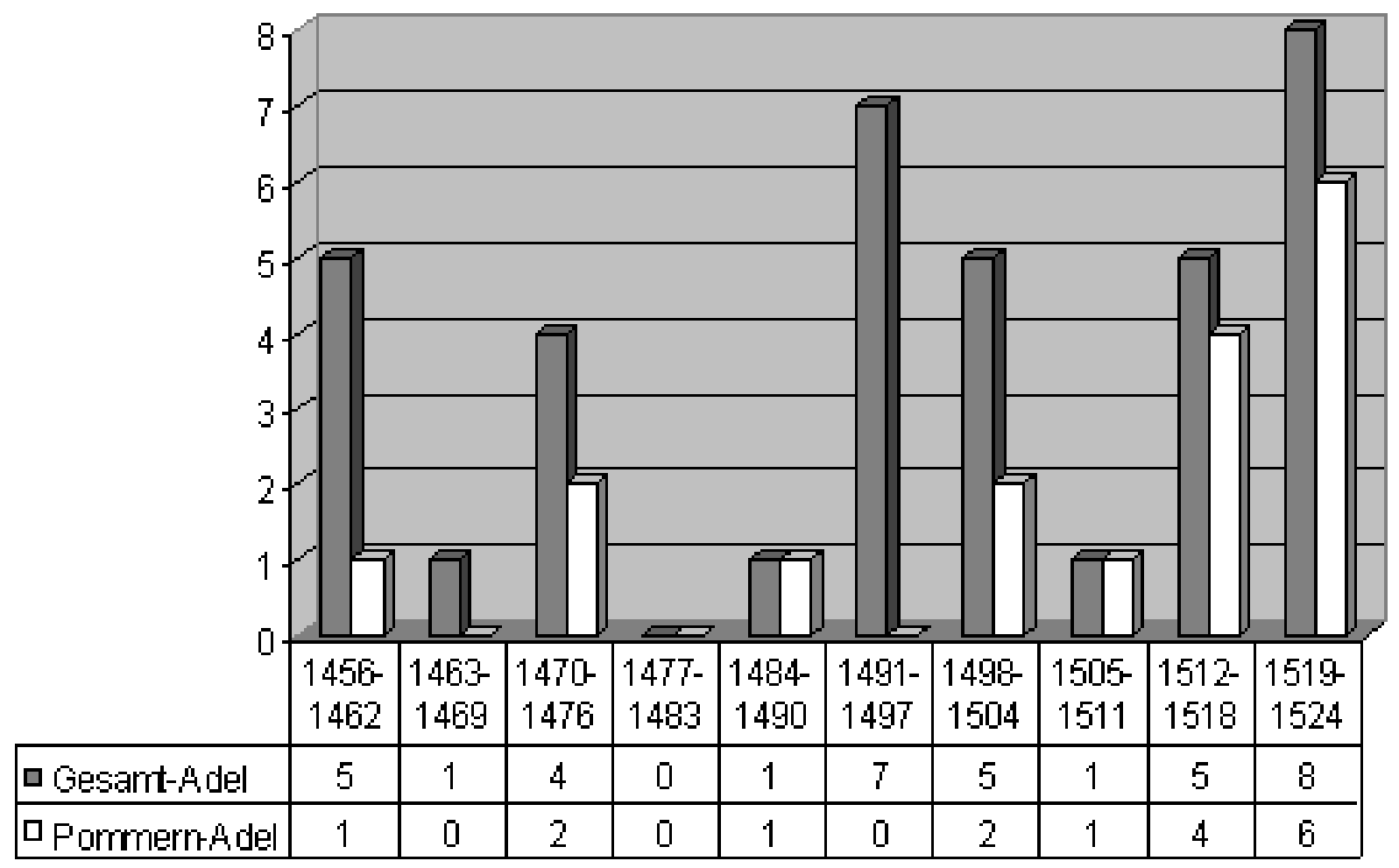

Abbildung 4: Adelsfrequenz Greifswald

\subsection{Die geistlichen Würdenträger}

Der Rektor machte gewöhnlich einen Eintrag in die Matrikel, wenn die Studenten bereits ein Amt ausübten oder irgendeine Würde in der Kirche bekleideten. Diesen Angaben kommt eine wichtige sozialgeschichtliche Bedeutung zu, denn sie veranschaulichen eine soziale Realität des mittelalterlichen Universitätsstudiums, nämlich daß Studenten zum Teil erst durch Pfründen in die Lage versetzt wurden, ihr Studium zu finanzieren. ${ }^{80}$ Kirchenrechtliche Voraussetzung war die Lockerung der Residenzpflicht, die einen Geistlichen an den Ort von Amt und Pfründe band. Die Päpste förderten maßgeblich das mittelalterliche Universitätsstudium, indem sie den Klerikern erlaubten, den Ertrag ihrer Pfründe während des Studiums weiter zu genießen. ${ }^{81}$ Man unterschied zwischen Pfründen mit und ohne Seelsorgeverpflichtung (cum und sine cura animarum). ${ }^{82}$

Während ein Pleban, der sich zum Studium entschloß, einen Vikar einstellen mußte, und sich nur vom Überschuß der Pfründeinkünfte versorgen konnte, blieben den zumeist hochdotierten Kanonikern an Stifts- und Kathedralkapiteln sämtliche Einkünfte auch im Studium. Sie zählten daher zu den privilegiertesten Studenten. Es ist anzunehmen, daß ein Großteil der Studenten nicht über solch ergiebige Pfründen verfügten, sondern höchstens als Vikare, Meßpfründner oder Altaristen ein Zubrot zum Studium verdienten. Sie kommen dem heutigen "nebenjobbenden" Studenten sicherlich am nächsten. Zum Kreis derer, die in Greifswald über eine Versorgung verfügten, gehörten neben der hohen Geistlichkeit, den Kanonikern, Äbten, Bischöfen, Prioren und Pröpsten, auch einige weltliche Kleriker in niederen Rängen, angefangen beim Pleban bis zum einfachen Vikar oder Meßpfründner. 
Leider scheint auch hier die Matrikel in erster Linie die höheren Ränge zu verzeichnen, während die Pfründen des Niederklerus oft übergangen wurden, obwohl man sicherlich von einer proportional höheren Beteiligung dieser Kategorie ausgehen kann. Die Kirche war und blieb nämlich der wichtigste Arbeitgeber und Entlohner mittelalterlicher Studenten, oft auch dann, wenn diese in den Dienst der Könige, Fürsten, Herren und Städte eintraten, denn auch diese benötigten das Pfründengebäude der Kirche. ${ }^{83}$ So war die staatliche Verwaltung mit ihren geringen Mitteln kaum in der Lage "öffentliche Aufgaben" zu entlohnen. Vielmehr war es die Kirche, die im Mittelalter den einzigen organisatorischen Rahmen dafür bot. 84

Da man aufgrund der Quellenlage nur ungenaue bzw. zu niedrige Zahlen niedergeistlicher Pfründeninhaber an der Greifswalder Universität erhält, bleibt allein der Weihegrad eines Studenten übrig, anhand dessen vielleicht weitere Erkenntnisse zu erzielen sind. Diese als "clericus" oder "presbyter" bezeichneten Personen können sicherlich nicht alle mit solchen niederen Pfründen in Verbindung gebracht werden, doch sollen sie in der Untersuchung trotzdem berücksichtigt werden, um wenigstens eine Annäherung an die reellen Zahlen zu bekommen. Dabei ist die erste Kategorie noch problematischer einzuschätzen, denn der Begriff "clericus" wurde im Mittelalter sehr weit gefaßt. Es reichte zum Teil schon die Tonsur als äußeres Zeichen für eine solche Titulierung. 85

Schwinges sieht für eine sozialgeschichtliche Untersuchung der "clerici" außerdem quellenkritische Probleme, da der Begriff bis zur ersten Hälfte des 15. Jahrhunderts noch so geläufig war, daß die matrikelführenden Rektoren keine besondere Rücksicht darauf genommen haben und diesen Stand nur sehr lückenhaft verzeichnet haben. ${ }^{86}$ Da die vorliegende Untersuchung erst in der zweiten Hälfte des Jahrhunderts einsetzt, kann dieser Einwand ein wenig entschärft werden, doch sollten auch hier Interpretationen immer nur mit Rücksicht auf die gegebene Quellenlage erfolgen. Ähnliches gilt auch für die "presbyteri". Obwohl mit der Priesterweihe nach kanonischem Recht bereits ein regulärer Anspruch auf eine kirchliche Pfründe verbunden war, wurde diese Vorschrift in der Praxis häufig umgangen, so daß auch hier eine klare Einschätzung über den Pfründenbesitz nicht möglich ist. ${ }^{87}$ Die etwas unklare Bezeichnung "dominus" wurde nur für Personen geistlichen Standes angewandt, was sich an gelegentlichen Erkenntnissen über den weiteren Lebensweg erkennen läßt. ${ }^{88}$ Auch eine gehobenere Herkunft ist als sicher anzunehmen, wie schon an dem überproportionalen Besuch der "vornehmen" juristischen Fakultät zu erkennen ist (in Köln: 48,1\%) ${ }^{89}$, doch lassen die Quellen eine genauere Beurteilung über Position oder Bepfründung der "domini" zur Zeit der Immatrikulation ebenfalls nicht zu. Eine weitere Personengruppe, die wesentlich einfacher einzuordnen ist, stellen Mönche aller unterschiedlichen Orden dar. Der Titel "frater" wurde in ziemlicher Regelmäßigkeit verzeichnet, zumeist mit Angabe des zugehörigen Ordens, so daß eine genauere Untersuchung des Ordensklerus möglich ist.

In Greifswald haben sich im behandelten Zeitraum insgesamt 220 Personen immatrikulieren lassen, die nachweislich bereits über irgendeine kirchliche Versorgung verfügten (als Welt- oder Ordensgeistliche), was einem Anteil von 6,6 Prozent der Gesamtstudentenschaft entspricht. Während die 64 "domini" (1,9\%) bereits einbezogen wurden, sind die "clerici" und "presbyteri" darin nicht enthalten, so daß der Prozentsatz demnach den untersten Wert möglicher Bepfründung darstellt, den man einwandfrei verifizieren kann. Zählt man Weihegrade hinzu, so erhält man insgesamt 20,2 
Prozent (672), worunter nur 43 Priester (1,3\%), aber 409 Kleriker (12,3\%) zu finden waren. Um von gleicher Betrachtungsposition zu werten, sollen jedoch nur die einwandfrei identifizierbaren Angaben mit den anderen Universitäten verglichen werden.

Durchaus vergleichbar ist demnach der Anteil der Leipziger Geistlichen, der zwischen 1409 und 1430 bei 6,1 Prozent lag. ${ }^{90}$ Gegenüber der Kölner und Heidelberger Universität nimmt sich der Greifswalder Anteil eher bescheiden aus. Zwischen 1395 und 1495 waren es in Köln etwa 10,5 Prozent $^{91}$, zwischen 1390 bis 1445 in Heidelberg etwa 13,7 Prozent ${ }^{92}$ geistliche Würdenträger. Diese Universitäten standen wohl auch reichsweit an der Spitze, da sie sich inmitten einer dichten Stifts- und Kirchenlandschaft befanden. ${ }^{93}$ Die rheinische Metropole war aufgrund der vielen Kirchen sogar als "heiliges Köln" bekannt. ${ }^{94}$ Die strukturgeschichtliche Tatsache, daß Pommern ärmer an Kirchen und Stiften war, schlägt sich auch bei der Verteilung der geistlichen Studenten auf die einzelnen Herkunftsgebiete nieder. Der Pommernanteil fällt gegenüber dem Gesamtanteil um fast 20 Punkte ab, auf 30 Prozent (69 Personen). Selbst wenn man die 20 Prozent unzulänglichen Herkunftsangaben (43), bei denen es sich vermutlich eher um Nicht-Pommern gehandelt hat, nicht einbezieht, liegt der Anteil mit 38 Prozent immer noch deutlich niedriger. ${ }^{95}$

Fast gleichauf liegen ausländische Pfründner (59) mit fast 15 Punkten über dem GesamtAusländeranteil (19\% zu 33\%). ${ }^{96}$ Diese Zahlen sind keineswegs als ungewöhnlich zu bewerten, sondern verdeutlichen vielmehr, wie wichtig insbesondere für weit gereiste Studenten eine sichere Pfründe zur Finanzierung ihres Studiums war. Daß fast 17 Prozent der Pfründner aus dem übrigen Reichsgebiet und nur 12 Prozent aus den Nachbarländern kommen, könnte möglicherweise ebenfalls mit der geringen Kirchendichte in diesen nördlichen Reichsregionen zusammenhängen.

In der folgenden Grafik wird die Frequenz der bepfründeten Studenten dargestellt, aus der ebenfalls eine klare Tendenz zu erkennen ist. Während sie zu Beginn des Betrachtungszeitraums mit 73 Studenten noch äußerst stark vertreten sind, nimmt ihre Zahl bis zum Betrachtungsende kontinuierlich ab. Geringe Abweichungen sind nur in den auch für die Allgemeinfrequenz ungewöhnlichen Hochjahren 1484 bis 1490, 1498 bis 1504 sowie 1512 bis 1518 zu beobachten, doch können auch diese kurzen Anstiege nicht über den offensichtlichen Sachverhalt der rückläufigen Zahlen hinwegtäuschen. 


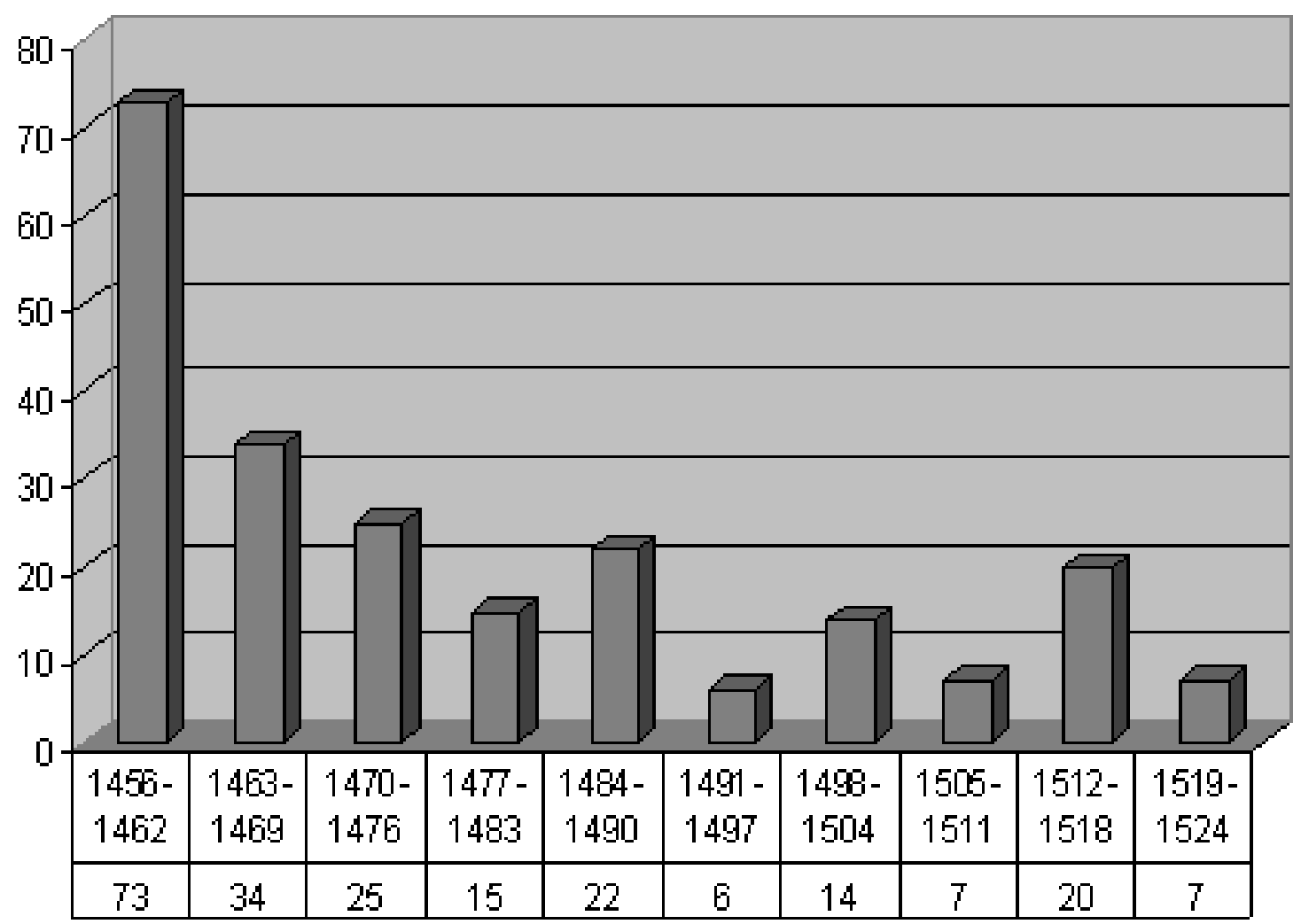

Abbildung 5: Geistliche Würdenträger in Greifswald

Der tendenzielle Rückzug der Geistlichkeit im 15. Jahrhundert ist schon bei anderen Universitäten festgestellt worden ${ }^{97}$, doch weist die Forschung immer wieder mit Recht darauf hin, daß er nichts mit "Verweltlichung" des Studiums zu tun hatte. ${ }^{98}$ Vielmehr läßt sich an dieser Entwicklung eine allmähliche "Professionalisierung" des Universitätsstudiums ablesen, denn ein Student ging nun immer häufiger zur Universität, um erst danach seine Karriere in der Kirche zu beginnen. ${ }^{99}$ Das Studium entwickelte sich demnach immer mehr zur Karrierevoraussetzung, wofür die Greifswalder Zahlen als Beispiel gelten können. Je mehr allerdings die Pfründe als Finanzierungsmöglichkeit des Studiums wegfiel, desto stärker mußte auch eine Pauperisierung der Studentenschaft eintreten, denn diese verlor damit eine wichtige existentielle Basis. In Heidelberg ließ sich dieser soziale Strukturwandel anhand der Gebührenzahlung beobachten. ${ }^{100}$ Im folgenden Abschnitt sollen die verschiedenen Gruppen der Würdenträger betrachtet werden, da sie sich in Anzahl und sozialer Position erheblich unterschieden. ${ }^{101}$

\subsubsection{Die hohe Geistlichkeit}

Solche Studenten, die bereits eine hochdotierte Pfründe zum Zeitpunkt ihres Studiums besaßen, gehörten zu den privilegiertesten Studenten, die mit gewissen Sonderrechten in der Universität zu rechnen hatten. Sie wurden in der Regel nicht nur an erster Stelle in die Matrikel eingeschrieben, sondern erhielten auch bei Vorlesungen die besten Plätze. ${ }^{102}$ Nur der Hochadel und die höchsten 
Würdenträger wurden freilich auch von der Immatrikulationsgebühr befreit. ${ }^{103}$ Häufig brachten diese Studenten gleichzeitig einen oder mehrere Diener mit sich, die sich ebenfalls immatrikulieren ließen, um an den rechtlichen Privilegien teilzuhaben, die der Universitätsangehörigenstatus mit sich brachte. $^{104}$

In Greifswald ist die hohe Geistlichkeit durch insgesamt 48 Personen vertreten, also etwa 1,5 Prozent der Gesamtbesucherschaft und 21 Prozent aller bepfründeten Studenten. Darunter befinden sich in den höchsten Rängen drei Bischöfe, zwei Hilfsbischöfe und vier Äbte. Im Jahre 1464 wird außerdem Birgerus aus Werben als Pauper inskribiert, von dem die Matrikel nachträglich vermerkt, daß er am 26. Juni 1497 zum Erzbischof von Lund erwählt worden sei, doch wird er nicht mitgezählt, da dies erst nach seinem Studium geschah. Unter den anderen Würdenträgern in Greifswald befanden sich neun Priore, ein Subprior, acht Pröpste, fünf Dekane, drei Archidiakone sowie 13 Kanoniker. Ihre Verteilung entsprach in etwa der gesamten Klerikerverteilung mit 16 Pommern (34\%), 15 Ausländern (32\%), neun Nachbarn (sechs Mecklenburger und drei Brandenburger) sowie sechs aus dem übrigen Reichsgebiet stammenden Personen.

Auch die Frequenzentwicklung entsprach etwa der Gesamtentwicklung, doch sanken die Zahlen in der ersten Betrachtungshälfte weniger drastisch (Vgl. Abbildung 5 und Abbildung 6). Außerdem sind die drei Anstiegsphasen noch deutlicher zu bemerken. Demnach war die hohe Geistlichkeit am Rückzug der Gesamtgeistlichkeit wesentlich später beteiligt, erst ab 1490. Auch erschienen sie während der Humanistenjahrgänge in geballterer Form als die übrigen Kleriker. Dies mag damit zusammenhängen, daß der Renaissance-Humanismus eher eine Sache von Adeligen und reichem Bürgertum war, zu denen die hohen Geistlichen allesamt gehörten. ${ }^{105}$ Sie besaßen aufgrund ihrer materiellen Freistellung eben auch die Möglichkeit solchen Ambitionen zu folgen und reagierten mit verstärktem Universitätsbesuch auf die Anwesenheit solch berühmter Lehrer. 


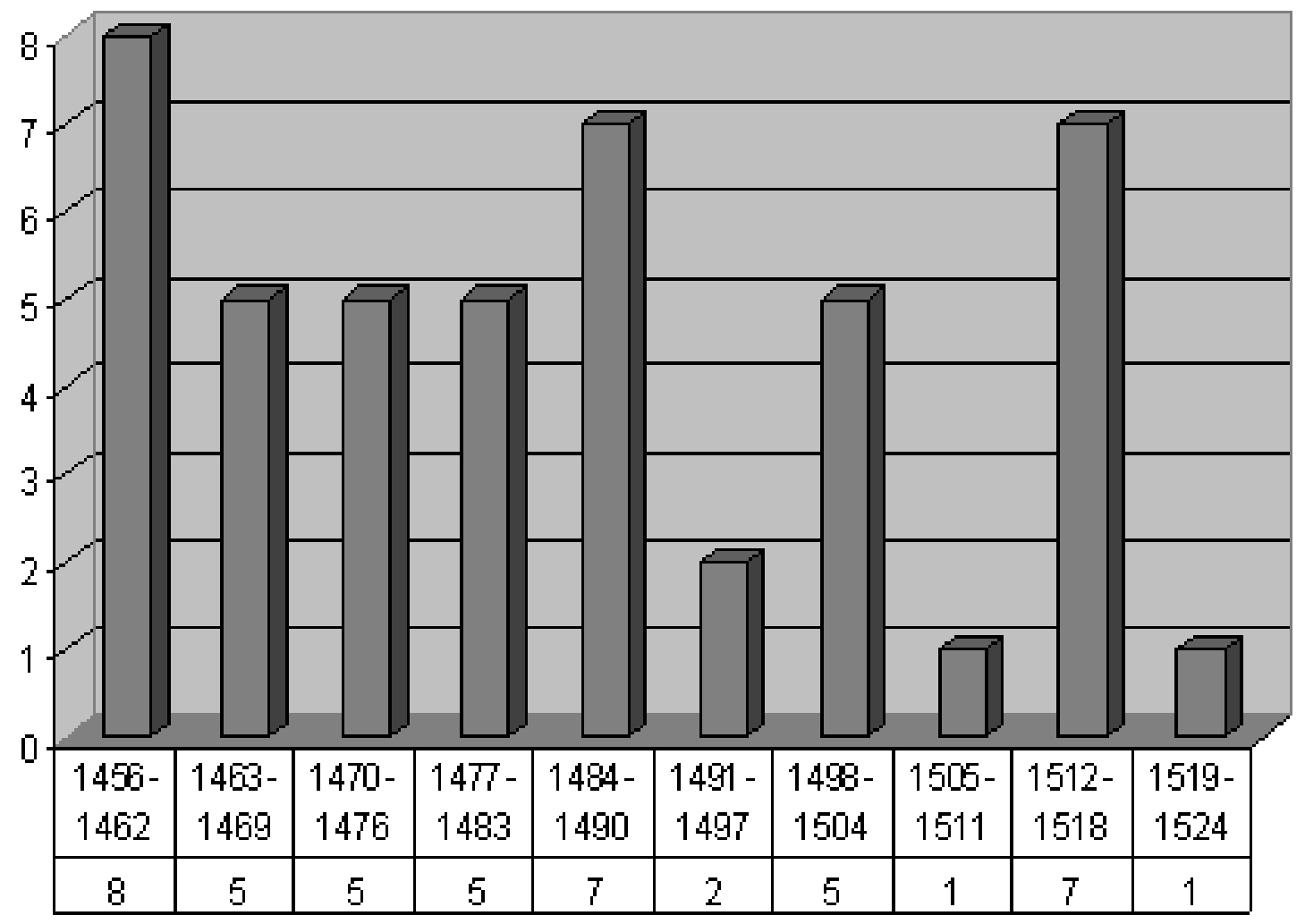

Abbildung 6: Hohe Geistliche in Greifswald

\subsubsection{Der weltliche Niederklerus}

Gerade für die Kategorie des niederen Klerus sind die Angaben nur spärlich vorhanden. 18 Eintragungen fanden sich für diese Kategorie, von der man doch annehmen sollte, sie sei am häufigsten vertreten. ${ }^{106}$ Der größte Teil (9) fiel auf den höchsten Rang, die Plebane, so daß auch hier noch eine ungleichmäßige Verteilung zu beobachten ist. Ansonsten waren ein Vizepleban, fünf Kapläne und drei Vikare vertreten. Aufgrund der geringen Zahlen lassen sich hier keine weitergehenden Aussagen machen, doch fällt schon bei diesen wenigen Personen die Verteilung auf. Ganz im Gegensatz zur hohen Geistlichkeit kamen 15 (84\%) niedere Geistliche aus Pommern. Diese fulminante Verschiebung gegenüber dem Gesamtverhältnis hängt offensichtlich damit zusammen, daß diese Pfründen keine "Sinekuren" waren, sondern eben die Seelsorge einschlossen. Nur drei Plebane, die aus Polen, Schweden und Holstein stammen, konnten sich wahrscheinlich vom Überschuß ihrer Pfründe einen Vikar leisten, der während ihrer Abstinenz diese Tätigkeiten verrichtete. Ferner ist der Großteil der Niederpfründner (12) in Vorpommern beheimatet, was einmal mehr diesen Sachverhalt verdeutlicht. Die zeitliche Verteilung ist wiederum auffallend einheitlich. Ausgerechnet die Hochphase Greifswalder Inskriptionen zwischen 1477 und 1503 brachte nicht einen einzigen solcher Geistlichen hervor, während die Angaben davor und danach einigermaßen regelmäßig erscheinen. Sicherlich verzichteten die Rektoren aufgrund der hohen Frequenzrate auf ausführlichere Angaben, so daß man sie unter den anderen Studenten nur vermuten kann. 


\subsection{3. "domini"}

Die Gruppe der "domini" soll an dieser Stelle gesondert betrachtet werden, da dieser Titel keine genauere Aussage über die Art der Bepfründung zuläßt. Zu den 64 Studenten dieser Gruppe wurden ausschließlich solche gezählt, bei denen keine weiteren Angaben zu finden waren, denn in den meisten Fällen wurde auch den hochbepfründeten und hochadeligen Studenten, die vorher bereits behandelt worden sind, dieser Titel hinzugefügt. Wie die Grafik verdeutlicht, sind vor allem in den ersten Semestern solche Angaben zu finden, die ab 1470 nur noch sehr vereinzelt vorkommen. 17 hatten keine Herkunftsangaben gemacht, was einem Anteil von etwa 27 Prozent entspricht. Pommern entsandte 17, das Ausland 12, die übrigen Reichsgebiete 11 "domini".

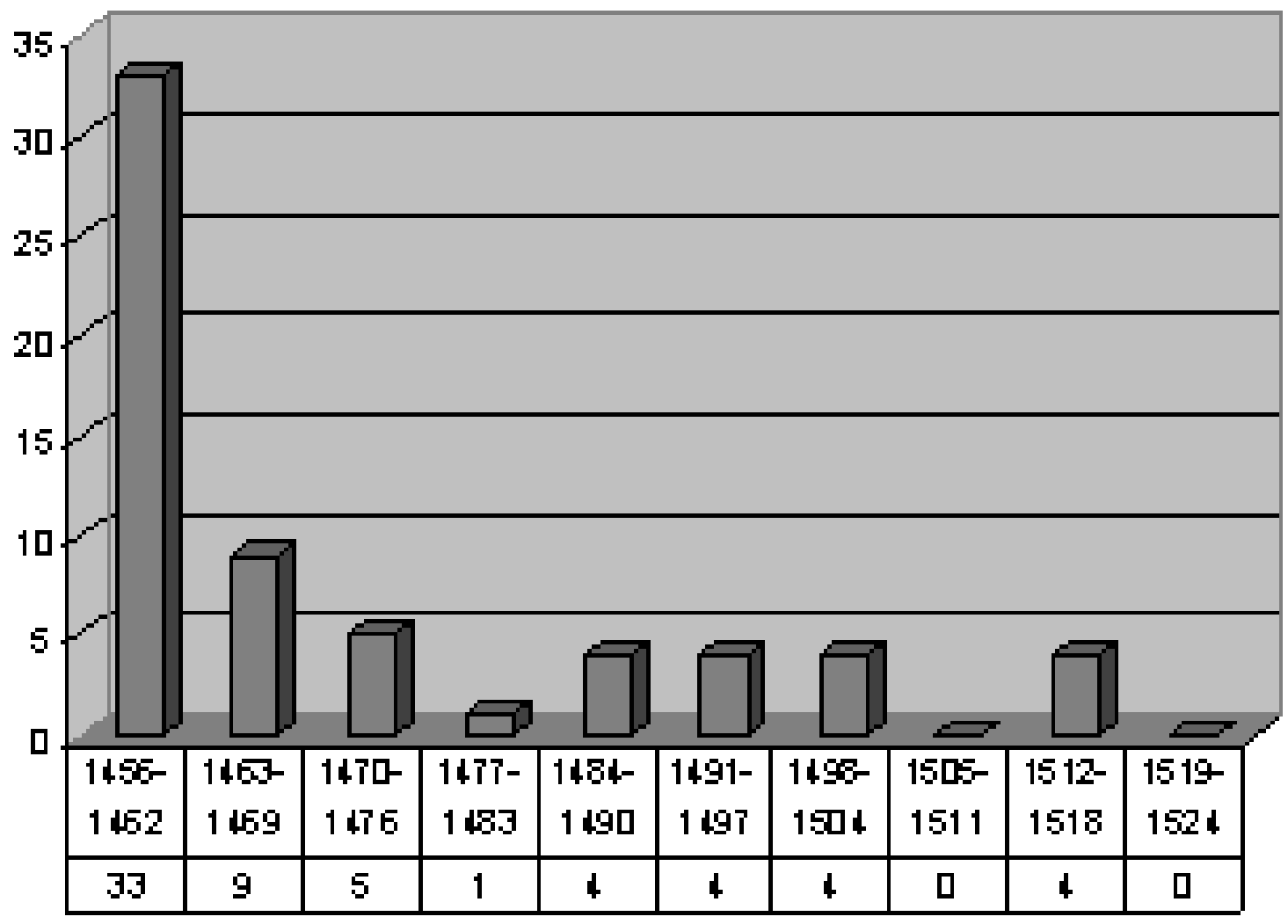

Abbildung 7: "domini"

\subsection{4. "presbyter" und "clericus"}

Um wenigstens einen Teil der übrigen bepfründeten Studenten in Greifswald zu erfassen, muß man sich den Weihegraden zuwenden, die wesentlich häufiger angegeben wurden, wobei die "presbyteri" (43) eine einheitlichere Gruppe als die "clerici" darstellten. Daß die Matrikel gerade in der Hochphase 1486 bis 1504 die meisten Priester verzeichnete (19), wie in der Grafik zu erkennen ist, deutet darauf hin, daß die Rektoren vielleicht aus Bequemlichkeit auf die ausführlichen Angaben verzichteten, und man daher wohl, wenn nicht mit niederen Pfründeninhabern, so doch immerhin mit Pfründenanwärtern zu rechnen hat. Die Verteilung der Priester deckt sich in etwa mit der 
Gesamtklerikerverteilung, denn der große Teil von 16 (37\%) Priestern kam aus Pommern, während das Ausland knapp dahinter mit 15 (35\%) Inskribierten folgt, wovon fünf aus Dänemark, sechs aus Schweden stammen. Sechs mal wurden die angrenzenden Territorien erwähnt sowie zwei mal das Bistum Hildesheim.

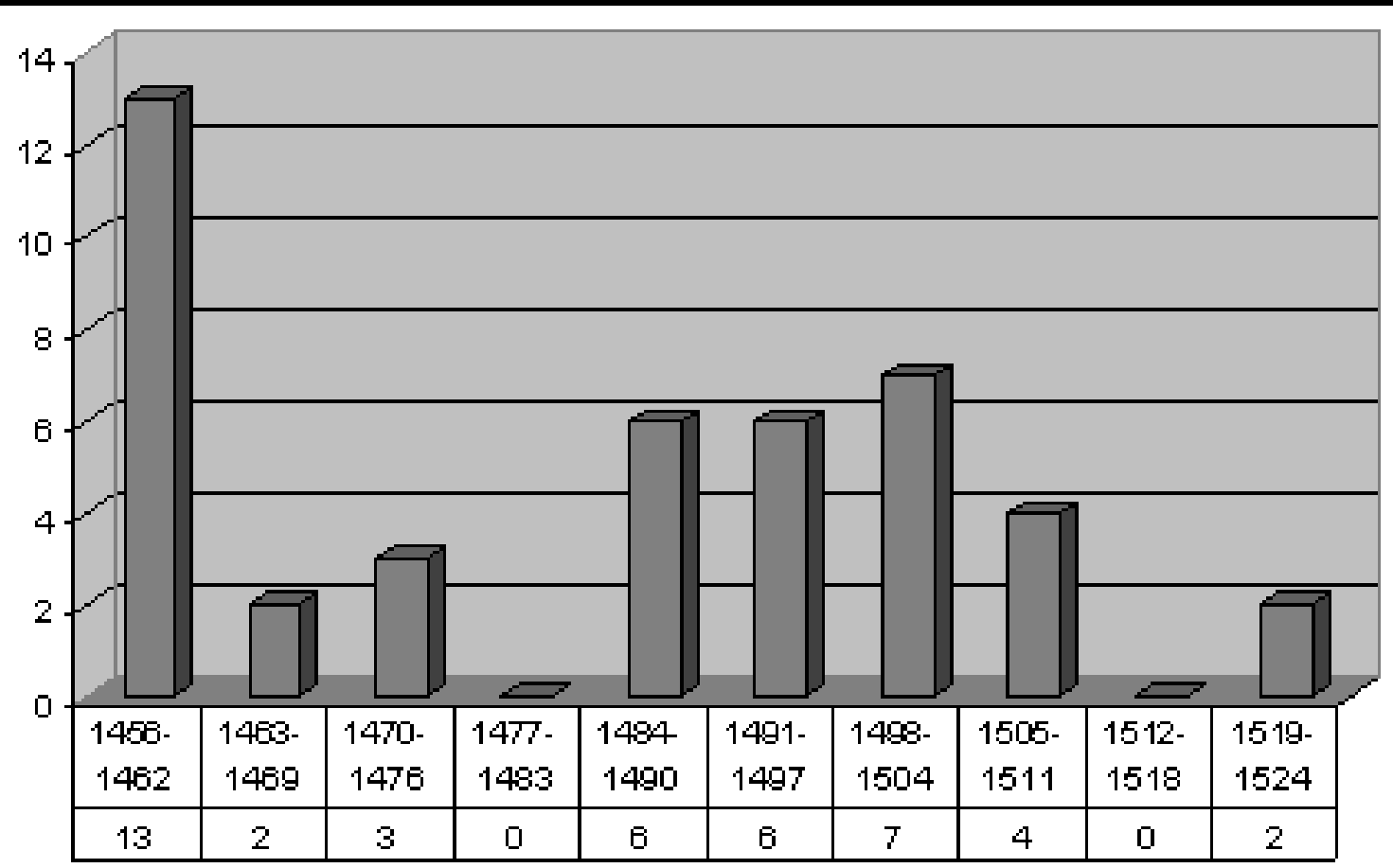

Abbildung 8: "presbyteri"

Bei den als "clerici" verzeichneten Studenten stößt man, wie schon bei anderen Universitäten bemerkt, auf größte Unregelmäßigkeiten. Während der Rektor Georg Walther aus Preußen im Sommersemester 1458 insgesamt 26 Studenten als Kleriker inskribierte, wurde von Hermann Slupwachter im folgenden Semester kein einziger vermerkt. Ähnlich auffällige Steigerungen findet man in den Jahren 1459, 1466, 1467, 1469, 1473, 1486 (50 clerici!), 1488, 1490, 1499, 1500, 1502 und 1519, so daß eine sinnvolle Verwertung dieser Weiheangabe kaum möglich ist. Immerhin verteilen sich 60 Prozent (242) der Angaben auf Pommern (159) und Nachbarländer (83), was wegen der Nähe eine niedere Bepfründung in den Bereich des Möglichen rückt. 24 Prozent (98) erreichte der Ausländeranteil, der vor allem von Dänen (57) und Livländern (20) gestellt wurde, während 16 Prozent (66) der "clerici" aus dem übrigen Reich stammen, das hauptsächlich durch Niederlande, Niederheingebiet und Westfalen vertreten war. Wie in der Grafik zu sehen ist, stechen die frequenzhöchsten Jahrgänge bei den Klerikern deutlich heraus, in denen die Rektoren scheinbar häufiger auf nähere Angaben verzichteten. Nimmt man sie beiseite, so ist über den gesamten Zeitraum ein leichter Abstieg zu bemerken, der auch in anderen Matrikeln beobachtet werden konnte, doch kann man in Greifswald keineswegs von einem "enormen Schwund" sprechen, den die ältere Forschung festgestellt hatte. ${ }^{107}$ Vielmehr blieb "clericus" bis zum Ende des Mittelalters eine gängige Bezeichnung der Scholaren. Die ungleichmäßigen Bewegungen der Frequenzkurve machen aber vor allem deutlich, daß weitere Schlüsse aufgrund quellenkritischer Einwände nicht gezogen werden können. 


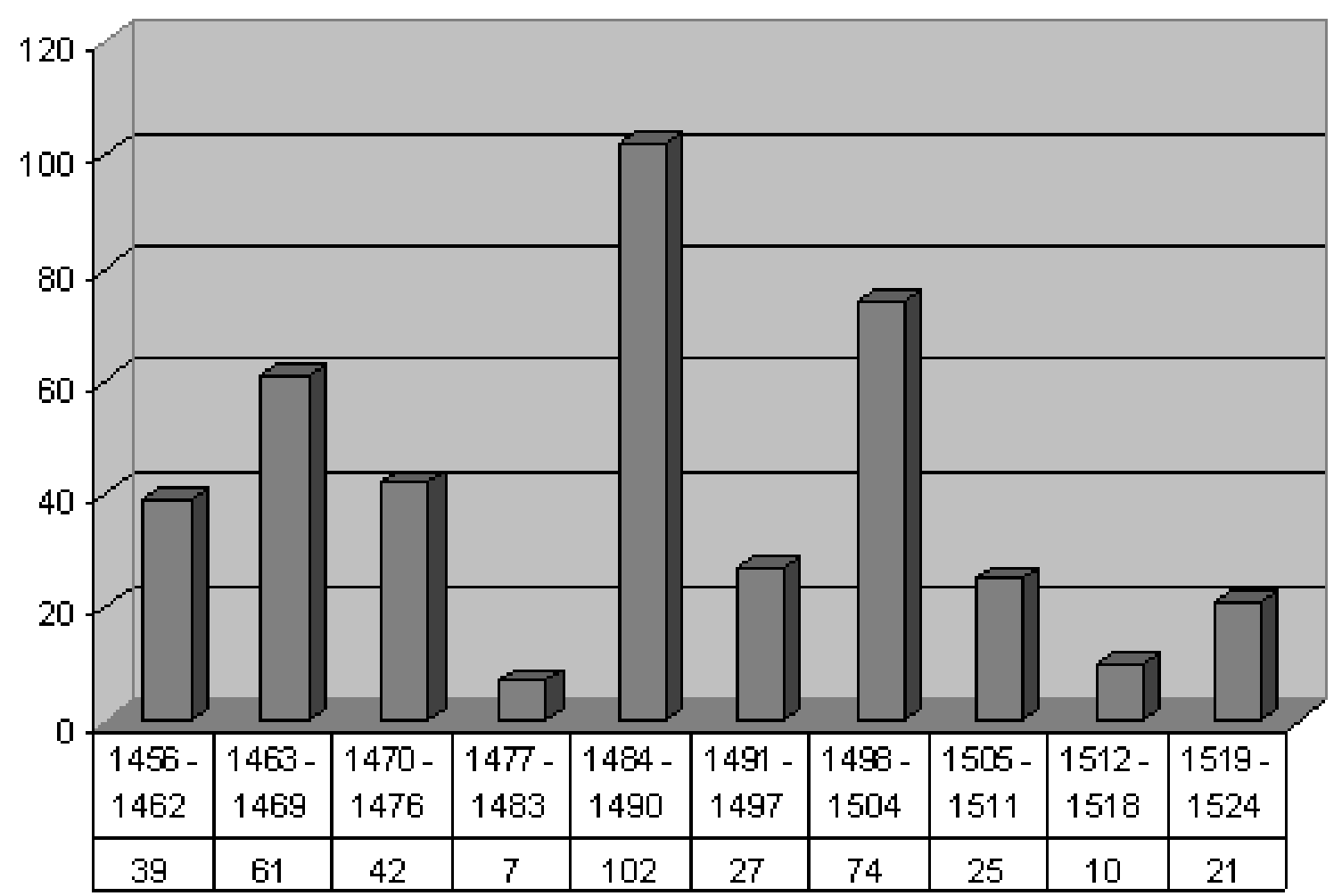

Abbildung 9: "clerici"

\subsubsection{Der Ordensklerus}

Eine gute Basis für eine weitere Auswertung, bietet der Ordensklerus. Einschließlich der bereits behandelten höchsten Ordensgeistlichkeit (Äbte, Prioren), konnte von 105 Studenten eine Ordenszugehörigkeit festgestellt werden, die damit 3,2 Prozent der Gesamtbesucherschaft, und 46 Prozent der nachweislich versorgten Kleriker ausmachten. Von 85 Ordensklerikern (81\%) wurde außerdem der dazugehörige Orden erwähnt, von 79 (75\%) findet man räumliche Herkunftsangaben. Da keine vergleichbaren Daten anderer Universitäten in diesem Zeitraum vorhanden sind, muß man auf frühere Zeiten zurückgreifen. Leipzig verzeichnete zwischen 1409 und 1430 nur 46

Ordensgeistliche, was knapp einem Prozent der gesamten Studentenschaft entsprach, ${ }^{108}$ während Heidelberg zwischen 1386 und 1450 dagegen etwa 3,6 Prozent Religiosi immatrikulierte. ${ }^{109}$ Die Bettelorden waren an diesen Universitäten fast überhaupt nicht beteiligt. ${ }^{110}$ In Köln waren gerade sie am Gründungserfolg maßgeblich beteiligt, denn die vier großen Bettelorden der Stadt unterhielten bis zur Universitätsgründung eigene Generalstudien, die ab 1388/89 der Universität angeschlossen wurden. Dies hatte zur Folge, daß die Mönche nur selten in die Matrikel eingetragen wurden, und man sie daher nicht anteilmäßig erfassen kann. ${ }^{111}$ Auch in Greifswald waren die Bettelorden von dominierender Bedeutung. Mit 43 Angaben stellten die Dominikaner mit Abstand die meisten Studenten. Außerdem kamen 11 Minoriten, neun Zisterzienser, sechs Franziskaner, vier Benediktiner, drei Karmeliter, drei Premonstratenser, drei Johanniter und zwei Eremiten. Pommern stellte mit 26 Angaben genau ein Drittel der regulierten Kleriker, die örtlich zu bestimmen waren, wovon zehn dem Predigerorden angehörten. Aus Dänemark zogen 21 Mönche nach Greifswald (27\%), während 
Schweden und Schlesien sechs, die Niederlande fünf, Brandenburg vier und Mecklenburg drei Ordensleute zu verzeichnen hatte. Der Zuzug des Ordensklerus nach Greifswald ist von einer negativen Gesamttendenz bestimmt, wie die folgende Grafik verdeutlicht. Lediglich der Pommernanteil unter diesen regulierten Geistlichen kann sich zum Betrachtungsende hin leicht verbessern.

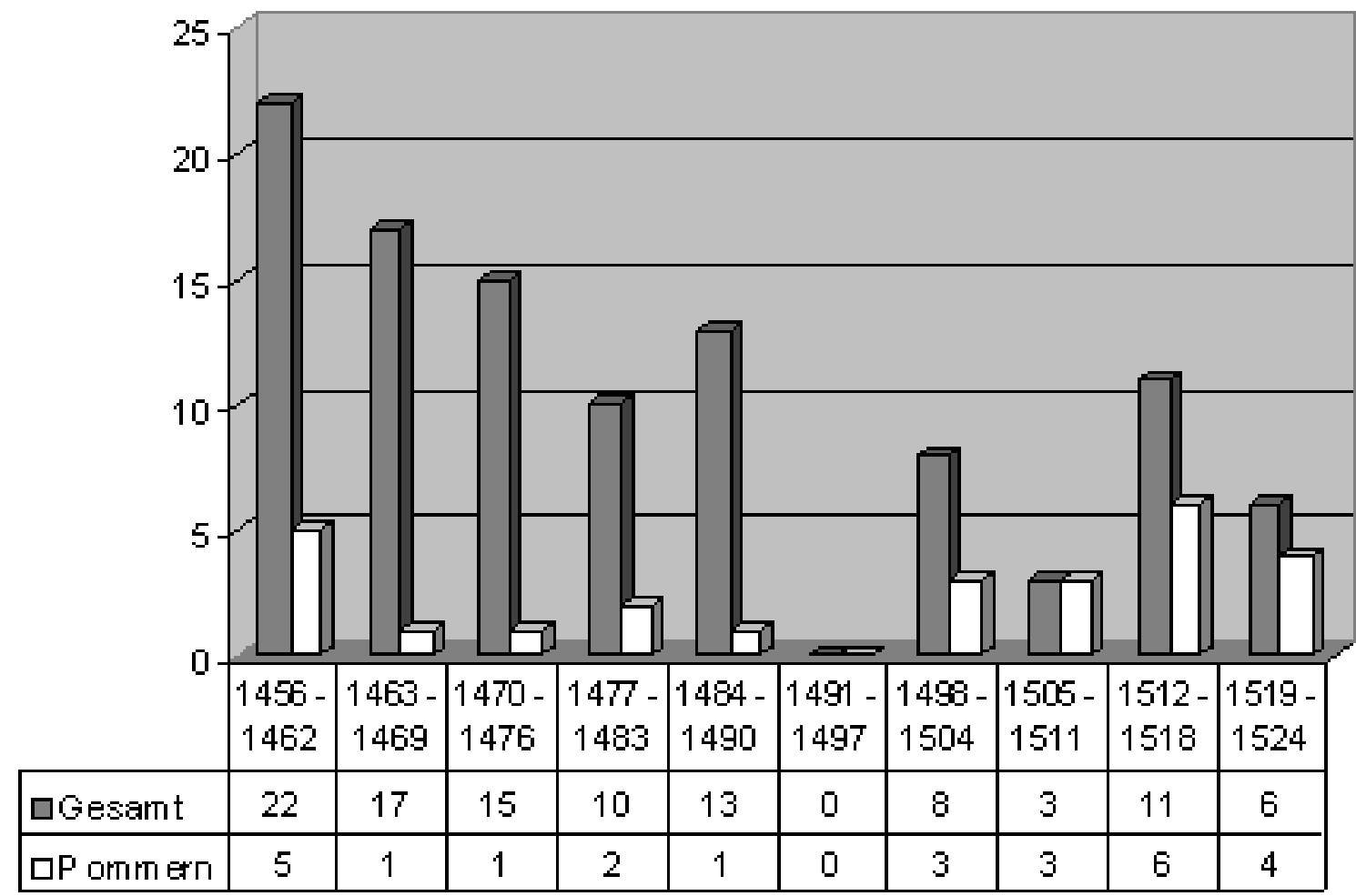

Abbildung 10: Ordensklerus Gesamt - Pommern

\subsection{Sonstige Angaben}

\subsection{1. "pauperes"}

Wie an allen Universitäten konnte auch in Greifswald ein ärmerer Student um Erlaß der Immatrikulationsgebühren bitten. Von 90 Studenten (2,7\%) ist durch den Rektor der Vermerk "pauper" gemacht worden. Diese Zahl entspricht allerdings nicht der wirklichen Relation, die wesentlich höher zu veranschlagen ist. Am Eintrag zur Gebührenzahlung der einzelnen Studenten ist abzulesen, ob sie die Gebühren wirklich entrichtet haben, oder ob sie dazu nicht in der Lage waren. Offensichtlich wurde die "pauper"-Angabe nicht sehr sorgfältig durch die Rektoren eingetragen, was man auch an der unregelmäßigen Verteilung auf die einzelnen Zeitabschnitte erkennen kann. Während zwischen 1456 und 1462 nur fünf Studenten den Zusatz "pauper" erhielten, sind zwischen 1463 und 1469 insgesamt 29 solcher Angaben zu finden. Es ist auffällig, daß viele dieser "pauperes" gar nicht vollständig, sondern nur teilweise von den Gebühren befreit worden sind. Von den 40 zahlenden "pauperes", waren immerhin 18 imstande den Universitätsdiener zu entlohnen, weitere 18 konnten sogar noch einen Teil der Gesamtgebühr bezahlen. Von zweien findet sich der Vermerk 
"dedit totum". Eine differenzierte soziale Einstufung der "pauperes" scheint demnach gar nicht möglich zu sein. Stattdessen soll daher später anhand der Gebührenzahlung eine soziale Differenzierung erfolgen.

\subsubsection{Berufe}

In manchen Fällen notierte der Rektor den Beruf eines Studenten, falls dieser einen solchen angegeben hatte. Von 50 Studenten konnten solche Berufe identifiziert werden. Bei dem größten Teil (30) handelte es sich um Diener einzelner Lehrer oder reicherer Studenten. Außerdem wurden zwei "scriptores", zwei "cancellarii", zwei "rectores scholarium", zwei "cursores" (Stadtbedienstete), vier "officiales", zwei "poetae", nämlich Johannes Hadus (1514) und Ulrich Hutten (1509), drei "notarii", ein "apothecarius", ein "medicus" und ein "coccus" (Koch) verzeichnet.

In einigen Fällen ist der Beruf des Vaters oder eines anderen näheren Verwandten angegeben worden. In diesem Sinne ließen sich neun Angaben verwerten, darunter zwei Apothekerssöhne, zwei Prokonsulsssöhne sowie der Sohn eines Konsuls. Außerdem wurde ein Neffe eines Kantors und eines Officialis sowie zwei des Kamminer Bischofs verzeichnet.

\subsection{Akademische Grade}

Einer großen Zahl von Immatrikulierten war vom Rektor ein akademischer Titel beigefügt worden, den sie bereits an einer anderen Universität erworben hatten. Da nach kanonischem Recht ein Studienabschluß im Mittelalter zur Lehrbefugnis an allen studia generalia der mittelalterlichen Welt berechtigte, hat man es bei diesen Personen mit Lehrern zu tun, die entweder angeworben wurden, oder aber aus eigenem Entschluß als "wandernde Magister" in Greifswald Station machten. Diese lehrten dann in der Artistenfakultät und studierten gleichzeitig an den höheren Fakultäten weiter. In Greifswald ließen sich insgesamt 163 bereits graduierte Personen immatrikulieren, was einem Anteil von 4,9 Prozent entspricht. Höhere Anteile erreichten vor allem die Eröffnungsjahrgänge 1456 bis 1462, als sich 37 Graduierte (6,7\%) einfanden, doch ist der höchste Anteil von 7,9 Prozent in den Jahren 1512 bis 1518 zu finden, als Johannes Hadus in Greifswald lehrte, der offensichtlich ein größeres akademisches Publikum anlocken konnte. Ansonsten bewegen sich die Graduiertenanteile in allen Zeitabschnitten bei 0,5-prozentigen Abweichungen an der Durchschnittsmarke. Unter den einzelnen Graden stehen die der Artistenfakultät mit 113 Eintragungen zahlenmäßig an der Spitze, da sie als Grundfakultät an allen Universitäten auch den höchsten Anteil der Studenten stellte. Sie verteilen sich auf 49 Bakkalare und 64 Magister. Die größere Zahl hatte demnach den höheren Abschluß, was offensichtlich damit zu tun hatte, daß man Bakkalaureat und Magisterium häufiger an der gleichen Universität ablegte, und ein Studienortwechsel erst im seltenen Fall eines weiteren Studiums in Betracht gezogen wurde. Die restlichen 50 Graduierten verteilen sich auf 25 Juristen, wovon acht Bakkalare, vier Lizentiaten und 13 Doktoren waren, auf weitere 22 Theologen, mit neun Bakkalaren, vier Lizentiaten und neun Doktoren sowie auf drei Doktoren der Medizin. Auch ihre Anteile repräsentieren die reellen Dimensionen dieser Fakultäten im Mittelalter, denn die Juristen 
stellten fast immer das Hauptkontingent, gefolgt von den Theologen und den Medizinern, welche im Mittelalter stets die kleinste Fakultät bildeten.

Wie man am Beispiel des Johannes Hadus sehen konnte, hingen Ruf und Geltung einer Universität wesentlich mit der Rekrutierung ihrer Lehrerschaft zusammen. Es ist ein typischer Charakterzug der frühneuzeitlichen Landesuniversität, daß sich ihr Lehrpersonal weitgehend aus dem regionalen und städtischen Umfeld zusammensetzte und man bei der Professorensuche auf überregionale Maßstäbe verzichtete, so daß es zur Herausbildung regelrechter Professorendynastien kam. Inwieweit dieser Prozeß bereits ins späte Mittelalter zurückzuverfolgen ist, kann man anhand der Herkunft der höher graduierten Magister und Doktoren ablesen. Leider wurde nur in den wenigsten Fällen etwas über den Studienort berichtet, so daß man weitgehend auf die räumliche Herkunftsangabe angewiesen ist. Pommern stellte im gesamten Zeitraum nur 21,4 Prozent der bereits Graduierten, und fällt damit nicht nur hinter die entfernten Reichsgebiete (35,9\%), sondern auch hinter das Ausland (26,9\%) zurück, während die Nachbarn mit 15,9 Prozent etwa ihrem Gesamtanteil entsprachen. Der niedrige Anteil der Pommern kann kaum verwundern, da diese sicherlich vor allem in Greifswald ihre Graduierungen ablegten, und ein weiteres Studium ohnehin nur für eine Minderheit in Betracht kam. Gegenüber dem Ausland stellten die entfernten Reichsgebiete fast 10 Prozent mehr Graduierte. Die Universitätsbesucher aus den Ostseeländern werden vor allem in Rostock ihren akademischen Grad erworben haben, um ihr Studium dann in Greifswald fortzusetzen. Ab 1477 kommt es zu einer Zunahme der ausländischen Graduierten, als in Kopenhagen und Uppsala weitere Universitäten für das nördliche Europa entstanden. Bei den 52 aus fernen Reichsgebieten stammenden Studenten mit Graduierungen stellte der niedersächsische Kreis mit 16 Einträgen den Hauptteil, gefolgt von den Niederländern mit 12 sowie den Sachsen mit neun Graduierten. Die rheinischen Kreise erreichten zusammen ebenfalls neun, während die übrigen Reichsgebiete sechs solcher Studenten stellten. Insgesamt blieb der Zuzug der Graduierten über die gesamte Zeitspanne recht konstant, so daß die vorher besprochene regionale Verengung des Lehrkörpers im behandelten Zeitraum, sogar im letzten Zeitabschnitt, noch nicht zu beobachten ist. Vielmehr rekrutierte sich die Professorenschaft aus dem gesamten Handelsgebiet der Hanse, aufgrund der größeren Universitätsdichte vor allem Norddeutschlands, ab 1477 aber auch verstärkt aus den ausländischen Bereichen.

\subsection{Resümee: soziale Differenz in Greifswald}

Obwohl die Angaben zur sozialen Herkunft der Greifswalder Studenten sehr viel ungleichmäßiger vorhanden sind, als dies bei der räumlichen Herkunft der Fall ist, konnten im Rahmen dieser Untersuchung trotzdem einige Erkenntnisse über die Sozialstruktur der Studentenschaft in der Vorreformationszeit gewonnen werden. Das charakteristische bürgerliche Potential im Norden des Reichsgebiets fand sich in den Matrikeln bestätigt. Der Adel war und blieb in Greifswald eine eher unterrepräsentierte Gruppe. Erst gegen Ende des Betrachtungszeitraums ist ein leichter Anstieg des pommerschen Adels zu verzeichnen. Auch bei der Geistlichkeit ließen sich höhere Würdenträger nur sehr vereinzelt wiederfinden, die zu einem geringen Teil aus Pommern stammen, wofür die strukturgeschichtliche Tatsache des stiftskirchenarmen Nordostdeutschlands als Hauptursache erkannt worden ist. Die regulierte Geistlichkeit stellte einen recht hohen Anteil am Greifswalder Studium und wurde vor allem durch die Dominikaner repräsentiert. Bei der niederen Geistlichkeit erwies sich die Quellenlage als äußerst unbefriedigend. Das wirkliche Ausmaß ihrer Beteiligung am 
Greifswalder Studium läßt sich wohl niemals exakt bestimmen, doch deuten die hohen Kleriker- und Priesterzahlen darauf hin, daß sich ein großer Teil der Studenten eine weitere berufliche Laufbahn vor allem in der Kirche versprach. Daß die Zahl der Geistlichen im Betrachtungszeitraum rückläufig war, ist nicht, wie häufig angenommen, ein Indiz für eine gegenläufige Entwicklung, sondern muß vor allem mit einer Professionalisierung erklärt werden: das Studium setzte sich immer mehr als allgemeine Voraussetzung einer Kirchenkarriere durch.

Nur selten erlaubte die Quellenlage, Rückschlüsse auf die soziale Herkunft des Normalstudenten zu ziehen. Berufs- oder Verwandtschaftsangaben blieben die absolute Ausnahme. Anhand einer systematischen Analyse der Eintragungen zur Gebührenzahlung soll im nächsten Kapitel versucht werden, weitere Erkenntnisse über Tendenzen und Entwicklungen der Sozialstruktur zu gewinnen.

Bei der Rekrutierung des Greifswalder Lehrkörpers zeigte die Greifswalder Hohe Schule eine durchgängig überregionale Ausstrahlung, wobei die Handelswege der Hanse offensichtlich auch in dieser Hinsicht einen förderlichen Einfluß ausübten. Das gesamte nördliche Reichsgebiet, seit 1477 auch vermehrt die skandinavischen Länder, gehörten zu den wichtigsten Herkunftsgebieten Greifswalder Lehrer. Der regionale Charakter der neuzeitlichen Universität, welcher sich auch in der Zusammensetzung des Lehrkörpers wiederspiegeln sollte, konnte daher im behandelten Zeitraum für Greifswald noch nicht beobachtet werden. 


\section{Die Sozialstruktur im Spiegel der Gebührenzahlung}

\subsection{Zusammenhänge von räumlicher und sozialer Herkunft}

Wir haben bisher anhand der in der Matrikel gemachten Eintragungen zur sozialen Herkunft der Studenten einen Eindruck von der Gliederung und sozialen Ausdifferenzierung innerhalb der Greifswalder Universität erhalten. Dabei konnte aufgrund der Ungleichmäßigkeit der Quellenlage ein Bild hauptsächlich der oberen Schichten innerhalb der Studentenschaft gewonnen werden. Um die sozialgeschichtlichen Hintergründe und Zusammenhänge zu erfassen, die mit der Wandlung der spätmittelalterlichen Universität zur territorialisierten Landesuniversität verbunden waren, wäre nach Veränderungen der Sozialstruktur in der gesamten Studentenschaft zu fragen. Die traditionelle Forschung, die sich vornehmlich mit verfassungsgeschichtlichen Aspekten der Universität befaßt hat, sah eine Wandlung vor allem in ihrer rechtlichen Beziehung zum eigenen Territorium und Landesherrn, der sie ihrer Einflußnahme und Nutzung unterwarf. Die Reformierung und Konfessionalisierung der Universitäten sah man als Möglichkeit des Landesherrn, die Universität zur "staatlichen Anstalt" umzufunktionieren. Sie diente fortan der Schulung und Ausbildung von Juristen und Amtsträgern des frühneuzeitlichen Beamtenstaates und wurde in diesem Sinne häufig als Faktor im Prozeß der Territorialstaatsbildung interpretiert. ${ }^{11}$

Sozialgeschichtliche Vorgänge blieben bei dieser Betrachtungsweise verborgen, da sie den Willen des Herrschers nach Einschränkung der korporativen Freiheit der universitären Organisation unterstellte. $^{113}$

Im Ausgang des Mittelalters ist jedoch auch eine Veränderung in der Sozialstruktur der Studenten zu konstatieren. Schon die rückläufigen Zahlen der bepfründeten Studenten ließen auf einen solchen Wandel schließen, denn diese prägten bis ins späte Mittelalter das Bild der Hohen Schulen. Sie waren sicherlich auch ein Garant einer gewissen Souveränität gegenüber lokalen und örtlichen Machthabern, die es auf eine stärkere Kontrolle ihrer Universitäten abgesehen hatten. Die geringere persönliche Bindung zum Studienort dieser gut situierten zumeist aus größerer Entfernung stammenden Studenten und das gehobenere Herkunftsbewußtsein wird dem Landesherrn hier natürliche Grenzen gesetzt haben. Seit im 15. Jahrhundert die Zahl der Universitäten im Reich ständig wuchs und die Frequenz immer neue Größenordnungen annahm, ebnete der Faktor "Nähe" auch einem ärmeren Publikum den Zugang zum Studium, so daß dieser unabhängige Studenttyp gegenüber dem stärker sozial und lokal mit der Hochschule verwurzelten Scholaren zurücktrat. Während jener sich vom Studium die Umsetzung der bereits bestehenden sozialen Position versprach, sah dieser im Studium die Möglichkeit zum sozialen Aufstieg. Dies hatte zur Folge, daß viele der Studenten nicht einmal die Gebühren zum Eintritt in die spätmittelalterliche Universität aufbrachten und sich daher als "Pauper" inskribieren ließen. Gegen Ende des Jahrhunderts verschärften einige Universitäten unter dem Eindruck steigender Armenzahlen die Gebührenordnung. ${ }^{114}$ Freilich hatte dies eher die Verschleierung des Sachverhalts zur Folge, als daß es die Armen tatsächlich aus dem Studium verdrängt hätte. ${ }^{115}$ Viele Studenten gingen dann an andere Hochschulen, zumeist an jene in 
den großen Städten des Reiches. Die soziale Ausweitung des spätmittelalterlichen Studiums, die man auch als erste Überfüllungskrise der Universitäten bezeichnen könnte, ist als Faktor bei der Aushöhlung der Unabhängigkeit der Universität zu bewerten. Schon am Ende des Jahrhunderts griffen die Landesherren zunehmend in finanzielle Belange der Universitäten ein, die seit der Reformation zumeist die vollständige Kontrolle über die Haushalte erlangten und sich damit auch personelle Besetzungsrechte sicherten. ${ }^{116}$

Die Untersuchung der Gebührenzahlung einer Universität stellt einen interessanten Fragenkomplex dar, denn sie kann darüber Aufschluß geben, wann sich Veränderungen in der sozialen Zusammensetzung der gesamten Studentenschaft vollzogen. Dabei sind Phasen der Pauperisierung und solche, in denen eine wohlhabendere Studentenschaft auszumachen ist, herauszuarbeiten. Die Phasen können in Beziehung zueinander sowie mit äußeren Anlässen, seien es Universitätsgründungen, seien es Kriegs- und Pestzeiten, gebracht werden. Auch einzelne Herkunftsgebiete der Studenten können in dieser Hinsicht verglichen werden.

Solche Studien erzielten bereits einige Ergebnisse, die unterstrichen, daß beim Eintritt in die spätmittelalterliche Universität keineswegs die Unterschiede der Herkunft zwischen den Studenten verwischt worden sind. Dies gehört inzwischen zum Allgemeingut der

Universitätshistoriographie. ${ }^{117}$ Schon die Angaben zur sozialen Herkunft der Studenten in der Greifswalder Matrikel haben deutlich gemacht, daß Standesunterschiede zwischen den Studenten immer wieder hervorgehoben wurden. Von einer egalitären Gemeinschaft zu sprechen, widerspricht den allgemeinen sozialen Lebensbedingungen. ${ }^{118}$ So unterlag jede Hochschule, wie jede andere Gruppe der Gesellschaft, den gleichen Bedingungen der wirtschaftlichen und sozialen Schichtung. Sie war insofern ein Spiegelbild einer stark ständisch differenzierten Gesellschaft. ${ }^{119}$ Es zeigte sich außerdem, daß die Universitäten des Reiches nicht nur intern durch eine starke soziale Differenzierung gekennzeichnet waren. Auch zwischen den einzelnen Institutionen gab es Unterschiede und Verschiebungen in den Sozialstrukturen der Studenten. ${ }^{120}$ Man könnte daher von vornehmen Universitäten bzw. Armenuniversitäten sprechen. ${ }^{121}$ Die räumliche Lage der Universitätsstadt, aber auch die räumliche Zusammensetzung der Studentenschaft, hatte entscheidenden Einfluß darauf, nach welchen Kategorien sich die Sozialstruktur aufbauen sollte. Köln zählte im 15. Jahrhundert als größte Stadt des Reiches etwa 40.000 Einwohner, so daß sich auch die Kölner Universität in diesem Jahrhundert zu einer der größten Hochschulen im Reich entwickelte. $^{122}$ Der rheinische Raum war durch eine erhebliche Kirchendichte gekennzeichnet, die kaum eine Parallele in anderen Regionen hatte. ${ }^{123}$ Bei der Untersuchung der Studentenschaft dieser westdeutschen Hohen Schule zeigte sich ein besonders hoher Anteil bepfründeter Studenten. ${ }^{124}$ In den südlichen Territorien des Reiches konzentrierte sich dagegen der Adel, wo es viele kleinräumige Adelsherrschaften sowie die große fränkische und schwäbische Reichsritterschaft gab. ${ }^{125}$ Auch hier waren Auswirkungen auf den Universitätsbesuch zu konstatieren: die südlichen Universitäten Heidelberg, Ingolstadt, Tübingen und Freiburg zeigten den höchsten Anteil adeliger Studenten, so daß man sie sogar als "Adelsuniversitäten" bezeichnet hat. ${ }^{126}$ Die nördliche Universitätslandschaft war dagegen durch eine bürgerliche Struktur gekennzeichnet, doch hatte dies nur geringe 
Auswirkung auf das Prestige der einzelnen Hochschulen: die hansische Oberschicht definierte sich selbst als ritterlich-bürgerlicher "communis status". ${ }^{127}$ Die besondere Stellung wird an den höheren Gebührenanforderungen deutlich, die reichsweit an der Spitze lagen. 12 128

Anhand der Gebührenzahlung ließen sich weitere Einblicke über unterschiedliche Sozialstrukturen gewinnen: die nördlichen Universitäten Rostock und Greifswald, aber auch Erfurt wurden bevorzugt von reichen Studenten besucht, während die armen Studenten vor allem dem Sog der großen Städte mit ihren "Massenuniversitäten" folgten, wozu man Köln, Leipzig und Wien zählen kann. ${ }^{129}$ Dabei teilte sich der Universitätsbesuch des Reiches in eine nördliche und eine südliche "Hemisphäre", denn ärmere Studenten stammten im 14. und 15. Jahrhundert zum größeren Teil aus südlichen Territorien, während die Zahlungsbereitschaft im Norden des Reiches wesentlich höher lag. ${ }^{130}$ Schwinges spricht sogar vom "ärmeren Süden" gegenüber dem "reicheren Norden". ${ }^{131}$ Wie ist diese unterschiedliche Sozialstruktur zu erklären? Schwinges geht beim reichen Norden von einer "hansischen Qualität" aus, wenngleich er die preußischen Studenten als Ausnahme deklariert, die ebenfalls eine geringere Zahlungsbereitschaft vorwiesen. ${ }^{132}$ Hansestädte, so zeigt er, lagen dagegen leicht über dem Durchschnitt. Für den Süden gibt er die längeren Wegstrecken als mögliche Ursache der niedrigeren Zahlerquote an. ${ }^{133}$

Neben lokalen und regionalen Strukturunterschieden werden bei der Beurteilung auch universitätsgeschichtliche Zusammenhänge zu berücksichtigen sein: das Netz der Universitäten in südlichen und zentralen Gebieten des Reiches war im 15. Jahrhundert wesentlich dichter als in den Ost- und Nordseegebieten. Auf den Computerkarten im Kartenteil wird die Zunahme der Universitäten in Nord- und Mitteleuropa zwischen 1400 und 1524 etappenweise dargestellt. Aus ihnen geht hervor, daß die Gründungswellen geradezu von Süden und Westen in Richtung Norden und Osten verliefen. Rostock sticht bis zur zweiten Hälfte des 15. Jahrhunderts als nördlichster Universitätsausläufer heraus. Erst zu Beginn des 16. Jahrhunderts werden die nördlichen Universitäten Rostock und Greifswald durch Frankfurt und Wittenberg mit dem dichteren südlichen Universitätsnetz verbunden.

Das größere Angebot an Hochschulen führte im Süden des Reiches sicherlich nicht nur zu einer stärkeren Gesamtfrequenz, sondern auch zu einer zeitlich vorgezogenen Verbreiterung der sozialen Herkunftsbasis der Studenten. In Heidelberg kam es z.B. schon mit der Regionalisierung der Universität am Anfang des 15. Jahrhunderts zu einem Anstieg der "pauperes"-Inskriptionen. ${ }^{134}$ Das geringere Zahlungsverhalten aus dem Süden stammender Studenten könnte daher eine anzunehmende Ursache auch in diesem universitätsgeschichtlichen Entwicklungsunterschied haben. Erst im Verlaufe des 15. und 16. Jahrhundert, als sich auch im Norden die Zahl der Universitäten vergrößerte, mußte sich diese Entwicklung allmählich angleichen. Daß Preußen hier aus dem Rahmen fiel, könnte eine Erklärung ebenfalls in der Frequenzstärke finden. Zwar lag Preußen in einer universitätsgeschichtlich noch unerschlossenen Landschaft, dennoch war die Zahl der Studenten aus den Ordensgebieten gegenüber anderen nördlichen Territorien überdurchschnittlich hoch ${ }^{135}$; ein Sachverhalt, der sicherlich auch durch die klerikale Organisationsstruktur des Ordens begünstigt wurde. ${ }^{136}$ 
Im folgenden soll anhand der Angaben zur Gebührenzahlung in der Greifswalder Matrikel nach Entwicklungen und Veränderungen der Sozialstruktur der Greifswalder Studenten gefragt werden.

\subsection{Die Angaben zur Gebührenzahlung}

Die Angaben zur Gebührenzahlung der einzelnen Studenten gehören neben Namen- und Herkunftsbezeichnungen zu den regelmäßigsten Kategorien in der Greifswalder Matrikel mit etwa 3000 verwertbaren Angaben (90\%). Sie erlauben, eine grobe soziale Einordnung der Studenten vorzunehmen, denn es wurden, trotz statutarisch festgelegter Gebühr, immer wieder Ausnahmen von der Regel gemacht. Einerseits konnten sich wohlhabende Studenten durch höhere Zahlungen gewisse Privilegien erkaufen, andererseits waren viele Studenten finanziell nicht in der Lage, die vollständige Gebühr zu entrichten. Wenn auch eine Teilzahlung nicht möglich war, inskribierte man sie sogar gratis, häufig mit dem Zusatz "pauper", als Ausdruck ihrer Mittellosigkeit. Der hohe Anteil Teil- und Nichtzahler an der Studentenschaft auch in Greifswald macht deutlich, wie teuer ein Studium im Mittelalter war. ${ }^{137}$ Um einen reellen Eindruck über die Größenverhältnisse zu bekommen, braucht man nur die Immatrikulationsgebühr mit anderen mittelalterlichen Geldangaben zu vergleichen. So betrug die Normalgebühr in Greifswald zwei Sundische Mark. Während Greifswalder, intranei, nur eine Mark zu zahlen hatten, gaben Vermögendere bisweilen einen Gulden. ${ }^{138}$ Ab 1457 kam es zu einer Umstellung der Gebühr, die fortan in Schillingen bezahlt werden sollte, doch blieb auch weiterhin die Bezahlung in Mark üblich. Normalzahler mußten jetzt 24 Schillinge ${ }^{139}$ aufbringen, während von Greifswaldern weiterhin nur die halbe Gebühr verlangt wurde. Ferner wurde für den Universitätsdiener und den Universitätsschreiber in der Regel je drei Schillinge genommen.

Gegenüber anderen Universitäten standen die Greifswalder Gebührenanforderungen reichsweit an der Spitze, zusammen mit Rostock, Erfurt und nominell auch Leipzig, das allerdings ein verstärktes stufenförmiges Teilzahlungssystem entwickelte. ${ }^{140}$

Als Ausstattung für die Universität waren den Universitätslehrern verschiedene Pfründen bereitgestellt worden. Die jährlichen Einkünfte betrugen zwischen 20 und 70 Mark, wobei den höheren Fakultäten gewöhnlich auch die besser dotierten Stellen vorbehalten wurden. ${ }^{141} 30$ Mark stellte wohl die Mindestgrenze einer Artistenbesoldung dar, denn 1473 wird dem Magister Petrus Petri eine Ausgleichszahlung aus der Fakultätskasse versprochen, da dessen Einnahmen darunter lagen. ${ }^{142}$ Auch wenn man berücksichtigt, daß in diesem Betrag noch keine Vorlesungsgebühren enthalten sind, die gerade für Artistenlehrer sehr wichtig waren, spiegelt er etwa die Dimension eines mittelalterlichen Einkommens wider. Würde man den niedrigsten Artistenverdienst von 30 Mark dem heutigen studentischen Baföghöchstbetrag gleichsetzen (1000 DM $\approx 500$ EURO monatlich), so entsprächen die zwei Mark Einschreibungsgebühr ungefähr 800 heutigen Mark ( $\approx 400$ EURO). Freilich konnte ein solch hoher Betrag nicht von jedem Studenten direkt bezahlt werden, weshalb die Rektoren sich häufig mit Teilzahlungen begnügen mußten. In einigen Fällen fand sich ein späterer Eintrag in der Matrikel, daß die vollständige Gebühr nachträglich beglichen worden sei, doch war dies eher die Ausnahme. ${ }^{143}$ 


\subsection{Studenten mit voller Inskriptionsgebühr}

Wie an allen anderen Universitäten konnte auch in Greifswald die große Mehrheit der Studenten ihre Gebühr vollständig bezahlen, die damit den Anteil der "Normalstudenten" oder "divites" darstellten. Von 2068 (62,3\%) Personen fand sich eine entsprechende Angabe, indem der Rektor entweder einen Betrag über zwei Mark, 24 Schillingen oder einen Gulden eingetragen hatte, bzw. die Notiz "dedit totum" gemacht hatte. Nur bei Greifswaldern wurde auch ein Betrag über 12 Schillingen oder einer Mark als vollständige Inskriptionsgebühr gewertet. Wenn man die fehlenden Angaben nicht einbezieht, bei denen der Rektor vielleicht aus Bequemlichkeit das "dedit totum" wegließ, steigt der Anteil sogar auf über zwei Drittel der Studentenschaft (68,9\%). Damit liegen die Zahlen um fünf Prozent über den Ergebnissen, die in Köln errechnet wurden (63,8\%). ${ }^{144}$ Mit nur 54 Prozent hatte Leipzig den niedrigsten Anteil "divites" in der Studentenschaft, der im Laufe des 15. Jahrhunderts eher noch sinken sollte. ${ }^{145}$ Schwinges bezeichnete die Universitäten Rostock und Erfurt als vornehme Universitäten und Domänen der "divites", im Gegensatz zu Wien, Köln und Leipzig, die ein höheres Kontingent armer Studenten zu verzeichnen hatten. ${ }^{146}$ Greifswald läßt sich demnach der ersten Kategorie hinzurechnen, vor allem wenn man die verhältnismäßig hohe Gebühr berücksichtigt.

Bei der Gebietsverteilung der "divites" gab es kaum Verschiebungen zum Gesamtverhältnis, da sie die breite Mittelschicht der Universitätsbesucher repräsentierten. Während die Pommern mit 47,3 Prozent etwa einen Punkt unter dem Gesamtwert lagen, konnten die Nachbarländer Mecklenburg und Brandenburg dafür ein Prozent zulegen, so daß der Anteil des Nahbereichs der Universität relativ unverändert blieb. Geringe Verschiebungen waren einerseits beim Ausland zu bemerken, das von 20 auf 21,5 Prozent anstieg, während die übrigen Reichsgebiete von 14,9 auf 13,2 Prozent herabsanken.

Dennoch sind einige bemerkenswerte Abweichungen innerhalb der Herkunftsgebiete festzustellen. So ist bei der Herkunft der vermögenden Normalzahler ein Nord-Südgefälle zu konstatieren, das vor allem am Reichsgebiet deutlich wird. Aus den südlichen Reichsgebieten, die nur eine geringe Beteiligung am Greifswalder Studium vorweisen, kamen mit 14,6 Prozent verhältnismäßig wenige Vollzahler (vgl. Tabelle 4). Etwas höher, aber noch deutlich unter dem Durchschnitt, lag der Wert für Sachsen, das einen Anteil von nur 46,2 Prozent "divites" zu verzeichnen hatte. Sogar der südliche niedersächsische Kreis (ohne Holstein) brachte es nur auf 54,6 Prozent Vollzahler, während Holstein mit knapp 67,2 Prozent bereits fast Durchschnittswerte erreicht. Auch der niederrheinischwestfälische sowie der kurrheinische Kreis lagen zusammen bei 68,1 Prozent und damit etwa im Gesamtdurchschnitt.

Ein Vergleich mit der Kölner Universität bringt ähnliche Ergebnisse, wie eingangs bereits erwähnt wurde. Während die nördlichen Reichsgebiete dort 62,5 Prozent Normalzahler stellten, kamen aus den südlichen Reichsteilen 59 Prozent Nichtzahler, was einem fast umgekehrten Verhältnis entspricht. ${ }^{147}$ Dieses Nord-Süd-Gefälle spiegelt die Wirtschafts- und Handelskapazität des Ost- und Nordseeraums wider, wobei die Hansezugehörigkeit an sich eine untergeordnete Rolle gespielt hat, denn die Hansestädte wiesen mit 72,2 Prozent nur leicht überdurchschnittliche "divites"-Anteile in 
Greifswald auf. ${ }^{148}$ Andererseits werden sich die längeren und wegen fehlender Seewege schwierigeren Wegstrecken der südlichen Universitätsbesucher auf die Zahlungsfähigkeit ausgewirkt haben.

Auch auf einen Entwicklungsunterschied weisen diese Zahlen hin, der mit dem dichteren Netz an Universitäten in den südlichen Reichsteilen zusammenhing. Die größere Konkurrenz im Süden des Reiches führte zur Erschließung neuer "Bildungsrecourcen", indem die Universitäten auf ärmere soziale Schichten ausgriffen. Weniger wohlhabende Studenten waren dabei nicht so sehr auf die kleinen regionalen Universitäten im Süden fixiert, sondern versprachen sich durch einen Ortswechsel bessere soziale Aufstiegsmöglichkeiten als in ihrem "übersättigten" heimatlichen Territorium.

Der Kernraum des Greifswalder Einzugsbereichs erreichte einen deutlich höheren Vollzahleranteil, wobei Brandenburg mit 77,8 Prozent an der Spitze steht, gefolgt von Mecklenburg mit 73,4 Prozent und Pommern mit 72,2 Prozent. Da aus diesen drei Gebieten auch zahlenmäßig die meisten Greifswalder Studenten stammen, stellen sie numerisch das Hauptkontingent der "divites". Aus den Zahlen könnte man nun schließen, daß die Zahlungsbereitschaft mit größerwerdender Entfernung zwischen Heimat- und Hochschulort nachläßt, doch war dies generell nicht der Fall. Von allen Gebieten kann nämlich die Niederlande mit 83,6 Prozent den höchsten Anteil Vollzahler vorweisen. Bei den auswärtigen Studenten steht Livland mit fast 80 Prozent an der Spitze, gefolgt von Schweden mit 79 Prozent und Dänemark mit mit 73,6 Prozent. Diese Länder gehörten alle dem Wirtschafts- und Handelsraums der Hanse an, und konnten offensichtlich ein wohlhabendes Handelsbürgertum zum Studium schicken. Insofern unterstreichen die Zahlen nochmals die Wichtigkeit solcher strukturgeschichtlichen Gegebenheiten für den Universitätsbesuch im späten Mittelalter. Vom sonstigen Ausland liegt Polen leicht unter dem Durchschnitt (65,4\%), worauf Preußen mit 62,9 Prozent folgt. Das übrige Ausland liegt zusammen bei 60,7 Prozent. Man sieht an den letzten Werten, daß sich im Gegensatz zum Reich bei den auswärtigen Vollzahlern kein übermäßiges Gefälle zwischen den einzelnen Gebieten feststellen läßt. ${ }^{149}$

Tabelle 4: Der Anteil der "divites" an den einzelnen Herkunftsgebieten

\begin{tabular}{|l||r||}
\hline Gebiet & $\begin{array}{l}\text { Prozentualer Anteil der } \\
\text { "divites" (Durchschnitt: 68,9\%) }\end{array}$ \\
\hline \hline Niederlande & 83,6 \\
\hline \hline Baltikum & 79,8 \\
\hline \hline Schweden & 79 \\
\hline \hline Brandenburg & 77,8 \\
\hline \hline Dänemark & 73,6 \\
\hline \hline Mecklenburg & 73,4 \\
\hline \hline Pommern & 72,2 \\
\hline \hline Nieder-Kurrh. Kreis & 68,1 \\
\hline \hline Holstein & 67,2 \\
\hline
\end{tabular}




\begin{tabular}{|l|r|}
\hline Polen & 65,4 \\
\hline \hline Preußen & 62,9 \\
\hline \hline übr. Ns. Kreis & 54,6 \\
\hline \hline Sächs. Kreis & 46,2 \\
\hline \multicolumn{2}{|c|}{} \\
\hline übr. Reich & 14,6 \\
\hline \hline übr. Ausland & 65,4 \\
\hline
\end{tabular}

In der folgenden Grafik wurde der Anteil zahlungskräftiger Besucher neben den der sonstigen Studenten gestellt. Es fällt auf, daß erst ab 1477 ein höheres Zahlungsverhalten auftritt, während bis dahin nur ausgesprochen ungünstige "divites"-Werte erreicht werden. Demnach war der vorher besprochene Gesamtdurchschnitt der "divites" von 68,9 Prozent nur begrenzt aussagekräftig. Vielmehr muß man drei Phasen unterscheiden: in der Zeit vor 1475 sind es etwa 36 Prozent, bis 1512 etwa 90 Prozent, und bis zum Betrachtungsende nur noch etwa 80 Prozent Vollzahler. Im längsten Zeitraum war also das Zahlungsniveau in Greifswald so hoch, wie an kaum einer anderen Universität im Reich, womit die Stellung der Universität als Bildungsstätte eines reichen Handelsbürgertums zum Ausdruck kommt. Die negative Bilanz bis 1475 ist vor allem auf die pommerschen Studenten zurückzuführen, die in dieser Zeit fast 65 Prozent Nichtzahler vorweisen. Während im ersten Jahrsiebt nach der Gründung immerhin noch 108 von 228 Pommern die Gebühr entrichteten $(=47,4 \%)$, sank die Quote im folgenden Jahrsiebt auf 16 Zahler, die der großen Zahl von 97 Teiloder Nichtzahlern gegenüber standen $(=14,2 \%)$. Auch in den nächsten sieben Jahren sieht das Verhältnis noch nicht viel besser aus: 42 Gebührenzahler gegenüber 76 Teil- oder Nichtzahlern (=35,6\%). Eine Erklärung dafür scheint in den Krisenerscheinungen dieser Zeit zu liegen. Seit 1464 stand Pommern im Krieg mit Brandenburg und Mecklenburg, ausgelöst durch den soganannten Stettiner Erbfolgestreit. Die Auseinandersetzungen fanden zum Teil in direkter Nachbarschaft Greifswalds statt, und verbreiteten dort erhebliche Verwüstungen. ${ }^{150}$ Außerdem herrschte zu dieser Zeit mehrfach die Pest in Pommern, so daß bereits Kosegarten von einer negativen Auswirkung auf den Universitätsbesuch sprach. ${ }^{151}$ Während die Studentenzahlen aber weitgehend konstant blieben, ab 1464 sogar leicht angestiegen sind, scheint der geringe Anteil zahlungskräftiger Studenten, vor allem aus Pommern, mit diesen Krisenerscheinungen in Verbindung zu stehen, denn er steigt erst wieder mit dem Regierungsantritt Bogislaws X. (1474), der 1479 ganz Pommern unter seiner Herrschaft vereinen, und dem Land einen gewissen Wohlstand bringen sollte. Eine differenzierte Untersuchung dieser ersten Phase nach dem Zahlungsverhalten der Studenten soll im nächsten Abschnitt erfolgen. 


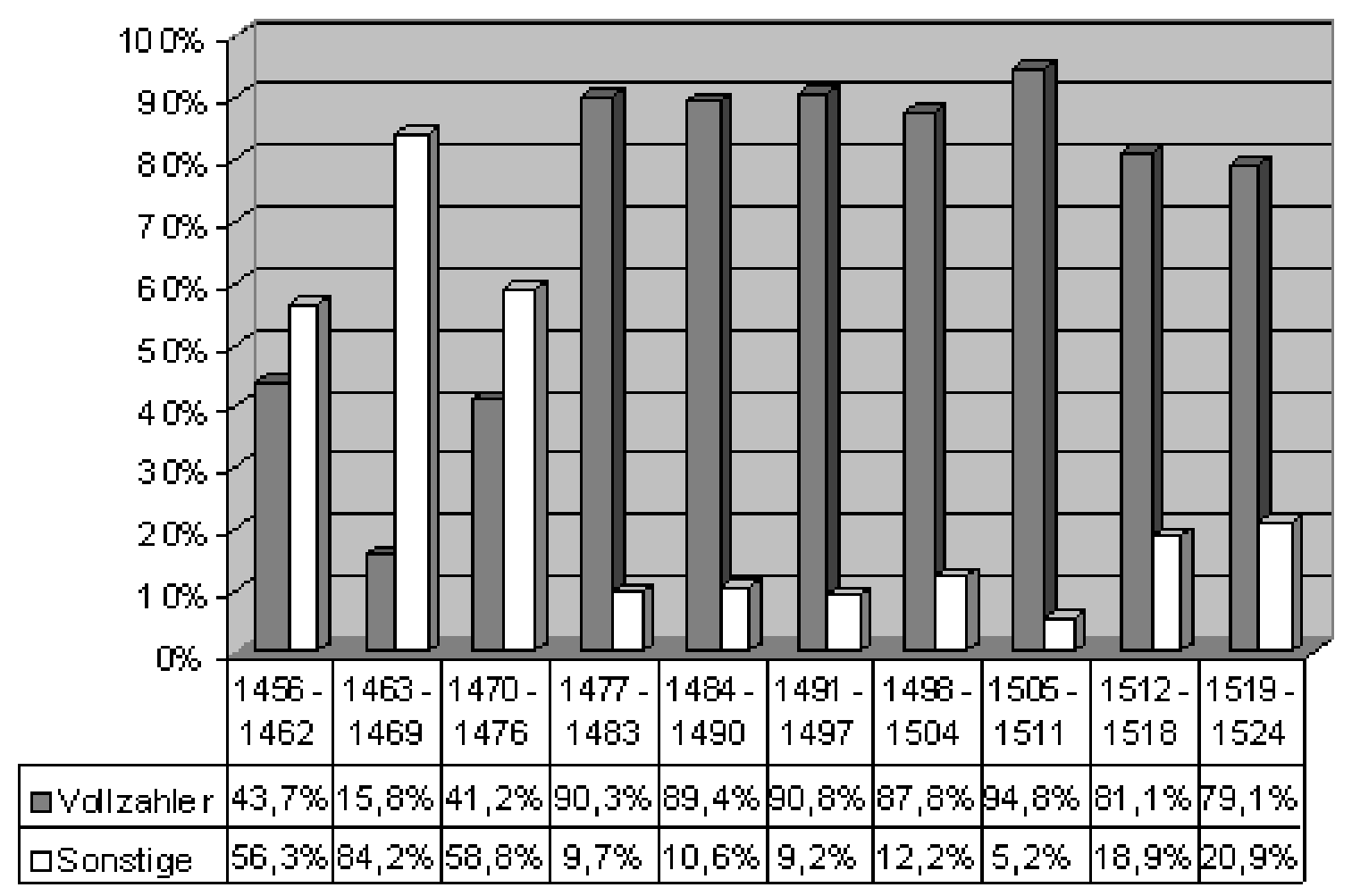

Abbildung 11: Anteil Vollzahler - Sonstige

\subsection{Studenten mit Teilgebühren}

Zu den Immatrikulierten mit Teilgebühren zählten alle Personen, die irgendeinen Betrag bezahlen konnten, der jedoch nicht die vorgeschriebene Imatrikulationstaxe erreichte. Einige unter ihnen konnten nur den Universitätsdiener oder den Universitätsschreiber bezahlen, während andere bereits dicht an der Sollgrenze lagen. Schwinges beschreibt solche Studenten als "Konjunkturpendler", eine Zwischengruppe zwischen Arm und Reich, die sich ökonomisch stets in einer kritischen Zone befand. Jeder Preisanstieg konnte für sie unmittelbare negative Auswirkungen auf den Lebensstandard haben. ${ }^{152}$ Mit 480 Eintragungen stellte diese Gruppe in Greifswald knapp 16 Prozent der Studentenschaft. Pommern stellte fast 52 Prozent der Teilzahler, und lag damit knapp drei Prozent über seinem Gesamtanteil an der Studentenschaft. Es scheint, als ob solche konjunkturell abhängigen Personen eher dem Nahkreis einer Universität angehörten, während sich bei entfernten Gebieten eine deutlichere Trennung zwischen Arm und Reich vollzog. Eine genaue Betrachtung der Herkunftsbezirke nach Teilgebührenzahlern kann weitere Erkentnisse darüber liefern.

Während die Niederlande den höchsten Prozentsatz Vollzahler aufwies, und man daher erwarten konnte, daß die übrigen Studenten immer noch einen Teil ihrer Gebühren entrichten würden, ist das geringe Auftreten dieser Zwischengruppe mit 2,3 Prozent bemerkenswert (vgl. Tabelle 5). Auch bei den vollzahlerstarken Schweden und Livländern liegen die Teilzahlerwerte nur geringfügig über denen der Nichtzahler mit 11,6 und 11,4 Prozent. Am krassesten finden sich die Gegensätze bei den sächsischen Studenten, wo nur vier Prozent Teilzahler den in fast gleicher Stärke vertretenen Armen und Reichen gegenüber stehen. Spitzenwerte für Teilzahler erreichen dagegen die rheinischen Kreise 
mit 21,3 Prozent, gefolgt von den ebenfalls Vollzahler-schwachen Preußen und Polen mit etwa 19 Prozent sowie den Dänen mit 17,1 Prozent, die damit insgesamt einen höheren Anteil zahlender Studenten als die Niederlande aufweisen.

Tabelle 5: Der Anteil der Teilzahler an den einzelnen Herkunftsgebieten

\begin{tabular}{|c|c|}
\hline Gebiet & $\begin{array}{l}\text { Prozentualer Anteil der Teilzahler } \\
\text { (Durchschnitt: 16\%) }\end{array}$ \\
\hline Nieder.-Kurrh. Kreis & 21,3 \\
\hline Preußen & 19,4 \\
\hline Polen & 19,2 \\
\hline Dänemark & 17,1 \\
\hline Pommern & 15,9 \\
\hline Holstein & 14,9 \\
\hline Brandenburg & 13,8 \\
\hline übr. Ns. Kreis & 13 \\
\hline Mecklenburg & 11,9 \\
\hline Schweden & 11,6 \\
\hline Baltikum & 11,4 \\
\hline Sachsen & 3,9 \\
\hline Niederlande & 2,7 \\
\hline übr. Ausland & 7,7 \\
\hline südl. Reich & 24,4 \\
\hline
\end{tabular}

Für eine Frequenzuntersuchung der Teilzahler kommen in erster Linie die "divites"-schwachen Jahrgänge in Betracht. Die folgende Grafik stellt das Verhältnis der Teilzahler zu den Nichtzahlern in den ersten 20 Jahren nach der Universitätsgründung dar. Der Zeitraum ist durch zwei Phasen gekennzeichnet. Die erste dauert genau bis 1464, als der Anteil der Teilzahler nach einem starken Anstieg wieder zurückfiel, die andere bis 1475, als nach einem erneuten Anstieg die Teilzahlerwerte bei fast 100 Prozent lagen. Offensichtlich hatten sowohl die schwere Pest, die 1464 in Pommern grassierte, als auch die Wirren und Kämpfe des Stettiner Erbfolgestreits eine Entwicklung beendet, in der sich das Zahlungsverhalten kontinuierlich besserte. Ein Umschwung fand erst wieder 1467 statt, als in einem längeren Prozeß deutlich mehr Teilzahler immatrikuliert wurden. 1473 erreichten die Teilzahler dann gegenüber den Nichtzahlern Höchstwerte um 100 Prozent, und gingen seit 1475 in die Gruppe der "divites" über, die ab jetzt etwa 90 Prozent der Gesamtbesucherschaft stellte. Offenbar war das bessere Zahlungsverhalten nach 1475 nicht sprunghaft eingetreten, sondern hatte sich vorher bereits in einem Anstieg der Teilzahler abgezeichnet. Schon 1464 wäre es demnach zu 
einer besseren Zahlungsbilanz gekommen, doch verhinderten Krieg und Pest, daß die höheren Teilzahlerwerte in "divites"-Immatrikulationen umschlagen konnten.

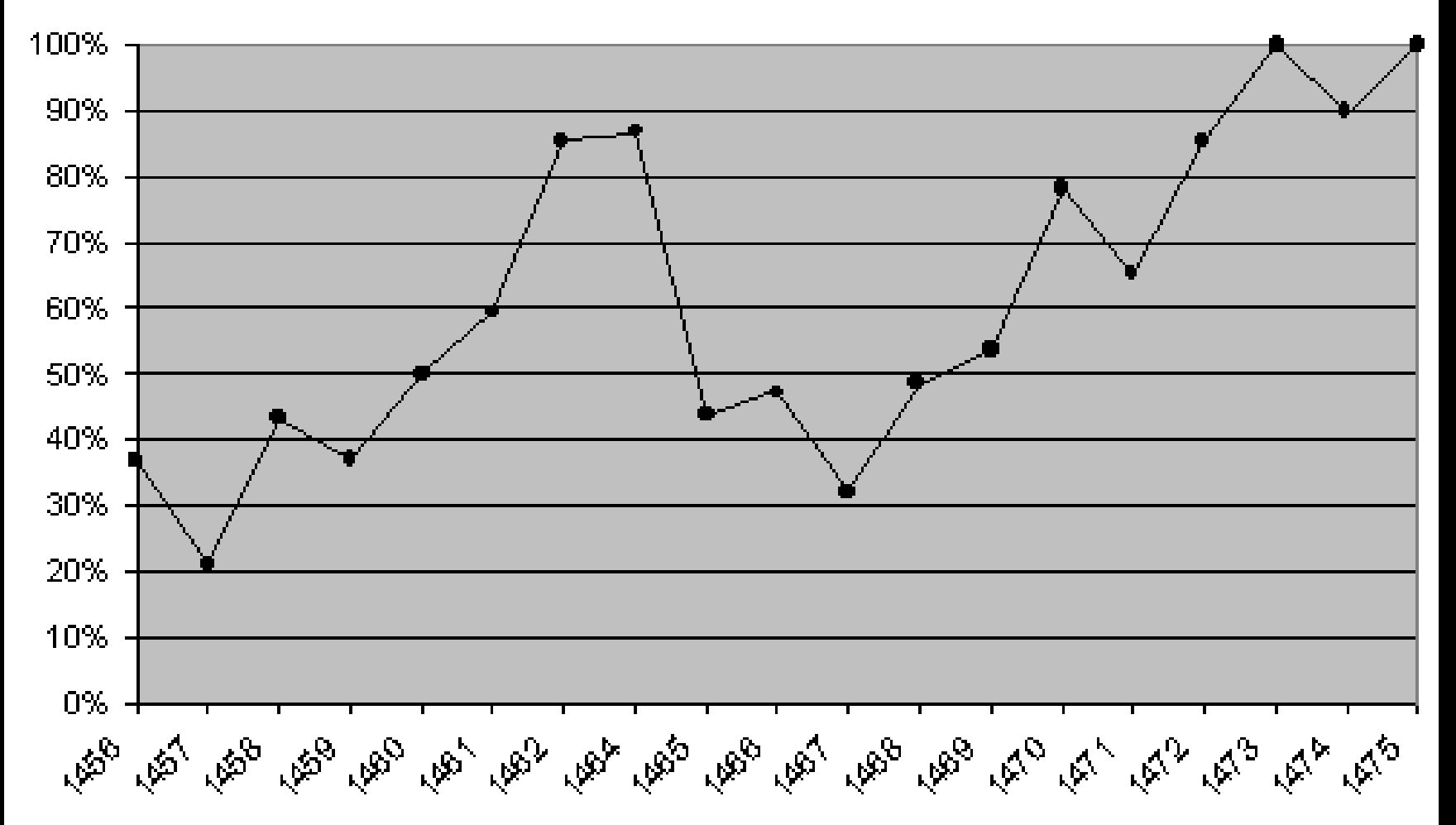

Abbildung 12: Das Verhältnis der Teil- und Nichtzahler von 1456 bis 1475

In den übrigen Jahrgängen sind nur geringe Ausschläge der Teilzahlerkurve zu verzeichnen. Sie fallen fast immer mit frequenzstarken Jahrgängen zusammen, in denen äußere Ereignisse auf den Universitätsbesuch einwirkten. So stiegen die Werte in den Jahren 1488 bis 1490 auf 17 Teilzahler, als die Rostocker Domfehde einen allgemeinen Studentenzuwachs verursachte sowie in den Humanistenjahrgängen 1500 und 1501, in denen sich immerhin 11 nur zum Teil zahlende Studenten immatrikulieren ließen. In der letzten Phase, bevor die Reformation zur Schließung der Universität führte, wurden die Teilzahlerimmatrikulationen wieder regelmäßiger, doch war der Rückgang der "divites" vor allem mit einer steigenden Zahl solcher Studenten verbunden, die überhaupt keine Gebühren entrichten konnten, welche im nächsten Abschnitt gesondert behandelt werden sollen.

\subsection{Studenten ohne Inskriptionsgebühr}

Zu den Studenten, denen die Gebühr erlassen wurde, zählten nicht nur jene, die über mangelnde finanzielle Möglichkeiten verfügten, sondern zum Teil auch Personen, die durch familiäre oder sonstige Verbindungen eine Gratisimmatrikulation erwirken konnten. Manchmal wurde der Grund einer Gebührenbefreiung mitgeteilt, doch in den meisten Fällen steht nur die Notiz "nihil dedit" hinter dem Namen. Wie schon im letzten Abschnitt gezeigt werden konnte, fand die Heraushebung als "pauper" in Greifswald nur sehr unregelmäßig statt, doch wird wohl der Hauptteil der nichtzahlenden Studenten dieser ärmsten Schicht in der Universitätsbesucherschaft zuzuordnen sein. Bei ihnen 
handelte es sich um Personen, die im Studium die einzige Möglichkeit für einen gewissen sozialen Aufstieg erkannten, doch muß man die reellen Chancen gering bewerten. Viel zu sehr war die Gesellschaft noch in soziale Schichten unterteilt, in die man geboren wurde und denen man sein Leben lang verhaftet blieb. Selbst einzelne biographische Sonderfälle, für die eine Karriere oder ein sozialer Aufstieg nachgewiesen werden konnte, sollten über diese gesellschaftliche Realität nicht hinwegtäuschen, denn schon ihre Überlieferung deutet auf eine Sonderposition hin. ${ }^{153}$ Wie die neuere Forschung betont, fand selbst innerhalb des universitären Betriebs eine klare soziale Differenzierung statt, auf deren Einhaltung größter Wert gelegt wurde. ${ }^{154}$ In Greifswald lag die Zahl der Nichtzahler bei 455 Immatrikulierten, was einem Anteil von 15,2 Prozent entspricht. Mit 26,4 Prozent lag der Anteil der entfernten Reichsgebiete um fast 12 Prozentpunkte über dem Gesamtanteil, während der Anteil aller übrigen Gebiete stark zurückfiel. Wie schon vorher bemerkt wurde, waren es vor allem die südlichen Reichsteile, aus denen verhältnismäßig viele Nichtzahler stammten, aber auch Nieder- und Obersachsen war stark vertreten. Der Anteil Pommerns sank gegenüber dem Gesamtverhältnis um mehr als fünf Punkte und kam auf 43 Prozent. Nur 11,2 Prozent der Pommern waren Nichtzahler, was um vier Prozent unter dem Durchschnitt der anderen Länder liegt. Selbst in den ersten 20 Jahren der Universität, in denen allgemein nur sehr wenige Vollzahler immatrikuliert wurden, liegt der Nichtzahleranteil der Pommern noch leicht unter dem Durchschnitt mit 24,7 gegenüber 26,2 Prozent. Das Zahlungsverhalten der Pommern war demnach davon geprägt, sogar in Krisenzeiten immer noch einen Teil der vorgeschriebenen Gebühr zu entrichten. In der Zeit zwischen 1476 und 1511, als die Zahlungsbereitschaft bei über 90 Prozent lag, war der Anteil der Pommern an den Nichtzahlern mit knapp 30 Prozent um fast 20 Punkte unter dem Gesamtanteil, so daß sie von den übrigen Reichsgebieten mit 31 Prozent ein einziges Mal auch numerisch übertroffen werden. Diese Zahlen verdeutlichen einerseits, wie wohlhabend die bürgerliche Oberschicht im Norden Deutschlands war, andererseits beweisen sie, daß Pommerns strukturgeschichtliche Randlage im Reich, die in späterer Zeit auch wirtschaftlich zum tragen kam, in vorreformatorischer Zeit kaum Auswirkung auf die Sozialstruktur der Studentenschaft hatte. Offenbar muß man jedoch die erhebliche Verarmung in der Anfangszeit der Universität als Indiz dafür werten, daß der pommersche Wohlstand sehr konjunkturabhängig und durch äußere Krisen in verstärkter Form beeinflußbar war.

Ab 1512 ließ sich wieder eine zunehmende Pauperisierung der Studentenschaft feststellen (vgl. Abbildung 13). Vor allem ab 1522 ist ein Anstieg zu beobachten, der zuerst die Teilzahlerkurve erfaßt, und im nächsten Jahr in eine Aufwärtsbewegung der Nichtzahler um fast 20 Prozent übergeht. Auch im letzten Untersuchungsjahr geht der Wert nur leicht zurück.

Diese Zahlen verdeutlichen die konjunkturelle Krise Pommerns kurz vor und während der Zeit der Reformation, die in vielen Städten zur erheblichen Verarmung der Bevölkerung geführt hat. ${ }^{155}$ Die Armenwerte erlebten 1516 und 1517 nur einen Scheinrückgang, denn es kommt in diesen Jahren nicht etwa zu einem Anstieg der Vollzahler, sondern nur zu einem Rückgang der Nicht- und Teilzahler, die in dieser Zeit aus finanzieller Not wahrscheinlich ganz auf ein Studium verzichten mußten. 


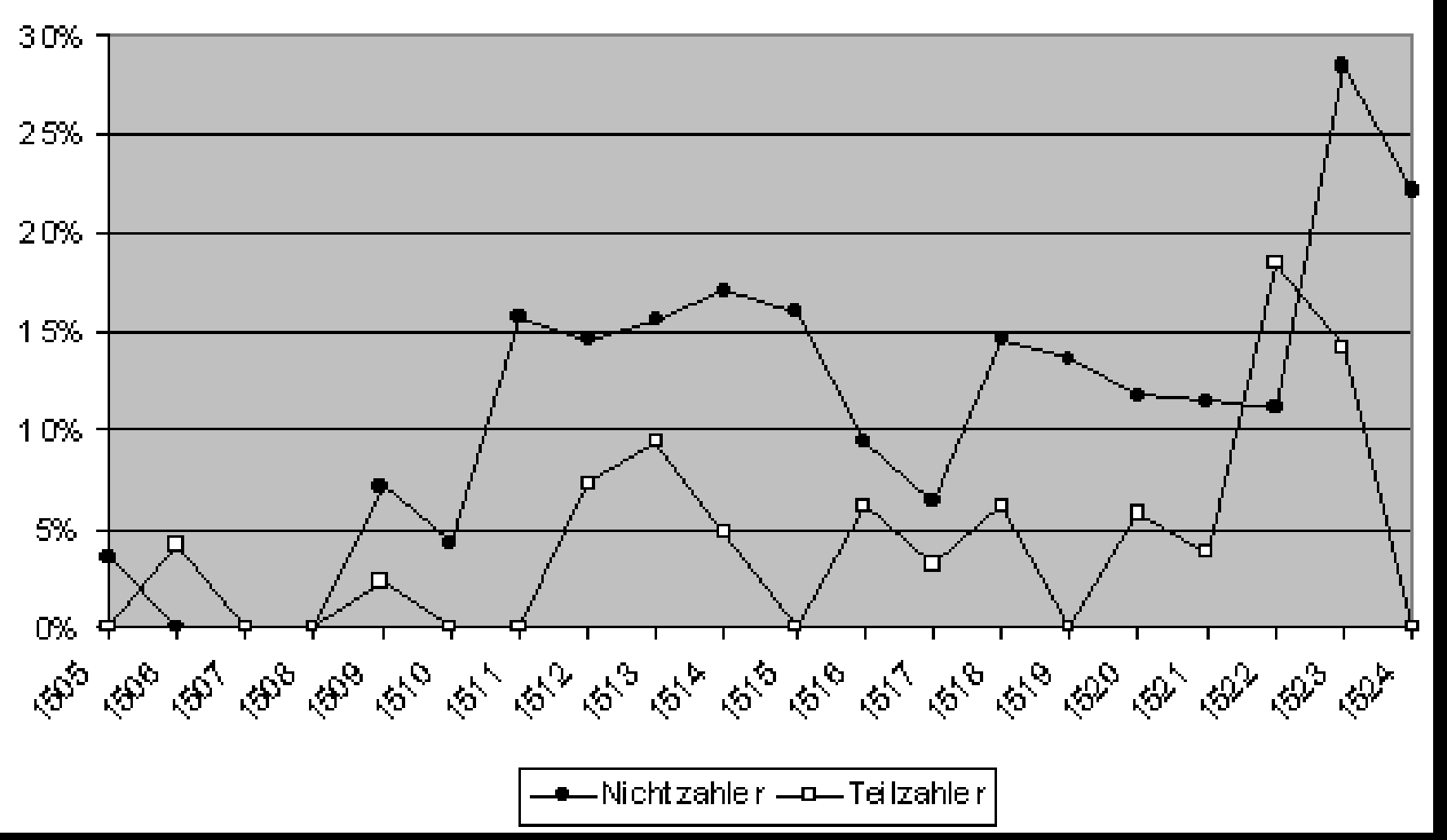

Abbildung 13: Nicht- und Teilzahleranteil von 1505 bis 1524

\subsection{Resümee: Sozialstrukturen im Wandel}

Die Untersuchung der Gebührenzahlung in Greifswald zwischen 1456 und 1524 hat gezeigt, daß die These des reichen bürgerlichen Publikums im längsten Zeitraum berechtigt ist, denn zwischen etwa 1475 und 1510 konnten fast 90 Prozent der Greifswalder Studenten die vergleichsweise hohen Immatrikulationsgebühren vollständig entrichten. Als Grund dürfte vor allem die konjunkturelle Entwicklung Pommerns genannt werden, das sich unter Herzog Bogislaw X. in einer Phase der inneren Konsolidierung befand. Demgegenüber stellte die Greifswalder Frühphase von 1456 bis etwa 1474 eine Krisenzeit dar, denn die Armut in der Studentenschaft lag in dieser Zeit überdurchschnittlich hoch. Krieg und Pest in Pommern sind als Gründe dieser Entwicklung anzuführen. Auffällig ist, daß vor allem die pommerschen Studenten von der Armut betroffen waren, die ansonsten als Basis des Greifswalder Einzugsbereichs immer einen überdurchschnittlich hohen Anteil zahlender Studenten stellten. Erst seit etwa 1484 erfolgt eine Verschiebung unter den armen Studenten, die von nun an vermehrt aus fremden Territorien stammen. Im Gesamtverlauf steigt der Anteil der Pommern seither kontinuierlich an, wie aus der folgenden Grafik hervorgeht.

Wie ist dieser Anstieg der Armut bei den Pommern, der gegen Ende des Betrachtungszeitraum sogar die Werte der Anfangsphase übersteigt, zu erklären? Einerseits werden ökonomische Krisenzeiten in den Jahren vor der Reformation ausschlaggebend gewesen sein, andererseits kann die Gesamtfrequenz der Pommern hier eine befriedigende Erklärung liefern: das zu Beginn des 16. Jahrhundert nun auch im Norden des Reiches dichter gewordende Netz an Universitäten führte zu einem Anstieg der Studierenden aus Pommern. Die Mobilisierung der Pommern zum Studium wird 
zu einer Verbreiterung der sozialen Herkunftsbasis geführt haben, wie es für Gebiete im Süden und Westen des Reiches schon in der zweiten Hälfte des 15. Jahrhunderts zu beobachten war. Im folgenden soll nun eine differenzierte Analyse der räumlichen Herkunft aller Greifswalder Studenten erfolgen, um so die verschiedenen Entwicklungsphasen des Einzugsbereichs herauszustellen.

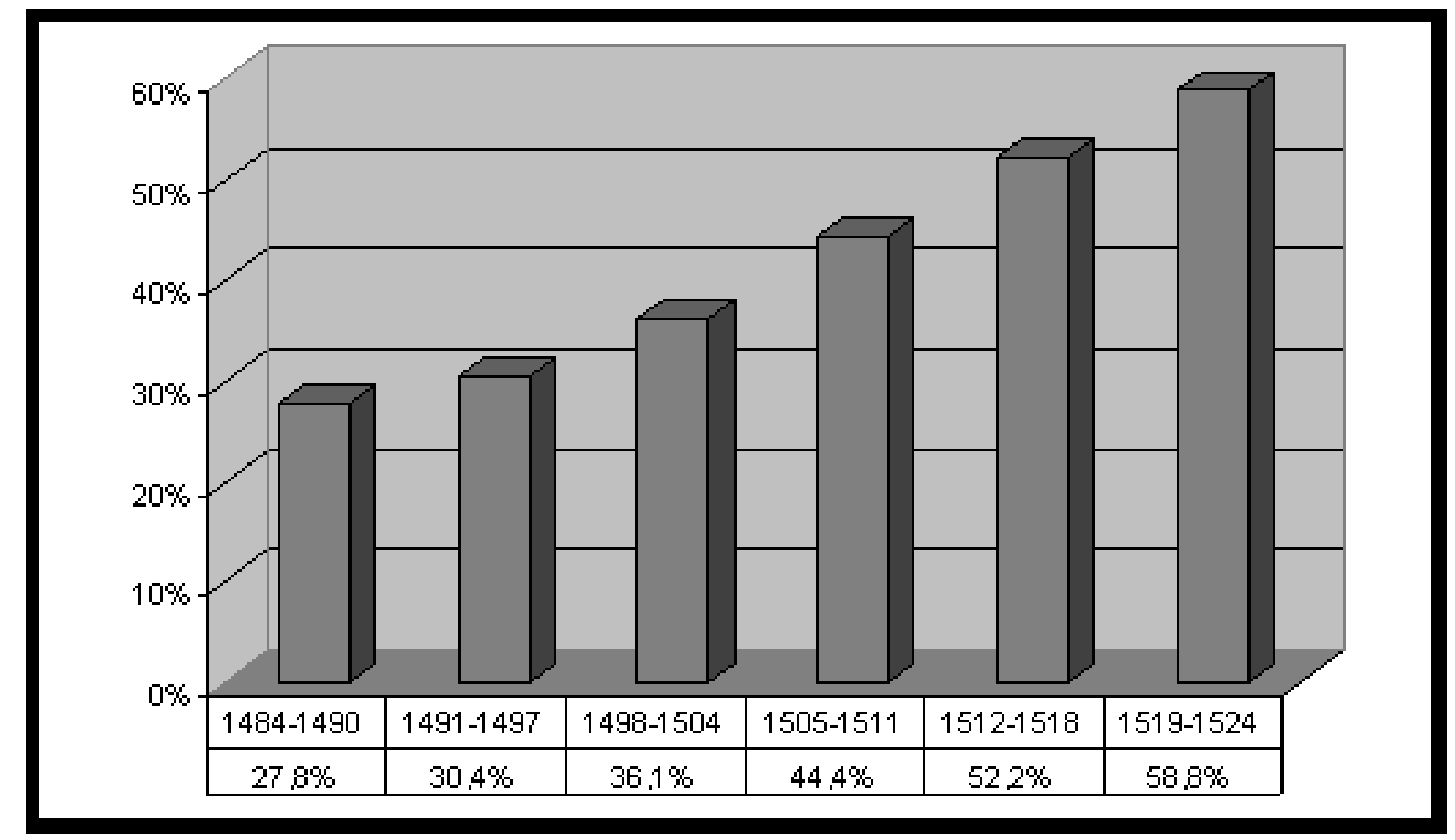

Abbildung 14: Anteil der Pommern an den Teil- und Nichtzahlern 


\section{Einzugsbereiche und Wirkungsgrade Greifswalds 1456-1524}

\subsection{Zur "regionalen Existenz" der Universität Greifswald}

In jüngerer Zeit hat die Universitätsforschung verschiedene traditionelle Vorstellungen vom Universitätsbesuch im späten Mittelalter revidieren können. Auch die Frage der räumlichen Herkunft der Studenten unterlag bisher einer gewissen anachronistischen Betrachtungsweise, indem man allzuoft eine größere Reiselust der Universitätsbesucher des späten Mittelalters unterstellte. Die Vorstellung ging dahin, daß die Studenten weite Entfernungen zurücklegten, um zum Studienort zu gelangen, und daß sie in der Regel die Universitäten mehrfach gewechselt hätten.

Der Begriff des "fahrenden Scholarentum" war ein Synonym für diesen Studententyp, doch übertrug man mit solchen Aussagen den Ausnahmefall auf die Allgemeinheit, wie neuere Forschungen erwiesen haben. ${ }^{156}$ Der gemeine Student war finanziell gar nicht in der Lage, Reisen an entfernte Universitäten zu unternehmen. Dies war nur einem kleinen Teil der sozial besser gestellten Studenten möglich. Dementsprechend beurteilte man auch die spätmittelalterlichen Universitäten anachronistisch, wenn man ihre überregionale Ausstrahlung hervorhob. Damit versuchte man, sie in einen Gegensatz zur neuzeitlichen, konfessionalisierten Landesuniversität zu stellen. ${ }^{157}$ Rainer Christoph Schwinges konnte in einer umfassenden Studie über die Universitätsbesucher des 14. und 15. Jahrhunderts feststellen, daß schon die Universitäten des spätmittelalterlichen Reichsgebietes im wesentlichen regional organisiert waren. Er spricht von einer Kernlandschaft, in der eine Universität ihre Existenzbasis fand und sozial verwurzeln konnte. Die Studenten bevorzugten die nächstgelegene Universität, weil sie sich vor allem dort größere Chancen auf soziale Anbindung und Förderung erhoffen konnten. 158

Schon in der Gründungsphase der ersten Universitäten im Reichsgebiet ließ sich diese Entwicklung nachweisen: wer eine ältere Universität verließ, um an die neuen Universitäten Heidelberg, Erfurt und Köln zu wechseln, stammte zumeist aus deren näheren und weiteren Umgebung. ${ }^{159}$ Eine etwas andere Entwicklung nahmen die Universitäten Prag und Wien, deren Gründung in eine universitätsgeschichtliche Übergangsphase fiel. Dies wird an dem Umstand deutlich, daß beide Universitäten im Gegensatz zu den späteren Gründungen über Nationenverfassungen verfügten. ${ }^{160}$

Ein gemeinsames Merkmal fast aller Universitäten war die "Normalisierung" der Frequenz nach einer ungewöhnlich starken Eröffnungsphase. ${ }^{161}$ Auch die Herkunftsstruktur der Studenten war von dieser Entwicklung betroffen. ${ }^{162}$ Kennzeichnend für diese Phase war ein hoher Anteil aus dem regionalen Umfeld der Hochschule stammender Studenten, so daß man von einer Phase sprechen könnte, in der sich eine Universität eine "regionale Existenz" sicherte. ${ }^{163}$ Erst im dritten Jahrzehnt nach der Gründung konnte die Kölner Universität stärker über die Grenzen der drei regionalen Diözesen Köln, Lüttich und Utrecht hinausgreifen, ohne dabei jedoch die regionale Basis zu verlieren: trotz 
Austauschvorgängen und Schwerpunktverlagerungen blieb die Grundstruktur der regionalen Existenz bis zur Reformation erhalten. ${ }^{164}$ Schwinges geht davon aus, daß die Universitäten der sogenannten zweiten Gründungswelle nicht die notwendige Zeit hatten, von sicherer Basis aus eine Überregionalität aufzubauen: sie waren zur Blütezeit Kölns im ausgehenden 15. Jahrhundert noch in der Phase der "regionalen Existenzsicherung". ${ }^{165}$ Ein Ausgreifen auf überregionale Gebiete wurde im 16. Jahrhundert dann durch die Reformation und Konfessionalisierung stark eingeschränkt. ${ }^{166}$ Greifswald wurde 1456 gegründet und gehört damit dieser Gründungswelle an ${ }^{167}$, so daß sich die Frage stellt, wie die Entwicklung dort verlief.

Bevor man jedoch eine genaue Analyse der räumlichen Organisation des Greifswalder Einzugsbereichs anstellt, sollte man die besonderen geographischen und demographischen Daten analysieren, die für die unterschiedlichen Entwicklungen innerhalb der einzelnen Universitäten verantwortlich waren. Es ist anzunehmen, daß die Besonderheiten des "Standorts" Pommern gegenüber den übrigen Reichsteilen Auswirkungen auch für die Ausstrahlung der neuen Universität gehabt haben.

Einerseits ermöglichte die Lage der Universitätsstadt an der Ostsee den Studenten eine Anreise per Schiff. Es ist davon auszugehen, daß sich dieser Umstand auch auf den Einzugsbereich der Universität ausgewirkt hat: während größere Entfernungen über Land nicht nur beschwerlicher, sondern auch wesentlich gefährlicher waren, bot das Schiff hier eine bequeme Alternative. Andererseits bewirkte die Randlage im Reich die automatische Nähe zum soganannten "Ausland". Internationalität und Regionalität schlossen sich in Greifswald daher nicht zwangsläufig aus. Ein weiterer Unterschied liegt in der Bevölkerungsstruktur, denn Pommern gehörte zu den am geringsten besiedelten Gebieten im Reich gegenüber den südlichen und westlichen Ländern. ${ }^{168}$ Eine regionale Verengung des Einzugsbereichs mußte sich in Greifswald daher umso mehr auf die Gesamtzahl der Studierenden auswirken. Auch die Größe der Universitätsstadt spielt hier eine wichtige Rolle: während Greifswald im ausgehenden Mittelalter als mittlere Kleinstadt zu bewerten ist, war Köln die größte Stadt des gesamten Reichsgebietes. Daher verwundert es nicht, wenn 57 Prozent der Kölner Studenten in den Eröffnungsjahrgängen direkt aus der Universitätsstadt stammten. ${ }^{169}$ Ein letzter Punkt hängt mit der universitätsgeschichtlichen Erwägung zusammen, daß es, wie schon erwähnt, im Süden und Westen des Reiches früher als im Norden zur Verdichtung der Universitätslandschaft kam. ${ }^{170}$ Die geringere Konkurrenz wird sich auch auf den Besuch dieser Universitäten ausgewirkt haben. Die grobe Verteilung der Greifswalder Studenten zeigte zwar bereits mit 49 Prozent das Übergewicht der aus Pommern stammenden Studenten, doch waren 20 Prozent ausländische Studenten eine nicht zu übersehende Größe. Die Ergebnisse bestätigen die These, daß Greifswald innerhalb der Universitäten des Reiches eine gewisse Sonderrolle eingenommen hat, wie schon Roderich Schmidt betont hat. ${ }^{171}$ Begreift man das 15. Jahrhundert als Übergangsphase der Universitätsgeschichte, in der sich eine steigende Tendenz zum haimatnahen Studium vollzog ${ }^{172}$, so verlief diese Entwicklung keineswegs gleichmäßig an allen Universitäten, sondern war von äußeren Faktoren geprägt und unterschied sich von Region zu Region. Außerdem scheint die These von Rainer Christoph Schwinges nur schwer auf Greifswald übertragbar zu sein, der schrieb, daß bei den Universitäten der zweiten Gründungswelle aus entwicklungslogischen Gründen noch gar nicht an 
Ausgreifen auf überregionale Gebiete zu denken war, weil sie noch im Aufbau ihrer "regionalen Existenz" begriffen waren. ${ }^{173}$ Greifswalds überregionaler Anteil spricht dagegen. Nur eine systematische Untersuchung des gesamten Zeitraums kann zur Klarheit verhelfen, ob und wie sich die Herkunftsstruktur veränderte.

In der folgenden Grafik wird das prozentuale Verhältnis der Pommern zur übrigen Studentenschaft auf die Jahre verteilt dargestellt. Aus ihr kann man ablesen, in welchen Zeiträumen die Universität mehr "Landesuniversität" war und in welchen sie überregionale Ausstrahlung hatte. Es wird deutlich, daß die prozentuale Gesamtverteilung der Studenten nur ein einheitliches Bild vortäuscht: das Verhältnis der Pommern zu den übrigen Besuchern war keineswegs immer gleichbleibend. Die Werte der Pommern setzten zwar sehr hoch ein und erreichten von Beginn an Werte über 50 Prozent, doch sanken die Zahlen bis zum Jahre 1491, wenn man von dem kurzen Anstieg zwischen 1474 und 1479 absieht. Erst ab 1492 erfolgt eine kontinuierliche Zunahme, wobei 1499 noch einmal der niedrigste Wert von nur 19 Prozent erreicht wird. Ab der zweiten Hälfte des behandelten Zeitraums kann man tatsächlich von einer verstärkten Regionalisierung der Universität sprechen, während die Universität in den am besten frequentierten Jahrgängen 1486 bis 1491 und 1499 die größte überregionale Ausstrahlung hatte. Die Ergebnisse machen deutlich, daß eine differenzierte Untersuchung zur räumlichen Herkunft der Studenten erforderlich ist, um die besondere Entwicklung in Greifswald herauszustellen.

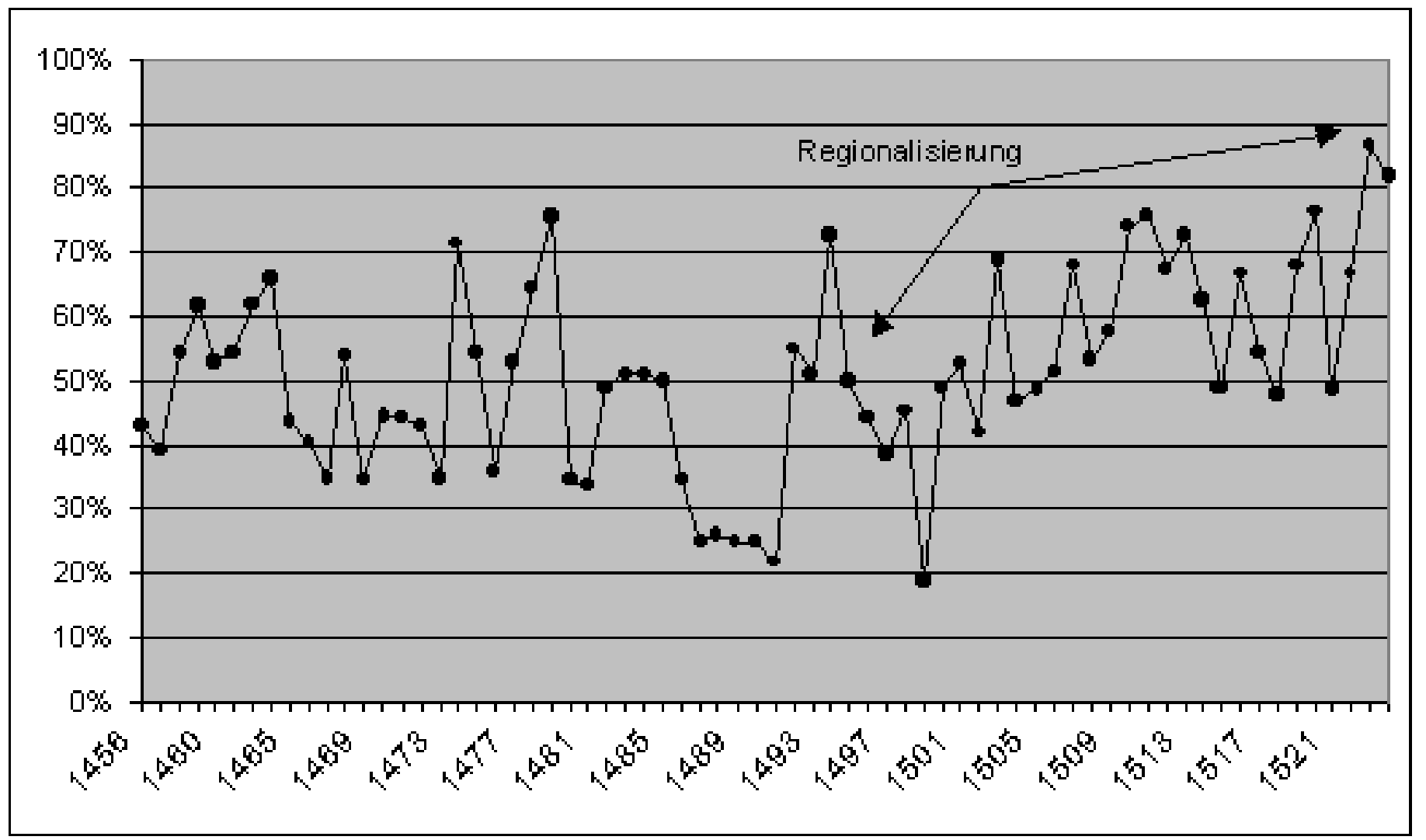

Abbildung 15: Das Verhältnis Pommern-Nichtpommern (\% pro Jahr) 
Zuerst soll nun die Frequenz von 15 Orten des Greifswalder Einzugsbereichs analysiert werden, aus denen die meisten Studenten an die pommersche Universität zogen. Die Nähe zur Universitätsstadt ist das gemeinsame Merkmal fast aller 15 Orte. 12 befinden sich in Pommern, zwei in Mecklenburg, das freilich auch zum regionalen Umfeld gezählt werden kann. Außerdem ist mit Danzig ein Ort aus dem etwas weiter entfernten Preußen vertreten. Es soll mit den Studenten begonnen werden, die direkt aus Greifswald stammen, da sie zusammengenommen die größte Gruppe bilden.

Insgesamt stellte die Stadt 185 Studenten, was ein Anteil von 12 Prozent aller Studenten Pommerns darstellt. Keck zählt bei einer Betrachtungszeit von 21 Jahren 58 Leipziger Studenten ${ }^{174}$, während in den ersten 85 Jahren Ingolstadts $579^{175}$, in den ersten 123 Jahren Tübingens 828 Studenten ${ }^{176}$ aus der Universitätsstadt selber kamen.

Damit entsprechen sich die Ergebnisse für Greifswald und Leipzig, woher durchschnittlich etwa drei Studenten pro Jahr kamen, während Ingolstadt und Tübingen mit fast sieben Studenten erheblich darüber liegen. Obwohl eine Bewertung solcher Zahlen aufgrund der unterschiedlichen Betrachtungszeiträume problematisch ist, weisen sie auf eine unterschiedliche Bildungsstruktur zwischen den nördlichen und südlichen Städten des Reiches hin. Während die Schulverhältnisse in Leipzig $^{177}$ und Greifswald ${ }^{178}$ vor den Universitätsgründungen als mangelhaft zu bewerten sind, die dort den Anfang höherer Bildung darstellten, blühte in den südlichen Städten Tübingen und Ingolstadt, bereits eine größere Schullandschaft, die den stärkeren Zulauf erklären könnte.

Unter den ersten Studenten aus Greifswald befanden sich zwei Adelige, sieben Ordensgeistliche (sechs vom Prediger-Orden, darunter ein Prior sowie ein Zisterzienser) und 11 Weltgeistliche, von denen einer als Pfarrer von St. Jakobi, zwei als Kaplane, zwei als Domini, zwei als Priester und die restlichen vier als Kleriker bezeichnet werden. Ferner zählen zu ihnen zwei Pauperes und ein Rostocker Magister. Um einen Eindruck davon zu bekommen, ob die Universitätsgründung längerfristig eine Veränderung im Studienverhalten der Greifswalder Bürger bewirkte, wäre nach Entwicklung bzw. Anwachsen der Inskriptionen aus der Universitätsstadt zu fragen.

Die Zahl der Studenten aus Greifswald war nicht durchweg gleichbleibend. Während in der Anfangsphase der Universität von 1456 bis 1462 (also in sieben Jahren) noch 46 Greifswalder immatrikuliert wurden, waren es in den folgenden sieben Jahren nur neun Studenten. Erst $1473 \mathrm{kam}$ es wieder zu einem kurzen Anstieg der Immatrikulationen, der allerdings nur fünf Jahre anhielt, in denen 19 Studenten verzeichnet wurden. Von 1478 bis 1491 blieben die Zahlen sehr niedrig bei einem Durchschnitt von einem Studenten pro Jahr (14 Immatrikulierte in 14 Jahren). Zwischen 1491 und 1511 konsolidierten sich die Immatrikulationen auf den Mittelwert von etwa 2,3. Ab 1511 bis zum Betrachtungsende kam es zu einem stärkeren Anstieg der Zahlen (durchschnittlich fast vier Studenten pro Jahr).

Als Ergebnis kann man sagen, daß die Gründung in der Eröffnungsphase zu einer überdurchschnittlich hohen Beteiligung geführt hat, bei der allerdings ein sozialgeschichtlicher Vorgang zu berücksichtigen ist. Wie an anderer Stelle bereits erwähnt wurde, schrieben sich nicht nur Studenten in die Matrikel ein, sondern auch Bürger, welche die Universitätsprivilegien genießen wollten. Ganz beliebig war eine solche Inskription aber nicht; man mußte schon in einer Beziehung, 
und sei sie auch noch so locker, zur Hohen Schule gestanden haben, sei es als Buchbinder, sei es als Schreiber oder Notar. Die hohen Zahlen der Anfangszeit werden mit den Inskriptionen solcher Greifswalder Bürger zusammenhängen; natürlich dauerte es seine Zeit, bis diese gestorben waren und z. B. erneut ein Buchbinder das akademische Bürgerrecht erlangen konnte. Der Rückgang der Immatrikulationen aus der Universitätsstadt in den folgenden Jahren erhält damit eine einleuchtende Erklärung. Sie bleiben für lange Jahre auf recht niedrigem Niveau: eine Phase, in der sich die Universität eine Klientel in der eigenen Stadt erst sichern mußte. Zum Jahrhundertwechsel scheint dieses Ziel erreicht zu sein, so daß die Zahlen einen deutlichen Zuwachs erfuhren. Dies ist um so bemerkenswerter, da die Gesamtfrequenz eher rückläufig war. Genau wie in Köln scheint die regionale Basis der Universität durch äußere Faktoren kaum beeinflußt worden zu sein. ${ }^{1}$ 179

Neben Greifswald konnten nur zwei andere Städte Pommerns über 100 Studenten aufweisen: Stralsund (160) und Stettin (107). Zusammen stellten diese drei Städte etwa ein Drittel aller pommerschen Studenten, während aus den sechs meistgenannten Orten über die Hälfte kamen. Stralsund, das 1234 Stadtrecht erhielt, wurde von den Studenten neben der Universitätsstadt als häufigster Herkunftsort genannt, was einerseits mit der Nähe, andererseits mit der vergleichbaren Einwohnerzahl zusammenhängt. 180

Als Hansestädte waren sowohl Stralsund als auch Greifswald in Handel und Verkehr die bedeutendsten Städte der Region. ${ }^{181}$ Unter den 160 Stralsunder Studenten befand sich ein Doktor, der außerdem Dekan in Güstrow war, und ein Greifswalder Propst. Ferner fanden sich 13 Kleriker, drei Domini und zwei Mönche (ein Zisterzienser und ein Prediger) sowie ein Bakkalar beider Rechte, ein Leipziger Theologiebakkalar, ein Hofbeamter und ein Pauper. Diese Angaben sind selbstverständlich unvollständig, da sie nur aufzeigen, was die Greifswalder Rektoren über die Studenten notiert haben. Anhand der Stralsunder Ratsherrenliste sowie den Stralsunder Bürgerttestamenten vom Anfang des 14. bis zum Ausgang des 16. Jahrhunderts wurde versucht, weitere Erkenntnisse über die Herkunft der Studenten zu gewinnen. ${ }^{182} 32$ Namen der Studenten wiesen eine Verwandtschaft mit einem Ratsmitglied im späten Mittelalter auf, was etwa 20 Prozent der Studenten Stralsunds entspricht, acht Studenten (=5\%) mit einem Bürgermeister, die damit zu den obersten Schichten der Stadt gezählt werden müssen. Unter den 32 Namen befinden sich lediglich vier Studenten, die selber die Mitgliedschaft im Rat erreichten, von denen drei wiederum bis zum Bürgermeisteramt aufstiegen.

Dazu zählte Johannes Prucze, der sich 1457 in Greifswald immatrikulieren ließ, 1459 das Bakkalaureat, 1464 das Magisterium erreichte. Bis 1467 ist er als Lehrer an der Universität nachzuweisen. 1482 wurde er in den Stralsunder Rat aufgenommen, 1487 erreichte er das Bürgermeisteramt und verstarb bei einer Pestepidemie im Jahre 1497. Zwei weitere Studenten seines Namens ließen sich nicht eindeutig verifizieren, doch scheint es sich bei dem 1507 eingeschrieben Joachim um den Bürgermeister des Jahres 1534 zu handeln, der 1524 in den Rat aufgenommen wurde und im Jahre 1545 verstarb. Ob es sich bei dem 1494 eingeschriebenen Johannes um einen Sohn des ersten Bürgermeisters gehandelt hat, läßt sich nicht belegen. Dennoch wird deutlich, daß man es hier mit einer frühen Stralsunder Akademikerfamilie zu tun hat, die in Stadt und Universität tätig war. Ebenso erreichte wahrscheinlich der 1482 eingeschriebene Johannes Trittelvitz 1516 das Bürgermeisteramt, der bereits 1502 in den Rat aufgenommen wurde und im Jahre 1524 verstarb. Mit 
ihm schrieb sich auch Sabellus Buchow 1482 in die Matrikel ein, der seit 1505 als Ratsmitglied geführt wurde und vor 1516 gestorben ist. Ein weiteres Stralsunder Ratsmitglied war der Doktor der Rechte Arnoldus Zhegeberg, der sich 1464 als Greifswalder, intranei, immatrikulieren ließ, und daher nicht zu den Inskriptionen aus Stralsund gerechnet werden kann. Die engen Bindungen der beiden Hansestädte werden jedoch an seiner Person deutlich. Er übte dreimal das Amt des Rektors in Greifswald aus (SS 1479, WS 1481, WS 1483) und wurde im Jahr 1500 in den Stralsunder Rat aufgenommen. Sein Tod fällt in das Jahr 1506.

Schon frühere Gegenproben dieser Art haben gezeigt, daß ein Studium im späten Mittelalter keineswegs den sicheren Aufstieg in der sozialen Hierarchie bedeutete. Vielmehr blieben Absolventen, wenn sie nicht eine kirchliche Karriere anstrebten, häufig in den unteren Stellungen der Stadtkanzlei stecken. ${ }^{183}$ Die geringe Zahl von vier Ratsmitgliedern unter den Studenten bestätigt diese Erkenntnis. Auch der Blick in die Stralsunder Testatorenliste bringt keine anderen Ergebnisse. 1200 Testamente vor allem wohlhabender Bürger wurden bis zum Ende des 16. Jahrhunderts im Stralsunder Rathaus hinterlegt, doch keiner der 160 Studenten ließ eine Verfügung im Falle seines Ablebens zurück. Immerhin waren auch hier einige Familiennamen der Studenten in den Listen vertreten, doch ist es schwierig anhand der Nachnamen, eindeutige Identifizierungen vorzunehmen. 56 Studenten hatten einen Familiennamen, der in den Listen irgendwann im 14. bis 16. Jahrhundert auftauchte. Hier waren nur neun Studenten zu finden, die einen namensverwandten Ratsherr als Testator hatten, worunter sich zwei Bürgermeister befanden.

Auch in der Greifswalder Matrikel wird der Bakkalar beider Rechte Albertus Darne im Sommersemester 1473 als Sohn eines Stralsunder Prokonsuls eingeschrieben. ${ }^{184}$ Sein Vater Matthias, der seit 1453 als Ratsmitglied geführt und 1465 Bürgermeister wurde, hinterlegte 1485 ein Testament im Stralsunder Rathaus und verstarb im darauf folgenden Jahr. Der Bürgermeister Johann Swarte hinterlegte ein Testament 1468, doch bleibt unklar, ob er in Beziehung zu den beiden Studenten Hermann (immatrikuliert im Wintersemester 1457) und Martin Swarte (immatrikuliert im Sommersemester 1498) stand. Immerhin hatten 46 Studenten den Namen eines Testatoren, der das Bürgerrecht der Stadt Stralsund besaß. Zu diesen Bürgern gab es zwei Berufsbezeichnungen, nämlich die eines "lopgesellen" (Familienname Holste) sowie eines Ältermann der "wandsneider" (Familienname Bisschop oder Biscop). Bei den übrigen sieben Namensgleichen wurde zwar auf die Bezeichnung "Bürger" verzichtet, doch deutet das Vorhandensein eines Testamentes auf eine bessere soziale Position hin. Als Berufsbezeichung findet sich außerdem ein "Riemer". Faßt man die Ergebnisse zusammen, so hatten etwa 35 Prozent der Studenten aus Stralsund einen namensverwandten Testatoren. Auch diese Gegenprobe bestätigt die Aussage, daß mit einem Studium im späten Mittelalter keineswegs eine sichere Karriere und ein Aufstieg in die städtischen Oberschichten verbunden waren. Vielmehr blieben Verwandtschaft und Patronage die wichtigeren Voraussetzungen eines sozialen Aufstiegs. ${ }^{1}$

Zurück zur Frequenz in Greifswald: im gesamten Zeitraum beläuft sich der Inskriptionsdurchschnitt aus Stralsund auf 2,3 Immatrikulationen pro Jahr. Während die Greifswalder Studenten schon zur Eröffnung des Studiums sehr zahlreich erschienen, stiegen die Stralsunder Studentenzahlen allmählich an und erreichten erst 1465 ihren Höhepunkt. ${ }^{186}$ Etwas später als bei den Greifswalder Zahlen kommt es zum Rückgang: eine Phase, die bis zum Jahre 1481 andauert. Ab jetzt konsolidieren 
sich die Inskriptionszahlen auf etwa zwei bis drei Studenten jährlich.

Auffällig sind die hohen Schwankungen der Jahre 1480 bis $1488 .{ }^{187}$ In diese Zeit fällt eine Spaltung der Artistenfakultät, in deren Verlauf der Doktor Heinrich ter Porten nach Stralsund fliehen mußte. Ebenso zog später eine Reihe von Lehrern mit etwa 80 Studenten nach Stralsund, um dort eine neue Schule zu gründen. ${ }^{188}$ Herzog Bogislaw konnte den Streit erst 1483 beilegen ${ }^{189}$ Die höheren Zahlen der Jahre 1482/83 könnten mit diesen Ereignissen in Zusammenhang stehen. Die Schwankungen der Jahre 1486/87 hingen sicherlich mit dem zweiten Auszug der Rostocker Universität im Jahre 1486 zusammen, während der starke Rückgang 1484/85 mit einer Epidemie zu erklären ist, die in ganz Pommern grassierte. ${ }^{190}$ Insgesamt läßt sich für Stralsund sagen, daß die Studentenzahlen in den 69 Jahren zwar keine nennenswerten Steigerungen aufwiesen, doch waren die Stralsunder seit der Gründung in regelmäßigen Abständen vertreten und nutzten die Nähe zum Universitätsort (siehe folgende Grafik). Die Tendenz über den gesamten Zeitraum ist eher rückläufig, wofür man die zunehmende Konkurrenz anderer Universitäten als Ursache anzunehmen hat.

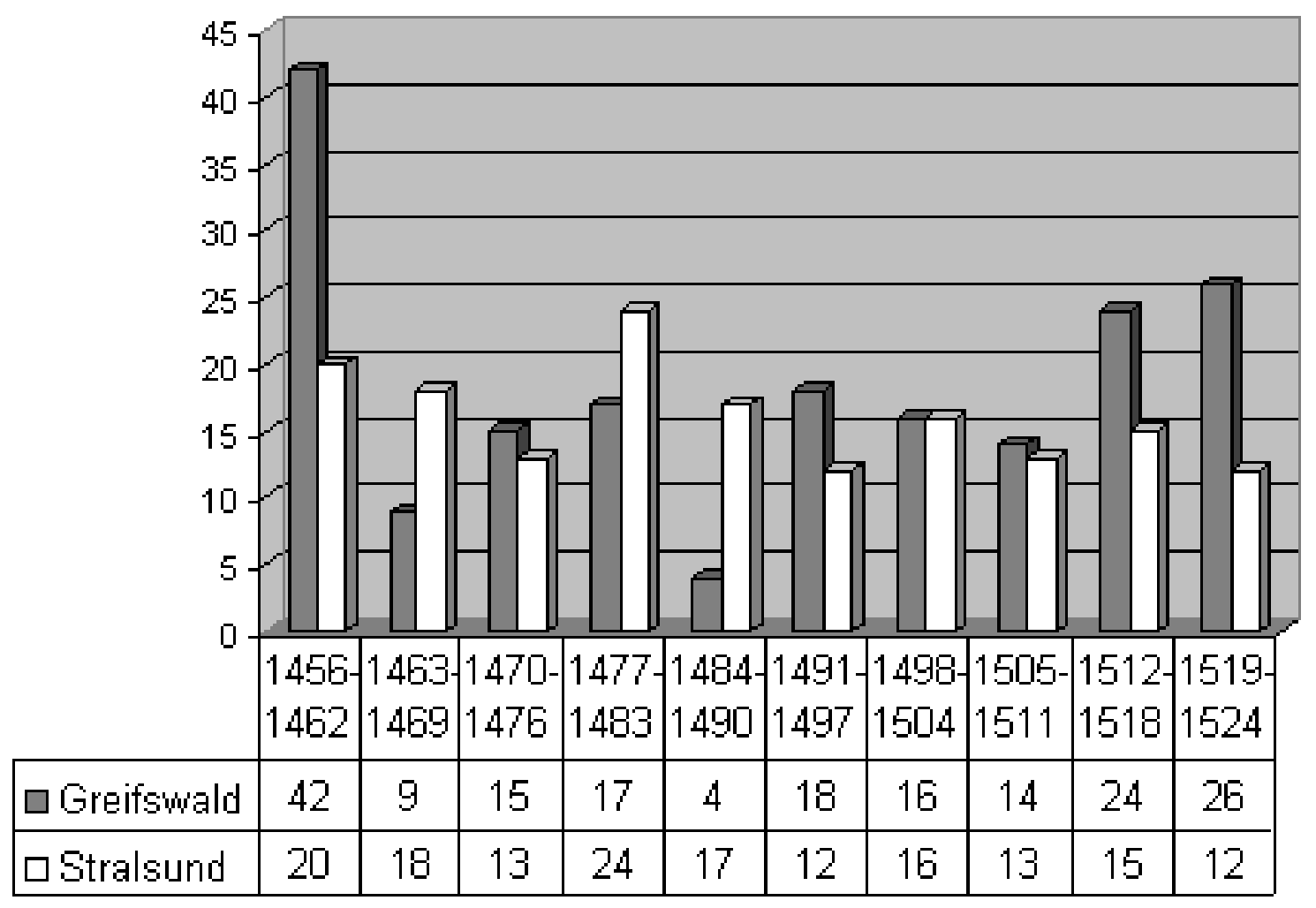

Abbildung 16: Studenten aus Greifswald und Stralsund

Mit 107 Inskriptionen konnte neben Greifswald und Stralsund nur noch Stettin über 100 Studenten aufweisen. Seit jeher wird die Frage gestellt, warum ausgerechnet das kleine Greifswald und nicht das zentraler in Pommern gelegene Stettin zur Universitätsstadt wurde. ${ }^{191}$ Eine Ursache dafür ist in den politischen Verhältnissen zu suchen, denn Pommern war zur Gründungszeit geteilt in Wolgaster, Stettiner und Stolper Land. ${ }^{192}$ Erst mit dem Aussterben der Stettiner Linie 1464 wurden die Landesteile vereint, so daß sich Stettin zum Zeitpunkt der Gründung nicht im gleichen 
Herrschaftsgebiet wie Greifswald befand. ${ }^{193}$ Außerdem muß man bedenken, daß Stettin und Greifswald im 15. Jahrhundert von vergleichbarer Größe waren. Die Einwohnerzahlen werden etwas über 5000 betragen haben, und der zeitgenössische pommersche Geschichtsschreiber Thomas Kantzow, erwähnt, daß Greifswald sogar noch etwas größer gewesen sein soll. ${ }^{194}$ Als sich dieses Größenverhältnis in späteren Jahrhunderten erheblich zugunsten Stettins veränderte, hat es zwar verschiedene Umzugspläne gegeben, doch konnten sie nie verwirklicht werden. ${ }^{195}$ Sogar der Gedanke einer zweiten pommerschen Universität in Stettin wurde erwogen, was angesichts der geringen Greifswalder Frequenz allerdings kaum sinnvoll gewesen wäre. ${ }^{1}$

Unter den 107 Stettinern auf der Greifswalder Hohen Schule befanden sich einige Würdenträger, darunter auch Herzog Swantobor, der nachweislich bis zu seinem plötzlichen Tode, verursacht durch eine Pestepidemie im Jahre 1464, in Greifswald studiert hat. ${ }^{197}$ In der Stadt gab es zwei Kollegiatstifte, das Marien- und das Ottostift, die in loser Verbindung miteinander standen und denen je 12 Kanoniker angehörten. ${ }^{198}$ Dieser Umstand begünstigte sicherlich den Zulauf zur Universität. So finden sich außerdem ein Dekan, der dazu noch das Amt eines Archidiakons in Demmin bekleidet hat, ein Propst, ein Kanoniker, 11 Weltgeistliche (neun werden als Kleriker, einer als Dominus und einer als Priester bezeichnet) und drei Mönche, von denen einer den akademischen Grad eines Bakkalaureus des Rechts anführt. Dazu werden noch zwei Magister und zwei Artistenbakkalare eingeschrieben.

Die Entwicklung der Inskriptionen aus Stettin ist durch stetiges Absinken gekennzeichnet. Während sich der Gesamtdurchschnitt auf 1,6 Immatrikulationen jährlich beläuft, finden sich in den letzten Jahrzehnten nur noch etwa ein Student pro Jahr aus Stettin in Greifswald ein. Nur im ersten Jahrzehnt werden fast vier Studenten jährlich inskribiert. Die Werte liegen zwar bis etwa 1476 recht hoch, doch kommt es seitdem zu einem ziemlich abrupten Rückgang. Dies erscheint umso merkwürdiger, da in diese Zeit der Regierungsantritt Bogislaws X. fällt, der das Land nach längeren Kriegszeiten wieder zu einigem Wohlstand verhalf. Auch in diesem Fall wird man die Ursache in der Konkurrenz anderer Universitäten zu suchen haben. Vielleicht bewirkten die Gründungen von Kopenhagen (1479) und Uppsala (1476) den Abzug einiger Stettiner nach Skandinavien, doch bleibt dies reine Vermutung, da von den skandinavischen Universitäten keine Matrikelbücher überliefert sind. Zwischen 1498 und 1504 kommt es wieder zu einem kurzen Anstieg der Inskriptionen, allerdings kann er die negative Tendenz kaum beeinflussen. Als Ergebnis bleibt auch hier zu sagen, daß die Universitätsgründung anfänglich zu einer stärkeren Mobilisierung der Stettiner zum Studium geführt hat, doch normalisieren sich die Zahlen schon sehr bald. Trotz der negativen Gesamttendenz blieb Stettin bis zum Betrachtungsende einer der wichtigsten Einzugsorte Greifswalder Studenten.

Meistgenannte Stadt nach Stettin war mit 84 Eintragungen Kolberg, das von Greifswald noch etwas weiter als Stettin entfernt liegt. Wohlstand und Macht, die Kolberg im Mittelalter erlangten, beruhten auf zwei Grundlagen: einerseits waren die Salzquellen ein wichtiger Wirtschaftfaktor, andererseits führten Handel und Fischfang dazu, daß die Stadt in den Kreis der Hansestädte hineinwuchs. 199 Anhand der Kolberger Stadtbücher legte Peter Tepp 1978 eine Arbeit zur Sozial- und Wirtschaftsgeschichte Kolbergs vor, die zeigt, daß Kolberg als Salinenstadt von einer sehr vermögenden Oberschicht beherrscht wurde. Unter Hinzunahme seiner Daten wurde versucht, das 
Universitätsstudium reicher Kolberger Bürgerfamilien in Greifswald nachzuvollziehen. Die Untersuchung ergab, daß etwa 30 Prozent der Studenten (=25) aus der reichen Oberschicht Kolbergs stammten, die zumeist am Salzhandel beteiligt war. Davon hatten allein 20 Prozent $(=17)$ irgendwann im späten Mittelalter einen Verwandten, der im Kolberger Rat gesessen hat. Zur obersten Schicht, die auch zum Bürgermeisteramt aufstieg, gehörten immerhin acht Prozent (=7). Damit lassen sich die Ergebnisse durchaus mit Stralsund vergleichen (20\% Ratsverwandtschaft, 5\% Verwandtschaft zu einem Bürgermeister).

Die Gebührenzahlung der Studenten wies mit 78 Prozent eine überduchschnittlich hohe Zahl solcher Studenten auf, die die vollständige Immatrikulationsgebühr entrichten konnten (im Vergleich dazu Stralsund: 68\%). Daß aus Kolberg und nicht aus einer nähergelegenen Stadt so viele Studenten kamen, hing daher sicherlich mit ihrem ökonomischen Wohlstand aber auch mit ihrer Größe und Einwohnerzahl zusammen. Außerdem dürfte es mit Schuleinrichtungen und Bildungsmöglichkeiten besser bestellt gewesen sein als in manch anderer Stadt Pommerns. ${ }^{200}$ Da ein Universitätsstudium eine gute Voraussetzung vor allem kirchlichen Pfründbesitzes darstellte, spiegelt der Anteil von 30 Prozent auch in etwa die Beteiligung der reichsten Oberschicht am Klerus der Stadt wider, der in Kolberg nur bei etwa 35 Prozent lag. 201

Die folgende Grafik, in der die Immatrikulationen aus Stettin und Kolberg dargestellt werden, macht deutlich, daß höhere Immatrikulationszahlen aus Kolberg regelmäßig erst ab 1491 einsetzten. Vorher hatte es bereits einen kurzen Anstieg in den Jahren 1477 bis 1483 gegeben. Der Rückgang, der in den folgenden sieben Jahren zu verzeichnen ist, könnte mit der Pestepidemie des Jahres 1485

zusammenhängen, die damals wie das übrige Pommern auch Kolberg heimgesucht hat. ${ }^{202} \mathrm{Ob}$ die Epidemie aber den Universitätsbesuch der folgenden Jahre noch beeinflussen konnte, bleibt fraglich, denn in Kolberg soll sie nicht allzu verheerend gewesen sein. ${ }^{203}$ Außerdem konnten die Epidemien in den Jahren 1495 und $1507^{204}$, wie an der Grafik deutlich wird, auch keine Wirkung auf den Universitätsbesuch ausüben, so daß eine Erklärung für den Rückgang offen bleiben muß. Die niedrigen Zahlen des letzten Betrachtungszeitraums 1519 bis 1524 können allerdings als Ausnahme gelten, da dieser einerseits nur sechs Jahre umfaßt, andererseits man sicherlich schon von einer Beeinflussung durch die Reformation sprechen kann. Für Kolberg ist eine verstärkte Tendenz zum Studium demnach erst einige Jahrzehnte nach der Universitätsgründung zu beobachten. Während bis 1491 nur 29 Studenten kamen, konnten sich im gleichen Zeitraum darauf die Zahlen fast verdoppeln. Wenn man nun vergleicht, wie sich die Entwicklung hinsichtlich der Verwandtschaft der Studenten mit reichen Kolberger Familien vollzog, so kommt man zum Ergebnis, daß hier kaum Steigerungen stattgefunden haben. Vielmehr sind alle sieben Jahre etwa drei solcher Beziehungen zu konstatieren. Der Gesamtanstieg der Immatrikulationen seit 1491 wurde dagegen hauptsächlich von solchen Studenten getragen, deren Namen keine Verwandtschaft zu erkennen gab. Auch wenn man hier die Ungenauigkeit der Quellenlage berücksichtigen muß, zeigt dieses Beispiel, wie die Nähe einer Universität allmählich auch zur Verbreiterung der sozialen Schichtung der Studenten führte. Freilich blieb die Basis der Kolberger Studenten wohlhabend genug, um bis zum Ausgang des Mittelalters ihre Gebühren vollständig zu entrichten, was wiederum die besondere ökonomische Kraft dieser Hansestadt unterstreicht. Aus der folgenden Grafik kann man ablesen, wie sich die Verhältnisse zwischen Stettin und Kolberg verschoben haben. Bis 1477 liegen die Stettiner noch deutlich über den Kolbergern, doch kehrt sich schon bald das Verhältnis zugunsten Kolbergs um, das von nun an 
regelmäßiger in Greifswald vertreten war.

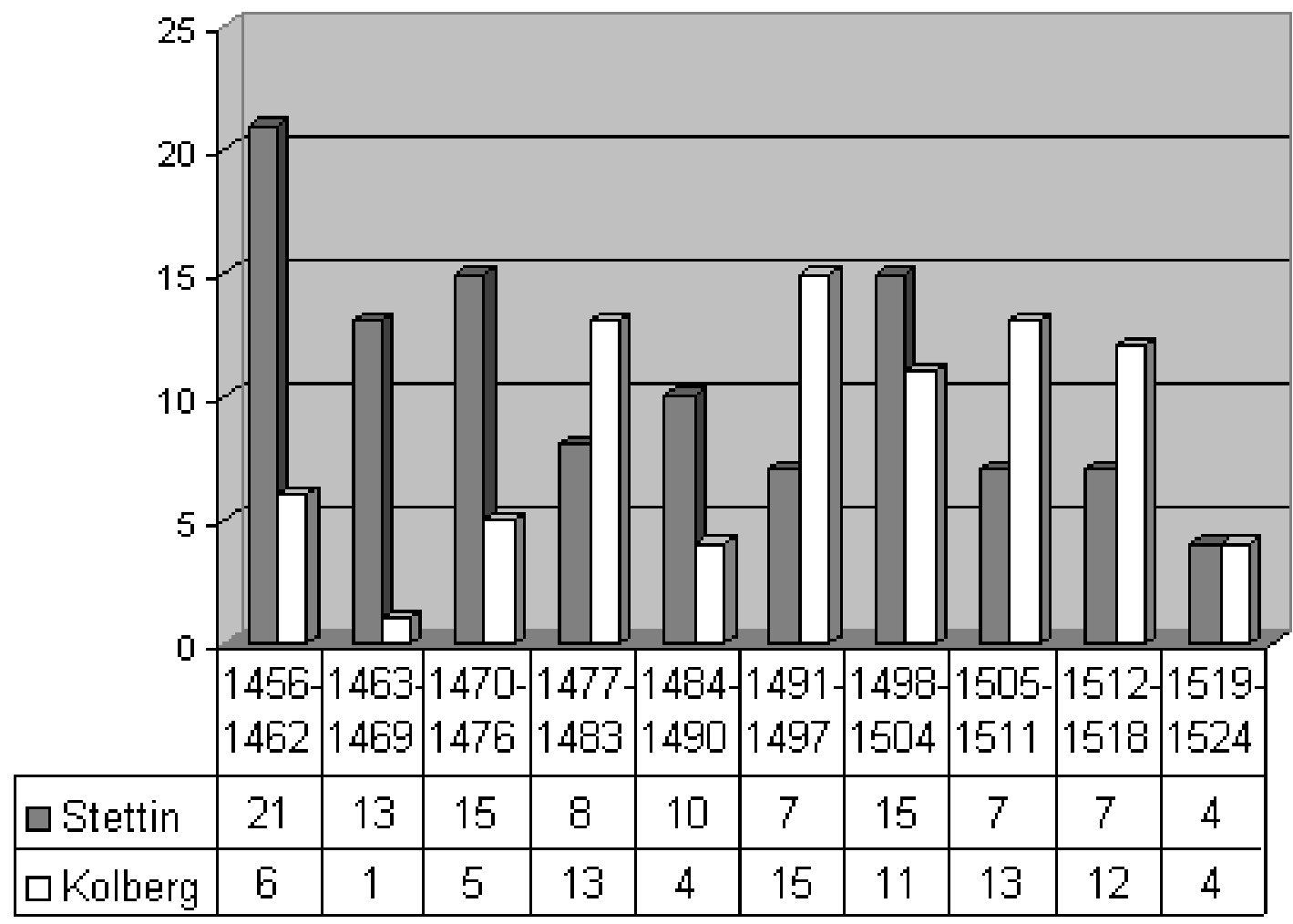

Abbildung 17: Studenten aus Stettin und Kolberg

Mit größerem Abstand hinter Kolberg folgen Orte, die sich wieder in direkter Nachbarschaft zur Universität befinden. In den meisten Fällen wurde für die Bewohner der Insel Rügen, die 63 Studenten vorwies, keine weitere Ortangabe gemacht. Da Rügen ein weitgehend ländliches Gebiet war, und die einzige Stadt Garz nicht ein einziges Mal verzeichnet ist, kann man bei diesen Studenten von bäuerlicher Herkunft ausgehen. Keiner der genannten Orte verfügte bereits über Stadtrecht, wie etwa Bergen, das vier Mal erwähnt wurde, Jasmund (2) ${ }^{205}$, Altenkirchen, Reddewitz und Vilmnitz (jeweils 1 Student). Unter den Rügener Studenten befindet sich ein Adeliger, ein Stettiner Prior, ein Diener sowie sechs Weltgeistliche (ein Pleban, zwei Domini, drei Kleriker). Auffällig am Zuzug der Rügener Studenten sind die geringen Schwankungen der Zahlen in den einzelnen Zeitabschnitten.

Zwar beginnen die Zahlen mit 10 Studenten auf recht hohem Niveau, doch pendeln sich die Werte in den nächsten Zeitabschnitten auf vier bis sechs Studenten alle sieben Jahre ein. Nur in den Jahren 1484 bis 1490 (11 Studenten) sowie in den letzten sechs Jahren (9 Studenten) werden diese Werte übertroffen. 206

Das gleiche gilt für die ebenfalls mit 63 Studenten vertretene Hansestadt Demmin, in der näheren Umgebung, südlich von Greifswald. Die Stadt spielte unter den Städten Vorpommerns eine aktive Rolle, wenngleich ihre Bedeutung als Hansestadt eher gering war. Wichtig für die Stadt war neben der Sicherung des Handels im vorpommerschen Raum vor allem die Schiffahrt auf der Peene, auch wenn diese nur mit kleinen Schiffen betrieben werden konnte. ${ }^{207}$ 
Im Jahre 1301 sind für Demmin erstmalig Stadtschulen erwähnt, die sicherlich dem einen oder anderen Studenten die Vorbildung gegeben hatten. ${ }^{208}$ Während in den ersten sieben Jahren noch eine Anzahl von 11 Studenten erreicht wird, liegen die Zahlen im übrigen Zeitraum durchschnittlich bei sechs bis sieben Studenten pro Jahrsiebt. ${ }^{209}$ Als Ergebnis kann man sagen, daß die Greifswalder Universität direkt nach der Gründung von den Orten in der Nachbarschaft angenommen und als Bildungsmöglichkeit regelmäßig genutzt wurde. Dies ist nicht ungewöhnlich, denn diese Gebiete stellten die regionale Basis des Greifswalder Einzugsbereichs dar: die Universitätsstadt war durch familiäre und soziale Beziehungsnetze mit solchen Orten verbunden.

Nach Demmin und Rügen wurde Stargard in Pommern von immerhin 61 Studenten als Heimatort angegeben. Die Stadt im heutigen Polen liegt süd-östlich von Stettin und ist damit etwa 150 Kilometer von Greifswald entfernt. Sie gehörte zu den wichtigeren Handelsstädten Pommerns, die regelmäßig Sendeboten zu den Tagfahrten der Hansestädte schickten. Seit der zweiten Hälfte des 13. Jahrhunderts verfügte die Stadt über ein Augustinerkloster. Von hoher Wichtigkeit für den Handel der Stadt war der Zugang zum Meer über die Ihna. Da die Ihnamündung Teil von Pommern-Stettin war, während Stargard zu Pommern-Wolgast gehörte, kam es immer wieder zu Konflikten. Wegen der Stargarder Getreideausfuhr brach 1454 eine Fehde mit Stettin aus, bei dem die Stettiner Getreideschiffe aus Stargard plünderten und die Ihnamündung verpfählten. Der Streit konnte 1460 vorläufig beigelegt werden, lebte aber immer wieder auf. ${ }^{210}$

Vielleicht bewirkte er, daß höhere Immatrikulationszahlen aus Stargard erst ab 1470 einsetzten. Während in den ersten 14 Jahren nur 9 Studenten nach Greifswald gezogen sind, kamen allein in den folgenden sieben Jahren (1470-1476) 12 Studenten. Insgesamt bilden die Jahre 1470 bis 1511 eine Hauptphase der Immatrikulationen (47), wenn man von dem kurzen Abstieg 1484 bis 1489 (3) absieht. Ab 1511 ist ein Rückgang der Studentenzahlen zu erkennen, der sicherlich mit der Universitätgründung im nahegelegenen Frankfurt (1505) zusammenhängt.

Die Stadt Anklam, die mit ihren 52 Studenten etwas hinter Stargard zurückbleibt, liegt wieder in näherer Umgebung von Greifswald, etwa 30 Kilometer in süd-östlicher Richtung. Auch diese Stadt gehörte dem Hansebund an. Ihre Bedeutung wird daran deutlich, daß Anklam als einer der vier Vorderstädte des Herzogtums Pommern-Wolgast 1452 das "Goldene Privileg" mit dem Recht, die Land- und Wasserstraßen zu sichern, bekam. In den folgenden Jahrzehnten sank die Stadt von einer weitgehend unabhängigen Hansestadt zu einer vom Herzog abhängigen Landstadt herab. In der Stadt befand sich seit dem 14. Jahrhundert ebenfalls ein Augustinerkloster. ${ }^{211}$

Während in den ersten sieben Jahren 11 Studenten aus Anklam zu verzeichnen sind, gehen die Zahlen im zweiten Zeitabschnitt zurück und belaufen sich zwischen 1463 und 1505 auf durchschnittlich zwei Studenten alle sieben Jahre. Zwischen 1491 bis 1497 kommt es zu einem kurzen Anstieg der Inskriptionen (13), für den man kaum eine Erklärung finden wird, wenn man auf reine Spekulationen verzichten will. Im Gegensatz zu Stargard nehmen hier die Zahlen in den letzten Jahren zu. Die Universitätsgründungen in Frankfurt (1505) und Wittenberg (1503) haben vor allem den Zuzug aus weiter entfernt liegenden Orten geschmälert, während sich bei Orten der direkten Umgebung die Nähe weiterhin bezahlt machte. 
Mit 42 Studenten folgte Stolp als meistgenannte Herkunftsstadt. Man kann dies als durchaus hohe Zahl einschätzen, denn Stolp liegt am östlichen Rande Pommerns und ist etwa 250 Kilometer von Greifswald entfernt. Ihre Bedeutung als Handels- und Hansestadt wird für die hohen Zahlen verantwortlich gewesen sein. Die Handelsverbindungen der Stadt reichten bis Flandern, Holland und England. Durch den Wasserweg und einen 19 km langen Korridor war die Stadt mit dem Hafen Stolpmünde und der Ostsee verbunden, ${ }^{212}$ so daß viele Studenten sicherlich per Schiff zur Universität gelangten. Trotz der Entfernung kommen die Studenten bereits in den ersten Semestern ziemlich zahlreich. Schon ab 1463 bis etwa 1476 sinken die Zahlen wieder (3 in 14 Jahren!). Von 1476 bis zur Reformation sind im Durchschnitt vier bis fünf Stolper Studenten in sieben Jahren zu verzeichnen, wobei die Jahre 1505 bis 1519 größere Schwankungen aufweisen und daher im Zusammenhang gesehen werden müssen.

Bei Betrachtung der Reihenfolge der meistgenannten Orte, sind die ersten neun Plätze nur von Orten Pommerns ${ }^{213}$ belegt. Auf Stargard (61), Anklam (52) und Stolp (42), folgt das mecklenburgische Neubrandenburg mit 40 Studenten an zehnter Stelle. Wenn man bedenkt, daß dessen Entfernung zu Greifswald geringer ist als die Stettins, so erscheint eine Abgrenzung zu den anderen Orten des regionalen Einzugsbereichs nicht sinnvoll. Obwohl die Neubrandenburger sicherlich ebenfalls an der eigenen Landesuniversität Rostock studiert haben, so sieht man an der hohen Studienbeteiligung in Greifswald, daß die Neugründung in Pommern als weitere Alternative angenommen wurde; die Landesgrenzen an sich waren für den Universitätsbesuch von untergeordneter Bedeutung.

Die Stadt gehörte zwar nicht dem Hansebund an, doch spielte Fernhandel neben Landwirtschaft, Tuchmacherei und Hopfenanbau zu den wichtigen Wirtschaftsfaktoren. Neben den Minoriten gab es zahlreiche andere Bruderschaften in der Stadt. Dazu zählten eine Priester-, eine Schulbruderschaft, die Bruderschaft der Marienzeiten und die Beginen, die sich dem Franziskanerkloster angeschlossen hatten. $^{214}$

Sie förderten sicherlich das Interesse am Studium, doch zog es Neubrandenburger erst spät nach Greifswald. In den ersten 21 Jahren kommen fünf Studenten aus diesem Ort. Ab 1477 werden es mehr, so daß die Zahlen von erst vier Studenten bis 1483, in den Jahren 1484 bis 1490 auf 10 Studenten steigen. Danach sinken sie zwar wieder, liegen aber weiterhin bei etwa fünf Studenten pro Jahrsiebt. In der Reformationszeit bleiben Neubrandenburger Studenten aus; vielleicht ein Hinweis auf eine stärkere Fixierung zur eigenen Landesuniversität.

Pasewalk wurde von 38 Studenten als Heimat angegeben. Die Stadt liegt zwar wieder in Pommern, doch ist ihre Entfernung zur Universität um einige Kilometer größer als die Neubrandenburgs. Sie war Sitz eines Propstes und besaß ein Dominikanerkloster, daß den Studenten die Möglichkeit zur Vorbildung bot. $^{215}$

Zwei bis vier Studenten kommen alle sieben Jahre aus Pasewalk. Nur in den Jahren 1491 bis 1497 (8) sowie 1512 bis 1518 (6) liegen die Zahlen darüber. Das gleiche gilt für Barth, einige Kilometer westlich von Greifswald an der Ostsee gelegen, welches mit 36 Studenten am Greifswalder Studium teilnahm. Etwas höher setzen die Zahlen mit acht Studenten im ersten Zeitraum ein, pendeln sich 
dann ohne nennenswerte Schwankungen auf Werte zwischen zwei und vier Studenten in jeweils sieben Jahren ein. Weder durch die Reformationsereignisse noch durch andere Universitätsgründungen wurden die Studentenzahlen aus diesen Orten beeinflußt, andererseits erlebten die Zahlen auch keine größeren Steigerungen.

Treptow, das etwas vor Kolberg an der Ostseeküste liegt und damit schon ein erhebliches Stück Fußmarsch für einen jungen Studenten bedeutete, wurde von 32 Studenten genannt. Auch hier werden viele Studenten über den Seeweg zur Universität gelangt sein, da Treptow durch Regamünde mit der Ostsee verbunden war. Die Stadt gehörte ebenfalls dem Hansebund an, doch spielte sie dort nur eine untergeordnete Rolle. ${ }^{216}$

Wie nicht anders bei einer solchen Entfernung zu erwarten war, sind die Schwankungen der Zahlen größer. Während in den ersten sieben Jahren nach der Gründung sechs Studenten zu verzeichnen sind, gehen sie in den folgenden 14 Jahren zurück (nur ein Student). Zwischen 1477 und 1490 sind es acht Studenten; in den sieben Jahren darauf kommt nur noch ein Student. Ab 1498 steigen die Werte von erst vier, dann drei auf 10 Studenten in den Jahren 1512 bis 1518. Im letzten Abschnitt sinken die Zahlen wieder auf drei Studenten ab.

Danzig zählte im 15. Jahrhundert wahrscheinlich über 20.000 Einwohner und gehörte damit zu den größten Städten im Reich, dem es allerdings nur bis 1466 angehörte. Daher ist es nicht verwunderlich, daß 35 Studenten aus dieser weiter entfernten preußischen Stadt nach Greifswald zogen; sie sind allerdings fast ausschließlich zur Gründungszeit und zwischen 1498 und 1503 zu finden.

Das mecklenburgische Friedland folgt in der Rangfolge mit 32 Studenten auf Danzig. Es soll als letzter dieser größten Rekrutierungsorte behandelt werden. Die Stadt an der Datze liegt näher zur Universität als Neubrandenburg, so daß erst danach mit Lübeck (30) und erstaunlicherweise dem niederländischen Groningen (29) gleich drei weiter entfernte Städte folgen.

Zahlreiche Bruderschaften der Stadt werden für die höheren Immatrikulationszahlen aus Friedland verantwortlich sein. Dazu gehörte eine Kalandsbruderschaft, eine Bruderschaft des hl. Gregorius und eine des hl. Augustinus sowie die vom Rosenkranz St. Mariae (erst 1488 gestiftet). Außerdem ist eine

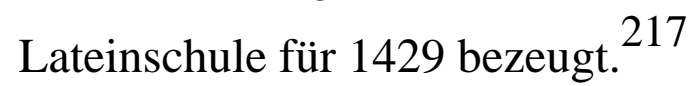

Die Inskriptionen aus Friedland beginnen mit drei Studenten in den ersten sieben Jahren, worauf bis 1470 keine weiteren folgen. In den folgenden 21 Jahren sind es 13 Studenten; bis 1498 bleiben sie wieder aus. In den folgenden drei Zeitabschnitten sind sie wieder vertreten mit jeweils zwei, fünf und drei Inskribierten.

Bei Betrachtung der 15 Orte kann man erkennen, daß fünf über 100 Kilometer in östlicher Richtung von Greifswald entfernt liegen und ein Drittel der Studenten aller 15 Orte stellten. ${ }^{218}$ Die folgende Tabelle soll die Entwicklung der Studentenzahlen aus den letztgenannten Orten aufzeigen. Aus ihr wird deutlich, daß relativ nahegelegene Orte wie Barth und Pasewalk in ziemlicher Regelmäßgkeit vertreten sind, während Stolp in den Jahren 1505 bis 1511 nicht einen einzigen, in den folgenden 
sieben Jahren aber 10 Studenten vorweisen konnte. Die Entfernung zur Universitätstadt mag für solche Schwankungen verantwortlich gewesen sein, da ein Fremder sicherlich erst dann zum Studium aufbrach, wenn er noch einen oder mehrere Begleiter aus seiner Heimat gefunden hatte.

Tabelle $6^{219}: 15$ Orte mit den höchsten Studentenzahlen

\begin{tabular}{|l|l|l|l|l|l|l|l|l|l|l||r|r||}
\hline Herkunft & Entfernung & I & II & III & IV & V & VI & VII & VIII & IX & X & Gesamt \\
\hline Greifsw. & - & 42 & 9 & 15 & 17 & 4 & 18 & 16 & 14 & 24 & 26 & 185 \\
\hline \hline Stralsund & I/W & 20 & 18 & 13 & 24 & 17 & 12 & 16 & 13 & 15 & 12 & 160 \\
\hline \hline Stettin & II/O & 21 & 13 & 15 & 8 & 10 & 7 & 15 & 7 & 7 & 4 & 107 \\
\hline Kolberg & II/O & 6 & 1 & 5 & 13 & 4 & 15 & 11 & 13 & 12 & 4 & 84 \\
\hline \hline Rügen & I/N & 11 & 4 & 4 & 6 & 11 & 4 & 4 & 5 & 6 & 9 & 64 \\
\hline Demmin & I/S & 11 & 5 & 7 & 5 & 3 & 6 & 4 & 8 & 7 & 7 & 63 \\
\hline \hline Stargard & II/O & 6 & 3 & 12 & 9 & 3 & 9 & 7 & 7 & 4 & 1 & 61 \\
\hline \hline Anklam & I/O & 11 & 2 & 2 & 4 & 1 & 13 & 3 & 2 & 6 & 8 & 52 \\
\hline Stolp & III/O & 7 & 1 & 2 & 5 & 3 & 4 & 5 & 0 & 10 & 5 & 42 \\
\hline \hline Neubrand. & I/S & 1 & 3 & 1 & 4 & 10 & 4 & 7 & 4 & 6 & 0 & 40 \\
\hline \hline Pasewalk & I/S & 3 & 2 & 3 & 4 & 4 & 8 & 3 & 3 & 6 & 2 & 38 \\
\hline \hline Barth & I/W & 8 & 3 & 4 & 2 & 1 & 2 & 3 & 6 & 3 & 4 & 36 \\
\hline \hline Treptow & II/O & 6 & 0 & 1 & 5 & 3 & 1 & 4 & 3 & 10 & 3 & 36 \\
\hline \hline Danzig & III/O & 11 & 3 & 1 & 4 & 2 & 1 & 11 & 1 & 1 & 0 & 35 \\
\hline \hline Friedland & I/S & 3 & 0 & 4 & 6 & 3 & 0 & 6 & 2 & 5 & 3 & 32 \\
\hline \hline Gesamt & & 167 & 67 & 89 & 116 & 79 & 104 & 115 & 88 & 122 & 88 & 1035 \\
\hline
\end{tabular}




\subsection{Die Ausstrahlung Greifswalds auf die umliegende Region}

\subsubsection{Die Herkunftsorte der pommerschen Studenten}

Waren bisher die wichtigsten Einzugsorte ungeachtet ihrer geographischen Lage im Blickfeld, sollen nun die Ortschaften in ihrem jeweilig zugehörigen Territorium betrachtet werden. Zuerst zu den pommerschen Studenten in Greifswald: insgesamt konnten von den 3317 Immatrikulierten 1510 als Pommern identifiziert werden. Davon hatten 672 Studenten nur einen Ort, 603 Ort und Diözese/Land angegeben; von 235 Studenten konnte nur die Herkunftsdiözese ermittelt werden. Obwohl sich die Kamminer Bistumsgrenzen über die damaligen politischen Grenzen Pommerns hinaus erstreckten, wurden Kamminer Diözeseangaben zu den Pommern gerechnet. Die Diözesen Schwerin und Roeskilde, die auch Teile Pommerns umfaßten ${ }^{220}$, wurden dagegen zu Mecklenburg bzw. Dänemark gezählt, womit ein gewisser Ausgleich zu erzielen ist. ${ }^{221}$ Im folgenden sollen die übrigen Orte Pommerns behandelt werden, aus denen weniger als 30 Studenten nach Greifswald kamen. Auch bei diesen Orten lohnt es sich der Überschaubarkeit halber eine Vergrößerung des Betrachtungsradius vorzunehmen. Die 69 Jahre wurden dafür in vier Abschnitte unterteilt, von denen drei 17 Jahre umfassen und der letzte 18 Jahre zählt.

Angeführt werden diese Orte von Grimmen, das sich nicht weit entfernt in westlicher Richtung von Greifswald befindet an der alten Handelsstraße von Rostock nach Greifswald. Die engen Bindungen zur Universität werden daran deutlich, daß ihr 1455 das Patronat über die Grimmener Marienkirche übertragen wurde. 222

Insgesamt zogen 30 Studenten nach Greifswald. Im ersten Betrachtungszeitraum werden noch sieben Studenten immatrikuliert, die sich relativ gleichmäßig auf die 17 Jahre verteilen. Es folgt eine lange Pause, in der nur ein einziger Grimmener nachgewiesen werden kann und die eigentlich bis 1498 anhält. Fast genau mit dem Eintreffen der beiden berühmten Humanisten Petrus und Vincentius aus Ravenna erfolgen erneute Immatrikulationen aus Grimmen. Zwischen 1491 und 1507 werden insgesamt sechs, zwischen 1508 und 1524 sogar 16 Studenten aus Grimmen in die Matrikel eingeschrieben, was mehr als doppelt so viele sind wie alle Jahre davor zusammengenommen. Auch hier lassen sich allerdings Phasen unterscheiden, denn zwischen 1498 und 1502 werden fast alle Studenten des dritten Abschnitts aufgenommen, was etwa genau dem Zeitraum des Wirkens der beiden Humanisten entspricht. $^{223}$ Die nächste Phase setzt erst wieder 1510 an und dauert bis 1520, in der alle 16 Studenten des letzten Abschnitts nach Greifswald kamen. Damit wird das Bild einer Steigerung der Zahlen in diesem Zeitraum noch verstärkt.

Aus Belgard im heutigen Polen, das knapp 200 Kilometer von Greifswald entfernt liegt, kamen 29 Studenten. Auch diese Stadt nahm am Handel der Hanse teil, so daß man von Verbindungen zur Universitätstadt ausgehen kann. Die Studenten verteilen sich ziemlich gleichmäßig auf die vier Zeitabschnitte (6/9/5/9). Etwa 50 Kilometer in süd-östlicher Richtung von Stettin befindet sich Pyritz. Augustiner und Franziskaner gab es in der Stadt, die möglicherweise den höheren Zulauf erklären. In der zweiten Hälfte der Betrachtungszeit ist ein Anstieg aus Pyritz stammender Studenten zu beobachten; während bis 1490 insgesamt nur fünf Studenten diesen Herkunftsort nannten, können 
sich diese Zahlen in den folgenden 35 Jahren mit 23 Studenten fast verfünffachen.

Aus der Stadt Kammin, die als Bischofssitz eine relativ hohe Zahl von 11 Klerikern vorwies, lassen sich insgesamt 27 Studenten wiederfinden. Neben dem Domstift gab es ein Dominikanerkloster. Außerdem gehörte die Stadt der Hanse an und nahm im 15. Jahrhundert mehrfach an Städtebündnissen teil. ${ }^{224}$ Auch hier häufen sich mit 12 Studenten die Immatrikulationen vor allem im letzten Zeitabschnitt. Die Einschreibungen aus Köslin zeigen dagegen eher eine negative Tendenz. Seehandel war im 15. Jahrhundert ein wichtiger Wirtschaftsfaktor dieser Stadt im hinteren Pommern, wenngleich es darüber immer wieder Streit mit den Städten Kolberg und Rügenwalde gab. ${ }^{225}$ Die 27 Studenten aus Köslin verteilen sich auf die vier Abschnitte mit acht, sieben, sieben und fünf Immatrikulationen.

Wolgast, das nur etwa 25 Kilometer von Greifswald entfernt an der Ostsee liegt, entwickelte sich dank ihrer günstigen Lage vor der Peene-Einfahrt zur Seehandelsstadt und gehörte der Hanse an, ohne allerdings deren Versammlungen zu beschicken. Auch ihre Funktion als Residenzstadt brachte ihr im 15. Jahrhundert einen gewissen Wohlstand. ${ }^{226}$ In den ersten siebzehn Jahren nannten noch sieben Studenten Wolgast als Herkunftsort. In den folgenden beiden Abschnitten werden es immer weniger von zuerst vier auf zwei Studenten. Erst in der Regionalisierungsphase der Universität steigen auch hier die Immatrikulationen auf 11, so daß Wolgast insgesamt 24 Studenten zu verzeichnen hat.

Aus den Städten Rügenwalde und Greifenberg, welche beide im hinteren Pommern liegen, kamen jeweils 22 und 19 Studenten. Rügenwalde war eine wichtige Handelsstadt Hinterpommerns und gehörte der Hanse an. Neben dem Handel war Fischfang ein wichtiger Wirtschaftsfaktor. Vor der Stadt gab es seit dem 14. Jahrhundert ein Kartäuserkloster. ${ }^{227}$

In Greifenberg befand sich ein Franziskanerkloster, außerdem ist für 1386 eine Lateinschule erwähnt. Die Stadt gehörte ebenfalls der Hanse an, doch gab es immer wieder Konflikte mit der Stadt Treptow, als die Schiffahrt durch Sperrung der Rega unterbrochen wurde. ${ }^{228}$ Die Studenten aus diesen beiden Städten verteilen sich recht gleichmäßig auf die vier Zeitabschnitte.

Wollin am Oderhaff gehörte zwar der Hanse an und betrieb einen gewissen Seehandel, doch blieb seine Bedeutung gering. Seit 1317 war dem Zisterzienserinnenkloster eine Schule angeschlossen. 229 In Schivelbein an der Rega kreuzten sich im Mittelalter zwei Verkehrswege, eine von Plathe kommende Straße, auf der man über Neustettin ostwärts zog, und eine zweite, die von Frankfurt nach Danzig führte. Ein Kartäuserkloster befand sich vor der Stadt. Während von den 18 Studenten aus Wollin am Oderhaff in den ersten drei Abschnitten 16, im letzten Abschnitt nur zwei Studenten kamen, fängt der Abstieg der Zahlen für Schivelbein an der Rega schon nach der Hälfte der Zeit statt. In den ersten beiden Abschnitten belaufen sich die Zahlen dabei auf 12 Schivelbeiner, in den beiden nächsten nur noch auf vier.

Für die an der schiffbaren Ihna gelegenen Hansestadt Gollnow, nord-östlich von Stettin, ist ein Anstieg der Immatrikulationen zu konstatieren. Erst im dritten und vierten Abschnitt kommen einige 
Studenten aus Gollnow. Insgesamt handelt es sich um 15 Einschreibungen, wovon eine noch im zweiten Abschnitt (1486) erfolgte. Aus dem nahegelegenen Tribsees zogen 12 Studenten nach Greifswald. Vier von ihnen kamen in den ersten beiden, acht in den letzten beiden Abschnitten. Damit ist auch hier ein kleiner Anstieg der Zahlen zu beobachten.

Gartz an der Oder lag im Mittelalter an der Handelsstraße von Schwedt nach Stettin. Als Hansestadt betrieb sie Seehandel über Oder und Haff und gelangte so zu einiger Bedeutung. In der Stadt befand sich ein Nonnen- und ein Augustiner-Eremitenkloster. Die Hälfte ihrer 10 Studenten zogen zwischen 1473 und 1489 an die Universität Greifswald. Fünf der insgesamt acht Studenten aus dem auf der gleichnamigen Insel gelegenen Usedom zogen erst ab 1507 nach Greifswald. Die Stadt Schlawe im hinteren Pommern, in deren Umgebung sich ein Johanniterkloster befand, wurde von acht Studenten als Herkunftsort angegeben, wovon sieben in den ersten beiden Zeitabschnitten erschienen.

Die Mehrheit der 15 Orte Pommerns, die gerade behandelt wurden, lag nicht im Wolgaster Gebiet, in dem sich Greifswald befand. Sieben Orte, nämlich Pyritz (28), Kammin (27), Greifenberg (19), Wollin (18), Schivelbein (16), Gollnow (15) und Gartz (10) befanden sich bis zur Vereinigung Pommerns im Jahre 1464 noch im angrenzenden Stettiner Land, während die vier Orte Belgard (29), Köslin (27), Rügenwalde (22) und Schlawe (8) im fernen Hinterpommern lagen. Im Wolgaster Gebiet sind es nur die vier Orte Grimmen (30), Wolgast (24), Tribsees (12) und Usedom (8). Viele Studenten werden hier den kaum längeren Weg zum älteren Rostock gewählt haben. Daß in der näheren Umgebung Greifswalds so wenig Orte mit größeren Studentenzahlen vertreten sind, weist uns auf die Konkurrenz zur Nachbaruniversität Rostock hin, die den Wirkungsgrad der Greifswalder Hohen Schule dort erheblich minderte.

Wenn man nach Entwicklung und Veränderung der Immatrikulationen aus diesen 15 Orten fragt, so ergibt sich das Bild, daß etwa die Hälfte der Orte (Belgard, Köslin, Rügenwalde, Greifenberg, Wollin, Gartz und Usedom) relativ gleichbleibende Zahlen aufweisen, während bei sechs Orten (Grimmen, Pyritz, Wolgast, Kammin, Gollnow und Tribsees) ab 1490 oder 1507 eine leichte Steigerung, bei zwei von ihnen (Schivelbein und Schlawe) eher eine negative Tendenz zu erkennen ist. Folgende Tabelle, in der die 69 Jahre in vier Zeitabschnitte unterteilt wurden, soll dieses Bild bekräftigen. ${ }^{230}$ Am Gesamtergebnis der Spalten kann man auch die zunehmende Regionalisierung des Einzugsbereichs erkennen, denn im letzten Zeitabschnitt von 1507 bis 1524 wird das höchste Ergebnis erreicht.

Tabelle 7: Orte Pommerns mit 8 bis 30 Studenten ${ }^{231}$

\begin{tabular}{|l|l|l|l||l|l|r||}
\hline Herkunft & Entfernung232 $^{232}$ & A & B & C & D & Gesamt \\
\hline \hline Grimmen & I/W & 7 & 1 & 6 & 16 & 30 \\
\hline \hline Belgard & II/O & 6 & 9 & 5 & 9 & 29 \\
\hline \hline Pyritz & I/O & 4 & 1 & 11 & 12 & 28 \\
\hline \hline Kammin & II/O & 4 & 6 & 5 & 12 & 27 \\
\hline \hline Köslin & II/O & 8 & 7 & 7 & 5 & 27 \\
\hline
\end{tabular}




\begin{tabular}{|l|l|l|l|l|l||r|}
\hline Wolgast & I/O & 7 & 4 & 2 & 11 & 24 \\
\hline \hline Rügenwalde & III/O & 6 & 7 & 4 & 5 & 22 \\
\hline \hline Greifenberg & II/O & 7 & 3 & 5 & 4 & 19 \\
\hline Wollin & I/O & 6 & 5 & 5 & 2 & 18 \\
\hline \hline Schivelbein & II/O & 6 & 6 & 2 & 2 & 16 \\
\hline \hline Gollnow & II/O & 0 & 1 & 6 & 8 & 15 \\
\hline Tribsees & I/W & 2 & 2 & 4 & 4 & 12 \\
\hline Gartz & II/S & 2 & 5 & 0 & 3 & 10 \\
\hline \hline Usedom & I/O & 2 & 1 & 0 & 5 & 8 \\
\hline Schlawe & III/O & 3 & 4 & 0 & 1 & 293 \\
\hline \hline Gesamt & & 70 & 62 & 62 & 99 & \\
\hline \hline
\end{tabular}

Von den 11 Orten Pommerns, aus denen drei bis sechs Studenten an die Greifswalder Hohe Schule zogen, befinden sich sechs in der näheren Umgebung der Universität. Vier Ortschaften liegen in zentralpommerschen Gebieten um Stettin und ein Ort im hinteren Pommern um Stolp. Bei den kleineren Ortschaften zeichnet sich wieder die Tendenz ab, daß ein einzelner Scholar durch eine kurze Entfernung eher zum Studium bewegt wurde, als ein solcher, der einige Tagesmärsche vor sich hatte, um die Universität zu erreichen. An der Spitze dieser Orte steht Franzburg aus direkter Umgebung Greifswalds mit sechs Studenten. Dort befand sich auch das Zisterzienserkloster Neuenkamp. Außerdem lassen sich drei Orte mit fünf Studenten nachweisen. Es handelt sich zum einen um fünf Mönche aus dem Zisterzienserkloster Eldena, die ihre Vorbildung sicherlich in der dortigen Klosterschule erworben haben, zum anderen um je fünf Studenten aus den hinterpommerschen Ortschaften Freienwalde und Greifenhagen. Die Mönche aus Eldena begannen im zweiten und vierten Abschnitt ihr Studium. Vier Studenten aus Freienwald kamen im zweiten, einer im dritten Abschnitt. Die Studenten aus der Hansestadt Greifenhagen waren in den ersten drei Abschnitten vertreten.

Drei Orte schickten vier Studenten: Loitz, südlich von Greifswald gelegen sowie Dramburg und Naugard, nord-östlich von Stettin, wobei die ersten Dramburger erst nach der Hälfte der Zeit erschienen. Aus den übrigen vier Orten zogen jeweils drei Studenten nach Greifswald. Dazu zählen Wusterhusen, Altentreptow an der Tollense (nur im letzten Abschnitt vertreten) und das nahegelegene Lassan. Auch Lauenburg in Hinterpommern wurde dreimal erwähnt, allerdings nur in den ersten Jahrzehnten. Die folgende Tabelle soll über diese letzten 12 Orte Auskunft geben.

Tabelle 8: Orte Pommerns mit 3 bis 6 Studenten

\begin{tabular}{|l|l||l|l|l|l||r|}
\hline Herkunft & Entfernung & A & B & C & D & Gesamt \\
\hline \hline Franzburg & I/S & 3 & 1 & 0 & 2 & 6 \\
\hline \hline Eldena & I/O & 0 & 2 & 0 & 3 & 5 \\
\hline
\end{tabular}




\begin{tabular}{|l||l||l|l|l|l||r|}
\hline Freienwalde & II/O & 0 & 4 & 1 & 0 & 5 \\
\hline \hline Greifenhagen & II/O & 1 & 2 & 2 & 0 & 5 \\
\hline \hline Dramburg & II/O & 0 & 0 & 2 & 2 & 4 \\
\hline \hline Loitz & I/S & 1 & 0 & 1 & 2 & 4 \\
\hline \hline Naugard & II/O & 3 & 0 & 1 & 0 & 3 \\
\hline \hline Wusterhusen & I/O & 2 & 0 & 0 & 1 & 3 \\
\hline \hline Lassan & I/O & 0 & 1 & 1 & 1 & 3 \\
\hline \hline Lauenburg & III/O & 2 & 1 & 0 & 0 & 45 \\
\hline \hline Altentreptow & I/S & 0 & 0 & 0 & 3 & 3 \\
\hline \hline Gesamt & & 12 & 11 & 8 & 14 & 3 \\
\hline \hline
\end{tabular}

Bei der Behandlung der restlichen Orte Pommerns, aus denen nur ein oder zwei Studenten kamen, wird eine zusammenfassende Verfahrensweise genutzt. Es handelt sich insgesamt um 48 Orte, von denen 9 mit je zwei Studenten, die übrigen 39 mit jeweils nur einem Studenten vorkommen; insgesamt sind es also 57 Einschreibungen.

Wie nicht anders zu erwarten war, handelt es sich bei den meisten Orten um kleine Ortschaften der näheren Umgebung Greifswalds. Direkt aus dem Umkreis von Greifswald sind es 11 Orte $^{233}$, aus dem Demminer Umkreis sind es zwei Orte ${ }^{234}$, aus dem Grimmener vier ${ }^{235}$, aus dem Anklamer sechs ${ }^{236}$ sowie aus dem Franzburger drei ${ }^{237} .13$ Orte $^{238}$ befinden sich in der Gegend um Stettin, während neun Orte ${ }^{239}$ in ferneren Gebieten Hinterpommerns liegen. Damit sind über die Hälfte der Orte (26) mit 31 Studenten in einem Umkreis unter 50 Kilometer von Greifswald entfernt, während 22 von ihnen in Richtung Osten und Hinterpommern liegen. Von den 57 Studenten fallen 31 auf die erste Kategorie, während 26 zur zweiten gehören. Wir haben bisher die räumliche Herkunft nur jener pommerschen Studenten erfaßt, die einen Ort angegeben hatten, während solche mit Bistums- oder Landesangabe übergangen worden sind. Obwohl eine genaue örtliche Bestimmung für diese Personen offen bleiben muß, kann man sie bei der Gesamtbetrachtung der pommerschen Immatrikulationen miteinbeziehen.

176 Studenten gaben die Diözese Kammin als Herkunftsgebiet an, drei nannten das Land Pommern, und einer das Herzogtum Stettin. Die Studentenzahlen der Pommern, die aus der folgenden Grafik hervorgehen, entwickelten sich im Betrachtungszeitraum relativ gleichmäßig. Nach dem Eröffnungshoch fallen die Zahlen bis etwa 1471, können sich in den folgenden Jahren dann wieder fangen und steigen kontinuierlich ab 1492, als sich der Einzugsbereich der Universität in verstärktem Maße regionalisierte. An den Gesamtimmatrikulationen aus Pommern bestätigt sich die These, daß der spätmittelalterliche Universitätsbesuch von einer Phase der "regionalen Existenzsicherung" geprägt war. Nach der ungewöhnlichen Eröffnungsphase kam es zu einem starken Rückgang der Immatrikulationen aus dem pommerschen Territorium. Bis etwa 1493 sind die Werte von erheblichen Schwankungen gekennzeichnet. Seit der Jahrhundertwende jedoch ist eine erstaunliche Konstanz bei den pommerschen Einschreibungen zu beobachten, die trotz der äußeren Krisenzeiten bis zum 
Betrachtungsende gewahrt bleibt. Es stellt sich die Frage, wie diese Phase der "regionalen Existenzsicherung" in den beiden Nachbarländern verlief.

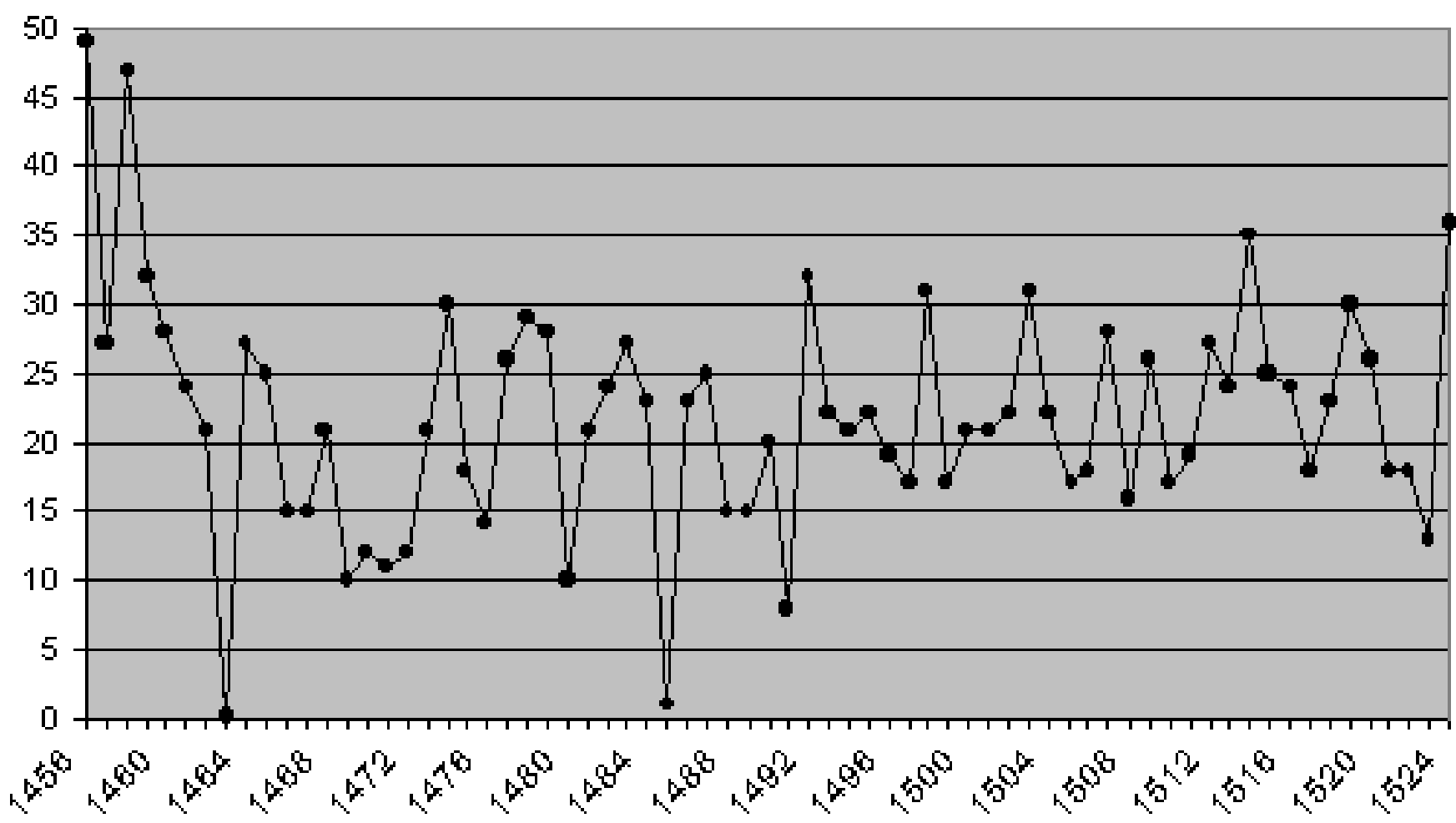

Abbildung 18: Studenten aus Pommern

\subsubsection{Die Nachbarländer}

\subsubsection{Die Herkunftsorte der mecklenburgischen Studenten}

Im folgenden soll Mecklenburg behandelt werden, das als Nachbarland von Pommern ebenfalls zum regionalen Einzugsgebiet gerechnet werden kann. Als Mecklenburger konnten 242 Personen identifiziert werden, wobei 55 nur den Ort, 139 Ort und Diözese/Land sowie 48 nur eine Diözese/ Land-Angabe gemacht haben. Insgesamt lassen sich 25 Orte wiederfinden.

Auf Neubrandenburg und Friedland, die mit einer Beteiligung von je 40 bzw. 32 Studenten an der Spitze standen und schon vorher betrachtet worden sind ${ }^{240}$, folgte mit 25 Immatrikulationen Malchin, das etwa 60 Kilometer in süd-westlicher Richtung von Greifswald entfernt ist.

Malchin war im wesentlichen eine Ackerbürgerstadt, obwohl sich seit dem 15. Jahrhundert auch Gewandschneider und eine Kaufleutegilde nachweisen lassen. ${ }^{241}$ Bis 1483 steigen die Immatrikulationen aus Malchin von nur einem Studenten in den ersten sieben Jahren auf sieben zwischen 1477 und 1483. Von 1484 bis zum Ende der Betrachtungszeit sind nur noch wenige 
Immatrikulationen zu finden. Vor allem in den Jahren 1498 bis 1504, als die italienischen Humanisten Petrus und Vincentius in Greifswald lehrten (3) sowie 1512 bis 1518 (7) kam es zu einem kurzen Anstieg der Zahlen.

Aus der Universitätsstadt Rostock wurden insgesamt 19 Immatrikulationen vorgenommen, unter denen sich sieben Personen befinden, die als Lehrer nach Greifswald kamen und den Titel eines Doktors oder Magisters trugen; zwei weitere waren bereits Artistenbakkalare. In allen Zeitabschnitten sind Rostocker vertreten, doch findet auch hier in dem Zeitraum von 1498 bis 1504 eine Steigerung auf immerhin fünf Immatrikulierte statt.

Aus der bedeutenden Hansestadt Wismar zogen 17 Studenten nach Greifswald, doch waren sie unterschiedlich auf die Zeiträume verteilt. Mit fünf Einschreibungen lagen die Zahlen in den ersten sieben Jahren höher als in allen späteren Zeitabschnitten. Nur zwischen 1477 und 1499 ist ein leichter Anstieg zu vermerken (7). In den beiden folgenden Abschnitten kamen zwei, in den letzten beiden nicht ein einziger Student. Aus dem mecklenburgischen Penzlin, das westlich von Neubrandenburg liegt, erfolgen Immatrikulationen erst ab 1470 (insgesamt 14). In den Jahren 1477 bis 1483 werden sieben Studenten verzeichnet. Danach erscheint nur noch etwa ein Student pro Jahrsiebt. Die 10 Studenten aus dem südlich von Rostock gelegenem Güstrow sind fast nur in den ersten beiden Abschnitten zu finden (4 und 2). Fünf Studenten kamen aus Teterow, das etwa 30 Kilometer von Güstrow in östlicher Richtung entfernt liegt. Sie sind ausschließlich zwischen 1477 und 1490 in Greifswald erschienen (1477-83: 4). Waren und Malchow liegen etwa 100 Kilometer in südwestlicher Richtung von Greifswald. Fünf bzw. drei Studenten wurden aus diesen Orten immatrikuliert. Ebenfalls drei Studenten kamen aus Schwerin sowie dem süd-östlich davon gelegenen Parchim.

Bei Betrachtung dieser zehn meistvertretenen Orte Mecklenburgs erkennt man, daß die Mehrheit (7) mit einer Entfernung von weniger als 100 Kilometer eigentlich dem direkten Umkreis Greifswalds angehören. Nur drei Orte liegen im westlichen Teil Mecklenburgs, wo Studenten sicherlich fast ausschließlich das nähere Rostock bevorzugt haben. Auffällig an den Immatrikulationsentwicklungen dieser Orte ist, daß bei vier von ihnen (Malchin, Wismar, Penzlin und Güstrow) insbesondere in den Jahren ab 1477 höhere Immatrikulationen einsetzen. Die Überblickstabelle soll diese Ergebnisse veranschaulichen. Aus ihr geht außerdem hervor, daß sich die Regionalisierung der letzten Zeitabschnitte offensichtlich nicht auf das direkte Nachbarland Pommerns bezog. Die stärksten Immatrikulationswerte sind vor allem im vierten und fünften Abschnitt (1477-1490) zu bemerken, als die eigene Landesuniversität Rostock unter den Auswirkungen der sogenannten "Domfehde" litt.

Tabelle 9: Orte Mecklenburgs mit 3 bis 25 Studenten

\begin{tabular}{|l|l|l|l|l|l|l|l|l|l||l||r|r|}
\hline Herkunft & Entfernung & I & II & III & IV & V & VI & VII & VIII & IX & X & Gesamt \\
\hline Malchin & I/S & 1 & 2 & 3 & 7 & 1 & 1 & 3 & 0 & 7 & 0 & 25 \\
\hline \hline Rostock & I/W & 1 & 3 & 1 & 2 & 1 & 2 & 5 & 1 & 2 & 1 & 19 \\
\hline Wismar & II/W & 5 & 1 & 0 & 3 & 4 & 2 & 1 & 1 & 0 & 0 & 17 \\
\hline \hline Penzlin & I/S & 0 & 0 & 1 & 7 & 1 & 0 & 1 & 1 & 2 & 1 & 14 \\
\hline
\end{tabular}




\begin{tabular}{|l|l|l|l|l|l|l|l|l|l|l|l|r|}
\hline Güstrow & I/W & 4 & 2 & 0 & 0 & 2 & 0 & 0 & 1 & 1 & 0 & 10 \\
\hline \hline Teterow & I/W & 0 & 0 & 0 & 4 & 1 & 0 & 0 & 0 & 0 & 0 & 5 \\
\hline \hline Waren & I/S & 1 & 0 & 0 & 0 & 1 & 0 & 0 & 0 & 1 & 2 & 5 \\
\hline \hline Malchow & I/S & 0 & 0 & 0 & 1 & 1 & 0 & 0 & 0 & 0 & 1 & 3 \\
\hline \hline Parchim & II/W & 0 & 0 & 0 & 0 & 2 & 0 & 0 & 0 & 0 & 1 & 3 \\
\hline \hline Schwerin & II/W & 0 & 1 & 0 & 0 & 0 & 1 & 0 & 1 & 0 & 0 & 3 \\
\hline \hline Gesamt & & 12 & 9 & 5 & 23 & 14 & 6 & 10 & 5 & 13 & 6 & 103 \\
\hline
\end{tabular}

Bei Betrachtung der übrigen 13 mecklenburgischen Orte, die lediglich einen oder zwei Studenten in Greifswald vorwiesen, finden wir drei östlich von Rostock wieder, nämlich Ribnitz, Bad Sülze und Laage (je 1 Student). Zwei (Gnoien und Neukalen mit 2 und 1 Student) liegen westlich von Demmin. Vier $^{242}$ befinden sich dagegen im Schweriner, weitere vier ${ }^{243}$ im Neubrandenburger Raum, also in etwas größerer Entfernung von Greifswald. Die Immatrikulationsentwicklung der Mecklenburger geht aus der folgenden Grafik hervor, die auch 47 Bistumsnennungen (Schwerin) sowie eine Landesnennung (Mecklenburg) enthält. Darin kommt ein erheblicher Anstieg der Zahlen ab 1477 zum Ausdruck, der bis etwa 1490 andauert, wenn man von dem Pestjahr 1485 absieht. Ein nächster Anstieg ist dann in den Jahren 1499 bis 1502 sowie 1514 und 1518 zu verzeichnen, in denen bekannte Humanisten in Greifswald lehrten.

Der Gesamtbesuch der mecklenburger Studenten in Greifswald zeigt die Tendenz, daß die Phase der regionalen Existensicherung in Greifswald gegen Ende der siebziger Jahre des 15. Jahrhunderts offensichtlich in ein Ausgreifen auf das Nachbarland Mecklenburg übergegangen ist. Es wird interessant sein, zu beobachten, wie die Entwicklung im südlichen Brandenburg verlief.

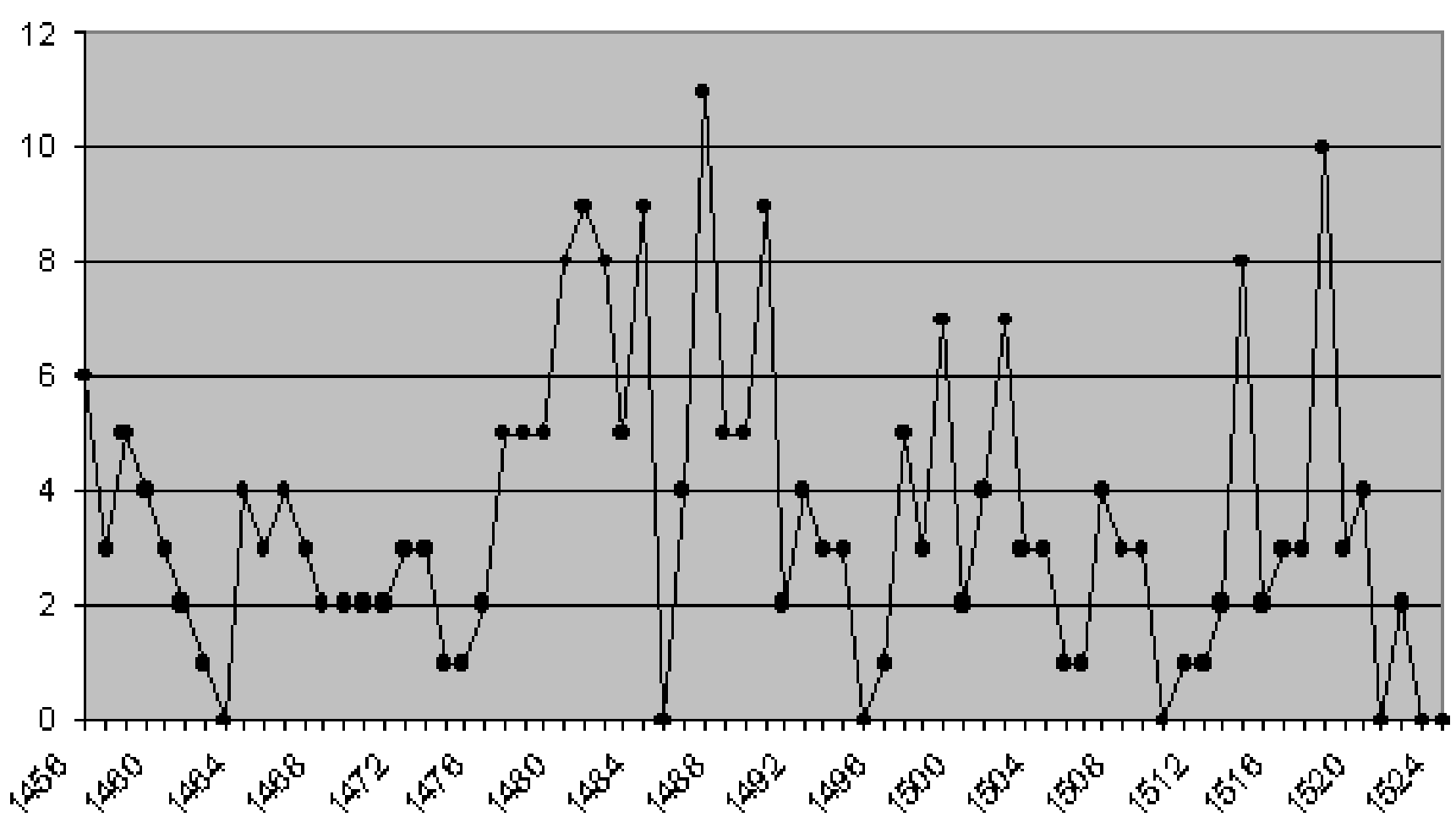


Abbildung 19: Studenten aus Mecklenburg

\subsubsection{Die Herkunftsorte der brandenburgischen Studenten}

Auch die brandenburgischen Studenten gehörten zumeist dem Greifswalder Umfeld an, wenngleich das gesamte Territorium eine recht große Ausdehnung hatte. Von den 268 Brandenburgern waren 63 Ortsangaben, 144 Orts- und Landangaben und 61 Diözese/Landangaben zu verzeichnen. Mit 51 Angaben verteilen sie sich auf fast doppelt so viele Orte wie die Mecklenburger, weswegen die Orte im einzelnen eine geringere Beteiligung vorweisen.

Mit nur 25 Studenten kamen aus Prenzlau, das zwischen Stettin und Neubrandenburg liegt und knapp 100 Kilometer von Greifswald entfernt ist, die meisten brandenburgischen Studenten. Die Studentenzahlen aus Prenzlau verteilen sich sehr unregelmäßig auf die gesamte Zeitspanne. Während in den ersten 14 Jahren neun Studenten die Greifswalder Universität besuchten, bleiben sie in den folgenden 14 Jahren aus. Erst ab 1484 kommen sie etwas häufiger (12 Studenten in 14 Jahren), wahrscheinlich bedingt durch die Rostocker Domfehde 1487, als es zum zweiten Auszug der Rostocker Universität diesmal nach Lübeck kam. ${ }^{244}$ In den 14 Jahren darauf nehmen die Zahlen mit vier Immatrikulierten allerdings schon wieder ab, und seit 1506 findet sich überhaupt kein Prenzlauer mehr in Greifswald ein. Dies hing sicherlich mit den Universitätsgründungen von Frankfurt und Wittenberg zusammen.

Auf Prenzlau folgen die beiden Bischofsstädte Brandenburg und Havelberg mit 14 bzw. 12 Immatrikulierten. Die zu erwartende größere Zahl Kleriker ließ sich bei diesen Städten nicht wiederfinden, was aber auch mit der unzulänglichen Sorgfalt des Rektors zu tun haben kann; Weihegrade und kirchliche Würden wurden allgemein sehr unregelmäßig verzeichnet. Während aus der Bischofsstadt Brandenburg 12 von 14 Studenten in der ersten Hälfte des Zeitraums nach Greifswald kamen, erfolgen neun der 12 Havelberger Immatrikulationen erst ab 1490.

Eine ähnliche Entwicklung nehmen die Zahlen aus Arnswalde. Die Stadt liegt etwa 50 Kilometer südöstlich von Stettin. Sechs Immatrikulierte sind es zwischen 1490 und 1506, drei weitere bis zum Ende des Betrachtungszeitraums. Da nur zwei Studenten im zweiten Abschnitt kamen, liegt die Gesamtzahl bei 11 Einschreibungen.

Die Ortschaft Neuruppin befindet sich nord-westlich von Berlin. 10 mal wurde sie in der Matrikel erwähnt vornehmlich in den ersten drei Abschnitten (3/3/3/1).

Aus Frankfurt an der Oder zogen sieben der insgesamt neun Studenten im zweiten und dritten Abschnitt nach Greifswald.

Die Stadt Pritzwalk liegt auf halbem Wege zwischen Schwerin und Berlin. Der letzte ihrer acht Studenten wurde bereits im Wintersemester 1500 immatrikuliert. 
Wittstock befindet sich nur wenige Kilometer östlich von Pritzwalk, doch zogen vier der insgesamt acht Studenten gerade in diesem letzten Abschnitt nach Greifswald.

Zwischen 1473 und 1489 kamen fünf von sieben Studenten aus Templin. Der Ort liegt südlich von Greifswald zwischen Prenzlau und Neustrelitz.

Angermünde, Bernau und Landsberg nannten je sechs Studenten. Während die Orte Angermünde und Bernau nord-östlich von Berlin liegen, befindet sich Landsberg weiter östlich im heutigen Polen. Aus Landsberg kamen die Studenten vornehmlich im zweiten, aus Bernau im dritten Abschnitt; aus Angermünde im zweiten und dritten Abschnitt.

Fünf Studenten sind aus Soldin, nord-östlich von Berlin ebenfalls im heutigen Polen gelegen, zu verzeichnen, die sich gleichmäßig verteilen, während die fünf aus Strasburg, westlich von Neubrandenburg, fast alle im letzten Abschnitt nach Greifswald ziehen (4).

Als Ergebnis bleibt festzuhalten, daß wahrscheinlich aufgrund der Universitätsgründungen zu Beginn des 16. Jahrhunderts ein Rückgang der Studentenzahlen aus diesen Orten verursacht wurde, der sich am Gesamtergebnis der Spalten in der folgenden Tabelle gut ablesen läßt. Nur Havelberg, Arnswalde, Wittstock und Strasburg können die Zahlen in diesem letzten Abschnitt halten. Bei Betrachtung der Entfernungen der einzelnen Orte von Greifswald, ist eine deutliche Mehrheit im nördlichen also näher zu Greifswald gelegenen Teil des brandenburgischen Gebiets wiederzufinden. Nur Frankfurt liegt etwa 200 Kilometer von Greifswald entfernt. Ansonsten bewegen sich die Entfernungen immer zwischen 100 und 200 Kilometer, während Prenzlaus Entfernung knapp darunter liegt.

Tabelle 10: Orte Brandenburgs mit 5 bis 25 Studenten

\begin{tabular}{|l||l|l|l|l||l|l||}
\hline Herkunft & Entfernung & A & B & C & D & Gesamt \\
\hline \hline Prenzlau & I/S & 9 & 6 & 10 & 0 & 25 \\
\hline \hline Brandenburg & II/S & 6 & 6 & 2 & 0 & 14 \\
\hline \hline Havelberg & II/S & 2 & 1 & 6 & 3 & 12 \\
\hline \hline Arnswalde & II/S & 0 & 2 & 6 & 3 & 11 \\
\hline \hline Neuruppin & II/S & 3 & 3 & 3 & 1 & 10 \\
\hline Frankfurt /O. & III/S & 1 & 3 & 4 & 1 & 9 \\
\hline Pritzwalk & II/S & 2 & 3 & 3 & 0 & 8 \\
\hline Wittstock & II/S & 2 & 2 & 0 & 4 & 8 \\
\hline \hline Templin & II/S & 1 & 5 & 1 & 0 & 7 \\
\hline \hline Angermünde & II/S & 1 & 2 & 3 & 0 & 6 \\
\hline \hline Bernau & II/S & 1 & 1 & 3 & 1 & 6 \\
\hline \hline Landsberg & II/S & 1 & 4 & 1 & 0 & 6 \\
\hline
\end{tabular}




\begin{tabular}{|l|l|l||l|l||l|l||}
\hline Soldin & II/S & 2 & 1 & 1 & 1 & 5 \\
\hline \hline Strasburg & II/S & 0 & 1 & 0 & 4 & 5 \\
\hline \hline Gesamt & & 31 & 40 & 43 & 18 & 132 \\
\hline
\end{tabular}

Die übrigen Orte Brandenburgs mit weniger als fünf Studenten sollen wieder zusammenfassend behandelt werden. Es handelt sich insgesamt um 36 Orte, von denen drei ${ }^{245}$ mit vier Studenten, vier $^{246}$ mit jeweils drei Studenten sowie fünf Orte ${ }^{247}$ mit zwei Studenten verzeichnet wurden. Die übrigen 24 Orte ${ }^{248}$ waren nur durch eine Person in Greifswald vertreten, so daß man bei den restlichen Brandenburgern auf eine Anzahl von 58 Studenten kommt. 14 dieser Orte mit zusammen 22 Studenten liegen etwa 100 Kilometer von Greifswald entfernt, während die Mehrheit von 19 Orten mit 28 Studenten etwas unter 200 Kilometer und vier Orte mit acht Studenten noch weiter weg liegen. Die größere Zahl von 16 Orten (=28 Studenten) ist in südlicher Richtung zu finden, wobei die Gegend um Berlin den Schwerpunkt bildet. Ferner ist eine leichte Tendenz gegen Osten hin erkennbar: 11 östlich gelegene Orte (=19 Studenten) sind gegenüber neun (=15 Studenten) aus westlicher Richtung zu verzeichnen. Aus der folgenden Grafik, in der die Entwicklung der brandenburgischen Immatrikulationen einschließlich der 59 Diözese/Landnennungen (Havelberg 44, Brandenburg 13, Mark Brandenburg 2) dargestellt wird, geht hervor, daß in der Anfangszeit der Universität nur geringe Studentenzahlen aus Brandenburg erreicht werden. Erst mit der Krisensituation an der Rostocker Universität setzen die Immatrikulationen ab 1486 schlagartig ein, gehen aber schon ab 1490 wieder auf den alten Stand zurück. 1499 werden nochmals zahlreiche Brandenburger von den beiden berühmten Humanisten in Greifswald angezogen. Die Universitätsgründungen von Frankfurt und Wittenberg führen allerdings wieder zum Absinken der Immatrikulationen, die in den letzten Jahrzehnten dann völlig unbedeutend werden. Im Gegensatz zu den Inskriptionen aus Mecklenburg kann die Greifswalder Universität erst seit den achtziger Jahren stärker auf Brandenburg ausgreifen, doch bekommt der Anstieg aufgrund der beiden Ausnahmesituationen in Rostock (Domfehde) und Greifswald (Humanisten) einen recht künstlichen Charakter. Vielmehr möchte man meinen, daß der nördliche, direkt an Pommern angrenzende Teil des brandenburgischen Gebiets eher gleichbleibend in Greifswald vertreten war, selbst gegen Ende des Betrachtungszeitraums, als Brandenburg in Frankfurt eine eigene Universität erhielt. 


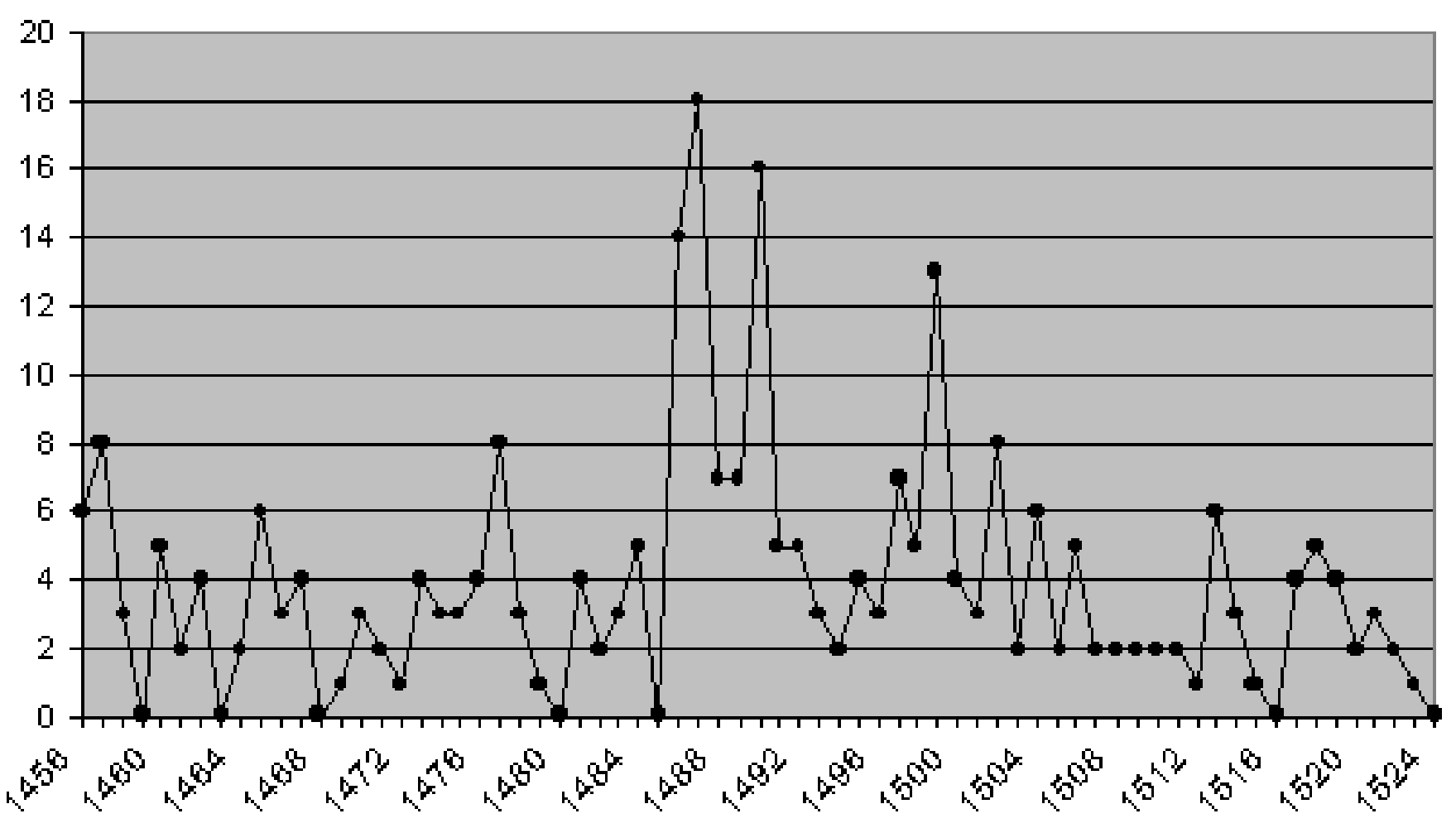

Abbildung 20: Studenten aus Brandenburg

\subsubsection{Resümee: Die regionale Basis in Greifswald 1456-1524}

Es hat sich gezeigt, daß sich im Kerngebiet des Greifswalder Einzugsbereichs innerhalb der Zeitspanne einige Verschiebungen eingestellt haben. Die äußeren Faktoren und die besondere Lage der Greifswalder Universität schufen hier ganz eigene Konstellationen.

Die regionale Basis des Greifswalder Einzugsbereichs baute sich über einen längeren Prozeß auf und ging vorerst fast ausschließlich von Pommern aus. Die ungewöhnliche Eröffnungsphase, die in erster Linie bei den Pommern und nur geringfügig in Mecklenburg, jedoch überhaupt nicht in Brandenburg zu Buche schlug, ging über in eine längere Talsohle. Die Region mußte allmählich für die neue Universität erschlossen werden. Seit 1477 war dies im großen und ganzen erreicht und die Universität griff erstmalig auf das direkte Nachbarterritorium Mecklenburg aus. Erst in der allgemeinen Hochphase der Greifswalder Einschreibungen in den achtziger Jahren weitete sich der regionale Einzugsbereich auch in das südliche Brandenburg aus, das bisher nur sporadisch aus den direkt an Pommern angrenzenden Gegenden einige Vertreter entsandt hatte. Mit der Regionalisierung seit Beginn des 16. Jahrhundert wurde diese Entwicklung wieder zurückgenommen. Dies hing vor allem damit zusammen, daß Brandenburg nun eine eigene Landesuniversität in Frankfurt erhielt. Mecklenburgische Studenten waren auch in dieser Phase stärker vertreten, jedoch mit größerer Unregelmäßigkeit. Auf Pommern konzentrierte sich jetzt eindeutig der Einzugsbereich, so daß man sagen könnte, daß sich um 1500 Greifswald zur reinen Landesuniversität entwickelt hat. Für ein abschließendes Urteil muß jedoch noch die Tendenz bei den überregionalen Studenten untersucht werden, was im folgenden Kapitel geschehen soll. Vorher sollte man noch die bemerkenswert 
geringe Anzahl an Herkunftsorten in den drei Territorien betrachten. Die strukturelle Uneinheitlichkeit des Reiches kommt dadurch deutlich zum Vorschein. Nur 91 Orte wurden von den Studenten aus Pommern genannt. Das sind 22 Prozent aller genannten Ortschaften. Bei den Mecklenburgern sind es nur 25 Orte. Brandenburg brachte es bei fast gleicher Studentenzahl bereits auf das Doppelte (51). Die geringe Städte- und Bevölkerungsdichte in den nördlichen Reichsteilen wird durch solche Zahlen bestätigt. Die drei regionalen Territorien, aus denen fast zwei Drittel aller Studenten stammen, brachten es nur auf 42 Prozent aller genannten Ortschaften. Ein Umstand, der sicherlich eine erhebliche Auswirkung auf die Größenordnung der Studentenzahl in den nördlichen Universitäten hatte. 


\subsection{Die Ausstrahlung Greifswalds auf überregionale Gebiete}

\subsubsection{Die Verteilung der Studenten auf entfernte Reichsgebiete}

Waren bisher die Territorien des regionalen Umfelds der Greifswalder Universität im Blickfeld, sollen nun die überregionalen Gebiete untersucht werden. Dabei gilt es zwischen

"Reichsangehörigen" und "Ausländern" zu unterscheiden. Freilich sind diese Kategorien nicht als qualifizierende Wertungen zu verstehen, denn die politische Zugehörigkeit an sich war für den Universitätsbesuch von untergeordneter Bedeutung. Zuerst zu den Reichsangehörigen: insgesamt konnten 461 Studenten aus entfernteren Reichsgebieten gezählt werden, von denen sich 324 Studenten auf 130 Orte verteilen, während 137 nur eine Landschaft oder eine Diözese erwähnt hatten. Die Bedeutung Greifswalds als Hansestadt wird an der Verteilung dieser Studenten sichtbar. Fast ausschließlich Gebiete in der Nähe von Nord- und Ostsee sind zu finden. Eine relativ hohe Zahl der Studenten stammt aus den rheinischen Gebieten. Der burgundische Kreis, in erster Linie die heutigen Niederlanden, stellte ebenfalls einen recht hohen Anteil (115), aber auch der kurrheinische und niederrheinisch-westfälische Kreis wird noch einigermaßen häufig erwähnt (105), so daß aus diesen beiden Kreisen mit 220 Studenten etwa 48 Prozent der Studenten entfernter Reichsgebiete zu verzeichnen sind. Der niedersächsische Kreis verbindet das Kerngebiet mit diesen entfernten Provinzen, woher insgesamt 164 Studenten stammen, die damit einen Anteil von etwa 36 Prozent der Studenten erreichen. Der obersächsische Kreis stellte mit 36 Immatrikulierten nur 8 Prozent der Studenten. Bei diesen Zahlen wurden Mecklenburg, Pommern und Brandenburg als regionale Territorien ausgeklammert. Die übrigen 41 Studenten verteilen sich auf süd- und mitteldeutsche Territorien, wie Schlesien (13), den oberrheinischen Kreis (12), den bayrischen und fränkischen Kreis (9), den schwäbischen Kreis (3), Böhmen (2), die Schweizer Eidgenossenschaft (1) und den österreichischen Kreis (1), die mit 10 Prozent damit insgesamt eine äußerst niedrige Beteiligung aufweisen.

Die dichtere Universitätslandschaft im Süden des Reiches war sicherlich hierfür verantwortlich. Die älteren Universitäten Wien, Leipzig, Heidelberg, Erfurt und Köln sammelten solche Studenten, ab der zweiten Hälfte des 15. Jahrhunderts kamen noch die Universitäten Basel, Tübingen, Ingolstadt, Mainz und Trier hinzu. Da die Immatrikulationen aus diesen Gegenden schon zur Anfangszeit sehr gering waren, konnten die Neugründungen keine Einbußen der Zahlen in Greifswald bewirken. Aus der folgenden Grafik, in der die Einschreibungen aus den entfernten Reichsgebieten hervorgeht, erkennt man einen erheblichen Rückgang nach dem Eröffnungshoch. Nur in der Gründungsphase stieß die Greifswalder Universität demnach im Reichsgebiet auf größeres Interesse, doch schon vier Jahre danach reduzierte sich die Studentenzahl und blieb bis zum Ende der siebziger Jahre auf äußerst niedrigem Niveau. Auch hier brachten die achtziger Jahre den Umschwung, als die Frequenzkurve starke Ausbrüche erlebte. Bis zum Ende des Betrachtungszeitraum verlief die Kurve sehr ungleichmäßig. Dies ist darauf zurückzuführen, daß es sich um kein einheitliches Betrachtungsgebiet handelt. Die einzelnen Gebiete innerhalb des Reiches sollen daher in den folgenden Kapiteln analysiert werden. 


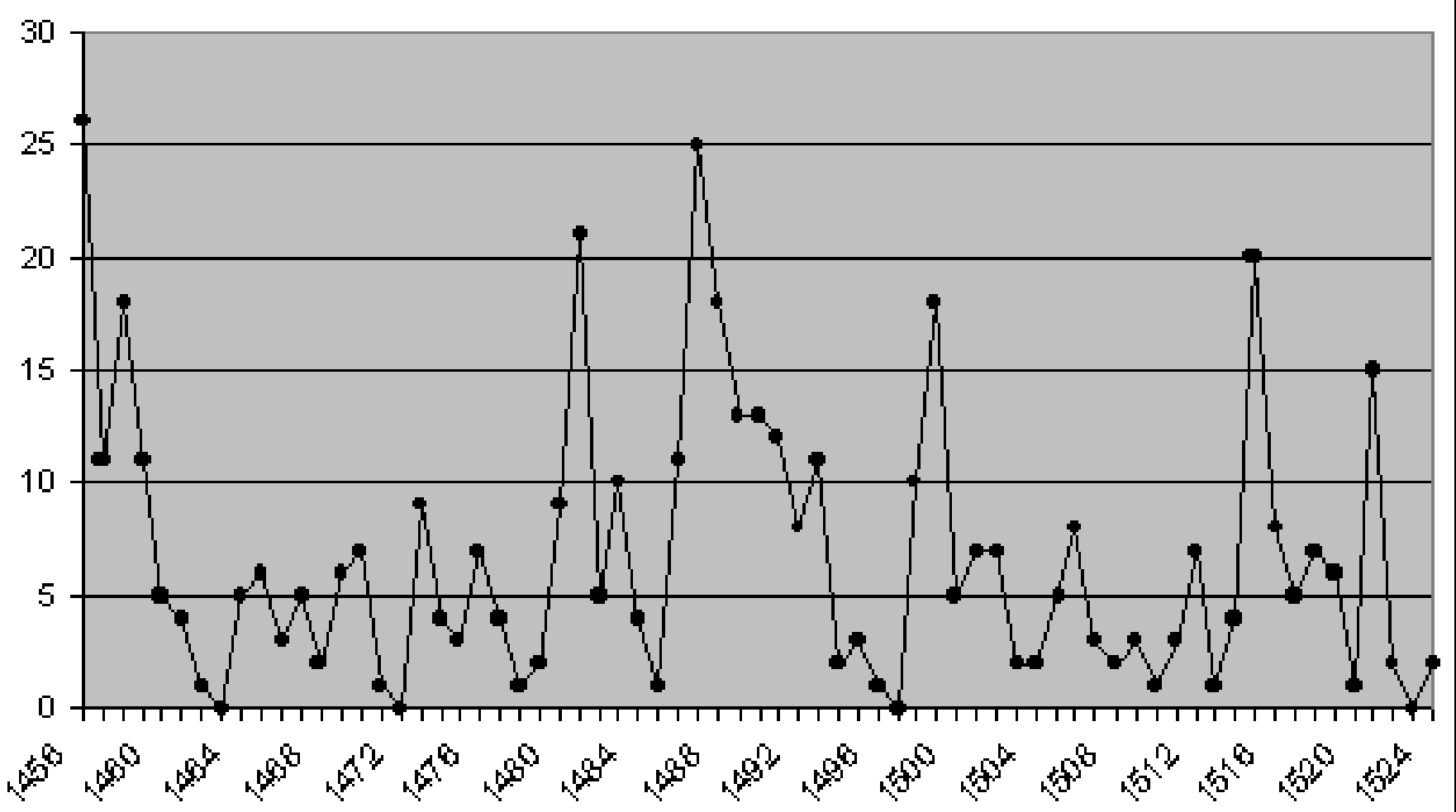

Abbildung 21: Studenten aus dem übrigen Reichsgebiet

\subsubsection{Die Herkunftsorte im niedersächsischen Kreis}

Zuerst sollen die Orte des niedersächsischen Kreises von Norden nach Süden behandelt werden. Die nördliche Reichsgrenze verlief entlang der Eider, weshalb das Herzogtum Schleswig, obwohl seit 1440 in Personalunion mit Holstein verbunden ${ }^{249}$, hier nicht mitberücksichtigt wird. Von den 164 Studenten des niedersächsischen Kreises kam fast die Hälfte (74) aus dem nördlichsten Teil, dem Gebiet Holsteins. Wenn man die 25 Hamburger einbezieht, sind es fast zwei Drittel, wobei der größte Teil aus Lübeck stammte. 30 Studenten nannten diesen Herkunftsort, während 13 nur die Herkunftsdiözese Lübeck angaben. Obwohl die Rostocker Domfehde zur Auslagerung der Universität gerade nach Lübeck führte, finden sich genau in diesen Jahren die meisten Immatrikulationen, während sie in den letzten Jahrzehnten zurückgehen. Weit dahinter folgen Orte wie Kiel und Plön mit vier und zwei Immatrikulierten. Aus den übrigen Orten zog jeweils nur ein Student nach Greifswald. Dazu zählen Ratzeburg, Busdorf, das Gebiet Dithmarschen, Heide, Lunden, Mölln, Bad Oldesloe, Ottmarschen, Rellin und Bad Segeberg. Neben Lübeck wurde die Diözese Ratzeburg siebenmal sowie einmal der Holsteiner Teil der Odenser Diözese erwähnt. Für sieben Studenten wurde nur die Angabe Holstein gemacht.

Bei Betrachtung der Immatrikulationsentwicklung dieses nördlichsten Reichsterritorriums stellt man, neben einem kurzen Anfangshoch nach der Gründung, einen starken Anstieg der Zahlen in den Jahren 1484 bis 1490 fest, der mit der Krisensituation in der Rostocker Universität zusammenhängt. An diesem Anstieg wird deutlich, daß Rostock der wichtigere Studienort für diese Studenten 
darstellte. Nach der Normalisierung der Situation in Rostock sinken die Zahlen wieder und bleiben in den nächsten Jahren relativ unbedeutend.

Hamburg hatte mit 25 Studenten Anteil am Greifswalder Studium. 21 von ihnen kamen erst ab 1498 an die Universität, die übrigen vier waren zur Eröffnung des Studiums erschienen. Aus Bremen fanden sich 13 Studenten ein, von denen 10 allerdings nur das Bistum angegeben hatten. Die übrigen 52 Studenten des niedersächsischen Kreises verteilten sich auf insgesamt 21 Orte, von denen im nördlicheren Teil die Orte Stade (4), Buxtehude (5), Winsen (1) und Lüneburg (2) zu finden waren, während in Richtung Süden Uelzen (3), Walsrode (1), Celle (1), Hannover (2), Wunstorf (1), Stadthagen (3), Braunschweig (3) und Helmstedt (1) sowie Bodenwerder (1), Goslar (1) und Duderstadt (1) in den Matrikeln auftauchten. Unter den 10 Hildesheimer Einträgen befanden sich sechs Bistumsangaben. Im Osten des Kreises finden sich die Orte Halberstadt (1), Halle (2) und Schauen (1). Vier der acht Magdeburger gaben nur die Diözese als Herkunft an.

Auch beim Gesamtbesuch aus dem niedersächsischen Kreis läßt sich die Tendenz erkennen, daß die Studenten vor allem in den achtziger Jahren zahlreich erschienen sind, während in den letzten Jahrzehnten ein deutlicher Rückgang zu verzeichnen ist, der sich sicherlich mit der Konkurrenzgründung in Wittenberg erklärt. In der folgenden Tabelle werden die Immatrikulationen aus den größten Rekrutierungsorten Lübeck und Hamburg dargestellt, während in der daran anschließenden Grafik die gesamte Immatrikulationsentwicklung der niedersächsischen Studenten skizziert werden soll. Aus ihr kann man ablesen, daß offensichtlich vor allem dieser Kreis für das Eröffnungshoch bei den entfernten Reichsgebieten verantwortlich ist. Es handelt sich hierbei um den regionalen Einzugsbereich der Rostocker Universität, in den die Greifswalder Universität jedoch nur kurzfristig ausgreifen konnte.

Tabelle 11: Studenten aus Lübeck und Hamburg

\begin{tabular}{|l|l|l|l|l|l|l|l|l|l|l||r||}
\hline Herkunft & I & II & III & IV & V & VI & VII & VIII & IX & X & Gesamt \\
\hline \hline Lübeck & 4 & 3 & 1 & 4 & 9 & 4 & 2 & 0 & 0 & 3 & 30 \\
\hline \hline Hamburg & 4 & 0 & 0 & 0 & 0 & 0 & 4 & 6 & 3 & 8 & 25 \\
\hline
\end{tabular}




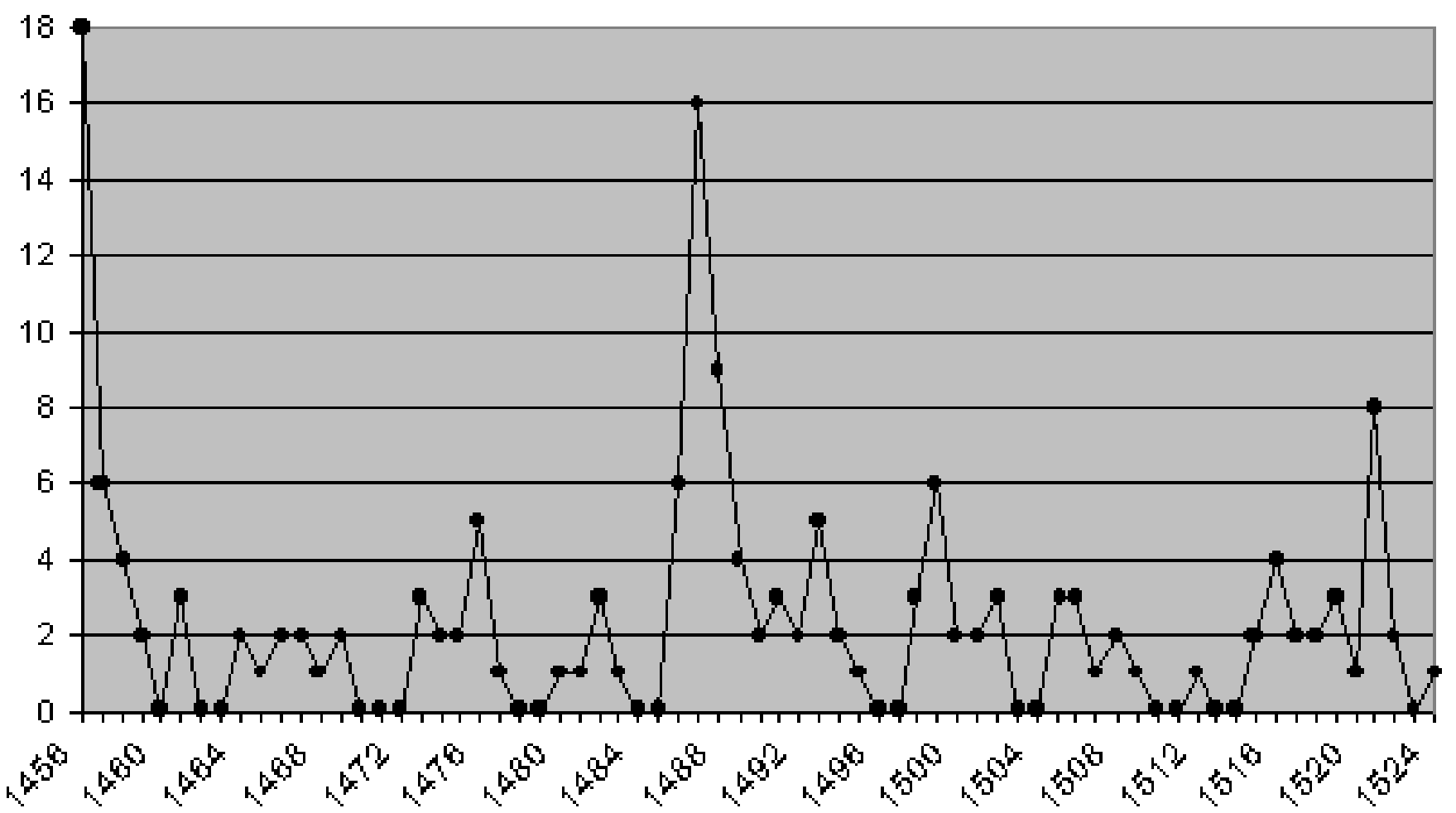

Abbildung 22: Studenten aus dem niedersächsischen Kreis

\subsubsection{Die Herkunftsorte in den rheinischen Kreisen}

Nun zu den Studenten aus den rheinischen Gebieten: Von den 117 Studenten aus den drei rheinischen Kreisen (des niederrheinisch-westfälischen, des kurrheinischen und des oberrheinischen) kamen nur 13 aus dem oberrheinischen Kreis, der die hessischen und süddeutschen Gebiete umfaßt. Die 45 angegebenen Orte der drei Kreise wiesen alle weniger als 10 Studenten auf. Sie sollen ebenfalls von Norden nach Süden behandelt werden. Aus dem Landstrich Budjadingen, gegenüber von Wilhelmshaven, kamen zwei Studenten, während die Landschaft Ostfriesland von drei Studenten als Herkunft bezeichnet wurde. Aus diesem nordwestlichen Teil des Kreises kamen insgesamt 13 Studenten, und zwar vier aus Emden, zwei aus Aurich sowie jeweils einer aus Betteweer, Hatzum, Marienhafe und Norden. In Richtung Süden finden wir drei Immatrikulierte aus Neuenhaus, je zwei aus Hoya, Nordhorn und Schüttorf und einen aus Meppen und Roffhausen. Außerdem kamen neun Studenten aus Lingen, das damit die Orte dieser Kreise anführt. Aus dem heutigen NordrheinWestfalen, also den kurheinischen Gebieten, bzw. den südlichen Teilen des niederrheinischwestfälischen Gebietes fanden sich aus der Bischofstadt Minden acht Studenten, aus Borken vier sowie aus Rheda und Siegen zwei Studenten. Nur je ein Student kam aus Soest, Unna, Rheine, Hamm, Kastren und Wesel im Westen und aus Quernheim, Borgentreich, Wiedenbrück und Warburg im Osten nach Greifswald. Ein Student kam aus Bingen am Rhein, während einer den Westerwald als Herkunftsregion angab. Bei den Bischofsstädten ist wieder zwischen Orts- und Diözesanangaben zu unterscheiden. An der Spitze steht Münster mit sieben Stadtbewohnern und acht Bistumsangehörigen, gefolgt von Osnabrück mit drei bzw. neun solcher Angaben. Während Köln und Paderborn je zwei Inskribierte aus dem Bistum vorwies, und die Stadt nur von zweien bzw. einem angegeben wurde, 
verzeichneten Verden und Mainz lediglich Bistumsangaben, und zwar sechs bzw. zwei. Die 13 Studenten des oberrheinischen Kreises verteilen sich auf sechs Studenten aus Kassel sowie je einem Studenten aus Fritzlar, Marburg, Hanau und Salz im Norden, und aus Kaiserslautern, dem Elsäßischen Schlettstadt und dem Lothringischen Forbach im Süden.

Bei der Verteilung der Studenten aus den rheinischen Kreisen ist ein Übergewicht für den westfälischen Raum zu finden, während in Richtung Süden die Immatrikulationen immer seltener werden. Im friesländischen Küstenbereich ist eine Ballung der Herkunftsorte zu verzeichnen, die als Ausläufer des niederländischen Einzugsbereichs mit der Hochburg Groningen zu bewerten ist. Die Studenten sind ungleichmäßig auf die Zeitspanne verteilt, wie aus der Grafik deutlich wird. Während der Eröffnungsjahrgang bei den Reichsgebieten noch vom niedersächsischen Kreis dominiert wird, verschiebt sich die Herkunft der Studenten offensichtlich in Richtung Westen. Erst 1458 kommt es hier zu einer kurzen Hochphase. Nach diesem Gründungshoch ist in den achtziger Jahren, also den Krisenjahren in Rostock, ein weiterer Aufschwung der Immatrikulationen zu verzeichnen, der wiederum deutlich macht, daß Rostock gegenüber Greifswald auch von Studenten aus weiter entfernten Orten im Westen des Reiches bevorzugt wurde.

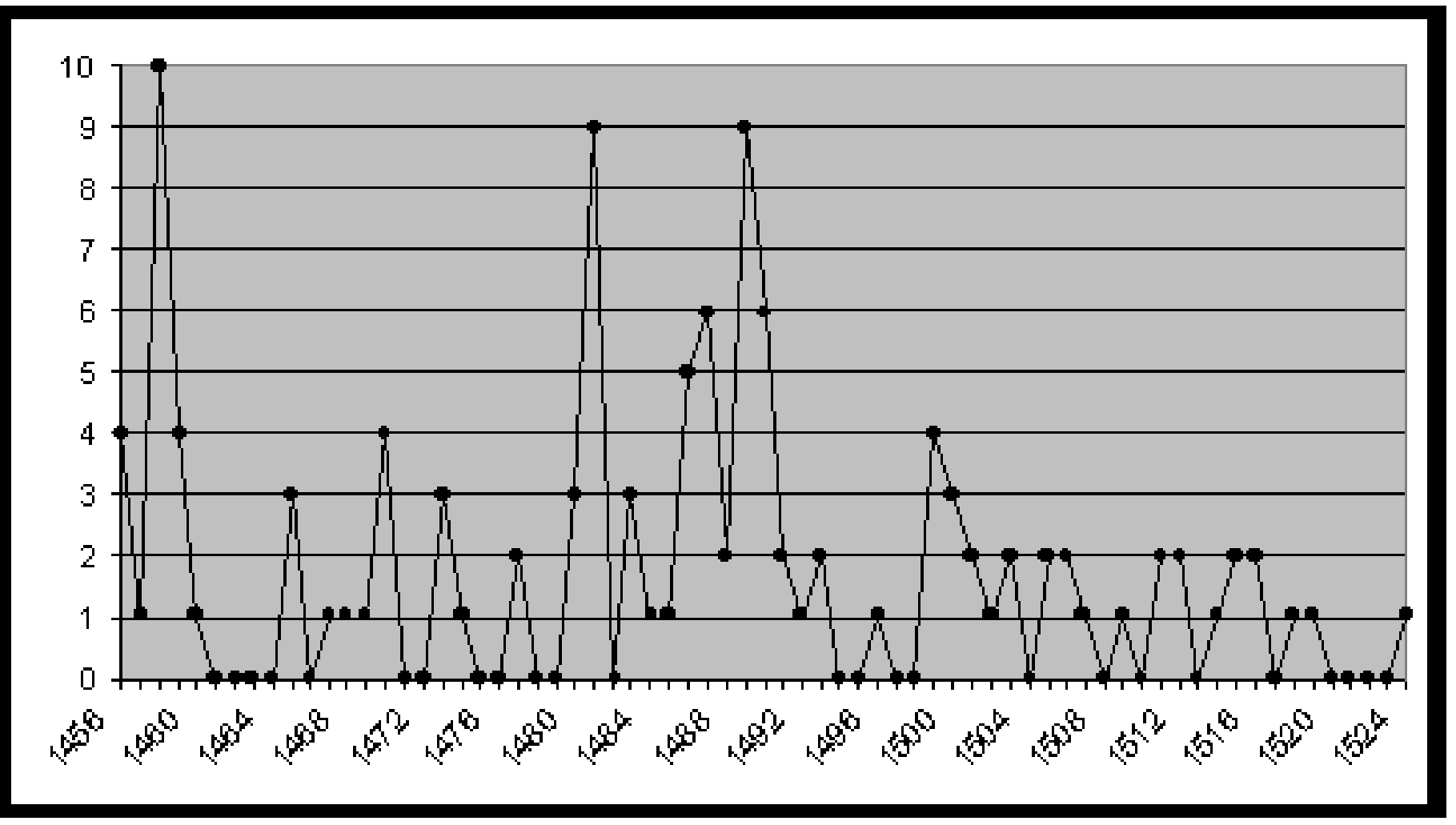

Abbildung 23: Studenten aus den rheinischen Kreisen

\subsubsection{Die Herkunftsorte im burgundischen Kreis}

Aus dem burgundischen Kreis, der etwa den heutigen Beneluxstaaten entspricht, zogen insgesamt 115 Studenten nach Greifswald, die fast ausschließlich aus dem nördlichsten Teil dieses Kreises, den heutigen Niederlanden, kamen. ${ }^{250}$ Sicherlich ist eine Erklärung dafür, in den Handelsbeziehungen zu suchen. Acht der 26 Orte waren Hansestädte, aus denen 41 der 76 genau zuzuordnenden Studenten 
stammen. Auch die übrigen Orte standen über verschiedene Handelswege mit Greifswald in Verbindung, und boten daher den Studenten einen bequemen Zugang zur Greifswalder Universität. Schwinges formulierte 1985, es sei "eine bekannte Tatsache, die sicher nicht nur in der Neuzeit und sicher nicht nur in weiträumiger Hinsicht gültig ist, daß den wirtschaftlichen Beziehungen im allgemeinen auch die kulturellen Beziehungen und umgekehrt folgten." ${ }^{251}$ Diese These scheint sich am Zuzug der Greifswalder Studenten aus solch entfernten Gebieten wie den Niederlanden ebenso zu bestätigen wie an der überregionalen Ausstrahlung Leipzigs, das als Handelsmetropole seiner Hochschule fortdauernde Anziehungskraft gab. ${ }^{252}$

Die Hochburg der niederländischen Einschreibungen ist mit Abstand Groningen, das von 29 Studenten als Heimatstadt angegeben wurde, und damit in der Reihenfolge der größten Rekrutierungsorte hinter Danzig und Lübeck an 16. Stelle steht. Bemerkenswert am Zuzug der Groninger Studenten ist die sehr unterschiedliche Verteilung auf den gesamten Zeitraum. Der erste Student, ein Artistenbakkalar, wird zwar bereits 1456 immatrikuliert, doch unterbleiben bis zum Jahre 1478 weitere Inskriptionen.

Im Sommersemester 1478 verzeichnet die Matrikel dann den Groninger Doktor der Medizin, Heinrich ter Porten. Ab jetzt beginnt ein reger Zulauf der Studenten aus dieser Stadt, die bis 1483 weitere 18 Inskriptionen vorwies. Wahrscheinlich war es der Ruf dieses Gelehrten, der den Studentenzuwachs verursachte, denn auch aus verschiedenen anderen Gebieten der Niederlande sind genau in dieser Zeit häufige Immatrikulationen zu verzeichnen.

Die übrigen Groninger finden sich nur noch vereinzelt zwischen 1498 und 1518 in Greifswald ein. Aus dem friesischen Teil der Niederlanden zogen außerdem Studenten aus Sneek (9), Leeuwarden (4), Workum (2), Beilen (1), Dwinglo (1), Giethoorne (1), Uithuisen (1) und aus Ylst (1) nach Greifswald. Vier Studenten gaben nur den niederländischen Teil Frieslands als Herkunft an. Wenn man noch die Ostfriesischen Studenten des niederrheinisch-westfälischen Kreises hinzurechnet (insgesamt 13), dann tritt die höhere Frequenz aus diesem Gebiet mit 66 Studenten noch stärker vor Augen. Außerdem sind sicherlich von den 28 Immatrikulierten, von denen nur die Herkunftsdiözese Utrecht erwähnt wurde, einige hinzuzurechnen. Neben dem Anstieg, den der Groninger Doktor der Medizin verursachte, finden sich aus diesem Gebiet vor allem im Jahre 1515 häufige Immatrikulationen, die vielleicht mit der Anwesenheit des Humanisten Johannes Hadus zusammenhängen. Eine größere Zahl niederländischer Studenten stammt aus den zentralniederländischen Gebieten, vor allem der Provinz Overijssel um die Städte Deventer und Zwolle, wo bekannte Schulen den Studenten sicherlich eine gute Vorbildung für das weitere Studium geben konnten. Kosegarten geht davon aus, daß es sich bei diesen Studenten und Professoren bereits um Vertreter des aufkommenden Humanismus handelt, die in Greifswald, genau wie in anderen Hohen Schulen dieser Zeit, von sich reden machten. Die neuere Forschung will diese Sichtweise freilich nicht ungeprüft teilen, denn aus der Tatsache, daß in diesen Gegenden frühhumanistische Schulen bestanden, vermag man noch keine Einwirkung auf das Universitätsstudium festzustellen. Vielleicht würde eine nähere Untersuchung dieser Studenten, die bereits in den siebziger und achtziger Jahren des 15. Jahrhunderts in Greifswald auftauchten, weitere Erkenntnisse darüber liefern, ob bereits engere Kontakte zu humanistischen Kreisen bestanden. ${ }^{253}$ Aus Zwolle kamen sechs Studenten, aus Kuinder drei, aus Hasselt und Stenwijk zwei. Hardenberg, Hattem, Kampen, Maurick, Rande, 
Züthpen und Nymwegen schickten nur je einen Studenten. Im Westen der Niederlande fanden sich aus Utrecht, neben den 28 Diözesannennungen, noch sechs Stadtbewohner ein. Außerdem kamen zwei Besucher aus Den Haag und je einer aus Amsterdam, Schiedam und Alkmaar sowie im Süden noch einer aus Roermond. Nur zwei Belgier waren verzeichnet, der eine aus Brabant, der andere aus Löwen. Löwen besaß seit 1426 eine Universität, die im letzten Viertel des 15. Jahrhunderts zur frequenzstärksten Hohen Schule des Reiches zählte. ${ }^{254}$ Das Ausbleiben weiterer Immatrikulationen aus dem südlichen Teil des burgundischen Kreises ist damit sicherlich zu erklären. Die Gesamtentwicklung dieses Kreises geht aus der folgenden Grafik hervor. Die Gründung einer Universität in Pommern bewirkte in solch entfernten Gebieten keine besondere Aufmerksamkeit, so daß hier keine Ausschläge in den ersten Jahren zu bemerken sind. Erst seit den siebziger Jahren werden hier höhere Immatrikulationszahlen erreicht. Es entsteht der Eindruck, daß wir nun in eine Phase der Greifswalder Universitätsgeschichte eintreten, in der sich die Handelsverbindungen der Universitätsstadt auch auf den Universitätsbesuch auswirkten. Es bedurfte offensichtlich erst einer längeren Phase der inneren Konsolidierung bevor die Universität imstande war, solche Verbindungen in Immatrikulationen umzusetzen.

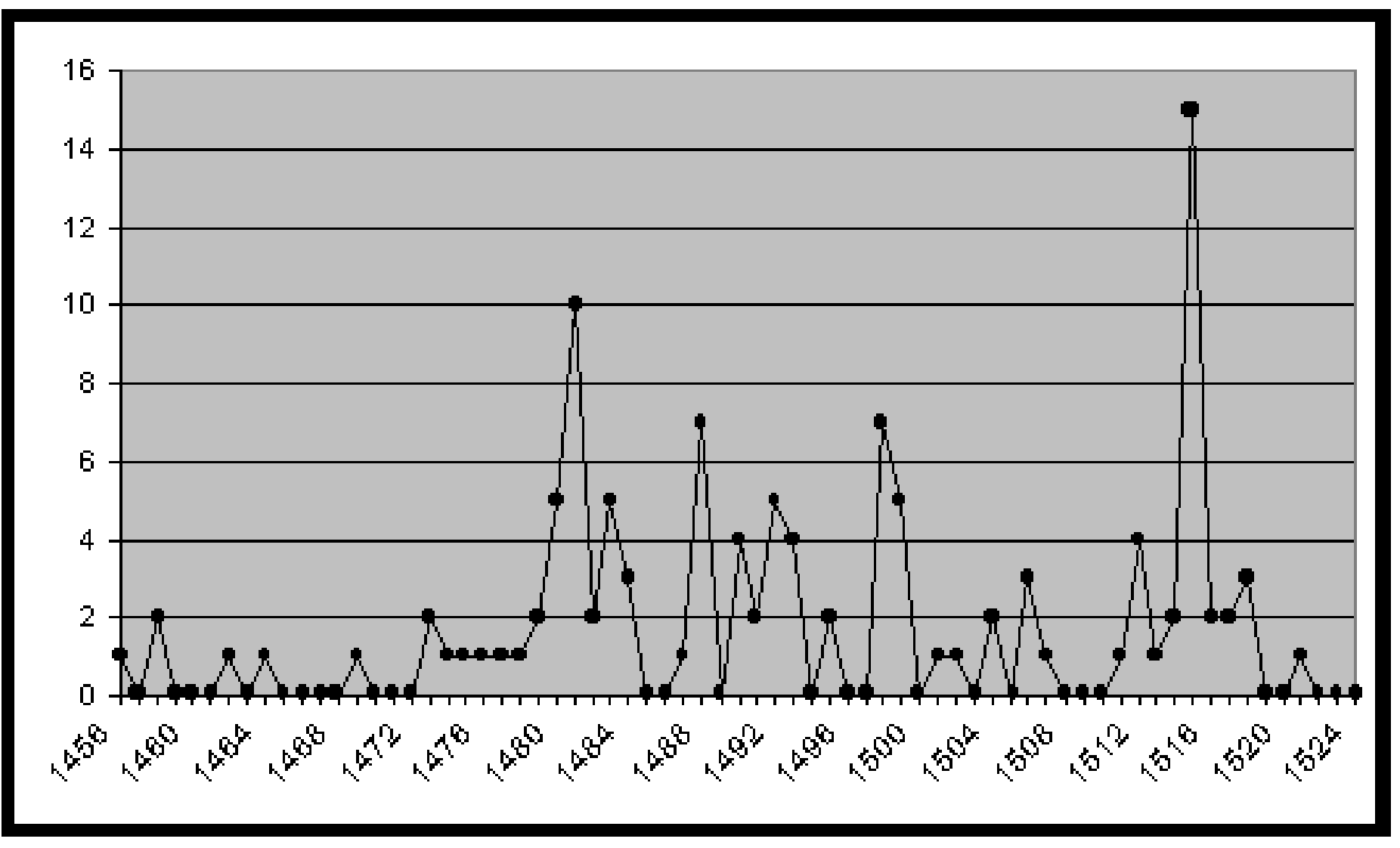

Abbildung 24: Studenten aus dem burgundischen Kreis

\subsubsection{Die Herkunftsorte in den übrigen Reichsgebieten}

Die übrigen Gebiete des Reiches, aus denen Studenten nach Greifswald zogen, fallen gegenüber den gerade behandelten drei nördlichen Kreisen, kaum ins Gewicht. Von den 35 obersächsischen Studenten (ohne Pommern und Brandenburger) kamen vier aus Borna, südlich von Leipzig, je drei 
aus Bautzen und Zerbst sowie zwei aus Querfurt und Werben. Nur ein Student ist aus Dresden, Leipzig, Jena, Freiberg, Kolditz, Löbau, Meiningen, Öderan, Saalfeld, sowie Sonneberg erschienen. Unter den obersächsischen Immatrikulationen finden sich außerdem sieben Personen, die nur die Diözese Meißen als Herkunftsgebiet angegeben hatten, während von den vier Naumburgern zwei Bistumsangaben zu verzeichnen waren. Nur zur Gründungszeit der Universität waren die Zahlen der obersächsischen Studenten relativ hoch, doch schon in den folgenden Jahren sind sie fast gar nicht mehr vertreten. Mit Erfurt und Leipzig hatte dieses Gebiet gleich zwei Universitäten, die den Bedarf an universitärer Bildung dort sicherlich abdeckten, zumal diese Universitäten in dieser Zeit zu den

größten des gesamten Reichsgebiets zählten. ${ }^{255}$ Die 13 Studenten aus Schlesien kamen aus Löwenberg (2), Görlitz (2) und Gurau (1), während von den sieben Breslauer Studenten, fünf Bistumsnennungen abzurechnen sind sowie einer sich mit der Angabe Schlesien begnügte. In Richtung Süden werden die Immatrikulationen immer spärlicher. Aus Böhmen sind zwei Angaben zu finden, wovon einer aus Elbogen ganz im Norden stammt, der andere nur das Herkunftsland Böhmen angab. Aus dem fränkischen Kreis kamen immerhin sechs Studenten, von denen vier Würzburg als Herkunft nannten, wobei zwei nur die Diözese meinten. Leinleiter, Ochsenfurt und Rothenburg ob der Tauber wurde nur von einem genannt. Aus dem bayrischen Kreis kamen zwei Studenten, nämlich aus Regensburg und Rain. Der schwäbische Kreis entsandte je einen Vertreter aus Aalen, Rottenburg und Konstanz, die Schweizer Eidgenossenschaft einen aus Rapperswil. Schließlich findet 1521 noch ein Bakkalar aus Linz im österreichischen Kreis den Weg nach Greifswald.

\subsubsection{Die Verteilung der Studenten auf ausländische Gebiete}

Brachten die Ergebnisse über Studenten aus den entfernten Reichsgebieten eigentlich nur für das Gebiet der nördlichen Niederlanden Besonderheiten zu Tage, so fiel dagegen die hohe Zahl "ausländischer" Studenten auf: mit 620 Immatrikulationen verteilten sich 20 Prozent der Greifswalder Studenten auf Territorien, die nicht dem Reich angehörten (einschließlich allerdings der 148 Studenten des Deutschordensgebiets). Dieser Anteil liegt damit weit über den Werten anderer Universitäten des Reiches, deren internationaler Anteil an der Studentenschaft sehr viel niedriger war. ${ }^{256}$ Wenn die moderne Universitätsforschung im 15. Jahrhundert "einen Epochenwechsel in der gesamteuropäischen Universitätsgeschichte", und "einen Übertritt von einem universalen in ein national-regionales Zeitalter" ${ }^{257}$ konstatiert, so gilt es die Unterschiede zwischen den einzelnen Institutionen zu berücksichtigen, die sich häufig solch grober Einteilungen entziehen. Sicherlich ist die verstärkte Regionalisierung am Beispiel Heidelbergs nachzuvollziehen, dessen Einzugsbereich durch verschiedene Neugründungen schon im beginnenden 15. Jahrhundert verkleinert wurde ${ }^{258}$, doch ergeben die Zahlen für Greifswald ein etwas anderes Bild, obwohl die Gründung bereits in die zweite Hälfte des Jahrhunderts fällt. Das gleiche gilt auch für die Universitäten Rostock, Erfurt und Leipzig, die von Regionalisierungstendenzen im 15. Jahrhundert ebenfalls weitgehend unberührt blieben. ${ }^{259}$ Vielleicht kommt man hier durch eine Differenzierung der Universitätslandschaft zwischen nord-östlichen und süd-westlichen Reichsgebieten zu einer angemesseneren Beurteilung. Natürlich sollte man bei einer Bewertung solcher Zahlen auch berücksichtigen, daß man Internationalität nicht nach modernen Maßstäben messen darf. ${ }^{260}$ Man kann davon ausgehen, daß es 
sich bei den Studenten aus Preußen und den übrigen Deutschordensgebieten um deutschsprachige Personen gehandelt hat. Das gleiche gilt auch für die Polen, und selbst die skandinavischen Studenten waren den Studenten aus den Reichsgebieten kulturell noch nicht allzu fern. Für die Greifswalder Universität stellten die Ausländer trotz starker Frequenzschwankungen bis zum Ausgang des 15. Jahrhunderts eine wichtige Größe dar. Die Schwankungen sind sicherlich damit zu erklären, daß die Studenten aus diesen Gebieten häufiger in Reisegruppen erschienen, die den beschwerlichen und gefährlichen Weg zur Universität gemeinsam unternahmen. Die auffälligsten Jahre ausländischer Immatrikulationen sind die Jahre 1486 bis 1490 sowie 1495 bis 1499. Mit dem Beginn des 16. Jahrhunderts sinken dann die ausländischen Studentenzahlen, und werden bis zum Ende des Zeitraums immer bedeutungsloser. Für Greifswald erkennt man am Ausbleiben der ausländischen Studenten, daß erst jetzt der Regionalisierungprozeß beginnt. Aus der "Universität für den Norden Europas" wird allmählich eine reine Landesuniversität Pommerns, wie man gut an der folgenden Grafik erkennen kann. Auch hier täuscht die Grafik ein einheitliches Bild vor, denn es unterschieden sich die einzelnen ausländischen Gebiete in ihrer Präferenz für Greifswald, so daß nun eine differenzierte Untersuchung der einzelnen Länder erfolgen soll.

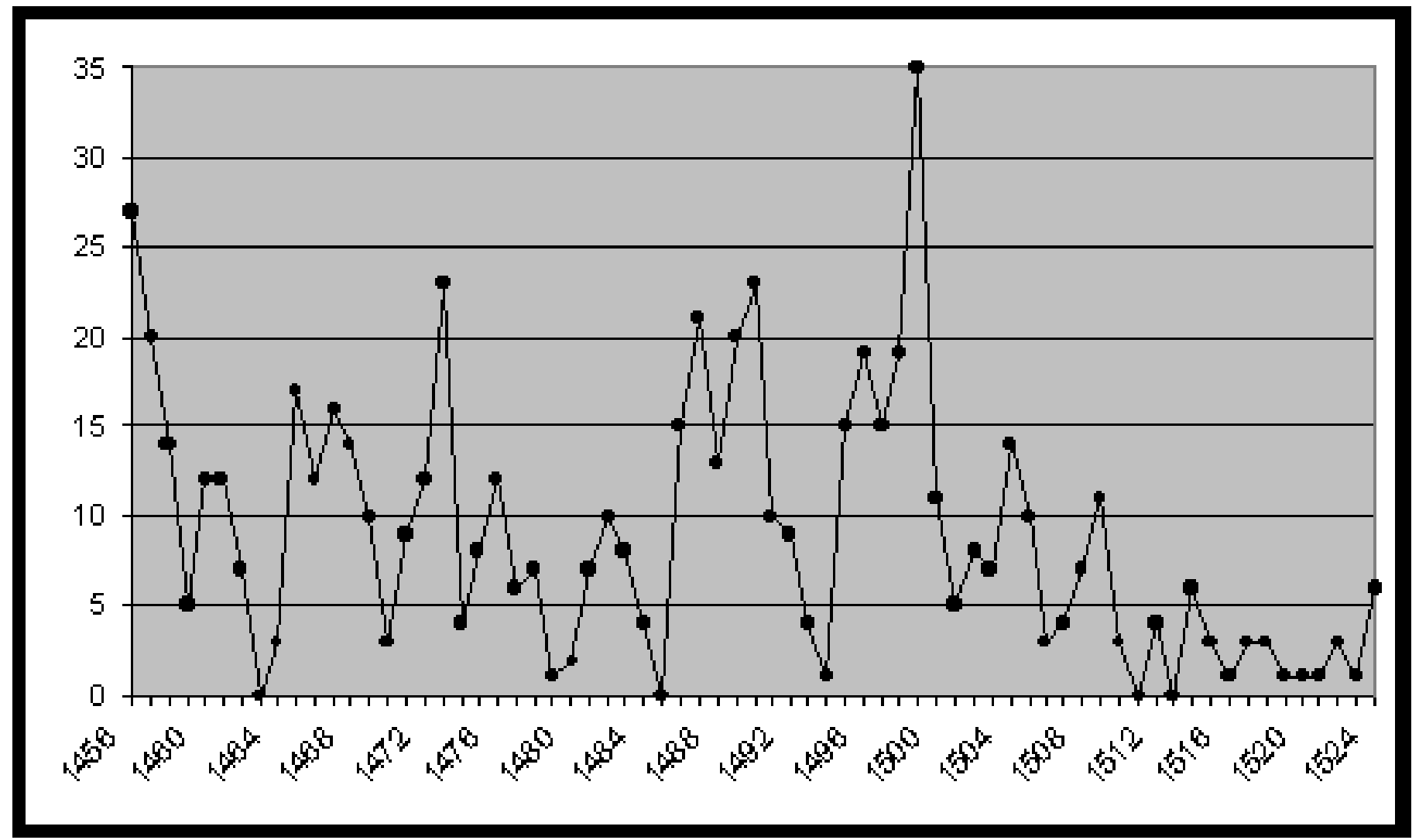

Abbildung 25: Studenten ausländischer Herkunft

\subsubsection{Die Herkunftsorte in Dänemark}

Aus Dänemark zogen die meisten ausländischen Immatrikulierten nach Greifswald. 326 Studenten, mehr als Mecklenburg und Brandenburg, sind im behandelten Zeitraum wiederzufinden, was einem Anteil von 9,8 Prozent aller und 51 Prozent der ausländischen Studenten entspricht. Schwinges gab für den Zeitraum zwischen 1456 und 1505 einen Anteil von 11 Prozent dänischer Studenten in 
Greifswald an ${ }^{261}$, was sich ebenfalls mit meinen Berechnungen deckt. ${ }^{262}$ Allein die letzten 19 Jahre bewirkten den Rückgang von über einem Prozentpunkt. In diesem Zeitabschnitt liegt der Anteil der Dänen nur noch bei 3,4 Prozent (24 von 712 Studenten).

Gerade unter den Dänen sind viele Immatrikulationen ohne genaue Ortsnennung zu finden. Häufig wird nur das Land, eine Diözese oder eine Insel erwähnt. Nur 118 Personen können einem Ort zugeordnet werden. Sie verteilen sich auf 33 Orte, während die übrigen 208 Studenten 20 unterschiedliche Gebiete angaben. Unter ihnen sind 30 Studenten, die sich einfach mit der Angabe "de dacia" zufriedengaben.

Seeland, das sich fast direkt gegenüber der pommerschen Küste befindet, verzeichnete insgesamt 97 Studenten und stellte damit den höchsten Anteil aller dänischen Inseln. 69 Studenten kamen aus Roeskilde, wovon 55 nur das Bistum als Herkunft angaben. Kopenhagen wird 12 mal genannt, neun kamen allerdings vor der dortigen Universitätsgründung 1479. Sieben Studenten gaben die Insel Seeland $a^{263}$, die Orte Helsingöer und Kjöge wurden je zwei mal erwähnt. Nur ein Student kam aus Holbeck, Kallundborg, Söeborg, Tybierg und Nestved. Die Immatrikulationen Seelands setzen regelmäßig ab 1465 ein, doch kommt es 1479 durch die Kopenhagener Universitätsgründung zu einer längeren Pause mit nur vereinzelten Inskriptionen. Ab 1495 immatrikulieren sich Seeländer wieder häufiger, jedoch nur für etwa fünf Jahre, während sie ab 1513 gar nicht mehr anzutreffen sind.

Die Insel Fünen war mit 46 Studenten am Greifswalder Studium beteiligt, wobei aus der Odenser Diözese 31 Studenten, aus der Stadt selber neun Studenten kamen. Nyeborg nannten vier, Fünen zwei Studenten. Auf Jütland, dem dänischen Festland, sind die Diözesen Ribe, Aarhus, Viborg und Borglum wiederzufinden. Die Reichsgrenze befand sich entlang der Eider, so daß man die Orte Schleswig (sechs Orts-, sechs Bistumsangaben), Flensburg (1) und Dytteböl (1) zum dänischen Einzugsbereich zählen muß. Das gleiche gilt für die beiden Studenten der Insel Fehmarn. Aarhus stellte den größten Teil Jütländer mit 26 Immatrikulierten, worunter sich auch 11 Stadtbewohner befinden. Wiborg folgte mit 23, Ribe mit 18 Studenten, bei denen außerdem je neun Stadtbewohner eingerechnet sind. Aus Borglum, das ganz im Norden des dänischen Festlandes liegt, fanden sich 10 Studenten ein (darunter zwei Stadtbewohner). Jütland wurde acht mal genannt, die Orte Göthia, Kolding, Ringkjöbing, Rodby, Wedel und Sonderburg je einmal, so daß insgesamt 107 Studenten aus Jütland zu verzeichnen waren. Aus dem östlichen Teil Dänemarks, der sich auf der schwedischen Halbinsel befindet und die Erzdiözese Lund umfaßte, kamen 39 Studenten. 10 von ihnen gaben Lund als Herkunftsdiözese, 14 als Herkunftsort an. Die Gebiete Blekinge, Schonen und Halland hatte je ein Student als Herkunftsangabe, während Halmstadt und Warberg von drei, Falkenberg und Malmö von zwei Studenten genannt wurden. Je eine Immatrikulation ist aus Landskrona und Ystad zu vermelden. Die Inseln Laland und Falster befinden sich direkt gegenüber der pommerschen Küste und verzeichneten insgesamt fünf Vertreter, zwei aus Nakskow, zwei bzw. einer mit der Angabe Laland und Falster. Ganz im Norden Dänemarks findet sich noch eine Immatrikulation von der Insel Läesöe.

Die Verteilung der Dänen unterstreicht den Sachverhalt, daß auch bei den ausländischen Studenten die geographische Nähe das entscheidende Kriterium für den Universitätsbesuch darstellte. Die dänischen Inseln und der dänische Teil des schwedischen Festlandes stellten mit 178 Immatrikulationen fast zwei Drittel aller dänischen Studenten in Greifswald. Diese Gebiete lagen trotz vergleichbarer Größe mit den jütländischen Diözesen einfach näher an der pommerschen Küste. 
Wenn man also nach Regionalität und Überregionalität der Greifswalder Studentenschaft fragt, muß man diesen Umstand berücksichtigen.

Jan Pinborg konnte in einer Studie über den Universitätsbesuch dänischer Studenten bereits 1981 feststellen, daß trotz der Neugründung in Kopenhagen der Zuzug dänischer Studenten nach Greifswald nicht nachgelassen hat. ${ }^{264}$ Aus der folgenden Grafik wird ersichtlich, daß man nur von einer kurzen Einbruchsphase 1479 sprechen kann, die bereits 1482 überwunden war. Diese ist allerdings deshalb auffällig, weil im zweiten Jahrzehnt nach der Greifswalder Gründung die Zahl der Dänen noch erheblich zugelegt hatte. Hohe Immatrikulationen aus Dänemark sind dann erst wieder ab 1482 bis etwa 1500 zu verzeichnen, unterbrochen durch eine dreijährige Pause von 1492 bis 1494. Vor allem bei den Dänen ist der Rückgang seit Beginn des 16. Jahrhunderts zu bemerken, die dann nur noch sehr vereinzelt in Greifswald erschienen. Es ist auffällig, daß die sechziger und siebziger Jahren, als Greifswald noch im Aufbau einer regionalen Basis begriffen war, maßgeblich von Dänen geprägt war. Dies ist damit zu erklären, daß im Norden Europas noch keine Universitäten existierten. Daher entfaltete sich der Greifswalder Einzugsbereich automatisch direkt in diese nördlichen Regionen hinein. Man könnte zusammenfassend formulieren, daß die Greifswalder Hohe Schule eine zeitlich versetzte Entwicklung gegenüber den Universitäten vor allem der "Zweiten Gründungswelle" nahm, die alle in zentralen und südlichen Gebieten des Reiches lagen. Ihr Weg zur Regionalisierung und ihre Entwicklung hin zur reinen "Landesuniversität" trat erst zu Beginn des 16. Jahrhunderts ein, während ein solcher Prozeß im Süden des Reiches schon in der Mitte des 15. Jahrhundert begann. 265

Bei Betrachtung der östlichen Universitäten könnte man zu einem ähnlichen Ergebnis kommen. Leipzig als östlicher Ausläufer der Universitätslandschaft blieb noch im 15. Jahrhundert als Universität eine Domäne für das östliche Europa. ${ }^{266}$ Auch Frankfurt konnte diese Position sogar noch zu Beginn des 16. Jahrhundert weiterführen, zum Teil wohl übernehmen. ${ }^{267}$ Der Umstand, daß Greifswald noch bis ins 16. Jahrhundert als Universität für den Norden Europas wirkte, wird ebenfalls durch die Immatrikulationen aus den übrigen Ostseeanrainern unterstrichen, wie in den folgenden Kapiteln gezeigt werden soll. 


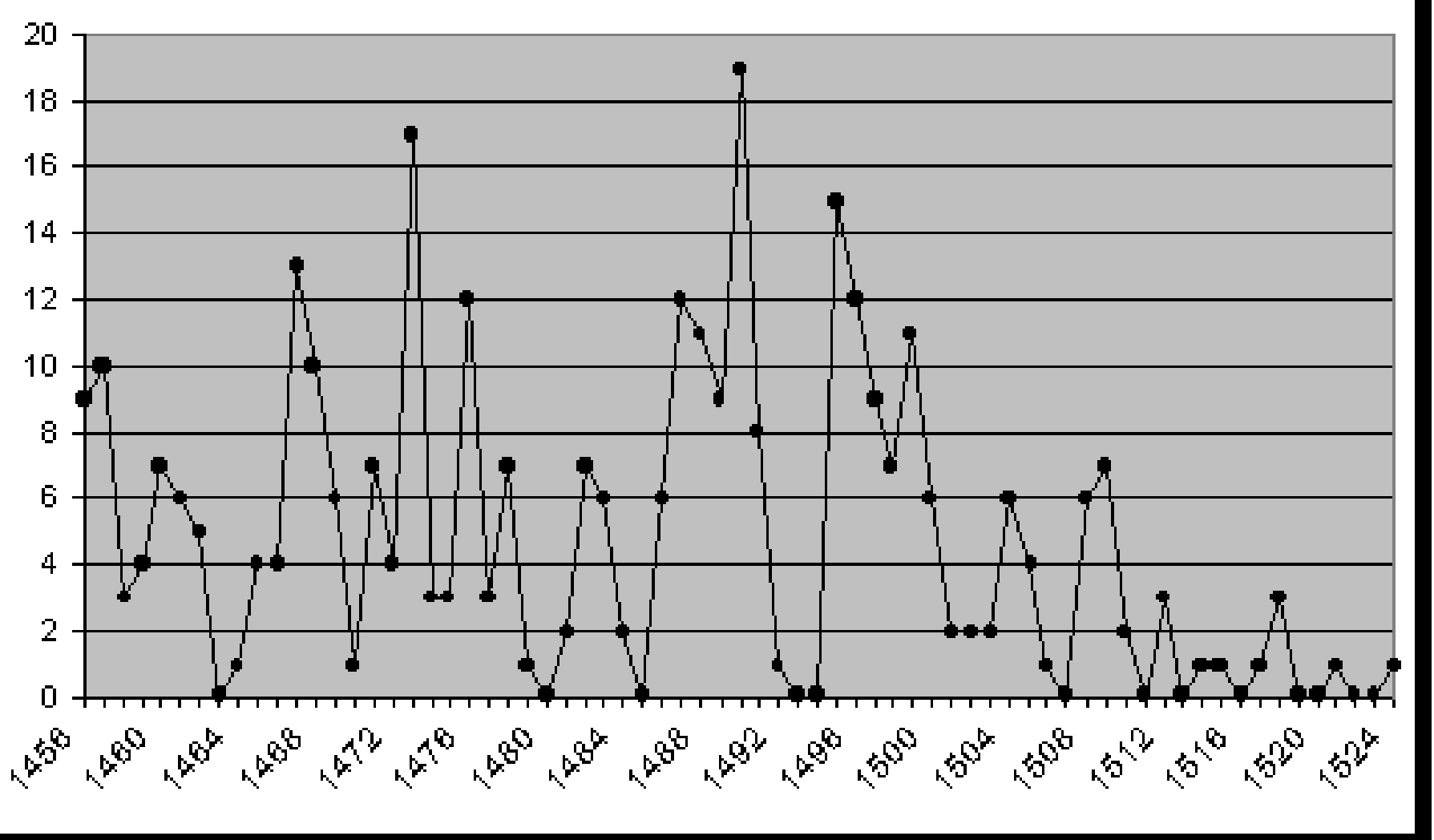

Abbildung 26: Dänische Studenten in Greifswald

\subsubsection{Die Herkunftsorte in Schweden, Norwegen und Finnland}

Auch aus Schweden ist noch eine beachtliche Zahl von Studenten in Greifswald erschienen. Mit 91 Einschreibungen stellen sie 15 Prozent der ausländischen Studenten. Dazu sind außerdem noch fünf aus Norwegen und sogar elf aus dem weit entfernten Finnland zu rechnen, so daß man insgesamt eine Zahl von 433 Skandinaviern erhält, die damit im gesamten Zeitraum etwa 13 Prozent der gesamten Studentenschaft ausmachen. 50 Personen gaben nur Landbezeichnungen an, und zwar neun unterschiedliche, während sich 41 Inskribierte auf 16 Ortschaften verteilen.

10 Studenten machten nur die Landesangabe Schweden, die keine genauere Zuordnung zuläßt, von 31 sind Bistumsangaben bekannt. Linköping und Skara stehen dabei mit zehn und sechs Studenten an der Spitze, zu denen noch vier bzw. sechs Ortsansässige gerechnet werden müssen. Zehn Studenten kamen aus der Diözese Västeras, zwei davon aus der Stadt selber. Die Erzdiözese Uppsala wurde genau wie Vexiö fünf mal verzeichnet, jedoch beinhalten diese Immatrikulationen noch zwei Stadtbewohner. Die Inseln Gotland und Bornholm sind mit sieben und zwei Studenten vertreten, wobei drei Gotländer den Ort Visby angaben. Värmland, nördlich des Vänersees, kam drei mal vor, womit bereits alle Gebietsangaben genannt sind. Unter den übrigen Ortschaften wurde Stockholm mit acht Studenten verzeichnet, Kalmar, das sich gegenüber der Insel Ölland befindet, mit sechs, die übrigen Orte Eskilstuna, Kakelunde, Kara, Kerne, Nyköping, Steghelin, Strängnäs, Südköping, Vadstena, die alle zwischen Uppsala und Linköping zu finden sind, mit je einem Immatrikulierten. Die fünf Norweger kamen aus Hammer (2), Oslo (2) und einer sogar aus dem nördlichen Trondheim. Die 11 Studenten aus Finnland kamen alle aus der Diözese Abo, wobei zwei von ihnen aus dem Ort 
selber stammen. An der Immatrikulationsentwicklung dieser Studenten läßt sich ablesen, daß die Gründung der schwedischen Universität in Uppsala 1477 kurzfristig zu einem Ausbleiben schwedischer Studenten führte. Schon ab 1484 sind sie allerdings wieder häufiger vertreten, doch kann man auch hier die hohen Zahlen als Folge der zugespitzten Situation in Rostock werten. Auch der Anstieg zur Jahrhundertwende muß als künstlicher Einschnitt bewertet werden, der mit den beiden Humanisten aus Italien zusammenhängt. Auffällig ist nämlich nach deren Weggang der rasante Abstieg der Immatrikulationen aus Schweden, die ab diesem Zeitpunkt so gut wie keine Bedeutung mehr haben, wie aus der folgenden Grafik ersichtlich wird, die auch Norweger und Finnen beinhaltet.

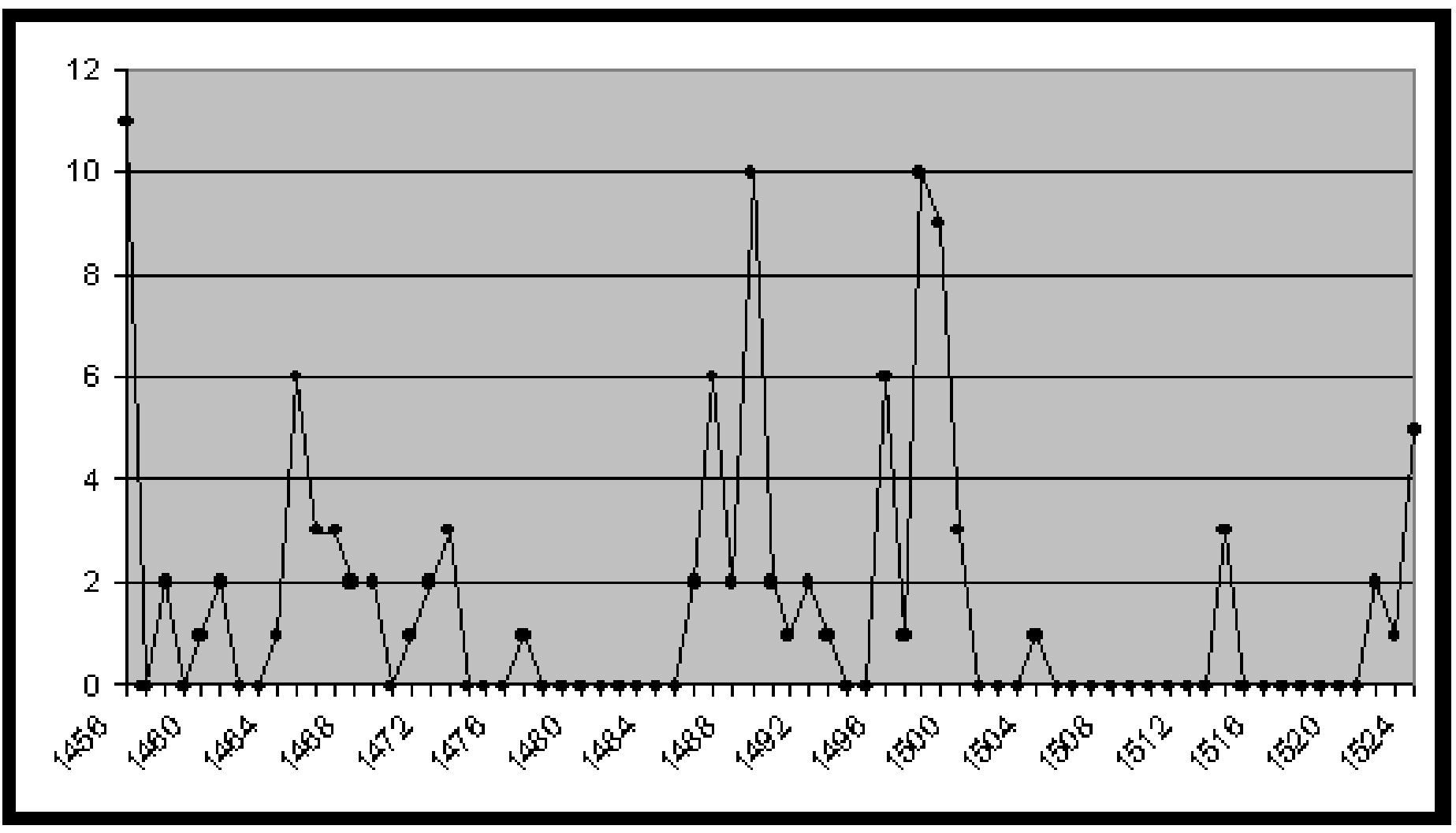

Abbildung 27: Studenten aus Schweden, Norwegen und Finnland

\subsubsection{Die Herkunftsorte der Gebiete des Deutschen Ordens}

Etwas problematisch ist die Zuordnung der Studenten aus den Ordensgebieten, die hier aufgrund der Sonderstellung zum Ausland gezählt wurden. Das Deutschordensland reichte zu Beginn des 15. Jahrhunderts von Reval im Norden bis nach Danzig, fast an der Grenze Pommerns. Bei den Studenten aus diesen Gebieten handelte es sich wohl ausschließlich um deutschsprachige Personen, die über Handelswege der Hanse zum Universitätsort gelangten. ${ }^{268}$ Die südlichen Ordensgebiete um Danzig stellten dabei den wirtschaftlich am weitesten entwickelten Teil dar. ${ }^{269}$ Ihre personelle Beteiligung am europäischen Universitätsstudium korrelierte mit dieser Position, denn im gesamten Mittelalter stellte dieses Gebiet den höchsten Studentenanteil des Deutschordensgebiets. ${ }^{270} 1466$ wurden diese strukturstärksten Gebiete im Zweiten Thorner Frieden an Polen abgetreten, und gingen 
fortan im Königlichen Preußen auf. Die Studenten dieser Gebiete, die sich bis dahin vornehmlich an deutsche Universitäten, vor allem Leipzig, gewandt hatten, wählten nun ihre neue "zuständige" Landesuniversität, nämlich Krakau, die schon bald Leipzig von der ersten Position verdrängte. ${ }^{271}$ Gleichzeitig erlebten die verbliebenen Ordensgebiete eine Steigerung der Studentenzahlen. ${ }^{272}$ Obwohl die Greifswalder Zahlen zu niedrig sind, um weitreichende Schlüsse zu ziehen, läßt sich auch an den dortigen Immatrikulationen diese Verschiebung erkennen. Nicht etwa Preußen mit seinen 64 Studenten stellte den höchsten Anteil des früheren Deutschordensgebiets, sondern eindeutig die livländischen Regionen mit zusammen 83 Inskribierten, und dies trotz des immer noch hohen Andrangs aus Danzig (35) und der großen Entfernung zur pommerschen Universität. Die Studenten Danzigs konzentrierten sich außerdem fast ausschließlich auf die Eröffnungsphase 1456 bis 1462 und die Zeit der italienischen Humanisten 1498 bis 1504 mit je 11 Immatrikulierten, so daß man diese Abschnitte eher als Ausnahmeerscheinung werten kann. Zwischen den beiden Hochphasen waren 11 Immatrikulationen zu verzeichnen, während die nachfolgenden Jahre nur noch zwei Studenten aus Danzig brachten, so daß man den Bedeutungsverlust der Reichsuniversitäten für dieses Gebiet, nach dem Zweiten Thorner Frieden, auch an diesem Beispiel nachverfolgen kann. Aus den abgetretenen Gebieten des Deutschordenslandes ließen sich in Greifswald außerdem noch vier Studenten mit der Angabe Ermland sowie einer aus Bankau, Elbing, Gutstadt, Neuenburg und Schwetz wiederfinden, womit man insgesamt sogar nur 44 Studenten dieser Gebiete erhält. Die Verteilung folgt bei all diesen Studenten dem Beispiel Danzigs. Von den im Ordenland verbliebenen preußischen Orten ist an erster Stelle Königsberg zu nennen, das immerhin mit 12 Studenten verzeichnet ist, ferner wurde das Samland von drei Studenten als Herkunftsregion erwähnt, während Heiligenbeil, Nelberg und Osterode je einmal vorkommen. Zwei mal fand sich die ungenaue Angabe "de Prussia" in den Matrikeln. Aus den livländischen Gebieten des Deutschen Ordens findet sich die Mehrzahl der Studenten mit der Angabe Riga wieder, wobei 21 aus der Diözese stammen, und 15 die Stadt selber meinten. Zwischen 1498 und 1511 allein kamen 20 Studenten, während sie sonst recht vereinzelt auftauchten. Reval nannten 17 Studenten, unter denen sich acht Diözesanangehörige befinden, Dorpat folgte mit 15 Immatrikulierten, von denen wiederum sechs als solche zu beurteilen sind. Die Angabe Livland machten 10 Studenten, während sich fünf Personen auf drei livländische Orte verteilten, nämlich Wenden, Wolmar und Kokenhausen. Wenn man die Immatrikulationsentwicklung des gesamten Deutschordenslandes betrachtet, einschließlich der 1466 abgetrennten Gebiete, so fällt die grundsätzlich negative Tendenz auf, die immer wieder nur durch kurze Ausbrüche unterbrochen wird. Die Gründungsjahre ab 1456 und die Humanistenjahre ab 1498 sind hier besonders hervorzuheben. Die Krise in Rostock führte dagegen bei diesen Studenten nur zu einem geringen Anstieg der Immatrikulationen. Bis immerhin 1511 sind sie noch häufiger in Greifswald vertreten, erst jetzt beginnt auch hier der Rückgang. 


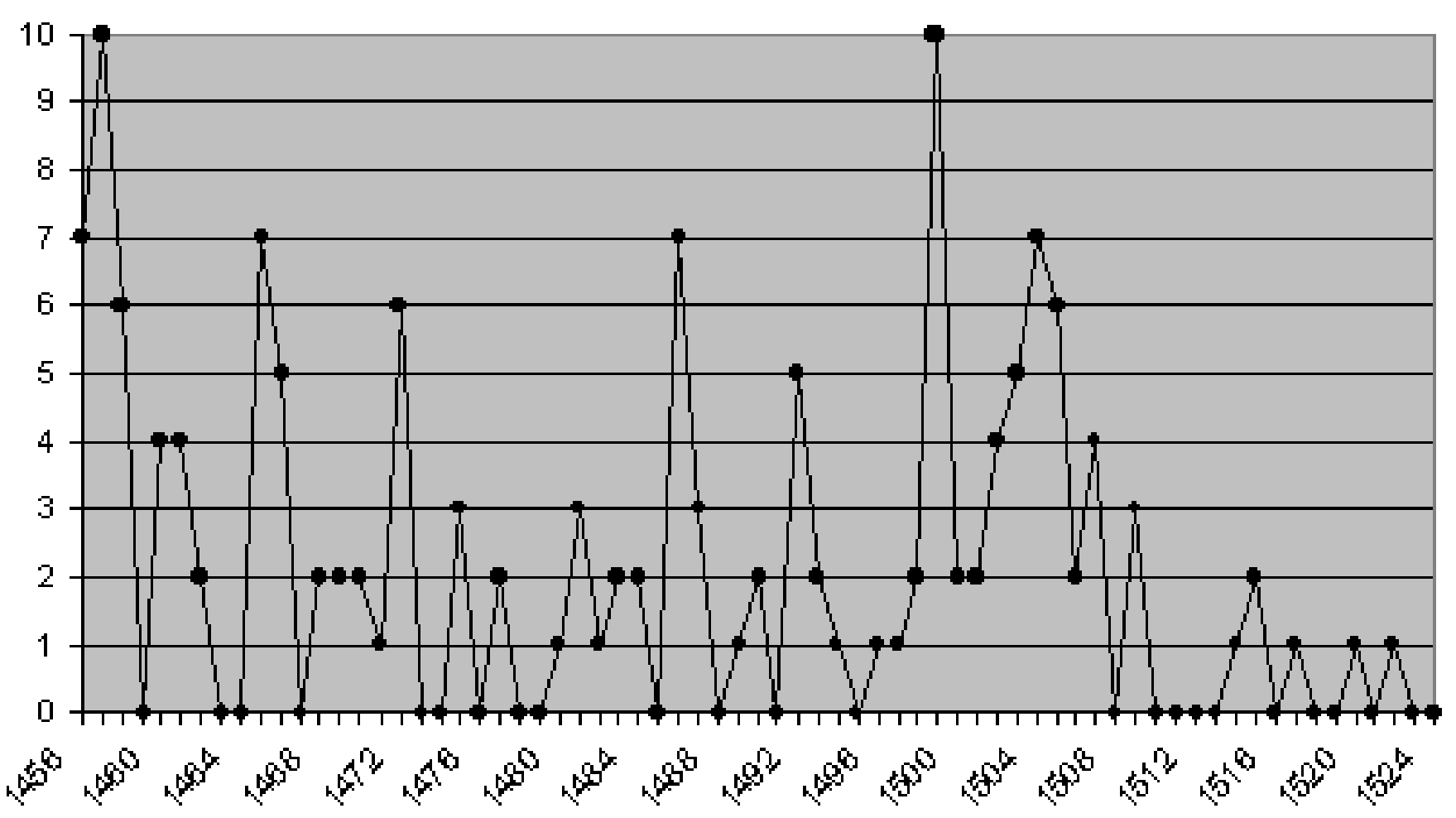

Abbildung 28: Studenten aus den Gebieten des Deutschen Orden

\subsubsection{Die Herkunftsorte in den übrigen ausländischen Gebieten}

36 Studenten sind noch aus anderen europäischen Ländern zu verzeichnen, von denen die Mehrheit von 27 Studenten aus Polen stammen. Unter ihnen steht die Diözese Leslau mit acht Studenten an erster Stelle, die freilich auch aus den preußischen Teilen der Diözese stammen könnten. Posen wurde sechs mal erwähnt, während Gnesen vier mal auftaucht. Ein Student nannte die Diözese, ein anderer die Stadt Krakau, Premysl war Heimat nur eines Studenten, genau wie Grätz, Krone und Fischhausen. Vom Herzogtum Litauen fand außerdem ein Student aus Wilna den Weg nach Greifswald.

Auch die polnischen Studenten in Greifswald werden deutscher Sprache und Herkunft gewesen sein, doch sieht man an der niedrigen Beteiligung, daß die eigene Landesuniversität Krakau, der bevorzugte Studienort gewesen sein wird. Dieser Umstand wird auch an den Leipziger Zahlen deutlich, denn, wie Keck bemerkt, klafft zwischen Schlesien und Preußen "eine bedenkliche Lücke" ${ }^{273}$, die eben auch ihre einfache Erklärung in der eigenen Landesuniversität findet. Seine Behauptung, der "hohe Anteil der polnischen Nation ${ }^{274}$ an der Leipziger Schülerschaft" veranschauliche "die Lebenskraft der deutschen Gebiete" 275 , ist wohl etwas überzeichnet und kann anhand der späteren Entwicklung entkräftet werden, denn gerade für die königlich-preußischen Studenten war es direkt nach dem Thorner Frieden eine Selbstverständlichkeit, die polnische Universität als "zuständige" Landesuniversität zu bevorzugen. 276 
Aus Italien finden sich insgesamt sieben Immatrikulationen, in denen die beiden Humanisten Petrus und Vincentius aus Ravenna enthalten sind. In den folgenden Jahren sind noch drei weitere Italiener zu vermelden, einer aus Padua, einer aus Modena sowie einer aus Verona, die sicherlich mit diesen beiden in Beziehung standen. Gallipoli und Monopoli, ganz im Süden des Landes, verzeichnete je einen Student, der eine kam im Jahre 1464, der andere 1517. Sogar aus Griechenland sind zwei Studenten verzeichnet: die Insel Samos wurde zwei mal erwähnt. Von den Britischen Inseln kam außerdem ein Student aus dem schottischen Aberdeen.

\subsubsection{Resümee: Die "Universität für den Norden Europas"}

Es hat sich gezeigt, daß Greifswalds Einzugsbereich bis zum Beginn des 16. Jahrhundert maßgeblich von Studenten geprägt war, deren Herkunft als überregional einzustufen ist. Eine Phase, in der die Greifswalder Universität vor allem regionale Ausstrahlung hatte, ist eigentlich erst zum Ende des Betrachtungszeitraums zu konstatieren. Damit widersprechen die Ergebnisse den Beobachtungen, daß eine Universität nach ihrer Gründung zuerst im Kernbereich ihrer Region Fuß fassen konnte, um nach einer längeren Phase der "regionalen Existenzsicherung" auch auf entferntere Gebiete auszugreifen. Dabei muß man jedoch berücksichtigen, daß der Norden Europas erst am Ende der siebziger Jahre des 15. Jahrhunderts Universitäten erhielt. Das natürliche und nächstgelegene Einzugsgebiet für die nördlichen Universitäten Rostock und Greifswald lag daher bis zu diesem Zeitpunkt im gesamten Ostseebereich. Die Greifswalder Universität entwickelte sich dort als wäre es ihr direktes regionales Umfeld. Innerhalb der Gesamtentwicklung der Universitäten nimmt sie insofern eine Sonderposition ein. Überregionalität war ein Zeichen von fehlender Konkurrenz. Durch die größere Universitätsdichte in den südlichen und westlichen Regionen des Reiches läßt sich eine unterschiedliche Entwicklung zwischen nördlicher und südlicher Universitätslandschaft konstatieren. Die eine konnte wesentlich länger ein größeres Potential überregionaler Studenten behaupten und folgte damit zeitversetzt zur südlichen Entwicklung. In Greifswald war sie erst seit Beginn des 16. Jahrhundert zu beobachten. Dieser Befund soll nun anhand der Gesamtverschiebungen im Einzugsbereichs der Universität Greifswald überprüft werden. Es wird wieder das gewohnte Raster der Siebenjahreseinteilung gewählt, um die Tendenzen auszudrücken. 


\subsection{Veränderungen des Einzugsbereichs von 1456 bis 1524}

\subsection{1. regionale Existenzsicherung und Ostseeuniversität}

\subsubsection{Die ungewöhnliche Eröffnungsphase von 1456 bis 1462}

Wie bei allen mittelalterlichen Universitäten stellte auch in Greifswald die Gründungsphase eine Ausnahmeerscheinung dar, in der nicht nur höhere Immatrikulationszahlen erreicht werden, sondern auch eine fast internationale Ausstrahlung des Studiums zu erkennen ist. Sowohl die Immatrikulationen aus dem Ausland als auch die aus ferneren Reichsgebieten liegen mit fast zwei bis vier Prozentpunkten über den durchschnittlichen Werten. Man kann davon ausgehen, daß der gerade in diesem Abschnitt besonders hohe Anteil nicht verwertbarer Angaben (18\%) dieses Bild eher noch verstärken würde. Diese Gebiete profitierten dabei offensichtlich weniger von den Pommern, die trotzdem über die Hälfte der Studenten stellten, sondern in erster Linie von den Nachbargebieten Mecklenburg und Brandenburg, deren Anteil zu dieser Zeit zusammen fast fünf Prozent (je 2,5\%) unter dem Normalwert liegt. Die hohen Werte der ausländischen Gebiete in dieser Anfangsphase sind vor allem dem Deutschordensland zuzuschreiben. Sowohl die preußischen als auch die livländischen Regionen sind gleich hoch beteiligt, woran sichtbar wird, daß wir uns noch vor dem Zweiten Thorner Frieden befinden, der das Fallen des preußischen Anteils bewirken wird. Außerdem sind die Schweden etwas häufiger beteiligt als in den anderen Abschnitten. Die Dänen stellen zwar wie immer das Hauptkontingent der ausländischen Besucher, doch liegen die Zahlen noch etwas unter den später erreichten Werten, vor allem denen der nächsten beiden Abschnitte. Bei den ferneren Reichsgebieten sind höhere Werte vor allem in den süd-, mittel- und norddeutschen Territorien zu finden, wovon die nieder- aber auch die obersächsischen Gebiete hervorzuheben sind. Die traditionellen Handelsgebiete der Hanse in den Niederlanden und Nordrhein-Westfalen sind dagegen noch äußerst selten zu finden. Die Etablierung Greifswalds als Hanseuniversität scheint erst in späteren Jahren geschehen zu sein, während in der Gründungszeit noch ein weiter gefächertes Reichspublikum auszumachen ist. Wie auch Roderich Schmidt feststellen konnte, kam der überwiegende Teil der Pommern zu dieser Zeit aus der näheren Umgebung, nämlich dem Herzogtum Wolgast, in dem sich die beiden Hochburgen Greifswald und Stralsund befanden, während das Herzogtum Stolp im hinteren Pommern bereits darauf folgt, und nicht etwa das nähere Stettiner Herzogtum. ${ }^{277}$ Dies hing einerseits sicherlich mit der Küstenlage des Stolper Landes zusammen, das eben eine Anreise per Schiff ermöglichte, während man aus dem Stettiner Land nur über den Umweg des Oderhaffs einen Schiffsweg nach Greifswald fand. Hier bot sich den Studenten sicherlich eher ein Fußmarsch an, der freilich mehr Zeit kostete und weitaus beschwerlicher war. Andererseits mag die anfängliche Zurückhaltung der Stettiner auch mit den noch getrennten Herrschaftgebieten zusammenhängen. Erst 1464, mit der Beilegung des Stettiner Erbfolgestreits, scheinen diese Gebiete eine stärkere Beteiligung zu erfahren.

\subsubsection{Die Etablierung der Ostseeuniversität von 1463 bis 1469}

In den folgenden Zeitabschnitt fällt die Immatrikulationslücke des Jahres 1463, die allerdings mitgerechnet wird, da es vielleicht zu nachträglichen Immatrikulationen in späteren Jahren kam. Wir 
befinden uns in der Tiefphase Greifswalder Immatrikulationswerte. Von 553 Studenten im vorigen Abschnitt, haben sich die Zahlen halbiert, auf 273 Personen. Auch in der Zusammensetzung der neuen Studentenschaft kommt es zu starken Verschiebungen. Der relativ hohe Anteil ober- und niedersächsischer Studenten im ersten Abschnitt reduziert sich im zweiten praktisch auf null, so daß der Anteil der Reichsstudenten aus ferneren Gebieten um etwa sieben Prozentpunkte sinkt. Die brandenburgischen und mecklenburgischen Gebiete sind es, die jetzt ihren Rückstand ein wenig aufholen können auf etwa 13 Prozent, wobei die mecklenburger Zahlen noch über denen der Brandenburger liegen, doch bleiben auch sie weiterhin unter dem Durchschnitt. Fast 30 Prozent der Studenten kamen dagegen aus dem Ausland, das damit neben Pommern (45\%) in den Vordergrund tritt. Es ist eine Hochphase der Dänen, die zwar genau so viele Studenten wie im vorigen Abschnitt schickten, doch wird durch die allgemein niedrige Frequenzrate ein sechsprozentiger Zuwachs erreicht, der sie damit zu einer beherrschenden Gruppe in Greifswald macht. Man kann sich vorstellen, daß sich diese Verschiebung auch auf das Bild der Universität auswirkte, die nun einen fast skandinavischen Charakter bekam, vor allem wenn man den gleichzeitigen Zuwachs der Schweden mitberücksichtigt. Auch die livländischen Ordensgebiete können ihren Anteil noch festigen, während sich die preußischen Zahlen bereits im Abstieg befinden. In diese Zeit fällt bereits der Abtritt des Königlichen Preußen an Polen, dessen Studenten ab jetzt den Reichsuniversitäten immer mehr absagten.

\subsubsection{Die Konzentration auf Dänemark von 1470 bis 1476}

Fast das gleiche Bild findet sich im folgenden Zeitabschnitt. Die Gesamtfrequenz erholt sich nur mühsam, mit insgesamt 289 Immatrikulationen. Reich und Nachbarn liegen unverändert etwa bei 13 Prozent. Die Pommern erreichen mit 46 Prozent weiterhin Werte leicht unter dem Durchschnitt, doch bleibt auch der Ausländeranteil sehr hoch bei 28 Prozent. Während die Zahlen der Schweden und Livländer sinken, legen die Dänen nochmals zu, und stellen damit über zwei Drittel aller Ausländer. Bei den Reichsterritorien werden die traditionellen Hansegebiete, nämlich das nördliche Niedersachsen, Nordrhein-Westfalen und die Niederlande immer stärker, während die südlichen Territorien kaum mehr vertreten sind. Bei den Nachbarn werden die Mecklenburger nun von den Brandenburgern leicht überrundet, was allerdings angesichts der Größe des brandenburgischen Territoriums nur als Scheinerfolg zu werten ist. Insgesamt scheint nun die Phase der "regionalen Existenzsicherung" allmählich in eine Phase des Ausgreifens auf entferntere Reichsgebiete überzugehen.

\subsubsection{Die erste regionale Ausdehnung von 1477 bis 1483}

Die Immatrikulationswerte erleben in den folgenden Jahren eine etwas deutlichere Steigerung auf 333 Studenten. In diesen Jahren kommt es zu erheblichen Verschiebungen in der Studentenschaft. Die Pommern legen in diesen Jahren kräftig zu, und liegen wieder über 50 Prozent, genauso wie die Nachbarn, die sich fast verdoppeln können und nun über 20 Prozent der gesamten Studentenschaft ausmachen, wobei die Zugewinne fast ausschließlich den Mecklenburgern zuzuschreiben sind, die 
sich mehr als verdreifachen. Seit 1472 kam es in Ingolstadt, Mainz, Trier und Tübingen zu erneuten Universitätsgründungen, denen man kaum irgendeine Bedeutung für Greifswald zumessen kann, denn die südlichen Reichsteile stellten ohnehin eine völlig unbedeutende Zahl der Greifswalder Besucherschaft. Vielleicht wäre ohne die Gründungen auch für Brandenburg ein stärkeres Wachstum in dieser Zeit zu verbuchen gewesen, doch bleiben solche Vermutungen reine Spekulation.

Die Zahlen der Ausländer erleben den größten Einbruch. Sie halbieren sich trotz steigender Gesamtfrequenz. Man sieht hieran die Auswirkung der Universitätsgründungen in Uppsala 1477 und Kopenhagen 1479, die genau in diese Zeitspanne fallen. Vor allem die Zahlen der Dänen sind betroffen, denn die Schweden waren schon im vorigen Abschnitt nur gering beteiligt. Wenn Pinborg behauptet: "So the foundation of the new university [Kopenhagen] augmented the number of Danes

acquainted with higher education ..., but it did not decrease the number of students going abroad"278, so kann man dies für Greifswald nur auf weite Sicht gelten lassen, denn der Rückgang der Dänen, und auch der Schweden, hängt offensichtlich mit diesen Gründungen zusammen, auch wenn sich die Zahlen später wieder erholen können. ${ }^{279}$ Auch die Zahl der Balten sinkt noch tiefer in diesen Jahren, während die der Preußen konstant bleibt.

Die ungewöhnlichste Verschiebung in diesen Jahren ist bei den entfernteren Reichsgebieten zu verzeichnen. Obwohl die bisher stärkste Gruppe der sächsischen Gebiete fast überhaupt keine Studenten mehr hervorbrachte, was vielleicht am ehesten mit den neuen Reichuniversitäten in Verbindung gebracht werden könnte, legt der Gesamtanteil des Reichs um fast vier Prozentpunkte zu. Dies hängt mit dem explosionsartigen Anstieg der niederländischen und niederrheinischwestfälischen Studentenzahlen zusammen, die vorher immer etwa auf gleicher Höhe mit den Sachsen gestanden hatten. Die Niederländer stehen dabei an der Spitze, deren Studentenzahl sich insgesamt verfünfachen konnte, während Nordrhein-Westfalen sich immerhin verdoppelte. Diese wichtigen Handelsgebiete der Hanse werden auch in der folgenden Zeit zu den wichtigsten Herkunftsgebieten Greifswalder Studenten zählen, so daß man sich eigentlich erst zu diesem Zeitpunkt der hansischen Bedeutung der Universität bewußt wird. Wie man an solchen Zahlen sieht, stellten die Handelswege der Stadt Greifswald nicht nur wirtschaftliche Verbindungen zu fernen Regionen her, sondern vermochten ebenso bildungs- und kulturgeschichtliche Verknüpfungen zu schaffen.

\subsubsection{Die Hochphase in Greifswald}

\subsubsection{Die Krise in Rostock - Überregionalisierung von 1484 bis 1490}

Der Anstieg der Greifswalder Studentenzahlen erreicht im nächsten Abschnitt seinen Höhepunkt. Sie können etwa um ein Fünftel auf 415 Immatrikulationen zulegen, doch ist dieser Anstieg vor allem mit einem äußeren Anlaß zu begründen. Der gesamte Zeitraum ist durch die Krise in der Nachbaruniversität Rostock, der sogenannten "Rostocker Domfehde", gekennzeichnet, von der die Greifswalder Zahlen eindeutig profitieren konnten. 280

In dieser Hochphase für Greifswald ist es nicht verwunderlich, daß der Anteil Pommerns an der 
Gesamtheit stark absinkt und nur noch 29 Prozent beträgt, doch fallen ihre Zahlen auch allgemein um fast ein Drittel. An diesem Rückgang läßt sich ablesen, daß die Pest des Jahres 1485 besonders in Pommern verheerend gewesen sein muß, denn erst im folgenden Abschnitt erholen sich die Werte wieder. Bei den Nachbarn, die 26 Prozent stellen, hätte man einen Anstieg der Mecklenburger erwarten können, doch blieben deren Zahlen konstant, die allerdings bereits im vorigen Abschnitt überdurchschnittlich hoch waren. Durch die hohe Gesamtfrequenz sinkt ihr Anteil insgesamt auf 10 Prozent. Gerade die Brandenburger sind es, die in diesem Abschnitt auf 16 Prozent zulegen, woran ihre Präferenz für die Rostocker Universität deutlich zu Tage tritt. Auch die übrigen Reichsgebiete können mächtig dazugewinnen. Mit 22 Prozent der Gesamtbesucherschaft erreichen sie ihre höchste Beteiligung überhaupt. Der niederrheinisch-westfälische Kreis steht zusammen mit dem niedersächsischen Kreis (je 7\%) hier an der Spitze, gefolgt wiederum von den Niederlanden, die zwar gegenüber dem vorigen Zeitraum zusammenschrumpfen, doch immer noch einen beachtlichen Anteil von fast vier Prozent stellen. An diesen Zahlen wird deutlich, daß Rostock, noch stärker als Greifswald, diese hansischen Reichsteile an sich ziehen konnte. Insbesondere Schleswig-Holstein und Nordrhein-Westfalen sind demnach sicherlich eher als Rostocker Domäne zu verstehen. An der weiterhin fast ausschließlichen Beteiligung norddeutscher Gebiete wird ersichtlich, daß sich trotz des erheblichen Alters- und Größenunterschieds von Rostock und Greifswald im Einzugsbereich der gleiche Hanse- und Ostseebereich wiederfindet, wenn dies für Rostock auch noch mehr in westlicher Richtung gilt.

Auch der ausländische Anteil an der Studentenschaft bekommt in diesem Zeitraum einen kräftigen Zugewinn, und zwar um neun Prozentpunkte auf einen Wert von 21 Prozent, womit das Tief des vorherigen Abschnitts, ausgelöst durch die skandinavischen Universitätsgründungen, wieder überwunden ist. Die Dänen können ihren Anteil verdoppeln, und kommen auf 13 Prozent der Gesamtbesucherschaft. Schweden und Ordensland folgen mit drei und vier Prozent, wobei die preußischen Teile kaum mehr verteten sind. Daran, daß auch in den folgenden Jahren die Zahl der Skandinavier und Livländer relativ hoch bleibt, kann man erkennen, daß die Rostocker Ereignisse nur beschränkte Wirkung auf deren Immatrikulationen in Greifswald hatten. Sie wirkten sich in erster Linie auf Schleswig-Holstein, Niedersachsen und Nordrhein-Westfalen aus, deren Zahlen, mit der Beilegung der Krise 1491, wieder zurückfallen in die alte Größenordnung.

\subsubsection{Die Normalisierungsphase von 1491 bis 1497}

Mit der Beendigung der Rostocker Krise fallen die Immatrikulationswerte in Greifswald wieder auf 308 Studenten, was eher als Normalisierung zu verstehen ist. Nach dem Tief, das die Pest für die Pommern verursachte, können sich ihre Zahlen nun wieder auf 47 Prozent erholen. Obwohl die Zahl der Ausländer im Ganzen sinkt, steigt ihr Anteil durch die niedrigere Frequenzrate auf fast 24 Prozent. Dänemark stellt über die Hälfte der Ausländer (15\%), gefolgt von Schweden (3\%) und den livländischen Gebieten des Deutschen Ordens (3\%). Preußen ist fast gar nicht mehr vertreten. Nachbarn und übrige Reichsteile erleben einen deutlichen Rückgang, begründet eben mit der Situation in Rostock. Bei den Nachbarn verlieren beide Länder über die Hälfte ihrer vorigen Zahl und liegen damit wieder im Gesamtdurchschnitt (16\%), wobei die Zahlen Brandenburgs noch etwas über dem Durchschnitt (10\%) liegen, die Zahlen Mecklenburgs etwas darunter (6\%). 
Wie schon bemerkt, sind es der niederrheinisch-westfälische und der niedersächsische Kreis, deren Zahlen erheblich zurückgehen. Der Anteil der fernen Reichsteile liegt insgesamt nur noch bei 14 Prozent. Während die Niederländer ihre Zahlen weitgehend halten können und prozentual sogar noch einen Prozentpunkt zulegen können, verlieren die niederrheinischen und westfälischen Gebiete fast vier Fünftel ihrer Studentenzahl und kommen nur noch auf zwei Prozent. Schleswig-Holsteins und Niedersachsens Studentenzahl halbiert sich, und erreicht zusammen noch knapp vier Prozent.

\subsubsection{Die Humanisten - eine letzte Hochphase von 1498 bis 1504}

Wie gut sich die Zeiteinteilung den besonderen Phasen der Universitätsentwicklung anpaßt, zeigt auch der folgende Abschnitt, der sich fast vollkommen mit dem Wirken der beiden italienischen Humanisten Petrus und Vincentius aus Ravenna überschneidet (1498 bis 1503). Mit 395 Studenten erfahren die Immatrikulationen ihren höchsten Wert seit der Gründungsphase, abgesehen von den Jahren 1484 bis 1490. Ein Zuwachs ist bei allen Betrachtungsgebieten zu verzeichnen, doch sind es vor allem Ausländer und Nachbarn, die am deutlichsten zulegen. Die Pommern sinken im Gesamtdurchschnitt wieder auf 42 Prozent, während übrige Reichsgebiete prozentual auf gleicher Höhe bleiben. Schweden (6\%) und Preußen (5\%) sind für den Anstieg der Ausländer verantwortlich, während die Livländer sich in etwa halten, die Dänen bei fast gleicher Gesamtzahl allerdings auf neun Prozent absinken. Bei den Nachbarn legen beide Länder um je zwei Punkte zu. Im Reichsgebiet bleibt die Zahl der Niederländer und Niedersachsen auf etwa gleichem Niveau (je 4\%), die niederrheinisch-westfälischen Studenten können jedoch wieder etwas zulegen. Außerdem sind wieder etwas häufiger südliche Territorien wiederzufinden.

\subsubsection{Auf dem Weg zur Landesuniversität}

\subsubsection{Die Konkurrenz von Frankfurt und Wittenberg von 1505 bis 1511}

Die folgenden Jahre führen wieder zu einem Einbruch der Immatrikulationsfrequenz. Sicherlich wirkten sich in diesen Jahren die norddeutschen Neugründungen in Wittenberg (1502) und Franfurt/ Oder (1505) auf den Universitätsbesuch aus. Die Zahlen sinken um fast 40 Prozent auf 243 neue Studenten. Daß sich durch die neuen Universitäten der Einzugsradius verkleinert, sieht man an den Zahlen der Pommern, die zwar ebenfalls leicht absinken, jedoch insgesamt über 60 Prozent der Greifswalder Besucher stellen. Alle übrigen Gebiete verlieren nämlich über die Hälfte ihrer vorherigen Zahl. Nachbarn stellen nur noch 13 Prozent, die den kürzesten Weg zu den neuen Universitäten hatten. Vor allem Niederländer und Niedersachsen sind es bei den Reichsstudenten, die zum Absinken auf 11 Prozent führen. Bei den Ausländern halbiert sich die Zahl der Dänen, während die der Livländer noch in etwa gleich bleibt. Schweden ist überhaupt nicht mehr vertreten. 
304 Studenten sind es im folgenden Abschnitt, die nach Greifswald ziehen. Der leichte Anstieg ist sicherlich mit der Anwesenheit des berühmten Humanisten Johannes Hadus begründet, von dem die Matrikel 1514 schreibt: "Johannes Hadus, poeta, huc missus per illustrissimum principem Bugslaum, ut interpretaretur oratores et poetas" ${ }^{281}$ Pommern bleibt trotz dieses Gesamtanstiegs bei 60 Prozent, woran man die seit Wittenberg und Frankfurt einsetzende Regionalisierung des Einzugsbereichs erkennen kann. Ausländer sind kaum noch in Greifswald zu finden, was vor allem bei den Dänen sichtbar wird, die nochmals drei Viertel ihrer Zahl verlieren. Livländer und Schweden spielen überhaupt keine Rolle mehr, so daß man inzwischen nur noch von einer Landesuniversität in Pommern sprechen kann. Bei den Nachbarn sind es vor allem Mecklenburger, die von dem Humanisten angelockt werden (10\%), während bei den Reichsstudenten, die Zahl der Niederländer wieder strohfeuerartig in die Höhe schnellt (fast 10\%), die ab diesem Zeitpunkt dann aber endgültig ausbleiben.

\subsubsection{Greifswald während der Reformation 1519 bis 1524}

Die Immatrikulationsrate in den folgenden Jahren sinkt auf 204 Studenten, doch muß man berücksichtigen, daß die Zeitspanne nur sechs Jahre beträgt, und daher der Rückgang weniger drastisch zu bewerten ist. Außerdem ist bereits mit einem Einfluß der Reformationsereignisse auf den Universitätsbesuch zu rechnen. Die Tendenz der letzten Jahre wird in diesem Abschnitt eindeutig fortgesetzt, denn die Pommern machen jetzt sogar 70 Prozent der Gesamtbesucherschaft aus. Bei den Nachbarn sinken die Zahlen der Mecklenburger wieder deutlich auf 4,5 Prozent, so daß der Gesamtanteil der Nachbarn nur noch bei 10 Prozent liegt. Das Ausland spielt mit sechs Prozent fast überhaupt keine Rolle mehr. Während Dänen und Livländer fast gar nicht vertreten sind, kommt es wieder zu einem leichten Anstieg der Schweden. Im Reich sorgt das Ausbleiben weiterer Niederländer und Westfalen für die große Lücke, die zur Halbierung der Zahlen führt. Nur vereinzelte Studenten aus den sächsischen Kreisen, vor allem aus Hamburg, vermögen die 13 Prozent am Gesamtdurchschnitt aufrecht zu halten. Von Überregionalität geschweige denn Internationalität kann in diesen letzten Jahren, in denen die Konkurrenz von Frankfurt und Wittenberg deutlich vor Augen tritt, sicherlich keine Rede mehr sein. Greifswald zeigt sich nunmehr als reine Landesuniversität Pommerns.

\subsection{Resümee: "Ostseeuniversität", "hansische Universität" und "Landesuniversität"}

Roderich Schmidt formulierte 1974: "Was die beiden Ostsee-Universitäten [Rostock und Greifswald] im besonderen auszeichnete, war ihre Wirkung als geistige Zentren und Bildungsstätten für den gesamten Norden Europas." 282

Es galt in der vorliegenden Untersuchung anhand der Herkunftsangaben, die in der Greifswalder Matrikel von den einzelnen Studenten gemacht wurden, dieses häufig wiederkehrende Urteil für 
Greifswald zu überprüfen, gegebenenfalls zu relativieren, bzw. zu präzisieren. Mit 93 Prozent auswertbarer Daten war eine relative Exaktheit für die Ergebnisse zu erwarten. Es konnte bewiesen werden, daß dieses Urteil durchaus berechtigt ist, denn der Ostsee- und Hanseraum, und damit der Norden Europas, stellte tatsächlich einen großen Teil der Greifswalder Studentenschaft, doch haben wir es mit verschiedenen Entwicklungsphasen zu tun, die eine differenziertere Beurteilung nötig machen. Wenn man eine Phaseneinteilung für ausländische Studenten vornehmen will, so kann man, nach der etwas ungewöhnlichen Eröffnungsphase, eine zweite skandinavisch geprägte Phase konstatieren, die etwa bis zum Jahre 1477 andauert, in der sich die "Ostseeuniversität" etabliert, und die beendet wird, als dortige Universitätsgründungen zum kurzfristigen Ausbleiben weiterer Immatrikulationen aus Skandinavien führen. Bei den Studenten aus dem Reich ist eine niederländische Phase zu beobachten, die 1477 einsetzt, und bis etwa 1504 andauert, in der der Charakter Greifswalds als "hansische Universität" hervortritt, denn der niederländische Raum war wichtigstes Handelsgebiet der Hanse. Ob es sich bei diesen niederländischen Besuchern um frühhumanistische Kreise gehandelt hat, die auch in anderen mitteleuropäischen Universitäten dieser Zeit häufig auszumachen sind, läßt sich aufgrund der Forschungslage nicht eindeutig beantworten. Trotz dieses überregionalen Anteils an der Greifswalder Studentenschaft bleibt festzuhalten, daß die Universität vor allem Landesuniversität war und blieb, denn der große Anteil von knapp 50 Prozent der Studenten kam fast immer aus Pommern selbst. Auch hier lassen sich einzelne Phasen unterscheiden: während in der Zeit zwischen 1483 und 1504 die überregionale Ausstrahlung am größten war, stellte sich seit Beginn des 16. Jahrhunderts eine erhebliche Regionalisierung des Einzugsbereichs ein, der mit den Konkurrenzgründungen in Wittenberg und Frankfurt in direktem Zusammenhang steht. Pointiert formuliert, könnte man den Greifswalder Universitätsbesuch trotz Überschneidungen also in drei grobe Phasen unterteilen, in denen besondere Merkmale der studentischen Zusammensetzung sichtbar wurden: "Ostseeuniversität" war Greifswald vor allem bis 1477, "Universität für den hansischen Raum" bis 1502 und "Landesuniversität" bis 1524. Es hat sich demnach bestätigt, daß die Greifswalder Universität eine zeitlich versetzte Entwicklung zur südlichen Universitätslandschaft durchgemacht hat, was offensichtlich mit der späteren Verdichtung der nördlichen Universitätslandschaft zusammenhing. Erst seit Beginn des 16. Jahrhunderts setzte eine starke Regionalisierung ein, die im südlichen Universitätsraum zum Teil schon zu Beginn des 15. Jahrhunderts eingetreten war. Bei der Untersuchung eines so weitgefächerten Publikums kamen auch strukturelle Unterschiede zwischen einzelnen Regionen zum Vorschein, denen man eine gewisse Bedeutung auch für den Universitätsbesuch im späten Mittelalter zuerkennen kann. Obwohl sich die Greifswalder Studentenschaft zu knapp zwei Dritteln aus den drei nördlichen Territorien Pommern, Mecklenburg und Brandenburg rekrutierte, stellten diese drei Länder nur 42 Prozent aller genannten Ortschaften. Ein ähnliches Bild ergibt sich bei der Betrachtung der überregionalen Gebiete. Der nordwestliche Reichsraum um Niedersachsen, Nordrhein-Westfalen und den Niederlanden brachte es bei einer Anzahl von 384 Studenten bereits auf 91 Orte, also genau so viele wie Pommern. Der gesamte entfernte Reichsraum bei 460 Studenten sogar auf 130 Ortschaften. Im Vergleich dazu verteilten sich die 326 dänischen Studenten nur auf 33 unterschiedliche Orte, während das Deutschordensgebiet mit 148 Studenten sogar nur 15 Orte vorwies. Auch wenn man hier sicherlich zum Teil mit fehlender Sorgfalt der Rektoren zu rechnen hat, bestätigen diese Zahlen die strukturellen Unterschiede von denen das spätmittelalterliche Europa geprägt war. 


\section{Konkurrenz und Migration zwischen den Universitäten}

\subsection{Zielsetzung und Methode}

Die bisher erzielten Ergebnisse konnten lediglich Auskunft darüber geben, welche Orte und Landschaften für das Greifswalder Studium in der Vorreformationszeit von Bedeutung waren und wann sich Veränderungen und Verschiebungen dabei einstellten. Die Frage nach der Bedeutung der Universität für die einzelnen Orte selber mußte weitgehend unbeantwortet bleiben. Dazu wäre erforderlich, die Matrikel der anderen Universitäten dieser Zeit heranzuziehen, um sie nach Studenten aus den verschiedenen Ortschaften zu untersuchen. Damit hätte man nicht nur eine Vergleichsmöglichkeit für die Greifswalder Zahlen geschaffen, sondern könnte außerdem die Auswirkungen verschiedener Neugründungen, bzw. Migrationen einzelner Studentengruppen erfassen. Für die Frage der entstehenden "Landesuniversität" bietet eine solche Untersuchung die Möglichkeit, den Faktor "Konkurrenz" in einer sich verdichtenden Universitätslandschaft zu beleuchten. Wie verhielt sich z.B. das regionale Umfeld gegenüber den entfernteren Einzugsgebieten beim Besuch der anderen Hochschulen?

Eine solcher Ansatz kann freilich nur unter Begrenzung des Datenmaterials erfolgen, und muß auf solche Orte konzentriert werden, die für die Universität Greifswald von besonderer Wichtigkeit waren. Im folgenden Abschnitt soll daher der Universitätsbesuch aller Orte dargestellt werden, die in Greifswald zwischen 1456 und 1524 mehr als 20 Studenten verzeichneten. Es handelt sich dabei um 26 Orte, von denen knapp zwei Drittel in Pommern liegen und genausoviele dem Hansebund angehört haben (je 18). Durch das Übergewicht der pommerschen Orte kann man insbesondere der Frage nachgehen, wie sich die Phase der "regionalen Existenzsicherung" in Greifswald vollzog. Die Stichprobe scheint nähere Erkenntnisse zuzulassen, wie aus der Verteilung der Greifswalder Studenten hervorgeht: obwohl es sich nur um etwa sieben Prozent der vertretenen Orte handelt, stellten diese bereits 57 Prozent aller Studenten, die einem Herkunftsort zugeordnet werden konnten. Ihre Relevanz ist also deutlich zu erkennen. ${ }^{283}$

Wie schon erwähnt, bilden die überlieferten Matrikelbücher der einzelnen Universitäten die Quellengrundlage für eine solche Untersuchung. ${ }^{284}$ Leider stoßen wir hier auf Überlieferungsprobleme, denn nicht alle alten Universitätsmatrikel sind uns erhalten geblieben. Da die zu behandelnden Orte allesamt im Norden des Reiches liegen, sind die Matrikeln der nord- und mitteldeutschen Universitäten als Hauptquelle heranzuziehen. Hierzu zählten neben der Nachbaruniversität Rostock, vor allem Leipzig und Erfurt, deren Matrikel von Gründungszeit an auf uns gekommen und ediert sind. Das gleiche gilt für die Universitäten Wittenberg und Frankfurt, die zu Beginn des 16. Jahrhunderts hinzukamen. Die südlichen und westlichen Universitäten des Reiches Wien, Heidelberg, Köln, Löwen, Basel, Freiburg im Breisgau, Trier, Ingolstadt, Mainz und Tübingen waren dagegen nur von untergeordneter Bedeutung, so daß der Verlust des Mainzer und des Trierer Matrikelbuches für die vorliegende Arbeit keine besondere Relevanz hat. Schwerwiegender ist das Fehlen des Prager Matrikelbuches, denn bis zur Leipziger Gründung war Prag ein wichtiger 
Studienort der Pommern. ${ }^{285}$ Das erhaltene Liber Decanorum der Artisten, welches von 1367 bis 1585 geführt wurde, bietet wenigstens die Möglichkeit die promovierten Studenten nachzuweisen. Für den Zeitraum von 1372 bis 1418 ist außerdem die Fakultätsmatrikel der Juristen ediert. Sehr ungünstig sieht es bei ausländischen Matrikeln aus. Während die für die Untersuchung sicherlich interessanten Matrikeln von Kopenhagen und Uppsala fehlen, ist für Krakau ein Matrikelbuch seit 1400 überliefert. ${ }^{286}$ Für die Universitäten in Italien und Frankreich wurde zum einen der Index von Knod herangezogen, der die Bologneser Nationsmatrikel auf Studenten deutscher Herkunft hin untersucht hat, zum anderen die Arbeit von Budinszky über fremde Studenten, die im Mittelalter in Paris studierten. Auch die Pariser Prokuratorenverzeichnisse konnten einbezogen werden. Durch die Überlieferungsverluste gilt es an dieser Stelle zu betonen, daß die Zahlen und Ergebnisse dieser Untersuchung keinen Anspruch auf Vollständigkeit haben können. Vielmehr geben sie wider, was in den Quellen zu finden war. Außerdem gelten die quellenkritischen Einwände hinsichtlich des Greifswalder Materials selbstverständlich auch für die anderen Universitäten, deren Matrikelbücher niemals vollständige Aussagen zum Universitätsbesuch erlauben, sondern bestenfalls Annäherungen an die realen Zahlen bieten können. Zu Beachten bleibt außerdem, daß es sich bei den Zahlen nicht um Studenten, sondern um Studienaufenthalte handelt. Es ist ist also durchaus möglich, daß ein Student, der an zwei oder mehreren Universitäten studiert hat, auch mehrfach gezählt wird. ${ }^{287}$

Für die Universitäten, die bereits vor der Greifswalder Gründung existierten, wurden außerdem noch die Studierenden vor der eigentlichen Zeitspanne (1456-1524) berücksichtigt, um auf diese Weise eine etwaige studienfördernde Wirkung Greifswalds auf die einzelnen Orte darzustellen. ${ }^{288}$ Da die Forschung immer wieder auf die konkurrierende Stellung Rostocks hingewiesen hat, soll gerade diesem Punkt besondere Aufmerksamkeit geschenkt werden, um Wechselwirkungen und Einflüsse der beiden Universitäten aufzuhellen. Ferner sollen auch in dieser Untersuchung Veränderungen und Verschiebungen anhand von Grafiken und Tabellen veranschaulicht werden, da es nicht um statische Größen geht, sondern um Prozesse und Entwicklungen, die in besonderem Maße äußeren Einflüssen unterworfen waren. Die Orte werden in Einzelkapiteln für Pommern, Nachbarregionen (Mecklenburg und Brandenburg) und überregionale Gebiete (übriges Reich und Ausland) zusammengefaßt, und innerhalb der Kapitel in der Reihenfolge ihrer Wichtigkeit für Greifswald einzeln behandelt. Da die Mehrzahl der Orte in Pommern liegt, werden diese Orte nochmals räumlich unterteilt, und zwar in solche Orte, die in direkter Umgebung Greifswalds lagen, in zentralpommersche Orte sowie Orte Hinterpommerns. Am Ende soll dann ein Gesamtbild entworfen werden, indem die Ergebnisse eine zusammenfassende Analyse erfahren. 


\subsection{Pommersche Studenten auf anderen Universitäten}

\subsubsection{Die Orte der direkten Umgebung}

\subsubsection{Greifswalder auf anderen Universitäten}

Die Universitätsstadt Greifswald hatte mit 185 Studenten im behandelten Zeitraum den höchsten Anteil am eigenen Studium gegenüber allen anderen Ortschaften. Dies ist kaum verwunderlich, bot sich den Einwohnern ein Studium doch nicht nur wegen der Nähe zur Universität an, sondern auch wegen der um die Hälfte verminderten Studiengebühr. Gerade für Greifswald ist es interessant zu erfahren, wieviele Studenten an andere Universitäten gingen und welche Studienorte dabei gewählt wurden. Zuerst soll nun die Gesamtfrequenz der Greifswalder an allen Universitäten zwischen 1456 und 1524 ermittelt werden. Man konnte erwarten, daß es sich nur um eine Minderheit gehandelt hat, die einen anderen Studienort vorzog. Dieses Bild bestätigt sich beim Blick in die übrigen Universitätsmatrikel. Nur 27 Greifswalder ließen sich zwischen 1456 und 1524 in anderen Universitäten nachweisen. Davon studierten 19 Studenten im nahegelegenen Rostock. Drei ließen sich außerdem in Wittenberg, zwei in Leipzig sowie je einer in Erfurt, Frankfurt und Köln immatrikulieren. Greifswald war demnach in Rostock genauso häufig vertreten wie umgekehrt, während die übrigen Universitäten keine nennenswerte Bedeutung gehabt haben. ${ }^{289} 90$ Prozent der Studenten besuchten die eigene Universität, Rostock stellte neun Prozent, die übrigen Universitäten erreichten nur 3,8 Prozent. Die Vorangstellung der pommerschen Hohen Schule tritt daher deutlich zu Tage (vgl. folgende Grafik).

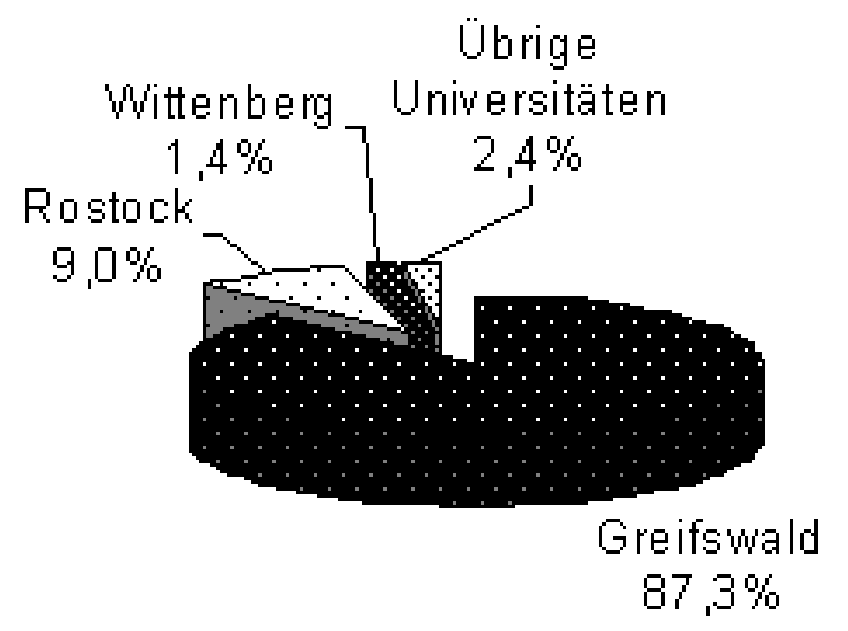

Abbildung 29: Studenten aus Greifswald 1456-1524 (Verteilung auf Universitäten)

Da die Zahlen so niedrig sind, lassen sich nur begrenzte Aussagen über Entwicklungen und 
Veränderungen machen. Besonders auffällig erscheint, daß in den für Greifswald frequentiell bedeutsamen Jahren keine fremden Universitäten aufgesucht wurden, während in Zeiten niedriger Immatrikulationsraten auch Greifswalder häufiger zu anderen Universitäten wechselten (vgl. folgende Grafik). In den Eröffnungsjahrgängen ließ sich daher nicht ein einziger Greifswalder an einer anderen Hohen Schule immatrikulieren, während bereits im folgenden Zeitabschnitt einige Greifswalder das nahegelegene Rostock bevorzugten. Erst als die Krise in der Rostocker Universität ausbrach und dort den Unterricht lahmlegte, verschwinden die Greifswalder von den Rostocker Immatrikulationslisten, doch kann der Rückgang auch mit einer pestbedingten Dezimierung der studienfähigen Einwohnerschaft Greifswalds zusammenhängen. 1485 berichtet die Greifswalder Matrikel von einer Pest, die in der Universitätsstadt gewütet haben soll. ${ }^{290}$ Eine solche Erklärung erscheint sinnvoll, da in dieser Zeit auch an der Universität Greifswald die Immatrikulationen aus der Universitätsstadt zurückgehen. Erst ab 1491 tauchen sie in Greifswald stärker, in Rostock vereinzelt wieder auf.

Als die beiden Humanisten aus Italien in Greifswald lehren, zieht es wiederum keine Greifswalder an andere Universitäten. Ab etwa 1512 kommt es zu einer leichten Steigerung des Immatrikulationsniveaus: nicht nur an der eigenen Universität und in Rostock, sondern auch in Leipzig und Köln sowie den neuen Universitäten Wittenberg und Frankfurt wurden sie, jedoch dort nur vereinzelt, eingeschrieben.

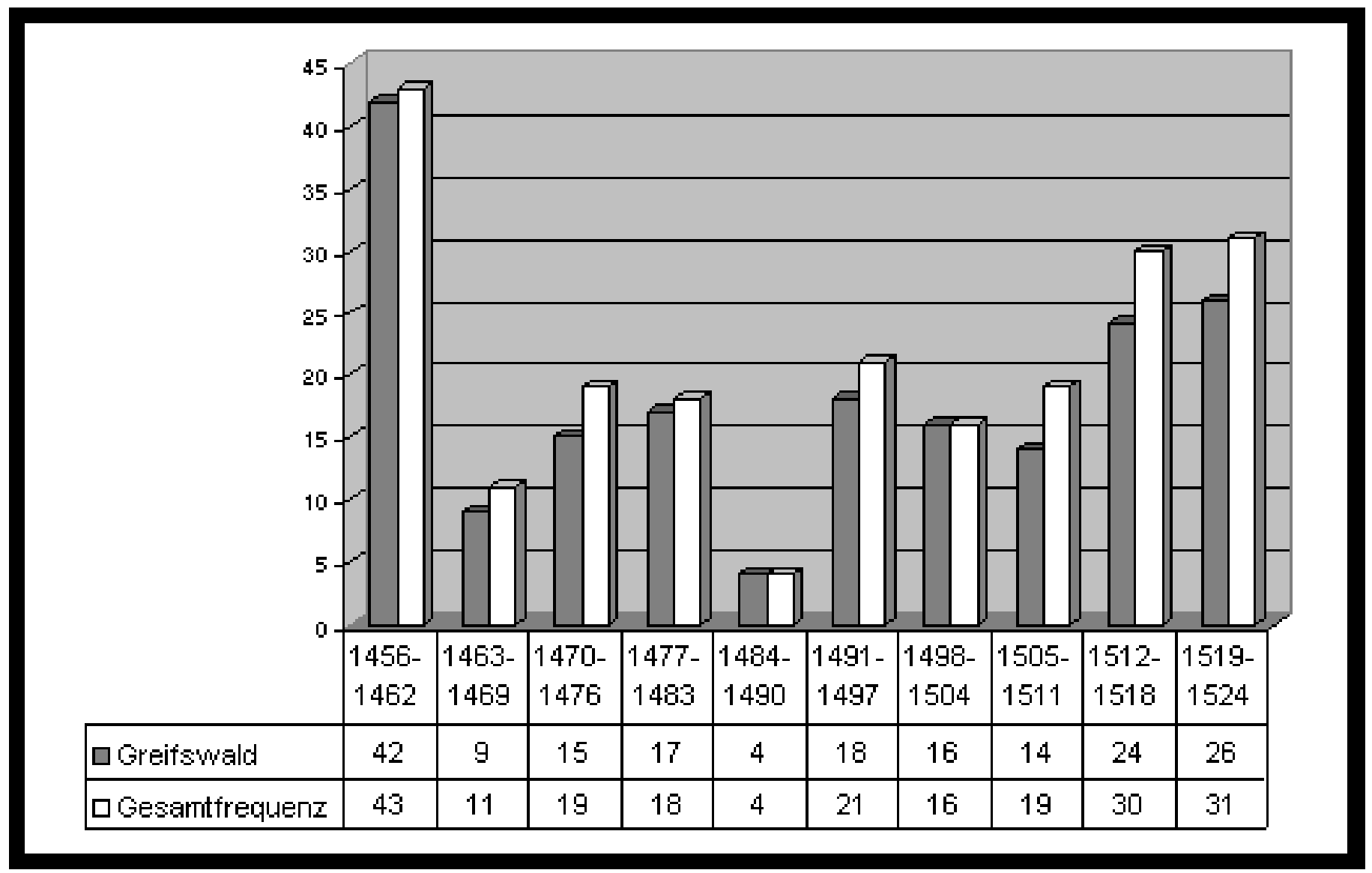

Abbildung 30: Studenten aus Greifswald (Greifswald - Gesamtfrequenz)

Auch darüber, ob und in welchem Ausmaß die Greifswalder Gründung eine studienfördernde Wirkung in der Universitätsstadt hervorrief, können die Matrikel der anderen Universitäten Auskunft 
geben. Es fällt auf, daß in den Jahren vor der Gründung selbst in Rostock nur sehr vereinzelt Studenten aus Greifswald erschienen sind. Von 1419 bis 1456 werden dort nur 15 Greifswalder immatrikuliert. In älteren Zeiten muß man allerdings berücksichtigen, daß die Herkunftsangaben noch weit weniger sorgfältig eingetragen wurden, und man mit etwas höheren Werten rechnen kann. So wurde etwa Heinrich Rubenow, der spätere Greifswalder Universitätsgründer, 1436 ohne Herkunftsangabe immatrikuliert, so daß er den 15 Studenten noch hinzuzuzählen ist. Ebenso ungenau werden die Angaben der Leipziger Matrikel sein. Keck errechnete zwischen 1409 und 1430 einen Anteil von fast 22 Prozent solcher Studenten, bei denen keine Herkunftsangabe gemacht worden

ist. $^{291}$ Bis 1456 sind dort trotzdem 13 Greifswalder zu finden, von denen nur vier vor der Rostocker Gründung erschienen sind, so daß Leipzig als wichtiger Studienort hervortritt. In Erfurt finden sich vier Greifswalder ${ }^{292}$, während Köln trotz Hansezugehörigkeit nur einen Studenten verzeichnen konnte, da die Stadt den Greifswaldern offensichtlich zu weit entfernt war. Das gleiche gilt für Wien, das nur 1396 einen Greifswalder verzeichnete. In die Wiener Juristenmatrikel ließ sich 1416 außerdem der Magister Andreas Burmeister inskribieren, den die Hauptmatrikel ohne Herkunftsangabe führt. Ebenso zog es 1326 zwei Greifswalder nach Bologna.

Bis zur Leipziger Universitätsgründung blieb die Universität Prag ein wichtiger Studienort für deutsche Studenten, vor allem auch für die Pommern ${ }^{293}$, doch verlor sie 1409 mit dem Auszug der deutschen Nation nach Leipzig offensichtlich ihre Bedeutung für Pommern und das Reichsgebiet. Im erhaltenen Dekanatsbuch der Artisten und in der Fakultätsmatrikel der Juristen lassen sich bis 1409 auch einige Greifswalder wiederfinden. Insgesamt handelt es sich dabei um 11 Personen, von denen sechs an der philosophischen Fakultät einen Abschluß gemacht haben, während fünf an der juristischen Fakultät studierten. ${ }^{294}$ In keiner anderen Universität ließen sich Greifswalder vorher nachweisen, was nicht bedeuten muß, daß sie überhaupt nicht vorkamen. Es ist möglich, daß die Rektoren gerade bei weiter entfernten Orten, deren Namen ihnen fremd erschienen, auf eine Angabe verzichteten, doch werden die Abweichungen nur geringfügig sein. Insgesamt handelte es sich um 49 Studenten, die nachweislich vor der Greifswalder Gründung ein Universitätsstudium begannen. Da es sich bei den 42 Immatrikulationen der ersten sieben Jahren, wie schon an anderer Stelle erwähnt wurde, nicht ausschließlich um Studenten gehandelt hat, zeigen erst die folgenden Jahre welche Bedeutung der neuen Bildungseinrichtung zukam. Erst zu Beginn des 16. Jahrhunderts erleben die Zahlen stärkere Zuwächse.

\subsubsection{Stralsund: Konkurrenz zwischen Rostock und Greifswald}

Mit 160 Studenten erreichte Stralsund eine vergleichbare Beteiligung am Greifswalder Studium wie die Universitätsstadt. Die räumliche Nähe, aber auch die wirtschaftlichen und sozialen Beziehungen und Verbindungen zur Universitätsstadt scheinen dafür verantwortlich zu sein. Da die Stadt nah an der Grenze Mecklenburgs liegt, kann man anhand ihrer Einschreibungen Aussagen über das Konkurrenzverhältnis zwischen Rostock und Greifswald machen. Bis zum 16. Jahrhundert blieb als Ortsname die Bezeichnung "Sund" gebräuchlich, die fast ausschließlich in allen Matrikeln auftaucht.

138 Studenten gaben zwischen 1456 und 1524 im Rostocker Matrikelbuch diesen Herkunftsort an. 
Zwar reichten die Zahlen Rostocks nicht an die der eigenen Landes- und Nachbaruniversität heran, doch wird die Konkurrenz der beiden Universitäten sichtbar. Auch die Tendenz innerhalb des Zeitraums bestätigt dies, denn die Studentenzahlen können in Rostock sogar noch zugewinnen. Dabei ist jedoch zu berücksichtigen, daß einige Studenten ein Studium an der einen und später an der anderen Universität absolviert haben.

Zwischen 1419 und 1456 waren es lediglich 33 Personen, die in der Rostocker Matrikel verzeichnet wurden. Zwischen 1456 und 1469 liegen die Rostocker Werte noch unter denen in Greifswald. Dies hing sicherlich mit dem größeren Interesse zusammen, das eine Neugründung immer wieder auslöste. Ab 1470 steigen die Zahlen in Rostock, und liegen bis 1505 zwischen 10 und 14 Studenten pro Jahrsiebt. Auch in der Krisenphase der mecklenburgischen Universität ändert sich daran nichts. In dieser Zeitspanne liegt die Zahl der Greifswalder Einschreibungen immer etwas über der in Rostock. Erst ab 1505 kommt es zu einem Umbruch, als Rostock an Bedeutung zugewinnen kann. Zwischen 1505 und 1511 ließen sich 30, zwischen 1512 und 151822 Studenten in Rostock immatrikulieren. Im letzten Abschnitt sind es zwar nur noch 16 Inskriptionen, doch liegen auch in diesem Abschnitt die Zahlen über denen der pommerschen Landesuniversität, die für Stralsund seit Beginn des 16. Jahrhunderts an Bedeutung verlor.

Stralsund war die bedeutendste Hansestadt Pommerns, deren Einwohnerzahl ebenfalls alle anderen Städte der Gegend übertraf. Daher ist es kaum verwunderlich, daß vor und nach der Greifswalder Universitätsgründung auch an anderen Universitäten immer wieder Studenten aus Stralsund auftauchten, doch bleiben die Zahlen weit zurück hinter denen der beiden Ostseeuniversitäten. Neben Rostock und Greifswald finden sich zwischen 1456 und 1524 in Leipzig, Erfurt, Wittenberg, Frankfurt und Basel Studenten aus Stralsund.

Während die Bedeutung Rostocks, wie wir gesehen haben, auch nach der Greifswalder Gründung zunahm, gingen in Leipzig die Stralsunder Eintragungen zurück. Nur acht Studenten werden dort zwischen 1456 und 1524 immatrikuliert. Vorher waren es noch 46 Studenten, so daß Leipzig bis 1456 häufiger als Rostock besucht wurde. Erfurt zeichnet sich durch fast gleichbleibende Zahlen aus. Bis 1456 werden dort sieben Stralsunder eingeschrieben, bis 1524 kommen weitere sechs hinzu. Nur zwei Eintragungen fanden sich im Wittenberger Matrikelbuch, beide im letzten Zeitabschnitt, als der dortige Universitätsprofessor Martin Luther durch seine Schriften bereits für Aufsehen gesorgt hatte. In Frankfurt hatten sich schon zur Gründungszeit drei Stralsunder eingefunden, doch blieben sie im letzten Abschnitt aus. 1471 ließen sich zwei Stralsunder in Basel immatrikulieren, deren Herkunftsort der dortige Rektor fälschlicherweise als "sungis" notierte. ${ }^{295}$ In keiner anderen Universität fanden sich im behandelten Zeitraum weitere Eintragungen, so daß die Gesamtzahl bei 319 Studenten liegt. Die prozentuale Verteilung auf die verschiedenen Unversitäten wird in der folgenden Grafik dargestellt. Aus ihr geht hervor, daß über die Hälfte aller Stralsunder Studenten nach Greifswald gezogen sind. Rostock wurde von 43 Prozent, die übrigen Universitäten von knapp sieben Prozent der Stralsunder Studenten aufgesucht, von denen Leipzig (2,5\%) und Erfurt (1,9\%) an der Spitze stehen (vgl. folgende Grafik). 


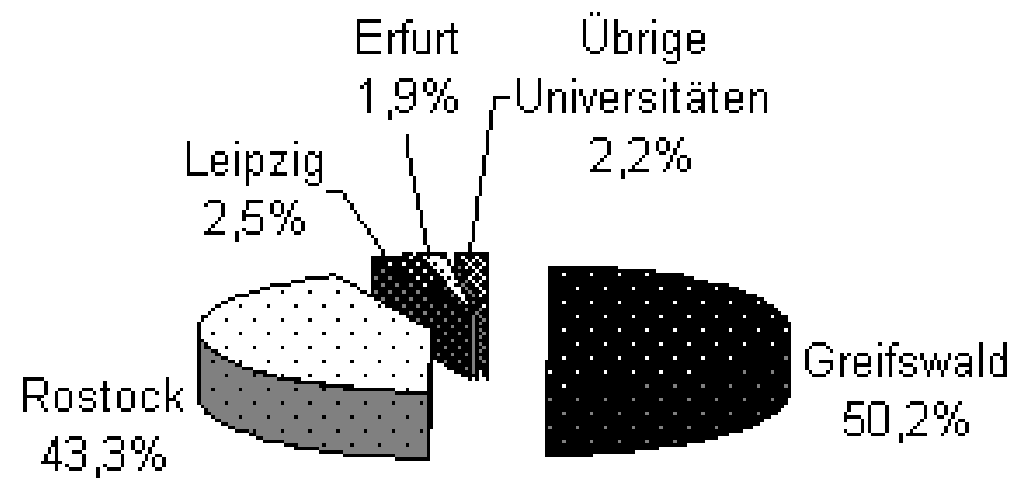

Abbildung 31: Stralsunder Studenten 1456-1524 (Verteilung auf Universitäten)

Vor der Universitätsgründung gingen außerdem sechs Studenten nach Wien sowie drei nach Heidelberg. In Köln inskribierten sich nur zwei Studenten, die beide vor dem Jahre 1456 erschienen. Das gleiche gilt für Bologna, wo je eine Eintragung in den Jahren 1302 und 1380 gemacht worden ist. 11 Stralsunder konnten bis 1409 in Prag nachgewiesen werden, so daß man vor der Greifswalder Gründung insgesamt auf 110 Stralsunder Eintragungen stößt. Die Verdreifachung der Zahlen seit 1456 veranschaulicht, wie sich die Nähe gleich zweier Universitäten auswirkte. Dabei ist natürlich zu berücksichtigen, daß ein Großteil der in Greifswald Immatrikulierten bei Nichtgründung oder Scheitern der neuen Universität andere Universitäten besucht hätte, doch wäre der Anstieg der Zahlen sicherlich niedriger ausgefallen.

Aus der folgenden Grafik geht hervor, wie sich die prozentualen Anteile der verschiedenen älteren Universitäten vor und nach 1456 entwickelt haben. Man sieht, daß Rostock auch nach der Greifswalder Gründung zugewinnen kann, während die älteren Universitäten, vor allem Leipzig, deutlich an Bedeutung verlieren. Nach Leipzig zogen bis zur Greifswalder Gründung noch etwa 42 Prozent der Studenten, 12 Prozent mehr als nach Rostock. Ab 1456 verschiebt sich das Verhältnis, als Rostock trotz der pommerschen Neugründung 43 Prozent erreicht. Leipzig und Erfurt verzeichneten weniger als fünf Prozent aller Immatrikulationen. Alle übrigen Universitäten wurden nicht mehr besucht. An dem Ergebnis wird deutlich, daß die Universität Rostock nicht oder nur kurzfristig durch die Greifswalder Gründung eingeschränkt wurde. Vielmehr profitierte sie ebenfalls vom Gesamtzuwachs der Studentenzahlen. 


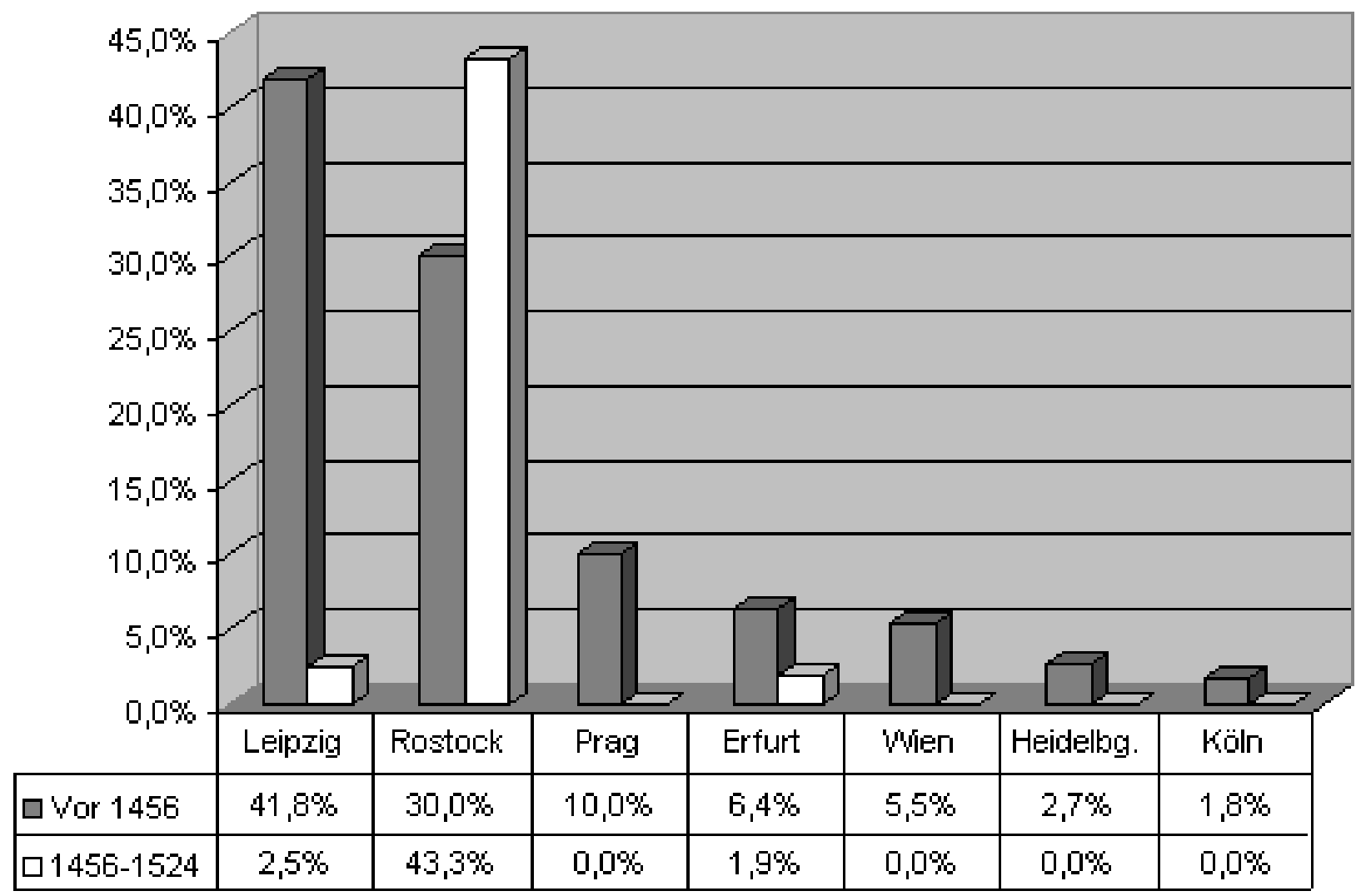

Abbildung 32: Verteilung der Stralsunder auf die alten Universitäten des Reiches

Verfolgt man die Entwicklung der Immatrikulationen aus Stralsund, so erkennt man eine stetige Aufwärtsentwicklung, die etwa bis zum Jahre 1484 andauert, als das Niveau in zwei Zeitabschnitten herabsinkt (vgl. folgende Grafik). Ein starker Anstieg der Immatrikulationen findet dann bis etwa 1511 statt. Zwischen 1505 und 1511 ist die höchste Beteiligung überhaupt zu verzeichnen, die im folgenden Jahrsiebt zwar zurückgeht, aber immer noch überdurchschnittlich hoch bleibt. Dies gilt auch für den letzten Abschnitt, bei dem man die kürzere Zeitspanne von nur sechs Jahren berücksichtigen muß. Eine Erklärung für den Einbruch der Zahlen in den achtziger und neunziger Jahren ist kaum zu bekommen. Fest steht, daß die Immatrikulationen in anderen Universitäten zwischen 1477 und 1504 recht gleichbleibend verlaufen, während sie in Greifswald größeren Schwankungen unterliegen. Der Zugewinn zu Beginn des 16. Jahrhunderts wird in erster Linie durch die Rostocker Universität getragen, die offensichtlich für die Stralsunder Bürger an Bedeutung noch zunehmen kann. ${ }^{296}$ Die Rostocker Domfehde bewirkte weder Einbußen für Rostock, noch Zugewinne für Greifswald, wo eher eine abnehmende Tendenz erkennbar wird. ${ }^{297}$ Auch die italienischen Humanisten konnten keinen Zuwachs bewirken, so daß deren Weggang 1503 als Erklärung für den Rostocker Anstieg ausscheidet. Wahrscheinlich sind die Gründe in den lokalen und innerstädtischen Verhältnissen zu suchen, doch sind solche Erklärungen als Vermutungen zu bewerten. 


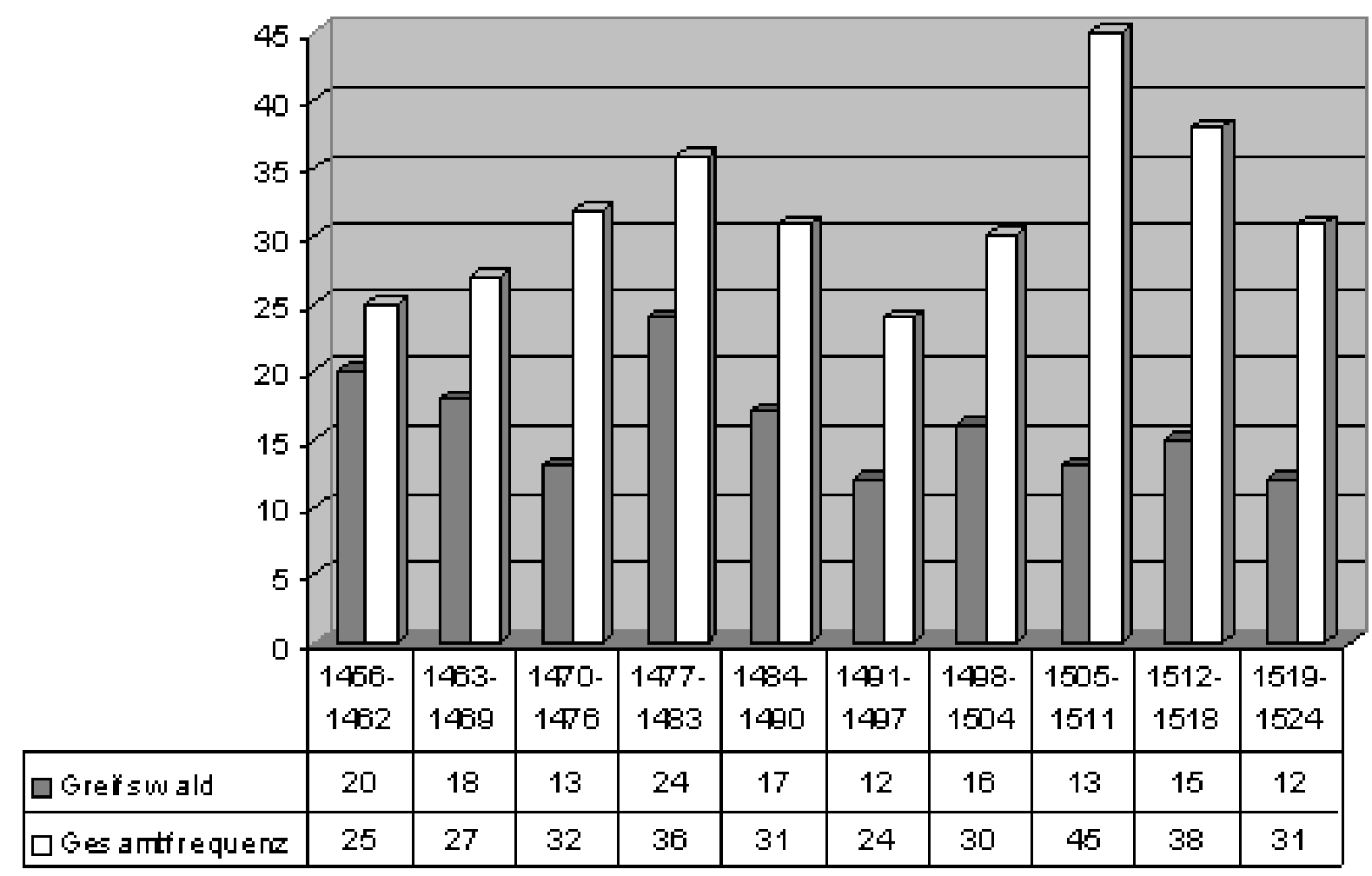

Abbildung 33: Stralsunder Studenten (Greifswald - Gesamtfrequenz)

Aufgrund der Immatrikulationsentwicklung läßt sich nun ein Bild über die Bedeutung Greifswalds für die Nachbarstadt Stralsund machen. Wie aus der folgenden Grafik zu erkennen ist, nimmt die Bedeutung kontinuierlich ab. Fast 80 Prozent der Stralsunder bevorzugten noch zur Gründungszeit die pommersche Landesuniversität, während kurz vor Schließung der Universität das Niveau bereits unter 40 Prozent gesunken war. Von 1470 bis 1476 werden Stralsunder erstmalig seit Gründung wieder häufiger an anderen Universitäten eingeschrieben, doch kann sich das Verhältnis von 1477 bis 1504 wieder umkehren. Dann folgt ein weiterer Einbruch, denn weniger als 30 Prozent gehen zwischen 1505 und 1511 nach Greifswald. Auch in den letzten beiden Abschnitten können sich die Werte nur leicht erholen und liegen nur noch beim Endstand von 40 Prozent. 


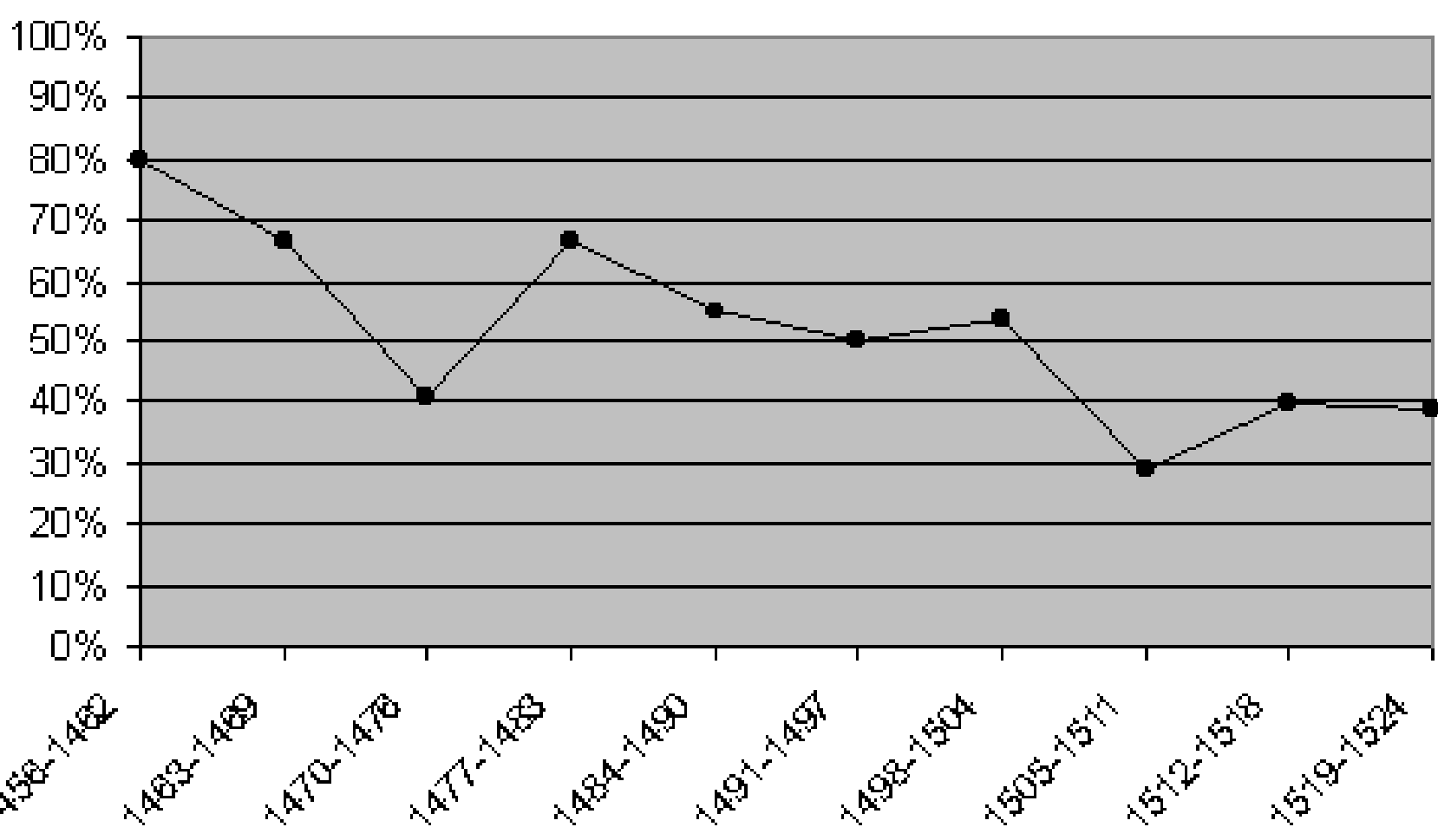

Abbildung 34: Stralsunder Studenten (Anteil Greifswalds an der Gesamtfrequenz)

\subsubsection{Demmin: starke Bindung zur Landesuniversität}

Demmin, süd-westlich von Greifswald, gehörte wie die Universitätsstadt dem Hansebund an, doch war die Stadt von geringerer Bedeutung und Bekanntheit. Wenn nun der Universitätsbesuch aus Demmin dargestellt wird, muß man berücksichtigen, daß viele der Rektoren den Ortsnamen nicht kannten und ihn vielleicht falsch oder gar nicht widergaben. Es bleibt allerdings fraglich, ob sich die Größenordnung der Zahlen ändern würde. Daß die Stadt über Möglichkeiten der schulischen Vorbildung verfügte, ist bereits erwähnt worden, doch war sie zu klein, um höhere Studentenzahlen zu erreichen.

Beim Blick in andere Matrikel bestätigt sich diese Vermutung. Im behandelten Zeitraum waren Demminer neben Greifswald nur in Rostock vertreten, doch reichen auch hier die Zahlen nicht an die der eigenen Landesuniversität heran. Während in Greifswald 64 Studenten mit Demminer Herkunftsangabe verzeichnet wurden, waren es in Rostock nur 13, die sich recht gleichmäßig auf die zehn Zeitabschnitte verteilen. Vor der Greifswalder Gründung ließen sich außerdem drei Immatrikulationen in Leipzig und zwei an der Prager Universität nachweisen. In Rostock verzeichnete trotz des kürzeren Zeitraums seit 1419 bereits sieben Demminer, das damit die alten Universitäten anführte. Insgesamt bleibt die Zahl mit 12 Einschreibungen bis 1456 allerdings gering.

Die Gesamtfrequenz zwischen 1456 und 1524 ist von einer gewissen Unregelmäßigkeit in der ersten Hälfte des Betrachtungszeitraums gekennzeichnet, als es zu einem kurzen Rückgang der Einschreibungen von 1463 bis 1469 kam, der als Normalisierung der höheren Zahl zur Gründungszeit 
zu werten ist. Zwischen 1477 und 1490 sind die Werte wieder sehr niedrig, und gehen ab der zweiten Hälfte der Zeit in ein recht gleichbleibendes Niveau bis zum Betrachtungsende über (vgl. folgende Grafik)

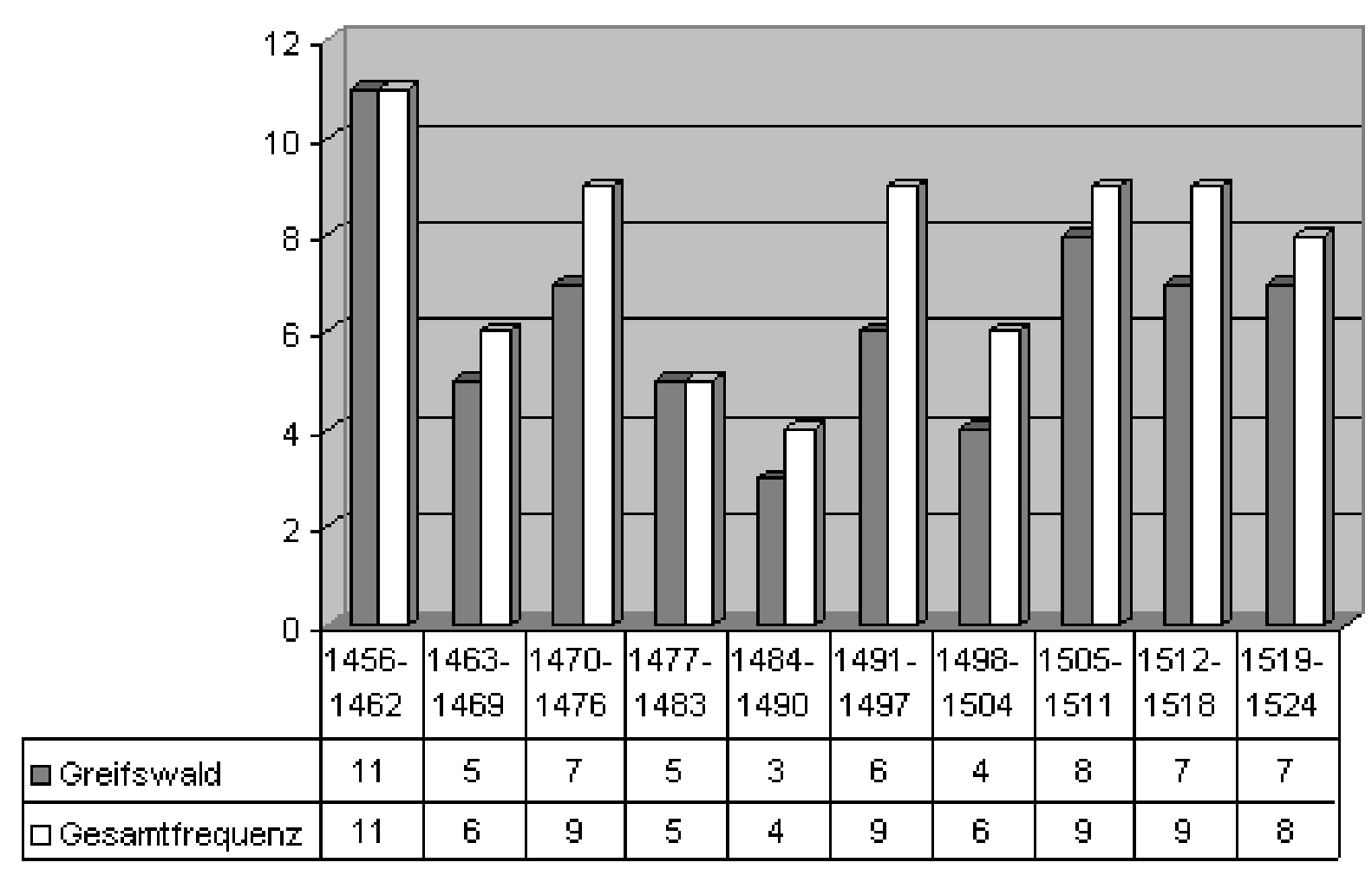

Abbildung 35: Demminer Studenten (Greifswald - Gesamtfrequenz)

Betrachtet man den Anteil Greifswalds an der Demminer Gesamtfrequenz, dann fällt die gleichbleibend hohe Bedeutung der pommerschen Landesuniversität auf. Ihr Anteil liegt fast immer über 80 Prozent (vgl. folgende Grafik). Nach der Gründungsphase, als kein Demminer an einer anderen Universität studierte, kommt es nur noch einmal zwischen 1477 und 1483 zu einer 100prozentigen Beteiligung für Greifswald. Ab 1484 bis 1504 sind die Anteile niedriger, und liegen bei etwa 70 Prozent, doch können sie in den letzten drei Abschnitten wieder auf 80 bis 90 Prozent zulegen. 


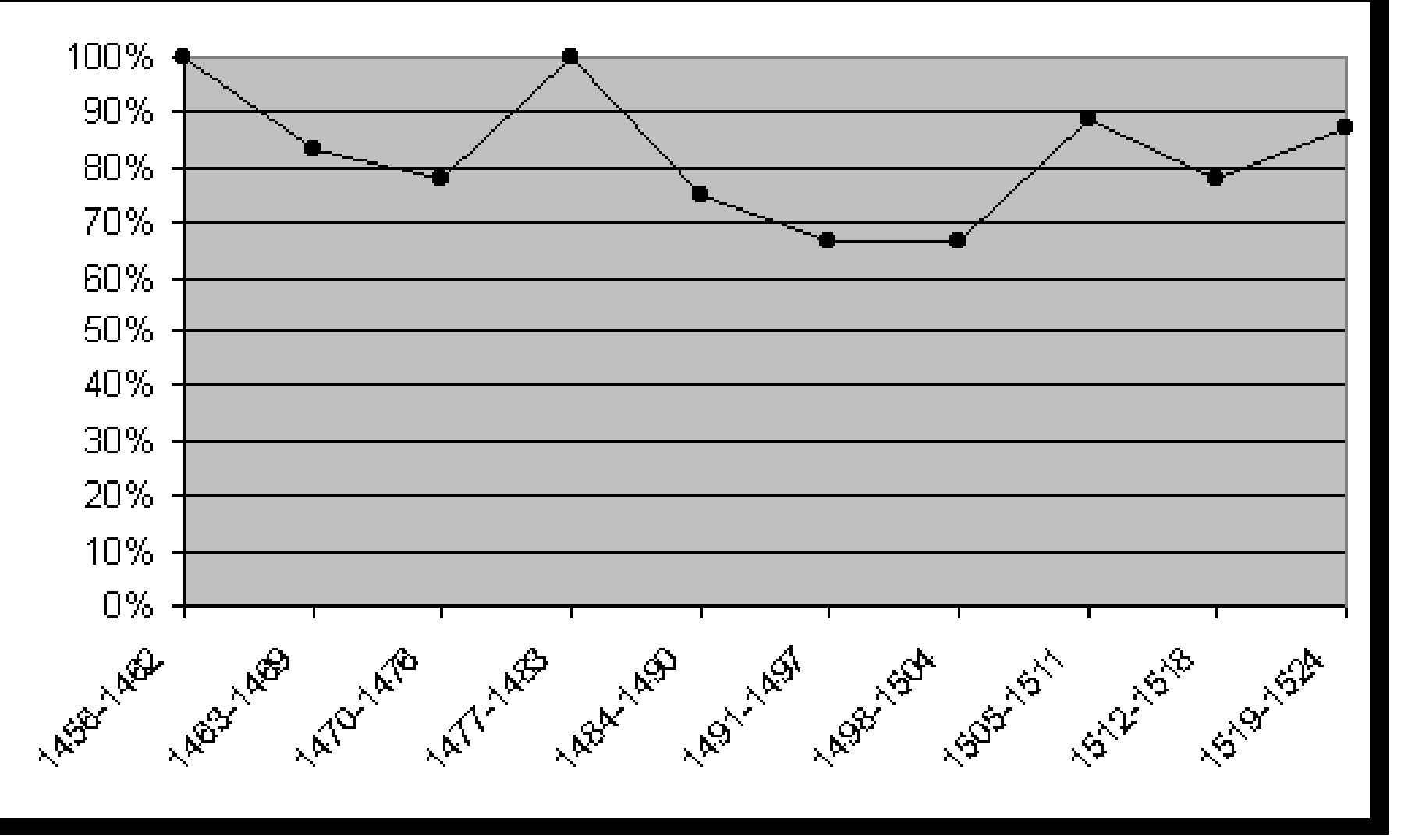

Abbildung 36: Demminer Studenten (Anteil Greifswalds an der Gesamtfrequenz)

\subsubsection{Anklam: Konzentration auf die Ostseeuniversitäten}

In den Quellen erscheint die pommersche Hansestadt Anklam auch häufiger unter dem Namen "Tanglim" oder "Tancklem". 52 Greifswalder Studenten nannten diese Stadt an der Ostseeküste als Herkunftsort. Hinsichtlich ihrer Bedeutung für die pommersche Landesuniversität folgt sie direkt hinter Stargard. Durch die geringe Entfernung zum Universitätsort zeigte sich auch hier eine recht dominierende Stellung Greifswalds. Nur die Rostocker Matrikel verzeichnete mit 27 Eintragungen ebenfalls eine höhere Zahl Anklamer Studenten. Sie verteilen sich relativ gleichmäßig auf die 10 Zeitabschnitte, wenn auch gegen Ende ein leichter Anstieg zu beobachten ist. Von 1484 bis 1490 fallen sie in Rostock ganz weg, während in Greifswald nur ein einziger Anklamer zu finden ist. Ab jetzt konsolidieren sich die Zahlen und erleben bis zum Ende des Betrachtungszeitraums keine nennenswerten Schwankungen. In Leipzig konnten drei Anklamer Studenten nachgewiesen werden, die nur vereinzelt auftauchten, während man in Frankfurt auf zwei Eintragungen im Zeitraum zwischen 1512 und 1518 stößt. 1494 machte sich eine Kleingruppe von sechs Personen aus der

Kamminer Diözese auf den Weg zur polnischen Universität Krakau. ${ }^{298}$ Zwei der Immatrikulierten nannten neben der Diözese Kammin den Herkunftsort "Thanklauz", womit vielleicht die Hansestadt Anklam gemeint sein könnte, doch wird aufgrund der Unklarheit auf eine Berücksichtigung verzichtet. Insgesamt handelt es sich um 84 Studenten, die sich mit knapp 62 Prozent auf Greifswald und mit knapp 32 Prozent auf Rostock verteilen. Vor der Universitätsgründung konnten außerdem sechs Anklamer in Prag, sechs in Leipzig, vier in Bologna sowie sieben in Rostock gefunden werden, womit sich die Gesamtzahl noch um 23 Personen erhöht, wie aus der folgenden Tabelle zu entnehmen ist. 
Tabelle 12: Anklamer Studenten bis 1524

\begin{tabular}{|l|l||l|l|l||l|l||r||}
\hline Jahr & Greifswald & Rostock & Leipzig & Frankfurt & Prag & Bologna & Gesamt \\
\hline \hline Vor 1456 & 0 & 7 & 6 & 0 & 6 & 4 & 19 \\
\hline $1456-1462$ & 11 & 2 & 1 & 0 & 0 & 0 & 14 \\
\hline $1463-1469$ & 2 & 3 & 0 & 0 & 0 & 0 & 5 \\
\hline $1470-1476$ & 2 & 1 & 0 & 0 & 0 & 0 & 3 \\
\hline $1477-1483$ & 4 & 2 & 0 & 0 & 0 & 0 & 6 \\
\hline $1484-1490$ & 1 & 0 & 0 & 0 & 0 & 0 & 1 \\
\hline $1491-1497$ & 13 & 5 & 1 & 0 & 0 & 0 & 19 \\
\hline $1498-1504$ & 3 & 2 & 0 & 0 & 0 & 0 & 5 \\
\hline $1505-1511$ & 2 & 4 & 0 & 0 & 0 & 0 & 6 \\
\hline $1512-1518$ & 6 & 5 & 1 & 2 & 0 & 0 & 14 \\
\hline \hline $1519-1524$ & 8 & 3 & 0 & 0 & 0 & 0 & 11 \\
\hline \hline Gesamt & 52 & 34 & 9 & 2 & 6 & 4 & 107 \\
\hline
\end{tabular}

Die Gesamtfrequenz der Anklamer auf allen Universitäten ist von zwei kurzen Anstiegsphasen gekennzeichnet, und zwar im ersten Abschnitt von 1456 bis 1463 sowie im sechsten zwischen 1491 und 1497 (vgl. folgende Grafik). Es ist offensichtlich, daß die Gründung einer eigenen pommerschen Universität gerade in der näheren Entfernung zu einer stärkeren Frequenz geführt hat, doch stellt der zweite Anstieg eine Besonderheit dar. Nicht nur in Greifswald, sondern auch in Rostock wird nämlich mit ihm ein Immatrikulationstief des vorherigen Abschnitts überwunden. Man gewinnt förmlich den Eindruck, daß ein Rückstau stattgefunden hat, den man einerseits mit der Pest in Pommern, andererseits mit der Auswanderung der Rostocker Universität erklären könnte. Ein solcher Immatrikulationsstau hat vielleicht zu dem stärkeren Anwachsen der Immatrikulationen im folgenden Abschnitt geführt, doch können ebenso innerstädtische Verhältnisse und Ereignisse Anklams dafür verantwortlich sein. Sieht man von diesen Ausnahmephasen ab, ist ein Gesamtzuwachs innerhalb des Zeitraums zu beobachten, der selbst zur Reformationszeit kaum gebremst wird. In der Bedeutung blieb Greifswald für Anklam stets der wichtigste Universitätsort, dicht gefolgt von Rostock. Keine der neuen oder alten Universitäten vermochte gegen diese Konstellation etwas auszurichten. 


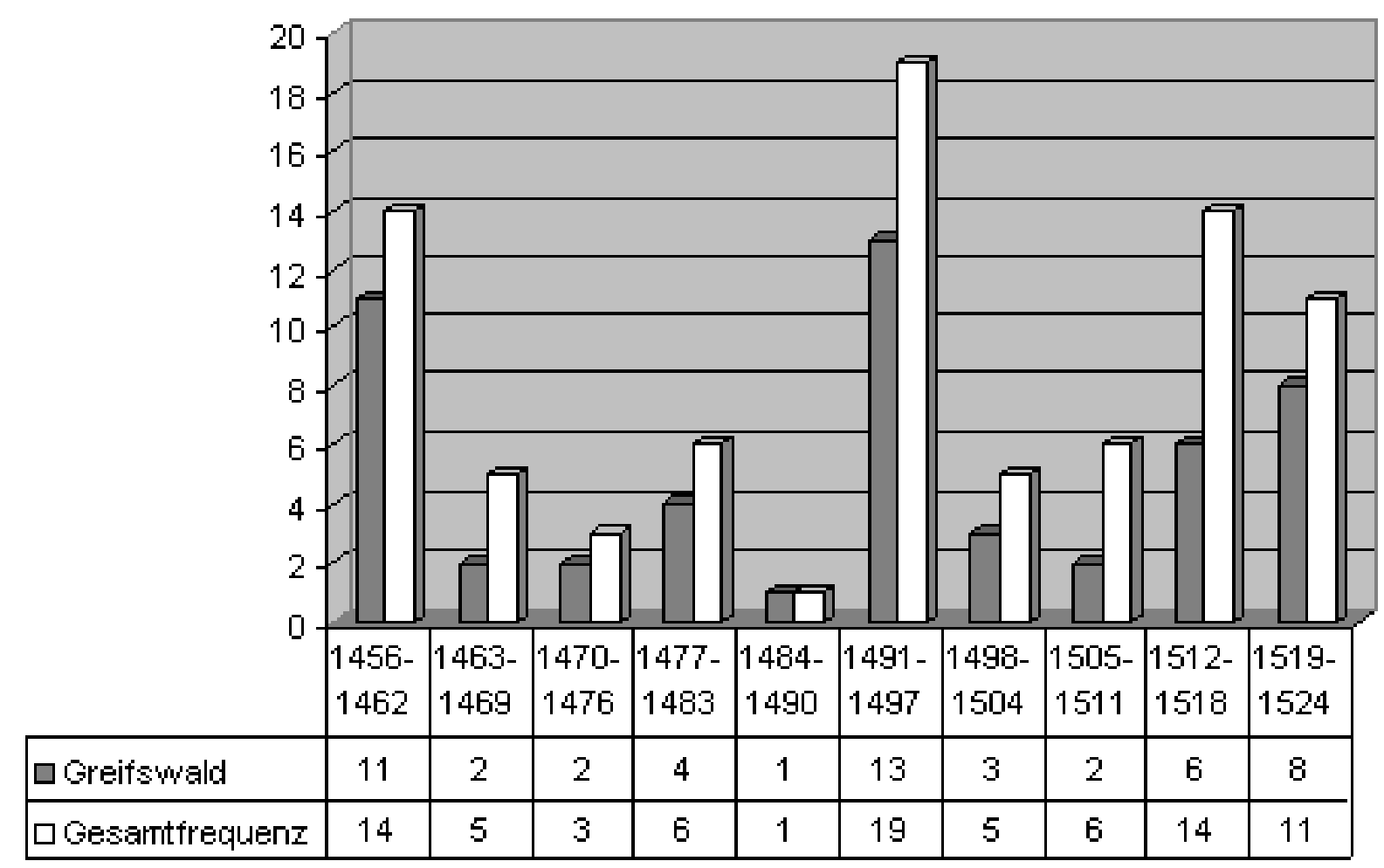

Abbildung 37: Anklamer Studenten (Greifswald - Gesamtfrequenz)

\subsubsection{Barth: Grenzlage und Konkurrenz}

Für die Bewohner der Stadt Barth, die sich auf dem Wege von Greifswald nach Rostock an der Ostseeküste befindet, kam von 1456 bis 1524 ein Studium nur in einer der beiden nächstgelegenen Universitäten in Frage. Die 69 Barther Studenten waren ausschließlich in deren Matrikelbücher zu finden. Mit 36 Eintragungen lag die eigene Landesuniversität nur um drei Einschreibungen über ihrer mecklenburgischen Konkurrenz.

Bis 1476 verliefen die Rostocker Einschreibungen knapp unter denen in Greifswald (9 gegenüber 16), wobei der Gründungsabschnitt verständlicherweise die größte Differenz vorwies (5). Von nun an war es die Rostocker Universität, die einen höheren Anteil verzeichnen konnte. Zwischen 1477 und 1497 immatrikulierten sich 13 gegenüber fünf Studenten an der mecklenburgischen Hohen Schule, wobei die Differenz von 1477 bis 1483 (5) am größten war. Zur Zeit der beiden Humanisten ließen sich insgesamt nur drei Barther in Greifswald immatrikulieren, während die beiden Osteseeuniversitäten in den letzten drei Abschnitten fast gleiche Zahlen vorwiesen. Von 1505 bis 1524 zogen 13 Studenten nach Greifswald, 11 nach Rostock. Vor der Greifswalder Gründung besuchten Barther neben Rostock (13) die Prager (2) und die Erfurter Universität (1). Im gesamten Mittelalter erreichte Barth eine Beteiligung von 84 Studenten an allen Universitäten. Die Frequenz verlief ohne nennenswerte Anstiegs- oder Abstiegstendenzen. Nur zwischen 1484 und 1504 liegen die Werte etwas unter dem Durchschnitt (vgl. folgende Tabelle).

Tabelle 13: Barther Studenten bis 1524 


\begin{tabular}{|l|l|l|l|l||r||}
\hline Jahr & Greifswald & Rostock & Prag & Erfurt & Gesamt \\
\hline \hline Vor 1456 & 0 & 13 & 2 & 1 & 16 \\
\hline \hline $1456-1462$ & 8 & 3 & 0 & 0 & 11 \\
\hline $1463-1469$ & 3 & 4 & 0 & 0 & 7 \\
\hline $1470-1476$ & 4 & 2 & 0 & 0 & 6 \\
\hline $1477-1483$ & 2 & 7 & 0 & 0 & 9 \\
\hline $1484-1490$ & 1 & 3 & 0 & 0 & 4 \\
\hline $1491-1497$ & 2 & 3 & 0 & 0 & 5 \\
\hline $1498-1504$ & 3 & 0 & 0 & 0 & 3 \\
\hline $1505-1511$ & 6 & 5 & 0 & 0 & 11 \\
\hline \hline $1512-1518$ & 3 & 2 & 0 & 0 & 5 \\
\hline \hline $1519-1524$ & 4 & 4 & 0 & 0 & 8 \\
\hline \hline Gesamt & 36 & 46 & 2 & 1 & 85 \\
\hline
\end{tabular}

\subsubsection{Grimmen: stärkere Beteiligung seit 1456}

Bei der kleinen Stadt Grimmen stößt man auf Probleme, will man ihr Studium an den anderen Universitäten errechnen, denn in Sachsen befindet sich ein Ort, der zwar Grimma heißt, durch die Latinisierungen der Rektoren jedoch nicht immer von dem pommerschen Ort Grimmen unterschieden werden kann. Es wurde versucht, die nicht eindeutig zuzuordnenden Herkunftsnamen im folgenden anzuzeigen.

Neben Greifswald wies nur Rostock eine gleichwertige Beteiligung Grimmener Studenten auf, wobei die pommersche Universität leicht bevorzugt wurde (22 gegenüber 30 Einschreibungen). Der geringe Unterschied muß allerdings verwundern, weil die Stadt in direkter Umgebung Greifswald liegt. Die Einschreibungen in Rostock verlaufen recht gleichmäßig, fast immer etwas unter denen in der Nachbaruniversität. Ein leichter Anstieg auf sechs Personen findet zwischen 1512 und 1518 statt, doch liegt die Zahl in Greifswald mit 12 Studenten noch darüber. In Erfurt waren außerdem vier Studenten mit dieser Herkunftsangabe verzeichnet, in Wittenberg drei, doch konnte die pommersche Herkunft nicht einwandfrei belegt werden. Vor 1456 zogen vier Grimmener nach Rostock und einer nach Leipzig. Eine Immatrikulation in Wien war ebenfalls nicht genau zuzuordnen. Ob nicht der eine oder andere Student, der im Leipziger Register dem sächsischen Ort zugeordnet wurde, sich bei genauerer Betrachtung als Pommer erweist, kann an dieser Stelle nicht eindeutig geklärt werden. Insgesamt stößt man auf eine Gesamtzahl von 61 Studenten, von denen sechs vor, 55 nach der Greifswalder Gründung erschienen sind (vgl. folgende Tabelle). Mit fast 55 Prozent steht Greifswald an der Spitze aller besuchten Universitäten, und man erkennt an der geringen Studienbeteiligung vor 1456, daß sich die neue Landesuniversität gerade für kleinere Städte der Umgebung studienfördernd 
ausgewirkt hat. Auch für Grimmen ergibt sich außerdem ein Studentenzuwachs zwischen 1456 und 1524. Während in der ersten Hälfte des Zeitraums 17 Studenten ein Studium unternahmen, konnte sich die Zahl in der zweiten Hälfte mit 38 Personen verdoppeln. Dabei kommt dem vorletzten Abschnitt eine besondere Bedeutung zu, in dem sich alleine 17 Studenten (11 in Greifswald, 6 in Rostock) für ein Studium entschlossen. Auch der prozentuale Anteil Greifswalds verbessert sich von 47 Prozent in der ersten, auf 58 Prozent in der zweiten Hälfte des Betrachtungszeitraums.

Tabelle 14: Grimmener Studenten bis 1524

\begin{tabular}{|l|l|l|r|}
\hline Universität & Vor 1456 & $1456-1524$ & Gesamt \\
\hline \hline Greifswald & 0 & 30 & 30 \\
\hline Rostock & $0,0 \%$ & $54,5 \%$ & $49,2 \%$ \\
\hline Erfurt & 4 & 18 & 22 \\
\hline & $66,7 \%$ & $32,7 \%$ & $36,1 \%$ \\
\hline Wittenberg & 0 & 4 & 4 \\
\hline & $0,0 \%$ & $7,3 \%$ & $6,6 \%$ \\
\hline Leipzig & 0 & 3 & 3 \\
\hline & $0,0 \%$ & $5,5 \%$ & $4,9 \%$ \\
\hline Wien & 1 & 0 & $1,6 \%$ \\
\hline Gesamt & $16,7 \%$ & $0,0 \%$ & 1 \\
\hline & 1 & 0 & $1,6 \%$ \\
\hline & $16,7 \%$ & $0,0 \%$ & 61 \\
\hline
\end{tabular}

\subsubsection{Wolgast: Dominanz der Landesuniversität}

24 Immatrikulationen verzeichnete die Greifswalder Matrikel aus der Küstenstadt Wolgast an der Ostsee, die damit ebenfalls zu den wichtigeren Herkunftsorten Greifswalder Studenten zählte. Nur 34 Studenten gingen an andere Universitäten. Damit erreicht Greifswald einen knapp 70-prozentigen Anteil an der Gesamtfrequenz im Mittelalter. Die Studenten verteilen sich auf vier Universitäten. In Rostock ließen sich acht Immatrikulationen nachweisen; vier erfolgten jedoch bereits vor der pommerschen Universitätsgründung. Je eine war außerdem in Frankfurt und Leipzig zu verzeichnen, wobei die Leipziger Eintragung schon vor dem Jahr 1456 erfolgte. Da fünf der 34 Wolgaster Studenten bereits vor dem Gründungsjahr studierten, steigt der Greifswalder Anteil im Betrachtungszeitraum auf 82 Prozent. Die Gesamtfrequenz findet ohne merkliche Zugewinne statt, doch kann der prozentuale Anteil Greifswalds auch innerhalb der Zeitspanne leicht zulegen, da 
Rostock vorwiegend in der ersten Betrachtungshälfte aufgesucht wurde (siehe folgende Tabelle).

Tabelle 15: Wolgaster Studenten bis 1524

\begin{tabular}{|l|l||l|l||r|}
\hline Universität & Vor 1456 & $1456-1490$ & $1491-1524$ & Gesamt \\
\hline \hline Greifswald & 0 & 11 & 13 & 24 \\
\hline \hline Rostock & 4 & 3 & 1 & 8 \\
\hline \hline Leipzig & 1 & 0 & 0 & 1 \\
\hline \hline Frankfurt & 0 & 0 & 1 & 1 \\
\hline \hline Gesamt & 5 & 14 & 15 & 34 \\
\hline
\end{tabular}




\subsubsection{Zentralpommersche Orte}

\subsubsection{Stettin: mitteldeutsche Universitäten treten hervor}

Mit 107 Studenten zählte Stettin neben Stralsund und Greifswald zur einzigen Stadt, die über 100 Personen in Greifswald zu verzeichnen hatte. Als Hauptstadt Pommerns sollte sie in späteren Jahren Greifswald an Größe weit übertreffen, doch waren die Städte in vorreformatorischer Zeit durchaus vergleichbar. Bis 1464 gehörte Stettin dem anderen pommerschen Teilherzogtum an, so daß man damit rechnen konnte, daß die Bindung zur Greifswalder Universität weniger stark, als die der Stralsunder war. Tatsächlich finden sich zwischen 1456 und 1524 mehr Stettiner auf anderen Universitäten als auf der eigenen Landesuniversität. In Rostock, Leipzig, Frankfurt, Wittenberg, Erfurt und Köln sind sie zu finden. Die Dominanz der Rostocker Universität, die bei Stralsund hervortrat, ist bei Stettin weit weniger ausgeprägt, was sicherlich mit der größeren Entfernung zusammenhängt. Andere Universitäten treten daher in den Vordergrund.

64 Stettiner waren im behandelten Zeitraum in der Rostocker Matrikel verzeichnet, was einem deutlichen Zuwachs entspricht, denn vorher ließen sich nur 17 Studenten mit einer solchen Herkunftsangabe nachweisen. Die Immatrikulationen verlaufen relativ gleichmäßig und betragen etwa sechs bis zehn Studenten pro Jahrsiebt mit Ausnahme des Abschnitts der Rostocker Domfehde sowie des letzten Abschnitts, als die Werte niedriger sind. Leipzig brachte es bereits auf die Hälfte der Rostocker Zahlen, denn 32 Stettiner schrieben sich zwischen 1456 und 1524 dort ein. Auch hier hat ein Rückgang stattgefunden, denn bis zum Jahre 1456 war Leipzig mit 43 Immatrikulationen offensichtlich die beliebtere Universität. Die Rostocker Domfehde führte nochmal zu einem kurzen Anwachsen der Stettiner Immatrikulationen, die in diesem Zeitraum mit neun Studenten fast auf gleicher Höhe mit Greifswald liegen. Im letzten Abschnitt sind keine Stettiner verzeichnet, während sich sonst die Zahlen bei drei bis fünf Studenten pro Zeitabschnitt bewegen. Obwohl die Frankfurter Universität im behandelten Zeitraum nur etwa 20 Jahre existierte, verzeichnete sie bereits 20 Stettiner in ihrer Matrikel. Hochgerechnet auf die 68 Jahre, überträfe sie Rostock bereits um vier Studenten. Bei einer solchen Rechnung muß man berücksichtigen, daß in Frankfurt ein starker Gründungsboom stattgefunden hat, nach dessen Abflauen auch hier normale Immatrikulationszahlen erreicht werden. Wittenberg wurde von 10 Studenten aufgesucht, die offensichtlich weniger durch die Neugründung der Universität, als durch Martin Luther angezogen worden sind, denn erst im dritten Abschnitt nach der Gründung erfolgen häufigere Immatrikulationen. Mit neun Studenten gingen im Erfurter Matrikelbuch die Stettiner Immatrikulationen zurück. Bis 1456 wurden dort immerhin 19 Studenten aus Stettin verzeichnet, das damit die pommerschen Orte in Erfurt angeführt hatte. ${ }^{299}$ Zwei Studenten waren in Köln nachzuweisen, wobei einer vor 1456 erschien, ein Stettiner ließ sich 1495 in Krakau immatrikulieren. Eine unklare Eintragung in der Löwener Matrikel im Jahr 1516 kann nicht berücksichtigt werden, so daß man auf eine Gesamtzahl von 244 Stettiner Studenten zwischen 1456 und 1524 stößt, die sich prozentual folgendermaßen verteilen: 


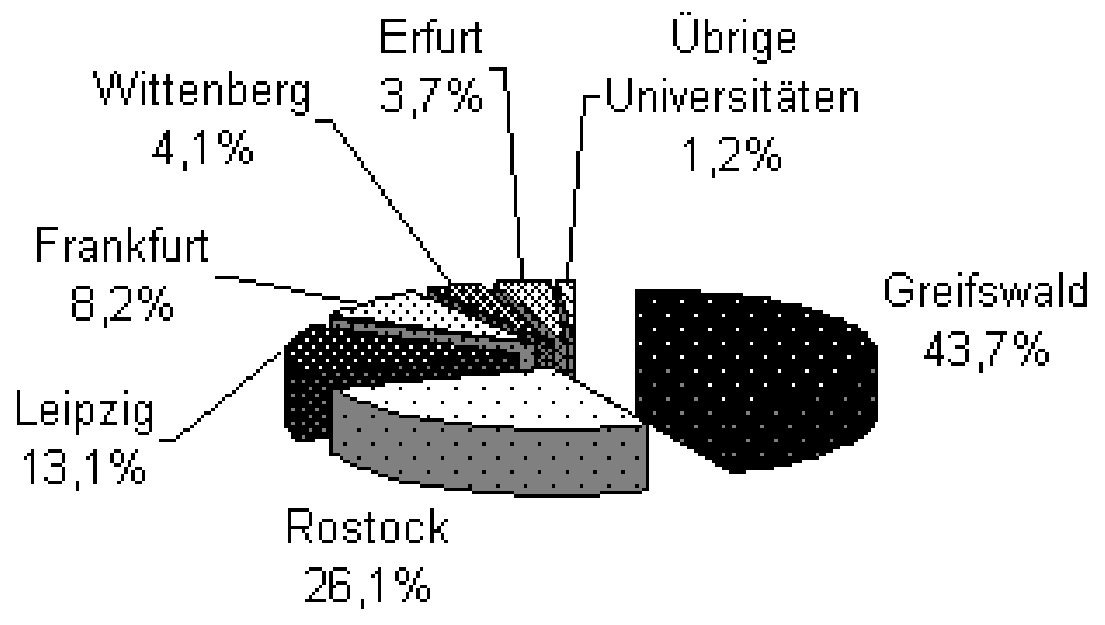

Abbildung 38: Stettiner Studenten 1456-1524 (Verteilung auf Universitäten)

Bis zur Greifswalder Universitätsgründung ließen sich außerdem je fünf Studenten in Prag und Wien nachweisen, einer 1302 in Bologna, so daß insgesamt 91 Studenten vor der Greifswalder Gründung an anderen Universitäten ein Studium begannen. An der prozentualen Verteilung auf die Universitäten wird deutlich, daß nicht nur die Greifswalder Gründung einen Wandel in der Wahl des Studienortes bewirkt hat. In der folgenden Grafik sind nur die Universitäten berücksichtigt, die vor 1456 im Reich existierten. Fast die Hälfte (48\%) der früheren Studenten sind nach Leipzig gezogen, während je ein Fünftel Erfurt und Rostock besuchte, wobei Rostock sogar leicht von Erfurt übertroffen wurde. In der Zeit nach der Greifswalder Gründung verschieben sich die Verhältnisse. Während Wien und Prag ganz ausscheiden, verlieren Leipzig und Erfurt 34 und 17 Prozentpunkte. Rostock dagegen kann seinen Anteil trotz der pommerschen Neugründung weiter ausbauen, wenngleich diese Tendenz gegenüber den Stralsunder Zahlen für Stettin weniger ausgeprägt erscheint. 


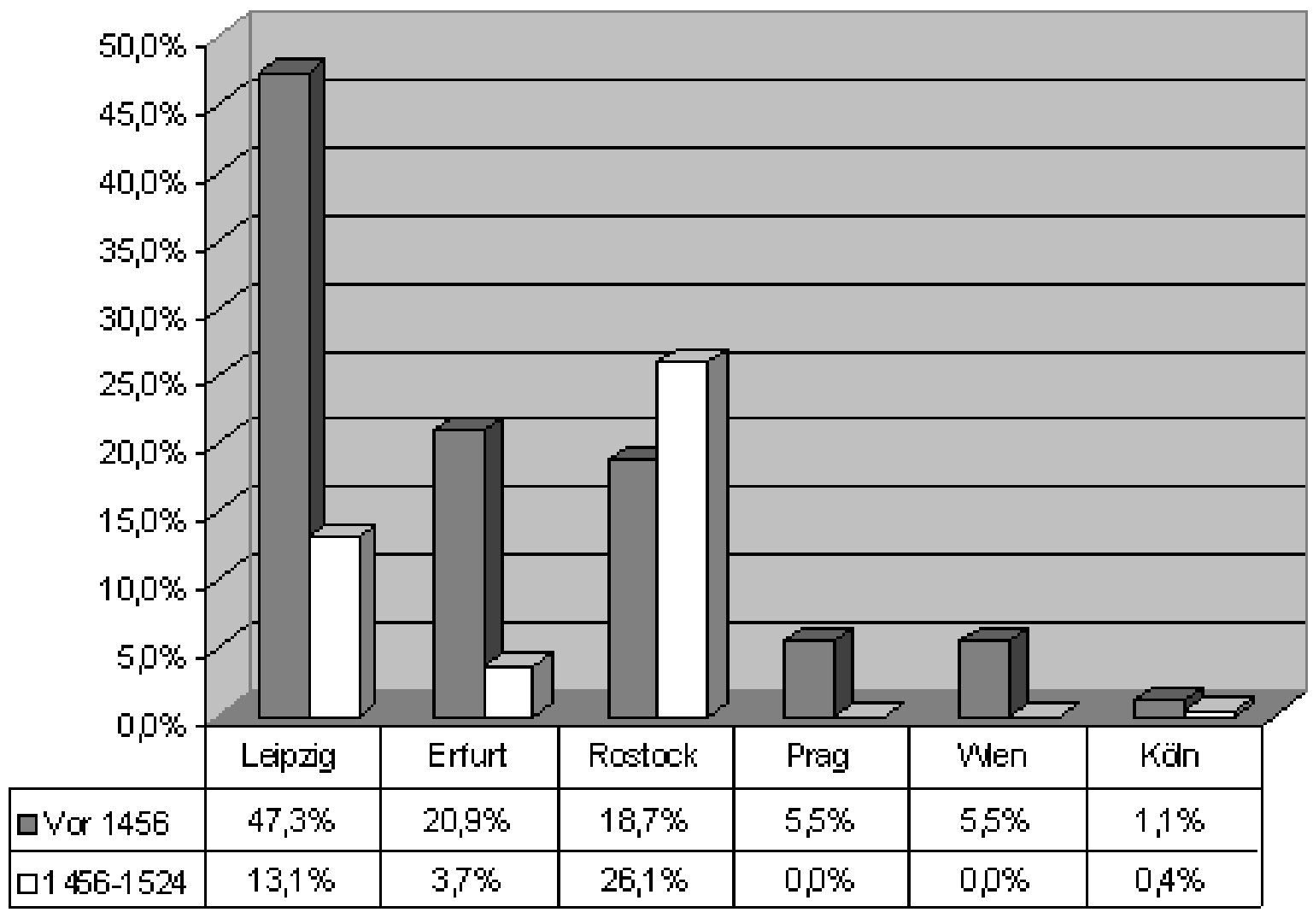

Abbildung 39: Verteilung der Stettiner auf die alten Universitäten des Reiches

Die Frequenzentwicklung der Stettiner Studenten ist geprägt durch verschiedene Phasen. Während die Greifswalder Gründung eine ungewöhnlich hohe Immatrikulationsrate in den ersten sieben Jahren des Zeitraums bewirkte, gehen die Werte im folgenden Zeitabschnitt zurück (vgl. folgende Grafik). Zwischen 1463 und 1490 sind die Zahlen recht gleichbleibend, doch verschiebt sich das Verhältnis innerhalb der Universitäten. Ab 1477 gingen Stettiner erstmalig seit 1456 häufiger an fremde Universitäten. Die Zeit von 1491 bis 1497 stellt einen stärkeren Einbruch dar, der aber schon im nächsten Zeitraum überwunden wird. Ab 1498 bis etwa 1518 können die Werte ihre Höchstmarke erreichen, doch fallen sie erneut im letzten Abschnitt. Die Reformationsereignisse dürften als Gründe dieser besonders niedrigen Zahlen anzuführen sein. 


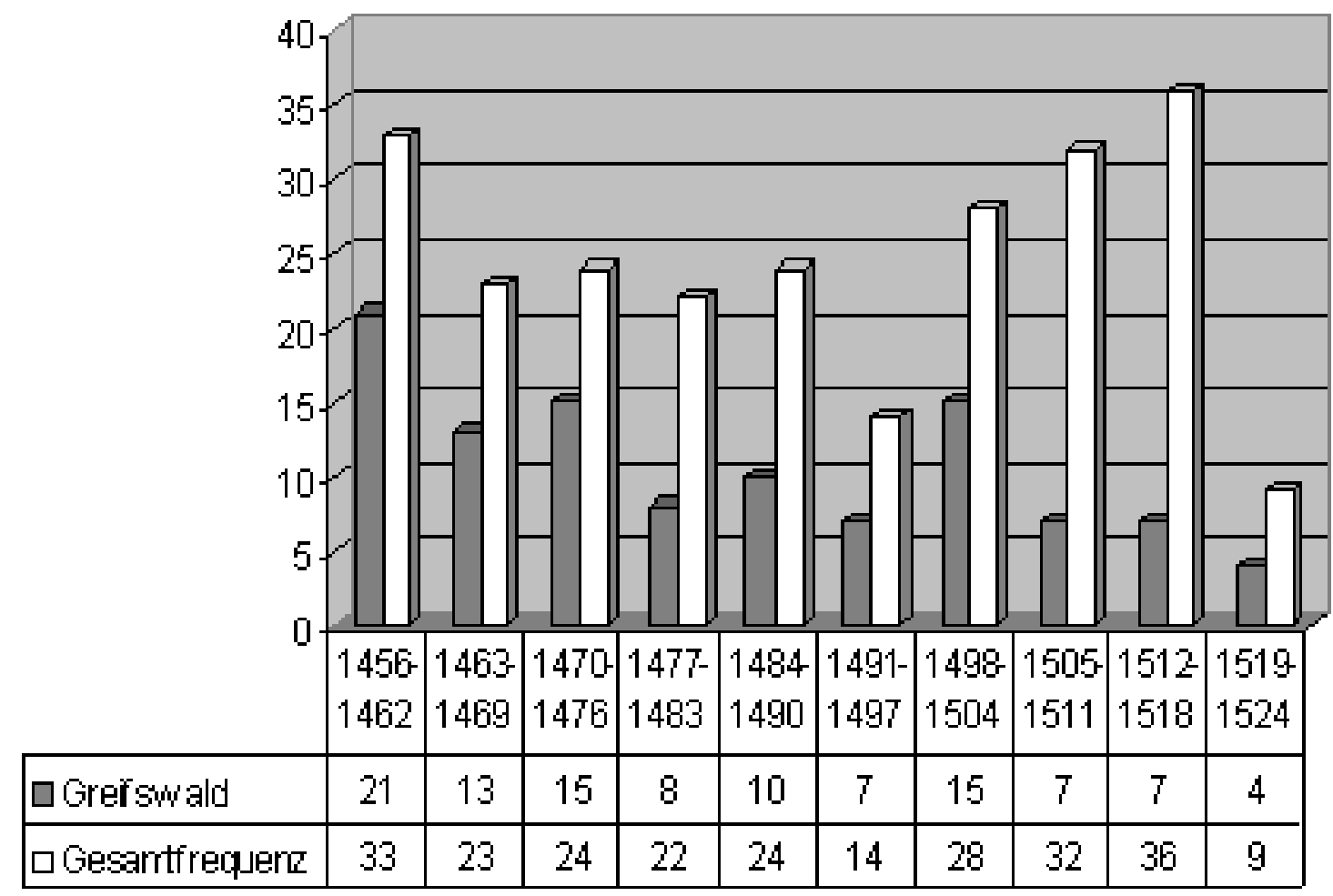

Abbildung 40: Stettiner Studenten (Greifswald - Gesamtfrequenz)

Auch für die Hauptstadt Pommerns sollen Veränderungen in der Bedeutung der Greifswalder Universität dargestellt werden. Wie aus der folgenden Grafik deutlich wird, konnte die neue Universität in den ersten 20 Jahren ihres Bestehens etwa 60 Prozent aller Stettiner Studenten anziehen. Zwischen 1477 und 1490, also während der Rostocker Auswanderung nach Lübeck, fallen die Werte um fast 20 Punkte. Die Stettiner mieden zwar die Rostocker Universität, doch wechselten sie lieber nach Leipzig, wo der Anteil zwischen 1484 und 1490 bei knapp 38 Prozent liegt. Schon ab 1491 steigt der Anteil Rostocks wieder auf Normalwerte. Bis 1504 kann auch Greifswald sein Niveau bei über 50 Prozent halten, was sicherlich mit der Anwesenheit der beiden berühmten italienischen Lehrer zusammenhängt. Mit der Gründung Frankfurts und Wittenbergs sinkt dann allerdings der Anteil Greifswalds auf 20 Prozent. Dies ist einerseits mit dem Gründungsboom zu erklären, den Neugründungen immer wieder auslösen, andererseits mit den Ereignissen der Reformationszeit. Der kurze Anstieg des Greifswalder Anteils im letzten Abschnitt ist nur auf die geringe Gesamtfrequenz zurückzuführen, welche wiederum ihre Ursache in den Wittenberger Ereignissen hat. 


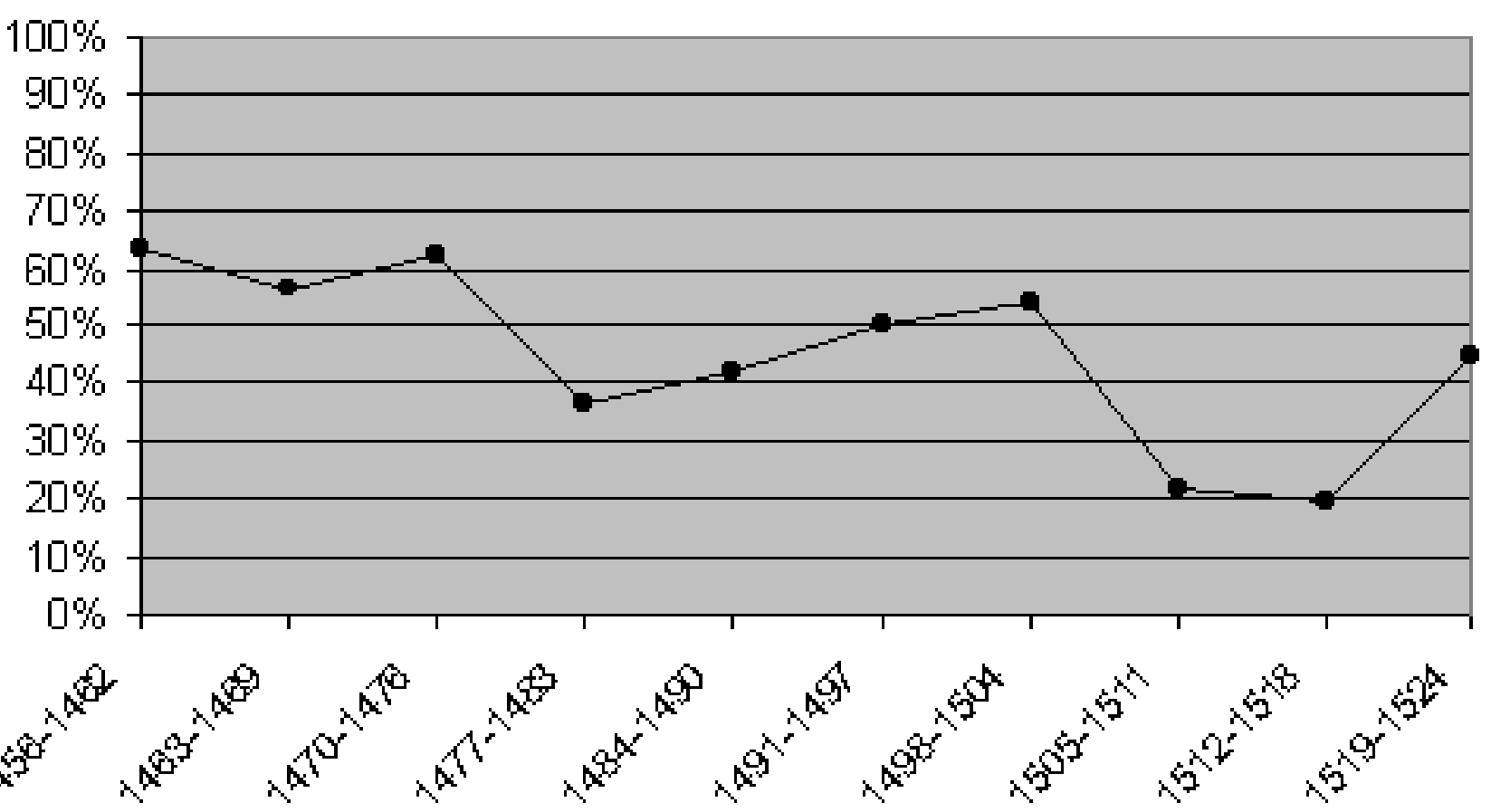

Abbildung 41: Stettiner Studenten (Anteil Greifswalds an der Gesamtfrequenz)

\subsubsection{Stargard: eine kleine Mehrheit an der Landesuniversität}

Aus der pommerschen Hansestadt Stargard sind 61 Studenten nach Greifswald gezogen. Da in Mecklenburg und Preußen zwei weitere Orte namens Stargard existieren und die Rektoren nur selten eine genauere Eingrenzung durch Angabe der Diözese machten, war eine eindeutige Zuordnung nicht immer möglich. Soweit keine andere Angabe vorhanden war, wurde für die vorliegende Untersuchung die pommersche Stadt als Herkunftsort angenommen, so daß die Zahlen über den Universitätsbesuch in anderen Universitäten gerade hier nur Annäherungscharakter haben können.

Vor allem bei der mecklenburgischen Universität Rostock sind die Herkunftsorte nur schwer auseinanderzuhalten, da erst ab dem 16. Jahrhundert eine häufigere Unterscheidung der Orte stattfand. Insgesamt wurden dort im behandelten Zeitraum 42 Personen aus Stargard immatrikuliert, so daß Rostock in der Beliebtheit dicht hinter der eigenen Landesuniversität folgt. Die Anzahl der Immatrikulationen schwankt zwischen drei und acht Studenten pro Jahrsiebt. Die Werte beginnen recht niedrig (3), steigen im folgenden Abschnitt (4), und können im dritten Abschnitt dann ihren Höchstwert (8) erreichen. Dieser Anstieg ging allerdings nicht auf Kosten Greifswalds, denn auch dort wurden in diesem Zeitraum höhere Zahlen erreicht. In den drei Zeitabschnitten bis 1497 gehen die Werte in Rostock leicht zurück (6, 4, 3). Zwischen 1498 und 1504 konnten wieder sechs Studenten ermittelt werden, je vier sind es in den nächsten beiden Abschnitten. Die Reformationsereignisse bewirkten ab 1419 bis 1524 das Ausbleiben weiterer Immatrikulationen in Rostock, doch kam es auch in Greifswald zu einem starken Rückgang, denn nur ein Student fand sich im letzten Jahrsiebt aus Stargard ein. 
Anders als bei den meisten vorher behandelten Orten konnte eine größere Zahl Stargarder auch in anderen Matrikeln nachgewiesen werden. So spielte die Universität Leipzig auch nach der Greifswalder Gründung eine wichtige Rolle. Mit 28 Immatrikulationen folgt sie in der Beliebtheit an dritter Stelle hinter der pommerschen und der mecklenburgischen Universität. In den ersten beiden Abschnitten waren die Zahlen noch auf gleicher Höhe wie Rostock (3 und 4). Zwischen 1470 und 1476 gingen die Zahlen jedoch gegenüber denen der näheren Konkurrenten zurück, die beide in diesem Abschnitt ihre höchste Frequenzrate erreichen. Der dortige Anstieg ging sicherlich zum Teil auch auf Kosten Leipzigs. Im folgenden Abschnitt ist nur noch eine Inskription zu finden, doch stiegen die Zahlen wieder zwischen 1484 und 1490, als es acht Stargarder nach Leipzig zog. Es ist bemerkenswert, daß trotz der Rostocker Domfehde die Immatrikulationen in Greifswald zurückgehen, während Rostock mit vier Einschreibungen fast auf Normalniveau bleibt. Als Erklärung kann auch hier nur die 1485 in Greifswald herrschende Pest angeführt werden, doch bleiben solche Schlüsse reine Spekulation. In Leipzig bringt dieser Umstand einen stärkeren Zugewinn, so daß die dortige Höchstmarke von acht Stargardern genau der höchsten Zahl in Rostock entspricht. Auch im folgenden Abschnitt wird mit fünf Einschreibungen ein überdurchschnittlicher Wert in Leipzig erreicht, doch wird er von den Greifswalder Zahlen wieder um vier Personen übertroffen. Nur je drei Stargarder Studenten werden in den folgenden Abschnitten immatrikuliert, so daß Rostock wieder an zweite Stelle aufrücken kann. Schon im vorletzten Abschnitt gehen die Leipziger Zahlen auf einen Studenten zurück, bevor sie im Letzten dann ganz ausbleiben, was, wie wir noch sehen werden, in erster Linie mit der Neugründung in Frankfurt zusammenhängt.

Mit 19 Studenten muß man die Bedeutung der seit 1505 bestehenden brandenburgischen Universität für Stargard besonders hoch einschätzen. Sie überböte die Greifswalder Schule bereits um zwei Studenten, würde man die Zahl auf die gesamte Zeitspanne hochrechnen. Mit Zehn Stargarder Studenten zwischen 1505 und 1511 übernimmt sie sogleich die Führung unter den anderen Konkurrenten, wobei man auch hier den Gründungsboom berücksichtigen muß. Auch im folgenden Abschnitt erreicht sie jedoch mit sieben Einschreibungen eine höhere Rate als Greifswald, so daß die Frankfurter Universität seit ihrer Gründung bis zum Ende des Betrachtungszeitraums die beliebteste Universität der Stargarder blieb, wenn auch der Frequenzeinbruch im letzten Abschnitt keine statistischen Schlüsse mehr zuläßt, denn mit nur zwei Immatrikulationen kann sie nun bereits alle anderen Universitäten überbieten.

Nicht etwa die nähergelegenen Universitäten Erfurt oder Wittenberg kommen in der Rangfolge hinter Frankfurt, sondern Köln mit acht Immatrikulationen. Bei einer solchen Enfernung hätte man eine Ansammlung auf bestimmte Jahrgänge erwarten können, doch verteilen sich die Immatrikulationen gleichmäßig auf die verschiedenen Zeitabschnitte. Im ersten Abschnitt nach der Greifswalder Gründung wurde kein Stargarder in Köln inskribiert, so daß die erste Immatrikulation erst zwischen 1463 und 1469 erfolgt. Weitere zwei Studenten kamen zwischen 1477 und 1483, und je ein Student in den nächsten drei Zeitphasen. Zwei Stargarder werden zwischen 1505 und 1511 erwähnt, doch scheiden sie in den letzten beiden Abschnitten aus.

Je vier Studenten gingen im behandelten Zeitraum an die Hohen Schulen zu Wittenberg und Wien. In Wien sind sie im ersten Abschnitt sowie zwischen 1484 und 1497 zu finden, während Wittenberg erst seit 1505 besucht wurde. Zwei Einschreibungen ließen sich in Erfurt, eine 1471 in Bologna nachweisen, so daß man eine Gesamtzahl von 169 Studenten erhält. Auf die Universitäten verteilen sie sich wie folgt: 


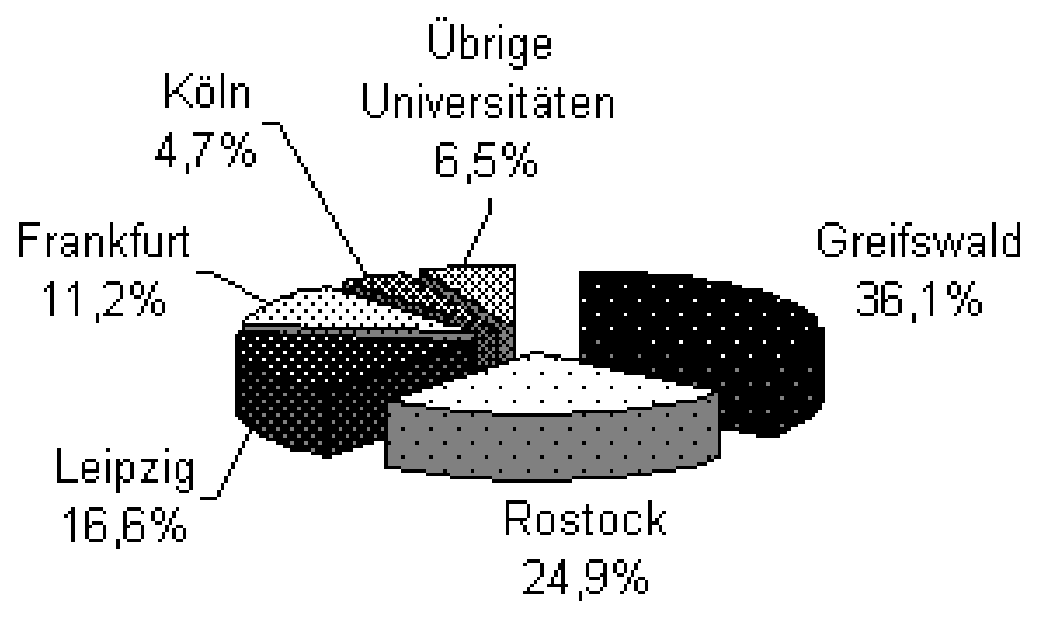

Abbildung 42: Stargarder Studenten 1456-1524 (Verteilung auf Universitäten)

Nur etwa 36 Prozent der Studenten besuchten im behandelten Zeitraum die Universität Greifswald, die damit um 11 Punkte über Rostock liegt. Da so viele Universitäten auch nach 1456 besucht wurden, wäre zu fragen, wo die Studenten zuvor studierten. Aus den Matrikeln geht hervor, daß bis 1409 die Prager Universität an erster Stelle steht (17 Eintragungen), während die Leipziger Universität allein zwischen 1409 und 1455 die gleiche Anzahl erreichen kann. Nur vier Namen wurden bis zur Gründung Rostocks 1419 verzeichnet, so daß die mecklenburgische Konkurrenz den Zuzug nach Leipzig offenbar nicht einschränkte. Drei Studenten zogen nach Erfurt, ein weiterer nach Wien. Die Beteiligung am Kölner Studium begann erst nach 1456, als einige Stargarder in den Matrikeln erscheinen. Zusammen erhält man 42 Studenten, die bis zur Greifswalder Gründung an anderen Universitäten studiert haben. Aus der Verteilung geht hervor, daß die Universität Prag und ihre Nachfolgerin Leipzig die weitaus beliebtesten Studienorte der Stargarder darstellten, bevor in ihrer Nähe zwei weitere Universitäten entstanden (vgl. folgende Grafik). Obwohl die Rostocker Universität schon 37 Jahre existierte, kann auch sie erst nach der Greifswalder Gründung deutlich zulegen. Bis dahin wurde Leipzig noch weitgehend bevorzugt. Der Rückgang des Leipziger Anteils fiel jedoch niedriger aus, als dies in anderen Orten zu beobachten war. Außer Rostock konnte nur Köln seinen Anteil leicht verbessern, während der Anteil Erfurts zurückging, der Anteil Wiens gleichblieb. 


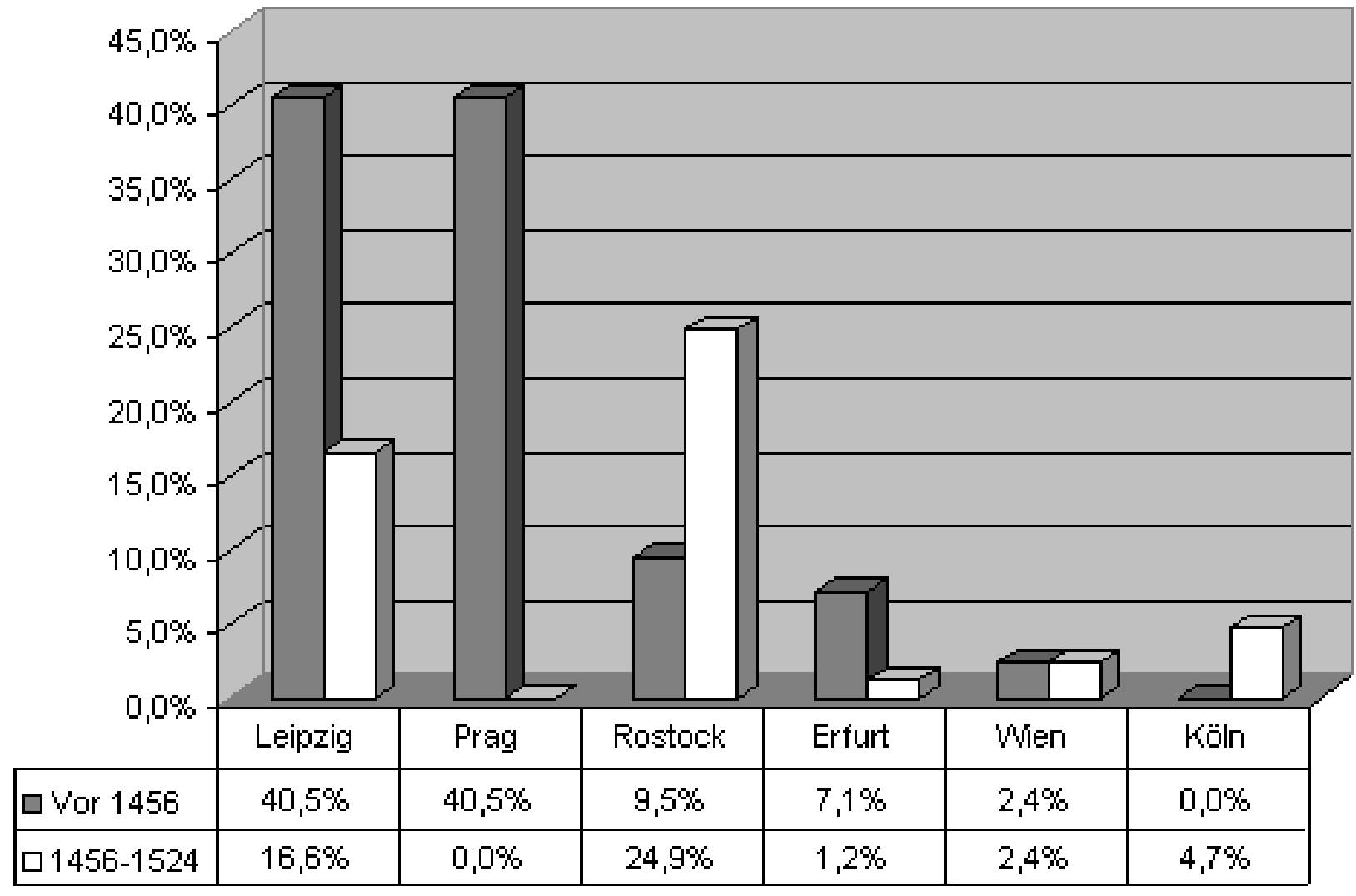

Abbildung 43: Verteilung der Stargarder auf die alten Universitäten

Die Gesamtfrequenz der Studenten aus Stargard zwischen 1456 und 1524 beginnt trotz der Greifswalder Gründung auf unterduchschnittlichem Niveau und geht im folgenden Abschnitt sogar noch zurück (vgl. folgende Grafik). Ab jetzt nehmen die Immatrikulationen zu. Sie liegen bis etwa 1518 gleichbleibend bei knapp 20 Studenten pro Jahrsiebt mit Ausnahme des Zeitraums von 1505 bis 1511. In diesem Zeitraum ist eine deutliche Immatrikulationssteigerung zu beobachten, die sicherlich durch die Frankfurter Universitätsgründung im Jahre 1505 ausgelöst wurde. Schon 1512 findet ein Rückgang der Zahlen auf Normalniveau statt, gefolgt auch hier von einem reformationsbedingten Einbruch im letzten Abschnitt. 


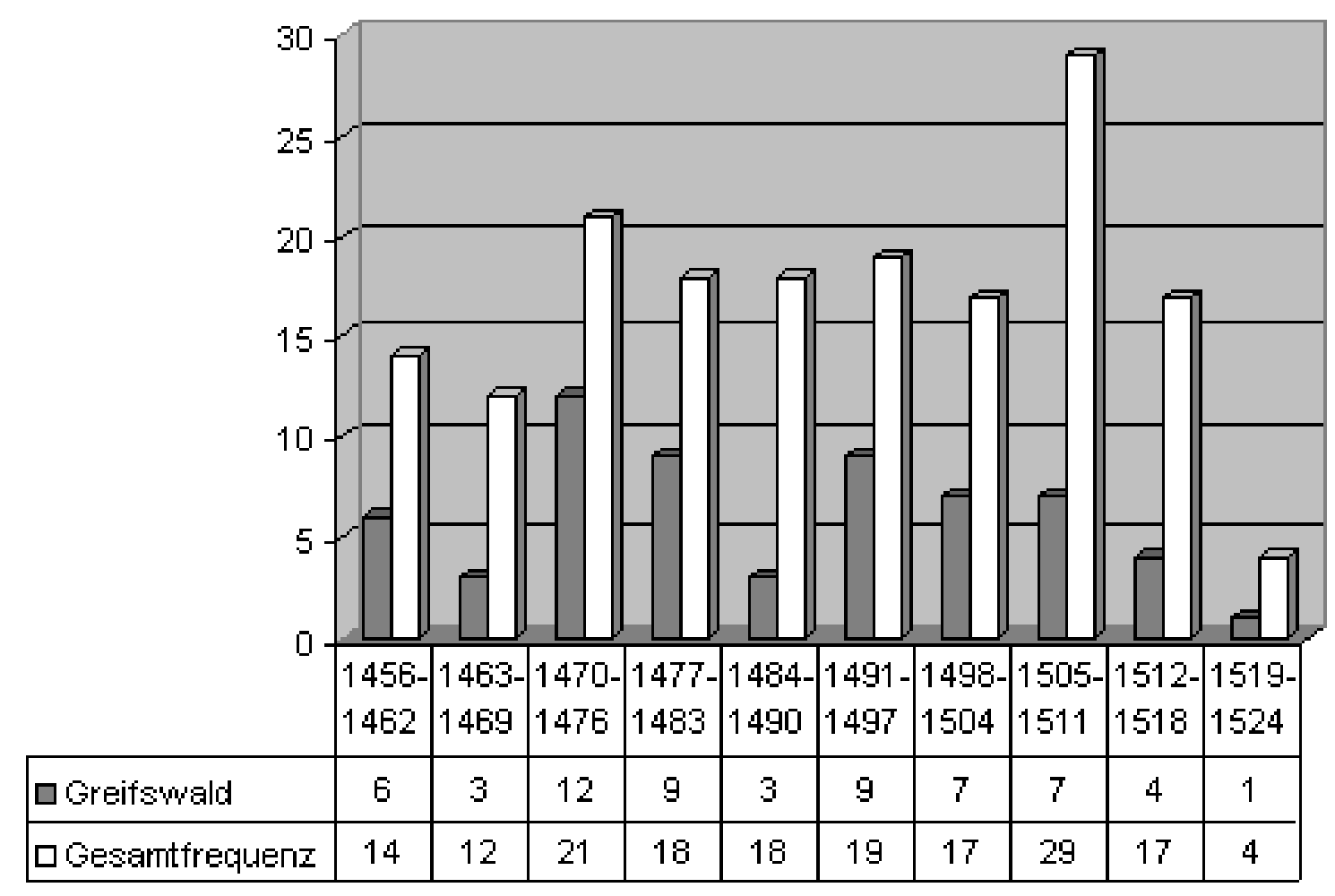

Abbildung 44: Stargarder Studenten (Greifswald - Gesamtfrequenz)

Will man nun Aussagen über die Bedeutungsentwicklung einzelner Universitäten für Stargard treffen, muß man ihre Anteile in den verschiedenen Zeitabschnitten errechnen. Aus der folgenden Grafik geht hervor, daß im längsten Teil des Zeitraums, nämlich zwischen 1456 und 1505, die Greifswalder Universität die beliebteste Universität war. Nur im zweiten und im fünften Abschnitt kommt es zu Abweichungen. Zwischen 1463 und 1469 könnte man den Bedeutungsverlust auf die Kriegszeiten in Pommern sowie die Wirren innerhalb der Universität nach der Ermordung Heinrich Rubenows zurückführen. Von 1484 bis 1490 fällt eine Erklärung, wie bereits erwähnt, schwerer, da die Rostocker Krise für gewöhnlich einen Anstieg der Greifswalder Zahlen bewirkt hat. Daß Leipzig in diesem Abschnitt den höchsten Anteil hat, reicht kaum als Erklärung aus, da sogar Rostock die Greifswalder Zahlen überbietet. Ob es tatsächlich die Pest von 1485 war, die viele Stargarder bewegt hat, in den folgenden Jahren die pommersche Universität zu umgehen, kann nicht eindeutig beantwortet werden, doch erscheint dies zumindest plausibel.

Wenn auch die Greifswalder Universität bis 1504 die meisten Immatrikulierten aus Stargard vorwies, so ist die Entwicklung doch eher von rückläufiger Tendenz, denn über die Hälfte der Studenten besuchte seit 1484 bereits andere Universitäten. Dies hing offensichtlich mit einer regelmäßigeren Beteiligung in Leipzig zusammen, die seit 1484 zu beobachten war. Aus der folgenden Grafik geht außerdem der Bedeutungsverlust hervor, den die Greifswalder Universität bei den Stargardern seit 1505 erlebt hat, als sie nur noch Werte unter 30 Prozent erreicht. 

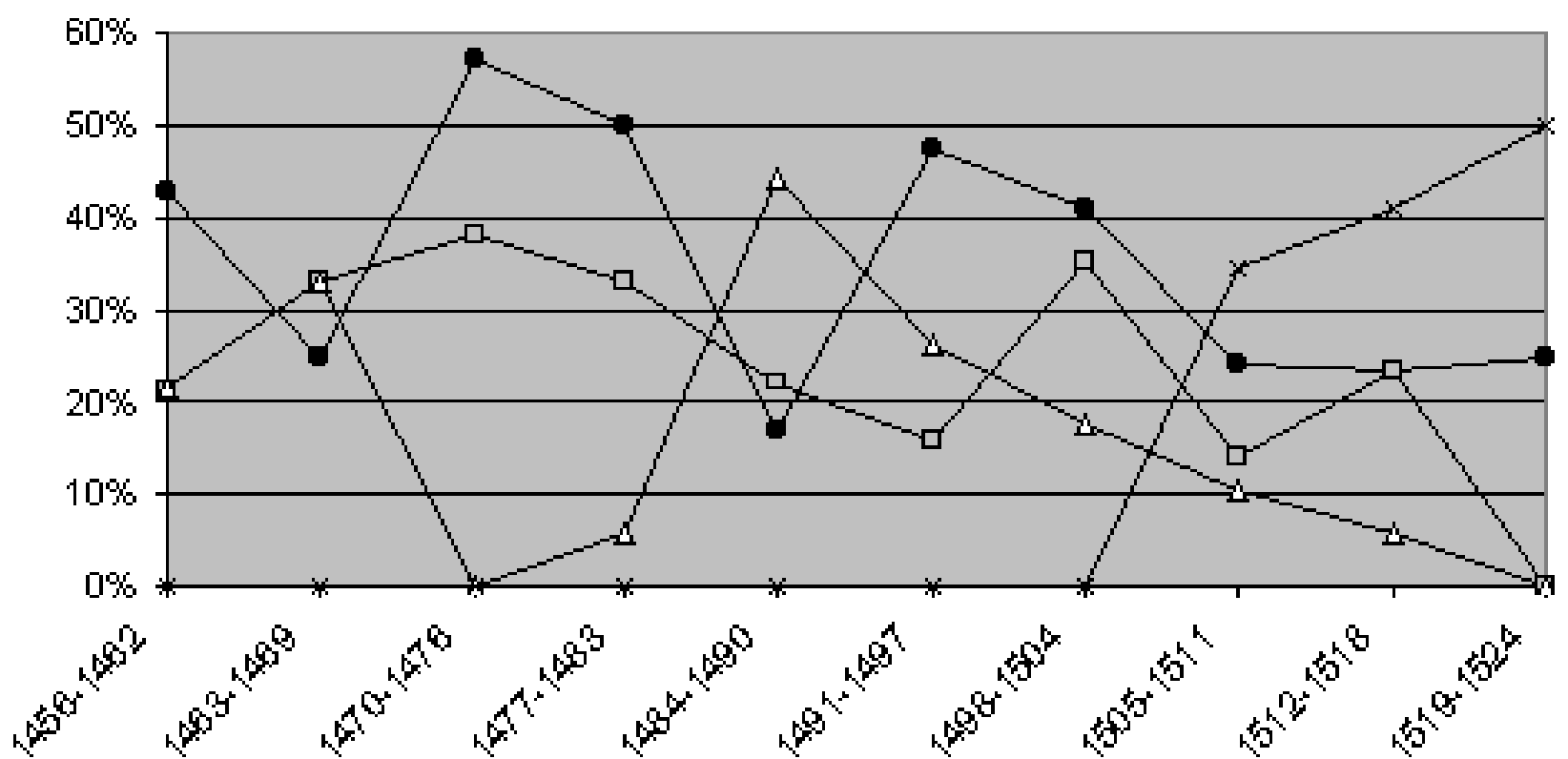

\section{Greifswald $\rightarrow \square$ Rostock $\rightarrow-$ Leipzig $\rightarrow-$ Frankfurt}

Abbildung 45: Stargarder Studenten (Anteil Universitäten an der Gesamtfrequenz)

\subsubsection{Pasewalk: von Leipzig nach Greifswald}

Die kleine Stadt Pasewalk liegt süd-östlich von Greifswald und war mit 38 Studenten am neuen Studium beteiligt. Auch hier ist eine stärkere Bindung an die eigene Heimatuniversität festzustellen, denn nur 22 Studenten besuchten im behandelten Zeitraum eine andere Universität. Dabei erreichte Leipzig mit acht Studenten ein besseres Ergebnis als Rostock, wo sich zwischen 1456 und 1524 nur sieben Pasewalker eingeschrieben hatten. Die Leipziger Einschreibungen fanden in den ersten beiden Abschnitten zwischen 1456 und 1469 sowie im vorletzten Abschnitt zwischen 1505 und 1511 statt, während die Rostocker Studenten sich recht gleichmäßig verteilen. Nur zwischen 1505 und 1511 kommt es auch hier zu einer Ansammlung von drei Studenten. Vier Personen fanden seit der Neugründung den Weg nach Frankfurt, die alle bis 1518 erschienen sind. Das gleiche gilt für Wittenberg, wo sich allerdings nur drei Studenten inskribierten. Vor der Greifswalder Universitätsgründung steht wiederum Leipzig an der Spitze der beliebtesten Universitätsorte mit weiteren acht Immatrikulationen, gefolgt von Prag mit vier. Drei Inskriptionen fielen auf Bologna, zwei auf Rostock. Insgesamt erhält man 77 Studenten dieser Herkunft, von denen 17 bis 1456 und 60 danach ihr Studium begannen (vgl. folgende Tabelle).

Tabelle 16: Studenten aus Pasewalk bis 1524

\begin{tabular}{|l|l|l|r|}
\hline Universität & Vor 1456 & $1456-1524$ & Gesamt \\
\hline \hline Greifswald & 0 & 38 & 38 \\
\hline
\end{tabular}




\begin{tabular}{|l|l|l|r|}
\cline { 2 - 4 } \multicolumn{1}{c|}{} & $0,0 \%$ & $63,3 \%$ & $49,4 \%$ \\
\hline Leipzig & 8 & 8 & 16 \\
\hline Rostock & $47,1 \%$ & $13,3 \%$ & $20,8 \%$ \\
\hline Frankfurt & 2 & 7 & 9 \\
\hline & $14,3 \%$ & $11,7 \%$ & $11,7 \%$ \\
\hline Prag & 0 & 4 & 4 \\
\hline & $0,0 \%$ & $6,7 \%$ & $5,2 \%$ \\
\hline Wittenberg & 4 & 0 & 4 \\
\hline & $23,5 \%$ & $0,0 \%$ & $3,2 \%$ \\
\hline Bologna & 0 & 3 & $3,9 \%$ \\
& $0,0 \%$ & $5,0 \%$ & 3 \\
& 3 & 0 & $3,9 \%$ \\
\hline \hline Gesamt & $17,6 \%$ & $0,0 \%$ & $100,0 \%$ \\
\hline
\end{tabular}

Die Gesamtfrequenz der Pasewalker Studenten ist von drei Phasen gekennzeichnet, in denen etwas höhere Immatrikulationswerte erreicht werden: in der Anfangszeit bis etwa 1469, zwischen 1491 und 1497 sowie von 1505 bis 1518, als sich aufgrund der Neugründungen insgesamt die meisten Studenten immatrikulierten. Aus dieser Beobachtung kann man schließen, daß die neuen Konkurrenzuniversitäten nicht etwa die Greifswalder Zahlen beeinträchtigt haben, sondern daß sie eher eine Mobilisierung zum Studium bewirkten. Ein Grund für den Anstieg in den neunziger Jahren, der fast ausschließlich von Greifswald getragen wird, ist nur schwer zu finden, denn die Zahlen verlaufen ansonsten recht gleichmäßig mit zwei bis vier Studenten pro Jahrsiebt (vgl. folgende Grafik). Der Anteil der Greifswalder Universität an der Gesamtfrequenz bleibt im längsten Zeitraum sehr hoch. Von 1470 bis etwa 1504 spielen die anderen Universitäten so gut wie überhaupt keine Rolle. Erst die Gründung der neuen Universitäten führt zu einer leichten Verschlechterung des Greifswalder Anteils. Der letzte Abschnitt kann aufgrund der niedrigen Frequenzrate nur als Ausnahmefall gelten. 


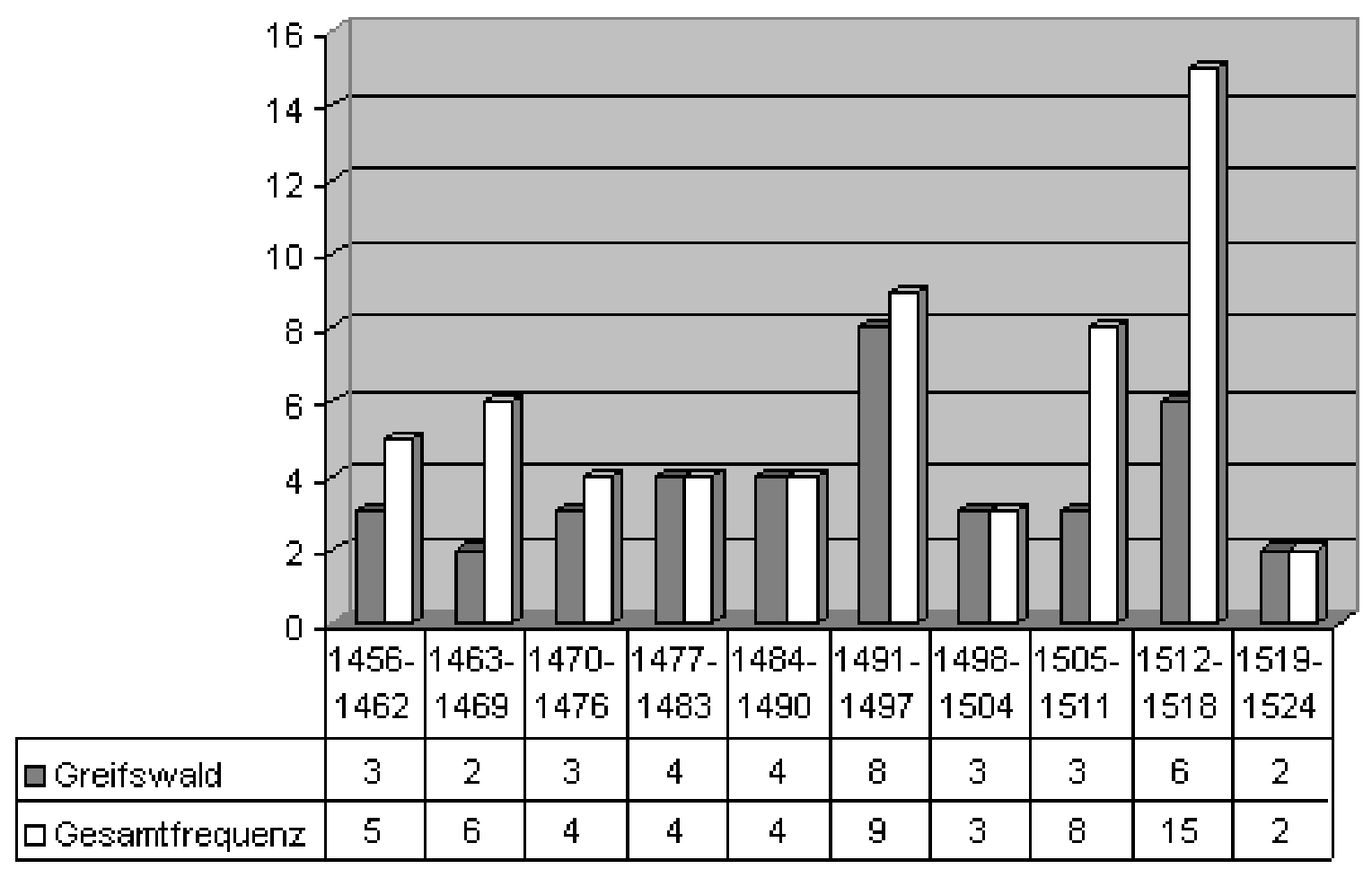

Abbildung 46: Studenten aus Pasewalk (Greifswald - Gesamtfrequenz)

\subsubsection{Pyritz: höhere Beteiligung am Leipziger Studium}

Die pommersche Stadt Pyritz wies eine Beteiligung von 28 Studenten am Greifswalder Studium auf. Das Studium in anderen Universitäten soll im folgenden dargelegt werden.

Als Landesuniversität erreichte Greifswald den höchsten Anteil, denn mehr als die Hälfte aller Pyritzer zog dorthin. Insgesamt gingen zwischen 1456 und 152462 Personen zum Studium. Nicht etwa die mecklenburgische Nachbaruniversität, sondern Leipzig steht in der Beliebtheit der Pyritzer an zweiter Stelle (16 Eintragungen). Zählt man alle Studenten des Mittelalters zusammen (+11), so beträgt der Abstand Greifswalds nur noch eine Person (27). Danach folgt die Universität Frankfurt, die acht Pyritzer verzeichnete. Allein sieben kamen im ersten Abschnitt nach der Gründung zwischen 1505 und 1511. Erst jetzt folgt die mecklenburgische Universität, die insgesamt nur sechs Studenten vorwies, alle nach 1456. Erfurt war offensichtlich vor allem vor der Greifswalder Gründung ein beliebtes Studienziel der Pyritzer. Bis 1456 ließen sich fünf Studenten nachweisen, während in der Zeit danach nur noch einer dorthin zog. Je zwei Eintragungen fielen außerdem auf die Universitäten Köln, Wien und Prag, wobei die Kölner Studenten und ein Wiener zwischen 1456 und 1524 immatrikuliert wurden, während der andere Wiener und die beiden Prager Studenten vor der Universitätsgründung in Pommern erschienen sind. Zusammen erhält man 81 Studenten, von denen 19 bis 1456 studierten. Aus der folgenden Tabelle geht hervor, daß die Frequenz durch einen Anstieg gekennzeichnet ist. Nur 18 Studenten kamen in der ersten Hälfte des Betrachtungszeitraums. Zwischen 1491 und 1524 kann sich die Zahl mehr als verdoppeln (44). Auch die Greifswalder Universität kann ihren Anteil deutlich steigern von einem Drittel auf die Hälfte aller Pyritzer 
Einschreibungen.

Tabelle 17: Pyritzer Studenten bis 1524

\begin{tabular}{|c|c|c|c|c|}
\hline Universität & Vor 1456 & 1456-1490 & 1491-1524 & Gesamt \\
\hline \multirow[t]{2}{*}{ Greifswald } & 0 & 6 & 22 & 28 \\
\hline & $0,0 \%$ & $33,3 \%$ & $50,0 \%$ & $34,6 \%$ \\
\hline \multirow[t]{2}{*}{ Leipzig } & 11 & 5 & 11 & 27 \\
\hline & $57,9 \%$ & $27,8 \%$ & $25,0 \%$ & $33,3 \%$ \\
\hline \multirow[t]{2}{*}{ Frankfurt } & 0 & 0 & 8 & 8 \\
\hline & $0,0 \%$ & $0,0 \%$ & $18,2 \%$ & $9,9 \%$ \\
\hline \multirow[t]{2}{*}{ Rostock } & 0 & 3 & 3 & 6 \\
\hline & $0,0 \%$ & $16,7 \%$ & $6,8 \%$ & $7,4 \%$ \\
\hline \multirow[t]{2}{*}{ Köln } & 0 & 2 & 0 & 2 \\
\hline & $0,0 \%$ & $11,1 \%$ & $0,0 \%$ & $2,5 \%$ \\
\hline \multirow[t]{2}{*}{ Erfurt } & 5 & 1 & 0 & 6 \\
\hline & $26,3 \%$ & $5,6 \%$ & $0,0 \%$ & $7,4 \%$ \\
\hline \multirow[t]{2}{*}{ Wien } & 1 & 1 & 0 & 2 \\
\hline & $5,3 \%$ & $5,6 \%$ & $0,0 \%$ & $2,5 \%$ \\
\hline \multirow[t]{2}{*}{ Prag } & 2 & 0 & 0 & 2 \\
\hline & $10,5 \%$ & $0,0 \%$ & $0,0 \%$ & $2,5 \%$ \\
\hline \multirow[t]{2}{*}{ Gesamt } & 19 & 18 & 44 & 81 \\
\hline & $100,0 \%$ & $100,0 \%$ & $100,0 \%$ & $100,0 \%$ \\
\hline
\end{tabular}




\subsubsection{Orte in Hinterpommern}

\subsubsection{Kolberg: Küstenorte und Ostseeuniversitäten}

Mit Kolberg trifft man auf einen Ort, der in etwas größerer Entfernung zur Universitätsstadt im hinteren Pommern liegt. Trotz dieses Umstands erreicht die Hansestadt mit 84 Eintragungen einen recht hohen Anteil am Greifswalder Studium. Im folgenden soll die Beteiligung der Kolberger an den anderen Universitäten dargestellt werden.

Wie nicht anders zu erwarten, reichte keine andere Universität an die Zahlen in Greifswald heran. Die neue Universität wurde als eigene Landesuniversität von 55 Prozent aller Kolberger Studenten bevorzugt, und dies trotz der wachsenden Zahl verschiedener Konkurrenzuniversitäten. Recht hoch sind trotzdem auch die Werte, die in Rostock erreicht werden. Zwischen 1456 und 1524 werden immerhin 60 Kolberger immatrikuliert, bei denen es sich zum Teil um bereits in Greifswald promovierte Personen handelt, die ein weiteres Studium anschlossen. Die Rostocker Immatrikulationen können sogar zwischen 1463 und 1476 den Greifswalder Anteil übertreffen, wo die eigentliche Hauptzeit erst etwa 1477 beginnt. In den folgenden Jahren wird Greifswald eindeutig bevorzugt und sehr wenige Kolberger sind bis etwa 1497 in Rostock zu finden. Nach einen leichten Anstieg im folgenden Abschnitt kommt es zu einem stärkeren Zuwachs zwischen 1505 und 1518. Dieser verlief allerdings parallel zu den Greifswalder Inskriptionen. Im letzten Abschnitt kommt es auch hier wieder zu einem Rückgang.

Die Kolberger scheint es weniger auf fremde Universitäten gezogen zu haben, denn seit der Greifswalder Gründung ist eine Konzentration auf die beiden Ostseeuniversitäten erkennbar. Erst mit der Neugründung in Frankfurt kommt ein Studienziel hinzu, daß durch die Nähe zum Heimatort einige Studenten anziehen konnte. Insgesamt wird durch die Kürze des Zeitraums allerdings nur eine Zahl von sieben Studenten erreicht, die sich in den letzten beiden Abschnitten dort einfanden. Auch wenn man die Zahl hier auf den Zeitraum von 68 Jahren hochrechnen würde, käme man nur auf etwa 24 Studenten, so daß beide Ostseeuniversitäten durch die Neugründung kaum beeinträchtigt worden sind. In Leipzig fand sich ebenfalls eine Kolberger Eintragung. Da die Immatrikulation des Petrus Persevaldi de Colberga in Löwen keine Eingrenzung durch eine weitere Herkunftsangabe hat, muß hier auf eine Berücksichtigung verzichtet werden, so daß man auf eine Gesamtzahl von 152 Immatrikulierten stößt.

Die Frequenz der Kolberger auf den Universitäten wird in der folgenden Grafik dargestellt. Darin kommt der Anstieg in der zweiten Hälfte des Zeitraums, der schon vorher für Greifswald ermittelt werden konnte, besonders ab 1505 zum Ausdruck. Bis auf den Einbruch Mitte der achtziger Jahre steigen die Werte während des gesamten Zeitraums sehr stark, und erleben erst im letzten Abschnitt dann wieder einen Rückgang. 


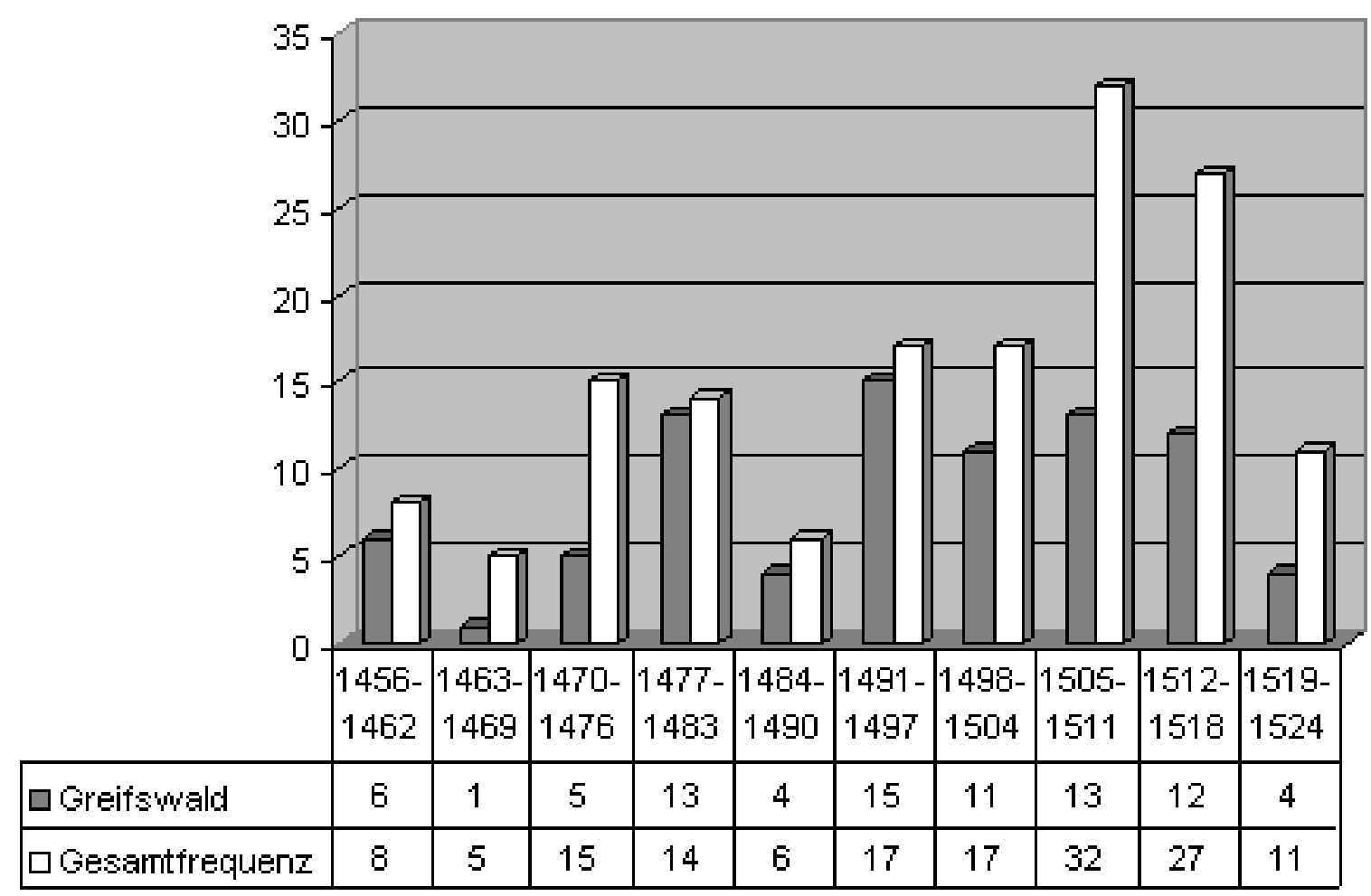

Abbildung 47: Kolberger Studenten (Greifswald - Gesamtfrequenz)

Da die Zahlen während des Zeitraums einen Anstieg der Immatrikulationen zu erkennen geben, stellt sich die Frage, wie das Studienverhalten vor der Universitätsgründung war und welche Universitäten von Kolbergern vornehmlich besucht wurden.

Nur 37 Kolberger konnten bis 1456 ermittelt werden (vgl. folgende Tabelle). Der starke Anstieg in der zweiten Hälfte des Betrachtungszeitraums markiert daher tatsächlich den Beginn regelmäßiger Studienbeteiligung. Selbst die Rostocker Universität wurde erst in späteren Zeiten stärker frequentiert. 12 Studenten sind dort bis 1456 erschienen, Prag hatte seine 10 Studenten bereits bis 1409 zu verzeichnen. Leipzig und Erfurt gehörten seit der Prager Sezession bis zur Rostocker Gründung zu den beliebtesten Studienorten der Kolberger (7 und 5 Eintragungen), während Bologna zwei, Köln lediglich einen Studenten vorwies.

Tabelle 18: Kolberger Studenten bis 1524

\begin{tabular}{|l|l|l||r|}
\hline Universität & Vor 1456 & 1456 bis 1524 & Gesamt \\
\hline \hline Greifswald & 0 & 84 & 84 \\
\hline & $0,0 \%$ & $55,3 \%$ & $44,4 \%$ \\
\hline Rostock & 12 & 60 & 72 \\
\hline & $32,4 \%$ & $39,5 \%$ & $38,1 \%$ \\
\hline Prag & 10 & 0 & 10 \\
\hline & $27,0 \%$ & $0,0 \%$ & $5,3 \%$ \\
\hline
\end{tabular}




\begin{tabular}{|l|l|l||r|}
\hline Leipzig & 7 & 1 & 8 \\
& $18,9 \%$ & $0,7 \%$ & $4,2 \%$ \\
\hline Frankfurt & 0 & 7 & 7 \\
\hline & $0,0 \%$ & $4,6 \%$ & $3,7 \%$ \\
\hline Erfurt & 5 & 0 & 5 \\
\hline & $13,5 \%$ & $0,0 \%$ & $2,6 \%$ \\
\hline Bologna & 2 & 0 & 2 \\
\hline & $5,4 \%$ & $0,0 \%$ & $1,1 \%$ \\
\hline Köln & 1 & 0 & 1 \\
\hline & $2,7 \%$ & $0,0 \%$ & 189 \\
\hline Gesamt & 37 & 152 & $100,0 \%$ \\
\hline & $100,0 \%$ & $100,0 \%$ & \\
& & &
\end{tabular}

Trotz des Kolberger Immatrikulationsanstiegs, der auch in Greifswald zu beobachten war, ist seit 1491 ein Bedeutungverlust der pommerschen Landesuniversität zu kontatieren, bei dem die Werte von fast 90 Prozent auf weniger als 40 sanken (vgl. folgende Grafik). Er wird verursacht durch eine erhebliche Steigerung des Niveaus in Rostock, aber auch durch die neue Frankfurter Universität. Nur in der Zeit zwischen 1477 und 1504 war die pommersche Hohe Schule für Kolberg die wichtigste Bildungseinrichtung, als sie Werte zwischen 70 und 90 Prozent an der Gesamtfrequenz erzielte. Zur Gründungszeit der Greifswalder Universität sehen wir uns außerdem einer hohen Anfangsbeteiligung gegenüber (fast 80\%), die dann zwischen 1463 und 1476 unter 50 Prozent zurückfällt.

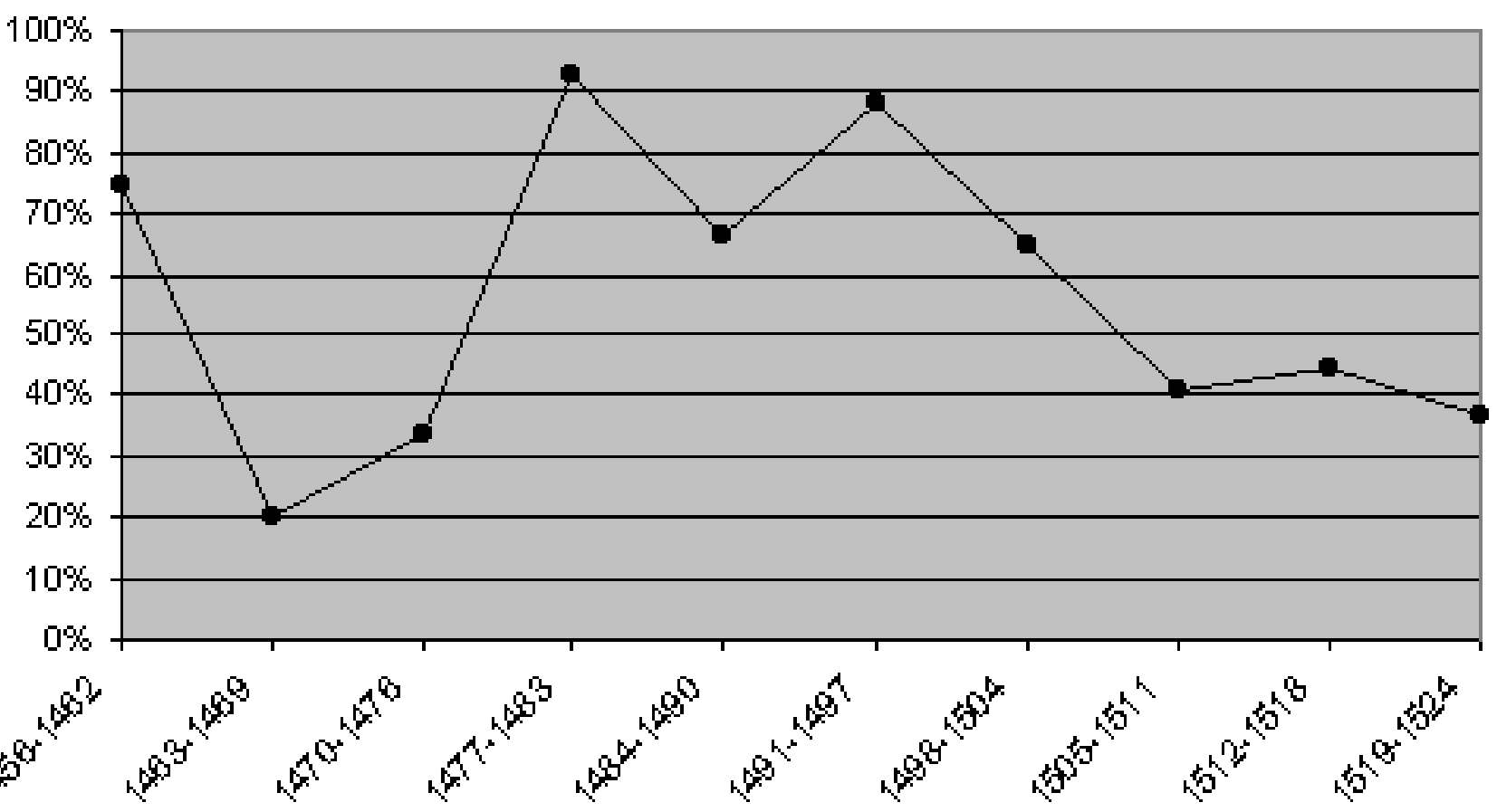


Abbildung 48: Kolberger Studenten (Anteil Greifswalds an der Gesamtfrequenz)

\subsubsection{Stolp: Distanz führt zu größerer Vielfalt}

Die hinterpommersche Hansestadt Stolp liegt zwar in recht großer Entfernung von Greifswald, mit 42 Studenten hatte sie dennoch einen recht hohen Anteil am Studium der Landesuniversität Pommerns. Auch in diesem Fall muß man berücksichtigen, daß es einige gleichnamige Orte in Pommern gibt, doch waren sie von geringerer Bedeutung als die Hansestadt. Bei den Matrikeln der entfernten Universitäten ist außerdem nicht immer klar, ob vielleicht das sächsische Stolpen gemeint ist, da die Rektoren auf eine Unterscheidung weitgehend verzichteten. Da die Entfernung Stolps von allen anderen Reichsuniversitäten größer war als die zu Greifswald, hätte man auch bei der Wahl des Studienortes eine mehr oder weniger klare Dominanz der eigenen Landesuniversität erwarten können. Dem war jedoch nicht so, wie aus den anderen Universitätsmatrikeln hervorgeht. Mit einem Unterschied von einem Studenten wurde in Rostock eine größere Zahl Stolper eingeschrieben als in Greifswald. Trotz der Unsicherheit hinsichtlich einer genauen Zuordnung macht dieser Umstand einmal mehr die starke Konkurrenzwirkung Rostocks deutlich: je größer die Entfernung zur landeseigenen Universität wurde, desto eher entschied man sich für die ältere und bekanntere mecklenburgische Nachbaruniversität. Während der erste Abschnitt aufgrund des größeren Interesse an einer Neugründung noch gleiche Zahlen brachte (7), blieb Rostock bis etwa zur Jahrhundertwende die beliebtere Universität, wo sich vier bis sieben Stolper pro Jahrsiebt einschreiben ließen. Seit dem Aufenthalt der italienischen Humanisten kehrt sich das Verhältnis allerdings um, denn die Greifswalder übertreffen von nun an die Rostocker Zahlen (20 gegenüber 9). Die fehlenden Greifswalder Inskriptionen zwischen 1505 und 1511 hingen sicherlich mit der Frankfurter Neugründung zusammen, denn dort ist ein erheblicher Gründungserfolg zu verzeichnen. Unklar bleibt, warum er keine Auswirkung auf Rostock gezeigt hat, da die Zahlen dort sogar recht hoch sind (7). Andererseits fällt der Greifswalder Anstieg (10) im nächsten Abschnitt auf. Auch hier bekommt man den Eindruck eines Immatrikulationsstaus, der vielleicht in den lokalen Verhältnissen seine Ursache findet.

Aufgrund des Anfangserfolg stellt Frankfurt ebenfalls einen größeren Anteil Stolper Studenten. Von den 17 dort eingeschrieben Personen kamen 12 zwischen 1505 und 1511, vier ließen sich im letzten Abschnitt immatrikulieren. Leipzig folgt mit 10 Studenten, die sich vor allem auf den ersten sowie den achten und neunten Abschnitt konzentrieren. Mit je zwei Studenten sind außerdem noch Wittenberg und Erfurt zu nennen sowie die Universitäten Köln und Ingolstadt mit je einem. Zusammen erhält man im behandelten Zeitraum 118 Studenten. Vor der Greifswalder Gründung gingen außerdem sieben Studenten nach Rostock, fünf nach Prag, vier nach Leipzig und zwei nach Wien, so daß man der Gesamtzahl weitere 18 Studenten hinzurechnen muß. Über 70 Prozent der Stolper verteilen sich zwischen 1456 und 1524 auf die beiden Ostseeuniversitäten (vgl. folgende Grafik). 


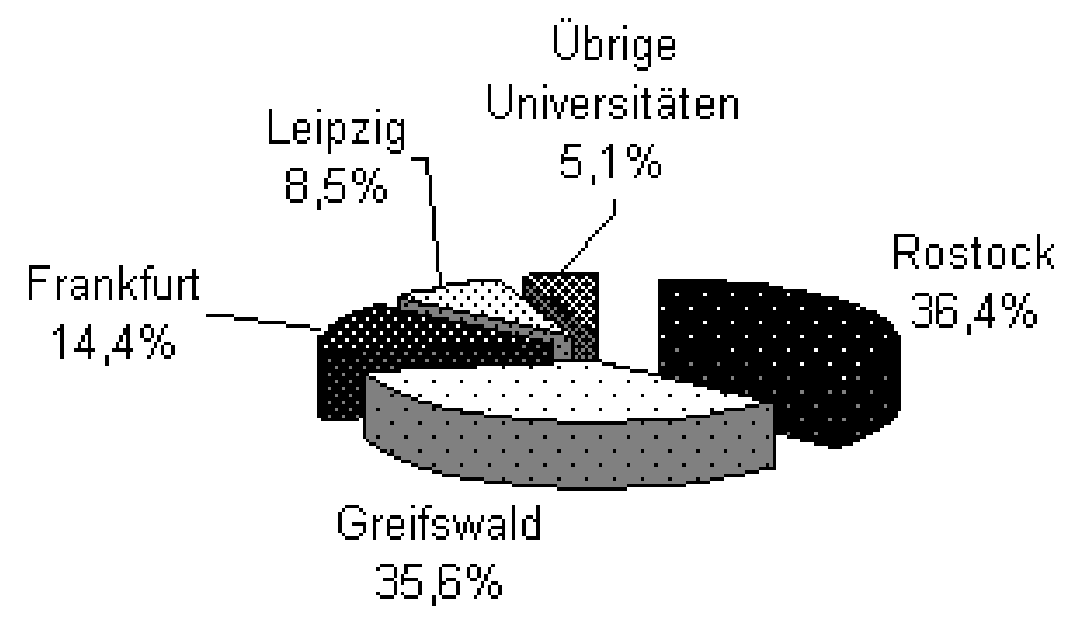

Abbildung 49: Stolper Studenten 1456-1524 (Verteilung auf Universitäten)

Auch die Stolper Frequenzkurve steigt insbesondere in den letzten Abschnitten. Vor allem die neugegründeten Universitäten bewirkten daher offenbar eine stärkere Mobilisierung zum Studium. Nur in den Jahren 1463 bis 1476 sowie 1498 bis 1504 kommt es zu leichten Rückgängen, wie aus der folgenden Grafik zu ersehen ist, doch bleibt die Gesamttendenz eher zunehmend.

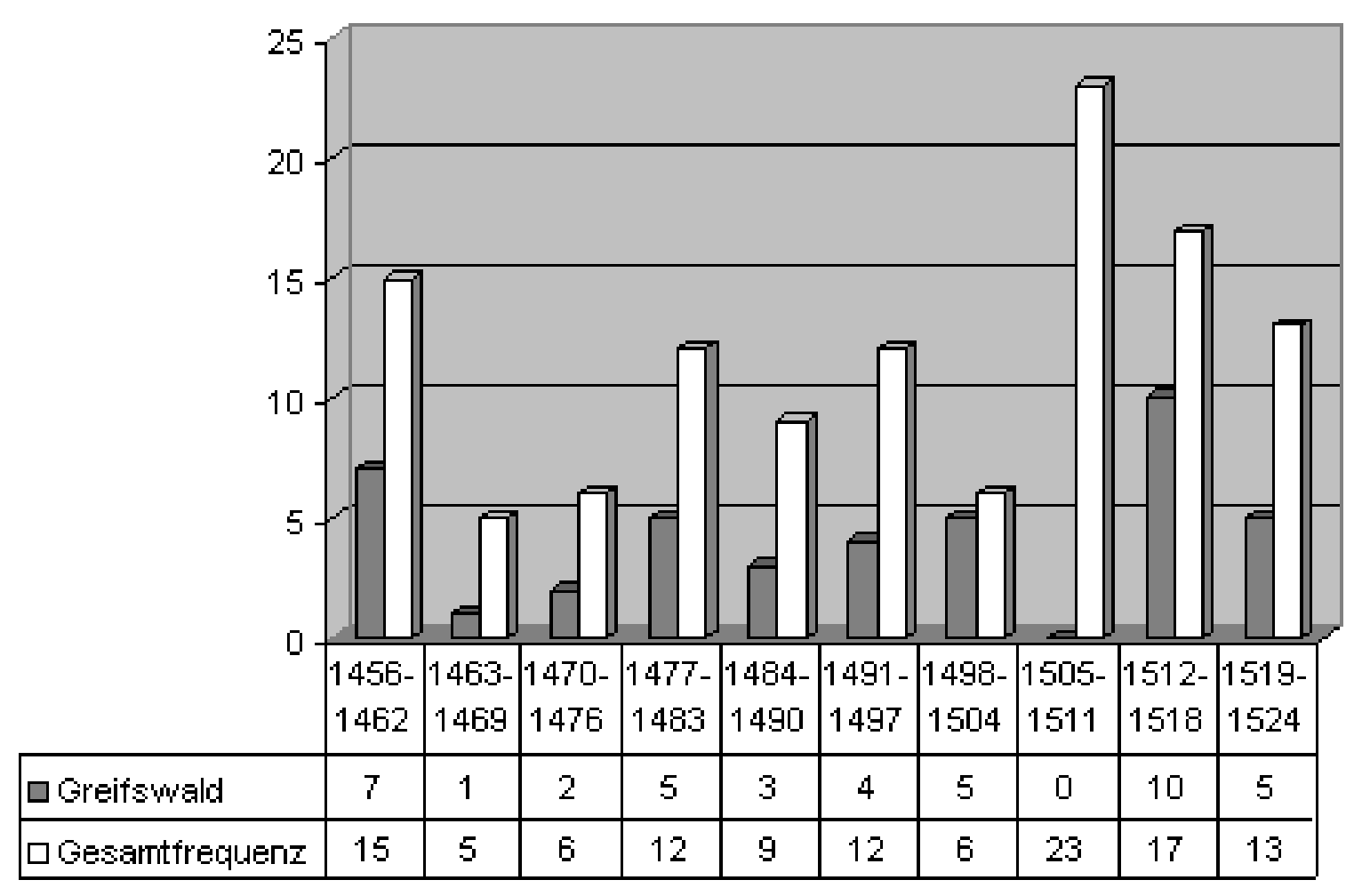

Abbildung 50: Stolper Studenten (Greifswald - Gesamtfrequenz)

Um die Bedeutungsveränderung der einzelnen Universitäten darzustellen, wurde in der folgenden 
Grafik deren prozentualer Anteil in den einzelnen Abschnitten als Entwicklung skizziert. Aus ihr geht hervor, daß der Greifswalder Anteil seit 1463 eine steigende Tendenz hatte, während die Rostocker Universität bis zum Ende des Betrachtungszeitraums an Bedeutung verloren hat. Für die Greifswalder Zahlen müssen die Abschnitte sieben und acht als Ausnahme gelten, denn bei dem einen zogen die italienischen Humanisten fast alle Stolper dorthin, im anderen wird das neugegründete Frankfurt der eigenen Universität vorgezogen.

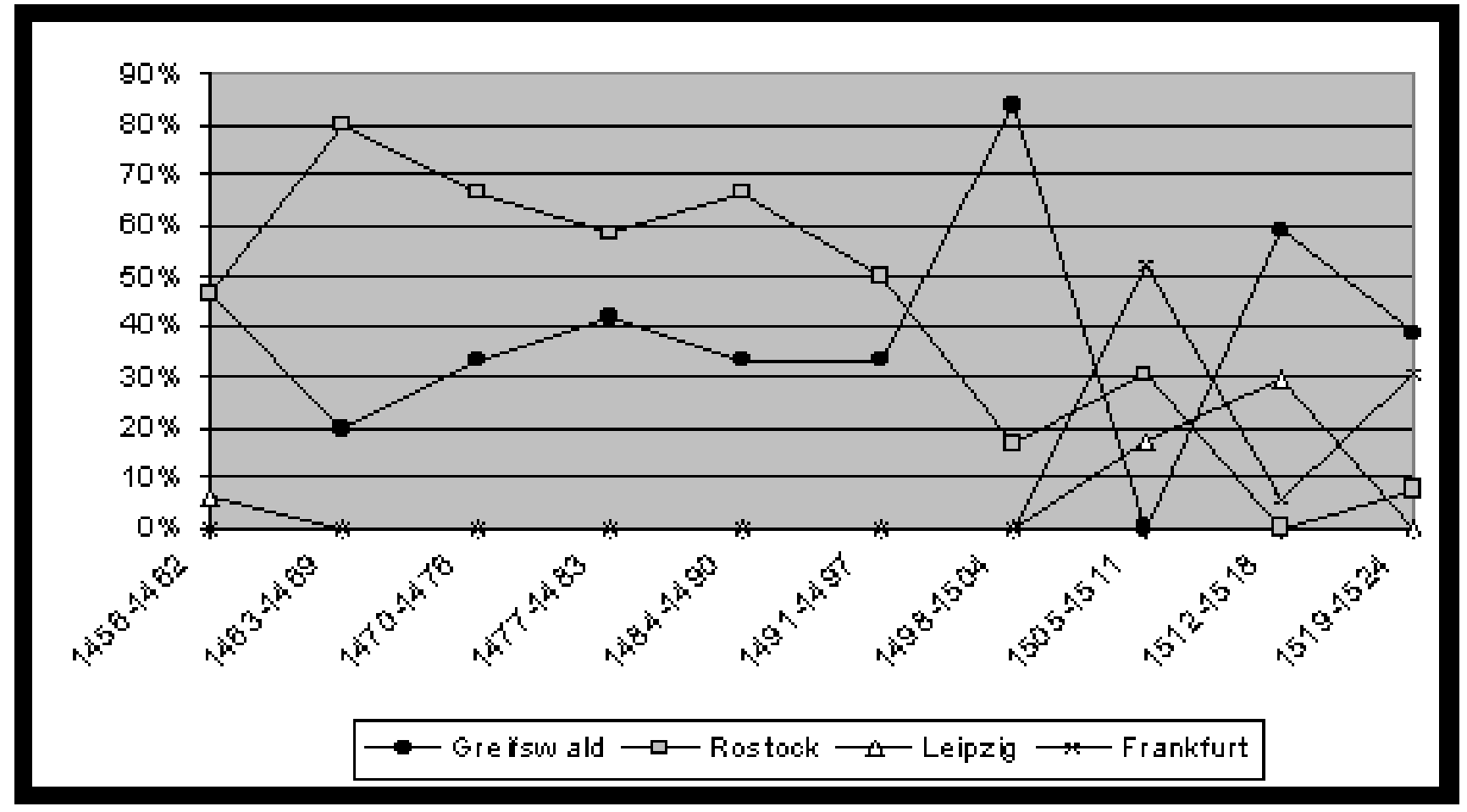

Abbildung 51: Stolper Studenten (Anteil Universitäten an der Gesamtfrequenz)

\subsubsection{Treptow an der Rega: Zuwachs an den Ostseeuniversitäten}

Aus der Hansestadt Treptow an der Rega zogen im behandelten Zeitraum insgesamt 36 Studenten nach Greifswald. Der Ort ist auch unter dem Namen Neutreptow bekannt, denn ein zweites Treptow befindet sich an der Tollense ebenfalls in Pommern. Ähnliche Ortsnamen finden sich mehrfach in Deutschland, so daß eine genaue Zuordnung nicht immer möglich war. Im folgenden werden diese nicht gesicherten Ortsangaben ausdrücklich erwähnt.

Mit 25 Verzeichnungen war Treptow im Rostocker Matrikelbuch eingetragen. 20 von diesen Studenten gaben nicht an, ob sie aus dem Ort im hinteren Pommern stammen. Erst im zweiten Abschnitt tauchen sie dort auf, während im Ersten alle Einschreibungen der Neugründung vorbehalten waren. Zwischen 1491 und 1497 sowie zwischen 1505 und 1511 trifft man auf die höchste Immatrikulationsquote (6 und 7). Ansonsten liegt die Zahl fast immer etwas unter der in Greifswald. Seit der Neugründung in Frankfurt sind auch dort einige Studenten aus Treptow erschienen. Die fünf Immatrikulationen sind auf alle drei Abschnitte verteilt. Auch in Wittenberg wurden fünf Personen aus Treptow inskribiert, allerdings nur im letzten Abschnitt, als Martin Luther dort zu Bekanntheit gelangte. Leipzig und Köln hatte jeweils eine Immatrikulation zu verzeichen, 
doch bleibt unklar, ob sich die Herkunftangabe "Trepko" im Kölner Matrikelbuch tatsächlich auf die pommersche Hansestadt bezieht. Auch der Leipziger Rektor verzichtete auf eine genauere Eingrenzung des Herkunftsortes, so daß man auf Vermutungen angewiesen bleibt. Zählt man alle Einschreibungen zusammen, so erhält man 73 Einschreibungen, die zwischen 1456 und 1524 an allen Universitäten erfolgten. Vorher konnten außerdem noch fünf Studenten aus Treptow ermittelt werden, deren Zuordnung allerdings ebenfalls nicht sicher ist. Es handelt sich um je zwei Prager und Leipziger sowie einem Rostocker Scholaren, womit die Gesamtzahl auf 78 ansteigt (vgl. folgende Tabelle).

Tabelle 19: Studenten aus Treptow bis 1524

\begin{tabular}{|c|c|c|c|}
\hline Universität & Vor 1456 & 1456-1524 & Gesamt \\
\hline \multirow[t]{2}{*}{ Greifswald } & 0 & 36 & 36 \\
\hline & $0,0 \%$ & $49,3 \%$ & $46,2 \%$ \\
\hline \multirow[t]{2}{*}{ Rostock } & 1 & 25 & 26 \\
\hline & $20,0 \%$ & $34,2 \%$ & $33,3 \%$ \\
\hline \multirow[t]{2}{*}{ Frankfurt } & 0 & 5 & 5 \\
\hline & $0,0 \%$ & $6,8 \%$ & $6,4 \%$ \\
\hline \multirow[t]{2}{*}{ Wittenberg } & 0 & 5 & 5 \\
\hline & $0,0 \%$ & $6,8 \%$ & $6,4 \%$ \\
\hline \multirow[t]{2}{*}{ Leipzig } & 2 & 1 & 3 \\
\hline & $40,0 \%$ & $1,4 \%$ & $3,8 \%$ \\
\hline \multirow[t]{2}{*}{ Wien } & 2 & 0 & 2 \\
\hline & $40,0 \%$ & $0,0 \%$ & $2,6 \%$ \\
\hline \multirow[t]{2}{*}{ Köln } & 0 & 1 & 1 \\
\hline & $0,0 \%$ & $1,4 \%$ & $1,3 \%$ \\
\hline Gesamt & $\begin{array}{l}5 \\
100,0 \%\end{array}$ & $\begin{array}{l}73 \\
100,0 \%\end{array}$ & $\begin{array}{r}78 \\
100,0 \%\end{array}$ \\
\hline
\end{tabular}

Die Gesamtfrequenz verläuft mit ansteigender Tendenz. Leichte Rückgange sind nur zwischen 1463 und 1469 sowie zwischen 1498 und 1504 zu verzeichen, wie aus der folgenden Grafik hervorgeht. In der zweiten Hälfte des Betrachtungszeitraums können sich die Immatrikulationszahlen mit 48 gegenüber 25 Eintragungen fast verdoppeln, doch sinkt der Greifswalder Gesamtanteil trotz numerischen Zuwachses von 60 auf 43 Prozent. 


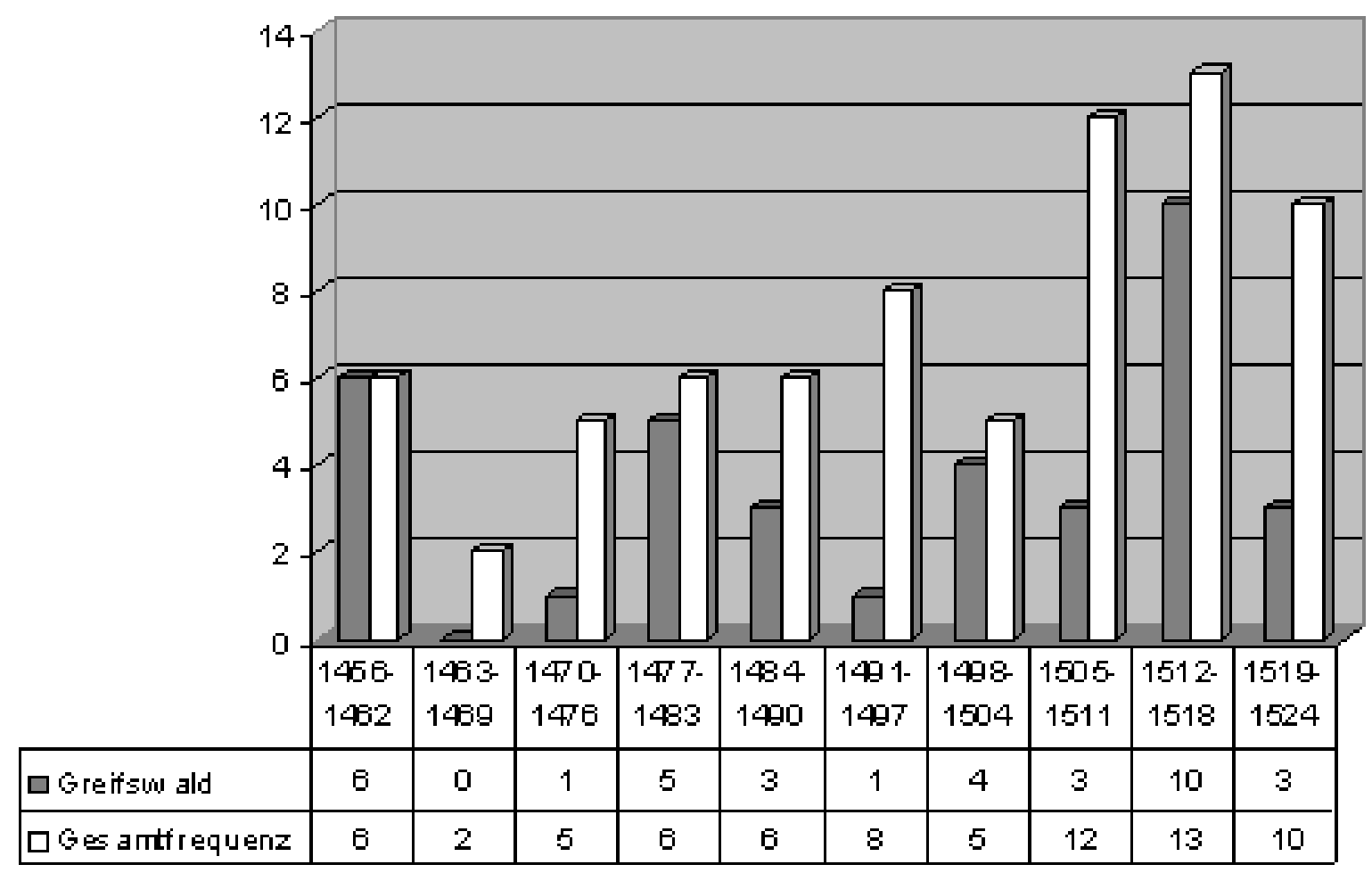

Abbildung 52: Studenten aus Treptow (Greifswald - Gesamtfrequenz)

\subsubsection{Belgard: geringe Frequenz und dominierende Stellung Greifswalds}

Nur 40 Studenten konnten insgesamt aus der Hansestadt Belgard im hinteren Pommern nachgewiesen werden. Mit 29 Inskriptionen erreicht Greifswald hier eine äußerst dominierende Stellung. Selbst die Universität Rostock stellt mit ihren drei Einschreibungen, die alle in den siebziger Jahren erfolgten, keine Konkurrenz dar. Leipzig erreichte mit vier Einschreibungen zwar eine höhere Zahl, doch kamen drei der Studenten bereits vor 1456. Daneben waren Belgarder nur in Frankfurt (2) und Wittenberg (1) zu finden. Prag verzeichnete außerdem eine Immatrikulation vor der Greifswalder Gründung, so daß man insgesamt vier Belgarder vor und 36 nach der Greifswalder Gründung erhält. Zwischen 1456 und 1524 kommt es zu keinem nennenswerten An- oder Abstieg der Zahlen, doch verteilen sich die Immatrikulationen gegen Ende des Betrachtungszeitraums durch die Neugründungen auf mehr Universitäten, so daß der Greifswalder Anteil in der ersten Hälfte bei knapp 85, in der zweiten nur noch bei etwa 75 Prozent liegt (vgl. folgende Tabelle).

Tabelle 20: Belgarder Studenten bis 1524

\begin{tabular}{|l|l|l|l||r||}
\hline Universität & Vor 1456 & $1456-1490$ & $1491-1524$ & Gesamt \\
\hline \hline Greifswald & 0 & 16 & 13 & 29 \\
\hline Leipzig & $0,0 \%$ & $84,2 \%$ & $76,5 \%$ & $72,5 \%$ \\
\hline & 3 & 0 & 1 & 4 \\
\hline Rostock & 0 & $0,0 \%$ & $5,9 \%$ & $10,0 \%$ \\
\hline
\end{tabular}




\begin{tabular}{|l|l|l|l||r|}
\multicolumn{1}{c|}{} & \multicolumn{1}{c|}{$0,0 \%$} & $15,8 \%$ & $0,0 \%$ & $7,5 \%$ \\
\hline Frankfurt & 0 & 0 & 2 & 2 \\
\hline Wittenberg & $0,0 \%$ & $0,0 \%$ & $11,8 \%$ & $5,0 \%$ \\
\hline & 0 & 0 & 1 & 1 \\
\hline Prag & $0,0 \%$ & $0,0 \%$ & $5,9 \%$ & $2,5 \%$ \\
\hline Gesamt & 1 & 0 & 0 & 1 \\
& $25,0 \%$ & $0,0 \%$ & $0,0 \%$ & $2,5 \%$ \\
& 4 & 19 & 17 & $100,0 \%$ \\
\hline
\end{tabular}

\subsubsection{Kammin: Frequenzsteigerung und Bedeutungsgewinn Rostocks}

Bei der Bischofsstadt Kammin fällt es schwer die Bistumsangaben von den Ortsangaben zu unterscheiden. Im Greifswalder Matrikelbuch gab es insgesamt 203 solcher Eintragungen, doch wurden als Stadtbewohner nur solche Studenten gezählt, bei denen der Rektor ausdrücklich die Zugehörigkeit zur Stadt gemeint hat. Die Zahl in Greifswald vermindert sich somit auf 27 Studenten, doch ist die Unterscheidung in anderen Universitäten nicht immer möglich.

Rostock wies zwischen 1456 und 1524 bereits 21 Kamminer Studenten auf, während sich zuvor nur drei Personen dort immatrikuliert hatten. Der Durchschnitt bewegt sich zwischen ein und drei Kamminern pro Jahrsiebt, doch kommt es von 1505 bis 1519 (13) zu einem stärkeren Anstieg. In Greifswald kommt es ebenfalls zu einem Anstieg, der allerdings nur von 1505 bis 1511 (10) andauert. Zusammen erreichen die beiden Abschnitte eine erhebliche Frequenzsteigerung aufgrund der Zuwächse in den beiden Ostseeuniversitäten. Von den neugegründeten Universitäten konnte Wittenberg drei sowie Frankfurt zwei Studenten vorweisen. 1512 zogen außerdem zwei Kamminer nach Ingolstadt, bei denen unklar ist, ob sie nur aus der Diözese stammen. Vor der Greifswalder Universitätsgründung sind neben den drei Immatrikulationen in Rostock noch drei in Prag, zwei in Erfurt sowie je eine in Wien und Heidelberg nachzuweisen, die wahrscheinlich nur als Diözesanangaben zu werten sind. Das gleiche gilt für die fünf Bolgneser Eintragungen, die alle bis zum Jahr 1427 erfolgten. Zusammen erhält man 70 Eintragungen, von denen 15 vor dem Jahr 1456, die übrigen 55 danach erfolgten. Durch die beiden immatrikulationsstärkeren Jahrsiebte zwischen 1505 und 1518, in denen vor allem Rostock zugewinnen kann, kommt es zu einem starken Anstieg der Immatrikulationszahlen in der zweiten Hälfte des Betrachtungszeitraums, bei dem sich die Zahlen mehr als verdoppeln können. Trotz numerischen Zuwachses sinkt der Greifswalder Anteil dabei von 59 auf 45 Prozent (vgl. folgende Tabelle).

Tabelle 21: Kamminer Studenten bis 1524 


\begin{tabular}{|c|c|c|c|c|}
\hline Universität & Vor 1456 & 1456-1490 & 1491-1524 & Gesamt \\
\hline \multirow[t]{2}{*}{ Greifswald } & 0 & 10 & 17 & 27 \\
\hline & $0,0 \%$ & $58,8 \%$ & $44,7 \%$ & $38,6 \%$ \\
\hline \multirow[t]{2}{*}{ Rostock } & 3 & 7 & 14 & 24 \\
\hline & $20,0 \%$ & $41,2 \%$ & $36,8 \%$ & $34,3 \%$ \\
\hline \multirow[t]{2}{*}{ Wittenberg } & 0 & 0 & 3 & 3 \\
\hline & $0,0 \%$ & $0,0 \%$ & $7,9 \%$ & $4,3 \%$ \\
\hline \multirow[t]{2}{*}{ Frankfurt } & 0 & 0 & 2 & 2 \\
\hline & $0,0 \%$ & $0,0 \%$ & $5,3 \%$ & $2,9 \%$ \\
\hline \multirow[t]{2}{*}{ Ingolstadt } & 0 & 0 & 2 & 2 \\
\hline & $0,0 \%$ & $0,0 \%$ & $5,3 \%$ & $3,1 \%$ \\
\hline \multirow[t]{2}{*}{ Bologna } & 5 & 0 & 0 & 5 \\
\hline & $33,3 \%$ & $0,0 \%$ & $0,0 \%$ & $7,1 \%$ \\
\hline \multirow[t]{2}{*}{ Prag } & 3 & 0 & 0 & 3 \\
\hline & $20,0 \%$ & $0,0 \%$ & $0,0 \%$ & $2,9 \%$ \\
\hline \multirow[t]{2}{*}{ Erfurt } & 2 & 0 & 0 & 2 \\
\hline & $13,3 \%$ & $0,0 \%$ & $0,0 \%$ & $2,9 \%$ \\
\hline \multirow[t]{2}{*}{ Wien } & 1 & 0 & 0 & 1 \\
\hline & $6,7 \%$ & $0,0 \%$ & $0,0 \%$ & $1,4 \%$ \\
\hline \multirow[t]{2}{*}{ Heidelberg } & 1 & 0 & 0 & 1 \\
\hline & $6,7 \%$ & $0,0 \%$ & $0,0 \%$ & $1,4 \%$ \\
\hline \multirow[t]{2}{*}{ Gesamt } & 15 & 17 & 38 & 70 \\
\hline & $100,0 \%$ & $100,0 \%$ & $100,0 \%$ & $100,0 \%$ \\
\hline
\end{tabular}

\subsubsection{Köslin: Rückgang der Bedeutung Greifswalds}

Die Hansestadt Köslin liegt im hinteren Pommern und war durch 27 Studenten am Greifswalder Studium beteiligt. Wie nicht anders zu erwarten, war die Gesamtfrequenz an allen Universitäten mit 61 Studenten recht niedrig. Rostock wies 23 Kösliner auf. Drei von ihnen kamen vor der 
Greifswalder Universitätsgründung. Zwischen 1491 und 1511 erfolgten dort die meisten Einschreibungen (15), während sie in den letzten beiden Abschnitten ausblieben. Vorher waren Kösliner nur vereinzelt vertreten, zwischen 1477 und 1490 überhaupt nicht. Auch in Leipzig ließen sich Kösliner (13) einschreiben, doch kam fast die Hälfte (6) vor dem Jahr 1456. Die übrigen Studenten konzentrierten sich vor allem auf die drei Abschnitte zwischen 1498 und 1518. Die sechs Frankfurter Eintragungen waren vor allem im Gründungsabschnitt (5 zwischen 1505 und 1511) zu finden, während eine Wittenberger Einschreibung im letzten Abschnitt erfolgte. Vor der Universitätsgründung verzeichnete Bologna zwei, Erfurt und Prag je einen Kösliner, so daß man bis zum Jahr 1456 auf insgesamt 13 Studenten stößt. Die Gesamtbeteiligung steigt damit auf 74 Studenten im gesamten Mittelalter.

Wie aus der folgenden Tabelle hervorgeht, konnte die Stadt Köslin ihre Studienbeteiligung deutlich steigern. Bereits nach der Hälfte des betrachteten Zeitraums haben sich die Werte mit 22 Studenten verdoppelt gegenüber der Zeit davor. Mit 39 Studenten in den folgenden 34 Jahren kommt es zu einer weiteren Steigerung um fast 80 Prozent. Auffällig ist allerdings der Bedeutungsrückgang, den Greifswald erlebt. Nur in der ersten Hälfte kann die pommersche Universität 68 Prozent aller Studenten anziehen. Aufgrund des Rostocker Anstiegs sowie der Frankfurter Neugründung fällt der Anteil auf 31 Prozent zurück. In dieser Phase verzeichnet Rostock mehr Studenten als die eigene Landesuniversität.

Tabelle 22: Kösliner Studenten bis 1524

\begin{tabular}{|l|l|l||l|r|}
\hline Universität & Vor 1456 & $1456-1490$ & $1491-1524$ & Gesamt \\
\hline \hline Greifswald & 0 & 15 & 12 & 27 \\
\hline & $0,0 \%$ & $68,2 \%$ & $30,8 \%$ & $36,5 \%$ \\
\hline Rostock & 3 & 5 & 15 & 23 \\
\hline & $23,1 \%$ & $22,7 \%$ & $38,5 \%$ & $31,1 \%$ \\
\hline Leipzig & 6 & 2 & 5 & 13 \\
\hline & $46,2 \%$ & $9,1 \%$ & $12,8 \%$ & $17,6 \%$ \\
\hline Frankfurt & 0 & 0 & 6 & 6 \\
\hline & $0,0 \%$ & $0,0 \%$ & $15,4 \%$ & $8,1 \%$ \\
\hline Wittenberg & 0 & 0 & 1 & 1 \\
\hline & $0,0 \%$ & $0,0 \%$ & $2,6 \%$ & $1,4 \%$ \\
\hline Bologna & 2 & 0 & 0 & $2,7 \%$ \\
\hline Prag & $15,4 \%$ & $0,0 \%$ & $0,0 \%$ & 1 \\
\hline & 1 & 0 & 0 & $1,4 \%$ \\
\hline Erfurt & $7,7 \%$ & $0,0 \%$ & $0,0 \%$ & 1 \\
\hline
\end{tabular}




\begin{tabular}{|l|l|l|l||r||}
\cline { 2 - 5 } \multicolumn{1}{c|}{} & $7,7 \%$ & $0,0 \%$ & $0,0 \%$ & $1,4 \%$ \\
\hline Gesamt & 13 & 22 & 39 & 74 \\
& $100,0 \%$ & $100,0 \%$ & $100,0 \%$ & $100,0 \%$ \\
\hline
\end{tabular}

\subsubsection{Rügenwalde: Rostocker Dominanz}

Die Hansestadt Rügenwalde liegt in Hinterpommern und war durch 22 Studenten im Greifswalder Matrikelbuch vertreten. Mit leichtem Vorsprung kann die Rostocker Universität diesen Anteil überbieten, denn 35 Rügenwalder studierten dort im gesamten Mittelalter, wobei nur eine Immatrikulation vor dem Jahre 1456 erfolgte. Bis zur Hälfte des Betrachtungszeitraums waren die Zahlen an der pommerschen und der mecklenburgischen Universität in etwa gleich, doch hat sich seitdem das Verhältnis zugunsten Rostocks verschoben, wo sich allein zwischen 1505 und 1511 alle 10 Studenten des gesamten Abschnitts inskribierten. Eine Konzentration auf die beiden Ostseeuniversitäten ist auch hier erkennbar, denn nur ein Rügenwalder ging im letzten Abschnitt nach Frankfurt. Vor dem Jahr 1456 wurden noch zwei Studenten in Prag sowie einer in Leipzig ermittelt, womit die Gesamtzahl bei 61 Studenten liegt. Vier Rügenwalder inskribierten sich vor der Greifswalder Gründung, 57 danach, so daß auch hier eine Frequenzsteigerung zu erkennen ist. Innerhalb des Betrachtungszeitraums blieb die Beteiligung jedoch recht gleichbleibend (vgl. folgende Tabelle). Während man in der ersten Hälfte des Zeitraums eine paritätische Verteilung der Studenten auf die beiden Ostseuniversitäten vorfinden konnte, verringert sich der Greifswalder Anteil in der zweiten Hälfte auf 27 Prozent, während Rostock nun auf 68 Prozent kommt und damit deutlich an Beliebtheit zulegen kann.

Tabelle 23: Rügenwalder Studenten bis 1524

\begin{tabular}{|l|l|l|l|r|}
\hline Universität & Vor 1456 & $1456-1490$ & $1491-1524$ & Gesamt \\
\hline \hline Rostock & 1 & 14 & 20 & 35 \\
\hline Greifswald & $25,0 \%$ & $50,0 \%$ & $69,0 \%$ & $57,4 \%$ \\
\hline & 0 & 14 & 8 & 22 \\
\hline Prag & $0,0 \%$ & $50,0 \%$ & $27,6 \%$ & $36,1 \%$ \\
\hline & 2 & 0 & 0 & 2 \\
\hline Leipzig & $50,0 \%$ & $0,0 \%$ & $0,0 \%$ & $3,3 \%$ \\
\hline & 1 & 0 & 0 & 1 \\
\hline Frankfurt & $25,0 \%$ & $0,0 \%$ & $0,0 \%$ & $1,6 \%$ \\
\hline & 0 & 0 & 1 & $1,6 \%$ \\
\hline
\end{tabular}




\begin{tabular}{|l|l|l||l||r|}
\hline Gesamt & 4 & 29 & 61 \\
& $100,0 \%$ & $100,0 \%$ & $100,0 \%$ & $100,0 \%$ \\
\hline
\end{tabular}




\subsubsection{Resümee: zur dominierenden Stellung Greifswalds in Pommern}

Im folgenden sollen die Ergebnisse über das Studium der Pommern an den mittelalterlichen Universitäten zusammenfassend analysiert werden, um dadurch genauere Erkenntnisse über die Bedeutung der Greifswalder Universität für die Ortschaften des eigenen Territoriums zu erlangen. Es hat sich gezeigt, daß es selbst innerhalb Pommerns regionale Unterschiede im Studienverhalten gab. Zwischen drei Kategorien pommerscher Orte wurde unterschieden: einerseits den vorpommerschen Orten in direkter Umgebung Greifswalds, andererseits den in südlichen und zentralen Gebieten Pommerns gelegenen Orten sowie den Orten im hinteren Pommern, die zumeist direkt oder indirekt mit der Ostsee verbunden waren. 1051 Studenten waren aus diesen 18 Orten zwischen 1456 und 1524 nach Greifswald gezogen. Insgesamt konnten in der Greifswalder Matrikel 1275 Pommern einem Herkunftsort zugeordnet werden, so daß die 1051 Personen einem Anteil von etwa 82 Prozent aller pommerschen Studenten in Greifswald entsprechen. ${ }^{300}$ Wie verhielt es sich mit dem Besuch anderer Universitäten?

Aus 10 Orten zogen mehr als die Hälfte der Studenten nach Greifswald, worunter sich vier befanden, deren Studenten sogar zu 80 Prozent an die eigene Landesuniversität gingen. Der Mittelwert der prozentualen Anteile aller Orte lag bei 56,3 Prozent. Bei der Verteilung der 1051 Personen kommt man auf den etwas niedrigeren Anteil von 54,4 Prozent. Die dominierende Stellung der Landesuniversität im eigenen Territorium ist mit diesen Zahlen bewiesen, nimmt man die 18 Orte als repräsentative Auswahl aller Orte Pommerns. Der Anteil der Pommern an der Greifswalder Besucherschaft (49\%) lag um knapp sechs Punkte darunter, woran das überregionale Potential der Greifswalder Studien noch deutlicher zu Tage tritt. Alle sieben Orte der direkten Umgebung waren durch mehr als 50 Prozent der Studenten in Greifswald vertreten. Bei den acht Orten, aus denen weniger als 50 Prozent der Studenten kamen, handelt es sich begreiflicherweise ausschließlich um Orte, die weiter enfernt sind und jenseits der Oder liegen. Aus Hinterpommern erreichte nur Kolberg (55,3\%) und Belgard (80,6\%) über 50 Prozent (vgl. folgende Tabelle).

Tabelle 24: Greifswalder Anteile zwischen 1456 und 1524 (Durchschnitt: 54,4\%)

\begin{tabular}{|l||l|l|l|l||l||}
\hline Greifswald & $87,3 \%$ & Kolberg & $55,3 \%$ & Pyritz & $45,2 \%$ \\
\hline \hline Demmin & $82,9 \%$ & Grimmen & $54,5 \%$ & Köslin & $44,3 \%$ \\
\hline \hline Wolgast & $82,8 \%$ & Barth & $52,2 \%$ & Stettin & $44,0 \%$ \\
\hline \hline Belgard & $80,6 \%$ & Stralsund & $50,2 \%$ & Rügenwalde & $38,6 \%$ \\
\hline \hline Pasewalk & $63,3 \%$ & Treptow & $49,3 \%$ & Stargard & $36,3 \%$ \\
\hline \hline Anklam & $61,9 \%$ & Kammin & $49,1 \%$ & Stolp & $35,6 \%$ \\
\hline
\end{tabular}

An die Universität Rostock zogen 29,9 Prozent der pommerschen Studenten, so daß sie in der Beliebtheit auf Greifswald folgt. Mit diesen Zahlen wird die Aussage bestätigt, daß sich die 
Einzugsbereiche der beiden Ostseeuniversitäten ganz erheblich überschnitten. Keineswegs zog die Rostocker Hohe Schule vornehmlich Publikum aus den westlichen Gebieten Norddeutschlands an: bis ins hintere Pommern reichte ihre Ausstrahlung trotz der Gründung einer eigenen Landesuniversität in Greifswald. In nur einem Fall (Rügenwalde) zog es allerdings über 50 Prozent der Studenten an die mecklenburgische Hohe Schule. Niedrige Inskriptionszahlen waren aus Orten zu vermerken, die nicht an der Ostseeküste, sondern in zentralen Gebieten Südpommerns lagen. Dies hing mit der Nähe der mitteldeutschen Universitäten Leipzig und Frankfurt zusammen, die aus diesen Ortschaften stärker frequentiert wurden. Auffällig ist, daß Bewohner der Küstenstädte auch jenseits der Oder zahlreich die mecklenburgischen Universität aufsuchten. Dies läßt darauf schließen, daß der Reiseweg der Studenten häufig über das Meer per Schiff erfolgte. Man kann dies ebenfalls als Anzeichen für die Rekrutierung der Studenten aus dem Handelbürgertum dieser Hansestädte ansehen.

Für die Universität Leipzig entschieden sich 6,1 Prozent der Studenten aus den untersuchten pommerschen Herkunftsorten. Den höchsten Anteil erreichte die Stadt Pyritz, aus der 25,8 Prozent aller Studenten an die meißnische Universität gingen; aus weiteren vier Orten kamen über 10 Prozent der Studenten. Insgesamt wurde von sechs Orten der Gesamtdurchschnitt von 6,1 Prozent übertroffen. Alle vier südlichen zentralpommerschen Orte gehörten dazu, deren Entfernung von Leipzig einfach geringer war, außerdem zwei Küstenstädte im hinteren Pommern (Stolp und Köslin).

5,1 Prozent der Studenten gingen an die neugegründete Universität Frankfurt. Um die wahre Bedeutung dieser neuen Universität zu erkennen, muß der Betrachtungszeitraum auf die Jahre ihres Bestehens begrenzt werden (seit 1505). Ihr Anteil steigt dann auf 13 Prozent. Dabei ist freilich ein Gründungsboom zu berücksichtigen, denn nur zwischen 1505 und 1511 zogen ein Fünftel der pommerschen Studenten nach Frankfurt. Schon im nächsten Abschnitt halbieren sich die Einschreibungen und fallen nochmals im letzten Zeitabschnitt. Dennoch ist auffällig, daß im Gründungsabschnitt nur der Greifswalder Anteil zurückgeht, während Rostock sogar den höchsten Frequenzgewinn überhaupt zu verbuchen hat. ${ }^{301}$ Die brandenburgische Neugründung ist in ihrer Anfangsphase offenbar vor allem der pommerschen Landesuniversität zur Konkurrenz geworden. Zu den acht Orten, aus denen überdurchschnittlich viele Studenten zur neuen Universität gingen, gehörten die vier in zentralen Gebieten Südpommerns, also in direkter Nähe Frankfurts, gelegenen Städte. Bei den übrigen vier Orten handelt es sich ausschließlich um Städte Hinterpommerns. Damit wird deutlich, daß die Frankfurter Universität, stärker als die Leipziger, in der Lage war, auch fernere pommersche Gebiete an sich zu ziehen und gerade deshalb besonders der Greifswalder Universität schadete.

Wittenberg zog 1,9 Prozent der Studenten an, doch muß man auch hier die Jahre auf die Zeit des Bestehens der Universität (seit 1502) beschränken, will man repräsentative Zahlen erlangen. Der Anteil steigt dann auf etwa 4,5 Prozent seit ihrer Gründung. ${ }^{302}$ Die Wittenberger Universität überzeugte nicht so sehr durch ihre Nähe. Vor allem ihre Bedeutung als Reformationsstadt ist hervorzuheben, was anhand der prozentualen Entwicklung in den letzten vier Abschnitten deutlich wird. Erst im letzten Abschnitt, als der Wittenberger Universitätsprofessor Martin Luther zu Bekanntheit gelangt war, erreichte die neue Universität einen höheren Anteil von über 10 Prozent aller Studenten der untersuchten Herkunftsorte (vgl. folgende Tabelle).

Tabelle 25: Die Beteiligung der Pommern an der Universität Wittenberg 


\begin{tabular}{|l|l|l|l|r|}
\hline $1498-1504$ & $1505-1511$ & $1512-1518$ & $1519-1524$ & Gesamt \\
\hline $1,1 \%$ & $2,4 \%$ & $3,7 \%$ & $10,2 \%$ & $4,1 \%$ \\
\hline
\end{tabular}

Alle übrigen Universitäten spielten nur eine untergeordnete Rolle für die behandelten Ortschaften in Pommern. Auf Erfurt verteilten sich 1,3 Prozent, auf Köln 0,7 Prozent der Studenten. Die Gesamtverteilung wird in der folgenden Grafik dargestellt.

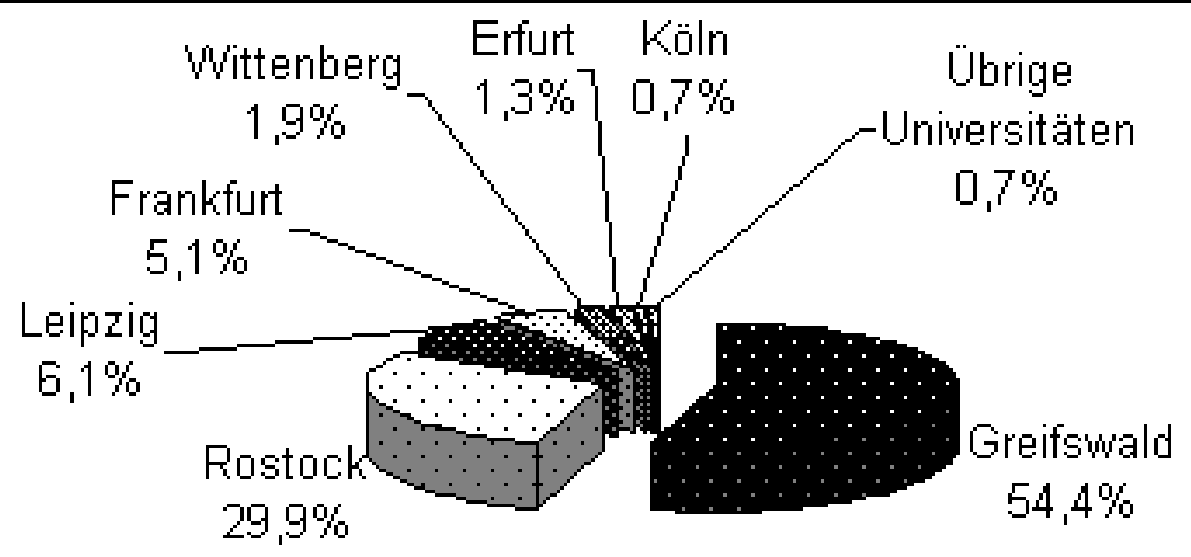

Abbildung 53: Verteilung der Pommern auf die Universitäten (1456-1524)

Die Gesamtfrequenz aus diesen 18 Orten ist durch einen Anstieg im gesamten Zeitraum gekennzeichnet (vgl. folgende Grafik). In der Greifswalder Gründungsphase lag die Einschreibungsquote deutlich über der der Folgezeit. Man sieht an der starken Frequenz in Greifswald, daß fast ausschließlich die Neugründung dafür verantwortlich ist. Nach einem als Normalisierung zu verstehenden Rückgang kam es zu einem erneuten Anwachsen der Inskriptionen. Dabei stiegen die Zahlen in Greifswald und in den anderen Universitäten fast proportional zueinander: die Nähe zweier Universitäten führte offensichtlich zu einem ersten stärkeren Frequenzgewinn der Pommern. Auch der Rückgang des folgenden Abschnitts, dessen Ursache wohl vor allem in der schweren Pestepidemie in Pommern zu suchen ist, verlief gleichermaßen an allen Universitäten. Bis 1518 nahmen die Immatrikulationen zu, und erreichten in den Jahren 1505 bis 1512 ihre höchste Zahl. Die neuen Universitäten, die das Universitätsnetz nun auch im Norden des Reiches verdichteten, sind für den Anstieg verantwortlich, während die Zahlen in Greifswald seit der Jahrhundertwende auf einem hohen, aber recht gleichbleibenden Niveau blieben. Die Reformation bewirkte im letzten Abschnitt dann einen erneuten Rückgang der Immatrikulationen, wobei die Greifswalder Inskriptionen auch hier bemerkenswert konstant verliefen.

Die Frequenzentwicklung ist für eine Interpretation äußerst aufschlußreich. Wenn für Greifswald gegen Ende des Betrachtungszeitraums eine zunehmende Fixierung auf das pommersche Territorium zu konstatieren war, so zeigte die pommersche Gesamtfrequenz eine gegenläufige Entwicklung, denn 
die pommerschen Studenten konzentrierten sich keineswegs auf die eigene Landesuniversität. Vielmehr verbreitete sich das Spektrum der besuchten Universitäten in gleichem Maße, wie neue Universitäten im Reich gegründet wurden. Für die Frage nach der entstehenden "Landesuniversität" bedeutet dies, daß eine zunehmende Tendenz zum heimatnahen Studium nicht mit einer Gebundenheit an nur eine Universität zu verwechseln ist. Vielmehr verkleinerte die Zunahme der Universitäten zwar einzelne Einzugsbereiche, gleichzeitig brachte die Nähe der Universitäten jedoch einen Gesamtzuwachs der Studentenzahlen. Auf diesem Weg blieb der Besuch aus der Heimatregion konstant, während demgegenüber die Überregionalität einer Universität zurückging. Dieser Wandel wurde sicherlich vor allem durch den Zugriff auf neue soziale Schichten ermöglicht, der in den steigenden Greifswalder Pauperes-Inskriptionen gegen Ende des Betrachtungszeitraums seinen Ausdruck findet.

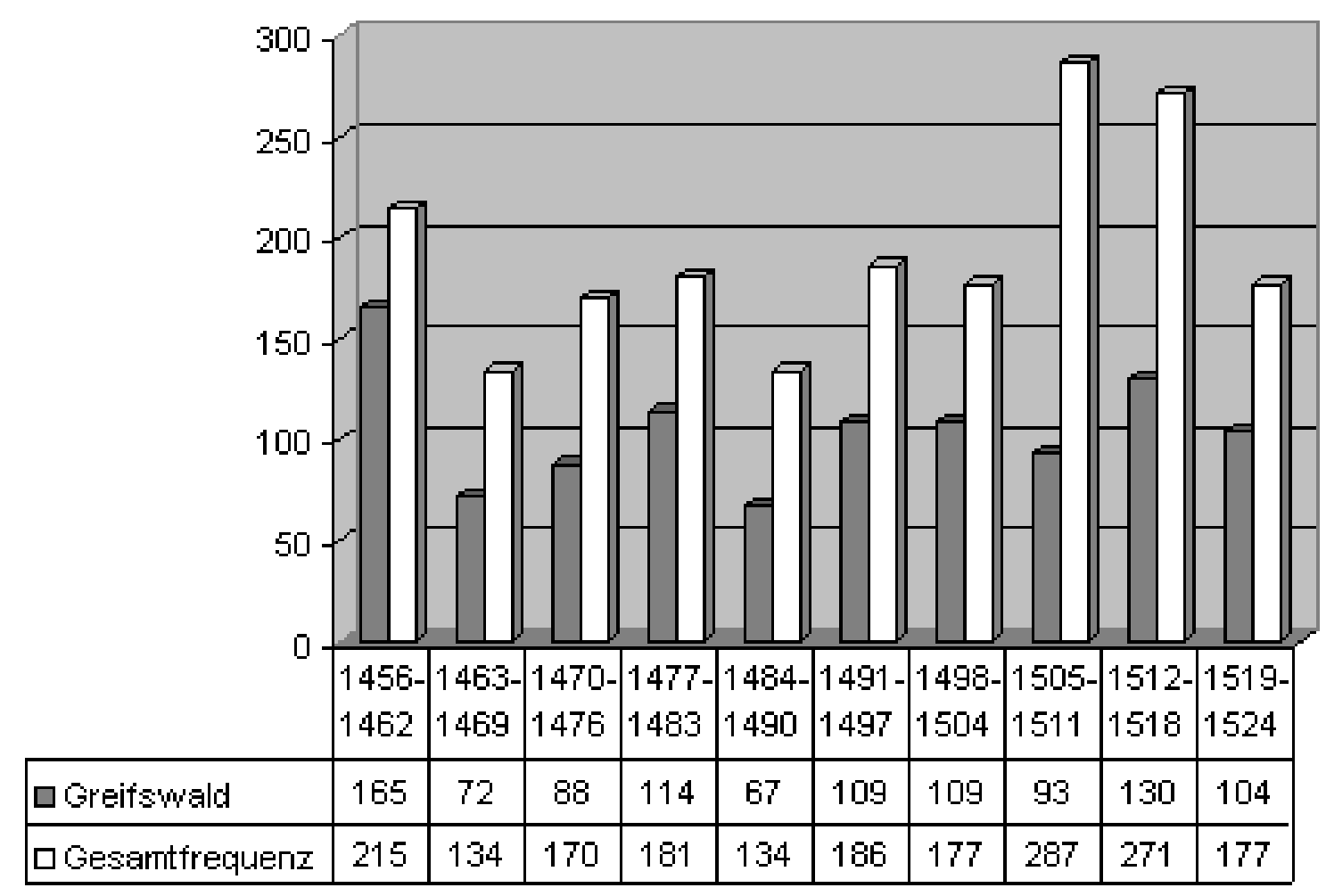

Abbildung 54: Universitätsbesuch der Pommern (Greifswald-Gesamtfrequenz)

Auch innerhalb der Gebiete Pommerns ist eine Tendenz zu ersehen, denn vor allem die Orte Hinterpommerns erlebten eine deutliche Frequenzsteigerung zwischen 1456 und 1524. Die universitätsgeschichtlich unerschlossene Lage dieser Landschaft ist sicherlich dafür verantwortlich. Erst als sich mit Frankfurt und Wittenberg das Netz der Universitäten verdichtete und Hinterpommern den Reichsuniversitäten näherbrachte, änderte sich das Studienverhalten. Dort konnten fast alle Universitäten seit Ende des 15. Jahrhunderts dazugewinnen, wobei der prozentuale Anteil der einzelnen Universitäten natürlich zurückging. Die Landesuniversität blieb freilich auch weiterhin der wichtigste Studienort, wenn auch vor allem mit Frankfurt ein weiteres wichtiges Studienziel hinzutrat.

Die Nähe der vier zentralpommerschen Orte zur mitteldeutschen Universitätslandschaft bewirkte bereits vor der Greifswalder Gründung eine wesentlich stärkere Studienbeteiligung gegenüber etwa 
den sieben hinterpommerschen Orten. Daß dies mit der Nähe der übrigen deutschen Universitäten zusammenhing, zeigt sich an der späteren Frequenz, welche trotz der Neugründungen in unmittelbarer Umgebung nur geringfügig angestiegen ist. In dieser Gegend um Stettin scheint bereits in der zweiten Hälfte des 15. Jahrhunderts daher eine Art "Sättigungsgrad" erreicht worden zu sein. Schon die Neugründung in Greifswald konnte hier nur verhältnismäßig geringe Zuwachsraten erzeugen.

Dagegen zeigten die Orte der direkten Umgebung Greifswalds seit der Neugründung eine gleichbleibend hohe Frequenz an der Landesuniversität, die während des Zeitraums nur noch leicht angestiegen ist. Auch andere mitteldeutsche Universitäten sowie die späteren Neugründungen spielten dort eine untergeordnete Rolle. Dagegen wird an den Einschreibungen aus diesen Orten die Konkurrenz der beiden Ostseeuniversitäten offenbar, denn Rostocks Anteil an deren Frequenz erreicht gegen Ende der Betrachtungszeit fast gleiche Werte wie Greifswald. Wie ist es zu erklären, daß Rostock, obwohl älter als Greifswald, erst gegen Ende des 15. und zu Beginn des 16. Jahrhunderts für diese Orte der direkten Umgebung an Bedeutung gewann? Hier ist sicherlich ein Nachteil der vorliegenden Untersuchung zu berücksichtigen, die nur Studienaufhalte aber keine Studienortswechsel aufzeigt. Viele der Studenten werden die Nähe dieser beiden Universitäten genutzt und nacheinander beide Universitäten aufgesucht haben, was allerdings erst durch eine weitergehende prosopographische Untersuchung der Scholaren geklärt werden kann.

Aus der folgenden Grafik kann man ablesen, wie sich die Bedeutung Greifswalds zwischen 1456 und 1524 entwickelte. Dazu wurde der prozentuale Anteil, den die Universität in den einzelnen Abschnitten hatte, als Kurve dargestellt. Während zur Gründungszeit ein ungewöhnlich hoher Anteil erreicht wird, pendelt er sich in den folgenden Jahrsiebten zwischen 50 und 60 Prozent ein. Die längste Zeit, nämlich von 1463 bis etwa 1502, kann die Universität ihre Bedeutung für Pommern auf diesem Niveau halten. Erst die Neugründung in Frankfurt führt zu einem stärkeren Rückgang auf etwa 30 Prozent. Noch innerhalb des betrachteten Zeitraums erholt sich die Kurve wieder und erreicht im letzten Abschnitt wieder fast 60 Prozent. Man kann daher sagen, daß nur der Gründungsboom in Frankfurt einen kurzen Bedeutungsverlust der eigenen Landesuniversität bewirkt hat. Auf lange Sicht blieb sie auch weiterhin der wichtigste Studienort dieser behandelten Städte. 


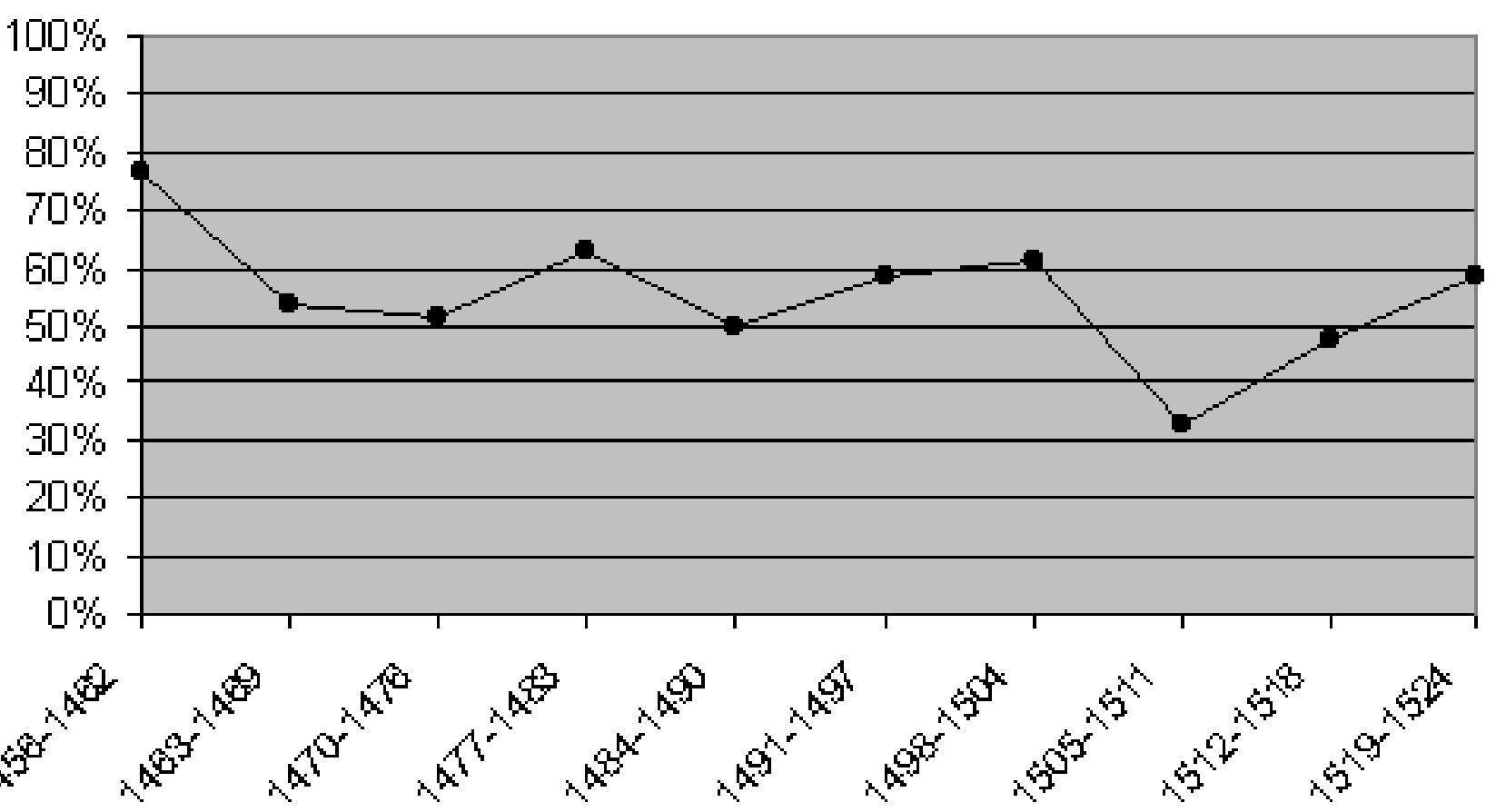

Abbildung 55: Anteil Greifswalds an der Gesamtfrequenz

Bis zur Greifswalder Universitätsgründung wurden insgesamt sieben Universitäten besucht. An der Spitze steht nicht etwa die Universität Rostock, die sich offensichtlich in den 37 Jahren ihres Bestehens noch nicht vollends bei den Pommern behaupten konnte, sondern Leipzig mit 35,5 Prozent aller Einschreibungen. Da das Prager Matrikelbuch verloren gegangen ist, und bereits mit den Personen aus den Dekanats- und Fakultätsbüchern ein Anteil von 16,9 Prozent an der Gesamtfrequenz erreicht wird, muß man die Bedeutung dieser Universität bis zum Jahr 1409 als besonders hoch einschätzten. Die hohe Beteiligung an der Universität Leipzig, die ja bekanntlich 1409 als Sezession der böhmischen Universität gegründet wurde, leuchtet dadurch umso mehr ein: sie übernahm einfach die bisherige Position Prags als beliebtester Studienort der Pommern. Auch Erfurts Bedeutung war mit 9,7 Prozent noch deutlich höher als in den Jahren nach der Greifswalder Gründung. Sogar die Universitäten Wien und Bologna wurden vor der Greifswalder Gründung häufiger frequentiert und erreichten mit 4,3 Prozent ein höheres Kontingent als Köln, das nur auf einen Prozentpunkt kam (vgl. folgende Grafik). 


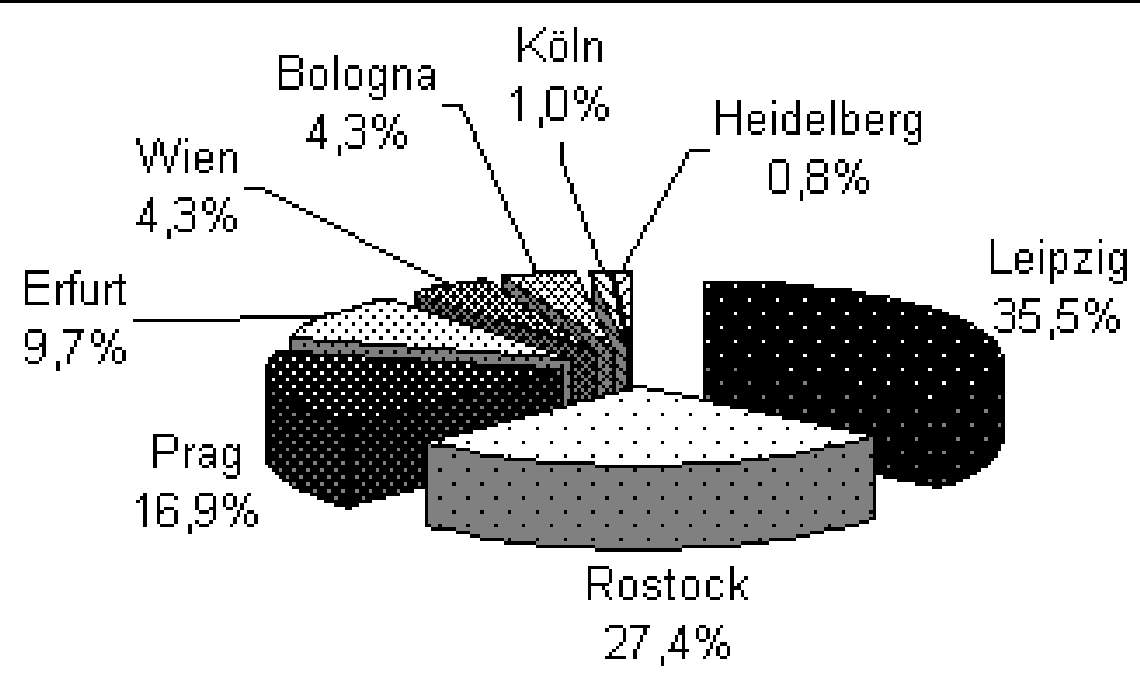

Abbildung 56: Verteilung der Pommern auf die alten Universitäten (vor 1456) 


\subsection{Herkunftsorte der Nachbarn}

\subsubsection{Neubrandenburg: Landeszugehörigkeit und Universitätsauswahl}

Mit Neubrandenburg soll nun ein erster Herkunftsort behandelt werden, der nicht direkt im Herzogtum Pommern, sondern im angrenzenden Mecklenburg lag. Gerade bei dieser Stadt ist es daher interessant zu erfahren, ob die 40 Greifswalder Studenten mit der Anzahl in Rostock konkurrieren können. Auch bei Neubrandenburg muß man einschränken, daß nicht immer eindeutig zu klären war, ob die alte Bischofsstadt Brandenburg oder die Stadt im südlichen Mecklenburg gemeint war. ${ }^{303}$ Die Zahlen können daher ebenfalls nur als Annäherungswerte verstanden werden.

In der Rostocker Matrikel ließen sich 41 Studenten nachweisen, die im behandelten Zeitraum aus Neubrandenburg stammen. Obwohl es sich um einen mecklenburgischen Ort handelt, kann die fast paritätische Verteilung auf die beiden Universitäten kaum verwundern, da die Entfernung zur pommerschen Hohen Schule sogar noch ein wenig geringer war. Trotz dieses Umstands machen die Zahlen deutlich, daß Landeszugehörigkeit im Mittelalter nur in geringem Maße ein Kriterium für die Wahl des Hochschulorts darstellte. Erst in nachreformatorischer Zeit sollte sich dies ändern, als konfessionelle Zugehörigkeit als weiteres Kriterium für den Universitätsbesuch hinzutrat.

Mit fünf Einschreibungen im ersten Abschnitt lag die Zahl in Rostock trotz der pommerschen Neugründung über der in Greifswald. Zwar konnte die neue Universität später leicht zugewinnen, doch blieb das Verhältnis erhalten (bis 1483: 15 gegenüber 9 Studenten). Erst mit dem Ausbruch der Domfehde in Rostock kam es zu einem Umschwung, als Greifswald von den Neubrandenburgern bevorzugt wurde. Der kurzfristige Umzug der mecklenburgischen Hohen Schule nach Lübeck scheint viele Neubrandenburger bewogen zu haben, das nähere Greifswald aufzusuchen. Von 1484 bis 1511 blieb die pommersche Hohe Schule die beliebtere Universität trotz Beilegung der Krise in Rostock (25 gegenüber 9). Ein Zuwachs der Immatrikulationen fand in Rostock erst wieder seit 1512 bis zum Ende des Betrachtungszeitraums statt (insgesamt 17). In diesem letzten Abschnitt waren Neubrandenburger in Greifswald überhaupt nicht mehr vertreten.

Durch sieben Scholaren war Neubrandenburg seit 1505 in Frankfurt vertreten, das in der Rangfolge der beliebtesten Hochschulen damit auf Rostock folgt. Erst in den beiden Abschnitten nach der Gründungsphase sind sie dort vertreten. Offensichtlich bot sich diese Universität aufgrund der Nähe als Alternative an. Leipzig verzeichnete lediglich zwischen 1484 und 1490 vier Neubrandenburger, die aufgrund der lokalen Rostocker Ereignisse dorthin auswichen. Drei Studenten waren außerdem in Köln sowie zwei in Wittenberg zu finden, so daß man zwischen 1456 und 1524 eine Gesamtzahl von 97 Neubrandenburger Studenten erhält. Vor der Greifswalder Universitätsgründung zogen je drei Studenten nach Leipzig und Rostock sowie je einer nach Wien und Prag. ${ }^{304}$ In der folgenden Tabelle wurden die Ergebnisse zusammengefaßt.

Tabelle 26: Neubrandenburger Studenten bis 1524 


\begin{tabular}{|c|c|c|c|}
\hline Universität & Vor 1456 & 1456-1524 & Gesamt \\
\hline \multirow[t]{2}{*}{ Rostock } & 3 & 41 & 44 \\
\hline & $37,5 \%$ & $42,3 \%$ & $41,9 \%$ \\
\hline \multirow[t]{2}{*}{ Greifswald } & 0 & 40 & 40 \\
\hline & $0,0 \%$ & $41,2 \%$ & $38,1 \%$ \\
\hline \multirow[t]{2}{*}{ Leipzig } & 3 & 4 & 7 \\
\hline & $37,5 \%$ & $4,1 \%$ & $6,7 \%$ \\
\hline \multirow[t]{2}{*}{ Frankfurt } & 0 & 7 & 7 \\
\hline & $0,0 \%$ & $7,2 \%$ & $6,7 \%$ \\
\hline \multirow[t]{2}{*}{ Köln } & 0 & 3 & 3 \\
\hline & $0,0 \%$ & $3,1 \%$ & $2,9 \%$ \\
\hline \multirow[t]{2}{*}{ Wittenberg } & 0 & 2 & 2 \\
\hline & $0,0 \%$ & $2,1 \%$ & $1,9 \%$ \\
\hline \multirow[t]{2}{*}{ Wien } & 1 & 0 & 1 \\
\hline & $12,5 \%$ & $0,0 \%$ & $1,0 \%$ \\
\hline \multirow[t]{2}{*}{ Prag } & 1 & 0 & 1 \\
\hline & $12,5 \%$ & $0,0 \%$ & $1,0 \%$ \\
\hline \multirow[t]{2}{*}{ Gesamt } & 8 & 97 & 105 \\
\hline & $100,0 \%$ & $100,0 \%$ & $100,0 \%$ \\
\hline
\end{tabular}

Die Gesamtfrequenz der Neubrandenburger zeichnet sich durch einen leichten Anstieg im gesamten Zeitraum aus, der allerdings von zwei größeren Zuwächsen zwischen 1484 und 1490 sowie 1512 und 1518 unterbrochen wird (vgl. folgende Grafik). 


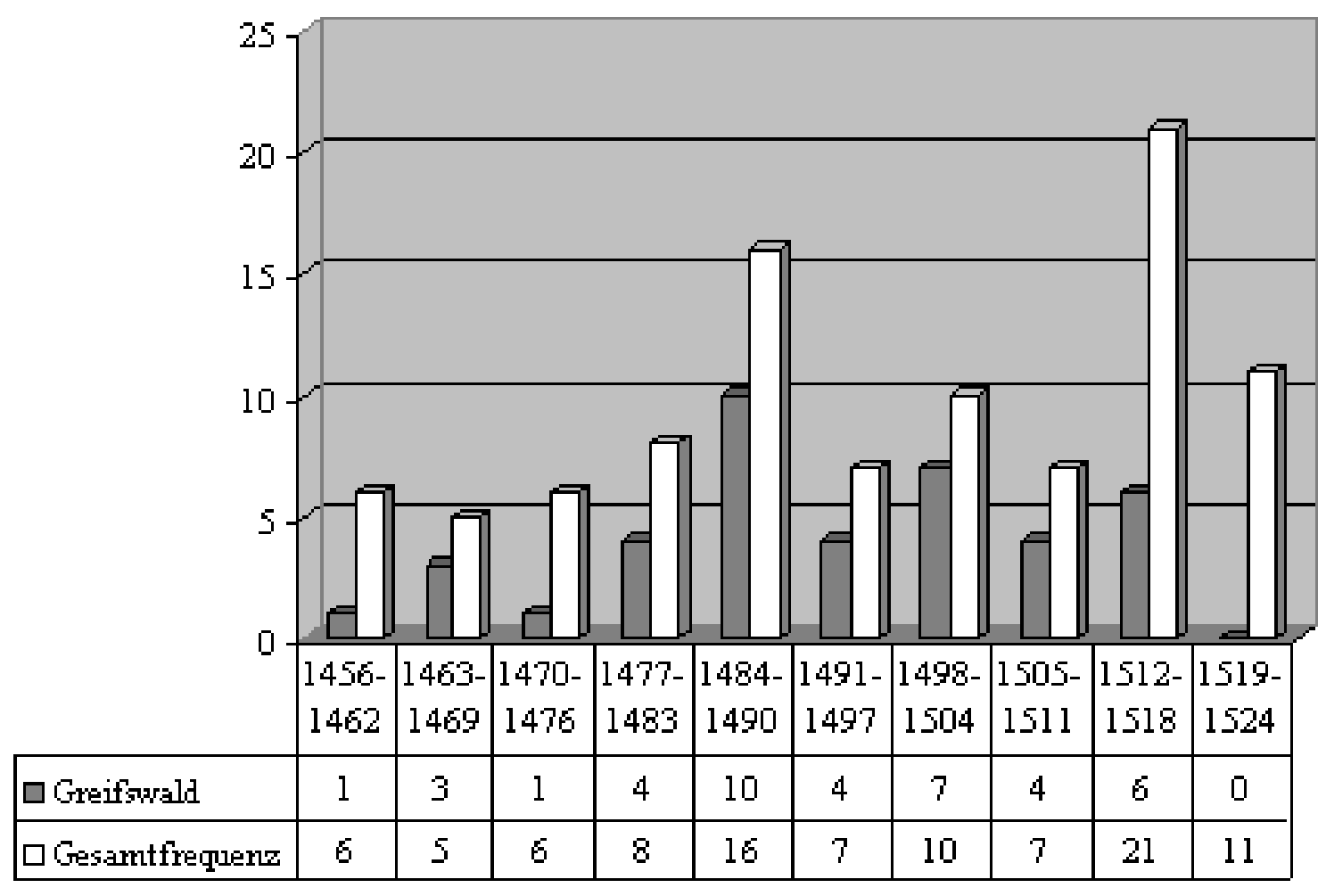

Abbildung 57: Neubrandenburger Studenten (Greifswald - Gesamtfrequenz)

Die folgende Grafik stellt den prozentualen Anteil Greifswalds an der Gesamtfrequenz dar. Sie macht deutlich, daß eine größere Bedeutung der Greifswalder Universität vor allem in der allgemeinen Hochphase der pommerschen Universität zu konstatieren ist (etwa von 1484 bis 1504). Die Studentenzahl blieb zwar noch bis 1518 recht hoch, doch nimmt die Beteiligung an der Rostocker Universität seit 1512 wieder zu, so daß der Greifswalder Gesamtanteil sinkt.

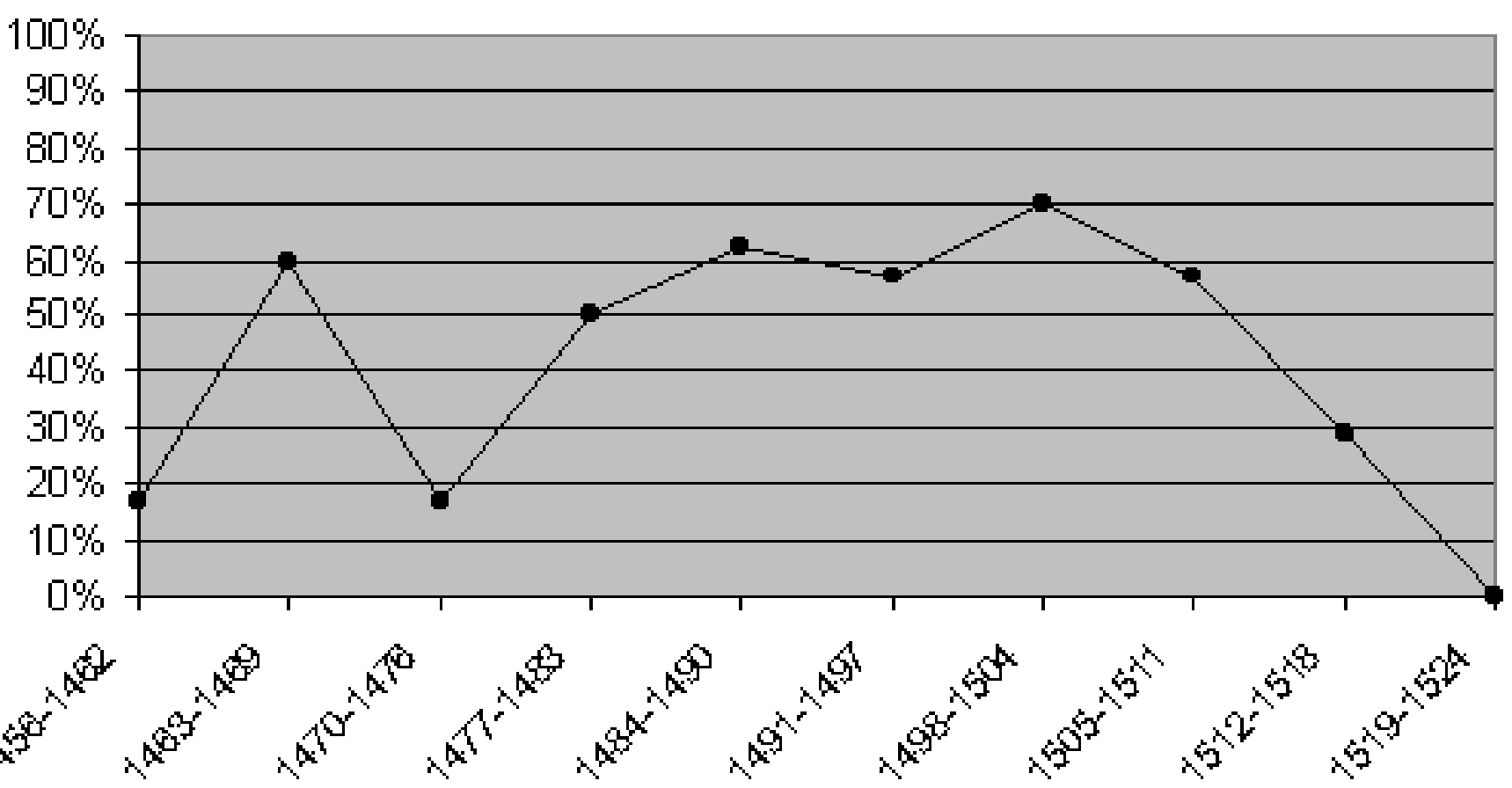




\subsubsection{Friedland: geographische Nähe führt zur Greifswalder Dominanz}

Während sich bei den Ostseeuniversitäten die Herkunftsbezeichnung Friedland fast ausschließlich auf die mecklenburgische Stadt bezog, kann es bei den übrigen Universitäten ebenfalls zu Verwechslungen mit dem preußischen oder dem niedersächsischen Ort gekommen sein. Auch hier sollen diese unklaren Herkunftsangaben explizit genannt werden.

32 Friedländer hatten sich zwischen 1456 und 1524 in Greifswald eingeschrieben. Obwohl der Ort im mecklenburgischen Herrschaftsgebiet lag, erreichte Rostock (14) nicht einmal die Hälfte der Zahl, die im Nachbarland gezählt wurde. Die Nähe Greifswalds führte hier zu einer stärkeren Identifizierung mit der pommerschen Universität als zur eigenen Landesuniversität. Während des gesamten Zeitraums lagen die Greifswalder über den Rostocker Zahlen. Zwischen 1470 und 1483 kam bereits die Hälfte aller Friedländer Studenten, die in Rostock studierten. Die andere Hälfte verteilte sich recht gleichmäßig auf die letzten vier Abschnitte (1498-1524). Leipzig wies sieben Studenten auf, die sich jedoch nicht immer eindeutig zuordnen ließen, da die Leipziger Rektoren auf eine genauere Eingrenzung des Herkunftsortes verzichteten. Die Friedländer konzentrierten sich dort auf den ersten Abschnitt (5). In den beiden folgenden Abschnitten kamen die übrigen Studenten. In Erfurt waren fünf Friedländer vertreten, die sich vor allem in den Jahren 1484 bis 1490 inskribierten (4). Da Rostock in diesem Abschnitt keine Friedländer zu verzeichnen hatte, könnte auch hier ein Zusammenhang mit der Auswanderung der Universität nach Lübeck bestehen. Das Wittenberger Matrikelbuch enthielt weitere fünf Einschreibungen, die sich auf den letzten Abschnitt konzentrierten (4). Auch die Frankfurter Neugründung verzeichnete im letzten Abschnitt drei Friedländer, so daß eine Gesamtzahl von 66 Studenten zwischen 1456 und 1524 erreicht wird.

Vor der Greifswalder Universitätsgründung war Leipzig die beliebteste Universität der Friedländer (7), gefolgt von Prag (3). Rostock gewann auch hier erst später an Bedeutung, denn nur zwei Einträge waren bis 1456 dort zu finden. Je eine Immatrikulation verzeichnete außerdem noch Bologna, Wien und Erfurt, so daß die Gesamtzahl auf 81 Studenten im gesamten Mittelalter ansteigt (vgl. folgende Tabelle). Die Frequenz verlief zwischen 1456 und 1524 recht gleichmäßig. Einbrüche sind nur zwischen 1463 und 1469 (1), 1491 und 1497 (0) sowie 1505 und 1511 (4) zu verzeichnen, deren Ursache aber nicht eindeutig zu klären ist. ${ }^{305}$ Der Anteil Greifswalds an der Gesamtfrequenz nimmt leicht zu, da sich die Gesamtfrequenz etwas verschlechtert, während in Greifswald etwa gleiche Zahlen erreicht werden.

Tabelle 27: Friedländer Studenten bis 1524

\begin{tabular}{|l|l|l|r|}
\hline Universität & Vor 1456 & $1456-1524$ & Gesamt \\
\hline \hline Greifswald & 0 & 32 & 32 \\
\hline & $0,0 \%$ & $48,5 \%$ & $39,5 \%$ \\
\hline
\end{tabular}




\begin{tabular}{|c|c|c|c|}
\hline \multirow[t]{2}{*}{ Rostock } & $\mid 2$ & 14 & 16 \\
\hline & $13,3 \%$ & $21,2 \%$ & $19,8 \%$ \\
\hline \multirow[t]{2}{*}{ Leipzig } & 7 & 7 & 14 \\
\hline & $46,7 \%$ & $10,6 \%$ & $17,3 \%$ \\
\hline \multirow[t]{2}{*}{ Erfurt } & 1 & 5 & 6 \\
\hline & $6,7 \%$ & $7,6 \%$ & $7,4 \%$ \\
\hline \multirow[t]{2}{*}{ Wittenberg } & 0 & 5 & 5 \\
\hline & $0,0 \%$ & $7,6 \%$ & $6,2 \%$ \\
\hline \multirow[t]{2}{*}{ Frankfurt } & 0 & 3 & 3 \\
\hline & $0,0 \%$ & $4,5 \%$ & $3,7 \%$ \\
\hline \multirow[t]{2}{*}{ Prag } & 3 & 0 & 3 \\
\hline & $20,0 \%$ & $0,0 \%$ & $3,7 \%$ \\
\hline \multirow[t]{2}{*}{ Wien } & 1 & 0 & 1 \\
\hline & $6,7 \%$ & $0,0 \%$ & $1,2 \%$ \\
\hline \multirow[t]{2}{*}{ Bologna } & 1 & 0 & 1 \\
\hline & $6,7 \%$ & $0,0 \%$ & $1,2 \%$ \\
\hline \multirow[t]{2}{*}{ Gesamt } & 15 & 66 & 81 \\
\hline & $100,0 \%$ & $100,0 \%$ & $100,0 \%$ \\
\hline
\end{tabular}

6.3.3. Prenzlau: von Leipzig über Greifswald nach Frankfurt

Das südlich an Pommern angrenzende Brandenburg wies mit Prenzlau nur einen Ort auf, aus dem über 20 Studenten nach Greifswald gezogen sind. Sicherlich war hierfür die Nähe anderer mitteldeutscher Universitäten verantwortlich. Welche Bedeutung der pommerschen Hohen Schule im Gesamtvergleich für Prenzlau zukam, soll im folgenden analysiert werden.

Zwar zogen die meisten Prenzlauer zwischen 1456 und 1524 an die Universität Pommerns (25), doch sind die Abstände der anderen Universitäten sehr gering. Nicht Rostock, sondern Leipzig erreichte eine vergleichbare Größenordnung. 20 Prenzlauer ließen sich dort immatrikulieren. Wenn man die Zeit vor der Greifswalder Gründung berücksichtigt, dann steigt die Zahl um weitere 23 Personen. Die Leipziger Universität war demnach der wichtigste Studienort bis zur Neugründung im näheren Greifswald, die der älteren Universität damit zur Konkurrenz geworden ist.

Während fast alle Einschreibungen des ersten Abschnitts in Greifswald erfolgten, kehrte sich schon im nächsten Abschnitt das Verhältnis wieder um. Bis 1483 favorisierten Prenzlauer die meißnische 
Universität. Während des Abschnitts der Rostocker Domfehde ist auch in Leipzig ein Rückgang der Immatrikulationen zu bemerken. Die Greifswalder Universität kann nun an Bedeutung gewinnen und behält eine dominierende Stellung bis etwa 1497, als die Leipziger Zahlen wieder zunehmen. Durch die Neugründungen zu Beginn des 16. Jahrhunderts werden dann allerdings beide Universitäten aus der Gunst der Prenzlauer verdrängt.

Rostock folgt in der Beliebtheit an dritter Stelle (18). Nur eine Immatrikulation fand bereits vor der Greifswalder Universitätsgründung statt, so daß man auch hier erst seit 1456 von einem Bedeutungszuwachs sprechen kann. Die Immatrikulationen blieben recht gleichbleibend auf niedrigem Niveau. Nur zwischen 1470 und 1477 wird ein besseres Ergebnis erzielt (6). Im letzten Abschnitt sowie im Abschnitt der Rostocker Domfehde blieben die Immatrikulationen aus.

Nicht etwa die neue brandenburgische Landesuniversität folgte auf Rostock, sondern Wittenberg mit 16 Eintragungen. Bisher zeigte sich, daß die Wittenberger Universität vor allem im letzten Abschnitt häufiger frequentiert wurde, als sie aufgrund der Reformationsereignisse größere Berühmtheit erlangte, doch ist kein Prenzlauer seit 1519 dort immatrikuliert worden. Vor allem in der Gründungsphase der Universität im Jahr 1502 sind sie zahlreich erschienen. Freilich fand auch ein Anstieg seit dem Ausbruch der Reformation im November 1517 statt, denn zwischen 1512 und 1518 stieg die Zahl auf acht Personen an, doch wurde die Universität offensichtlich in erster Linie aufgrund der günstigen Lage bevorzugt. Erst als eine weitere Gründung im näheren Frankfurt einige Jahre später erfolgte, wechselten die Prenzlauer von Wittenberg nach Frankfurt, wo im letzten Abschnitt alle Einschreibungen erfolgten. Durch den kürzeren Zeitraum erreicht diese Universität (11) allerdings noch nicht die Wittenberger Immatrikulationszahl. Im Jahre 1496 erfolgte außerdem noch eine Prenzlauer Eintragung in Wien, eine 1340 in Bologna sowie zwei 1494 in Krakau, so daß man zusammen 117 Immatrikulationen erhält, von denen 25 vor 1456 erfolgten, die restlichen 92 zwischen 1456 und 1524. An der prozentualen Verteilung aller Einschreibungen kann man die Lage der Stadt inmitten einer dichten Universitätslandschaft ablesen (vgl. folgende Grafik). Keine Universität erreichte einen Anteil über 30 Prozent: die größere Auswahl der verschiedenen Hohen Schulen war zu groß, als daß nur eine Universität zur Domäne hätte werden können. Man muß allerdings berücksichtigen, daß eine eigene Landesuniversität erst sehr spät gegründet wurde. In späteren Jahren hat sicherlich auch dort eine stärkere Monopolisierung auf Frankfurt stattgefunden. 


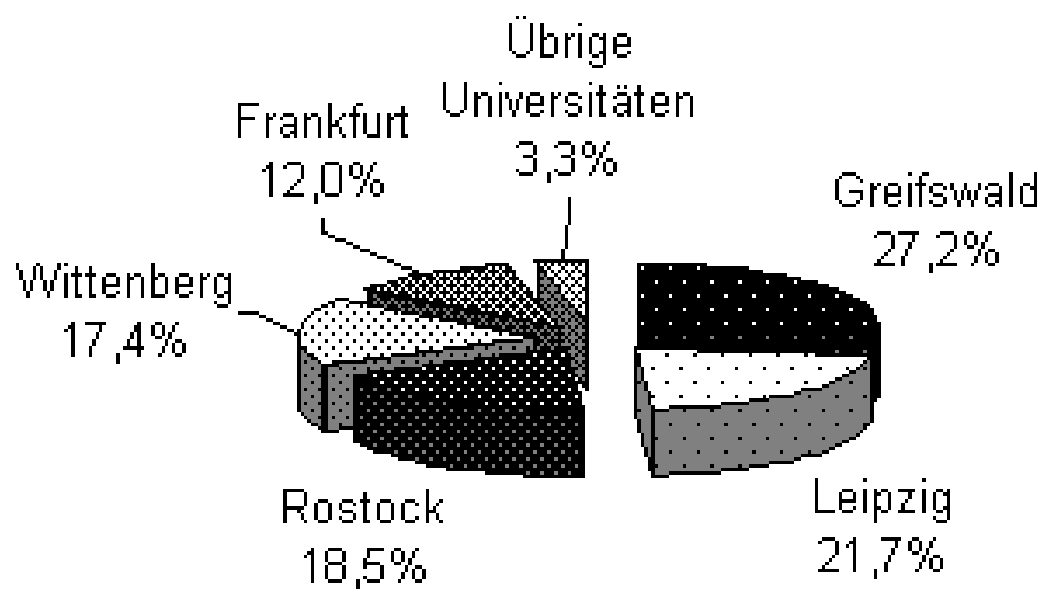

Abbildung 59: Prenzlauer Studenten 1456-1524 (Verteilung auf Universitäten)

Die Frequenz aller Einschreibungen aus Prenzlau verlief recht gleichbleibend. In der ersten Hälfte des Zeitraums erfolgten 40, in der zweiten 52 Immatrikulationen (vgl. folgende Tabelle). Nur im Gründungsabschnitt Frankfurts (1505-1511) sowie im Abschnitt, als die Reformation ausbrach (15121518), stiegen die Zahlen. Der Gesamtanstieg fiel vor allem deshalb so gering aus, weil die bisher wichtigen Universitäten Greifswald und Leipzig ihre Bedeutung fast vollständig verloren haben. In den Ergebnissen spiegeln sich Studentenmigrationen zwischen den verschiedenen Universitäten wider: während die Leipziger Universität bis zum Jahr 1483 eine dominierende Stellung einnahm, kann Greifswald deren Stellung seit 1484 bis etwa 1497 übernehmen. Am Ende des 15. Jahrhunderts gehen die Studenten wieder häufiger nach Leipzig, doch übernimmt Wittenberg seit 1502 die Führung unter den konkurrierenden Hochschulen, seit 1505 allerdings im Zusammenspiel mit Frankfurt. Erst im Jahre 1519 wird Wittenberg dann von der eigenen Landesuniversität als wichtigstem Studienort abgelöst.

Tabelle 28: Prenzlauer Studenten bis 1524

\begin{tabular}{|l|l|l||l|r|}
\hline Universität & Vor 1456 & $1456-1490$ & $1491-1524$ & Gesamt \\
\hline \hline Leipzig & 23 & 14 & 6 & 43 \\
\hline \hline Greifswald & 0 & 15 & 10 & 25 \\
\hline \hline Rostock & 1 & 11 & 6 & 18 \\
\hline \hline Wittenberg & 0 & 0 & 16 & 16 \\
\hline \hline Frankfurt & 0 & 0 & 11 & 11 \\
\hline \hline Krakau & 0 & 0 & 2 & 2 \\
\hline Wien & 0 & 0 & 1 & 1 \\
\hline \hline Bologna & 1 & 0 & 0 & 1 \\
\hline
\end{tabular}




\subsubsection{Malchin: Studentenzuwachs aufgrund der Rostocker Krise}

Die mecklenburgische Stadt Malchin wies mit 25 Inskriptionen die gleiche Studentenzahl in Greifswald auf wie das brandenburgische Prenzlau. Da die Stadt in näherer Umgebung der mecklenburgischen Universität liegt, zeigte sich jedoch eine dominierende Stellung der eigenen Landesuniversität, die 56 Malchiner verzeichnete. Drei der Rostocker Einschreibungen erfolgten vor 1456. Aufgrund der nördlichen Lage dieser Stadt ist auch eine Konzentration auf die beiden Ostseeuniversitäten zu konstatieren. Nur acht Immatrikulationen waren im gesamten Mittelalter an anderen Universitäten nachzuweisen, fünf davon erfolgten bereits vor der Greifswalder Gründung.

Die Rostocker Immatrikulationszahlen bewegten sich immer etwas über denen in Greifswald. Selbst in der Greifswalder Gründungsphase blieb es bei diesem Verhältnis. Vielmehr zogen Malchiner nur zögerlich an die pommersche Nachbaruniversität. Die Studentenzahl in Greifswald erreichte zwischen 1477 und 1484 ihre Höchstmarke, was mit dem Beginn der Rostocker Krise zusammenhängen könnte, doch nahmen auch die Zahlen in Rostock leicht zu. Zwischen 1505 und 1518 erreichte Rostock die höchste Frequenzrate, als in zwei Abschnitten 22 Malchiner erschienen sind. Greifswald blieb mit sieben Inskriptionen dahinter zurück. Im letzten Abschnitt waren sie dort überhaupt nicht mehr vertreten. Von den anderen Universitäten verzeichnete Prag bis zum Jahr 1409 weitere vier Malchiner, während Leipzig zwischen 1409 und 1456 nur eine Eintragung vorwies. Seit 1456 kam noch eine weitere Inskription hinzu. Je ein Student ließ sich außerdem in Wien und Erfurt nachweisen, so daß man insgesamt acht Studenten vor der Greifswalder Gründung sowie 81 seit dem Jahr 1456 erhält. Aus der folgenden Tabelle geht eine leichte Frequenzsteigerung nach der Hälfte des Betrachtungszeitraums hervor. Die Bedeutung der pommerschen Landesuniversität für die mecklenburgische Stadt ging jedoch zurück, denn nur 24,4 Prozent der Malchiner zogen zwischen 1491 und 1524 nach Greifswald, während es zwischen 1456 und 1524 noch 38,9 Prozent waren.

Tabelle 29: Malchiner Studenten bis 1524

\begin{tabular}{|c|c|c|c|c|}
\hline Universität & Vor 1456 & 1456-1490 & 1491-1524 & Gesamt \\
\hline \multirow[t]{2}{*}{ Rostock } & 3 & 20 & 33 & 56 \\
\hline & $37,5 \%$ & $55,6 \%$ & $73,3 \%$ & $62,9 \%$ \\
\hline \multirow[t]{2}{*}{ Greifswald } & 0 & 14 & 11 & 25 \\
\hline & $0,0 \%$ & $38,9 \%$ & $24,4 \%$ & $28,1 \%$ \\
\hline \multirow[t]{2}{*}{ Prag } & 4 & 0 & 0 & 4 \\
\hline & $50,0 \%$ & $0,0 \%$ & $0,0 \%$ & $4,5 \%$ \\
\hline \multirow[t]{2}{*}{ Leipzig } & 1 & 1 & 0 & 2 \\
\hline & $12,5 \%$ & $2,8 \%$ & $0,0 \%$ & $2,2 \%$ \\
\hline
\end{tabular}




\begin{tabular}{|l|l||l|l||r||}
\hline Wien & 0 & 1 & 0 & 1 \\
\hline & $0,0 \%$ & $2,8 \%$ & $0,0 \%$ & $1,1 \%$ \\
\hline Erfurt & 0 & 0 & 1 & 1 \\
\hline Gesamt & $0,0 \%$ & $0,0 \%$ & $2,2 \%$ & $1,1 \%$ \\
& 8 & 36 & 45 & $100,0 \%$ \\
\hline
\end{tabular}

6.3.5. Resümee: "Nähe" als Kriterium der Universitätsauswahl

Da nur aus vier Orten der Nachbarländer Pommerns über 20 Studenten nach Greifswald gezogen sind, konnte die Gegenprobe für diese Länder sicherlich keine repräsentativen Aussagen über die Bedeutung der neuen Universität machen. Die Ergebnisse gaben jedoch Hinweise über Zusammenhänge zwischen geographischer Herkunft und Universitätsauswahl der Studenten, die für andere Orte dieser Regionen ebenfalls von Bedeutung waren. Immerhin handelte es sich um drei Orte im nördlichen Mecklenburg, während nur eine Stadt im südlich angrenzenden Brandenburg lag. Folgt man der Reihenfolge dieser Orte nach dem Studentenanteil in Rostock, dann vergrößert sich ebenfalls die Entfernung zur mecklenburgischen Universität. Aus Malchin, welches der Universitätsstadt am nächsten liegt, zogen 65,4 Prozent aller Studenten nach Rostock, gefolgt von Neubrandenburg (42,3\%), Friedland (21,2\%) und Prenzlau (18,5\%). Umgekehrt verläuft die Reihenfolge, wenn man nach dem Besuch der mitteldeutschen Universitäten Leipzig, Erfurt, Frankfurt und Wittenberg fragt (Prenzlau: 51,1\%, Friedland: 30,3\%, Neubrandenburg: 13,4\%, Malchin: 2,5\%). Für ein Studium in Greifswald spielte neben der Entfernung zum Herkunftsort offensichtlich auch die Entfernung zur Nachbaruniversität eine Rolle, denn das südlich von Rostock gelegene Malchin liegt zwar in vergleichbarer Entfernung von Greifswald wie Friedland, doch zogen nur 30,9 gegenüber 48,5 Prozent der Studenten an die pommersche Universität. Aus Prenzlau zogen nur 27,2 Prozent aller Studenten nach Greifswald, das damit den niedrigsten Prozentsatz aufwies. Dieser Ort liegt nicht nur in größerer Entfernung zur pommerschen Hansestadt als die drei übrigen Ortschaften, auch war die Nähe zum mitteldeutschen Universitätsnetz sehr dicht, so daß die Stadt insgesamt die höchste Studentenzahl erreichte. Diese Nähe bewirkte, wie auch bei den südlichen pommerschen Orten, daß die Zahl der besuchten Universitäten größer war als die der nördlicheren Orten. Die einzelnen Universitäten hatten dafür einen geringeren prozentualen Anteil an der Frequenz. 


\section{4. Überregionale Herkunftsorte}

\subsubsection{Danzig: von Leipzig nach Krakau und Frankfurt}

Zu den größten und bedeutendsten Städten des alten Reiches gehörte die Hansestadt Danzig. Bis zum Jahre 1466 war sie noch Teil des Ordensgebietes, doch wurde sie zusammen mit anderen preußischen Territorien im Zweiten Thorner Frieden an die polnische Krone abgetreten. Bereits im Jahr 1895 veröffentlichte Perlbach eine Zusammenstellung aller Studenten Preußens im Mittelalter, in der die Danziger Studenten eigens aufgeführt worden sind. ${ }^{306}$ Wie in älteren Schriften zur Universitätgeschichte üblich, handelte es sich nur um eine namentliche Erfassung der Studenten, während die eigentliche Auswertung des Materials nie erfolgte. Die gründliche und ausführliche Darlegung der Studentendaten in Perlbachs Edition ermöglicht es, diese Auswertung für Danzig nachträglich auszuführen.

Insgesamt wurden 854 Danziger Studenten ermittelt, die im gesamten Mittelalter ein Studium begannen. Die Größenordnung dieser Zahl spiegelt die bedeutende Rolle dieser Hansestadt im Mittelalter wider. Kein bisher behandelter Ort hatte eine vergleichbare Studentenzahl vorzuweisen. Selbst Stralsund brachte es als bedeutendste Stadt Pommerns nur auf halb so viele Studenten (427), gefolgt von Stettin (334) und Greifswald (257). Auch der Anstieg, den die Zahlen im Mittelalter erlebten, ist beachtlich. Vor dem Jahr 1456 inskribierten sich insgesamt 332 Danziger an den Universitäten. Die Zeitspanne beginnt eigentlich mit der Gründung der ersten Universitäten in Bologna und Paris im 13. Jahrhundert, doch werden regelmäßige Zahlen aufgrund der problematischen Quellenlage erst seit dem Ende des 14. Jahrhunderts geliefert. Von 1456 bis 1524, in weiteren 69 Jahren, kann die Inskriptionsrate um fast 60 Prozent zulegen, denn 522 Danziger schrieben sich seither an den europäischen Universitäten ein. Auch innerhalb der Zeitspanne erlebten die Zahlen eine Steigerung. Aus der folgenden Tabelle geht der Anstieg nach der Hälfte des Zeitraums im Vergleich mit den größten Städten Pommerns hervor: keine Stadt konnte eine gleichartige Frequenzsteigerung erzielen.

Tabelle 30: Vergleich der vier Städte mit der höchsten Studienbeteiligung

\begin{tabular}{|l|l|l||}
\hline Ort & $1456-1490$ & $1491-1524$ \\
\hline \hline Danzig & 181 & 341 \\
\hline Stralsund & 151 & 168 \\
\hline Stettin & 126 & 118 \\
\hline \hline Greifswald & 95 & 117 \\
\hline
\end{tabular}

Auch die Frequenzkurve zeigt den erheblichen Anstieg der Studentenzahlen (vgl. folgende Grafik). Vor allem seit dem Beginn des 16. Jahrhunderts sind die stärksten Zugewinne zu verbuchen, die mit 
den neugegründeten Universitäten Frankfurt und Wittenberg zusammenhingen. Die Annäherung Danzigs zum mitteleuropäischen Universitätsnetz seit diesen Neugründungen im 16. Jahrhunderts zog eine erhebliche Frequenzsteigerung nach sich, wie schon bei vielen pommerschen Orten zu beobachten war. Man sieht zwar, daß auch die Greifswalder Universitätsgründung anfänglich eine etwas höhere Frequenz bewirken konnte, doch blieb die Gesamtkurve von den Greifswalder Inskriptionen eher unbeeinflusst.

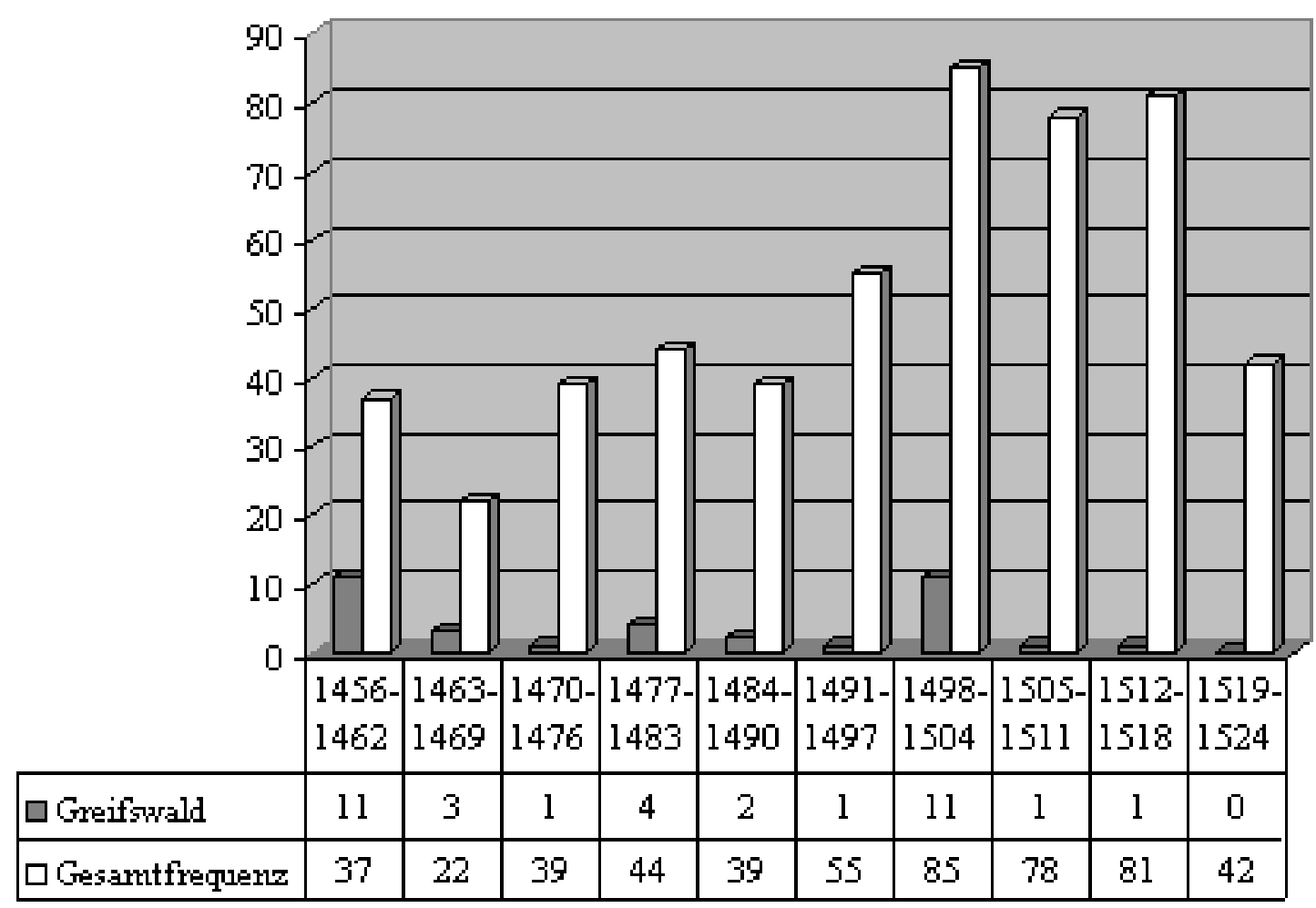

Abbildung 60: Danziger Studenten 1456-1524 (Greifswald - Gesamtfrequenz)

Nun zu den Zahlen im einzelnen: der größte Teil der Danziger (34,1\% = 178 Studenten) besuchte im behandelten Zeitraum die polnische Universität Krakau. Da die Stadt Danzig in 58 der 69 betrachteten Jahre zur polnischen Krone gehörte, stellt dieses Ergebnis keine Besonderheit dar: die Stadtbewohner besuchten im rechtlichen Sinne ihre eigene "Landesuniversität". Den Bedeutungsgewinn, den Krakau seit 1466 erreicht, wird am prozentualen Anteil Krakaus an der Gesamtfrequenz deutlich: bis zum Jahr 1466 besuchten nur 13,4 Prozent der Danziger die polnische Universität, von 1467 bis 1524 sind es bereits 36,4 Prozent. Erst seit 1470 erreichten die Zahlen in Krakau ihren Durchschnittswert von 17 Studenten pro Jahrsiebt. Die stärkste Frequenz ist zwischen 1484 und 1490 (25) sowie zwischen 1498 und 1502 (41) zu bemerken. Im letzten Abschnitt sind die Zahlen rückläufig, doch ist auch die Gesamtfrequenz von negativer Tendenz. ${ }^{307}$ Vor der Greifswalder Universitätsgründung inskribierten sich 45 Danziger in Krakau, so daß die Gesamtzahl auf 223 Studenten an der polnischen Hohen Schule ansteigt.

Leipzig verzeichnete im gesamten Mittelalter die meisten Danziger Studenten (229), doch nimmt der Besuch Leipzigs seit 1466 ab. 82 Studenten wurden seit dem Thorner Frieden immatrikuliert, während zuvor 147 Studenten nach Leipzig gingen. Der Anteil, den die Universität zwischen 1456 
und 1524 erreicht, liegt bei 17,8 Prozent. ${ }^{308}$ Die Universitätsgründung in Frankfurt führte zu einer weiteren Deklassierung, denn seit 1505 sinkt der Leipziger Anteil auf 9,5 Prozent. ${ }^{309}$ Die meisten Danziger inskribierten sich allerdings nicht zu Beginn des Betrachtungszeitraums ${ }^{310}$, sondern erst in den Jahren von 1477 bis 1483 (18) sowie zwischen 1491 und 1497 (19), als die meißnische Hohe Schule auch die Krakauer Zahlen überbietet.

Mit 80 Einschreibungen folgt Frankfurt in der Gunst der Danziger auf Leipzig. Obwohl die brandenburgische Universität erst im 16. Jahrhundert gegründet wurde, überbietet sie bereits die beiden Ostseeuniversitäten, betrachtet man nur den Zeitraum zwischen 1456 und 1524. Bezieht man das gesamte Mittelalter ein, so liegt Rostock mit 85 Danziger Studenten noch leicht über den Frankfurter Zahlen, doch kann man, um die wirkliche Bedeutung der Universität zu bemessen, eigentlich nur den Zeitraum zwischen 1505 und 1524 gelten lassen. ${ }^{311}$ Der Anteil steigt dann auf fast 40 Prozent, so daß Frankfurt seit Gründung zur wichtigsten Universität wurde.

In Rostock liegt die Zahl der Danziger zwischen 1456 und 1524 immer bei etwa sieben Studenten pro Jahrsiebt. Lediglich die Rostocker Domfehde bewirkte zwischen 1484 und 1490 das Ausbleiben weiterer Inskriptionen. Der Anstieg in Krakau spricht dafür, daß die Danziger vor allem auf die polnische Universität ausgewichen sind. ${ }^{312}$ In den letzten beiden Abschnitten ist auch für Rostock ein Bedeutungsrückgang zu konstatieren. ${ }^{313}$ Die 55 Studenten zwischen 1456 und 1524 entsprechen einem Anteil von 10,5 Prozent aller Danziger Einschreibungen. Betrachtet man den Zeitraum vor der Greifswalder Gründung, sind es nur neun Prozent. Greifswald ist der größeren Nachbaruniversität demnach keineswegs zur Konkurrenz geworden. Ihre Bedeutung für Danzig konnte sich nach 1456 ebenfalls steigern.

Erst an fünfter Stelle kommt in der Gunst der Danziger die pommersche Hohe Schule, denn 35 Einschreibungen ließen sich dort nachweisen. ${ }^{314}$ Greifswalds Anteil an der Gesamtfrequenz liegt zwischen 1456 und 1524 bei 6,7 Prozent, betrachtet man auch den Zeitraum vor der Gründung so liegt er bei 4,1 Prozent. Nur im Gründungsjahrsiebt ziehen die meisten Danziger nach Greifswald. 315 Im Abschnitt der beiden italienischen Humanisten wird zwar die gleiche Zahl erreicht (11 Einschreibungen), doch relativiert sie sich durch 41 Krakauer Immatrikulationen im gleichen Abschnitt. 316

Nach Wittenberg zogen in nur 22 Jahren fast ebensoviele Danziger (30). Auch hier führen vor allem die Reformationsereignisse zu einer stärkeren Beteiligung (vgl. folgende Tabelle)

Tabelle 31: Danziger Studenten in Wittenberg bis 1524

\begin{tabular}{|l|l|l|l|l||r|}
\cline { 2 - 6 } \multicolumn{1}{l|}{} & $1498-1504$ & $1505-1511$ & $1512-1518$ & $1519-1524$ & Gesamt \\
\hline Anzahl & 4 & 2 & 10 & 14 & 30 \\
\hline \hline Gesamtanteil & $4,7 \%$ & $2,6 \%$ & $12,3 \%$ & $33,3 \%$ & $10,5 \%$ \\
\hline
\end{tabular}


Nicht nur in der Höhe der Studentenzahl, sondern auch in der Auswahl der Universitäten unterschied sich Danzig von den bisher behandelten Ortschaften, denn neben den sechs zuvor genannten, wurden in weiteren sechs Universitäten Danziger immatrikuliert. 20 Studenten gingen zwischen 1456 und 1524 an die Kölner Universität. Vor dem Jahr 1456 waren es acht. Wien verzeichnete 66 Studenten aus Danzig, 57 zogen bereits vor dem Jahr 1456 dorthin. Die österreichische Universität wurde in ihrer Bedeutung daher bis zur Mitte des 15. Jahrhunderts nur von Leipzig übertroffen. Auch Erfurt spielte eine größere Rolle vor der Jahrhundertmitte, denn 22 der insgesamt 30 Einschreibungen fanden vor dem Jahr 1456 statt. Im Prager Dekanatsbuch der Artisten sowie der juristischen Fakultätsmatrikel waren weitere 16 Einschreibungen nachzuweisen, während die deutsche Nationsmatrikel in Bologna 16 Danziger Namen enthielt, von denen neun vor dem Jahr 1456 dort eingeschrieben wurden. Heidelberg wies sieben und Tübingen weitere drei Studenten auf (vgl. folgende Tabelle).

Tabelle 32: Danziger Studenten bis 1524

\begin{tabular}{|c|c|c|c|c|}
\hline Universität & Vor 1456 & 1456-1490 & \begin{tabular}{|l}
$1491-1524$ \\
\end{tabular} & Gesamt \\
\hline \multirow[t]{2}{*}{ Leipzig } & 136 & 44 & 49 & 229 \\
\hline & $41,0 \%$ & $24,3 \%$ & $14,4 \%$ & $26,8 \%$ \\
\hline \multirow[t]{2}{*}{ Krakau } & 45 & 64 & 114 & 223 \\
\hline & $13,6 \%$ & $35,4 \%$ & $33,4 \%$ & $26,1 \%$ \\
\hline \multirow[t]{2}{*}{ Rostock } & 30 & 29 & 26 & 85 \\
\hline & $9,0 \%$ & $16,0 \%$ & $7,6 \%$ & $10,0 \%$ \\
\hline \multirow[t]{2}{*}{ Frankfurt } & 0 & 0 & 80 & 80 \\
\hline & $0,0 \%$ & $0,0 \%$ & $23,5 \%$ & $9,4 \%$ \\
\hline \multirow[t]{2}{*}{ Wien } & 57 & 4 & 5 & 66 \\
\hline & $17,2 \%$ & $2,2 \%$ & $1,5 \%$ & $7,7 \%$ \\
\hline \multirow[t]{2}{*}{ Greifswald } & 0 & 21 & 14 & 35 \\
\hline & $0,0 \%$ & $11,6 \%$ & $4,1 \%$ & $4,1 \%$ \\
\hline \multirow[t]{2}{*}{ Wittenberg } & 0 & 0 & 30 & 30 \\
\hline & $0,0 \%$ & $0,0 \%$ & $8,8 \%$ & $3,5 \%$ \\
\hline \multirow[t]{2}{*}{ Erfurt } & 22 & 5 & 3 & 30 \\
\hline & $6,6 \%$ & $2,8 \%$ & $0,9 \%$ & $3,5 \%$ \\
\hline \multirow[t]{2}{*}{ Köln } & 8 & 9 & 11 & 28 \\
\hline & $2,4 \%$ & $5,0 \%$ & $3,2 \%$ & $3,3 \%$ \\
\hline Prag & 22 & 0 & 0 & 22 \\
\hline
\end{tabular}




\begin{tabular}{|l|l|l|l||r|}
\cline { 2 - 5 } \multicolumn{1}{c|}{} & $6,6 \%$ & $0,0 \%$ & $0,0 \%$ & $2,6 \%$ \\
\hline Bologna & 9 & 4 & 3 & 16 \\
\hline Heidelberg & $2,7 \%$ & $2,2 \%$ & $0,9 \%$ & $1,9 \%$ \\
\hline Tübingen & 3 & 1 & 3 & 7 \\
\hline Gesamt & $0,9 \%$ & $0,6 \%$ & $0,9 \%$ & $0,8 \%$ \\
& 0 & 0 & 3 & 3 \\
& $0,0 \%$ & $0,0 \%$ & $0,9 \%$ & $0,4 \%$ \\
\hline & 132 & 181 & 341 & $100,0 \%$ \\
\hline
\end{tabular}

Die Tabelle über das Studium der Danziger im Mittelalter relativiert die Bedeutung der Greifswalder Hohen Schule: obwohl Greifswald von dem Standpunkt der Nähe aus betrachtet ein durchaus attraktiver Universitätsort war, blieben die Immatrikulationszahlen aus Danzig weit hinter denen anderer Universitäten zurück. Die Zahlen verdeutlichen, daß die pommersche Hochschule in Ruf und Prestige kaum an das Niveau vor allem der älteren Universitäten im Reich heranreichen konnte. ${ }^{317}$

\subsubsection{Lübeck: im regionalen Einzugsbereich Rostocks}

Der Universitätsbesuch der Lübecker Studenten im Mittelalter war bereits das Thema einer Dissertation aus dem Jahre $1941{ }^{318}$ Sogar für italienische und französische Universitäten ermittelte Delhaes einige Studenten, die im folgenden aufgeführt werden sollen.

Mit insgesamt 1171 Einschreibungen im Mittelalter liegen die Lübecker Zahlen noch um ein Drittel über denen der Danziger Studenten. Dieses Ergebnis ist vor allem deshalb interessant, weil die Einwohnerzahl der preußischen Stadt über der Lübecks lag. Der Grund für die höhere Zahl liegt offensichtlich in der Nähe Rostocks. Dies wird schon an der Verteilung der Studenten deutlich. Keine Universität vermag an die Zahlen der Rostocker Hohen Schule heranzureichen, in deren regionalen Einzugsbereich diese bekannteste Hansestadt gehörte. Mit 726 Einschreibungen besuchten 62 Prozent der Lübecker die Universität im benachbarten Mecklenburg. Betrachtet man nur den Zeitraum seit Gründung der pommerschen Landesuniversität, so steigt der Anteil auf 73 Prozent. Es ist einigermaßen erstaunlich, daß Greifswald trotz der nicht viel größeren Entfernung von Lübeck einen solchen Zahlenunterschied gegenüber Rostock aufwies. Nur 30 Lübecker ließen sich dort bis zum Jahr 1524 immatrikulieren. Obwohl die mecklenburgische Universität während der Rostocker Domfehde nach Lübeck ausgewandert ist, läßt sich zwischen 1484 und 1490 ein Rückgang der Inskriptionen feststellen. Mit 44 Einschreibungen präferierten die Lübecker zwar noch die mecklenburgische Universität, doch stiegen in dem Zeitraum die Zahlen in Leipzig auf 10, in Greifswald auf 9 sowie in Köln auf 8 Immatrikulationen. Leipzig folgte in der Beliebtheit der Lübecker auf Rostock mit 118 Einschreibungen. 57 erfolgten vor dem Jahre 1456, so daß die 
Bedeutung dieser Universität für Lübeck seit Mitte des 15. Jahrhunderts eher abgenommen hat. Köln verzeichnete insgesamt 66 Lübecker, während Erfurt 90 Studenten aufwies, die vornehmlich bis zum Ende des 15. Jahrhunderts erschienen sind. Fünftbeliebtester Studienort war die Greifswalder Universität mit ihren 30 Einschreibungen, gefolgt von Löwen mit 18, Frankfurt mit 13, Wittenberg mit 11, Wien mit sechs (fünf vor 1456), Heidelberg mit drei (alle vor 1456) sowie Basel mit einer Immatrikulation. An auswärtigen Universitäten wurde Krakau (2), Paris (4), Orléans (5), Toulouse (1), Perugia (4), Siena (2) und Ferrara (1) aufgesucht. Allein in Bologna (36) ließen sich mehr Studenten als in Greifswald nachweisen, wobei seit dem Jahr 1456 nur noch 11 Studenten den weiten Weg an die italienische Universität machten (vgl. folgende Tabelle)

Tabelle 33: Lübecker Studenten bis 1524

\begin{tabular}{|c|c|c|c|c|c|}
\hline Land & Universität & Vor 1456 & $1456-1490$ & 1491-1524 & Gesamt \\
\hline \multirow[t]{21}{*}{ Reich } & Rostock & 70 & 331 & 325 & 726 \\
\hline & & $25,74 \%$ & $75,23 \%$ & $70,81 \%$ & $62,00 \%$ \\
\hline & Leipzig & 57 & 26 & 35 & 118 \\
\hline & & $20,96 \%$ & $5,91 \%$ & $7,63 \%$ & $10,08 \%$ \\
\hline & Erfurt & 56 & 25 & 9 & 90 \\
\hline & & $20,59 \%$ & $5,68 \%$ & $1,96 \%$ & $7,69 \%$ \\
\hline & Köln & 13 & 23 & 30 & 66 \\
\hline & & $4,78 \%$ & $5,23 \%$ & $6,54 \%$ & $5,64 \%$ \\
\hline & Prag & 34 & 0 & 0 & 34 \\
\hline & & $12,50 \%$ & $0,00 \%$ & $0,00 \%$ & $2,90 \%$ \\
\hline & Greifswald & 0 & 21 & 9 & 30 \\
\hline & & $0,00 \%$ & $4,77 \%$ & $1,96 \%$ & $2,56 \%$ \\
\hline & Löwen & 0 & 4 & 14 & 18 \\
\hline & & $0,00 \%$ & $0,91 \%$ & $3,05 \%$ & $1,54 \%$ \\
\hline & Frankfurt & 0 & 0 & 13 & 13 \\
\hline & & $0,00 \%$ & $0,00 \%$ & $2,83 \%$ & $1,11 \%$ \\
\hline & Wittenberg & 0 & 0 & 11 & 11 \\
\hline & & $0,00 \%$ & $0,00 \%$ & $2,40 \%$ & $0,94 \%$ \\
\hline & Wien & 5 & 0 & 1 & 6 \\
\hline & & $1,84 \%$ & $0,00 \%$ & $0,22 \%$ & $0,51 \%$ \\
\hline & Heidelberg & 3 & 0 & 0 & 3 \\
\hline
\end{tabular}




\begin{tabular}{|c|c|c|c|c|c|}
\hline & & & & & \\
\hline & & $1,10 \%$ & $0,00 \%$ & $0,00 \%$ & $0,26 \%$ \\
\hline & Basel & 0 & 1 & 0 & 1 \\
\hline & & $0,00 \%$ & $0,23 \%$ & $0,00 \%$ & $0,09 \%$ \\
\hline Italien & Bologna & 25 & 5 & 6 & 36 \\
\hline & & $9,19 \%$ & $1,14 \%$ & $1,31 \%$ & $3,07 \%$ \\
\hline & Perugia & 0 & 2 & 2 & 4 \\
\hline & & $0,00 \%$ & $0,45 \%$ & $0,44 \%$ & $0,34 \%$ \\
\hline & Siena & 0 & 0 & 2 & 2 \\
\hline & & $0,00 \%$ & $0,00 \%$ & $0,44 \%$ & $0,17 \%$ \\
\hline & Ferrara & 1 & 0 & 0 & 1 \\
\hline & & $0,37 \%$ & $0,00 \%$ & $0,00 \%$ & $0,09 \%$ \\
\hline Frankreich & Orleans & 2 & 1 & 2 & 5 \\
\hline & & $0,74 \%$ & $0,23 \%$ & $0,44 \%$ & $0,43 \%$ \\
\hline & Paris & 3 & 1 & 0 & 4 \\
\hline & & $1,10 \%$ & $0,23 \%$ & $0,00 \%$ & $0,34 \%$ \\
\hline & Toulouse & 1 & 0 & 0 & 1 \\
\hline & & $0,37 \%$ & $0,00 \%$ & $0,00 \%$ & $0,09 \%$ \\
\hline Polen & Krakau & 2 & 0 & 0 & 2 \\
\hline & & $0,74 \%$ & $0,00 \%$ & $0,00 \%$ & $0,17 \%$ \\
\hline Gesamt & & 272 & 440 & 459 & 1171 \\
\hline & & $100,00 \%$ & $100,00 \%$ & $100,00 \%$ & $100,00 \%$ \\
\hline
\end{tabular}

Die Gesamtfrequenz der Lübecker Studenten verlief im behandelten Zeitraum relativ gleichmäßig. Anders als in Danzig konnte hier kein Anstieg beobachtet werden (vgl. folgende Grafik). Von 1491 bis 1497 kommt es zur höchsten Immatrikulationszahl, die man mit einem Rückstau im vorherigen Abschnitt erklären könnte, als die Rostocker Domfehde eine geringere Frequenz herbeiführte. Im letzten Abschnitt ist der stärkste Rückgang zu verzeichnen, der bereits mit den Reformationsereignissen in Verbindung stehen dürfte. Die Lübecker Frequenzkurve mit ihrer geringeren Wachstumsrate zeigt, daß sie kaum durch Neugründungen des 15. und 16. Jahrhunderts beeinflußt wurde. Im Gesamtvergleich war die Zahl der Inskriptionen jedoch recht hoch, was mit der Nähe Rostocks zusammenhing. 


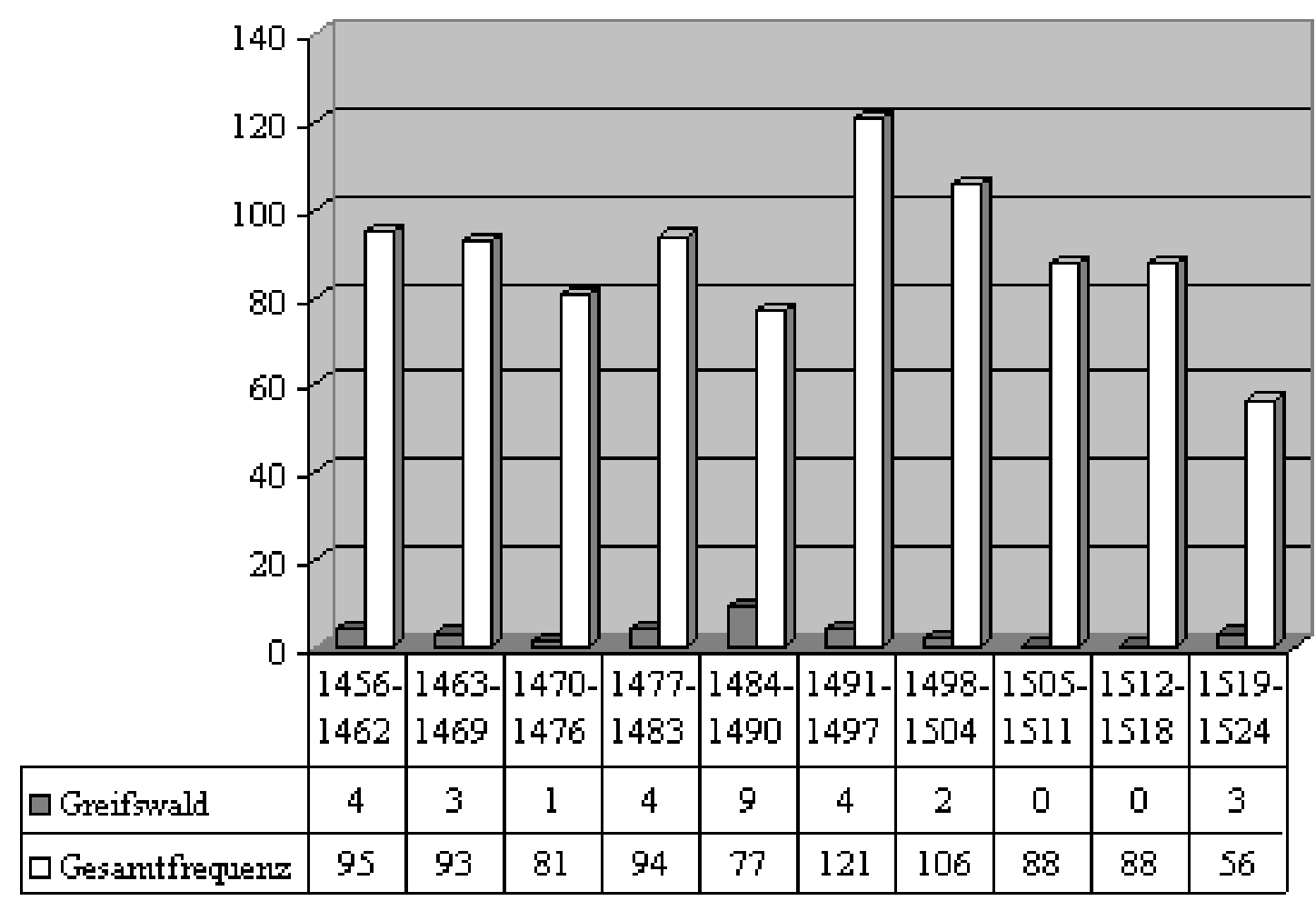

Abbildung 61: Lübecker Studenten 1456-1524 (Greifswald - Gesamtfrequenz)

\subsubsection{Groningen: im Einzugsbereich von Köln und Löwen}

Aus dem niederländischen Groningen ließen sich insgesamt 865 Studenten nachweisen, doch muß man hier von einem Annäherungswert ausgehen. In anderen Reichsterritorien gab es einige Orte, deren Namen sehr ähnlich klangen. 319

Insbesondere in den südlichen Universitäten Tübingen, Freiburg und Wien wird unter den Grüningern vielleicht noch der eine oder andere Niederländer zu finden sein. Es wurden nur jene Eintragungen verwertet, bei denen eine genauere Eingrenzung durch Angabe des genauen Herkunftsgebiets gegeben war. Ähnliche Unklarheiten gab es bei den Universitäten Leipzig und Erfurt, während in der Wittenberger Matrikel immer die Herkunftsdiözese erwähnt worden ist. Dennoch unterstreicht die Gesamtzahl der Studierenden die größere Bedeutung dieser Hansestadt im Mittelalter.

Der größte Teil der 865 Groninger besuchte die Kölner Universität, wo sich 488 Eintragungen nachweisen ließen. Dies entspricht einem Anteil von knapp 57 Prozent aller Groninger an den Universitäten des Mittelalters (bis 1524). ${ }^{320}$ Vor dem Jahre 1456 erreichte Köln fast 78 Prozent, da die Bedeutung Löwens erst in späterer Zeit zunahm. Köln blieb trotz des dichter werdenden Universitätsnetztes bis zum Ende des Betrachtungszeitraums die beliebtere Universität der Groninger, in der sich etwa 37 Studenten pro Jahrsiebt einfanden. Aufgrund der geographischen Nähe kann man die rheinische Hohe Schule als eigentliche Heimatuniversität dieser niederländischen Studenten 
ansehen. An die Universität Löwen zogen 178 Studenten aus der friesischen Hansestadt, was einem Anteil von etwa 20 Prozent entspricht. Ihre Wirkung kann sie allerdings erst lange nach der Gründung im Jahre 1425 entfalten, denn bis 1470 kamen Groninger nur sehr vereinzelt an die Brabanter Universität. ${ }^{321}$ Zwischen 1484 und 1490 (11) sowie zwischen 1491 und 1497 (7) erlebten die Zahlen leichte Einbrüche. Erst seit Beginn des 16. Jahrhunderts blieben die Werte auf dem Mittelwert von etwa 23 Studenten pro Jahrsiebt. ${ }^{322}$ Der Gesamtanteil stieg im behandelten Zeitraum daher auf 25 Prozent, während Köln nur noch auf 52 Prozent kam (vgl. folgende Grafik).

In Rostock ließen sich insgesamt 106 Groninger Studenten immatrikulieren, was einem Anteil von fast 13 Prozent entspricht. An der recht hohen Zahl, den die entfernte mecklenburgische Universität erreicht, kann man die Bedeutung der hansischen Handelswege für den Universitätsbesuch im Mittelalter ermessen, denn selbst näher gelegene Universitäten blieben dagegen weit zurück. Seit 1463 erreichte die Nachbaruniversität Greifswalds einen Mittelwert von etwa 10 Studenten pro Jahrsiebt, während bis dahin insgesamt nur 12 Studenten erschienen sind. In der "hansischen" Phase der Greifswalder Universität von etwa 1470 bis 1504 erreichten die Groninger Einschreibungen auch in Rostock ihre höchste Ausprägung, während sie davor und danach zahlenmäßig geringer ausfielen. Mit 34 Immatrikulationen war Erfurt ebenfalls ein beliebter Studienort der Groninger, doch konnte nicht immer geklärt werden, welcher Ort gemeint ist, da in der Matrikel fast ausschließlich Ortsangaben verzeichnet wurden. Neun Angaben fanden sich vor dem Jahr 1456, während die übrigen 25 danach erfolgten. Berücksichtigt man nur die Zeitspanne zwischen 1456 und 1524, so übertrifft Greifswald demnach die Erfurter Zahl. An der pommerschen Universität ließen sich 29 Eintragungen nachweisen, eine im Hinblick auf die Gesamtzahl der aus Groningen stammenden Studenten eher bescheidene Zahl. Begriffe wie "hansische Universität" oder "Bildungsstätte für den Norden Europas" geben ein verfälschendes Bild wider, wie man an solchen Gegenproben erkennt. Es handelt sich um "subjektive" Eindrücke, die aus dem Blick auf Matrikeln nur einzelner Universitäten hervorgehen. Freilich zeigt sich, daß näher gelegene Universitäten im Westen und Süden des Reiches von Groningern kaum aufgesucht wurden. Somit unterstreichen auch die Greifswalder Zahlen, wie sich die Verkehrs- und Handelsverbindungen nördlicher Reichsregionen günstig auf den Universitätsbesuch auswirken konnten. Zwischen 1477 und 1483 zogen die meisten Groninger an die Greifswalder Universität (18 Eintragungen), so daß sie in diesem Abschnitt Löwen und Rostock überbot, doch immer noch hinter Köln zurückblieb, wo sich 45 Groninger inskribierten.

An die übigen Universitäten zogen weniger als 10 Groninger: neun Studenten gingen nach Heidelberg, acht nach Leipzig, vier nach Wittenberg sowie je einer nach Bologna, Krakau, Basel, Ingolstadt und Tübingen. Paris scheint ebenfalls etwas häufiger besucht worden zu sein, denn allein in dem edierten Prokuratorenverzeichnis ließen sich drei Groninger nachweisen. Ein weiterer Groninger ist dem Verzeichnis Budinskys zu entnehmen. Die prozentuale Verteilung auf die Universitäten sah zwischen 1456 und 1524 folgendermaßen aus: 


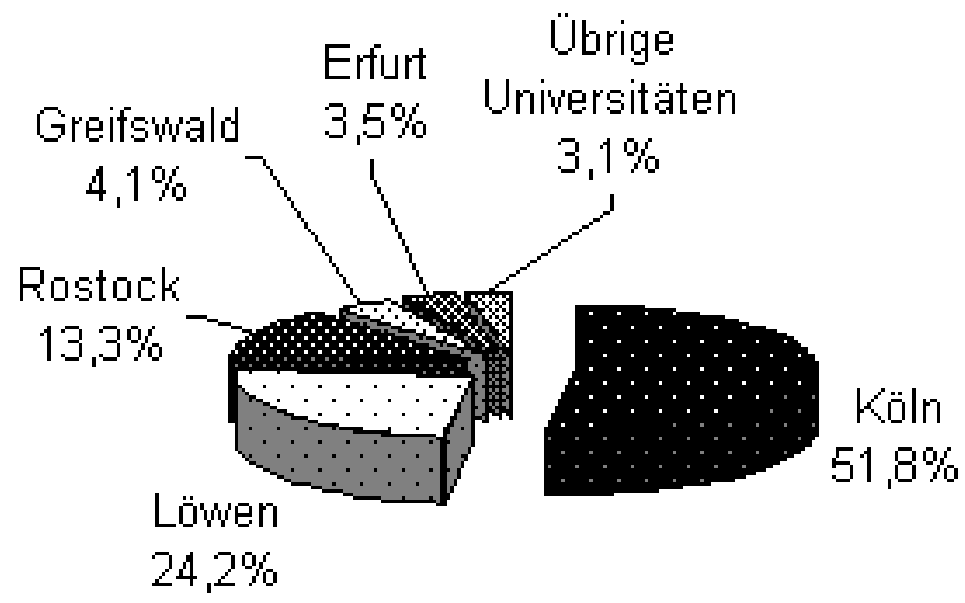

Abbildung 62: Groninger Studenten 1456-1524 (Verteilung auf Universitäten)

Aus der folgenden Grafik geht die Frequenzkurve der Groninger Inskriptionen hervor. Man erkennt darin, daß ein Anstieg der Immatrikulationszahlen bis etwa 1490 stattgefunden hat. Nach einem leichten Rückgang in den neunziger Jahren stiegen die Zahlen an und erreichten zwischen 1512 und 1518 ihre stärkste Ausprägung, während sie im letzten Abschnitt wieder leicht zurückgingen.

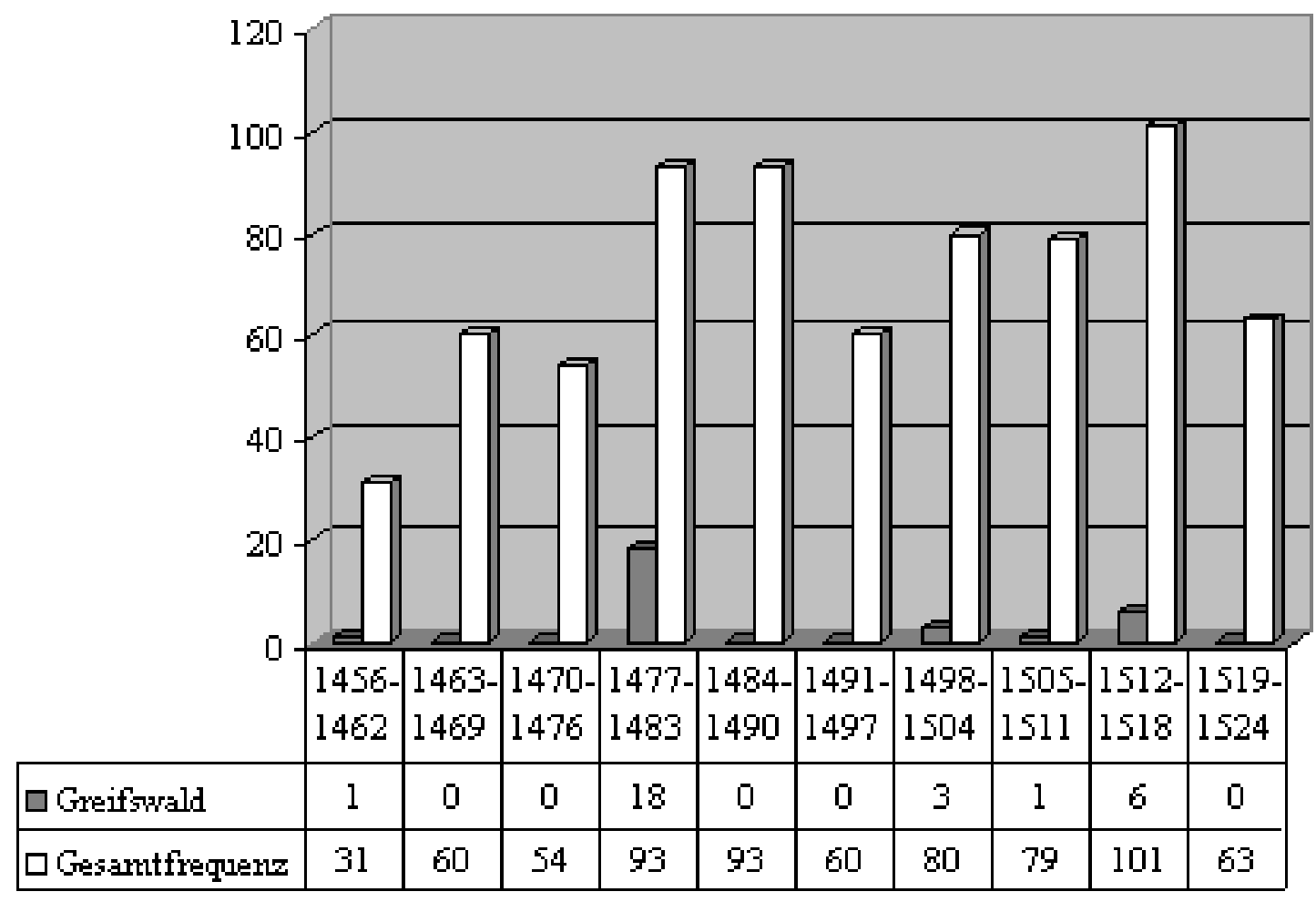

Abbildung 63: Groninger Studenten 1456-1524 (Greifswald - Gesamtfrequenz) 
Als letzter überregionaler Herkunftsort soll nun die Hansestadt Hamburg behandelt werden. Max Heraeus veröffentlichte bereits 1894 eine Zusammenstellung aller Hamburger Studenten auf deutschen und auswärtigen Hochschulen zwischen 1290 und 1650. ${ }^{323}$ Da ihm verschiedene Matrikeleditionen noch nicht vorgelegen haben, konnten einige Ergänzungen an seiner Tabelle vorgenommen werden. ${ }^{324}$

Mit 25 Einschreibungen gehörte Hamburg ebenfalls zu den stärker vertretenen Städten in Greifswald, doch spielte die pommersche Universität für den gesamten Universitätsbesuch der Hamburger nur eine untergeordnete Rolle. Bis 1525 wurden 923 Hamburger mit Universitätsstudium nachgewiesen. Ähnlich den Lübecker Studenten konzentrierten sie sich auf die mecklenburgische Universität. 550 Hamburger verzeichnete die Rostocker Matrikel, was einem Anteil von 60 Prozent aller Einschreibungen entsprach. Während bis zur zweiten Hälfte des 15. Jahrhunderts Erfurt noch wichtigster Studienort der Hamburger war, kommt es seit 1450 zum Anstieg der Studentenzahlen in Rostock. Demgegenüber blieben die Erfurter Eintragungen nur auf gleichem Niveau; seit dem Ende des Jahrhunderts verminderten sich dort die Einschreibungen. Auch Leipzig spielte lediglich vor der Rostocker Gründung eine größere Rolle. Erst auf die neugegründeten Universitäten Frankfurt und Wittenberg folgt die Greifswalder Hohe Schule in der Gunst der Hamburger. Berücksichtigt man die Zeit vor der Greifswalder Gründung, so wird sie von der Kölner Universität noch übertroffen. Bis 1409 ließen sich außerdem 25 Hamburger in Prag nachweisen. Da die Prager Hauptmatrikel fehlt, ist dies jedoch nur als Annäherungswert zu verstehen. Auffällig ist die seit 1450 gleichbleibend hohe Frequenz in Rostock, während die Zahl der besuchten Universitäten anstieg. Die Monopolstellung Rostocks wich somit gegen Ende des Jahrhunderts einer größeren Vielfalt an besuchten Universitäten. Dabei bewirkten vor allem die Neugründungen, daß die Zahl der Einschreibungen um fast ein Drittel anstieg. Auf diesem Weg ging der Anteil Rostocks an der Gesamtfrequenz trotz gleichbleibender Studentenzahl zurück (1451-1500: 82\%, 1501-1525: 57\%).

Tabelle 34: Hamburger Studenten bis 1525

\begin{tabular}{|c|c|c|c|c|c|}
\hline Universität & Vor 1451 & 1451-1475 & \begin{tabular}{|l|}
$1476-1499$ \\
\end{tabular} & \begin{tabular}{|l|}
$1501-1525$ \\
\end{tabular} & Gesamt \\
\hline Rostock & 43 & 169 & 169 & 169 & 550 \\
\hline Erfurt & 81 & 28 & 8 & 10 & 127 \\
\hline Leipzig & 40 & 15 & 5 & 3 & 63 \\
\hline Frankfurt & 0 & 0 & 0 & 39 & 39 \\
\hline Wittenberg & 0 & 0 & 0 & 31 & 31 \\
\hline Köln & 3 & 1 & 14 & 10 & 28 \\
\hline Greifswald & 0 & 4 & 3 & 18 & 25 \\
\hline Prag & 25 & 0 & 0 & 0 & 25 \\
\hline Bologna & 10 & 0 & 2 & 3 & 15 \\
\hline
\end{tabular}




\begin{tabular}{|l||l||l|l|l||r|}
\hline Löwen & 0 & 0 & 0 & 10 & 10 \\
\hline \hline Heidelberg & 3 & 0 & 1 & 0 & 4 \\
\hline \hline Wien & 2 & 0 & 1 & 0 & 3 \\
\hline \hline Krakau & 0 & 1 & 1 & 0 & 2 \\
\hline \hline Paris & 1 & 0 & 0 & 0 & 1 \\
\hline \hline Gesamt & 212 & 214 & 202 & 295 & 923 \\
\hline
\end{tabular}

6.4.5. Resümee: zur Relativierung der überregionalen Bedeutung Greifswalds

Die Betrachtung des Universitätsbesuchs der vier überregionalen Herkunftsorte Danzig, Lübeck, Groningen und Hamburg hat die Bedeutung der pommerschen Landesuniversität im Rahmen der gesamten Universitätslandschaft in ein objektiveres Bild gerückt, als es die bisher behandelten regionalen Ortschaften vermochten. Für keine der Städte war überhaupt irgendeine größere Bedeutung festzustellen. Die älteren Universitäten Rostock, Köln, Leipzig, Löwen (vor allem für Groningen) und Krakau (vor allem für Danzig) zeigten ganz andere Größenordnungen als die kleine pommersche Hohe Schule. Sogar gegenüber den neueren Universitäten Frankfurt und Wittenberg blieb Greifswald zumeist zurück, vor allem wenn man berücksichtigt, daß sie nur in fast einem Drittel des Zeitraums existierten. Insgesamt lag der Greifswalder Studentenanteil aus diesen Orten bei 4,3 Prozent, während Rostock auf 46,3 Prozent kam. Dabei muß man jedoch berücksichtigen, daß dieses Ergebnis vor allem durch Lübeck und Hamburg erreicht wurde, die beide dem direkten regionalen Umfeld der mecklenburgischen Universität angehörten. Ohne diese Orte kam auch Rostock nur auf 11,1 Prozent. Damit wird in erstaunlicher Eindeutigkeit die These von Schwinges bestätigt, der betonte, daß schon die spätmittelalterlichen Einzugsbereiche vornehmlich von regionaler Nähe bestimmt waren. Groninger gingen fast ausschließlich an die nächstgelegenen Universitäten Köln und Löwen, während die Danziger Studenten seit Übergabe der Hansestadt an Polen ihre eigene Landesuniversität Krakau, später das nähere Frankfurt bevorzugten. Es bleibt daher festzuhalten, daß man die überregionale Ausstrahlung einer Universität im späten Mittelalter nicht überbewerten sollte. Dennoch erscheint es ungewöhnlich, daß die südlichen Universitäten des Reichs beim Gesamtvergleich dieser vier überregionalen Ortschaften kaum vertreten waren. Da es sich bei allen Orten um bedeutende Hansestädte handelt, machen die Zahlen umso mehr die besondere Bedeutung der Handelswege und Handelsverbindungen für den spätmittelalterlichen Universitätsbesuch deutlich. Die ältere mecklenburgische Universität dominierte dabei in ihrer Stellung für den Hanseraum und erfuhr in Greifswald niemals eine ernsthafte Konkurrenz. Selbst in der Krisenzeit der Universität von 1484 bis 1490 fanden Abwanderungen nur in geringem Ausmaß nach Greifswald statt, und das, obwohl Rostock eine Halbierung der Einschreibungen aus den vier Orten erlebte. ${ }^{325}$ Nur an fünfter Stelle steht Greifswald bei drei der Ortschaften, während die Universität viertbeliebtester Studienort lediglich der Groninger Studenten war. 
Im Blickpunkt der vorangegangenen Untersuchung standen 26 Orte, aus denen mehr als 20 Studenten nach Greifswald gezogen sind. Die Zahl ihrer Studenten an anderen mittelalterlichen Universitäten sollte darüber Auskunft geben, welche Bedeutung der Greifswalder Universität für Pommern und für das übrige Reichsgebiet zukam, welche Veränderungen und Verschiebungen dabei stattfanden und wie sich das dichter werdende Universitätsnetz in den Immatrikulationen niederschlug. 6338 Immatrikulationen konnten im gesamten Mittelalter aus diesen Orten ermittelt werden. 3813 davon stellten alleine die vier überregionalen Herkunftsorte, die man im Mittelalter sicherlich auch reichsweit zu den Orten mit der stärksten Studienbeteiligung zählen kann.

Als Ergebnis bleibt festzuhalten, daß die Greifswalder Universität eine wichtige Rolle vor allem im Heimatland Pommern spielte, wo sie ihre regionale Basis hatte. Schon die geringe Anzahl außerhalb Pommerns gelegener Herkunftsorte, welche mehr als 20 Studenten in Greifswald vorwiesen, unterstreicht diese Tatsache. Der größte Teil der Pommern bevorzugte und nutzte die neugegründete Universität. Da keine vergleichbaren Untersuchungen für andere Universitäten vorliegen, bleibt eine abschließende Beurteilung darüber offen, ob der Prozentsatz als zu niedrig anzusehen ist. Auffällig ist jedoch, daß Rostock auch in Pommern über eine breite Besucherbasis verfügen konnte. Die Einzugsbereiche der beiden Ostseeuniversitäten überschnitten sich durch ihre räumliche Nähe zueinander, doch gereichte die Konkurrenzsituation offensichtlich in erster Linie der Greifswalder Universität zum Nachteil. Die Studenten aus den behandelten Orten der Nachbarländer wählten Greifswald hauptsächlich aufgrund der geographischen Nähe, da sie allesamt dem direkten regionalen Umfeld der pommerschen Universität angehörten. Über die Auswirkung der zu Beginn des 16. Jahrhunderts neugegründeten Universität Frankfurt ist zu sagen, daß sie nur in ihrer Gründungsphase eine stärkere Konkurrenz für Greifswald darstellte. Noch innerhalb des Betrachtungszeitraums kann Greifswald die Dominanz zurückgewinnen. Der kurze Bedeutungsverlust brachte jedoch keinen Rückgang der pommerschen Immatrikulationen an der Ostseeuniversität, sondern ausschließlich einen Zuwachs und eine stärkere Mobilisierung der Pommern zum Studium. Dies korreliert mit den Ergebnissen von Schwinges: die Kölner Universität drängte sich zwar im 15. Jahrhundert "in ,fremde‘ süd- und mitteldeutsche Einzugsbereiche hinein, ohne jedoch die Überregionalisierung auf Kosten der anderen Hochschulen zu erzielen."326 Als "Landesuniversitäten" konnten diese die "regionalen Bildungsressourcen"327 stärker ausschöpfen und Scholaren aus der Nähe anziehen, die den Rückgang der Studenten überregionaler Herkunft ausglichen. Die Kapazitäten möglicher Studienpartizipation waren offensichtlich bis zum Ausgang des Mittelalters noch keineswegs erschöpft.

Dennoch markiert diese Entwicklung einen wichtigen sozialgeschichtlichen Wandel innerhalb der Universitäten, denn durch sie wurde "auch ärmeren Schichten der Zugang" zum Studium geebnet. ${ }^{328}$ Mit der Verdichtung des Universitätsnetzes, die solche Frequenzsteigerungen bewirkte, veränderten sich die Sozialstrukturen der Studenten, deren soziale Basis sich verbreiterte und damit einen höheren Armenanteil an die Universitäten brachten. In Greifswald, das bis zum Ende des 15. Jahrhundert neben Rostock die einzige Bildungsstätte im nördlichen Reichsgebiet blieb, begann diese Tendenz erst zu Beginn des 16. Jahrhundert als die pommerschen Einschreibungen an den alten und neuen Universitäten ihre vorläufigen Höchstzahlen erreichten. Im Süden des Reiches dagegen, wo sich die Universitätszahl bereits in der zweiten Hälfte des 15. Jahrhundert fast verdoppelt hat, sind solche 
Erscheinungen früher aufgetreten. Fuchs spricht daher sogar von einer "konfliktträchtigen Situation", die durch das "Potential an Unzufriedenen" und den "Angebotsüberhang an Akademikern", bereits am Vorabend der Reformation geschaffen wurde. 329

Hinsichtlich der Austrahlung Greifswalds auf überregionale Gebiete muß man die große Zahl nicht eindeutig verwertbarer Angaben in der Greifswalder Matrikel mitberücksichtigen. Gerade für die skandinavischen Länder würde dann die Bedeutung der pommerschen Hohen Schule bis zum Ende des 15. Jahrhunderts zum Tragen kommen, die aufgrund der vielen Land- und Bistumsangaben nur in einer groben Richtungsuntersuchung ermittelt werden kann. ${ }^{330}$ Berücksichtigt man außerdem die geringe Gesamtfrequenz der Greifswalder Universität im Vergleich mit anderen Universitäten des Reichs, so muß man die Ergebnisse ebenfalls günstiger bewerten. Von über 20 untersuchten Universitäten, die zwischen 1456 und 1524 wesentlich höhere Studentenzahlen vorzuweisen hatten, war Greifswald für die Studenten aus überregionalen Orten etwa der fünft-beliebteste Studienort. Betrachtet man alle Herkunftsorte, so kommt die pommersche Universität sogar auf den zweiten Platz. Läßt man die Rostocker Hochburgen Lübeck und Hamburg weg, so kann sie Rostock bereits wieder vom ersten Platz verdrängen.

Hier noch ein kleiner Exkurs über die bedeutenden überregionalen Orte: Die Hansestädte Lübeck und Hamburg zeigten bis zum Ende des 15. Jahrhunderts eine starke Konzentration der Studenten auf die Rostocker Universität (Lübeck etwa 75\%, Hamburg etwa 81\%). Erst gegen Ende des Jahrhunderts lockerte sich bei den beiden Orten diese Monopolstellung (Lübeck nur noch etwa 70\%, Hamburg etwa 57\%) bei fast gleichbleibender Frequenzrate in Rostock. Die Konzentration auf Rostock hing damit zusammen, daß beide Städte dem regionalen Umfeld der Universität angehörten und daher als Basis des Rostocker Einzugsbereichs zu verstehen sind. ${ }^{331}$ Der Rückgang der prozentualen Bedeutung bei gleichbleibender Inskriptionsrate war ein Phänomen auch Greifswalder Einschreibungen. Es zeigt sich an diesem Ergebnis, was auch für die Wandlung Greifswalds zur reinen "Landesuniversität" charakteristisch war: die Tendenz zum heimatnahen Studium ist nicht zu verwechseln mit einer Fixierung auf nur eine Universität. Größere Universitätsdichte führte vor allem zu einem Gesamtzuwachs der Immatrikulationen.

In diesem Zusammenhang ist auch interessant zu erwähnen, daß die Gesamtzahl der Studierenden aus Lübeck um fast ein Viertel über der aus Danzig lag, obwohl Lübeck in Größe und Einwohnerzahl hinter Danzig zurücktrat. Dieser scheinbare Widerspruch erklärt sich mit der unmittelbaren Nähe Rostocks, durch die die Lübecker "Bildungsressourcen" stärker ausgeschöpft werden konnten. Dagegen zeigte Danzigs Frequenz einen wesentlich stärkeren Anstieg während des Betrachtungszeitraums. Die Annäherung Danzigs an das mitteldeutsche Universitätsnetz durch die Neugründungen im nordöstlichen Reichsgebiet ist als Grund für diesen späteren Anstieg zu werten, wie er in ähnlicher Weise auch bei den Inskriptionen aus dem fernen Hinterpommern zu beobachten war. Die gleichbleibenden Lübecker Zahlen sprechen dagegen für einen bereits erreichten "Sättingungsgrad". Auch diese Unterschiede unterstreichen damit die Bedeutung des Faktors "Nähe" für den Universitätsbesuch des späten Mittelalters. 


\section{Zusammenfassung: Greifswald auf dem Weg zur Landesuniversität}

Im Mittelpunkt der vorliegenden Untersuchung stand die soziale und geographische Herkunft spätmittelalterlicher Studenten, wobei die 1456 gegründete Universität Greifswald den Ausgangpunkt der Studien bildete. Mit diesem Forschungsansatz sollte die Arbeit einen Beitrag zur Universitätsgeschichte aus sozialgeschichtlicher Perspektive leisten. Freilich stößt ein solcher Ansatz auf überlieferungsbedingte Schwierigkeiten, doch erwiesen sich die Matrikel, trotz zum Teil spärlicher Angaben über die Studenten, als aussagekräftige Quelle. Sie gaben Einblicke in räumliche und soziale Herkunftsstrukturen, von denen die Studentenschaft in vorreformatorischer Zeit gekennzeichnet war. Schwerpunkt der Arbeit lag in der Frage, wie sich der Wandlungsprozeß der im Prinzip "universal" gedachten Universität zu einer reinen "Landesuniversität" am Beispiel Greifswalds vollzog. Das 15. Jahrhundert gilt allgemein in der Forschung als eine solche Übergangsphase der Universitätsgeschichte, die von einem "universal" geprägten in ein "nationalregional" geprägtes Zeitalter eintrat.

Mit Prag hielt das Universitätsmodell 1348 erstmalig Einzug im Reich. Bis zur Reformation wurden in verschiedenen Zeitphasen über ein Dutzend weiterer Hochschulen gegründet, so daß der zahlenmäßige Rückstand gegenüber den südlichen und westlichen Nachbarländern allmählich aufgeholt werden konnte. Während in den ersten Universitäten im Reichsgebiet noch ein weitgefächertes Publikum studierte, führte das dichter werdende Netz der Universitäten zur Verkleinerung und Regionalisierung der Einzugsbereiche. Greifswalds Gründung 1456 fällt genau in diese Übergangsphase, die man häufig als Beginn einer "Zweiten Gründungswelle" bezeichnet hat. Mit 93 Prozent verwertbarer Angaben konnte die räumliche Herkunft der Greifswalder Studenten exakt nachgewiesen werden.

Es hat sich bestätigt, daß schon die spätmittelalterlichen Universitäten im wesentlichen aus dem regionalen Umfeld frequentiert wurden. Fast zwei Drittel aller Studenten kamen zwischen 1456 und 1524 aus dem regionalen Umfeld Greifswalds, das sich aus den Territorien Pommern, Mecklenburg und Brandenburg zusammensetzte. Pommern stellte allein knapp 49 Prozent der Besucher. Mit 35 Prozent war der Anteil überregionaler Studenten jedoch durchaus mit dem der ersten Universitäten des Reiches vergleichbar, wobei vor allem der Anteil von 20 Prozent ausländischer Studenten bemerkenswert erschien.

Die Studenten aus den einzelnen Herkunftsräumen verteilten sich zwischen 1456 und 1524 auf unterschiedliche Phasen. Nach einer ungewöhnlichen Eröffnungsphase, in der die Frequenz überdurchschnittlich hoch war und ein großer Teil der Studenten aus überregionalen Gebieten kam, verzeichnete die Frequenzkurve einen starken Rückgang. Dies ist ein Phänomen, das auch bei fast allen anderen Universitätsgründungen zu beobachten ist. Man könnte von einer Zeit der "regionalen Existenzsicherung" sprechen, in der sich im direkten Umfeld einer Universität eine Besucherbasis formierte. Es ist auffällig, daß diese Phase in Greifswald maßgeblich von Dänen und anderen Ostseeanrainern geprägt war. Dies hing damit zusammen, daß der Norden Europas erst am Ende der siebziger Jahre des 15. Jahrhunderts Universitäten erhielt. Das natürliche und nächstgelegene 
Einzugsgebiet für die nördlichen Universitäten Rostock und Greifswald lag daher bis zu diesem Zeitpunkt im gesamten Ostseebereich. Die Greifswalder Universität entwickelte sich dort als wäre es ihr "direktes regionales Umfeld".

Gegen Ende der siebziger Jahre scheint die Phase der "regionalen Existenzsicherung" weitgehend abgeschlossen zu sein, denn nun griff die Universität, ausgehend von Mecklenburg später auch Brandenburg, in überregionale Reichsgebiete aus. Seit 1478 waren erstmalig Niederländer in Greifswald vertreten, während in den Achtzigern, bedingt durch die Krise in der Nachbaruniversität Rostock, die Zahl der aus dem gesamten nördlichen Reichsraum stammenden Studenten einen starken Zuwachs erfuhr. An den Ergebnissen wird deutlich, daß sich die Wirtschafts- und Handelswege der Universitätsstadt auch auf den Universitätsbesuch auswirkten. Man könnte von einer "hansischen" Phase der Greifswalder Universitätsgeschichte sprechen. Gegen Ende des Jahrhunderts führte die Anwesenheit der Humanisten Petrus und Vincentius aus Ravenna zu einem letzten großen Anstieg des überregionalen Anteils in der Studentenschaft.

Seit der Jahrhundertwende brachten die Universitätsgründungen in Wittenberg und Frankfurt eine zunehmende Regionalisierung des Greifswalder Einzugsbereichs mit sich, so daß man erst in dieser Zeit von der Herausbildung einer reinen "Landesuniversität" in Greifswald sprechen könnte. Weder ausländische Territorien noch entfernte Reichsgebiete waren noch in größerem Ausmaß vertreten. Bei den Nachbarländern fielen die Inskriptionen vor allem aus Brandenburg weg, das 1505 in Frankfurt eine eigene Universität erhielt.

Wenn man die Ergebnisse auf die gesamte Universitätslandschaft des 15. Jahrhundert überträgt, so ist eine unterschiedliche Qualität zwischen dem nördlichen Greifswald und den süd- und mitteldeutschen Universitäten zu konstatieren, die sich in einer zeitlich versetzten Regionalisierung der Einzugsbereiche ausdrückte. Während Regionalisierungsphasen in südlicheren Universitäten, vor allem denen der sogenannten "Zweiten Gründungswelle", aufgrund des dichteren Universitätsnetzes zum Teil schon zu Beginn des 15. Jahrhunderts zu beobachten waren, setzte die Entwicklung in Greifswald erst zu Beginn des 16. Jahrhunderts ein. Freilich kann dies endgültig erst durch eine weitergehende Beschäftigung mit den übrigen Universitäten des Reiches geklärt werden.

In einem weiteren Teil der Untersuchung sollte dem Faktor "Konkurrenz" nachgegangen werden. Dazu wurden 26 Orte dahingehend untersucht, wie oft sie in anderen Universitäten als Herkunftsort genannt wurden. Die Gegenprobe sollte aufzeigen, wie sich Studenten des Greifswalder Einzugsbereichs beim Besuch anderer Universitäten verhielten und welche Auswirkung mit Neugründungen im norddeutschen Raum verbunden waren. Führte etwa die konstatierte Regionalisierung und Verkleinerung des Greifswalder Einzugsbereichs auch zu einer Fixierung pommerscher Studenten auf die Landesuniversität?

Es konnte gezeigt werden, daß dem nicht so war: die pommerschen Studenten nutzten vielmehr die Nähe neuer Universitäten und beschränkten sich keineswegs auf ihre "Landesuniversität". Es ist also festzuhalten, daß die zunehmende Tendenz zum heimatnahen Studium nicht mit der Fixierung auf nur eine Universität zu verwechseln ist. Dennoch: auffällig ist, daß die Einschreibungen der Pommern in Greifswald gegen Ende des Betrachtungszeitraums auf äußerst hohem Niveau blieben. Die Pommern besuchten also weiterhin die Heimatuniversität, doch führte die Verdichtung des 
Universitätsnetztes zur Steigerung der Gesamtfrequenz aus der Heimatregion. Auf diesem Weg blieb der Besuch aus der Heimatregion konstant, während demgegenüber die Überregionalität einer Universität zurückging. Dieser Wandel wurde vor allem durch den Zugriff auf neue soziale Schichten ermöglicht, der in den steigenden Greifswalder "pauperes"-Inskriptionen gegen Ende des Betrachtungszeitraums seinen Ausdruck findet.

Zur Konkurrenz Rostocks: fast 55 Prozent der Studenten aller 18 untersuchten Orte Pommerns gingen an die Heimatuniversität. Mit knapp 30 Prozent erreichte Rostock zwar nicht die Zahlen der Greifswalder Universität, doch wird die Überschneidung der beiden Einzugsbereiche offensichtlich, zumal die Rostocker Zahlen von starken Zuwächsen gekennzeichnet waren. Während südliche und zentrale Gebiete Pommerns eher gleichbleibend vertreten waren, ist ein erheblicher Anstieg der Studenten aus den in direkter Umgebung Greifswalds gelegenen Orten auch nach der Greifswalder Gründung festzustellen. Hier wird zu berücksichtigen sein, daß viele Studenten die Nähe gleich zweier Universitäten genutzt haben und sich daher nacheinander in beiden einschrieben. Als Studienortwechsler konnten sie jedoch in der vorliegenden Untersuchung nicht erfaßt werden.

Prag, später Leipzig, zum geringeren Teil Erfurt und Wien waren die wichtigsten Studienorte, bevor in Pommern eine eigene Universität entstand. Hanseverbindungen spielten hier offenbar keine Rolle, denn die bedeutende Hanse- und Universitätsstadt Köln war den Studenten einfach zu weit entfernt.

Vor allem die neuen Universitäten in Frankfurt und Wittenberg verzeichneten viele Pommern, doch führten die Gründungen, wie schon erwähnt, zu keinem Einbruch der Zahlen in Greifswald, sondern zu einer stärkeren Gesamtfrequenz pommerscher Studenten. Frankfurt ist dabei wichtiger gewesen. Die neue Universität bewirkte, daß das universitätsgeschichtlich "rückständige" Hinterpommern die stärksten Frequenzgewinne vorwies, während bei den näheren zentralpommerschen Orten kaum Zuwächse stattgefunden haben. Dort ist durch die Nähe zum mitteldeutschen Universitätsnetz offensichtlich schon im 15. Jahrhundert eine Art "Sättigungsgrad" erreicht worden.

Die Inskriptionen aus den Einzugsorten der Nachbarregionen und der entfernten Reichsregionen zeigten, daß Überregionalität einer Universität nur als "subjektive" Größe zu verstehen ist, denn alle überregionalen Orte folgten dem gleichen Prinzip der nächstgelegenen Universität. Greifswald stand dort bestenfalls an vierter Stelle der meistbesuchten Universitätsorte, immer jedoch übertroffen durch die Rostocker Hohe Schule. Die Orte in Mecklenburg und Brandenburg lagen so dicht am pommerschen Territorium, daß eine unterschiedliche Qualifizierung schon deshalb nicht sinnvoll war. Es zeigte sich jedoch auch an ihren Einschreibungen, daß Landeszugehörigkeit an sich noch kein Kriterium der Studienort-Wahl darstellte, sondern daß fast immer "Nähe" als der entscheidende Faktor zu bewerten ist.

Auch über die soziale Herkunft der Greifswalder Studenten sollte die Untersuchung informieren. Obwohl die Aussagekraft der Matrikel gerade in dieser Hinsicht nur begrenzt war, konnten bereits die spärlichen Angaben weitere Erkenntnisse liefern. Durch den Vergleich der Ergebnisse mit anderen Universitäten, die eine ähnliche Quellenlage aufwiesen, spiegelten sich die allgemeinen räumlichen und sozialen Gegebenheiten im nördlichen Pommern auch in der Sozialstruktur der Studentenschaft wider. Die bürgerliche Gesamtstruktur im nördlichen Reichsterritorium wurde durch den geringen Adelsanteil bestätigt, der an den südlichen Universitäten deutlich höher lag. Ebenso verhielt es sich 
mit kirchlichen Würdenträgern, die im Gesamtvergleich einen sehr niedrigen Anteil ausmachten, was mit der geringeren Kirchendichte Pommerns zu erklären ist. Die ungleichmäßige Verteilung der Herkunftsorte wies auf die geringere Besiedlung im nördlichen Reichsraum hin.

Auch über den Wohlstand der Studenten gaben die Matrikel Auskunft, denn die Eintragung zur Gebührenzahlung erlaubte eine grobe Einschätzung der finanziellen Möglichkeiten eines Studenten. Es konnte gezeigt werden, daß die nördliche Universität durch eine äußerst hohe Zahlungsfähigkeit der Studenten gekennzeichnet war, obwohl sie zu den "teuersten" Universitäten des Reiches zählte. Die Wirtschaftskraft des norddeutschen Hanseraums spiegelte sich in solchen Zahlen wider. Dennoch waren unterschiedliche Phasen zu beobachten. In einer ersten Phase der Universität lag der Armenanteil in der Studentenschaft überdurchschnittlich hoch. Dies hing mit der politischen und sozialen Situation des Landes zusammen, welches in dieser Zeit unter den Einwirkungen von Krieg und Pest litt. Erst mit dem Regierungsantritt Bogislaws X., unter dem das Land konjunkturell aufblühte, sank der Armenanteil, was sich fast vollständig mit der konstatierten "hansischen Phase" der Universität überschnitt. Im längsten Zeitraum konnten fast 90 Prozent der Studenten die vergleichsweise hohen Gebühren entrichten. Gegen Ende des Betrachtungszeitraums nimmt die Zahl ärmerer Studenten vor allem aus Pommern wieder zu. Diese Entwicklung überschnitt sich mit der Regionalisierung der Universität und der Frequenzsteigerung pommerscher Studenten zu Beginn des 16. Jahrhunderts. Die Neugründungen führten daher nicht nur zu einer stärkeren Studienbeteiligung unter den Pommern, sondern wahrscheinlich auch zu einer ersten Verbreiterung der sozialen Schichtung innerhalb der Studentenschaft.

Dieses Phänomen ließ sich auch auf die gesamte Universitätslandschaft übertragen: in anderen Untersuchungen zeigte sich, daß die aus dem Norden und dem Süden des Reiches stammenden Studenten im 15. Jahrhundert häufig ein unterschiedliches Zahlungsverhalten der Immatrikulationsgebühren aufwiesen. Man könnte geradezu vom "ärmeren Süden" gegenüber dem "reicheren Norden" sprechen. Es ist zu vermuten, daß neben lokalen und ökonomischen Gesichtspunkten hier ein ähnlicher Sachverhalt zu berücksichtigen ist: das dichtere Universitätsnetz in den südlichen und zentralen Gebieten des Reiches wird auch eine stärkere Gesamtfrequenz zur Folge gehabt haben. Der höhere Anteil armer Studenten spiegelt daher einen verbreiterten sozialen Einzugsbereich wider. In den nördlichen Reichsgebieten verdichtete sich das Universitätsnetz dagegen erst zu Beginn des 16. Jahrhunderts. Die Frequenzsteigerung bewirkte nun auch dort eine Verbreiterung der sozialen Schichtung, die sich in verstärkten "pauperes"-Inskriptionen ausdrückte. In Greifswald war eine soziale Verschiebung innerhalb der Studentenschaft tatsächlich erst zu Beginn des 16. Jahrhundert festzustellen.

Hinsichtlich der Frage der entstehenden "Landesuniversität" zeigt auch dieses Beispiel, was als Kernaussage der vorliegenden Untersuchung zu verstehen ist: nämlich daß diese nicht nur als Produkt landesherrlicher Einflußnahme zu verstehen ist, sondern daß hier ein sozialgeschichtlicher Wandel der Studentenschaft vorausging, deren räumliche und soziale Herkunft sich mit steigender Universitätszahl und Frequenz verändert hat. Der sozial unabhängige, zumeist bepfründete Student trat zurück gegenüber dem "aufstiegsorientierten", sozial und lokal mit der Hochschule verwurzelten Scholaren. Indem aber die Unabhängigkeit und Souveränität der Studenten zurückging, vollzog sich die gleiche Entwicklung bei den Universitäten, deren Träger sie waren.

Weitere Erkenntnisse der vorliegenden Untersuchung würden zu sehr ins Detail führen und müssen 
an dieser Stelle daher übergangen werden. Natürlich konnten die hier zusammengefaßten Ergebnisse keine endgültigen Beweise für die genannten historischen Vorgänge liefern. Dem widersprach die Aussagekraft der Angaben in den vorhandenen Quellen. Außerdem spiegelten die Zahlen lediglich Tendenzen wider, so daß sie nur unter besonderem Vorbehalt interpretiert werden konnten. Das Hauptanliegen der Untersuchung lag in einer systematischen Auswertung des Quellenmaterials, das zwar zum größten Teil in edierter Form vorlag, doch bisher nur unzureichend analysiert worden ist. Wer sich für Studenten aus einer Stadt, einem Gebiet oder aus verschiedenen Bevölkerungsgruppen im späten Mittelalter interessiert, sollte mit dieser Arbeit eine einfache Informationsmöglichkeit über Zahlen und Daten erhalten, die aus den verschiedenen Quellen hervorgingen. Auch wenn die Ergebnisse keinen Anspruch auf Vollständigkeit und Endgültigkeit haben können, scheint mir dieses Unterfangen keineswegs überflüssig: die Studenten und späteren akademisch Gebildeten stellen eine Personengruppe dar, die in ihrer Gesamtheit durch ihre Tätigkeiten in Staat, Kirche und Gesellschaft zu einem wichtigen Träger der Geschichte wurden. Daß sich die Universität als Institution trotz historischer und sozialer Wandlungen bis auf den heutigen Tag erhalten hat, gibt Zeugnis von ihrer dauerhaften Bedeutung ab, die sich immer wieder den verändernden Umständen anzupassen vermochte. 


\section{Anmerkungsapparat}

1. Classen, Die Hohen Schulen, S. 172. Ausführliche bibliographische Angaben sind dem Quellen- und Literaturverzeichnis zu entnehmen. Die Verweisform in den Fußnoten besteht aus Nachname, Titelstichwort und Seitenangabe. Bei Autoren, die mit nur einem Beitrag vertreten sind, fällt das Titelstichwort weg.

2. So formuliert von Boockmann, Rechtsstudenten, S. 314, aber auch Schwinges, Universitätsbesucher, S. 487.

3. Bezeichnenderweise ein Außenseiter des Fachs, der Nationalökonom Franz Eulenburg, ermittelte Ende des 19. Jahrhunderts als erster die Frequenz der deutschen Universitäten seit ihren Anfängen. Seine Arbeit gilt heute noch als Standardwerk der Universitätshistoriographie.

4. Neuestes Beispiel ist die Arbeit von Häfele. Außerdem z.B. Boockmann, Die preußischen Studenten, S. 1-12 oder Pinborg, Danish students, S. 78, ältere Arbeiten Vgl. Keck, S. 7.

5. Z.B. Lieberich, Die gelehrten Räte, aber auch Bearbeitungen über Stifts- und Domkapiteln, zusammengestellt bei Moraw, Stiftspfründen, S. 271.

6. Rainer Christoph Schwinges: Deutsche Universitätsbesucher im 14. und 15. Jahrhundert. Siehe auch seine anderen Arbeiten: Pauperes an deutschen Universitäten des 15. Jahrhunderts oder Studentische Kleingruppen im späten Mittelalter. Außerdem der von ihm herausgegebene Sammelband: Gelehrte im Reich.

7. Ausgehend von den Matrikeln wurden außerdem noch das Dekanatsbuch der Artisten und die Annalen der Universität berücksichtigt, in denen Promotionen und kürzere historische Anmerkungen durch den Rektor verzeichnet worden sind. Sie boten die Möglichkeit, die Angaben in den Matrikeln zu kontrollieren, zum Teil sogar zu ergänzen. In einigen Fällen mußten Unklarheiten bei der edierten Vorlage anhand der alten Universitätsbücher überprüft werden. Für die Bereitstellung dieser Orginale sei an dieser Stelle dem Greifswalder Universitätsarchiv gedankt.

8. Schmidt, Anfänge, S. 11. Er spricht von 554 Studenten, doch scheint hier ein Fehler unterlaufen zu sein, denn auch seine zugrunde gelegte Übersichtstabelle (Anm. 42) zählt nur 553 Eintragungen.

9. Die Matrikeleditionen der für die Arbeit untersuchten Universitäten sowie verschiedene andere edierte Zusammenstellungen von Studenten sind im Quellenverzeichnis zu finden. Für die Universität Wien wurden außerdem Überprüfungen an den Orginalbüchern vorgenommen. Insbesondere anhand der unedierten Matrikel der juristischen Fakultät konnten einige Ergänzungen zu den Hauptmatrikeln vorgenommen werden. Für die Bereitstellung der Orginale sei an dieser Stelle dem Wiener Universitätsarchiv gedankt.

10. Neueste Darstellungen von Alschner zur Universität Helmstedt (1998); behandelter Zeitraum: 15761810 sowie Fuchs über die Heidelberger Universität (1995); behandelter Zeitraum: 1386-1450. 
Außerdem Schwinges, Universitätsbesucher, Teil C: Universitätsbesuch in Köln, S. 221-486, 1986, betrachtet den Zeitraum 1489 bis 1505. Alle übrigen neueren Arbeiten sind nur kurze Aufsätze, wie z. B. zur Universität Mainz: Matheus, Einzugsbereich; behandelter Zeitraum: 1473-1477. Universität Ingolstadt: Buzás, Herkunft; behandelter Zeitraum: 1472-1556. Eine reine kartographische Darstellung eines Einzugsbereichs bietet Langer, Einzugsbereich Wittenberg; behandelter Zeitraum: 1502-1812.

Von den älteren Darstellungen ist die 1935 erschienene Dissertation von Keck zur Universität Leipzig hervorzuheben; behandelter Zeitraum: 1409-1430. Außerdem zur Universität Tübingen: Cramer (1922); behandelter Zeitraum: 1477-1600. Universität Straßburg: Schulze (1926); behandelter Zeitraum: 1621-1793. Universität Königsberg: Lehmann (1929); behandelter Zeitraum: 1544-1649.

11. Zuletzt Roderich Schmidt, Rostock und Greifswald, S. 75-110.

12. Schmidt betont die Bedeutung der Universitäten für den "gesamten Norden Europas"; Rostock und Greifswald, S. 94. Über Dänische Studenten in Greifswald berichtet Pinborg, Danish students, S. 78.

13. Für Rostock bei Krabbe, S. 130. Dazu zuletzt Schwinges, Universitätsbesucher, S. 128.

14. Dies wird deutlich bei Johansen, Umrisse und Aufgaben, S. 1-105, und Schnitzler, zur hansischen Universitätsgeschichte, S. 354-387; siehe auch Wriedt, Stadtrat, S. 499 ff. Nowak fragt, "inwieweit diese beiden Universitäten tatsächlich ,hansische Universitäten` geworden sind." Nowak, S. 18.

15. So wies Nowak darauf hin, daß "der Fortschritt der Forschung über die Universitätszentren Rostock und Greifswald, über den Charakter ihrer Ausstrahlung in den hansischen Wirkungsbereich [...] zu den wichtigeren und dringenden Forderungen dieser Problematik [gehört]. Nowak, S. 18; in gleichem Sinne: Johansen, S. 102.

16. Dazu Fuchs, Dives S. 8 f.

17. Dazu Schubert, Motive, S. 13-74.

18. Vgl. dazu Moraw, Stiftspfründen, S. 272.

19. Vgl. die Arbeiten von Schwinges und Fuchs. Kritisch zum Verfahren: Alschner, S. 30 ff.

20. Vgl. dazu Schwinges, Universitätsbesucher, S. 153; Schmidt, Rostock und Greifswald, S. 75 ff.; Kosegarten führt die Matrikellücke nicht auf die Universitätsschließung zurück, sondern auf die spätere Entfernung der betreffenden Seiten aus dem Matrikelbuch, Bd. I S. 180, Bd. II S. 258. Dieser Einschätzung widerspricht Friedländer in seiner Einleitung. Drei Seiten wurden aus dem Buch nachträglich herausgetrennt, wie auch ich mich vergewissern konnte. Selbst wenn diese Seiten einmal beschrieben waren, so ist doch unwahrscheinlich, daß sie den gesamten fünfzehnjährigen Zwischenraum abgedeckt haben. Die Pause würde demnach lediglich ein bis zwei Jahre kürzer ausfallen, doch bewegt man sich mit einer solchen Aussage freilich auf dem Boden reiner Spekulation.

21. Als ersten Einschnitt in der Geschichte der Universität bezeichnet Hofmeister die Reformation, S. 11. Herzog Phillip I. wurde 1539 "der zweite Begründer der Universität". Hofmeister, S. 13. 
22. Kosegarten I, S. 33; Schmidt, Rostock und Greifswald, S. 92.

23. Kosegarten I, S. 27.

24. Schmidt, Rostock und Greifswald, S. 92 f.; Kosegarten I, S. 27 f.

25. Schmidt, Rostock und Greifswald, S. 93; Hofmeister, S. 7.

26. Vgl. etwa Hofmeister, S. 6 f.

27. Schmidt, Rostock und Greifswald, S. 94.

28. Schmidt, Rostock und Greifswald, S. 85.

29. Schmidt, Rostock und Greifswald, S. 85.

30. Ob Rubenow selber Einfluß auf die Wahl des Ortes hatte, läßt sich anhand der Quellen nicht belegen oder nachweisen. Vgl. dazu Schmidt, Rostock und Greifswald, S. 93.

31. Schmidt, Rostock und Greifswald, S. 85.

32. Schmidt, Rostock und Greifswald, S. 84. Über Rubenow siehe auch Boockmann, Stadt-Tyrannen.

33. Schmidt, Rostock und Greifswald, S. 83; Hofmeister, S. 7 f.; Kosegarten I, S. 56 f.

34. Stiftungsurkunde, gedruckt bei Kosegarten II, Nr. 9, S. 14 ff.: "...doctores et magistri in dicto studio existentes sufficienter et competenter possent sustentari."

35. Das Stift konnte allerdings erst am 12. Juni 1457 eingeweiht werden. Schmidt, Rostock und Greifswald, S. 84.

36. Hofmeister, S. 7 f.; Schmidt, Rostock und Greifswald, S. 83 f.; Kosegarten I, S. 55 ff.

37. Schmidt, Rostock und Greifswald, S. 81.

38. Gedruckt bei Kosegarten II, Nr. 10, S. 18 ff., Nr. 29, S. 59 ff.

39. Kosegarten II, Nr. 10, S. 18 ff.

40. Schmidt, Rostock und Greifswald, S. 82 f.; Kosegarten I, S. 63.

41. Nicht wie bei Kosegarten I, S. 65, 58 Ehreneinschreibungen, sondern wie bei Friedländer 69 Ehreneinschreibungen, dazu 173 Studenten sind zusammen 242 Immatrikulierte. Vgl. Friedländer, Matrikel I, Tab.II, S. XVIII. Dazu auch Schmidt, Anfänge (Anm. 42), S. 36. 
42. Die Zählung der Einschreibungen in den einzelnen Semestern ergab zum Teil Unstimmigkeiten zwischen Friedländers Übersichtstabelle und der gedruckten Matrikel. Unter Hinzunahme der Orginalmatrikel habe ich die Angaben überprüft und korrigiert. Folgende Veränderungen mußten vorgenommen werden: Vgl. Matrikel I, Tab. II.: WS 1458: 54 statt 53, SS 1460: 27 statt 28, SS 1465: 40 statt 39, WS 1465: 26 statt 28, WS/SS 1470: 43 statt 36, WS 1481: 22 statt 21, SS 1487: 58 statt 57, WS 1495: 34 statt 33, WS 1511: 15 statt 12, WS 1520: 23 statt 24, WS 1521: 26 statt 27. Im WS 1458 übersah Friedländer wahrscheinlich den Heinrich Sutoris, da dieser in der gleichen Zeile wie Jakob Droger steht. Vgl. S. 12 f. (Zeile b 40). Das gleiche gilt für das SS 1487, wo die Mönche Ulrich und Heinrich ebenfalls zusammen stehen. Vgl. S. 100 (Z. 25). 1470 kommt der große Unterschied von sieben Studenten dadurch zustande, daß Friedländer fünf Promoventen, die sich allerdings vorher noch nicht immatrikuliert hatten sowie zwei durchgestrichene Namen ausläßt. (Eigentlich sind es sechs Bakkalare, wobei Simon aus Läesö bereits im WS 1469, S. 42, Z. 30, immatrikuliert worden war.) Vgl. S. 45, Z. 35 bis S. 46, Z. b 5 sowie S. 45, Z. 5. Wylhelmus de Bueren wurde im WS 1520 nur examiniert (die Immatrikulation erfolgte ein Jahr zuvor). Im WS 1521 übersieht Friedländer, daß in einer Zeile nur die Doktorpromotion zweier Magister (Nicolaus Cornelius, Johannes Pfeil, vgl. S. 191, Z. b 40) erwähnt wird, die vorher (SS 1521) bereits eingeschrieben worden waren. Bei den übrigen Korrekturen handelt es sich um Fehler des Zusammenzählens.

43. Vgl. dazu auch Kosegarten I, S. 180.

44. Matrikel, S. 94.

45. Zur Rostocker Domfehde: Sauer, Hansestädte, S. 101 ff. und Hergemöller, Krisenerscheinungen, S. 332 ff. Zur Geschichte Rostocks: vgl. unter vielen anderen Arbeiten Koppmann; Bernitt. Zur Sozialgeschichte: vgl. Fritze, Bevölkerungsstruktur; Schildhauer. Zur Universitätsgeschichte: vgl. Krabbe; Schnitzler, Gründung; dies., Zur hansischen Universitätsgeschichte. Außerdem allgemein Keyser, Bd. 1, S. 322 ff., Handbuch, Bd. 12, S. 95 ff.

46. Dazu vgl. Schwinges, Universitätsbesucher, S. 147 f.

47. Schwinges, Universitätsbesucher, S. 149.

48. Keck, S. 12 f.; Kuhn, S. 9 f.

49. So handelt es sich bei den ersten 69 Immatrikulierten von Greifswald nur um Ehrenpersonen, die für diese Untersuchung nicht mitgezählt wurden. Bei allen folgenden Jahren mußte allerdings auf eine weitere Differenzierung verzichtet werden.

50. Abkürzungen I, II usw. siehe Abkürzungsverzeichnis.

51. Keck, S. 66.

52. Schwinges, Universitätsbesucher, S. 224. Schwinges untersuchte allerdings nur 10 Jahres-Stichproben im 15. Jahrhundert.

53. Es wurde vorgeschlagen, die Bistumsnennungen dem Bischofssitz zuzuordnen. Für eine solche Verfahrensweise kann es allerdings, wie schon Schwinges bemerkt hat, kaum plausible Argumente 
geben. Vgl. Universitätsbesucher, S. 225 f. Es stellt sich vielmehr die Frage, ob nicht solche allgemeinen Angaben den Tatbestand charakterisieren, daß der richtige Ort zu klein und unbedeutend war, und deshalb auf dessen Angabe verzichtet wurde. Damit könnte man bei diesen Studenten in der Mehrzahl von ländlicher Herkunft ausgehen, doch wird sich dies nur im Einzelfall beweisen lassen.

54. Z.B. Deturicia, Hitlande, Nesonum Castrum.

55. Z.B. Neustadt, Hagen, Aldendorp.

56. Grundsätzlich wurde verfahren wie bei Schwinges, Universitätsbesucher, vgl. S. 228 f.

57. Vgl. auch Keck, S. 18 f.

58. Keck, S. 20.

59. Also Vor- und Hinterpommern.

60. Zur Aufteilung der Reichskreise: siehe die Karte im Kartenteil.

61. Errechnet aus Cramer, der von 6000 Würrtembergern spricht, S. 6.

62. Buzás, S. 17, der das gesamte Gebiet des heutigen Bayern einbezieht.

63. Schwinges, Universitätsbesucher, S. 232 und 257.

64. In Ingolstadt betrug der Anteil nur 1,2\%. Berechnet nach Buzás, S. 17.

65. Errechnet aus Schwinges, Universitätsbesucher, Anhang S. 619 ff., Tabelle 27.

66. Schwinges, Universitätsbesucher, S. 234.

67. Siehe Kartenteil. Leider konnte als Vorlage für die computergestützte Darstellung des Einzugsbereichs keine Karte mit den zeitgenössischen Grenzverläufen gefunden werden, so daß die heutigen Grenzen (Stand 1998) genommen werden mußten.

68. Vgl. z.B. Keck, S. 69.

69. Vgl. etwa die Arbeiten von Schwinges und Fuchs.

70. Schwinges, Universitätsbesucher, S. 379.

71. Schwinges, Universitätsbesucher, S. 381.

72. Vgl. auch Fuchs, S. 25. 
73. Berechnet nach Keck, S. 91, für die Jahre 1409 bis 1430. Schwinges, Universitätsbesucher, S. 381, gibt für Leipzig einen Anteil von 0,8\% an, ohne einen Nachweis dafür zu liefern.

74. Schwinges, Universitätsbesucher, S. 381.

75. Berechnet nach Müller, Universität und Adel, S. 70 f.

76. Schwinges, Universitätsbesucher, S. 386.

77. Schwinges, Universitätsbesucher, S. 381.

78. Schwinges, Universitätsbesucher, S. 386.

79. Schwinges, Universitätsbesucher, S. 387.

80. Schwinges, Universitätsbesucher, S. 393.

81. Vgl. dazu Miethke, S. 309 ff.

82. Vgl. dazu Sägmüller, S. 247; Boockmann, Stauferzeit, S. 316 f.

83. Schwinges, Universitätsbesucher, S. 410.

84. Dazu Moraw, Zur Sozialgeschichte, S. 56; Boockmann, Lebenswelt, S. 288.

85. Diener, S. 361 f. Daß der Begriff "clericus" nur auf eine "gewisse akademische Vorbildung" des Studenten aufmerksam machen sollte, wie Klaus Spading meint, halte ich für unwahrscheinlich. Spading, S. 195.

86. Schwinges, Universitätsbesucher, S. 409.

87. Fuchs, S. 14.

88. Schwinges, Universitätsbesucher, S. 404.

89. Schwinges, Universitätsbesucher, S. 412.

90. Berechnet nach Keck, S. 89 f. (Tabelle 2,3,4).

91. Schwinges, Universitätsbesucher, S. 393.

92. Fuchs, S. 16, weitere Vergleichszahlen bei Overfield, University Studies, S. 254-294.

93. Vgl. dazu Moraw, Über Entwicklungsunterschiede, S. 583-622; ders. Stiftspfründen, S. 274 ff. 
94. Schwinges, Universitätsbesucher, S. 393.

95. Solche Angaben finden sich zum größten Teil in den ersten Semestern (27 bis 1461!), was auf eine überregionale Herkunft hindeutet.

96. Bei Nichteinbeziehung unzulänglicher Herkunftsangaben sind es immer noch knapp 27\%.

97. Overfield, University Studies, S. 277 ff.; Fuchs, S. 16, 136 f. (Tab. 4); Schwinges, Universitätsbesucher, S. 403, 654 f. (Tab. 51a, 52a).

98. Schwinges, Universitätsbesucher, S. 410 f.; auch Fuchs, S. 17.

99. Schwinges, Universitätsbesucher, S. 410 f.; Fuchs, S. 17.

100. Fuchs, S. 17.

101. Schwinges, Universitätsbesucher, S. 394.

102. Schwinges, Universitätsbesucher, S. 345.

103. Schwinges, Universitätsbesucher, S. 395.

104. Kuhn, S. 9; Keck, S. 12 f.

105. Schwinges, Universitätsbesucher, S. 388.

106. Ähnliches konnte bereits in anderen Untersuchungen festgestellt werden, so daß für einen Universitätsvergleich immerhin die gleichen Vorraussetzungen bestehen, vgl. z.B. Fuchs, S. 44 f.

107. Dazu Schwinges, Universitätsbesucher, S. 408 f.

108. Keck, S. 90.

109. Fuchs, S. 133.

110. Fuchs, S. 48 f.; Keck, S. 90.

111. Schwinges, Universitätsbesucher, S. 407.

112. Vgl. etwa die Arbeit Hufens oder das Kapitel "Territorialisierung und Humanismus" bei Müller, Geschichte, S. 45 f.

113. Moraw formuliert daher umgekehrt: "Der Freiraum der Universität war schon am Anfang schwerlich prinzipiell gewährt worden, ...; stattdessen ist eine möglicherweise größere Bewegungsfreiheit am Beginn vor allem als Folge der anfänglichen Schwächen des Staatswesens aufzufassen." Moraw, Heidelberg, S. 526. 
114. Schwinges, Universitätsbesucher, S. 447 f., 450.

115. Fuchs, S. 118.

116. Müller, Geschichte, S. 45 f.

117. Vgl. die Arbeiten von Schwinges und Fuchs.

118. So formuliert von Grundmann, Ursprung S. 17 f.; ebenfalls noch Schnitzler, Beiträge, S. 78 f.

119. Schwinges, Universitätsbesucher, S. 342.

120. Schwinges, Universitätsbesucher, S. 351.

121. Schwinges, Universitätsbesucher, S. 431, $456 \mathrm{f}$.

122. Schwinges, Universitätsbesucher, S. 258.

123. Vgl. etwa Moraw, Stiftspfründen, S. 274 ff.; für Köln: Schwinges, Universitätsbesucher, S. 393 ff.

124. Dazu Schwinges, Universitätsbesucher, S. 392 ff.

125. Schwinges, Universitätsbesucher, S. 386.

126. Vgl. dazu Müller, Universität und Adel, S. 70 ff.; Overfield, Nobles, S. 185 f.; Schwinges, Universitätsbesucher, S. 381, 385 f.

127. Schwinges, Universitätsbesucher, S. 385, $456 \mathrm{f}$.

128. Schwinges, Universitätsbesucher, S. 424.

129. Schwinges, Universitätsbesucher, S. 457.

130. Für Köln: Schwinges, Universitätsbesucher, S. 428: dort zahlten 62,5 Prozent der norddeutschen Studenten ihre Immatrikulationsgebühr. Nur 41 Prozent waren es bei den süddeutschen Studenten. Eine ähnliche Entwicklung vollzog sich in gleicher Richtung und Wertung in Wien. Vgl. Schwinges, Kleingruppen, S. 350 f.; ebenso Fuchs für Heidelberg, S. 66 ff.

131. Schwinges, Universitätsbesucher, S. 428.

132. Schwinges, Universitätsbesucher, S. 428.

133. Schwinges, Universitätsbesucher, S. 428. 
134. Vgl. dazu Fuchs, S. 66 ff.

135. Siehe dazu die Vergleichszahlen bei Boockmann, Die preußischen Studenten, S. 8 f.

136. Über Ordensstudenten vgl. Boockmann, Rechtsstudenten, S. 313-375.

137. Dazu vor allem Schwinges, Pauperes, S. 285-309; ders., Universitätsbesucher, S. 441 ff.

138. Kosegarten I, S. 65.

139. Matrikel I, S. 10: "Haec remissa pecunia fuit pro intitulatura exponenda ad 24 solidos."

140. Schwinges, Universitätsbesucher, S. 424.

141. Kosegarten I, S. 79 f., 67 f.

142. Kosegarten II, Dekanatsbuch, S. 221; Friedländer, Matrikel I, S. 56.

143. Vgl. z.B. Simon von Läesö, Matrikel I, S. 42 Z. 30.

144. Schwinges, Universitätsbesucher, S. 425.

145. Keck, S. 86, 95.

146. Schwinges, Universitätsbesucher, S. 431, 457.

147. Schwinges, Universitätsbesucher, S. 428.

148. In Köln 73,4\%, vgl. Schwinges, Universitätsbesucher, S. 428.

149. Ausland: zwischen 62,9 und 79,8\% = 16,9\% Varianz, Reich: zwischen 14,6 und 83,6 = 69\% Varianz.

150. Kosegarten I, S. 123.

151. Kosegarten I, S. 123.

152. Schwinges, Universitätsbesucher, S. 455.

153. Schwinges, Universitätsbesucher, S. 446.

154. Schwinges, Universitätsbesucher, S. 443; Fuchs, S. 111.

155. Vgl. dazu Schildhauer, Auseinandersetzungen, S. 42 ff. Siehe auch ders., Sozialstruktur, S. 341 ff.; Fritze, Wendepunkt, S. 157 f. 
156. Vgl. etwa Schwinges, Universitätsbesucher; S. 428 ff.; Kuhn, S. 16 ff.

157. Schwinges, Universitätsbesucher, S. 229.

158. Schwinges, Universitätsbesucher, S. 232.

159. Schwinges, Universitätsbesucher, S. 232.

160. Die späteren Gründungen in Leipzig, Löwen und Frankfurt übernahmen zwar noch die Nationenverfassung, doch spielten sie bei den übrigen Universitäten keine Rolle mehr. Vgl. Meuthen, S. 15.

161. Schwinges, Universitätsbesucher, S. 232.

162. Schwinges, Universitätsbesucher, S. 232.

163. In Köln kamen aus den Diözesen Köln, Lüttich und Utrecht: 1395 72,7\%, 1405 81,9\%, 1415 85,6\%, vgl. Schwinges, Universitätsbesucher, S. 250.

164. Schwinges, Universitätsbesucher, S. 232.

165. Schwinges, Universitätsbesucher, S. 257.

166. Schwinges, Universitätsbesucher, S. 257.

167. Schubert, S. 14 .

168. Vgl. dazu Moraw, Über Entwicklungsunterschiede, S. 583 ff.

169. Schwinges, Universitätsbesucher, S. 232. Auch hier wird man es aber nicht nur mit Studenten zu tun haben, die diesen hohen städtischen Anteil prägten, sondern wie in Greifswald mit Bürgern, die in den Genuß der Privilegien des Universitätsangehörigenstatus kommen wollten.

170. Siehe dazu auch die Karte im Kartenteil.

171. Schmidt, Rostock und Greifswald, S. 94.

172. Boockmann, Die preußischen Studenten, S. 11.

173. Schwinges, Universitätsbesucher, S. 257.

174. Keck, S. 20.

175. Buzás, S. 18. 
176. Cramer, S. 6.

177. Keck, S. 21.

178. Wahrscheinlich gab es nur eine Stadtschule in Greifswald.

179. Schwinges, Universitätsbesucher, S. 232.

180. Hofmeister, S. 11.

181. Hofmeister, S. 11. Über Stralsund: vgl. Ewe; Fritze, Hansestadt. Zur Sozialstruktur: vgl. Fritze, Bevölkerungsstruktur; Schildhauer, Auseinandersetzungen.

182. Dazu die Aufstellung der Ratsmitglieder bei Brandenburg, S. 79-97. Die Zusammenstellung sämtlicher Testatoren bei Schildhauer, Stralsunder Bürgertestamente, S. 329-403, siehe auch Schildhauer, Hansestädtischer Alltag.

183. Nowak, S. 23; siehe auch Wriedt, Gelehrte, S. 442 f.

184. Matrikel, S. 52.

185. Dazu auch Wriedt, Gelehrte, S. 442 f.

186. Die folgende Zahlenreihe veranschaulicht diese Tendenz:

\begin{tabular}{|l|l|l|l|l|l||l|l|l|}
\hline 1456 & 1457 & 1458 & 1459 & 1460 & 1461 & 1462 & 1464 & 1465 \\
\hline 2 & 3 & 3 & 3 & 2 & 3 & 4 & 4 & 10 \\
\hline
\end{tabular}

187. Vgl. folgende Zahlen:

\begin{tabular}{|l|l|l|l|l|l||l|l|l|}
\hline 1480 & 1481 & 1482 & 1483 & 1484 & 1485 & 1486 & 1487 & 1488 \\
\hline \hline 1 & 3 & 9 & 6 & 1 & 0 & 4 & 6 & 3 \\
\hline
\end{tabular}

188. Dazu auch Spading, S. 198. Dieser Streit beruhte offensichtlich auf der Einführung einer neuen Studienordnung nach Pariser, Löwener und Kölner Vorbild, vgl. Matrikel I, S. 76.

189. Matrikel I, S. 85.

190. 1485 wurden daher insgesamt nur drei Studenten immatrikuliert. Hintergründe des Rostocker Auszugs in Kapitel 2.1: Zur Frequenz der Greifswalder Universität.

191. Hofmeister, S. 10. 
192. Kosegarten I, S. 40; Hofmeister, S. 9 f.

193. Hofmeister, S. 10.

194. Das Zitat Kantzows in: Hofmeister, Anm. 20, S. 34.

195. Schmidt, Kräfte, S. 21; Hofmeister, S. 10.

196. Hofmeister, S. 10 f.

197. Kosegarten I, S. 119; II Annalen, S. 182.

198. Zur Geschichte Stettins: vgl. Wehrmann, Stettin; Keyser, Bd. 1, S. 235 ff.; Handbuch, Bd. 12, S. 280 ff.

199. Über Kolberg: vgl. die Arbeiten von Tepp und Riemann; außerdem Keyser, Bd. 1, S. 190 ff.; Handbuch, Bd. 12, S. 220 ff.

200. Die Quellen berichten uns von einer Domschule, die bereits seit 1300 existiert haben soll. wird, vgl. Riemann, S. $470 \mathrm{f}$.

201. Errechnet aus Tepp, Tabelle A 7, S. 60. Selbst an den höher dotierten Pfründen war die Oberschicht nur zu etwa 40 Prozent beteiligt, deren Inhaber vornehmlich dem Verwandtenkreis der Gildegenossen angehörten. Vgl. Tepp, S. 61.

202. In Kolberg verstarben etwa 900 Personen, darunter 180 Haushaltsvorstände. Siehe dazu Tepp, Tabelle C 8, S. 118.

203. Riemann, S. 388: Sie wird in den Quellen als "mediocris pestis" bezeichnet. Es ist bemerkenswert, daß eine Epidemie, die bei einer Gesamtzahl von rund 5500-6000 Einwohnern etwa 900 Verluste forderte, nur als "mäßige Pest" galt.

204. Riemann, S. 388. Auch in diesen beiden Pestjahren verstarben jeweils etwa 900 Personen. Vgl. Tepp, Tabelle C 8, S. 118.

205. Im folgenden wird die Anzahl der Studenten eines Ortes in Klammern hinter die Ortsbezeichnung geschrieben.

206. Siehe Tabelle 6. Zur Geschichte Rügens, vgl. Wehrmann, Rügen.

207. Über Demmin: vgl. Goetze; siehe auch Handbuch, Bd. 12, S. 175 ff.

208. Goetze, S. 158.

209. Siehe Tabelle 6 . 
210. Zur Geschichte Stargards: vgl. die Arbeit von Boehmer; außerdem Keyser, Bd. 1, S. 233 f.; Handbuch, Bd. 12, S. 276 ff.

211. Zum Augustinerkloster: vgl. Hofmeister, Augustinerkloster. Zum Schulwesen: vgl. Beintker, lat. Schule. Zur allgemeinen Geschichte: vgl. Handbuch, Bd. 12, S. 153 ff.

212. Über Stolp: vgl. Pagel, Stolp; Bonin; außerdem Keyser, Bd. I, S. 242 ff.; Handbuch, Bd. 12, S. 287 ff.

213. Die Insel Rügen wird nur als einzelner Ort gerechnet. Die Reihenfolge siehe Tabelle 6.

214. Über Neubrandenburg: vgl. Keyser, Bd. 1, S. 308 f.; Handbuch, Bd. 12, S. 69 ff.

215. Über Pasewalk: vgl. Hückstädt; außerdem Keyser, Bd. 1, S. 210 f.; Handbuch, Bd. 12, S. 245 f.

216. Vgl. dazu Keyser, Bd. 1, S. 254 f.; Handbuch, Bd. 12, S. 303 f.

217. Vgl. dazu Keyser, Bd. 1, S. 285; Handbuch, Bd. 12, S. 28.

218. 330 von 1029 Studenten. Es handelt sich um Stettin, Kolberg, Stargard, Stolp und Treptow.

219. Die zweite Spalte soll die Entfernungen der einzelnen Orte von Greifswald darstellen (siehe auch Abkürzungsverzeichnis). Sie sind in drei Kategorien eingeteilt: I=bis100 km, II=100-200km, III=über 200km (Luftlinie). Hinter dem Querstrich befindet sich die Angabe zur Himmelsrichtung (N=Nord, $\mathrm{S}=$ Süd,usw.), die allerdings nur grob die Richtung angeben soll. Küsten-Orte der Ostsee sind darin z. B. immer als West oder Ost gekennzeichnet, obwohl Anklam sicherlich eher süd-östlich von Greifswald liegt.

220. Schmidt, Anfänge, Anm.46, S. 36: das Rügener Festland unterstand z.B. der Schweriner Diözese, während Rügen zu Roeskilde zählte.

221. Diese Verfahrensweise wurde auch von Roderich Schmidt genutzt. Vgl. Schmidt, Anfänge, Anm.46, S. 36.

222. Vgl. dazu Keyser, Bd. 1, S. 178 f.; Handbuch, Bd. 12, S. 201 f.

223. Schmidt, Rostock und Greifswald, S. 79. Der Zeitraum ihres Wirkens war 1498 bis 1503.

224. Über Bistum und Stadt Kammin: vgl. Spuhrmann; Schmidt, Bischof H. Iwen; Keyser, Bd. 1, S. 184 ff.; Handbuch, Bd. 12, S. 212.

225. Über Köslin: vgl. Schwenkler; Treichel; Keyser, Bd. 1, S. 187 ff., Handbuch, Bd. 12, S. 216 ff.

226. Über Wolgast: vgl. Heberlein; Keyser, Bd. 1, S. 262 f.; Handbuch, Bd. 12, S. 317 ff.

227. Über Rügenwalde: vgl. Rosenow; Boehmer, Rügenwalde; Keyser, Bd. 1, S. 221 ff., Handbuch, Bd. 12, S. $262 \mathrm{ff}$. 
228. Über Greifenberg: vgl. Wehrmann, Greifenberg; Keyser, Bd. 1, S. 170 f.; Handbuch, Bd. 12, S. 191 ff.

229. Über die folgenden Ortschaften: vgl. die Artikel in Keyser, Bd. 1 und Handbuch, Bd. 12.

230. Akürzungen A, B usw. siehe Abkürzungsverzeichnis.

231. Zeitabschnitt 1-3 jeweils 17 Jahre, Zeitabschnitt 4 nur 16 Jahre!

232. Zur Entfernung der Orte: vgl. Anm. .

233. Dersekow, Horst (2), Boltenhagen, Buggenhagen, Kiesow, Kräplin, Leist, Ludwigsburg, Ranzin, Waschow, Zastrow (1).

234. Sophienhof, Verchen (1).

235. Görmin (2), Elmenhorst, Gristow, Reinberg (1).

236. Kamp (2), Kummerow / Anklam, Blesewitz, Kagenow, Kartelow, Wusseken (1).

237. Damgarten (2), Dievitz, Richtenberg (1).

238. Etwa 100km Umkreis: Altdamm, Göritz, Grünz (2), Borrin, Daber, Elsbruch, Jagow, Labes, Langkafel, Ramin, Oderam, Uckermünde, Vogelsang (1).

239. Körlin (2), Kummerow / Stettin, Boeck, Machmin, Mellen, Neustettin, Polzin, Valm, Zanow (1).

240. Vgl. Kapitel 5.2: Die Orte mit den höchsten Studentenzahlen.

241. Vgl. dazu Keyser, Bd. 1, S. 304 ff.; Handbuch, Bd. 12, S. 61 f.

242. Bützow, Gadebusch, Mecklenburg (2), Grabow (1).

243. Woldegk (2), Röbel, Neustrelitz, Stuer (1).

244. Vgl. dazu oben Kapitel 2.1: Zur Frequenz der Greifswalder Universität.

245. Gransee, Kyritz, Eberswalde.

246. Bärwalde, Drossen, Müncheberg, Spandau.

247. Fürstenwalde, Perleberg, Rathenow, Reetz, Reppen.

248. Seehausen, Wedel, Barnim, Beelitz, Berlin, Boitzenburg, Friedberg, Fürstenberg, Grünow, Guben, Herzsprung, Königsberg/B., Lenzen, Lichtenow, Meyenburg, Niemegk, Reppen, Wardin, Werneuchen, Wilsnack, Woldenberg, Wrietzen, Wusterhausen, Zinna. 
249. Vgl. auch Boockmann, Stauferzeit, S. 306.

250. Siehe auch die Arbeit von Klaus Spading über niederländische Studenten in Greifswald.

251. Schwinges, Universitätsbesucher, S. 242.

252. Keck, S. 68.

253. Roderich Schmidt sagte 1976, daß die "These von den humanistischen Anfängen Greifswalds"... "schon deswegen nicht stichhaltig ist, weil die dafür angeführten Zeugnisse nicht in die Gründungszeit ab 1456 fallen, sondern in den Anfang des 16. Jahrhunderts." Vgl. Schmidt, Rostock und Greifswald, S. 79; Kräfte, S. 5. Soweit ich sehe, hat Roderich Schmidt bei seiner Beurteilung die niederländischen Studenten und Professoren der siebziger und achtziger Jahre außer Acht gelassen, deren Biographien vielleicht einige humanistische Verbindungen zu Tage bringen könnten. So wäre vor allem die Rolle des Heinrich ter Porten zu klären, der zu Beginn der achtziger Jahre eine Reformierung der Artistenfakultät durchführen wollte, und dabei mit dieser in Konflikt geriet. Die Situation in der Fakultät spitzte sich zu, so daß er sich bald genötigt sah, nach Stralsund zu fliehen, von wo er allerdings bald wieder zurückgeholt, und der Streit beigelegt werden konnte. Vgl. Kosegarten I, S. 133 ff., 154, dazu auch Spading, S. 196 ff. Quelle: Annalen der Universität, in: Kosegarten II, S. 193. Ein Ansatz für eine weitere Beschäftigung bietet auch der Magister Johannes Sartoris, dessen Name Sartoris wohl eine Latinisierung des Familiennamen Schröder ist. Seine besondere Verbindung zu den klassischen Autoren wird aus einigen überlieferten Textpassagen deutlich. Vgl. Kosegarten I, S. 133, Quelle: Dekanatsbuch, in: Kosegarten II, S. 236, 240. Über ihn auch Klaus Spading, S. 198 f.

254. Vgl. dazu Schwinges, Universitätsbesucher, S. 95.

255. Vgl. dazu Schwinges, Universitätsbesucher, S. 544 (Tabelle 2a).

256. In Ingolstadt betrug der Anteil von 1472 bis 1556 nur 1,14\%, vgl. Buzás, S. 17, in Köln zwischen 1385 bis 1495 etwa 4,6\%, vgl. Schwinges, Universitätsbesucher, S. 234.

257. Fuchs, S. 9.

258. Dabei ist wohl an die Universitäten Köln (1388), Erfurt (1392) und Löwen (1426) zu denken, vgl. Fuchs, S. 8.

259. Vgl. dazu Schubert, Motive, S. 15.

260. Vgl. auch Schwinges, Universitätsbesucher, S. 234.

261. Schwinges, Universitätsbesucher, S. 150.

262. Bis 1505 wurden insgesamt 2605 Studenten immatrikuliert, worunter sich 286=10,98\% Dänen befanden.

263. Mit Seeland ist sicherlich immer die dänische Insel gemeint und nicht die gleichnamige 
niederländische Gegend, wie schon aus dem Ortsverzeichnis Fiedländers hervorgeht. S. 491. Der niederländische Student Georrius Rute de Zelandia (Matr. S. 12, Z.35), den Roderich Schmidt im Wintersemester 1458 gefunden hat, entpuppt sich daher auch als Däne. Vgl. Schmidt, Anfänge, S. 11.

264. Pinborg, S. 78.

265. Vgl. etwa Fuchs für Heidelberg, S. 8 f.

266. Vgl. etwa Boockmann über preußische Studenten in Leipzig, S. 10; auch Keck über die Frühphase, S. 49, $89 \mathrm{ff}$.

267. Boockmann, S. 11: Wittenberg spielt in dieser Hinsicht als Reformationsstadt eine Sonderrolle.

268. Schwinges, Universitätsbesucher, S. 235, S. 241 f.; Boockmann, Die preußischen Studenten, S. 11.

269. Boockmann, Die preußischen Studenten, S. 11.

270. Vgl. die Zahlen bei Boockmann, Die preußischen Studenten, S. 11, der bis 15242712 Studenten aus dem Gebiet des späteren Königlichen Preußen, gegenüber nur 881 Studenten aus den restlichen Ordensgebieten gezählt hat.

271. Schwinges, Universitätsbesucher, S. 241.

272. Boockmann, Die preußischen Studenten, S. $11 \mathrm{f}$.

273. Keck, S. 54 .

274. In diesem Fall ist die Universitätsnation gemeint, die Preußen, Schlesien und Polen umfaßte.

275. Keck, S. 55.

276. Boockmann, Die preußischen Studenten, S. 10 f.; Schwinges, Universitätsbesucher, S. 241.

277. Schmidt, Anfänge, S. 11.

278. Pinborg, S. 79.

279. Diese Aussage gilt genauso für die dementsprechenden Stellen bei Schwinges, Universitätsbesucher, S. 240.

280. Vgl. dazu Kapitel 2.1: Zur Frequenz der Greifswalder Universität.

281. Matrikel I, S. 45, Z. b5.

282. Schmidt, Rostock und Greifswald, S. 94. 
283. Von 2270 Studenten mit genauen Ortsangaben fielen 1292 auf diese 26 Ortschaften.

284. Die verschiedenen Matrikeleditionen sind im Quellenverzeichnis zu finden.

285. Kosegarten I, S. 13.

286. Siehe auch die Zusammenstellung aller deutschen Studenten in Krakau von Zeissberg, S. 70 ff.

287. Dies ist freilich auch gewollt, denn mit der Untersuchung soll die Bedeutung der Universitäten für einen Ort ermittelt werden, die ebenso an Studienortwechslern erkennbar wird.

288. Da einerseits einige Matrikel nicht mehr vorhanden sind sowie die Sorgfältigkeit der Eintragungen in früherer Zeit nachläßt, können diese Zahlen nur unter besonderem Vorbehalt verwertet werden.

289. Damit sind die von Roderich Schmidt gemachten Aussagen für den behandelten Zeitraum zu relativieren, der die Zahl der Greifswalder auf auswärtigen Universitäten offensichtlich überschätzte, als er schrieb: "Da in den Matrikeln der übrigen Universitäten immer wieder Studenten aus Greifswald begegnen, nicht nur bevor hier eine Universität errichtet wurde, sondern ebenso auch danach, bleibt es dennoch ein wenig auffällig, daß in der Greifswalder Matrikel die Universitätsstädte unter den Herkunftsorten fehlen." Schmidt, Anfänge, S. 12.

290. Matrikel I, S. 94: "Sub isto rectoratu non fuerunt plures intitulati propter pestilentiam."

291. Keck, S. 66.

292. Vgl. auch die Zahlen bei Kühne, der die Namen der Pommern bis 1456 aus der Erfurter Matrikel gesammelt hat, S. 45.

293. Kosegarten I, S. 13 f.

294. Vgl. auch die Zusammenstellung von Kosegarten, der das Dekanatsbuch und die Fakultätsmatrikel auf Studenten aus Pommern untersucht hat, S. $13 \mathrm{ff}$.

295. Eine Zuordnung konnte nur deshalb erfolgen, weil der Rektor außerdem die Diözese Schwerin angegeben hatte.

296. In Rostock verdoppeln sich die Immatrikulationen von 12 auf 30 Studenten aus Stralsund.

297. Die Zahlen sinken von 24 auf 17 Studenten.

298. Pauli, Album studiosorum II, S. 30.

299. Vgl. auch Kühne, S. 45.

300. Nimmt man die pommerschen Studenten mit Bistumsangaben hinzu, die freilich auch aus den genannten Ortschaften stammen konnten, liegt der Anteil bei etwa 70 Prozent. 
301. Gegenüber 45 Einschreibungen zwischen 1498 und 1504 steigen in Rostock die Zahlen auf 113 Einschreibungen zwischen 1505 und 1511. Dagegen konnte die Universität Frankfurt in ihrem Gründungsabschnitt nur 55 Inskriptionen erreichen.

302. Da die Zeitabschnitte nicht genau mit dem Gründungsjahr 1502 beginnen, handelt es sich um einen Annäherungswert. Von 1498 bis 1524 lag der Anteil Wittenbergs bei 4,1 Prozent, während er zwischen 1505 und 1524 4,8 Prozent betrug.

303. Dies gilt weniger für die Ostseeuniversitäten, deren Rektoren häufiger eine Unterscheidung vornahmen.

304. Vgl. die Zusammenstellung von Balck zur Beteiligung Neubrandenburgs und aller übrigen mecklenburgischen Orte an den verschiedenen Universitäten.

305. In den Jahren 1464 bis 1469 könnte der Krieg in Pommern, der auch in der Gegend um Friedland tobte, als Ursache für den Immatrikulationsrückgang angeführt werden. Dazu: Kosegarten I, S. 123.

306. Perlbach, S. $129 \mathrm{ff}$.

307. Hierfür dürften einerseits der kürzere Zeitraum von nur sechs Jahren, andererseits die Reformationsereignisse verantwortlich sein.

308. 93 von 522 Studenten.

309. Zwischen 1466 und 1505 waren es noch 63 von 273 Eintragungen (=23,1\%), später 19 von 200 Eintragungen $(=9,5 \%)$.

310. Dies hängt mit der relativ niedrigen Gesamtfrequenz in den Anfangsjahren zusammen.

311. Dabei muß man allerdings eine höhere Zahl an Einschreibungen zur Gründungszeit berücksichtigen. Aufgrund der Kürze des Zeitraums wird das Ergebnis durch diesen Umstand etwas entstellt. 25 der Einschreibungen erfolgten im ersten Jahr. 70 Einschreibungen erfolgten allein in den ersten 14 Jahren nach der Gründung. Ob die 10 Studenten des letzten Abschnitts als Normalisierung oder als reformationsbedingter Rückgang zu verstehen sind, kann an dieser Stelle nicht eindeutig geklärt werden, da man dafür die spätere Entwicklung mitberücksichtigen müßte.

312. Vgl. die Zahlen in Krakau: 1477-1483: 12, 1484-1490: 25.

313. Insgesamt fünf Studenten.

314. Bei Berücksichtigung des gesamten Mittelalters wird Greifswald durch Wien in der Bedeutung auf den sechsten Platz verwiesen.

315. 11 von 37 Studenten. Zum Vergleich: Leipzig 8, Rostock 8, Krakau 3. 
316. Sogar Leipzig erreicht mit 11 Einschreibungen das gleiche Ergebnis wie Greifswald.

317. Dazu auch die frequenzgeschichtlichen Beobachtungen bei Schwinges, der Greifswald zu den "in quantitativer Hinsicht kleinen deutschen Hochschulen der zweiten Gründungswelle" gezählt hat. Weiter heißt es: "Am deutlichsten zurück blieb immer Greifswald". Vgl. Schwinges, Universitätsbesucher, S. 147.

318. Delhaes, Lübecker.

319. So etwa Grüningen, Markgrüningen.

320. Nicht alle Namen sind in den Matrikeln wiederzufinden, da Keussen für das Register noch verschiedene andere Universitätsquellen verwertet hat.

321. Nur 13 Immatrikulationen ließen sich seit Gründung der Universität im Jahre 1425 bis 1469 wiederfinden. Von 1470 bis 1476 sind es bereits 22 Einschreibungen, wobei auch hier allerdings auf die Quellenproblematik in der ersten Hälfte des 15. Jahrhunderts hingewiesen werden muß.

322. Betrachtet man den gesamten Zeitraum (1456-1524), so liegt der Mittelwert nur bei etwa 17 Studenten pro Jahrsiebt.

323. Heraeus, Hamburger Studenten, vgl. Tabelle S. 563.

324. Es handelt sich um die Universitäten Leipzig, Köln (seit 1466) und Löwen. Vgl. dazu die Tabelle bei Heraeus, S. 563. Jacobus Winthorst aus Budinskys Verzeichnis der fremden Studenten an der Universität Paris, den Heraeus nur erwähnt, wurde ebenfalls integriert.

325. Vgl. die Einschreibungen der vier Orte in Rostock:

\begin{tabular}{|l|l|l|}
\hline $1477-1483$ & $1484-1490$ & $1491-1497$ \\
\hline 142 & 78 & 157 \\
\hline
\end{tabular}

326. Schwinges, Universitätsbesucher, S. 491.

327. Fuchs, S. 118.

328. Fuchs, S. 118.

329. Fuchs, S. 118.

330. Vgl. die Arbeit von Pinborg über dänische Studenten.

331. So auch Schwinges, Universitätsbesucher S. 247 f. und 249. 


\section{Abbildungsverzeichnis}

Abbildung 1: Frequenzkurve 1456-1524

Abbildung 2: Herkunftsangaben

Abbildung 3: Grobe Verteilung auf Gebiete 1456-1524

Abbildung 4: Adelsfrequenz Greifswald

Abbildung 5: Geistliche Würdenträger in Greifswald

Abbildung 6: Hohe Geistliche in Greifswald

Abbildung 7: "domini"

Abbildung 8: "presbyteri"

Abbildung 9: "clerici"

Abbildung 10: Ordensklerus Gesamt - Pommern

Abbildung 11: Anteil Vollzahler - Sonstige

Abbildung 12: Das Verhältnis der Teil- und Nichtzahler von 1456 bis 1475

Abbildung 13: Nicht- und Teilzahleranteil von 1505 bis 1524

Abbildung 14: Anteil der Pommern an den Teil- und Nichtzahlern

Abbildung 15: Das Verhältnis Pommern-Nichtpommern (\% pro Jahr)

Abbildung 16: Studenten aus Greifswald und Stralsund

Abbildung 17: Studenten aus Stettin und Kolberg

Abbildung 18: Studenten aus Pommern

Abbildung 19: Studenten aus Mecklenburg

Abbildung 20: Studenten aus Brandenburg

Abbildung 21: Studenten aus dem übrigen Reichsgebiet 
Abbildung 22: Studenten aus dem niedersächsischen Kreis

Abbildung 23: Studenten aus den rheinischen Kreisen

Abbildung 24: Studenten aus dem burgundischen Kreis

Abbildung 25: Studenten ausländischer Herkunft

Abbildung 26: Dänische Studenten in Greifswald

Abbildung 27: Studenten aus Schweden, Norwegen und Finnland

Abbildung 28: Studenten aus den Gebieten des Deutschen Orden

Abbildung 29: Studenten aus Greifswald 1456-1524 (Verteilung auf Universitäten)

Abbildung 30: Studenten aus Greifswald (Greifswald - Gesamtfrequenz)

Abbildung 31: Stralsunder Studenten 1456-1524 (Verteilung auf Universitäten)

Abbildung 32: Verteilung der Stralsunder auf die alten Universitäten des Reiches

Abbildung 33: Stralsunder Studenten (Greifswald - Gesamtfrequenz)

Abbildung 34: Stralsunder Studenten (Anteil Greifswalds an der Gesamtfrequenz)

Abbildung 35: Demminer Studenten (Greifswald - Gesamtfrequenz)

Abbildung 36: Demminer Studenten (Anteil Greifswalds an der Gesamtfrequenz)

Abbildung 37: Anklamer Studenten (Greifswald - Gesamtfrequenz)

Abbildung 38: Stettiner Studenten 1456-1524 (Verteilung auf Universitäten)

Abbildung 39: Verteilung der Stettiner auf die alten Universitäten des Reiches

Abbildung 40: Stettiner Studenten (Greifswald - Gesamtfrequenz)

Abbildung 41: Stettiner Studenten (Anteil Greifswalds an der Gesamtfrequenz)

Abbildung 42: Stargarder Studenten 1456-1524 (Verteilung auf Universitäten)

Abbildung 43: Verteilung der Stargarder auf die alten Universitäten

Abbildung 44: Stargarder Studenten (Greifswald - Gesamtfrequenz) 
Abbildung 45: Stargarder Studenten (Anteil Universitäten an der Gesamtfrequenz)

Abbildung 46: Studenten aus Pasewalk (Greifswald - Gesamtfrequenz)

Abbildung 47: Kolberger Studenten (Greifswald - Gesamtfrequenz)

Abbildung 48: Kolberger Studenten (Anteil Greifswalds an der Gesamtfrequenz)

Abbildung 49: Stolper Studenten 1456-1524 (Verteilung auf Universitäten)

Abbildung 50: Stolper Studenten (Greifswald - Gesamtfrequenz)

Abbildung 51: Stolper Studenten (Anteil Universitäten an der Gesamtfrequenz)

Abbildung 52: Studenten aus Treptow (Greifswald - Gesamtfrequenz)

Abbildung 53: Verteilung der Pommern auf die Universitäten (1456-1524)

Abbildung 54: Universitätsbesuch der Pommern (Greifswald-Gesamtfrequenz)

Abbildung 55: Anteil Greifswalds an der Gesamtfrequenz

Abbildung 56: Verteilung der Pommern auf die alten Universitäten (vor 1456)

Abbildung 57: Neubrandenburger Studenten (Greifswald - Gesamtfrequenz)

Abbildung 58: Neubrandenburg (Anteil Greifswalds an Gesamtfrequenz)

Abbildung 59: Prenzlauer Studenten 1456-1524 (Verteilung auf Universitäten)

Abbildung 60: Danziger Studenten 1456-1524 (Greifswald - Gesamtfrequenz)

Abbildung 61: Lübecker Studenten 1456-1524 (Greifswald - Gesamtfrequenz)

Abbildung 62: Groninger Studenten 1456-1524 (Verteilung auf Universitäten)

Abbildung 63: Groninger Studenten 1456-1524 (Greifswald - Gesamtfrequenz)

\section{Tabellenverzeichnis}

Tabelle 1: Fehlende Herkunftsangaben 
Tabelle 2: Land- und Diözeseangaben

Tabelle 3: Adel an süddeutschen Universitäten 1470-1520

Tabelle 4: Der Anteil der "divites" an den einzelnen Herkunftsgebieten

Tabelle 5: Der Anteil der Teilzahler an den einzelnen Herkunftsgebieten

Tabelle 6: 15 Orte mit den höchsten Studentenzahlen

Tabelle 7: Orte Pommerns mit 8 bis 30 Studenten

Tabelle 8: Orte Pommerns mit 3 bis 6 Studenten

Tabelle 9: Orte Mecklenburgs mit 3 bis 25 Studenten

Tabelle 10: Orte Brandenburgs mit 5 bis 25 Studenten

Tabelle 11: Studenten aus Lübeck und Hamburg

Tabelle 12: Anklamer Studenten bis 1524

Tabelle 13: Barther Studenten bis 1524

Tabelle 14: Grimmener Studenten bis 1524

Tabelle 15: Wolgaster Studenten bis 1524

Tabelle 16: Studenten aus Pasewalk bis 1524

Tabelle 17: Pyritzer Studenten bis 1524

Tabelle 18: Kolberger Studenten bis 1524

Tabelle 19: Studenten aus Treptow bis 1524

Tabelle 20: Belgarder Studenten bis 1524

Tabelle 21: Kamminer Studenten bis 1524

Tabelle 22: Kösliner Studenten bis 1524

Tabelle 23: Rügenwalder Studenten bis 1524

Tabelle 24: Greifswalder Anteile zwischen 1456 und 1524 (Durchschnitt: 54,4\%) 
Tabelle 25: Die Beteiligung der Pommern an der Universität Wittenberg

Tabelle 26: Neubrandenburger Studenten bis 1524

Tabelle 27: Friedländer Studenten bis 1524

Tabelle 28: Prenzlauer Studenten bis 1524

Tabelle 29: Malchiner Studenten bis 1524

Tabelle 30: Vergleich der vier Städte mit der höchsten Studienbeteiligung

Tabelle 31: Danziger Studenten in Wittenberg bis 1524

Tabelle 32: Danziger Studenten bis 1524

Tabelle 33: Lübecker Studenten bis 1524

Tabelle 34: Hamburger Studenten bis 1525

\section{Abkürzungsverzeichnis}

\section{Entfernungsangaben:}

I/N: 0-100 km in nördlicher Richtung, I/S: 0-100 km in südlicher Richtung, usw.

II/N: 100-200 km in nördlicher Richtung, II/S: 100-200 km in südlicher Richtung, usw.

III/N: über 200 km in nördlicher Richtung, III/S: über 200 km in südlicher Richtung, usw.

Zeiteinteilungen:

$\underline{\text { Sieben Jahre }}$

I: $1456-1462$ 
II: 1463-1469

III: $1470-1476$

IV : 1477-1483

V: $1484-1490$

VI: 1491-1497

VII: 1498-1504

VIII: 1505-1511

IX: 1512-1518

X: 1519-1524 (sechs Jahre!)

17 Jahre

A: $1456-1472$

B: $1473-1490$

C: $1491-1507$

D: 1508-1524 (18 Jahre!) 


\title{
Quellenverzeichnis
}

\author{
Ungedruckte Quellen
}

Universitätsarchiv Greifswald:

Album Gryphiswaldensis, Tom 1, ao. 1456 - 1598

Liber Decanatuum Facultate Artium Gryphiswaldensis, ao. 1456 - 1662

Annales Academiae Gryphiswaldensis, ao. 1456 - 1487 ac donationes

Universitätsarchiv Wien:

M 1 - M 3: Matricula Universitatis Viennensis I-II, 1377-1518

Ph 6 - Ph 9: Acta Facultatis Artium Universitatis Vindobonensis I-IV, 1385-1559

Ph 21: Receptoria Facultatis Magistrorum et Baccalariorum 1429-1472

J 1 - J 2: Matricula Facultatis Juristarum Studii Wiennensis I-II, 1402-1557

\section{Gedruckte Quellen}

Balck, C. W. A.: Meklenburger auf auswärtigen Universitäten bis zur Mitte des 17. Jahrhunderts. In: Mecklenburgische Jahrbücher 48, 1883, S. 54-88, 49, 1884, S. 73-144, 310-312, 50, 1885, S. 343-387. (Matrikelauszüge)

Denifle, H., u.a. (Hg.): Auctarium Chartularii Parisiensis I-III: Liber procuratorum nationis Anglicanae (Alemanniae) in Universitate Parisiensi 1333-1492, Paris 1894-1935.

Erler, G. (Hg.): Die Matrikel der Universität Leipzig 1409-1559 (=Codex diplomaticus Saxoniae regiae II, 1618), 3 Bde., Leipzig 1895-1903 (Ndr. 1976).

Friedländer, E. (Hg.): Ältere Universitätsmatrikeln I, Universität Frankfurt a. d. Oder 1506-1811 (Publikationen aus den königlich preußischen Staatsarchiven 32, 36, 49), 3 Bde., Leipzig 1887-1891 (Ndr. 1976)

— Ältere Universitätsmatrikeln II. Universität Greifswald 1456-1645, (Publikationen aus den königlich preußischen Staatsarchiven 52, 57), 2 Bde., Leipzig 1893-1894 (Ndr. 1976).

— u.a. (Hg.), Acta Nationis Germanicae Universitatis Bononiensis (1289-1543), Berlin 1887. 
Gabriel, A. L., u.a. (Hg.): Auctarium Chartularii Universitatis Parisiensis VI: Liber receptorum nationis Anglicanae (Alemanniae) in Universitate Parisiensi 1425-1494, Paris 1964.

Gaebel, G. (Hg.): Des Thomas Kantzow Chronik von Pommern. In niederdeutscher Mundart., in: Veröffentlichungen der historischen Kommission für Pommern, Bd. I, Heft 4, Stettin 1929.

Gall, F., u.a. (Hg.): Die Matrikel der Universität Wien, 1377-1558, 3 Bde. u. 3 Registerbde., Wien-Graz-Köln 1954-1967.

Hermelink, H. (Hg.): Die Matrikeln der Universität Tübingen 1477-1600, 2 Bde., Stuttgart 1906-1931.

Hofmeister, A. (Hg.): Die Matrikel der Universität Rostock, 1419-1831, 7 Bde, Rostock-Schwerin 1899-1922.

Keussen, H. (Hg.): Die Matrikel der Universität Köln (Publikationen der Gesellschaft. Für Rheinische Geschichtskunde 8), 3 Bde., Köln 1928, 1919, 1931.

Knod, G.: Deutsche Studenten in Bologna (1289-1562). Biographischer Index zu den Acta nationis Germanicae universitatis Bononiensis, Berlin 1899 (Ndr. Aalen 1970)

Kosegarten, J. G. L.: Geschichte der Universität Greifswald mit urkundlichen Beilagen, Teil II, Greifswald 1856-1857 (Ndr. Aalen 1976).

Mayer, H. (Hg.): Die Matrikel der Universität Freiburg im Breisgau von 1460-1656, 2 Bde., Freiburg 19071910 (Ndr. 1976).

Monumenta Historica Universitatis Carolo-Ferdinandeae Pragensis, 3 Bde.; Bd. I-II: Liber Decanorum Facultatis Philosophicae Universitatis Pragensis ab anno Christi 1367 usque ad annum 1585; Bd. III: Album seu Matricula Facultatis Juridicae Universitatis Pragensis ab anno Christi 1372 usque ad annum 1418, Prag 1830, 1834, 1848.

Pauli, Z., u.a. (Hg.): Album Studiosorum Universitatis Cracoviensis, 3 Bde., Krakau 1887-1904. - Indeks Studentow universytetu Krakowskiego wlatach 1400-1500. Opracowali J. Zathey i J. Reichan (Polska Akademia Nauk. Instytut Filozofii i Socjologii), Warschau u.a. 1974.

Perlbach, M.: Prussia scholastica: Die Ost- und Westpreußen auf den mittelalterlichen Universitäten, Braunsberg 1895. (Matrikelauszüge)

Pölnitz, G. Frhr. von (Hg.): Die Matrikel der Ludwig-Maximilians-Universität Ingolstadt-Landshut-München Teil I: Ingolstadt, Bd. I, 1472-1600, München 1937; Bd. IV, 1-2: Personenregister, Bd. V, 1-2: Ortsregister, erstellt von L. Buzás, München 1981, 1984.

Reusens, E. (Hg.): Matricule de l’Université de Louvain I, 1428-1453, Brüssel 1903.

Schillings, A. (Hg.): Matricule de l’Université de Louvain II, 2-III, 1-2, 1485-1527, Brüssel 1954-1962.

Schwinges, R. Chr., u.a. (Hg.): Das Bakkalarenregister der Artistenfakultät der Universität Erfurt (1392- 
1521), (Veröffentlichungen der Historischen Kommission für Thüringen, Große Reihe 3), Jena 1995.

Toepke, G. (Hg.): Die Matrikel der Universität Heidelberg von 1386-1662, 2 Bde., Heidelberg 1884-1893 (Ndr. 1976).

Wackernagel, H. G. (Hg.): Die Matrikel der Universität Basel, 1460-1666, 3 Bde., Basel 1951-1962.

Weissenborn, J. C. H. (Hg.): Allgemeine Studentenmatrikel, in: Acten der Erfurter Universität (Geschichtsquellen der Provinz Sachsen und angrenzender Gebiete VIII, 1-3), 3 Bde., Halle 1881-1899 (Ndr. 1976)

Wils, J. (Hg.): Matricule de l’Université de Louvain II, 1, 1453-1485, Brüssel 1946.

Zeissberg, H.: Das älteste Matrikelbuch der Universität Krakau. Beschreibung und Auszüge (1400-1508), Innsbruck 1872 (Ndr. Wiesbaden 1974, Liechtenstein/Vaduz).

\section{Literaturverzeichnis}

Abe, H. R.: Die frequentielle Bedeutung der Erfurter Universität im Rahmen des mittelalterlichen deutschen Hochschulwesens (1392-1521), in: Beiträge zur Geschichte der Universität Erfurt 2 (1957), S. 29-57 (2. Aufl. 1962, S. 31-60).

— Die Frequenz der Universität Erfurt im Mittelalter (1392-1521), in: Beiträge zur Geschichte der Universität Erfurt 1 (1956), S. 7-69 (2. Aufl. 1962, S. 7-69).

— Die soziale Gliederung der Erfurter Studentenschaft im Mittelalter (1392-1521) I: Der Anteil der Geistlichkeit an der Erfurter Studentenschaft im Mittelalter (1392-1521), in: Beiträge zur Geschichte der Universität Erfurt 8 (1961), S. 5-38.

Alschner, U.: Universitätsbesuch in Helmstedt 1576-1810. Modell einer Matrikelanalyse am Beispiel einer norddeutschen Universität, Wolfenbüttel 1998.

Baumgart, P., u.a. (Hg): Beiträge zu Problemen deutscher Universitätsgründungen der frühen Neuzeit, Nendeln 1978.

Beintker, E.: Zur Geschichte der lateinischen Schule in Anklam, in: Baltische Studien NF 4 (1899), S. 65-136.

Bernitt, H.: Zur Geschichte der Stadt Rostock, Rostock 1956.

Boehmer, F.: Geschichte der Stadt Stargard in Pommern, Bd. 1, Stargard 1903.

— Geschichte der Stadt Rügenwalde bis zur Aufhebung der alten Stadtverfassung (1720), Stettin 1900.

Bonin, R.: Geschichte der Stadt Stolp, 1985. 
Boockmann, H.: Die Lebenswelt eines spätmittelalterlichen Juristen, in: Festschrift für Karl Stackmann, Philologie als Kulturwissenschaft, Studien zur Literatur und Geschichte des Mittelalters, Göttingen 1987, S. 289-305.

— Die preußischen Studenten an den europäischen Universitäten bis 1525, in: Historisch-geographischer Atlas des Preußenlandes, Mortensen, H., u.a. (Hg), 3. Lfg. Wiesbaden 1973, S.1-12.

— Die Rechtsstudenten des Deutschen Ordens. Studium, Studienförderung und gelehrter Beruf im späteren Mittelalter, in: Festschrift für Hermann Heimpel, Bd.II (Veröffentlichungen des Max-Planck-Instituts für Geschichte, 36/II), Göttingen 1972, S.313-375.

— Spätmittelalterliche deutsche Stadt-Tyrannen, in: Blätter für deutsche Landesgeschichte 119 (1983), S.7391.

— Stauferzeit und spätes Mittelalter, Deutschland 1125-1517 (Deutsche Geschichte in zehn Bänden; Das Reich und die Deutschen), Berlin 1987.

Brandenburg, A.: Geschichte des Magistrats der Stadt Stralsund besonders in früherer Zeit, nebst einem Verzeichnisse der Mitglieder desselben, Stralsund 1837.

Budinzsky, R.: fremde Studenten auf der Universität Paris im Mittelalter, Berlin 1876.

Buzás, L.: Die Herkunft der Studenten der Universität Ingolstadt von der Gründung der Universität bis zur Gründung des Jesuitenkollegs (1472-1556), in: Sammelblatt des Historischen Vereins Ingolstadt 72 (1963), S.1-68.

Classen, P.: Die hohen Schulen und die Gesellschaft im 12. Jahrhundert, Archiv für Kulturgeschichte 48 (1966).

— Studium und Gesellschaft im Mittelalter (Schriften der Monumenta Germaniae Historiae 29), Stuttgart 1983.

Cramer, G.: Die örtliche und soziale Herkunft der ältesten Tübinger Studenten (1477-1600), Diss. Leipzig 1922.

Crusius, I. (Hg): Studien zum weltlichen Kollegiatstift in Deutschland, Göttingen 1995.

Delhaes, W.: Lübecker Studenten auf mittelalterlichen Universitäten, Diss. masch. Berlin 1941.

Diener, H.: Die Hohen Schulen, ihre Lehrer und Schüler in den Registern der päpstlichen Verwaltung des 14. und 15. Jahrhunderts, in: Fried, J. (Hg), Schulen und Studium im sozialen Wandel des hohen und späten Mittelalters, Sigmaringen 1986. S. 351-374.

Eggert, O.: Geschichte Pommerns, Bd. 1, Bielefeld 1974.

Eulenburg, F.: Die Frequenz der deutschen Universitäten von ihrer Gründung bis zur Gegenwart 
(Abhandlungen der philologisch-historischen Klasse der königlich Sächsischen Gesellschaft der Wissenschaften 24/2), Leipzig 1904

— Über die Frequenz der deutschen Universitäten in früherer Zeit, in: Jahrbücher der Nationalökonomie und Statistik 3. Folge 13 (1897) (=Bd. 68, 1897), S.481-555.

Ewe, H. (Hg): Geschichte der Stadt Stralsund, Weimar 1984.

Fried, J. (Hg): Schulen und Studium im sozialen Wandel des hohen und späten Mittelalters, Sigmaringen 1986.

Fritze, K.: Die Bevölkerungsstruktur Rostocks, Stralsunds und Wismars am Anfang des 15. Jahrhunderts. Versuch einer sozialstatistischen Analyse, in: Greifswald-Stralsunder Jahrbuch 4 (1964) S. 69-79.

— Die Hansestadt Stralsund. Die beiden ersten Jahrhunderte ihrer Geschichte, Schwerin 1961.

Fuchs, C.: Dives, pauper, nobilis, magister, frater, clericus: sozialgeschichtliche Untersuchungen über Heidelberger Universitätsbesucher des Spätmittelalters (1386-1450), Leiden 1995.

Goetze, K.: Geschichte der Stadt Demmin, Demmin 1903.

Graesse, J. G. Th., u.a.: Orbis Latinus. Lexikon lateinischer geographischer Namen des Mittelalters und der Neuzeit, 3 Bde., Braunschweig 1972.

Grundmann, H.: Vom Ursprung der Universität im Mittelalter, Darmstadt 1960 (Ndr. 1976).

Häfele, R.: Die Studenten der Städte Nördlingen, Kitzingen, Mindelheim und Wunsiedel bis 1580 : Studium, Berufe und soziale Herkunft, 2 Teile, (Trierer historische Forschungen ; 13), Trier 1988.

Handbuch der historischen Stätten, 12 Bde., Stuttgart (Kröners Taschenausgabe) verschiedene Auflagen $1959 f f$.

Heberlein, B.: Beiträge zur Geschichte der Burg und Stadt Wolgast, Wolgast 1892.

Heraeus, M.: Hamburger Studenten auf deutschen und ausländischen Hochschulen in dem Zeitraume von 1290-1650, in: Zeitschrift des Vereins für Hamburgische Geschichte, Bd. 9, Hamburg 1894.

Hergemöller, B.-U.: Krisenerscheinungen kirchlicher Machtpositionen in hansischen Städten des 15. Jahrhunderts, in: Städtische Führungsgruppen und Gemeinde in der werdenden Neuzeit, hg. von W. Ehrbrecht, Städteforschung (Veröffentlichungen des Instituts für vergleichende Städtegeschichte Münster A, 9), 1980, S. 332ff.

Heyden, H.: Kirchengeschichte von Pommern, 2 Bde., Stettin 1937-1938.

Höfer, J., u.a. (Hg): Lexikon für Theologie und Kirche, 10 Bde., Freiburg 1957-65. 
Hofmeister, A.: Die geschichtliche Stellung der Universität Greifswald, in: Greifswalder Universitätsreden 32, Greifswald 1932.

— Zur Geschichte des Augustinerklosters in Anklam und der Stadt Anklam, in: Baltische Studien 39 (1925), S. $22 f$.

Hückstädt, E. W.: Geschichte der Stadt Pasewalk von der ältesten bis auf die neueste Zeit (Historische Reprints der Uecker-Randow-Region 1), Neustadt an der Aisch 1995 (Nachdruck der Ausgabe von 1883).

Hufen, F.: Über das Verhältnis der deutschen Territorialstaaten zu ihren Landesuniversitäten im alten Reich, Diss. Phil. München 1955.

Johansen, P.: Umrisse und Aufgaben der hansischen Siedlungsgeschichte und Kartographie, in: Hansische Geschichtsblätter, Jg. 73, Münster 1955, S. 1-105.

Kaufmann, G.: Die Geschichte der deutschen Universitäten, Bd. II, Stuttgart 1896.

Keck, W.: Die Herkunft der Leipziger Studenten von 1409 bis 1430, Diss. Phil. Leipzig 1935.

Keussen, H.: Die alte Universität Köln, Grundzüge ihrer Verfassung und Geschichte, Köln 1934.

— Die Rotuli der Kölner Universität, in: Mitteilungen aus dem Stadtarchiv Köln 22 (1891), S. 1-38.

Keyser, E. (Hg): Deutsches Städtebuch. Handbuch städtischer Geschichte, Bd. I ff., Stuttgart-Berlin 1939 ff.

Koppmann, K.: Geschichte der Stadt Rostock I, Rostock 1887.

Kosegarten, J. G. L.: Geschichte der Universität Greifswald mit urkundlichen Beilagen, Teil I, Greifswald 1856-1857 (Ndr. Aalen 1976).

Krabbe, O.: Die Universität Rostock im 15. und 16. Jahrhundert, 2 Teile, Rostock 1854 (Ndr. in einem Band Aalen 1970).

Kuhn, W.: Die Studenten der Universität Tübingen zwischen 1477 und 1534. Ihr Studium und ihre spätere Lebensstellung, 2 Teile (Göppinger akademische Beiträge, 37/38), Göppingen 1971.

Kühne, G.: Studenten aus Gartz an der Oder an der Alten Erfurter Universität, in: 750 Jahre Gartz an der Oder 1249-1999, Beiträge zum Jubiläum der Stadtgründung, hg. von H.-F. Blume und G. Kühne, Gartz 1996, S. 4346.

Langer, G., u.a.: Vom Einzugsbereich der Universität Wittenberg (1502-1812), Halle 1967-1973.

Lehmann, J.: Die örtliche und soziale Herkunft der Königsberger Studenten 1544 bis 1649, Diss. Leipzig 1929.

Lieberich, H.: Die gelehrten Räte. Staat und Juristen in Bayern in der Frühzeit der Rezeption, in: Zeitschrift 
für bayrische Landesgeschichte 27 (1967), S.

Maschke, E., u.a. (Hg): Stadt und Universität im Mittelalter und in der frühen Neuzeit, Sigmaringen 1977.

Matheus, M.: Zum Einzugsbereich der alten Trierer Universität (1473-1477), in: Kurtrierer Jahrbuch 21 (1981), S.55-69.

Meuthen, E.: Kölner Universitätsgeschichte, 1. Die alte Universität, Köln und Wien 1988.

Miethke, J.: Die Kirche und die Universitäten im 13. Jahrhundert, in: Schulen und Studium im sozialen Wandel des hohen und späten Mittelalters, hg. von J. Fried, Sigmaringen 1986, S. 285-320.

Moraw, P.: Gelehrte Juristen im Dienst der deutschen Könige des Spätmittelalters (1273-1493), in: Die Rolle der Juristen bei der Entstehung des modernen Staates, hg. von R. Schnur, Berlin 1986, S. 77-148.

— Stiftspfründen als Elemente des Bildungswesen im spätmittelalterlichen Reich, in: Studien zum weltlichen Kollegiatstift in Deutschland, hg. von I. Crusius, Göttingen 1995, S. 270-297.

— Zur Sozialgeschichte der deutschen Universität im späten Mittelalter, in: Gießener Universitätsblätter 8 (1975), S. 44-60.

— Über Entwicklungunterschiede und Entwicklungsausgleich im deutschen und europäischen Mittelalter. Ein Versuch, in : Hochfinanz, Wirtschaftsräume, Innovationen. Festschrift für Wolfgang von Stromer, Bd. 2, Trier 1987, S. 583-622.

Müller, F.: Müllers Großes deutsches Ortsbuch. Vollständiges Gemeindelexikon, Wuppertal-Barmen 1972.

Müller, R. A.: Geschichte der Universität. Von der mittelalterlichen Universitas zur deutschen Hochschule, München 1990.

- Universität und Adel, eine soziostrukturelle Studie zur Geschichte der bayrischen Landesuniversität Ingolstadt 1472-1648 (Ludovico Maximilianea, 7), Berlin 1974.

Nowak, Z. H.: Preußen und seine geistigen Beziehungen zu den Universitäten Rostock und Greifswald im 15. und am Anfang des 16. Jahrhunderts, in: Baltische Studien 69 (1983), S. 18-29.

Overfield, J. H.: Humanism and Scholasticism in late medieval Germany, Princeton 1984.

— Nobles and Paupers at German Universities to 1600, in: Societas: A Review of Social History 4, 1974, S. $175-210$.

— Scholastic opposition to Humanism in Pre-Reformatory Germany, in: Viator 7, Berkeley 1976, S. 391-420.

- University Studies and the Clergy in Pre-Reformation Germany, in: Rebirth, Reform and Resilience, Universities in Transition 1300-1700, ed. By Kittelson, M., u.a., S. 254-292. 
Pagel, K.: Die Hanse, Braunschweig 1963 (3. Auflage).

Pagel, K.-H.: Stolp in Pommern: eine ostdeutsche Stadt, Lübeck 1977.

Paulsen, F.: Die Gründung der deutschen Universitäten im Mittelalter, in: Historische Zeitschrift 45 (1881), S. 251-311.

- Geschichte des gelehrten Unterrichts auf den deutschen Schulen und Universitäten vom Ausgang des Mittelalters bis zur Gegenwart, 2 Bde., Leipzig 1919.

— Organisation und Lebensordnung der deutschen Universitäten im Mittelalter, in: Historische Zeitschrift 45 (1881), S. 385-440.

Pinborg, J.: Danish students 1450-1535 and the University of Copenhagen, in: Cahiers de l'institut du moyenage grec et latin, Université de Copenhague 37 (1981), S. 70-122.

Rexroth, F.: Deutsche Universtätsstiftungen von Prag bis Köln, Köln (u.a.) 1992.

Riemann, H.: Geschichte der Stadt Kolberg, Kolberg 1924.

Ritter, G.: Die Heidelberger Universität. Ein Stück deutscher Geschichte, Bd. 1: Das Mittelalter (1386-1508), Heidelberg 1936.

Rosenow, C.: Chronik der Hansestadt Rügenwalde, Rottenburg am Neckar 1980.

Sägmüller, J. B.: Lehrbuch des katholischen Kirchenrechts, 2. Aufl., Freiburg 1909.

Sauer, H.: Hansestädte und Landesfürsten. Die wendischen Hansestädte in der Auseinandersetzung mit den Fürstenhäusern Oldenburg und Mecklenburg während der zweiten Hälfte des 15. Jahrhunderts, in: Quellen zur Darstellung der Hansischen Geschichte NF 16 (1971), S. 101ff

Schildhauer, J.: Die Sozialstruktur der Hansestadt Rostock von 1378-1596, in: Hansische Studien, Heinrich Sproemberg zum 70. Geburtstag, 1961, S. 341-353.

— Soziale, politische und religiöse Auseinandersetzungen in den Hansestädten Stralsund, Rostock und Wismar im ersten Drittel des 16. Jahrhunderts (Abhandlungen zur Handels- und Sozialgeschichte 2), Weimar 1959.

— u.a. (Hg.), Die Hanse, Berlin 1985 (6. Auflage)

- Aus der älteren Geschichte der Ernst-Moritz-Arndt Universität Greifswald, in: Wissenschaftliche Zeitschrift der Ernst-Moritz-Arndt Universität Greifswald. Gesellschafts- und Sprachwissenschaftliche Reihe XXII (1974), Nr 3/4, S. 117-122.

— Stralsunder Bürgertestamente vom Anfang des 14. bis zum Ausgang des 16. Jahrhunderts. Listen sämtlicher Testatoren in chronologischer und alphabetischer Reihenfolge, in: Akteure und Gegner der Hanse 
- Zur Prosopographie der Hansezeit, hg. von Kattinger, D., u. a. (Hansische Studien IX), Weimar 1998, S. 327-403.

— Hansestädtischer Alltag. Untersuchungen auf der Grundlage der Stralsunder Bürgertestamente vom Anfang des 14. bis zum Ausgang des 16. Jahrhunderts (Abhandlungen zur Handels- und Sozialgeschichte 28), Weimar 1992.

Schmidt, R.: Die Anfänge der Universität Greifswald, in: Festschrift zur 500-Jahrfeier der Universität Greifswald, Bd. 1, Greifswald 1956, S.9-52.

— Die Ausstattung der Universität Greifswald durch Herzog Wartislaw IX. Und Bürgermeister Heinrich Rubenow, in: Pommern und Mecklenburg, Beiträge zur mittelalterlichen Städtegeschichte, hg. von R. Schmidt, S. 133-157.

— Kräfte, Personen und Motive bei der Gründung der Universitäten Rostock (1419) und Greifswald (1456), in: Beiträge zur pommerschen und mecklenburgischen Geschichte, hg. von R. Schmidt, Marburg 1981. S. 134.

— Pommern und seine Universität, in: Greifswalder Universitätsreden NF, Nr. 60, Greifswald 1990.

— Rostock und Greifswald. Die Errichtung von Hochschulen im norddeutschen Hanseraum, in: Beiträge zu Problemen deutscher Universitätsgründungen der frühen Neuzeit, Baumgart, P., u.a. (Hg), Nendeln 1978, S.75-110.

— Bischof Henning Iwen von Kammin (1446-1468), in: Baltische Studien NF 53 (1967), S. 18-42.

Schnitzler, E.: Die Gründung der Universität Rostock 1419, Köln 1974.

— Zur hansischen Universitätsgeschichte, in: Hansische Studien, Heinrich Spromberg zum 70. Geburtstag, 1961, S. 354-387.

Schubel, F.: Die Universität Greifswald (Mitteldeutsche Hochschulen 4), Frankfurt/M. 1960.

Schubert, E.: Motive und Probleme deutscher Universitätsgründungen des 15. Jahrhunderts, in: Beiträge zu Problemen deutscher Universitätsgründungen der frühen Neuzeit, hg. von P. Baumgart, u.a., Nendeln 1978, S. 13-74.

Schulze, A.: Die örtliche und soziale Herkunft der Straßburger Studenten 1621 bis 1793, Frankfurt/M. 1926.

Schwenkler, F.: Köslin. 1266-1966, Köslin 1966 (2. Auflage).

Schwinges, R. Chr. (Hg): Gelehrte im Reich, Zur Wirkungs- und Sozialgeschichte akademischer Eliten des 14. bis 16. Jahrhunderts (Zeitschrift für historische Forschung, Beiheft 18), Berlin 1996.

— Deutsche Universitätsbesucher im 14. und 15. Jahrhundert, Stuttgart 1986 (immer unter der Abkürzung Schwinges, Universitätsbesucher). 
— Pauperes an deutschen Universitäten des 15. Jahrhunderts, in: ZHF 8, 1981, S. 285-309.

— Studentische Kleingruppen im späten Mittelalter. Ein Beitrag zur Sozialgeschichte deutscher Universitäten, in: Politik, Gesellschaft, Geschichtsschreibung. Gießener Festgabe für F. Graus zum 60. Geburtstag (Beiheft zum Archiv der Kulturgeschichte 18), Köln 1982, S. 319-316.

Spading, K.: Niederländer an der Universität Greifswald. Ein Beitrag zur Geschichte der geistig-kulturellen Beziehungen in der Zeit der Hanse, in: Autonomie, Wirtschaft und Kultur der Hansestädte (Hansische Studien VI), hg. von Konrad Fritze, u.a., Weimar 1984, S. 190-204

Spuhrmann, R.: Geschichte der Stadt Cammin in Pommern und des Camminer Domkapitels, Cammin 1924.

Tepp, P.: Untersuchungen zur Sozial- und Wirtschaftsgeschichte der Hanse- und Salzstadt Kolberg im Spätmittelalter, Diss. Phil. Hamburg 1980.

Treichel, F.: Die Geschichte der Stadt Köslin, Köslin 1939.

Wehrmann, M.: Geschichte der Insel Rügen (Pommersche Heimatkunde Bd. 1 und 2), Greifswald 1923.

— Geschichte der Stadt Stettin, Stettin 1911.

— Geschichte von Pommern, 2 Bde., Gotha 1919-1920.

— Geschichte von Land und Stadt Greifenberg, Hamburg 1988 (Nachdruck von 1927).

Wriedt, K.: Das gelehrte Personal in der Verwaltung und Diplomatie der Hansestädte, in: Hansische Geschichtsblätter 96 (1978), S. 15-37.

— Schulen und bürgerliches Bildungswesen in Norddeutschland im Spätmittelalter, in: Studien zum städtischen Bildungswesen des späten Mittelalters und der frühen Neuzeit, hg. von B. Moeller, Göttingen 1983, S. 152-172.

— Stadtrat - Bürgertum - Universität am Beispiel norddeutscher Hansestädte, in: Studien zum städtischen Bildungswesen des späten Mittelalters und der frühen Neuzeit, hg. von B. Moeller, Göttingen 1983, S. 499523.

— Bürgertum und Studium in Norddeutschland während des Spätmittelalters, in: Schulen und Studium im sozialen Wandel des hohen und späten Mittelalters, hg. von J. Fried, Sigmaringen 1986.

— Studienförderung und Studienstiftungen in norddeutschen Städten (14. - 16. Jahrhundert), in: Stadt und Universität, hg. von Heinz Duchhardt, Köln 1993, S. 33-49.

— Gelehrte in Gesellschaft, Kirche und Verwaltung norddeutscher Städte, in: Gelehrte im Reich, Zur Wirkungs- und Sozialgeschichte akademischer Eliten des 14. bis 16. Jahrhunderts, hg. von R. C. Schwinges (Zeitschrift für historische Forschung, Beiheft 18), Berlin 1996, S. 437-452. 
Teilausschnitt 1

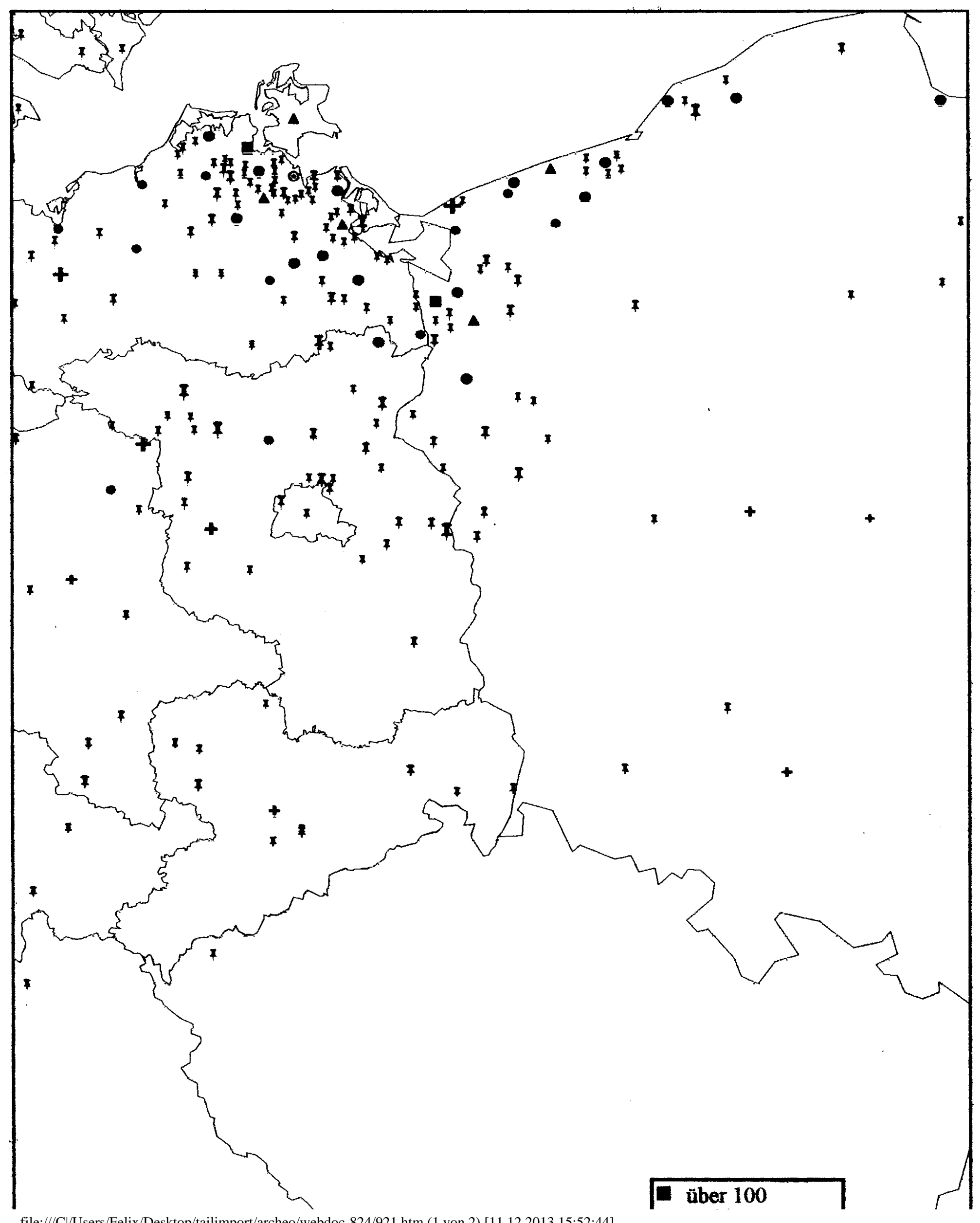


11.1. Teilausschnitt 1

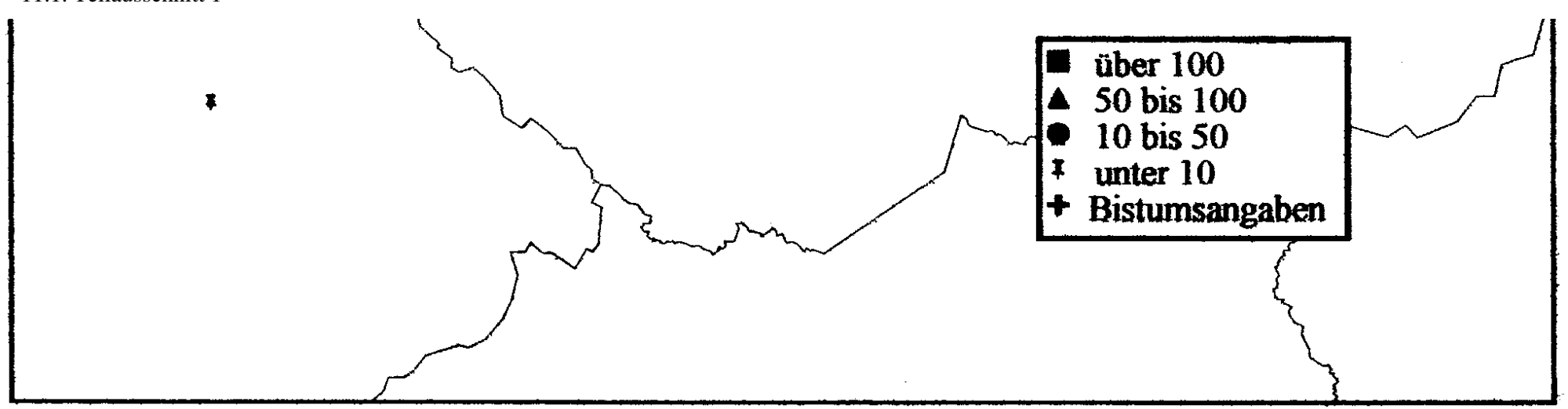


Teilausschnitt 2

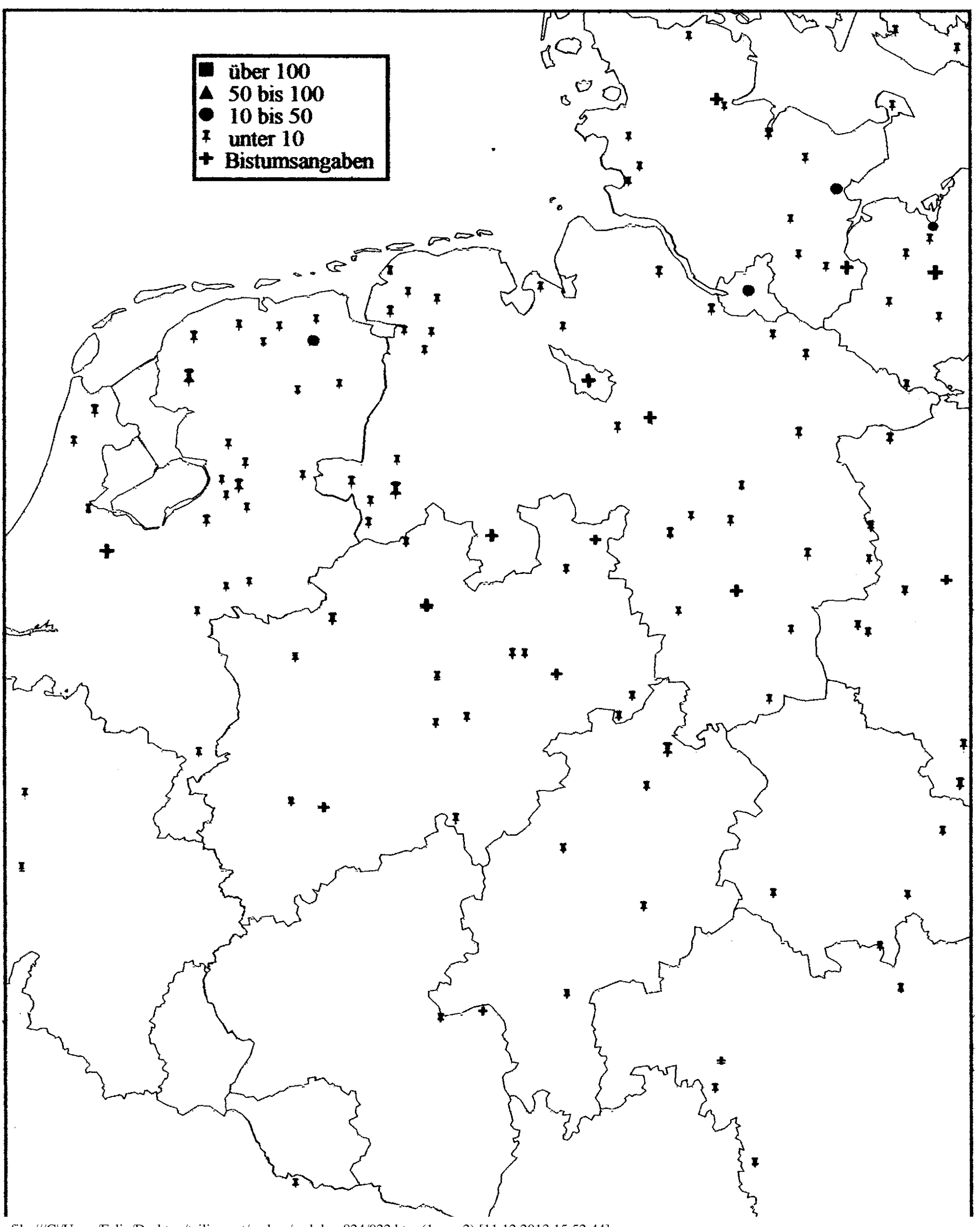


11.1. Teilausschnitt 2

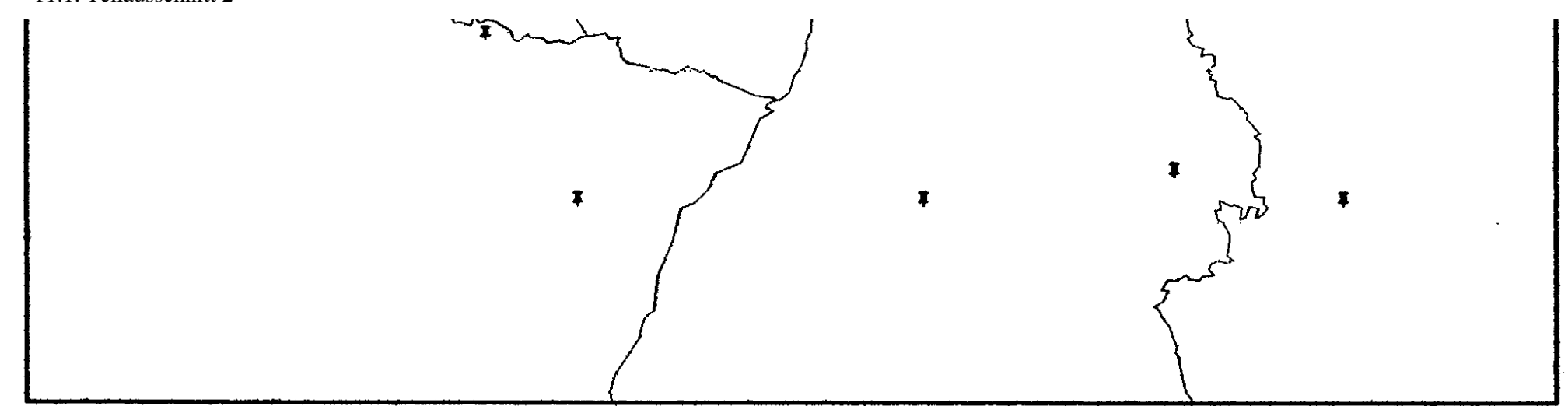


Teilausschnitt 3

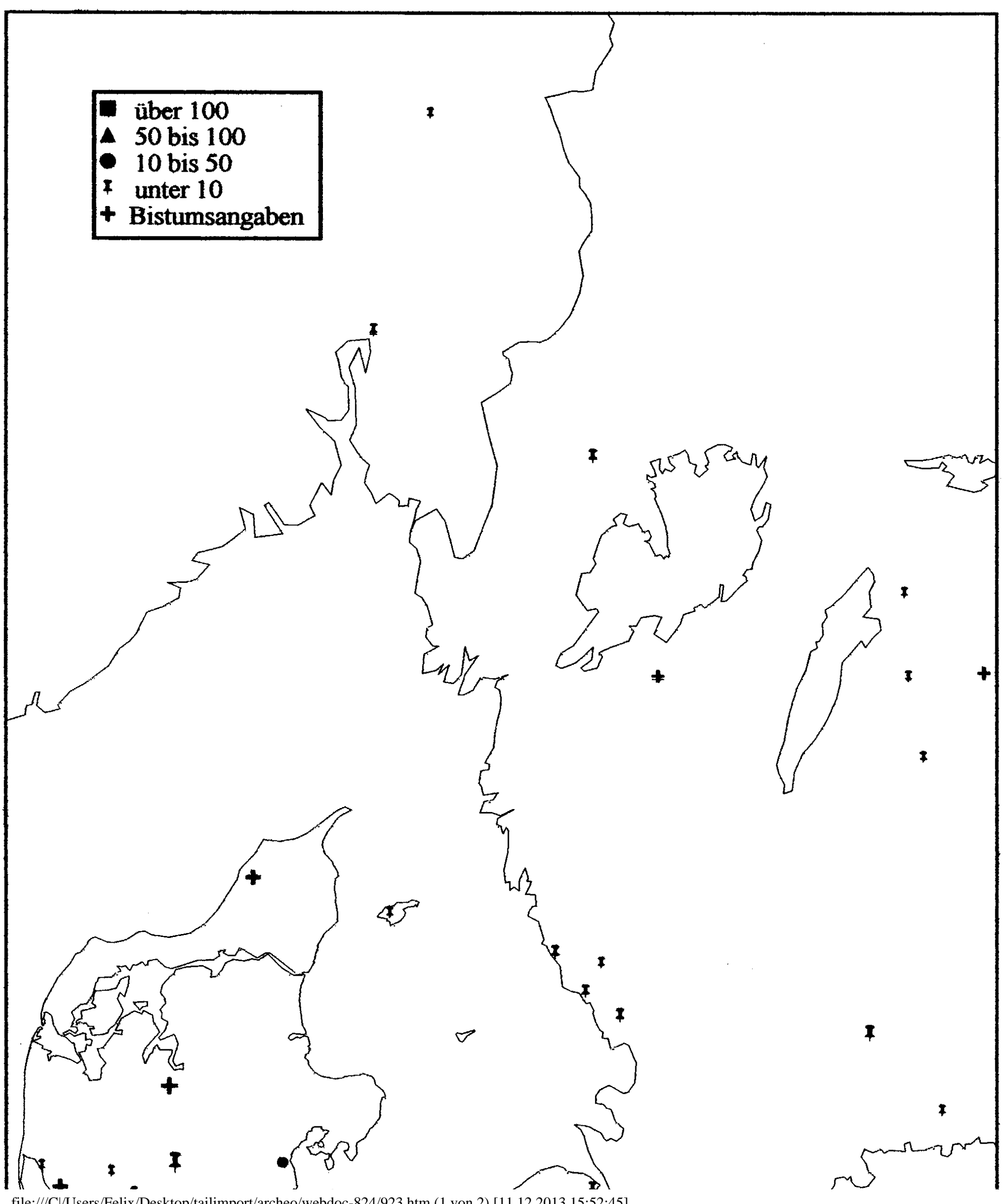


11.1. Teilausschnitt 3

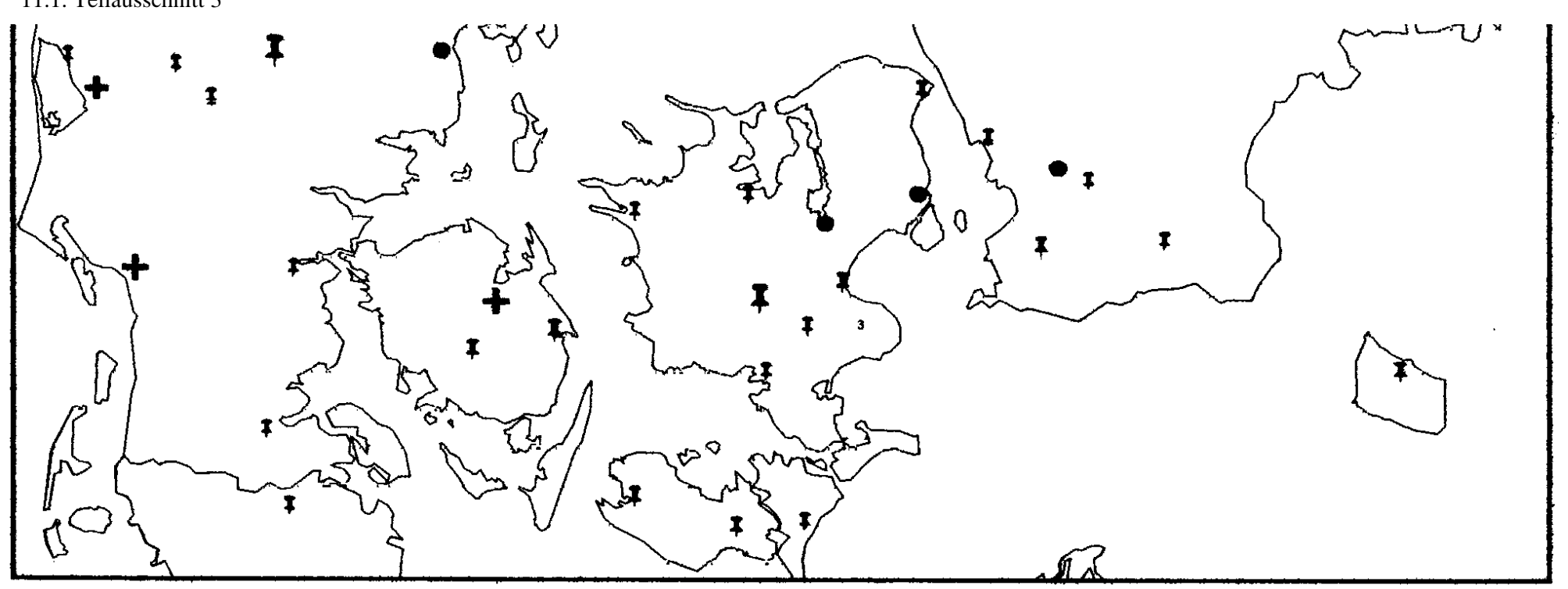


Teilausschnitt 4

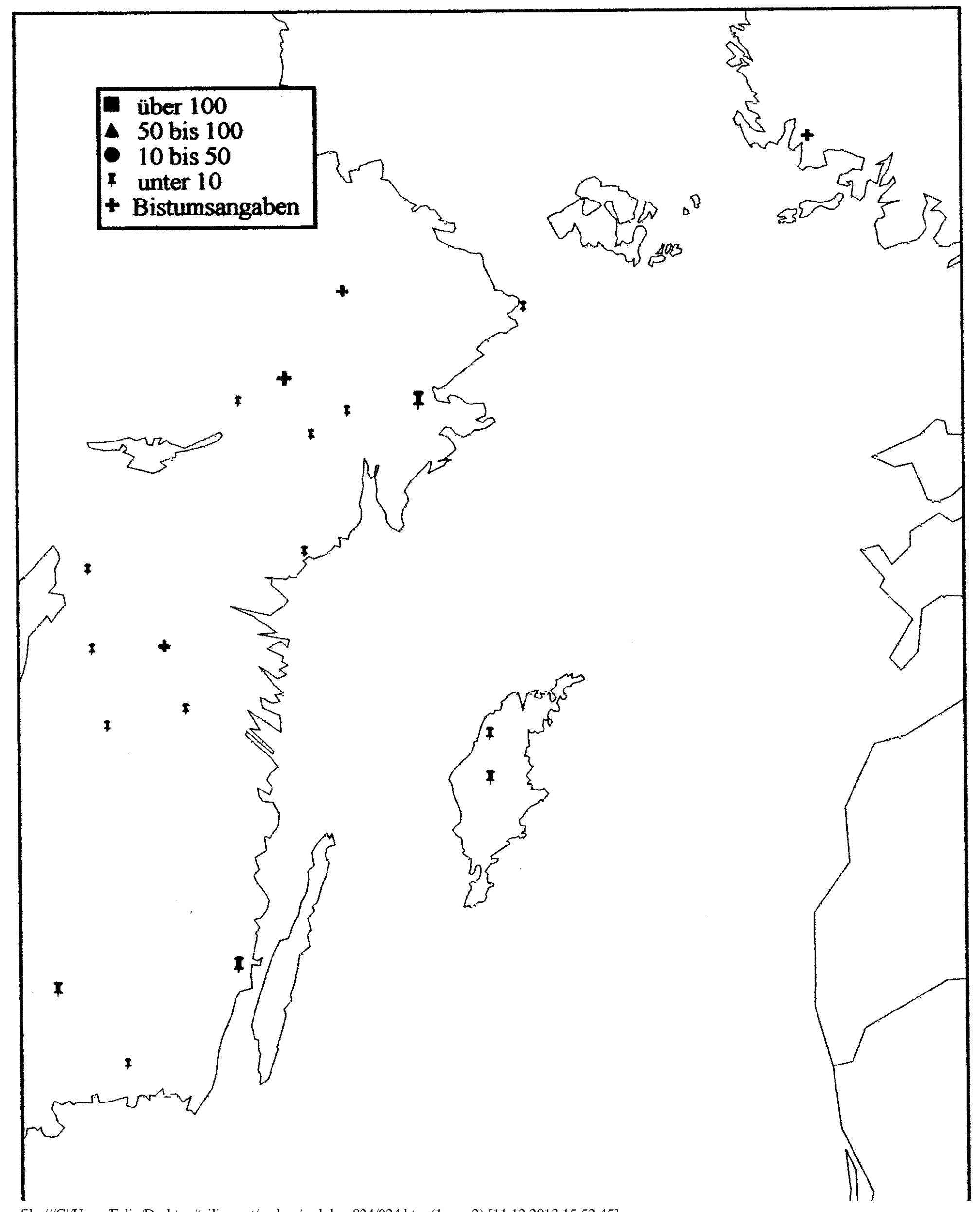


11.1. Teilausschnitt 4

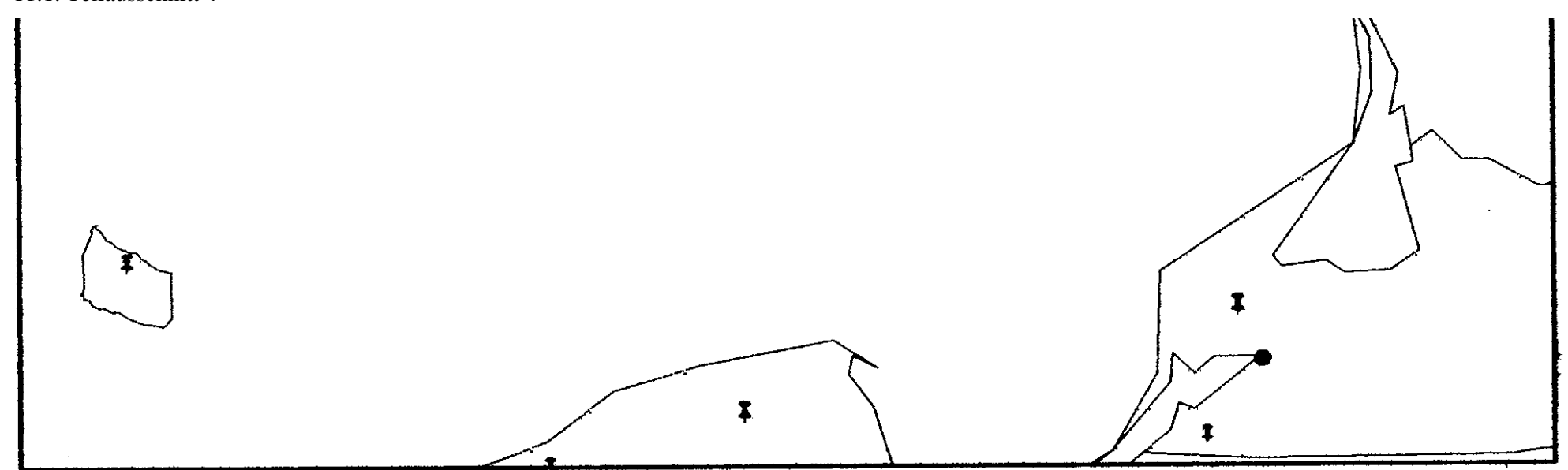


Teilausschnitt 5

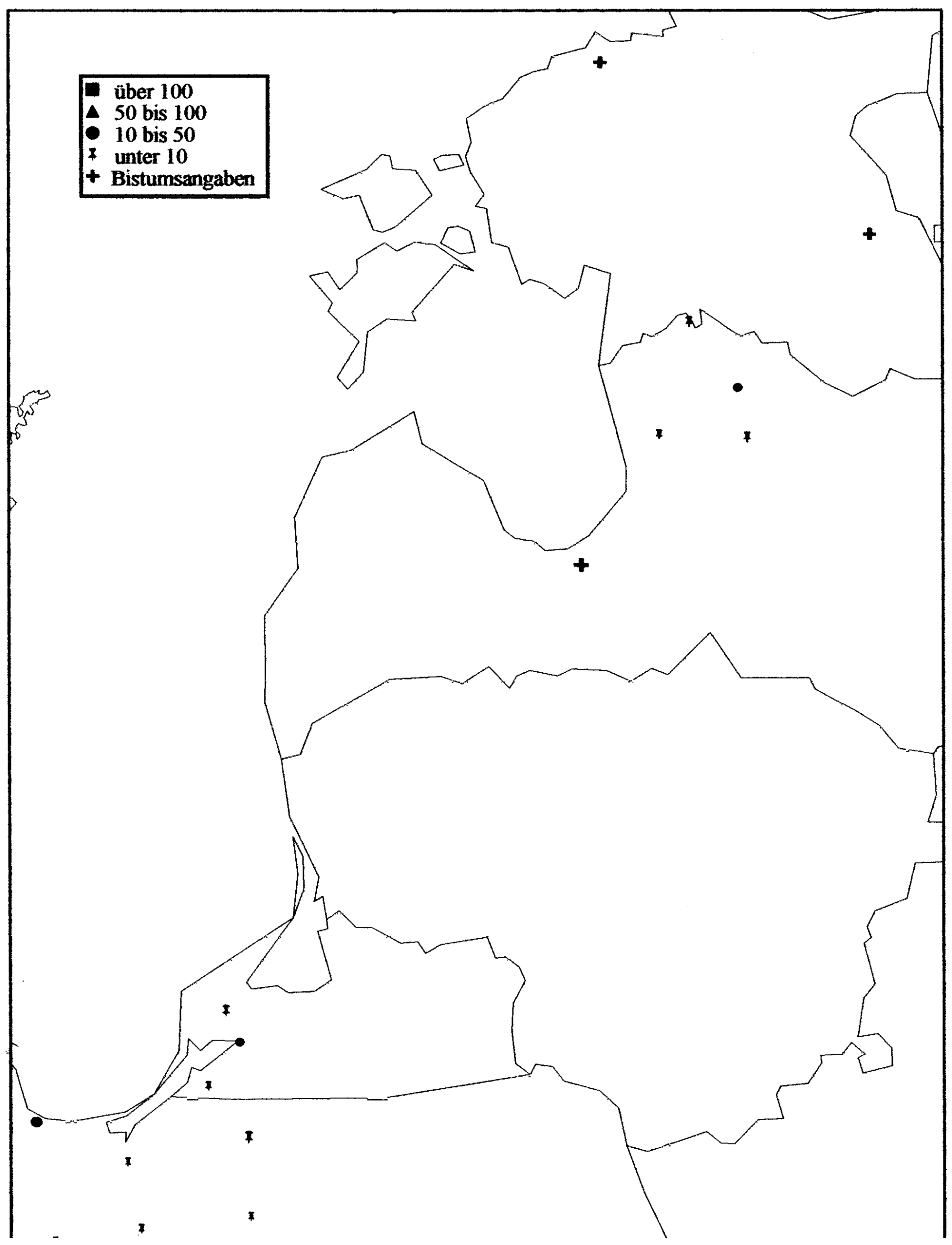


11.1. Teilausschnitt 5

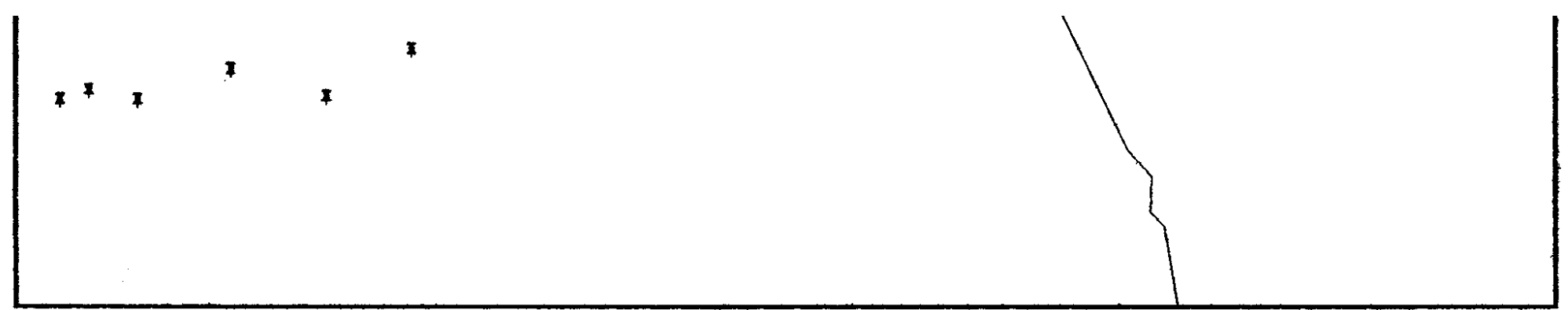


Die Reichskreise

Aus: Westermann, Großer Atlas zur Weltgeschichte, Braunschweig 1972 (8. Aufl.), S. 97.

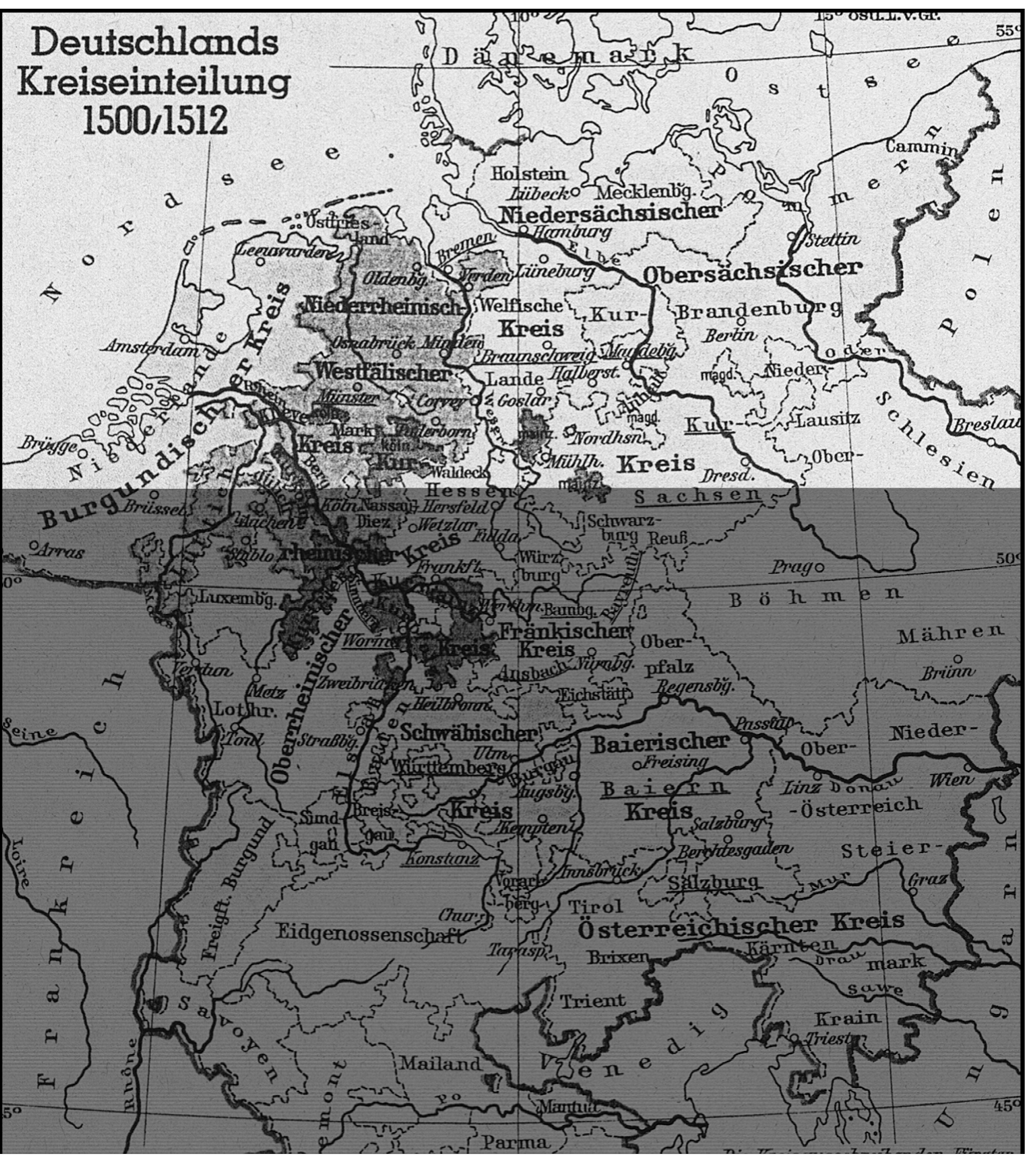


11.2. Die Reichskreise

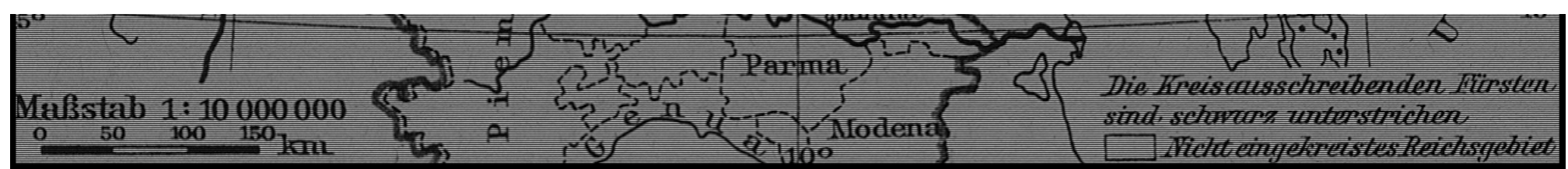




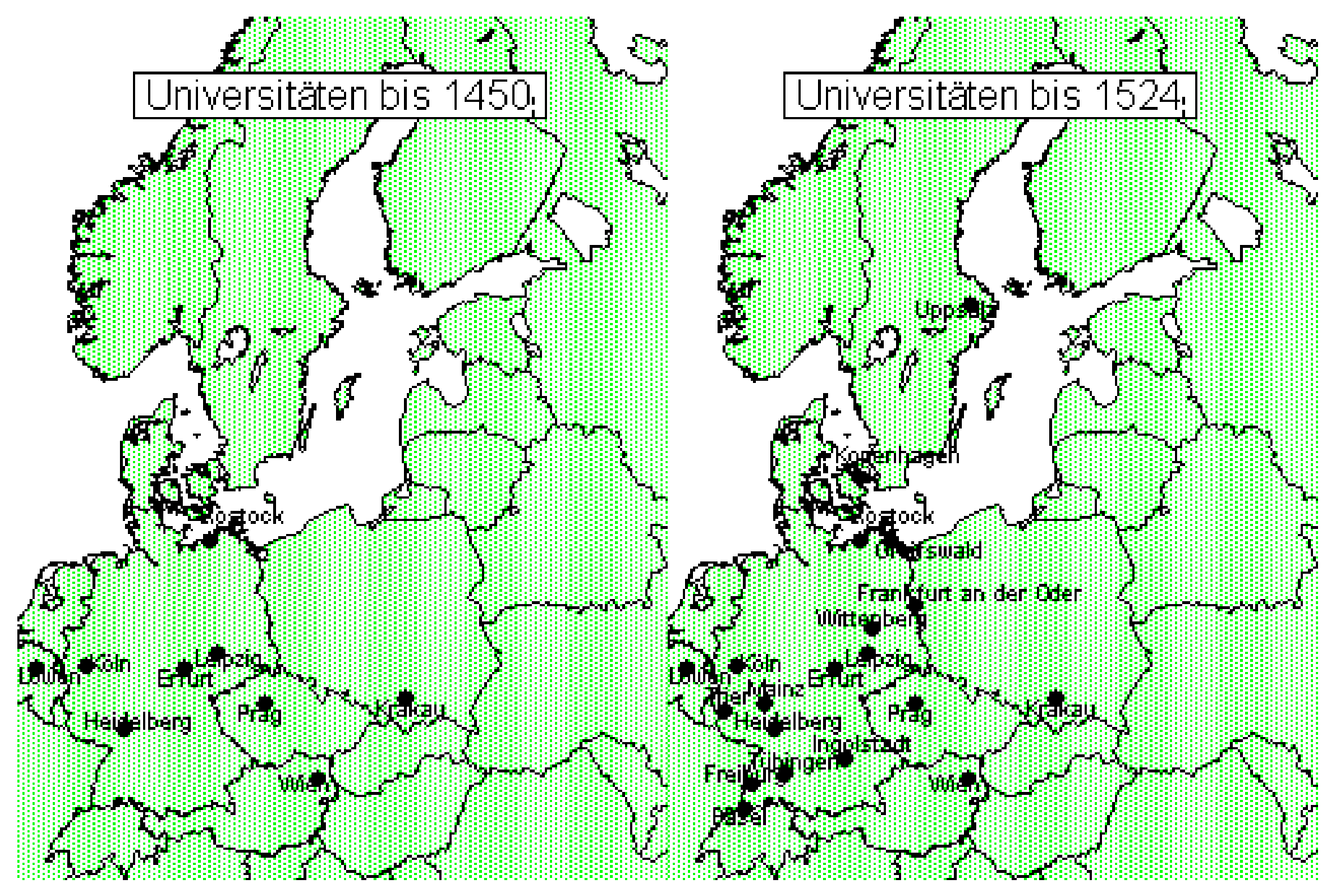




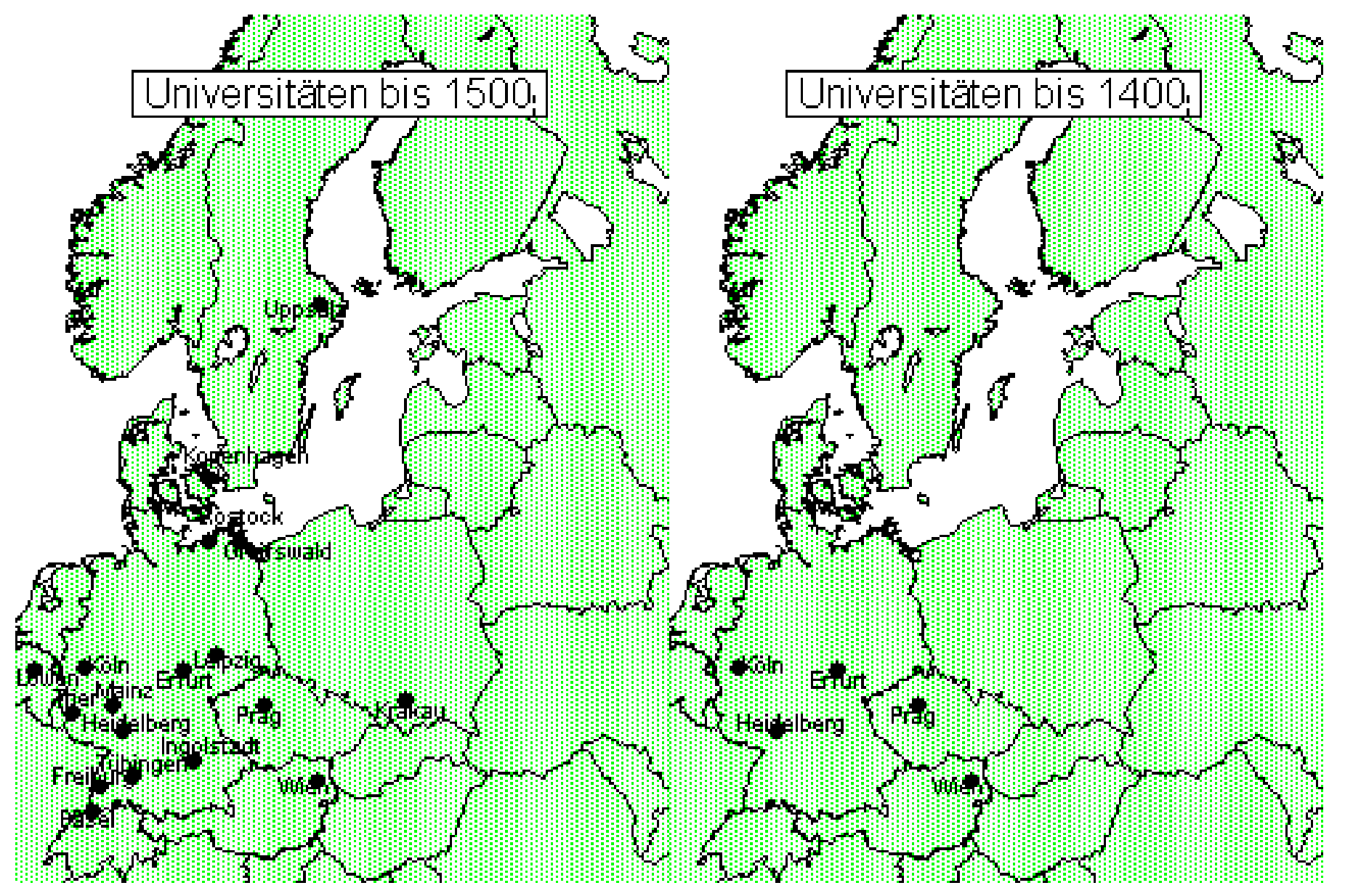

